LA COMPOSICIÓN ARQUITECTÓNICA Y LA CONSERVACIÓN

DE LAS EDIFICACIONES MONUMENTALES MAYAS

DEL NORESTE DE PETÉN

ÓSCAR ANTONIO QUINTANA SAMAYOA

2008

Escuela Técnica Superior de Arquitectura de Valencia

Departamento de Composición Arquitectónica

UNIVERSIDAD

POLITECNICA

de VALENCIA 
LA COMPOSICIÓN ARQUITECTÓNICA Y LA CONSERVACIÓN

DE LAS EDIFICACIONES MONUMENTALES MAYAS

DEL NORESTE DE PETÉN

Óscar Antonio Quintana Samayoa

UNIVERSIDAD

POLITECNICA
DE VALENCIA 
LA COMPOSICIÓN ARQUITECTÓNICA Y LA CONSERVACIÓN

DE LAS EDIFICACIONES MONUMENTALES MAYAS

DEL NORESTE DE PETÉN

Óscar Antonio Quintana Samayoa

\author{
Valencia \\ Julio \\ 2008 \\ Director de Tesis \\ Gaspar Muñoz Cosme \\ Escuela Técnica Superior de Arquitectura de Valencia \\ Departamento de Composición Arquitectónica \\ UNIVERSIDAD \\ POLITECNICA \\ DE VALENCIA
}




\title{
LA COMPOSICIÓN ARQUITECTÓNICA Y LA CONSERVACIÓN DE LAS EDIFICACIONES MONUMENTALES MAYAS DEL NORESTE DE PETÉN
}

\author{
Agradecimientos \\ Introducción \\ Objetivo de la tesis
}

\section{Primera parte}

Capítulo 1

El marco de referencia

1.1 Área de estudio 018

1.2 Los mayas y su espacio cultural 022

1.3 Antecedentes de investigación 027

Capítulo 2

$\begin{array}{ll}\text { Metodología } & 032\end{array}$

$2.1 \quad$ División del territorio 034

2.2 Obtención de datos 035

2.3 Presentación de la información 040

2 3.1 Datos individuales 040

2.3.2 Datos por grupos 041

2.4 Campo de investigaciones 042

2.4.1 Conservación del patrimonio 043

2.4.2 Composición arquitectónica 051

2.4.2.1 Metodología en otros sitios 052

2.4.2.2 Relaciones urbanas 053

2.4.2.3 Metodología aplicada en Petén 066

\section{Segunda parte}

Capítulo 3

Resultado de investigaciones $\quad 070$

3.1 Sitios y posición en el paisaje 070

3.1.1 Indicadores de tamaño 073

3.1.1.1 Indicador "espacios libres" $\quad 074$

3.1.1.2 Indicador "elementos masa" 076

3.1.2 Relaciones visuales 077

Capítulo 4

Elementos urbanos identificados 082

4.1 Espacios libres 086

4.1.1 Plazas 086

4.1.1.1 Plazas con monumentos $\quad 087$

4.1.1.2 Plazas con edificaciones 088

4.1.2 Calzadas 090

4.1.2.1 Calzadas inclinadas 090

4.1.2.2 Calzadas horizontales 091

4.1.2.3 Casos especiales 092

4.1.2.4 Calzadas entre sitios 093

4.1.3 Vías 094

4.1.3.1 Vías y grupos de edificios $\quad 095$

4.1.4 Patios 095

4.1.5 Plataformas con espacios vacíos 096 
4.2 Elementos sólidos 097

4.2.1 Edificios horizontales 098

4.2.1.1 Edificios representativos 102

4.2.1.2 Edificios aislados y peraltados 102

4.2.1.3 Salones abiertos 103

4.2.1.4 Salones con pórtico 104

4.2.1.5 Edificios circulares 105

4.2.1.6 Baños de vapor 106

4.2.1.7 Cancha para el juego de pelota 107

4.2.1.8 Grupos de edificios no elevados 109

4.2.1.9 Grupos de edificios elevados $\quad 110$

4.2.2 Edificios verticales 111

4.2.2.1 Pirámide sin construcción superior $\quad 112$

4.2.2.2 Pirámide con construcción superior 112

4.2.3 Combinaciones de edificios verticales $\quad 116$

4.2.3.1 Templos pirámides gemelas 116

4.2.3.2 Templos pirámides en hilera 116

4.2.3.3 Grupos de templos pirámide $\quad 117$

4.2.4 Edificios horizontales y verticales 118

4.2.4.1 Grupos E 118

4.2.4.2 Grupos Triádicos 120

4.2.4.3 Grupos de cuatro edificios 124

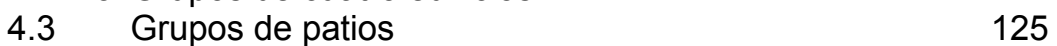

4.3.1 Grupos de pátios elevados (Acrópolis) 127

4.3.2 Grupos de patios no elevados 132

4.4 Otros elementos 135

$\begin{array}{lll}\text { 4.4.1 Depósitos de agua } & 135\end{array}$

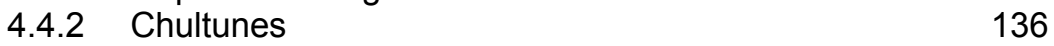

$\begin{array}{lll}4.4 .3 & \text { Terraplenes } & 137\end{array}$

$\begin{array}{lll}4.4 .4 & \text { Fosas y canales } & 138\end{array}$

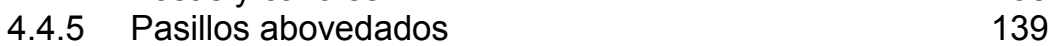

4.4.6 Tumbas 140

4.4.6.1 Tumbas excavadas $\quad 141$

4.4.6.2 Tumbas mixtas $\quad 141$

4.5 Consideraciones y relaciones 158

Capítulo 5

Elementos de arquitectura $\quad 164$

5.1 Superfície de muros $\quad 164$

5.1.1 Muros exteriores 165

$\begin{array}{lll}5.1 .2 & \text { Puertas } & 168\end{array}$

$\begin{array}{ll}5.1 .3 \text { Ventanas } & 170\end{array}$

5.1.3.1 Ventanas simuladas $\quad 171$

5.1.4 Perforaciones 171

$\begin{array}{lll}5.1 .5 & \text { Nichos } & 172\end{array}$

5.1.6 Otras perforaciones 173

5.1.7 Aberturas excavadas 173

5.2 Bancas y escalinatas 174

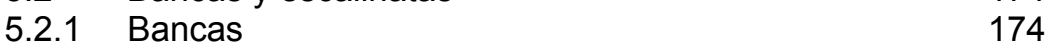

5.2.2 Escalinatas interiores 176

5.3 Superficie de techos 177

5.3.1 Paramento exterior $\quad 177$

$\begin{array}{lll}\text { 5.3.2 } & \text { Paramento interior } & 178\end{array}$

$\begin{array}{ll}\text { 5.3.3 Pasadores de madera } & 179\end{array}$

$\begin{array}{lll}5.4 & \text { Cresterías } & 180\end{array}$

Capítulo 6

Elementos constructivos 
6.1 Plataformas 189

6.2 Muros 197

6.3 Techos 203

Capítulo 7

Materiales 209

$\begin{array}{lll}7.1 & \text { Piedra } & 210\end{array}$

$\begin{array}{lll}7.2 & \text { Cal } & 213\end{array}$

$\begin{array}{lll}7.3 & \text { Madera } & 218\end{array}$

$\begin{array}{lll}7.4 & \text { Agregados } & 219\end{array}$

\section{Tercera parte}

Capítulo 8

Resultado de intervenciones 223

8.1 Saqueo arqueológico 223

8.1.1 Intentos para detener el saqueo 227

8.1.2 Cantidad de saqueos 230

8.2 Otros factores 233

8.3 Intervenciones en edificios 236

8.3.1 Uaxactún (1927-1937) 237

8.3.2 Proyecto Tikal (1956-1969) 238

8.3.2.1 Grupo Q 239

8.3.2.2 Gran Plaza 241

8.3.2.3 Acrópolis Central $\quad 245$

8.3.2.4 Otras intervenciones $\quad 246$

8.3.3 Administración Parque Nacional Tikal 247

8.3.4 Proyecto Nacional Tikal 249

8.3.4.1 Tikal (1980-1985) 249

8.3.4.2 Uaxactún (1983-1985) 252

Capítulo 9

Resultado de intervenciones 1987 agosto 2006

9.1 Uaxactún 1987-1991 259

9.2 Tikal 1987-1992 262

$\begin{array}{lll}9.2 .1 & \text { Templo V } & 262\end{array}$

9.2.2 Templo I 264

9.2.3 Otros edificios 265

9.3 Topoxté 1987-1996 266

9.4 Yaxhá 1987-2007 268

9.4.1 Acrópolis Este 268

$\begin{array}{lll}9.4 .2 & \text { Otros edificios } & 272\end{array}$

9.4.3 Intervenciones PDS-BID 273

$\begin{array}{lll}9.5 & \text { Nakum 1987-2007 } & 275\end{array}$

9.5.1 Plaza Central 276

$\begin{array}{lll}9.5 .2 & \text { Plaza Este } & 278\end{array}$

9.5.3 Plaza Sureste 278

9.5.4 Acrópolis $\quad 279$

$\begin{array}{ll}\text { 9.5.4.1 Patio } 1 & 279\end{array}$

9.5.4.2 Patio 2

9.5.4.3 Patio $3 \quad 282$

$\begin{array}{ll}9.5 .4 .4 \text { Patio } 4 & 282\end{array}$

9.5.4.5 Patio $5 \quad 283$

9.5.4.6 Patio 6 
$\begin{array}{ll}\text { 9.5.4.7 Patio } 7 & 284\end{array}$

9.5.4.8 Patio $8 \quad 285$

$\begin{array}{ll}\text { 9.5.4.9 Patio } 9 & 286\end{array}$

9.5.4.10 Patio $10 \quad 287$

9.5.4.11 Patio $11 \quad 287$

9.5.4.12 Patio $12 \quad 288$

9.5.4.13 Patio $13 \quad 288$

9.6 Naranjo 288

9.7 Otros del triángulo cultural 288

9.7.1 Poza Maya 288

$\begin{array}{lll}9.7 .2 & \text { Pochitoca } & 289\end{array}$

$\begin{array}{lll}9.7 .3 & \text { Naranjito } & 289\end{array}$

$\begin{array}{lll}9.7 .4 & \text { El Pital } & 289\end{array}$

$\begin{array}{lll}9.7 .5 & \text { Otros sitios } & 290\end{array}$

9.8 Alrededor del triángulo cultural 290

9.8.1 La Blanca 290

9.8.2 Tzikintakán 290

9.8.3 Corozal Torre 290

9.8.4 San Clemente $\quad 291$

9.8.5 Otros edificios 291

9.9 Prioridades de intervención 292

Capítulo 10

Programación y procedimiento de conservación 297

$\begin{array}{lll}10.1 & \text { Recorridos } & 300\end{array}$

$\begin{array}{lll}10.1 .1 & \text { Ficha técnica } & 301\end{array}$

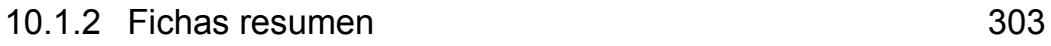

$\begin{array}{lll}10.2 & \text { Acciones preventivas } & 303\end{array}$

10.2.1 Campamentos 304

10.2.2 Documentación de saqueos 305

10.2.3 Pozos de sondeo 306

10.2.4 Plano de situación 307

$\begin{array}{lll}10.3 & \text { Control de vegetación } & 307\end{array}$

10.4 Personal, tiempo y logística 311

10.5 Arqueología de rescate y restauración 313

10.6 Intervenciones para uso frecuente 318

10.6.1 Acciones en arqueología 320

$\begin{array}{ll}\text { 10.6.2 Infraestructura } & 321\end{array}$

10.6.3 Documentación grafica 322

Capítulo 11

Presentación y uso del patrimonio cultural 326

11.1 San Clemente 326

11.2 Triángulo cultural Yaxhá-Nakum-Naranjo 332

Cuarta parte

Capítulo 12

Condiciones y posibilidades $\quad 337$

12.1 Descripción por cuencas 337

$\begin{array}{ll}\text { 12.1.1 Cuenca Mirador } & 337\end{array}$

12.1.2 Área Tikal $\quad 339$

12.1.3 Cuenca Ixcán 340

12.1.4 Cuenca Holmul 343

12.1.5 Cuenca de los Lagos $\quad 344$

12.1.6 Río Mopán 346

$\begin{array}{lll}12.2 & \text { Conjuntos estrategicos } & 347\end{array}$ 
12.2.1 Zonas restringidas 349

12.2.2 Zona central 351

12.2.3 corredores de comunicación 353

12.2.4 Zonas de concesiones 356

$\begin{array}{lll}12.3 & \text { Estrategia } & 357\end{array}$

Capítulo 13

Conclusiones

$\begin{array}{ll}\text { Bibliografía } & 378\end{array}$

Anexo 1

Figuras en cuadros

Cuadro 1 Sitios que forman la muestra (128 Sitios)

Cuadro 2 Intervención en sitios arqueológicos, el noreste de Petén

Cuadro 3 Posición del sitio con el paisaje

Cuadro 4 Elementos urbanos

Cuadro 5 Elementos de arquitectura visible

Cuadro 6 Registro de saqueos en edificios

Cuadro 7 Indicadores de saqueo

Cuadro 8 Indicadores de edificios en peligro

Cuadro 9 Prioridades de intervención

Cuadro 10 Principales programas y proyectos de inversión

Figuras con planos

Plano 1 Plano de sitios arqueológicos que conforman la muestra

Plano 2 Planos esquemáticos cuenca Mirador

Plano 3 Planos esquemáticos área Tikal

Plano 4 Planos esquemáticos cuenca Ixcán

Plano 5 Planos esquemáticos cuenca Holmul

Plano 6 Planos esquemáticos cuenca Los Lagos

Plano 7 Planos esquemáticos cuenca Mopán

Índice de ilustraciones

Créditos de ilustraciones

\section{Anexo 2}

\section{Conclusiones en alemán}

\section{Anexo 3}

\section{Resumen}

1- Resumen en español

2- Resumen en valenciano

3- Resumen en ingles

4- Resumen en alemán 
ÍNDICE

AA COMPOSICIÓN ARQUITECTÓNICA Y LA CONSERVACIÓN DE LAS EDIFICACIONES MONUMENTALES MAYAS DEL NORESTE DE PETÉN

Agradecimientos

Introducción

Objetivo de la tesis

Primera parte

Capítulo 1

El marco de referencia

11 Área de estudio

018

Los mayas y su espacio cultura

1.3 Antecedentes de investigación

Capítulo 2

$2.1 \quad$ División del territorio

2.2 Obtención de datos

2.3 Presentación de la información

2 3.1 Datos individuales 040

2.4 Campo de investigaciones 042

2.4.1 Conservación del patrimonio 043

2.4.2 Composición arquitectónica 051

2.4.2.1 Metodología en otros sitios 052

2.4.2.2 Relaciones urbanas 053

2.4.2.3 Metodología aplicada en Petén 066

Segunda parte

Capítulo 3

Resultado de investigaciones

070

3.1 Sitios y posición en el paisaje

3.1.1 Indicadores de tamaño

070

3.1.1.1 Indicador "espacios libres"

073

3.1.1.2 Indicador "elementos masa"

074

3.1 .2 Relaciones visuales 
Capítulo 4

$4.1 \quad$ Espacios libres

4.1.1 Plazas

086

4.1.1.1 Plazas con monumentos 087

4.1.1.2 Plazas con edificaciones 088

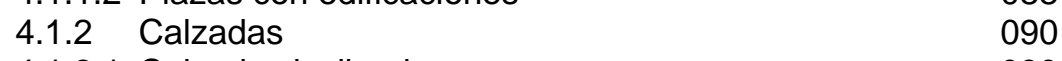

4.1.2.1 Calzadas inclinadas $\quad 090$

4.1.2.2 Calzadas horizontales 091

4.1.2.3 Casos especiales 092

$\begin{array}{ll}\text { 4.1.2.4 Calzadas entre sitios } & 093 \\ 4.1 .3 \text { Vías } & 094\end{array}$

4.1.3.1 Vías y grupos de edificios 095

$\begin{array}{lll}4.1 .4 & \text { Patios } & 095\end{array}$

4.1.5 Plataformas con espacios vacíos 096

4.2 Elementos sólidos 097

4.2.1 Edificios horizontales 098

4.2.1.1 Edificios representativos

4.2.1.2 Edificios aislados y peraltados 102

$\begin{array}{ll}\text { 4.2.1.3 Salones abiertos } & 103 \\ \text { 4.2.1.4 Salones con pórtico } & 104\end{array}$

4.2.1.5 Edificios circulares $\quad 105$

4.2.1.6 Baños de vapor 106

4.2.1.7 Cancha para el juego de pelota 107

$\begin{array}{ll}\text { 4.2.1.8 Grupos de edificios no elevados } & 109 \\ \text { 4.2.1.9 Grupos de edificios elevados } & 110\end{array}$

4.2.2 Edificios verticales 111

4.2.2.1 Pirámide sin construcción superior $\quad 112$

$\begin{array}{ll}\text { 4.2.2.2 Pirámide con construcción superior } & 112\end{array}$

4.2.3 Combinaciones de edificios verticales 116

4.2.3.1 Templos pirámides gemelas 116

$\begin{array}{ll}\text { 4.2.3.2 Templos pirámides en hilera } & 116 \\ \text { 4.2.3.3 Grupos de templos pirámide } & 117\end{array}$

4.2.4 Edificios horizontales y verticales 118

4.2.4.1 Grupos E 118

4.2.4.2 Grupos Triádicos 120

$\begin{array}{ll}\text { 4.2.4.3 Grupos de cuatro edificios } & 124 \\ 4.3 \quad \text { Grupos de patios } & 125\end{array}$

4.3.1 Grupos de pátios elevados (Acrópolis) 127

4.3.2 Grupos de patios no elevados 132

4.4 Otros elementos 135

4.4.1 Depósitos de agua 135

4.4.2 Chultunes 136

4.4.3 Terraplenes 137

$\begin{array}{lll}4.4 .4 & \text { Fosas y canales } & 138\end{array}$ 
4.4.5 Pasillos abovedados

4.4.6.1 Tumbas excavadas

4.4.6.2 Tumbas mixtas

4.5 Consideraciones y relaciones

Capítulo 5

Elementos de arquitectura

5.1 Superfície de muros

5.1.1 Muros exteriores 165

$\begin{array}{lll}5.1 .2 & \text { Puertas } & 168\end{array}$

5.1.3 Ventanas 170

5.1.3.1 Ventanas simuladas 171

5.1.4 Perforaciones 171

5.1.5 Nichos 172

5.1.6 Otras perforaciones 173

5.1.7 Aberturas excavadas 173

$\begin{array}{lll}5.2 & \text { Bancas y escalinatas } & 174 \\ 5.2 .1 & \text { Bancas } & 174\end{array}$

5.2.2 Escalinatas interiores 176

5.3 Superficie de techos 177

5.3.1 Paramento exterior 177

5.3.2 Paramento interior 178

5.3.3 Pasadores de madera 179

$\begin{array}{lll}5.4 & \text { Cresterías } & 180\end{array}$

Capítulo 6

Elementos constructivos

6.1 Plataformas 189

6.2 Muros 197

6.3 Techos 203

Capítulo 7

Materiales

Piedra

$\begin{array}{ll}7.2 & \text { Cal } \\ 7.3 & \text { Madera }\end{array}$

210

213

Agregados 
Tercera parte

Capítulo 8

8.1 Saqueo arqueológico

223

8.1.1 Intentos para detener el saqueo 227

8.1.2 Cantidad de saqueos 230

8.2 Otros factores 233

8.3 Intervenciones en edificios 236

8.3.1 Uaxactún (1927-1937) 237

8.3.2 Proyecto Tikal (1956-1969) 238

$\begin{array}{ll}\text { 8.3.2.1 Grupo Q } & 239 \\ 8.3 .2 .2 \text { Gran Plaza } & 241\end{array}$

$\begin{array}{ll}\text { 8.3.2.2 Gran Plaza } & 241 \\ \text { 8.3.2.3 Acrópolis Central } & 245\end{array}$

$\begin{array}{ll}\text { 8.3.2.4 Otras intervenciones } & 246\end{array}$

$\begin{array}{lll}\text { 8.3.3 Administración Parque Nacional Tikal } & 247 \\ 8.3 .4 & \text { Proyecto Nacional Tikal } & 249\end{array}$

8.3.4 Proyecto Nacional Tikal 249

$\begin{array}{ll}\text { 8.3.4.1 Tikal (1980-1985) } & 249 \\ \text { 8.3.4.2 Uaxactún (1983-1985) } & 252\end{array}$

Capítulo 9

Resultado de intervenciones 1987 agosto 2006

$9.1 \quad$ Uaxactún 1987-1991 259

9.2 Tikal 1987-1992 262

9.2.1 Templo V 262

9.2.2 Templo I 264

9.2.3 Otros edificios 265

$\begin{array}{lll}9.3 & \text { Topoxté 1987-1996 } & 266 \\ 9.4 & \text { Yaxhá 1987-2007 } & 268\end{array}$

$\begin{array}{lll}9.4 & \text { Yaxhá 1987-2007 } & 268 \\ 9.4 .1 & \text { Acrópolis Este } & 268\end{array}$

$\begin{array}{lll}9.4 .1 & \text { Acrópolis Este } & 268 \\ 9.4 .2 & \text { Otros edificios } & 272\end{array}$

9.4.3 Intervenciones PDS-BID 273

9.5 Nakum 1987-2007 275

9.5.1 Plaza Central 276

9.5.2 Plaza Este 278

9.5.3 Plaza Sureste 278

9.5.4 Acrópolis 279

9.5.4.1 Patio $1 \quad 279$

9.5.4.2 Patio 2

$\begin{array}{ll}9.5 .4 .3 \text { Patio } 3 & 282 \\ 9.5 .4 .4 \text { Patio } 4 & 282\end{array}$

9.5.4.5 Patio 5

9.5.4.6 Patio $6 \quad 284$

$\begin{array}{ll}9.5 .4 .7 \text { Patio } 7 & 284\end{array}$ 
9.5.4.8 Patio $8 \quad 285$

9.5.4.9 Patio 9

9.5.4.10 Patio $10 \quad 287$

9.5.4.11 Patio $11 \quad 287$

9.5.4.12 Patio 12

9.6 Naranjo 288

9.7 Otros del triángulo cultural 288

9.7.1 Poza Maya 288

9.7.2 Pochitoca 289

9.7.3 Naranjito 289

9.7.4 El Pital 289

$\begin{array}{lll}9.7 .5 & \text { Otros sitios } & 290 \\ 9.8 & \text { Alrededor del triángulo cultural } & 290\end{array}$

9.8.1 La Blanca 290

$\begin{array}{ll}9.8 .1 & \text { La Blanca } \\ 9.8 .2 & 290\end{array}$

9.8.3 Corozal Torre 290

9.8.4 San Clemente 291

9.9 Prioridades de intervención 292

Capítulo 10

Programación y procedimiento de conservación 297

10.1 Recorridos

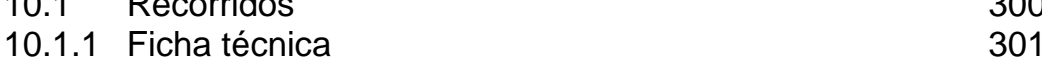

10.1.2 Fichas resumen 303

10.2 Acciones preventivas 303

10.2.1 Campamentos 304

10.2.2 Documentación de saqueos $\quad 305$

10.2.3 Pozos de sondeo 306

10.2.4 Plano de situación 307

10.3 Control de vegetación 307

$\begin{array}{lll}10.4 & \text { Personal, tiempo y logística } & 311 \\ 10.5 & \text { Arqueología de rescate y restauración } & 313\end{array}$

10.5 Arqueología de rescate y restauración 313

$\begin{array}{lll}10.6 & \text { Intervenciones para uso frecuente } & 318 \\ \text { 10.6.1 } & \text { Acciones en arqueología } & 320\end{array}$

$\begin{array}{ll}\text { 10.6.1 Acciones en arqueología } & 320 \\ \text { 10.6.2 Infraestructura } & 321\end{array}$

10.6.3 Documentación grafica 322

Capítulo 11

Presentación y uso del patrimonio cultural 326

11.1 San Clemente 326

11.2 Triángulo cultural Yaxhá-Nakum-Naranjo 332 
Capítulo 12

12.1 Descripción por cuencas 337

12.1.1 Cuenca Mirador 337

12.1.2 Área Tikal 339

12.1.3 Cuenca Ixcán $\quad 340$

12.1.4 Cuenca Holmul 343

12.1.5 Cuenca de los Lagos 344

12.1.6 Río Mopán 346

$\begin{array}{lll}12.2 & \text { Conjuntos estrategicos } & 347 \\ 12.1 & 349\end{array}$

12.2.2 Zona central 351

12.2.3 corredores de comunicación 353

$\begin{array}{lll}\text { 12.2.4 } & \text { Zonas de concesiones } & 356 \\ 12.3 & \text { Estrategia } & 357\end{array}$

Capítulo 13

Conclusiones $\quad 362$

$\begin{array}{ll}\text { Bibliografía } & 378\end{array}$

Anexo 1

Figuras en cuadros

Cuadro 1 Sitios que forman la muestra (128 Sitios)

Cuadro 2 Intervención en sitios arqueológicos, el noreste de Petén

Cuadro 3 Posición del sitio con el paisaje

Cuadro 4 Elementos urbanos

Cuadro 5 Elementos de arquitectura visible

Cuadro 6 Registro de saqueos en edificios

Cuadro 7 Indicadores de saqueo

Cuadro 8 Indicadores de edificios en peligro

Cuadro 9 Prioridades de intervención

Cuadro 10 Principales programas y proyectos de inversión

Figuras con planos

Plano 1 Plano de sitios arqueológicos que conforman la muestra

Plano 2 Planos esquemáticos cuenca Mirador

Plano 3 Planos esquemáticos área Tikal

Plano $4 \quad$ Planos esquemáticos cuenca Ixcán

Plano 5 Planos esquemáticos cuenca Holmul 
Plano 6 Planos esquemáticos cuenca Los Lagos

Plano 7 Planos esquemáticos cuenca Mopán

Índice de ilustraciones

Créditos de ilustraciones

Anexo 2

Conclusiones en alemán

Anexo 3

Resumen

1- Resumen en español

2- Resumen en valenciano

3- Resumen en ingles

4- Resumen en alemán 
AGRADECIMIENTOS

Como becado del gobierno Alemán, bolsa de estudios del Deutscher Akademischer Austauschdienst e. V. tuve la oportunidad de realizar la maestría de restauración de monumentos en la Technische Universtität München. Allí conocí a dos profesores que me animaron a continuar profundizando sobre la restauración y la cultura maya.

Uno de ellos fue Michael Petzet, quien me apoyo para trabajar como voluntario en el Bayerisches Landesamt für Denkmalpflege, AussenStelle Schloss Seehof, Bamberg y a repetir el curso de maestría en restauración de monumentos, ahora desde el punto de vista de la historia del arte en la Universidad de Bamberg con el profesor Achim Hubel.

En la Universidad Técnica de München, no había ningún catedrático que pudiera asesorarme en el tema maya; mis profesores me recomendaron solicitar a un ex estudiante de la TU München para apoyarme. Así realice un viaje en tren de München a Bonn a la Kommissión für Allgemeine und Vergleichende Archäologie des Deutschen Archäologischen Instituts y conocí a Wolfgang Wilhelm Wurster, padrino de este estudio.

Originalmente mi tema de tesis era sobre la composición arquitectónica de escalinatas mayas. Wurster me convenció de que mi estudio debería ser mas amplio y tener una proyección mas útil para Guatemala. La estrecha colaboración con Wolfgang Wurster termino en diciembre del año 2003, luego continúo el apoyo científico del nuevo director, Burkhard Vogt y de Markus Reindel, a quienes agradezco su entusiasmo y apoyo. 
La idea original de realizar mi investigación y escribir este documento se vio retrasada por la providencial oferta de trabajar para el Ministerio de Cultura y Deportes de Guatemala en Tikal. Oportunidad que me permitió poner en marcha mis ideas y materializar el aprendizaje adquirido en Alemania. Por muchos años mis esfuerzos se concentraron en la atención al patrimonio edificado prehispánico en el noreste de Petén.

En ese trabajo tuve la suerte de conocer en Tikal a mi director de tesis Gaspar Muñoz Cosme y a Cristina Vidal Lorenzo. Con ellos compartimos la ejecución de proyectos de restauración, tuvimos extensas discusiones sobre la arquitectura maya y realizamos varios viajes de observación y estudio en el área maya. Muy especialmente agradezco el invalorable apoyo, tutela, gestiones, motivación y consejos para llevar a buen fin este estudio.

Agradezco a los compañeros del Instituto de Antropología e Historia del Proyecto Nacional Tikal, por su colaboración en los trabajos de campo y en las oficinas centrales. Especialmente a Michelle Salazar, que me soporto por años y fue participe desde los primeros borradores de este documento y en la elaboración de cientos de informes. A Raúl Noriega Girón y Zoila Calderón Santizo por su compañerismo y orientación en mis investigaciones. También reconozco a todas las autoridades administrativas del Ministerio de Cultura y Deportes que apoyaron este proyecto, en especial a las administradoras del Proyecto Protección de Sitios Arqueológicos en Petén.

Gracias a los compañeros de trabajo en Petén que me guiaron y atendieron en los numerosos recorridos por la selva. Con ellos aprendí a compenetrarme más en la arquitectura maya y a apreciar 
los momentos de encontrar un nuevo sitio arqueológico; a disfrutar la emoción de documentar y discurrir por espacios urbanos perdidos. También reconozco los días de campamentos en hamacas y las historias contadas de viejos chicleros y saqueadores famosos alrededor de la hoguera.

En Austria, quiero reconocer especialmente a Herta Thym, madre de Roberto, por su constante motivación para concluir este proceso y su apoyo en las primeras versiones del texto en alemán. A Roberto Óscar por su ejemplo, ánimos y las traducciones en ingles y alemán; también a los amigos de Graz, gracias por su soporte científico y apoyo. Aquí también agradezco a los amigos interesados en el tema maya, que revisaron mis textos en Alemania, España y Guatemala. Especial reconocimiento a las arquitectas Michelle Méndez, Telma Tobar y Rocío Araujo por la revisión final de los textos, el arreglo de las figuras y la diagramación.

A mi familia en Guatemala por su incondicional apoyo durante casi dos décadas de investigación y trabajos de campo en el corazón del mundo maya. En especial a Luana por aportar la computadora y los fondos de los últimos veinte meses.

El poder presentar este estudio, es un merito de muchas personas que me apoyaron y es en conjunto la conclusión de un sueño por contribuir en el conocimiento y la preservación del patrimonio monumental maya. 


\section{INTRODUCCIÓN}

La investigación aquí presentada es el resultado de 19 años de trabajo de campo en la región noreste del departamento de Petén. El comienzo se remonta al año 1987, luego de cinco años de estudios de posgrado en Alemania. Este trabajo es posible gracias a que me fue permitido participar, como responsable de un proyecto de inversión del Ministerio de Cultura y Deportes de Guatemala, en el área de mi tesis.

El estudio se circunscribe a un espacio determinado de las tierras bajas mayas centrales. En este territorio se hicieron varios procesos de investigación, análisis, síntesis y acción. La primer tarea fue realizar múltiples recorridos por el territorio en estudio, para tener conocimiento de causa y propiedad sobre la composición arquitectónica y el estado de conservaron del patrimonio edificado monumental maya, tema especifico de este trabajo.

El objetivo general, fue dejar constancia de los procesos mentales y acciones realizadas durante el trabajo de campo en Petén. El objetivo científico fue dirigido en dos sentidos. El primero fue buscar mediante una metodología los fundamentos de la composición del espacio urbano y las formas arquitectónicas de los edificios monumentales prehispánicos maya; el segundo objetivo fue establecer indicadores y procedimientos para la conservación del patrimonio edificado maya. Inquietud traída desde la época de estudios de maestría en restauración de monumentos en Alemania

El tema principal del estudio se circunscribe a las edificaciones monumentales de piedra erigidas entre los periodos culturales de 500 a.C. a 1697 d.C. Este espacio temporal corresponde a las épocas de Preclásico Tardío, el Clásico y el Posclásico maya. Posteriormente a 1697, no se edifican más ciudades mayas y el territorio queda 
prácticamente deshabitado y cubierto por la selva tropical. Esta situación determino que el "objeto" a ser investigado o tratado, en este estudio, adquirió la condición de "ruina arqueológica" y por lo tanto el análisis de su composición arquitectónica requiere de una metodología particular. Igual circunstancia se requiere para entender y proponer esquemas de conservación en los edificios y sitios arqueológicos de la región.

La característica principal del territorio seleccionado (cuadrante noreste del departamento de Petén) es su gran actividad cultural prehispánica, que hasta ahora ha sido poco investigada. Aunque la muestra recabada para este trabajo no abarca la totalidad del recurso cultural del territorio, constituye una parte representativa del área en estudio que permite sacar conclusiones, comparaciones, acciones y propuestas de investigación y conservación.

Expediciones a sitios mayas se realizan desde finales del siglo XVI. Pero en el área del estudio (cuadrante noreste de Petén) las incursiones en el territorio se inician en 1848, con la visita oficial del gobernador de Petén Modesto Méndez a Tikal. Grandes partes del área de investigación no cuentan con poblados recientes ni vías o caminos para vehículos. A principios del siglo $X X$ la comunicación se realizaba a pie o en bestias, 30 años después se añaden pequeñas pistas de aterrizaje para avionetas que luego son abandonadas. La actividad principal de la región fue la recolección de chicle (látex del árbol chicozapote); mas tarde en la década de 1960, fue la extracción de codiciadas maderas de caoba y cedro. La mayor porción del área en estudio, es desde 1990 un segmento del área protegida culturalnatural llamada "Reserva de la Biosfera Maya". 
El propósito de los recorridos por la selva del noreste de Petén fue identificar y actualizar los datos sobre los sitios arqueológicos. Muchos de los centros urbanos mayas encontrados fueron registrados por primera vez, en otros casos no había información renovada con datos de hace 50 y más años. La muestra actualizada llego a 128 sitios. La metodología de registro permite su comparación entre unos y otros pues todos fueron realizados por el mismo equipo de registro.

Antes de este trabajo no se había realizado, en la región, estudios sistemáticos sobre la composición urbana y las formas de arquitectura de los edificios prehispánicos; tampoco sobre el estado de conservación del patrimonio edificado. Los resultados del estudio confirman que esta zona es prioritaria para la investigación y la realización de acciones correctivas para rescatar el patrimonio edificado prehispánico y la herencia cultural maya.

El estudio está dividido en cuatro partes. El primer segmento corresponde al marco de referencia y la metodología (capítulos 1 y 2). La segunda parte contiene el resultado de las investigaciones sobre los espacios construidos (capítulos 3 al 7). Conociendo la composición arquitectónica y sus sistemas constructivos se puede formular, con mayor propiedad, en ellos medidas de conservación. Este tema forma la parte tercera de este documento y se desarrolla en los capítulos 8 al 11. Los resultados de las investigaciones y acciones realizadas se integran y combinan para formula un esquema de conservación y desarrollo especifico para el noreste de Petén. Este proceso forma la cuarta parte de este documento (capítulo 12). La última parte recoge las conclusiones del estudio e identifica otras investigaciones necesarias para continuar conociendo y analizando la composición arquitectónica prehispánica maya. Además se mencionan los pasos 
necesarios, que deberían seguirse para recuperar este patrimonio edificado.

Para simplificar la lectura, los cuadros con los resultados se presentan fuera del texto en un apéndice (anexo 1); de esta forma el texto no se ve interrumpido por varias páginas con datos estadísticos. Igualmente se presenta en el anexo 1 los planos esquemáticas de los centros mayas, empleados para el análisis de los espacios construidos (segunda aparte de este estudio). La indicación del norte en la mayoría de las figuras con mapas, planos y tablas con formas esquemáticas no aparece, ya que en todos los casos las figuras están con el norte hacia arriba. También tomamos el criterio de acentuar los nombres de sitios arqueológicos cuya raíz procede de lenguas indígenas, a pesar de existir los acuerdos gubernativos 1046-87 y 129-88. Esto se hace para facilitar a las personas que no conocen la entonación adecuada de los nombres dados a los sitios arqueológicos.

\section{Objetivo de la tesis}

Un propósito fue iniciar a sistematizar un proceso sobre la composición arquitectónica de las ciudades mayas del noreste de Petén. Conocer la forma y las relaciones de los elementos arquitectónicos dominantes que le dan un carácter local y particular a la región. También se buscó contar con datos recientes y comparables que reflejen el estado de conservación actual del patrimonio edificado en el noreste de Petén. En este estudio, solamente se da una primera visión sobre los elementos, formas y condición de los sitios arqueológicos de la muestra recabada. La información actual no permite ir más adelante. La gran mayoría de los centros urbanos mayas, en condición de ruina arqueológica, aún se encuentran cubiertos de escombros y vegetación y sin investigación 
científica. Seguramente la región cuenta con mucho más sitios arqueológicos aún no identificados, condición que enriquecerá el conocimiento de los elementos de composición urbana y de arquitectura aquí presentados.

El otro objetivo fue, el contar con información sobre el estado de conservación actual de este patrimonio edificado. Para ello se tomaron dos indicadores "edificios con saqueos" y "edificios con arquitectura expuesta en peligro" que permiten tener una referencia o idea clara de la condición actual de las edificaciones mayas. La investigación y acciones de conservación realizadas en el patrimonio edificado pueden servir de base para formular una visión regional. Esta visión debería ser considerada para incorporar el patrimonio edificado maya a un esquema de rescate, participación y desarrollo.

El hilo conductor de este trabajo está sustentado en la metodología planteada en el capítulo 2. El proceso se realiza con un esquema distribuido en seis apartados. Estos apartados van desde la esfera del área del estudio (el territorio seleccionado) a las muestras recolectadas para la investigación. En el tercer apartado (investigaciones), se estudian los dos objetivos principales de este trabajo y sus resultados se presentan en la segunda y tercera parte de este documento. Los apartados siguientes ( 4,5 y 6 ) forman parte de la estrategia para rescatar, conservar y usar el patrimonio monumental edificado en piedra. El proceso continua y se retroalimenta constantemente formando así un esquema de planificación rescate y acción regional. 


\section{EL MARCO DE REFERENCIA}

\section{1 ÁREA DEL ESTUDIO}

El marco geográfico del estudio tiene un espacio físico de aproximadamente 100 kilómetros este-oeste por 100 kilómetros surnorte, formando un área estimada de 10000 kilómetros cuadrados; ubicado en el extremo noreste de Guatemala. El área limita al norte con México y al este con Belice. El territorio en estudio todavía presenta en la parte central y norte una cubierta boscosa continua con una alta diversidad de especies, característica de los bosques húmedos subtropicales cálidos que se extiende hacia los territorios vecinos al oeste, norte y este.

La parte de los grandes humedales, al norte y centro, se mantiene con poca población permanente y escasos caminos de difícil circulación en la época de lluvia. En la parte de los lagos, al sur, se concentran las nuevas poblaciones, una mejor red vial y abundante deforestación.

La región noreste de Petén está localizada sobre la plataforma de Yucatán, la cual corresponde a la prolongación meridional de la península de Yucatán, predominando las rocas sedimentarias con depósitos marinos de yeso y marga del paleoceno-eoceno. Además posee aluviones que se caracterizan por tener drenajes deficientes y numerosos "bajos" o humedales. La mayor parte de esta fisiografía es plana con la excepción de un relieve de colinas bajas al norte de la región central de los lagos que divide el territorio en dos partes; al oeste un área de bajos conocida como la cuenca Mirador y al este 
una serie de bajos con dos cuencas dominantes (Ixcán- río Azul y Holmul). En este grupo de colinas parte aguas se forma un paso natural este-oeste; en posición estratégica, cerca de estos pasos, se colocaron ciudades prehispánicas tales como Tikal, Uaxactún y El Zotz.

La característica fisiográfica de la parte sur, del área de estudio, es una cadena de cuerpos de agua que se desplazan este-oeste. El límite sur, lo forma un grupo de colinas llamada "El Cinturón Plegado del Lacandón", con relieves cársticos con una altura promedia de 300 $\mathrm{m}$ sobre el nivel del mar; son rocas sedimentarias plegadas que sobresalen del relieve plano con rocas calizas y dolomíticas del cretaceo-terciario.

Los suelos son poco profundos (0.24-0.50 m) de textura arcillosa y de color oscuro. La dureza de la roca madre no permite la penetración profunda de las raíces, sin embargo este frágil suelo sostiene árboles de $50 \mathrm{~m}$ de altura cuyas raíces se expanden horizontalmente. La vocación del suelo es forestal; altamente susceptible de erosión. El relieve va entre los 100 y $300 \mathrm{~m}$ sobre el nivel del mar con una pendiente promedio de $5 \%$ de sur a norte.

Una característica especial de la región noreste son los grandes sistemas de humedales de agua dulce. En 1931 el geólogo C. Wythe Cooke opinó que los bajos no son más que azolvados cuerpos de agua que durante el clásico maya eran lagos de agua clara con pescado y que permitía un comercio con canoas (Morley 1937 Vol.1, 2).

Al norte de Tikal, en el bajo la Juventud, nace el río Uaxactún que después se llama río Azul. Este río ahora estacionario pasa por los 
sistemas de humedales llamados El Azúcar e Ixcán; el drenaje continúa en territorio beliceño y mexicano con el nombre de río Hondo hasta llegar al Mar Caribe.

Al sur de Tikal nace el río Negro, que luego se llama río Holmul (ahora estacionario) formando varios grupos de humedales entre los que se encuentran el Bajo Santa Fe, La Justa, Las Chamacas, Jobal y la Laguna Yaloch; ese sistema penetra en Belice y continúa hasta el Mar Caribe con el nombre de río Nuevo. Al Oeste de Tikal una serie de humedales forma el nacimiento del río San Pedro, sistema que luego se une con el río Usumacinta para llegar al Golfo de México.

Fuera de los grandes humedales, al sur, la condición es distinta, aquí la característica del paisaje es un sistema de 14 cuerpos de agua en cadena, con una franja aproximada de 90 kilómetros de largo por 30 kilómetros de ancho.

El extremo sureste del área de estudio pertenece a otra depresión geológica que forma un corredor natural llamado "cuenca del río Mopán". Este sistema está formado por tres ríos permanentes (Salsipuedes, Mopán y Chiquibul) que se unen en el extremo norte de la cuenca formando luego el río Belice; sistema fluvial que continúa hasta llegar al Mar Caribe.

En el extremo noroeste del área de estudio, la característica dominante lo forma el sistema de bajos de "Laguna del TigreMirador-Calakmul" y el río Candelaria con un drenaje hacia el Golfo de México. 
Las características culturales, fisiográficas y climáticas son similares más allá del límite arbitrario del área de estudio.; hacia el norte el mismo paisaje llega hasta la zona cultural de Río Bec. Al este con la zona de río Hondo y río Nuevo hasta llegar al sistema costero.

En resumen, la condición general del área de estudio se divide en dos partes: al norte la región de los grandes humedales y al sur una área mas pequeña, que corresponde a los lagos y ríos permanentes. La característica original de la porción sur, ha sido la de un corredor de comunicación natural. Usado como tal, antes de la llegada de los mayas, durante la colonia y actualmente. La parte más grande, al norte, con los humedales, por el contrario forma una especie de bolsa aislada, difícil de comunicar, con periodos de sequía y de inundaciones.

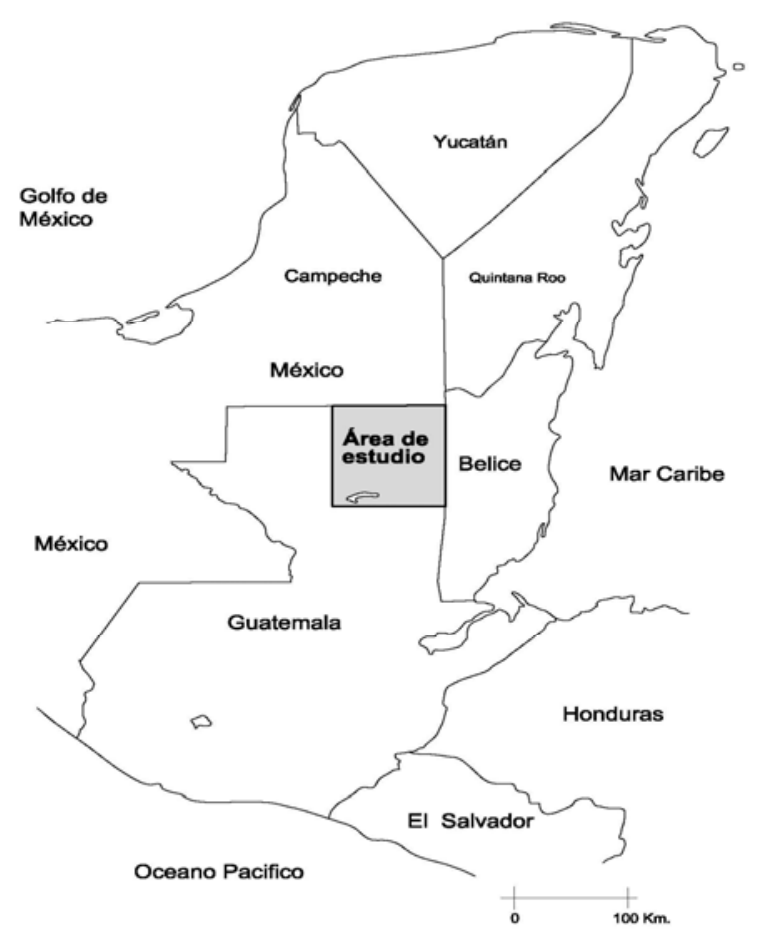

Fig.01. Mapa de la península de Yucatán con el área de estudio. 


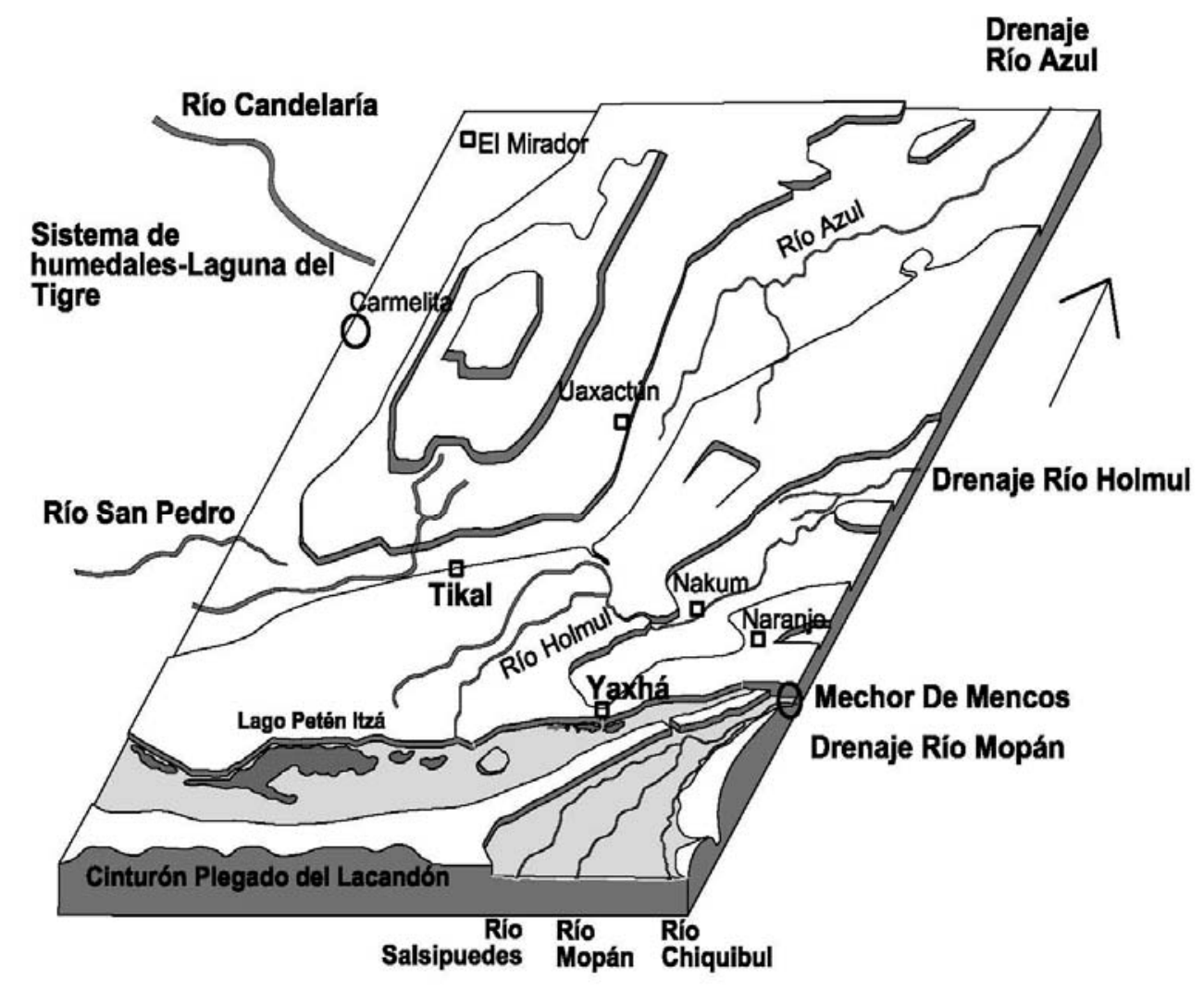

Fig.02. Esquema de la estructura orográfica en el noreste de Petén

\subsection{LOS MAYAS Y SU ESPACIO CULTURAL}

El cuadrante noreste de Petén, se encuentra dentro de la zona cultural conocida como "Tierras bajas centrales". En la figura 03 se presenta las tres grandes áreas en que se divide el territorio maya. Cada área tiene sus propias divisiones, por ejemplo el área sur se divide en tierras alta y tierras bajas del sur. El área central en las tierras bajas centrales, las montañas mayas y la cuenca de los ríos Pasión y Usumacinta; el área norte con las tierras bajas del norte. En esta sección hay varias subdivisiones como la zona PUUC, zona 
Chenes, Costa Caribe y otras. Nuestra investigación se ubica al centro, en las tierras bajas centrales. Para una referencia general de la cultura maya en el espacio y en el tiempo, ver (Muñoz Cosme 2003, 20-69).

Como referencia a los horizontes culturales para la región en estudio; se ha tomado los datos dados para la secuencia cerámica de la cuenca Yaxhá-Sacnab por Bernard Hermes (Hermes, en Wurster 2000, 164).

\begin{tabular}{|c|l|l|}
\hline \multirow{4}{*}{ Preclásico } & 900 a 300 a.C. & Medio \\
\cline { 2 - 3 } & 300 a.C. a 0 d.C. & Tardío \\
\cline { 2 - 3 } & 0 a 280 d.C. & $\begin{array}{l}\text { Terminal } \\
\text { Protoclásico }\end{array}$ \\
\hline \multirow{2}{*}{ Clásico } & 280 a 580 d.C. & Temprano \\
\cline { 2 - 3 } & 580 a 800 d.C. & Tardío \\
\cline { 2 - 3 } & 800 a 900 d.C. & Terminal \\
\hline Posclásico & 900 a 1200 d.C. & Temprano \\
\cline { 2 - 3 } & 1200 a 1500 d.C. & Medio \\
\cline { 2 - 3 } & 1500 a 1697 d.C. & Terminal \\
\hline
\end{tabular}

Fig.03. Cuadro cronológico del área en estudio

Por lo general los vestigios visibles, ahora en condición de ruina arqueológica, corresponden al último período de ocupación de esta sorprendente civilización. Para la gran mayoría del territorio en estudio, esta época concluye en el período Clásico Terminal, a partir del año 800-900 d.C. Sólo al sur, en la región conocida como la "cuenca de Los Lagos" el período cultural maya se extiende hasta 1697. Fecha en que la ciudad de Tayasal fue tomada por la fuerza. Último baluarte independiente en toda el área maya. 
Es sabido por las investigaciones realizadas en la región (Hansen 1998, 2000, Fialko 2005, Laporte 2001, Valdés 1992, 2000, 2005) y por las evidencias expuestas por el saqueo arqueológico, que este territorio fue densamente poblado a partir del Preclásico Tardío/Terminal. Desde esta época, alrededor de los años 300 a.C. a 280 d.C., el noreste de Petén presenta evidencia tangible de construcciones monumentales en piedra y continuó produciendo ciudades grandes, medianas y pequeñas, por todo el territorio, hasta aproximadamente los año 800-900 d.C. No se sabe con exactitud la magnitud de esta impresionante producción humana y hace falta aun buena cantidad de información para conocer su verdadera historia.

En relación a las entidades políticas que jugaron su papel en este territorio, podemos decir que el noreste de Petén ocupa una posición extraordinaria dentro el mundo de los mayas antiguos. Como en otras regiones de Petén, los mayas vivieron en éste espacio desde el Preclásico, y en la ciudad de El Mirador constituyeron el principal núcleo cultural de esta época. Aquí la pirámide de El Danto es la edificación más alta del Preclásico maya, sólo comparable con la Pirámide del Sol en Teotihuacan o la Pirámide de Cheops en Egipto. A finales del período Preclásico esta sorprendente ciudad y su sistema son abandonados.

En los comienzos de la época Clásica (280 d.C.), la región estaba llena de "pequeños" centros poblados como Yaxhá, Uaxactún, Holmul, Naranjo, Tikal y otros sitios más pequeños. En medio de la época Clásica, Naranjo era el sitio dominante de la región. Sus influencias llegaron hasta México y Belice. Su historia dinástica y sus guerras de conquista son conocidas por su gran corpus de inscripciones (Martin y Grube 2000, 24-53 y 68-83). 
A finales de la época Clásica, Tikal fue la ciudad dominante de la región. Las historias de esta ciudad, la más conocida y reconstruida de Petén, también es popular por su corpus de inscripciones. Sorprende en su historia que, después de una guerra perdida, la nobleza de Tikal desapareció por más de 120 años. Cuando aparecieron de nuevo, Tikal se puso al frente del poder dominante de la región casi al instante. En sólo dos generaciones, los gobernantes Jasaw Chan K'awiil (682-733d.C) y Yik'in Chan K'awiil (734-? d.C.) construyeron los templos pirámides, calzadas y grupos de patios que hoy le dan a Tikal su fisonomía monumental. Por los glifos emblemas, es conocido que a finales de la época Clásica crecieron muchas ciudades independientes en la periferia de Tikal. Aparentemente el dominio territorial de Tikal se fue igual de rápido como su época de esplendor.

Alrededor del año 900 d.C. Tikal y la región sufrió su segundo colapso. Los mayas dejaron de construir edificios monumentales y en los siguientes cien años abandonaron todas sus ciudades. Las razones exactas de este despoblamiento aun continúan en el misterio, a pesar de que existen varias teorías sobre esto. Interesante es que muchas ciudades subordinadas sobrevivieron unas décadas mas la caída del gran Tikal. El abandono de la región de los grandes humedales fue tal, que cuando aparecieron los españoles con Hernán Cortés en el año 1524, quien pasó por Tayasal en su viaje a Honduras, esta región no era tomada en cuenta.

Después del abandono de Tikal solamente en la zona de Los Lagos, unos pocos enclaves mayas continuaron con edificaciones monumentales en las orillas de los cuerpos de agua. 
En cuanto al complejo sistema político de la región quedan muchos interrogantes. Pues grandes ciudades del Clásico como Xultún, La Honradez, Chochkitam, Xmakabatún, Naachtún, El Zotz, Manantial y otras más, no han sido investigadas, y por lo tanto la historia aun está incompleta.

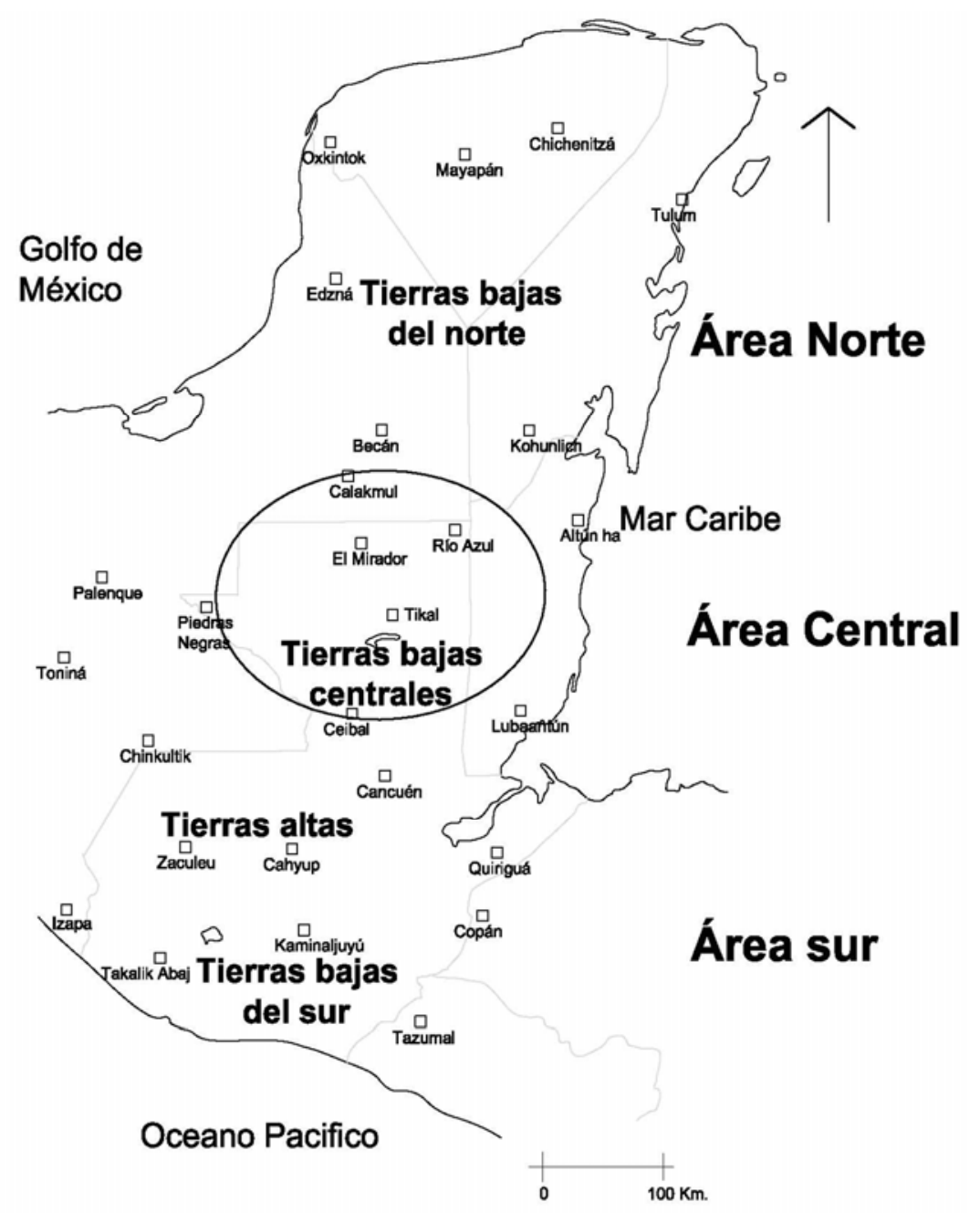

Fig.04. La región maya, con las tres principales áreas (norte, centro y sur) y algunos sitios arqueológicos de referencia. 


\subsection{ANTECEDENTES DE INVESTIGACIÓN}

Los recorridos para descubrir sitios mayas en la región noreste de Petén se inician relativamente tarde. Tikal fue descubierta oficialmente en 1848 (Méndez 1955, 3-7). Luego a finales del siglo XIX y principios del $X X$ una serie de personajes decimonónicos recorrieron el área de estudio; entre ellos Alfred P. Maudslay en Tikal (Maudslay 1889-1902); Karl Sapper en San Clemente (Sapper 1909); Teoberto Maler en Tikal, Tayasal, Motul de San José, Topoxté, Yaxhá y Naranjo (Maler 1908 y 1911); y Maurice de Périgny en Topoxté y Nakum (Périgny 1909 y 1910). Sobre este periodo, Miguel Rivera Dorado dice "...la época maya de Teoberto Maler fue por muchas razones cautivadora. Una pléyade de hombres valerosos se obsesionaron con un ideal arqueológico que había estado dormido durante siglos. Sus proezas todavía resultan atrayentes, y lo que hicieron y descubrieron se convirtió en los sólidos cimientos de la moderna mayistica..." (Rivera Dorado 2002, 43).

Entre 1905 y 1933 suceden las grandes expediciones de las instituciones extranjeras por Petén con investigadores como A. M Tozzer, R. Merwin, S. G. Morley y otros. En esa época se realizaron 17 recorridos por tierra y dos en avión por la región de estudio (Carnegie, Smitsonian Institution of Washington, Peabody Museum of Archaology and Ethnologie of Harvard University, Fiel archaeological expedition of British Museum, Fiel museum of Natural History of Tulane) y descubrieron 12 sitios arqueológicos en el cuadrante del noreste de Petén. Los resultados científicos de este periodo fueron recopilados en cinco volúmenes monumentales por Sylvanus G. Morley (Morley 1937-38). Morley fue el primero que empleó los valles naturales o cuencas para ordenar la información relativa a los sitios arqueológicos en este territorio; así apareció una sección para el Valle El Azúcar, el Valle Holmul y otros. 
Importantes registros en el área del estudio ha realizado, desde los años 1960, Ian Graham con documentación de monumentos de piedra con inscripciones y planos de sitios arqueológicos como Uaxactún, La Honradez, Naranjo, Ucanal, Xultún y otros (Graham, 1975, 1978, 1980, 1986, von Euw y Graham 1984).

Solo hay dos antecedentes de grandes intervenciones; una en Uaxactún entre los años 1926 y 1937 (Ricketson y Ricketson 1937 y Smith 1937,1955) y el famoso Proyecto Tikal (Shook 1958,1964 y Coe 1965, 1967, 1990).

Tikal es la principal carta de presentación maya de Guatemala y por lo tanto ha tenido atención especial. En Tikal se trabaja casi en forma continua desde 1955 con tareas de infraestructura, investigación arqueológica e intervención en edificios. Desde 1970 la responsabilidad de los trabajos científicos de Tikal pasó a Guatemala, formándose equipos de administración-funcionamiento y de inversión. El equipo de inversión tenía por tarea continuar con las investigaciones y los trabajos de restauración en los edificios. A partir de 1982 se extiende la atención a Uaxactún y para el año 1987 Tikal tomaba en cuenta a los sitios de El Zotz, Yaxhá, Topoxté, Nakum y Naranjo. En 1989 se trasladó formalmente personal de Tikal a la zona llamada Triángulo Cultural Yaxhá-Nakum-Naranjo.

Desde 1992 Tikal tuvo el apoyo adicional de proyectos de investigación y restauración de la Agencia Española de Cooperación Internacional AECI (Templo 1, Templo $V$ y Plaza de los 7 Templos). Además Tikal contó con otros contratos particulares para intervenciones en el Templo III, el Templo IV y otros edificios. 
Para la ampliación del área de trabajo de Tikal en el "triángulo cultural" se busco la cooperación técnica y financiera del gobierno Alemán. Contacto que se logro a través del Instituto Alemán de Arqueología. La Cooperación Alemana se debe en gran parte al personal interés del entonces director científico de la Comisión de Arqueología General y Comparada del Instituto Alemán de Arqueología (KAVA), Wolfgang Wilhelm Wurster.

Investigaciones alrededor de los centros principales se han realizado en Tikal y su área de influencia (Webster et al. 2006, 695-703, Martínez et al. 2004, 659-664, Ford 2003, Culbert 1990, Puleston 1983, Carr y Hazard 1961). En Uaxactún (Acevedo y Paz Bone 2005,165-170 Ricketson y Ricketson 1937). En Yaxhá-NakumNaranjo (Fialko 2005, 253-268, Grazioso et al. 2001, 205-209, Lou 2000, 74-76). En Río Azul (Adams 1990, 1986); y otras investigaciones regionales como (Rice y Rice 1990, Turner 1990 y Bullard 1960). Todos los informes confirman que la región del noreste de Petén es una de las zonas de mayor concentración de actividad humana prehispánica en el área maya.

El dominio de la investigación arqueológica de las instituciones norteamericanas en la región, que inició a principios del siglo $X X$, continúa hasta la fecha. La tendencia actual es que cada proyecto arqueológico poco a poco se trasforma en un proyecto regional, reservándose para sí extensos territorios. En el año 2007 había 10 instituciones extranjeras realizando investigaciones arqueológicas en la región del estudio, seis de ellas de universidades de EEUU, una de Canadá, una de Polonia y dos universidades Españolas. Estos proyectos son: Arqueología Cuenca Mirador de la University of California (Los Ángeles), Proyecto Arqueológico Holmul de la Vandervilt University (Nashville), Proyecto Arqueológico San Bartolo 
de la University of New Hampshire (Durham), Proyecto Arqueológico Naachtún de la University of Calgary (Canadá) y la University of Arizona (Tucson), Proyecto de Investigación Arqueológica El Bajo Azúcar de la University of Texas (Austin), Proyecto Maya Colonial de South Illinois University, Proyecto Arqueológico Motul de San José del Williams College (Williamstown), Proyecto arqueológico Nakum de la Universidad Jaguellónica de Polonia y el Proyecto La Blanca de la Universidad de Valencia, Universidad Politécnica de Valencia y La Universidad de San Carlos de Guatemala.

Sólo el Proyecto Nacional Tikal (PRONAT) con sus extensiones a Yaxhá- Nakum-Naranjo y Uaxactún tiene un diseño en donde también se incluye la conservación de los edificios; una condición que la mayoría de las instituciones extranjeras todavía no consideran. En los últimos años, algunos proyectos han incorporado pequeñas actuaciones de rescate de arquitectura como el Proyecto Cuenca Mirador o el proyecto La Blanca y San Bartolo. En principio el objetivo de los proyectos de investigación es obtener información científica, entrenar a sus estudiantes y buscar resolver sus propias teorías científicas

En el cuadro 2 del anexo 1 "intervenciones en sitios arqueológicos en el noreste de Petén", se presenta las actuaciones realizadas en los sitios mayas de la región en estudio. El cuadro esta ordenado en seis secciones y tiene una simbología que se refiere al tipo de actuación sobre los yacimientos. Por ejemplo si se realizaron solo expediciones y documentación, si se hicieron investigaciones arqueológicas con excavaciones, si se ejecutaron restauraciones, si se tomaron registros de daños, si cuenta con infraestructura turística y otros datos. En el mismo cuadro se observa como el conocimiento sobre los yacimientos mayas ha ido aumentando. A finales del año 1900 se 
conocían solo cinco sitios. En los primeros 30 años del 1900 aumento el número a 36 sitios y para finales de siglo alcanzo a 74 sitios arqueológicos. Para el año 2007 la muestra llegó a 128 sitios. La actualización de datos en un mismo formato inicio en 1987. Esta muestra es el sustento científico para las investigaciones y comparaciones de la composición arquitectónica de la región. También es el ámbito de los trabajos y propuestas de intervención de preservación al patrimonio. 
Mencionamos anteriormente que una de las razones que motivó este estudio fue buscar los fundamentos de la composición del espacio urbano y las formas arquitectónicas de los edificios monumentales prehispánicos mayas en el noreste de Petén. Otro propósito fue conocer el estado de preservación actual del patrimonio edificado y obtener un mayor conocimiento de sus sistemas constructivos con el fin de poder proponer y aplicar en ellos medidas de conservación.

Para poder lograr los objetivos mencionados arriba se diseño una metodología, que con seis apartados o esferas de profundidad. Los apartados van desde los aspectos más generales y amplios hasta los detalles. El concepto teórico contempla que luego de llegar al apartado de los detalles el proceso se repite en constante retroalimentación.

El apartado más amplio comprende al territorio en estudio, para este caso el cuadrante noreste de Petén. El segundo apartado se refiere a la técnica de recopilación de datos y su sistematización que representa el corpus de información procesada y actualizada.

El tercer apartado se refiere al proceso científico que da como resultado las investigaciones sobre el "objeto" de estudio. Esta investigación puede atender diferentes aspectos y procesa los datos disponibles y analizados con diferentes visiones. En el tercer apartado se puede procesar otros aspectos del objeto; como seria la investigación arqueológica, el uso del suelo y los recursos, los asentamientos humanos actuales, planificación regional y otros. 
El cuarto apartado es la esfera de las acciones físicas y tangibles realizadas sobre los edificios en piedra, un objetivo de este estudio. En este nivel se presenta los resultados de las acciones realizadas, mostrando el estado de preservación actual del patrimonio maya.

Los apartados cinco y seis integran las investigaciones realizadas y las acciones ejecutadas en un proceso de conservación y presentación del patrimonio edificado maya. Aquí también se analizan las lecciones aprendidas y lo procedimientos empleados. Además se diseña una visión general de las potencialidades del área del estudio.

Cada apartado está diseñado para obtener una o varias respuestas o resultados. La suma de los apartados y sus resultados nos dan una visión con propiedad y sustento teórico. Esta posición puede ser usada como un instrumento de planificación de nuevas investigaciones y de actuaciones. 


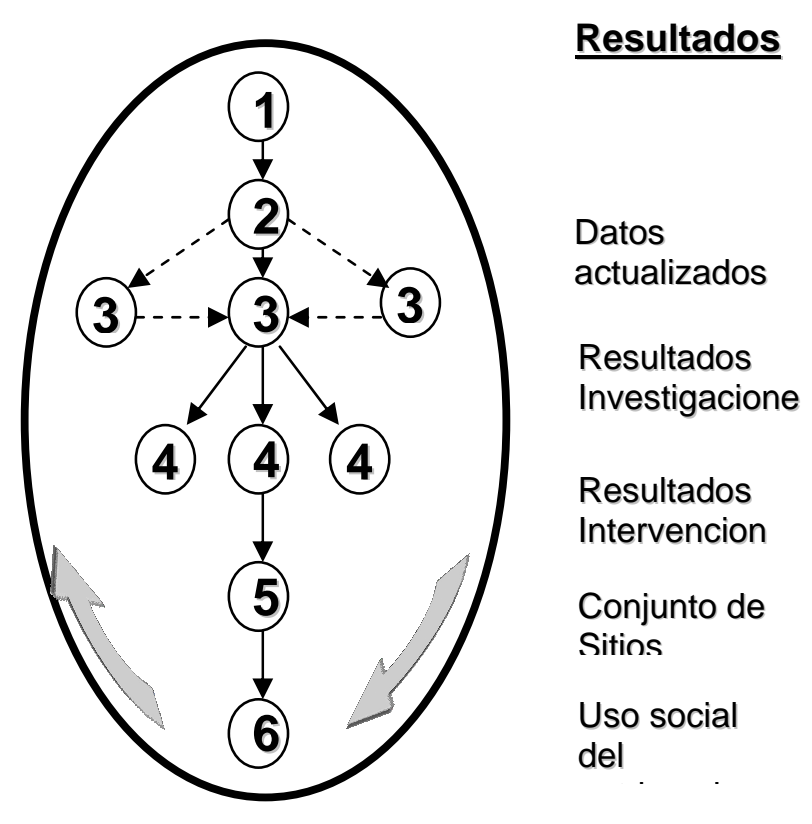

Simbología

1 Territorio seleccionado

4 Intervenciones de conservación

2 Objetos documentados

5 Conjuntos seleccionados

3 Investigación realizada

6 Estrategia

Fig. 05. Metodología, apartados y resultados parciales y totales del esquema.

\subsection{DIVISIÓN DEL TERRITORIO}

La metodología propone fraccionar el territorio en seis partes o cuencas naturales. Con esta división teórica es posible establecer posteriormente, en la fase de análisis y comparación, diferentes parámetros locales de la composición arquitectónica y el estado de conservación de los edificios. 
En principio el cuadrante noreste se divide en dos partes, cuatro segmentos o cuencas para la parte norte, que representa el $79 \%$ del territorio y dos cuencas con paisaje y condiciones diferentes en la parte sur.

El grupo norte tiene un paisaje común tipificado por los grandes humedales o bajos con ríos ahora estacionarios, con periodos de sequía e inundaciones. Los espacios seleccionados son, Mirador, Ixcán, Holmul y el área Tikal. El área Tikal es un espacio físico formado por tres segmentos de cuencas (Ixcán al norte, Holmul al este y río San Pedro al oeste).

El 21\% restante del territorio se refiere a la porción sur del cuadrante noreste. A su vez el extremo oeste del cuadrante es parte del área central del departamento. Este segmento se divide en dos partes una al oeste y centro con la cuenca de Los Lagos y en el extremo sureste la cuenca del río Mopán.

Cada segmento tiene un número o prefijo y cada sitio dentro de dicha cuenca recibe un número adicional. Como ejemplo el sitio El Mirador tiene el código 1-001, Nakbé recibe el código 1-002, La Muralla1-003. De esta forma el área Tikal recibe el prefijo 2 y el sitio Tikal el código 2-008, Ixcán el prefijo 3, Holmul 4, Los Lagos 5 y La cuenca del río Mopán el prefijo 6. En el cuadro 1, se encuentra el listado completo de sitios arqueológicos y su código correspondiente.

\subsection{OBTENCIÓN DE DATOS}

El procedimiento de obtención de datos se basó en recorridos de campo. Estos recorridos requirieron personal entrenado para identificar los rasgos arqueológicos de los yacimientos mayas perdidos en la selva tropical. Para tal efecto se capacitó a 
trabajadores del Instituto de Antropología e Historia (IDAEH) en tareas de levantamiento de planos esquemáticos, registro de elementos de arquitectura, daños en los edificios y otras referencias.

La selección de sitios arqueológicos no obedece a un sistema de rastreo sistemático de las cuencas. La técnica empleada fue arbitraria, dirigida a los yacimientos "grandes"; de preferencia con arquitectura expuesta o visible. Para lograr este objetivo se contrataron guías conocedores de la selva.

La técnica consiste en salidas de dos a siete días de recorridos. El responsable, con la ayuda del personal entrenado, recorre el sitio y elabora un informe técnico incluyendo un plano esquemático. Se anotan los rasgos urbanos visibles, la arquitectura expuesta, los saqueos, la condición de la vegetación sobre los edificios y otros datos. El trabajo en el campo es difícil, ya que la mayoría de los sitios están abandonados y con abundante vegetación.

Las condiciones de selva no han cambiado en buena parte del área en estudio. Por tal razón los planos esquemáticos de este corpus tomaron eL criterio de identificar el centro monumental de la ciudad y de allí hacer, en lo posible, el dibujo de la mayor parte del sitio arqueológico. Por lo tanto no se puede asegurar que esté registrada la totalidad de los grupos de edificios que componen un sitio arqueológico.

Es importante insistir en que el personal y el responsable del levantamiento del plano esquemático tengan entrenamiento. Identificar elementos urbanos en escombros y con abundante vegetación no es fácil. El ojo debe estar acostumbrado a recorrer la selva y a identificar los elementos que forman una estructura urbana 
prehispánica. También es importante que el personal de apoyo sepa leer planos y entender en el campo los leves indicios de una edificación maya y encontrar los detalles principales de las formas escondidas entre la vegetación, el escombro, los saqueos nuevos y los agujeros que dejan árboles gigantes caídos.

La metodología considera la visita del mismo sitio varias veces, esto permite mejorar los planos esquemáticos, rectificar datos y controlar el estado de condición de los edificios en peligro, si hay cambios en el comportamiento de saqueos o alteraciones en la vegetación.

Los nombres de las cuencas naturales, los bajos y los sitios arqueológicos corresponden a las denominaciones actuales dadas por los descubridores recientes; hay yacimientos mayas con nombre de animales como, La Perra, El Tigre, El Danto, El Gavilán, El Burro, El Venado; o parajes locales como: Jimbal, La Pita, Corozal, El Palmar, Manantial, Ramonal, Dos Aguadas, Riverona, Poza Maya, El Tumbo. Otros son llamados como los antiguos campamentos de chicleros cercanos a los sitios arqueológicos encontrados, con nombres como: El Burro, Salsipuedes, La Honradez, La Muerta, El Porvenir, San Bartolo, El Encanto, El Susto y otros.

Los chicleros son personas que llegaron al Petén a principios del siglo XX para trabajar la extracción del látex del árbol chicozapote (chicle), de allí el nombre de chicleros y su fama de conocedores de los secretos de la selva. Estos personajes apoyaron con su conocimiento de ruinas perdidas en la selva a los primeros investigadores. Los chicleros y otros nuevos trabajadores de la selva como los xateros (recolectores de plantas ornamentales) son ahora contratados frecuentemente para hacer recorridos en la selva. Habitualmente al localizar un sitio arqueológico nuevo, a ellos se les pregunta que 
característica local se encuentra cercana. En otros casos reciben un nombre "seudo maya" arbitrario dado por los arqueólogos como: Chunhuitz, Wakna, Uaxactún, El Zotz, Witzná, Kanajau, Nakum o Tikal. Solo el sitio Yaxhá en relación con la laguna del mismo nombre parece ser muy antiguo, pues en 1618 al pasar los monjes franciscanos por la zona de esa laguna, y preguntar como se llamaba, le respondieron "Yaxhá". A su vez Teoberto Maler en 1904 al llegar a la laguna recibe la misma respuesta. David Stuart pudo identificar ese topónimo en varias inscripciones Clásicas (Stuart 1985), demostrando la antigüedad de ese nombre que significa Yax (verde) y Há (agua).

Los conocedores de la selva (chicleros) tienen en su léxico un sistema para identificar los tamaños de los sitios arqueológicos ("Caballos", "Planteles" y "Reinados"). A los informantes se les solicitaba dirigir las comisiones a los sitios grandes o sea los Reinados. Los sitios intermedios son llamados Planteles y los sitios pequeños Caballos.

El procedimiento empleado deja muchos vacíos y no asegura si se ha identificado la mayoría de los sitios "grandes" o los sitios con arquitectura expuesta o visible en peligro en el área de estudio. La presente metodología tiene, como objetivo establecer un parámetro sobre la calidad y la cantidad del patrimonio edificado monumental en el noreste de Petén.

Una de las razones para usar esta metodología de selección arbitraria fue, el cumplir con el objetivo de identificar rápidamente la arquitectura monumental en peligro que requiere atención urgente. Con la muestra recabada tenemos una amplia selección de sitios 
grandes y medianos (reinados y planteles) que nos permiten sustentar la investigación realizada.

Otros autores utilizan otros sistemas de clasificación dependiendo de su foco principal de estudio. Por ejemplo, los epigrafistas se enfocan en sitios con monumentos con inscripciones; otros se concentran solamente en una época particular de actividad cultural. También puede ser que el interés científico sean las entidades políticas y sus áreas de influencia o la posición de un sitio en relación a rutas de comunicación y otros temas.

El interés de Morley por documentar monumentos esculpidos en piedra con inscripciones, determino que en los planos de las primeras expediciones del siglo $X X$, el objetivo principal se focalizara en los sitios con escritura. De esta manera, en la mayoría de los planos, solo aparece la parte central con los edificios principales y sus monumentos esculpidos (estelas y altares). En planos de esa época puede verse ahora lo complicado del levantamiento de ciudades en la selva. En 1932 el Instituto Carnegie envió a Yaxhá al arquitecto William Lincoln para hacer el plano del sitio (Morley 1937-38). Lincoln, en la Plaza $A$, sólo dibujo dos de las cuatro edificaciones que conforman el grupo conocido como "grupo de pirámides gemelas". En esa época la vegetación era tan tupida que Lincoln no pudo percibir el espacio completo de esta plaza y solo documento el espacio contiguo a la Estela 13.

La calidad de los planos disponibles es una limitante para el estudio de la composición arquitectónica. La mayoría de los sitios arqueológicos no cuenta con planos adecuados para realizar diferentes niveles de análisis. El criterio empleado en esta investigación, fue el homogenizar los pocos planos con detalles de 
curvas de nivel con los planos esquemáticos de la mayoría. De esta manera es posible comparar luego unos con otros.

Los resultados actualizados, en la recopilación de datos, forman el marco para las investigaciones y las acciones en el patrimonio.

\subsection{PRESENTACIÓN DE LA INFORMACIÓN}

Los datos recabados en los recorridos por la selva fueron ordenados en fichas técnicas individuales. A su vez, esta información particular se agrupa en cuadros por cuenca. Así es posible realizar posteriores comparaciones, como análisis tipológicos, balance de daños u otros temas de interés científico.

\subsubsection{Datos individuales}

La información por sitio inicia con el nombre y su código, con el prefijo de la cuenca y su número correspondiente. Si el sitio es conocido con diferentes nombres, estos son anotados en la tabla correspondiente. Luego se incorporan datos como ubicación, coordenadas geográficas y accesos. Después se anotan las características y observaciones principales, con indicaciones sobre la composición urbana dominante, los rasgos urbanos identificados, si cuenta con arquitectura expuesta en peligro, cantidad de saqueos, condición de la vegetación sobre las edificaciones y alrededor del sitio, cambios recientes y otros datos. Continúa después la información sobre intervenciones anteriores y publicaciones; aquí se anotan las visitas anteriores y los trabajos que se han realizado en el sitio. Por ultimo se anota su principal referencia bibliográfica. La parte escrita va acompañada de un plano esquemático y fotografías. 
2.3.2 Datos por grupos

Adicional a la información por sitio, la metodología consideró diseñar cuatro tablas resumen integrando los datos recabados de las seis cuencas. Estos cuadros tienen diferentes grados de información y corresponden a los planeamientos enunciados en los objetivos de este estudio.

La primera tabla resumen (cuadro 3) se refiere a los datos macro del estudio regional, con información sobre la posición de los sitios arqueológicos en relación con el paisaje. En este cuadro se incorporan referencias sobre el número de edificaciones y el número de patios y plazas. El propósito es presentar una idea del tamaño de cada sitio visitado. En las fichas técnicas no aparece información sobre áreas habitacionales o grupos dispersos. Es posible que estos datos sean ampliados con otros grupos de edificios no vistos durante los recorridos o sea que la información de las tablas debería leerse así: más de 20 edificios, más de 38 patios, dejando la posibilidad de que se incorporen otros edificios $u$ otros patios-plazas.

La segunda tabla resumen (cuadro 4) presenta los datos sobre los elementos urbanos hasta ahora identificados. Similar situación ocurre en este cuadro, pues buena parte de los rasgos urbanos aun se encuentran bajo los escombros y la vegetación, por lo que los datos aquí presentados son parciales. Una ventaja es que los datos fueron tomados por el mismo equipo de trabajo y se usaron los mismos criterios en los levantamientos de los planos esquemáticos, por lo que es válido hacer comparaciones entre uno y otros, ya que todos fueron recopilados de la misma manera.

El cuadro 5 se refiere a los elementos de arquitectura visible, identificados en los recorridos de campo. Las condiciones de 
recopilación de datos son similares a la expuesta en el acápite superior. El cuadro 6 corresponde a la información recopilada sobre el registro de saqueos en los edificios visitados.

Como referencia a los cuadros resumen, se presenta en el anexo 1 el cuadro 1 con el listado de todos los sitios que componen la muestra y el plano 1 con su ubicación en el área del estudio.

\subsection{CAMPOS DE INVESTIGACIÓN}

El apartado tercero es la esfera en donde se realizan las investigaciones. En este documento la investigación se concentro en dos campos, la composición arquitectónica y el estado de conservación del patrimonio edificado. Los resultados de las investigaciones luego se presentan en la parte dos y tres de este documento.

Para analizar la composición arquitectónica, se tomó como referencia el concepto desarrollado por los arquitectos austriacos Hasso Hohmann y Annegrete Hohmann-Vogrin. Esta metodología es presentada en el acápite 2.4.2.

El segundo tema de investigación es el análisis del estado de conservación del patrimonio edificado. Mencionamos anteriormente que, en la recopilación de datos se agregan referencias de campo en relación a la condición física actual de las edificaciones. Para ordenar el concepto de trabajo y poder tener indicadores sobre la condición, cantidad, importancia del estado actual del patrimonio edificado; se diseñaron dos variables o indicadores para medir el impacto del abandono y la acción de vandalismo en los edificios patrimonio monumental maya. Los indicadores seleccionados son: "saqueos en edificios" y "edificios en peligro". Estos condicionantes son 
sistematizados y priorizados para poder contar con un diagnostico general de la condición del patrimonio edificado en la región noreste de Petén.

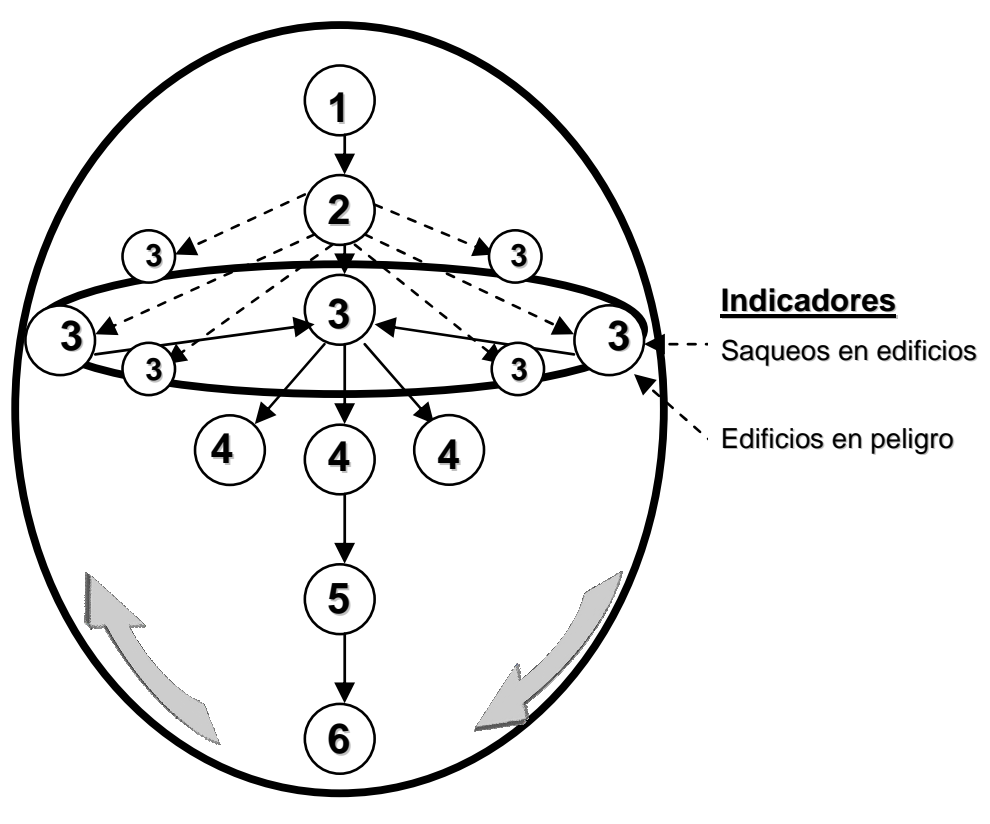

Simbología

1 Territorio seleccionado

4 Intervenciones de conservación

2 Objetos documentados

5 Conjuntos seleccionados

3 Investigación realizada

6 Estrategia

Fig.06. Apartado 3, Investigación, Estado de conservación del patrimonio edificado

\subsubsection{Conservación del patrimonio}

El apartado cuarto del concepto general, se refiere a las acciones físicas sobre el patrimonio edificado, o sea las intervenciones directas en las construcciones. 
Teniendo como referencia la visión general de emergencia en la región, se diseñó un esquema de atención, el mismo se concentro en los edificios prehispánicos con arquitectura expuesta en peligro de colapso. El concepto de conservación se basa en dos tipos de acciones sobre el patrimonio: una preventiva y otra permanente.

Estas dos variables se conjugan con una visión de tres fases amoldadas al tiempo y la condición actual. Considerando el corto, mediano y largo plazo. El ámbito de la tarea de conservación se comparte entre los sitios mayores, los sitios intermedios y los sitios reserva.

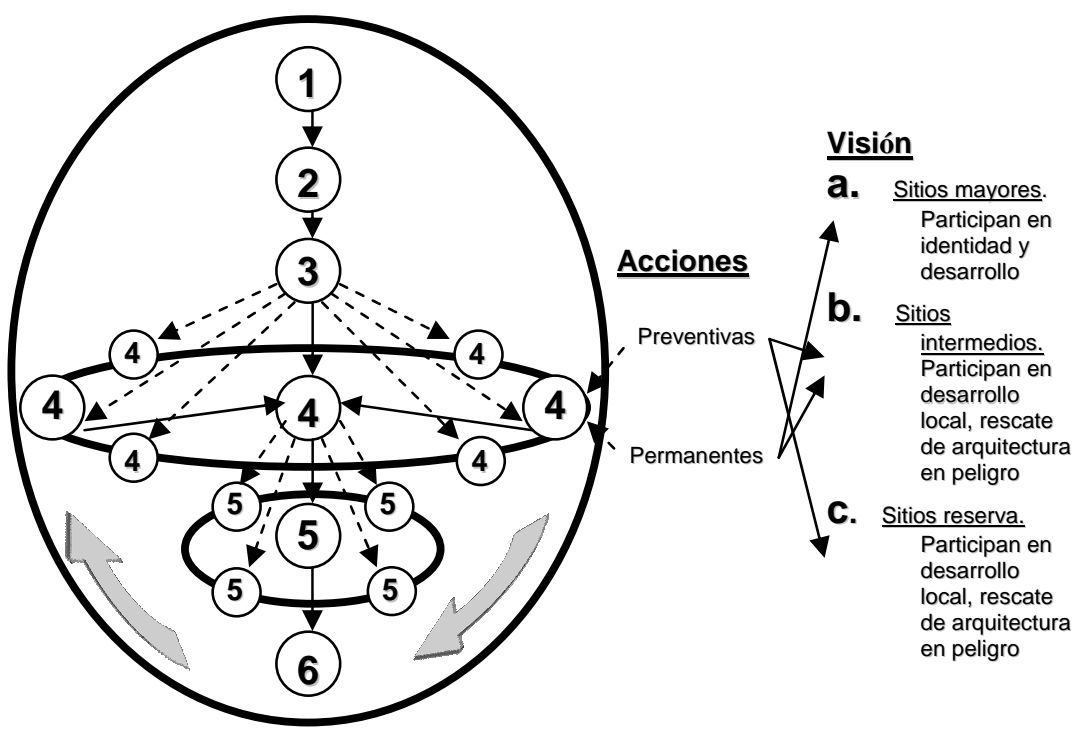

Simbología

1 Territorio seleccionado

2 Objetos documentados

4 Intervenciones de conservación

3 Investigación realizada

5 Conjuntos seleccionados

6 Estrategia

Fig.07. Apartado 4, Espacio construido intervenido 
El patrimonio edificado monumental maya, adquiere ahora la categoría de "ruina arqueológica". Para intervenir edificios patrimonio monumental prehispánico se tomo como referencia los principios y normas establecidas en los documentos internacionales de UNESCO, aunados a la experiencia del equipo multidisciplinario del campo.

Una ruina es un estado en que se encuentra un bien material (un edificio, un grupo o un conjunto) susceptible de ser estudiado por un método arqueológico. La condición de este bien material (ruina) se encuentra desarticulado por el abandono, el tiempo y la historia. Para el caso de los edificios patrimonio monumental maya, su condición de ruina arqueológica es un valor cultural que debe ser conservado. Es decir no podemos transformar el uso actual de este patrimonio más que para la educación, la contemplación y el estudio de las formas de vida pasadas.

No es posible pretender reintegrar todos sus elementos arquitectónicos, urbanos, texturas, colores, mobiliarios ya que sus elementos han desaparecido y solo contamos con pequeños indicadores de cómo pudo haber sido. Un aspecto fundamental es que los testimonios de sus habitantes no han sido registrados y por lo tanto no es posible reconstruir en su totalidad la forma de vida urbana de los antepasados mayas.

En el panorama actual, los principios de intervención se limitan a acciones urgentes. Tienen el propósito de dar a la arquitectura en peligro un estado que garantice su estabilidad. En el proceso se hace una distinción entre los elementos arquitectónicos originales y en lo posible se mantiene el carácter de reversibilidad. La zona de intervención en un edificio se limita a lo necesario para asegurar su estabilidad estructural. El uso de elementos modernos y reversibles es considerado para apoyar la conservación de los elementos 
originales, tales como las cubiertas protectoras permanentes o temporales.

Las acciones sobre los edificios se llamaron "restauración" para identificarlo fácilmente. En realidad la restauración es tan sólo una parte de la conservación, el cual es el concepto más amplio de la intervención en edificios y sitios que conforman el patrimonio cultural del área en estudio. En las acciones de conservación de los edificios mayas se usaron criterios multidisciplinarios considerando la opinión de arquitectos, arqueólogos, ingenieros estructurales, biólogos, arquitectos del paisaje y expertos en conservación.

Hay que tomar en cuenta que la conservación de monumentos es un proceso constante y que los procedimientos de intervención sólo retardan el irreversible deterioro natural de los elementos constructivos. Por otro lado, la tecnología actual, en el caso de la conservación de piedra caliza en ambiente de selva tropical húmedo, aún no apoya satisfactoriamente los procesos de intervención en los monumentos. Los años de no actuación por parte del Estado presentan ahora una acelerada pérdida de sustancia patrimonial por abandono y agresiones naturales no controladas.

En relación a los fundamentos conceptuales de la conservación de monumentos, a partir del año europeo de la conservación (1975), se dijo que "el pasado sólo puede tener un futuro cuando se logre integrar éste en nuestro presente y en nuestras vidas" (Gebssler y Eberl 1980, 3). Estos autores dicen que "El monumento es sustrato del recuerdo, el recuerdo puede ser ejemplo para el futuro, al actualizar un monumento, el presente igual que el futuro o él como pasado lo observa, y como pasado es aceptado y tomado". Al respecto de los monumentos arqueológicos dicen "Los monumentos arqueológicos están bajo el suelo rellenos y con vegetación y para 
poderlos ver es necesario escarbarlos. Los sitios arqueológicos son considerados frecuentemente, monumentos deficitarios, porque su presentación hace necesario un método especial, el método arqueológico". El significado histórico es la primera categoría del conocimiento o apreciación de un monumento. Los monumentos son únicos testigos como ningún otro, como el más directo testimonio, que el hombre en su sociedad no es de pasado sino existe y carga constantemente con su historia y en sus monumentos literalmente están con él (Gebssler y Eberl 1980, 70).

La ley del tiempo es de respetar y los cambios que ella produce en el monumento. La conservación no desea dejar caer las huellas del tiempo en los monumentos sino desea historicidad en materiales, testigos que frecuentemente solo son pedazos, que se conservan. Las partes incompletas y el perceptible paso del tiempo pertenecen a las propiedades de una ruina. La conservación en esta situación desequilibrada entre grandeza creada y total destrucción desea solo intervenir para que el estado actual y la actual vivencia del monumento permanezcan inalterados.

Es difícil en la conservación, ser consecuente con la teoría y la práctica. Con las ruinas (su característica) pertenecen grietas y raíces, que al mismo tiempo aceleran su destrucción. Otra característica es el no tener techo y la vegetación romántica. Gebssle y Eberl recomiendan que se debe calcular el riesgo de mantener monumentos en ese estado además de operar necesarias y pensadas intervenciones. (Ibíd., 70-94).

Paul Gendrop menciona dos extremos peligrosos; el primero es el de reconstruir de una manera generalmente excesiva y arbitraria para facilitar el turismo. En este caso a menudo obedece a la decisión bien 
intencionada pero caprichosa de algún funcionario en turno.

extremo opuesto consiste en dejar otras zonas arqueológicas en el más completo estado de abandono, exponiéndola no solo a una irremediable degradación natural sino -cosa infinitamente más gravea una insalvable labor de saqueo (practicada, con una constancia y una saña sistemática). El resultado en un caso como en el otro es nefasto, y el daño que estamos dejando que sufra nuestro patrimonio, difícilmente es reparable. "Reunámonos con otros especialistas para determinar los criterios más adecuados. Concienticemos a la gente con relación a su propio patrimonio cultural; motivémosla poniéndola frente a ejemplos concretos, hablando de ello entorno nuestro... igritando, si es preciso!......" (Gendrop 1984, 1-3).

El objetivo de recuperar sitios arqueológicos de la cultura maya no es sólo salvar vestigios antiguos sino también el reto de recuperar el espíritu de sus ciudades y edificios para insertarlos en la vida contemporánea. Los testigos del pasado, luego de ser investigados y restaurados, adquieren esta nueva función de "conectar" al espectador con un asombroso pasado. Debemos reconocer que los sitios son parte de nuestro patrimonio cultural, de nuestra identidad y orgullo y su presencia ayuda a definir el carácter histórico de la región y el país.

En relación al compromiso social de la conservación Daniel Schávelzon dice "La conservación del patrimonio cultural no es un hecho apolítico e independiente de la realidad que lo circunda. Todo lo contrario: es un hecho profundamente político, con salvedad que puede ser socialmente favorable o profundamente negativo. Puede ayudar a que los habitantes de una ciudad tengan un entorno mas humano, mas limpio, más agradable y más racional. Usar los sitios arqueológicos e históricos para comprender nuestra historia y a 
nosotros mismos, para crear y recrear cultura. Podemos dar a nuestros hijos un mundo un poco mejor que el que se nos dio a nosotros; pero para ello debemos entender que la conservaciónrestauración debe transformarse en un hecho social, en una reivindicación por la cual luchar.....El más importante patrimonio cultural de América Latina son los hombres que lo producen y que lo han producido a lo largo de los siglos". (Schávelzon 1984, 219-234).

Los procesos de intervención en un sitio arqueológico tienen diferentes fines $u$ objetivos y niveles de resultados. El elemento a intervenir puede ser un elemento cultural aislado, un edificio, un conjunto de edificios, un sitio arqueológico o un conjunto de ciudades en una región determinada.

Es importante que las acciones físicas de conservación y rescate del patrimonio maya estén dentro de un esquema de visión regional. Así mismo los estudios del espacio y forma de la composición arquitectónica y otras investigaciones deben estar acorde con la filosofía y las prioridades reales de la región, medidos en su justa dimensión y prioridad.

El concepto general, en el apartado quinto considera a los sitios arqueológicos estratégicos para formar grupos de recursos culturales prioritarios. Estos grupos son llamados "conjuntos". Un conjunto es un grupo de bienes seleccionados y preparados para ser "usados socialmente". Aquí se realizan otro tipo de acciones como el empleo de la arquitectura del paisaje para integrar y poner en valor los diferentes procesos de intervención en el tejido urbano (ver capitulo 11). 
En esta esfera, algunas acciones se realizan afuera o alrededor del objeto y tienen como función apoyar y reforzar la presentación, el conocimiento y el disfrute social. Aquí se considera el uso de nuevos elementos tales como la construcción de centros de interpretación, mejoras de accesos, instalaciones para servicios, y otros.

En los apartados quinto y sexto, se elaboran documentos de apoyo operativo, normativo y legal como planes de manejo, planes maestros, paneles informativos, y otros que en conjunto permitirán los mecanismos de conservación y el uso duradero y racional del patrimonio habilitado.

El patrimonio recuperado es un elemento de uso, conocimiento y disfrute social, y forma parte del apoyo para la economía local, para la identidad y orgullo nacional.

El proceso iniciado con el reconocimiento y documentación, las investigaciones y las primeras intervenciones hasta llegar al plan de uso y sus diversos programas, es evaluado para iniciar otro ciclo de acciones científicas sobre el patrimonio cultural. El apartado sexto representa a un grupo de conjuntos ya preparados (o identificados) para un uso social, cultual y económico, con esquemas de administración, participación, generación de ingresos para mantenimiento, monitoreo, otras intervenciones y estudios, todos bajo un esquema macro. Los resultados de las diferentes investigaciones y los resultados de las intervenciones en el patrimonio maya permiten formular una visión regional (planteada en el capitulo 12).

En la visión regional se integra todo los conocimientos adquiridos y tratan de darle un sentido común, integral y participativo al modelo. El propósito es incorporar los conocimientos adquiridos 
(potencialidades) y las acciones realizadas (puntos estratégicos) en un esquema de desarrollo sostenible.

\subsubsection{Composición arquitectónica}

Luego de recavados los datos de campo y elaboradas las fichas técnicas con sus planos esquemáticos, fue posible pasar al siguiente estrato del estudio (apartado tercero) correspondiente a la esfera de las investigaciones.

Para el análisis de la composición arquitectónica de los centros prehispánicos es necesario contar con un sistema descriptivo. Para este trabajo tomamos de base el concepto empleado por los arquitectos Annegrete Hohmann-Vogrin y Hasso Hohmann (Hohmann y Vogrin 1982; Hohmann-Vogrin 1992, 2000b; Hohmann 1995 y 1998). Ellos diseñaron una metodología para identificar y definir categorías de formas de arquitectura en sitios y edificios mayas.

El primer análisis urbano, empleando esta metodología se utilizó en el área central de Copán (Hohmann y Vogrin 1982). Aquí los autores hacen una distinción entre diferentes niveles de elementos, considerando a cada uno como parte de uno mayor, que a su vez se compone de elementos. Estos elementos se pueden diferenciar en dos categorías:

1- Elementos de espacio (área abierta como plazas, patios, plataformas y terrazas) y

2- Elementos que conforman espacios, los cuales delimitan y definen los espacios abiertos y también las edificaciones (graderías, edificios, muros aislados y monumentos escultóricos) 
2.4.2.1 Metodología en otros sitios

Copán, Topoxté y Becán. Después del centro de Copán, Hasso Hohmann empleo el mismo criterio de análisis para su publicación sobre el barrio habitacional de las Sepulturas-Copán (Hohmann 1995).

La metodología de los arquitectos austriacos fue empleada en 1996, en el estudio de los elementos espaciales de Topoxté (Quintana 1997b, 275-281).

La particularidad de esta metodología es que puede aplicarse a un sitio arqueológico completo (Copán y Topoxté), en un grupo de edificios o en un solo edificio.

Hasso Hohmann utilizo en 1998 la misma metodología para documentar y reconstruir en base de planos arquitectónicos la forma, construcción y función del Edificio IV de Becán. En este estudio el autor también realizo primero un minucioso levantamiento de plantas de arquitectura con planos topográficos y fotogramétrico del edificio. Hohmann divide sistemáticamente el edificio en elementos de arquitectura de diferentes tamaños. "Con los elementos de cada dimensión se puede describir la arquitectura entera en una forma más o menos detallada, dependiendo de la dimensión de los componentes". Por medio de cinco niveles de elementos arquitectónicos se puede describir la arquitectura. Los elementos de un nivel concreto están siempre definidos por la composición de elementos del nivel inferior, es decir del nivel de los elementos mas detallados. El siguiente nivel mas grande de los elementos arquitectonicos está igualmente definido por la composición de estos elementos arquitectonicos mas pequeños" (Hohmann 1998, 147). 
En el primer nivel de análisis se describe al complejo Edificio IV en su posición dentro del Patio A de Becán. Como elementos de segundo orden considera: las escalinatas, los mega escalones, el edificio, ofrendas enterradas dentro del edificio y los drenajes. Para los elementos de tercer orden están: las escaleras menores, las escaleras grandes, los pisos, paredes, molduras y paneles, paneles de paredes, escultura de paredes, grafitos, ventanas, puertas, agujeros en las puertas, cerramiento de puertas y agujeros cordelados, plataformas y bancas, bóvedas, pasadores de bóveda y techos.

Los elementos de cuarto orden son: la piedra, el mortero, los estucos, la pintura, madera y tierra. En el quinto orden, se considera: los edificios anteriores, plataformas, terrazas, bancas y escaleras, paredes, abertura de paredes y dinteles, bóvedas, estructuras multipisos, techos y bancas en el cuarto piso con segunda función (Ibíd., 147).

\subsubsection{Relaciones urbanas}

Annegrete Hohmann-Vogrin se preocupó por investigar el aspecto urbano y sustentó el componente teórico del "concepto" en su trabajo de habilitación Estructura y significado de la ciudad. Una propuesta de teoría de la arquitectura en base a culturas mesoamericanas como profesor docente en la Universidad Técnica de Graz (HohmannVogrin 1992).

Hohmann-Vogrin dice que los restos constructivos, en forma general son muestras de actividad humana y por lo tanto formulan la estructura de la sociedad. La autora busca una sistematización y utiliza la arquitectura como símbolo basado en la teoría cultural de Norberg-Schulz 1970 y otras publicaciones. Estas investigaciones 
van hacia el análisis de los componentes pragmáticos, semánticos, formalistas y técnicos; ya no como objetos aislados sino que se analiza el "espacio construido" en su totalidad.

Los edificios no son ya objetos sino medios para transformar el espacio. La autora estudia la diferencia entre varios conceptos de espacio:

1- El espacio pragmático (la acción física que el hombre hace en su ambiente natural)

2- El espacio reconocido (el cual sirve para la orientación),

3- El espacio existencial (ese es una visión del hombre o su concepción sobre su mundo-ambiente el cual hace a el hombre miembro de una unidad cultural o social),

4- El espacio cognitivo (el mundo físico sobre el cual es capaz de tomar en cuenta o pensar),

5- El espacio abstracto (el cual es construido en base a relaciones lógicas y cuya descripción puede describirse a otras personas), y

6- El espacio arquitectónico (el cual el hombre mismo crea, también conocido como el "espacio construido").

"El espacio arquitectónico es una concretización del espacio existencial, de donde se une una relación semántica entre forma (espacio arquitectónico) y un aspecto de significado cultural / social." (Hohmann-Vogrin 1992, 13).

La estructura de la forma puede dar información sobre las razones, intenciones y relaciones entre uno y otro o en si mismo, puede facilitar el análisis si se trae esta forma en un sistema. El análisis de la autora no solo abarca los componentes formales y semánticos sino también un análisis semiótico; y dice que la dimensión pragmática no es accesible ya que los habitantes que usaron la arquitectura no existen 
ya. Una aproximación la daría la arqueología. Hace falta competencia para adentrar en cada cultura como parte de su propia colectividad. El trabajo debe ir entre arquitectura y urbanismo y arqueología y etnología. Para otros autores y sus teorías véase las aportaciones de Hohmann-Vogrin 1992, 15-60.

El primer intento de plantear la descripción de la forma como independiente de la relación semántica y pragmática, fue realizado en el grupo central de Copán (Hohmann y Vogrin 1982). La autora define el "elemento" como una unidad característica (particular) que es parte de la arquitectura o del asentamiento; y dice que según Norberg-Schulz se pueden distinguir diferentes categorías de elementos arquitectonicos y da definiciones como masa, espacio y superficie. Solo así se puede entender un análisis de la arquitectura. La diferencia creada entre masa y espacio se complementan y se relacionan una con otra, en donde la superficie constituye un limite del espacio. Esta relación juega el principal papel en la organización de la forma. Bajo masa se entiende todo cuerpo sólido que forma el volumen y bajo espacio un volumen con una superficie límite formada por masas que le rodean.

Tanto la masa como el espacio peden asumir caracteres figurativos y forman los elementos espaciales de primer orden. Estos dos componentes son definidos a través de la superficie límite, que al mismo tiempo esta formada por elementos de menor jerarquía denominados de segundo orden. Pone como ejemplo, un patio que esta compuesto por elementos de segundo orden tales como: diferentes tipos de escalinatas, que lo circulan. Lo mismo para los elementos masa. Aquí, no solo lo visible es importante, un edificio puede contener varios espacios interiores. Estos no aportan más en forma directa a la forma del sitio. 
La categoría principal de elementos (masa-espacio y superficie) se combinan en diferentes niveles en donde un elemento del nivel inferior se ordena con otro de similar categoría y entre ellos y su organización interna se describe y definen. El análisis formal de arquitectura inicia aquí con cada espacio y masa, que como elementos de primer orden son definidos. Estos naturalmente se unen también como grupos de patios o grupos de edificios, que según su categoría van de poderosos grupos principales hasta los pequeños grupos de patios, que en conjunto definen el espacio urbano.

Definir los límites es difícil ya que masa y espacio son entre ellos complementarios. La Arquitectura de los grupos principales están formados por edificios masa, pero en gran parte por una acumulación de sobre posiciones y relaciones de elementos constructivos, estos no son fáciles de separar el uno del otro. A través de cientos de años fueron creados paisajes artificiales en cuyo interior quedo atrapado el completo desarrollo del sitio. Muchas veces solo la última fase de todas las anteriores se conoce; solamente excavaciones pueden dar información cortada de la secuencia cronológica de la ciudad o grupo. Solo a través de la investigación se puede conocer el significado de una siempre vuelta a edificar en un mismo espacio (Ibíd., 83).

Los elementos de primer orden son: elementos espaciales (plaza, patio, plataforma, terraza, calzadas) y elementos masa (base del edificio, edificio, monumentos, y muros aislados). Para los elementos de segundo orden: superficie limite (Pisos, escalones, fachada de edificios), y sistemas del espacios interior (corredores, celdas, cajas de escaleras, tumbas y ofrendas interiores), (Ibíd., 86-90).

Los elementos y sus relaciones entre ellos definen nuevas estructuras que completan su razón; las relaciones están en: la arquitectura 
sencilla, en la arquitectura monumental, en relaciones de los espacios abiertos, relaciones en los elementos masa y relaciones entre los elementos que forman el espacio.

Para las relaciones en la "arquitectura sencilla" la posición y frente, da inicios a otras relaciones de elementos, si la forma real no es conocida no se pueden hacer más análisis verdaderos del grupo (condición general en el noreste de Petén). El conocimiento y clasificación de estos grupos es una parte importante de la investigación de asentamientos. Los grupos son definidos a través de elementos topológicos, entre más cerca un elemento de otro debería tener más relación.

Una característica de las tierras bajas es la agrupación de edificios alrededor de un mismo espacio libre, (grupo de patio). Los grupos de patios y sus agregados se ubican y comparten topologicamente en el paisaje formando el esquema de un asentamiento. (Ibíd., 92). Cuando la construcción de grupos se vuelve muy densa se llega naturalmente a una mejor geometrización (relaciones en arquitectura monumental) estos se concentran en la zona central la cual necesita edificios monumentales y grandes plazas. En la relación de la arquitectura sencilla y monumental solo cambia el tamaño, los principios de posición y orientación son los mismos.

En relación a los elementos masa dice que los edificios monumentales se deben en parte al gran acumulamiento de masas a través del tiempo. Las relaciones de las grandes masas-elementos entre si, forman una característica urbana. La posición de los objetos masa en el espacio construido influye en el espacio y da la considerada impresión prevista. La base de este flexible uso de principios de orden está posiblemente en la estructura del elemento 
mismo (bases escalonadas, edificios pirámide cercanos, masas que se dirigen hacia arriba, relaciones con el eje central de los edificios) solo aquí puede conectarse un sistema de orden espacial. En base a estos principios se sientan los puntos medios-ejes como ordenadores del espacio; estos se convierten en tangentes de otros elementos masa o se comunican otra vez por ejes con otra mitad de otro edificio. Esto es lo que nos permite ahora la impresión de un orden en todo.

En el tema de las relaciones con los elementos generadores de espacio, la autora dice que, la relación solo a través de la disposición de los elementos-masa es un poco tosca. El espacio libre formado, fue el principal tema de la arquitectura, este se relaciona con un pequeño porcentaje de elementos masa-solitarios. Principalmente son las superficies-frontera o límite, las diferencias de altura, los patios y plazas los que definen. También influyen los cambios de masa constructiva, ya que los elementos masa generalmente son construidos en formas simétricas, la simetría es responsable que estos elementos (como bloques distintivos) sean marcados. Por el contrario los espacios libres (que forman este espacio) nunca son puestos en forma simétrica. Los simétricos edificios monumentales no necesitan o requieren una plaza simétrica delante de ellos. Un caso particular son las plataformas limite, una frente a otra, formando los juegos de pelota. Aquí por razones técnicas del juego se necesitan dos espacios iguales, creando una zona definida como elementomasa.

El principio de orden a través de tangentes, mitades, o líneas rectas es real en los siguientes niveles: en la posición de masas, en la relación de elementos generadores de espacio y en la posición de monumentos (estela y altares). Tiempo y espacio son inseparables. 
Simetría o líneas ejes, encuentran su razón en el espacio como elemento ordenador.

Hohmann-Vogrin en su análisis sobre la teoria del espacio prehispánico se refiere al "significado e intención" por lo cual fueron creados los yacimientos mayas (relaciones semánticas en asentamientos y arquitectura). Norberg- Shulz $(1970,104)$ describe la totalidad arquitectónica en tres categorías: la tarea constructiva, la forma y la técnica.

La intención física, social y cultural que determina los asentamientos y la arquitectura (tarea constructiva) encuentra los tres aspectos semánticos, pragmáticos y semióticos. Estas intenciones se relacionan principalmente con el ambiente, el ordenamiento de la tierra y los hombres en un marco de interacción. Esta función de orden tiene cuatro partes:

1- El control físico (relación de lo construido con su entorno natural a condiciones climáticas, vegetación, animales, relación de la estructura de un asentamiento y su topografía, la conservación del agua, etc.),

2- El marco funcional (se relaciona al tipo de medida de los cambios en el entorno en relación con la actividad humana),

3- Milieu social (desde grupos de personas sencillas hasta construcciones representativas de complejas estructuras sociales), y

4- Simbolismo cultural (estructura social basada en valores creados o formados y sistema de símbolos que se pueden manifestar con construcciones), (Hohmann-Vogrin 1992, 115-116).

En relación al "control físico" expone como ejemplo los diferentes ambientes de Mesoamerica, con desiguales características topográficas y climáticas que influyeron en la forma y técnica 
constructiva (ejemplo las diferentes formas de abastecimiento de agua en el área maya).

Hohmann-Vogrin expresa que las plazas y patios estucados no solo se aprovechaban para dirigir el agua de lluvia, sino servían de barrera a la agresiva flora y fauna local y así controlar el entorno cercano (protección contra animales, por ejemplo reptiles), definiendo espacio territorial privado de seguridad.

En relación con la superficie del espacio libre, este es mucho mayor a los espacios interiores, y supone que los espacios interiores se limitaban a espacios de retiro o almacén de depósito necesariofunción. En casi toda su relación directa hacia el espacio exterior deja suponer que la gran parte de todas las actividades se realizaban en los espacios libres; lo cual coincide con las condiciones climáticas de tierras calientes y húmedas. Las puertas son consideradas solo como conexiones entre afuera y adentro.

En relación al "marco funcional"; se compara la posibilidad de subsistir de los pobladores; otro aspecto son las grandes rutas comerciales y las posiciones de poder político. En cuanto a la estructura de asentamientos, las diferencias de densidad son marcadas entre los asentamientos de Yucatán (área norte), las tierras de Petén (área central) y el altiplano (área sur). En unos se requiere asentamientos dispersos porque escasea el agua y en otros se agrupan para tener protección de los enemigos.

El método-accesibilidad y centralidad de zonas-patios y plazas, en medidas y formas sin interpretar, lo usó por primera vez Norman Hammond en Lubaantún; identificando tres tipos de funciones: residencial, ceremonial y edificios de culto. Según la función del 
edificio le asigna la misma función a la plaza o patio. El mayor rango de centralidad es la plaza en donde esta la mayor cantidad de edificios de culto; el menor rango son los patios dedicados a vivienda (Hammond 1975).

Hohmann-Vogrin dice que según el clima también se debieron realizar funciones privadas en espacios abiertos. Lo accesible y central de los patios puede dar idea de su función privada o publica. El espacio interior con una función privada, y el espacio abierto con una función pública.

En relación al "milieu social", dice que no solo la presentación del edificio es valido sino una realidad social en conjunto tal como fue pensada. Los textos e inscripciones relacionan las plazas con monumentos y edificios con acontecimientos históricos de la ciudad. El espacio interior tiene por lo general definida relación social de categoría y rol; el espacio exterior es mas indefinido, menos controlado, extraño, ya que en el entran mas personas, las reglas son menores, la diferencia entre adentro y afuera forman la interacción dentro de una sociedad. Los espacios cerrados encierran (enclaustran), las casas juntas manejan el mismo concepto de espacio. En el espacio interior se concretan las "ideologías", y en el exterior pasan las "transacciones". Una relación afuera y adentro, es igual a, poder y control; principio de la desigualdad: lleno y vació, rápido y lento (Ibíd., 147-152).

Con el mismo argumento, Annegrete Hohmann-Vogrin presento en 1997, en la segunda Mesa Redonda de Palenque, el tema "Espacio estructurado y la visión del mundo". Aquí nos hace ver que es necesario una visión más estructurada y sistemática en función de la arquitectura de los mayas y propone cuatro pasos: 
1- Registro (examen geodésico, con mediciones precisas),

2- Documentación (de la representación objetiva de edificios, plazas y patios y poder así conocer los patrones en la estructura del diseño específico y más de la disposición de la arquitectura),

3- Análisis de la forma (Un análisis del diseño específico, en sus diferentes niveles y bajo diversos aspectos, nos podría conducir a una percepción mas amplia de la estructura forma -sintaxis especifica- de la arquitectura maya), y

4- Interpretación (para entender la arquitectura en su contexto cultural, es necesario resaltar las interrelaciones existentes entre el ambiente construido, el ser humano y las intenciones que impulsaron al ambiente creado).

Basado en la "teoria integral de la arquitectura" de Norberg-Schulz, Hohmann-Vogrin explica su punto de vista en cuanto a las relaciones en base a un esquema grafico. 


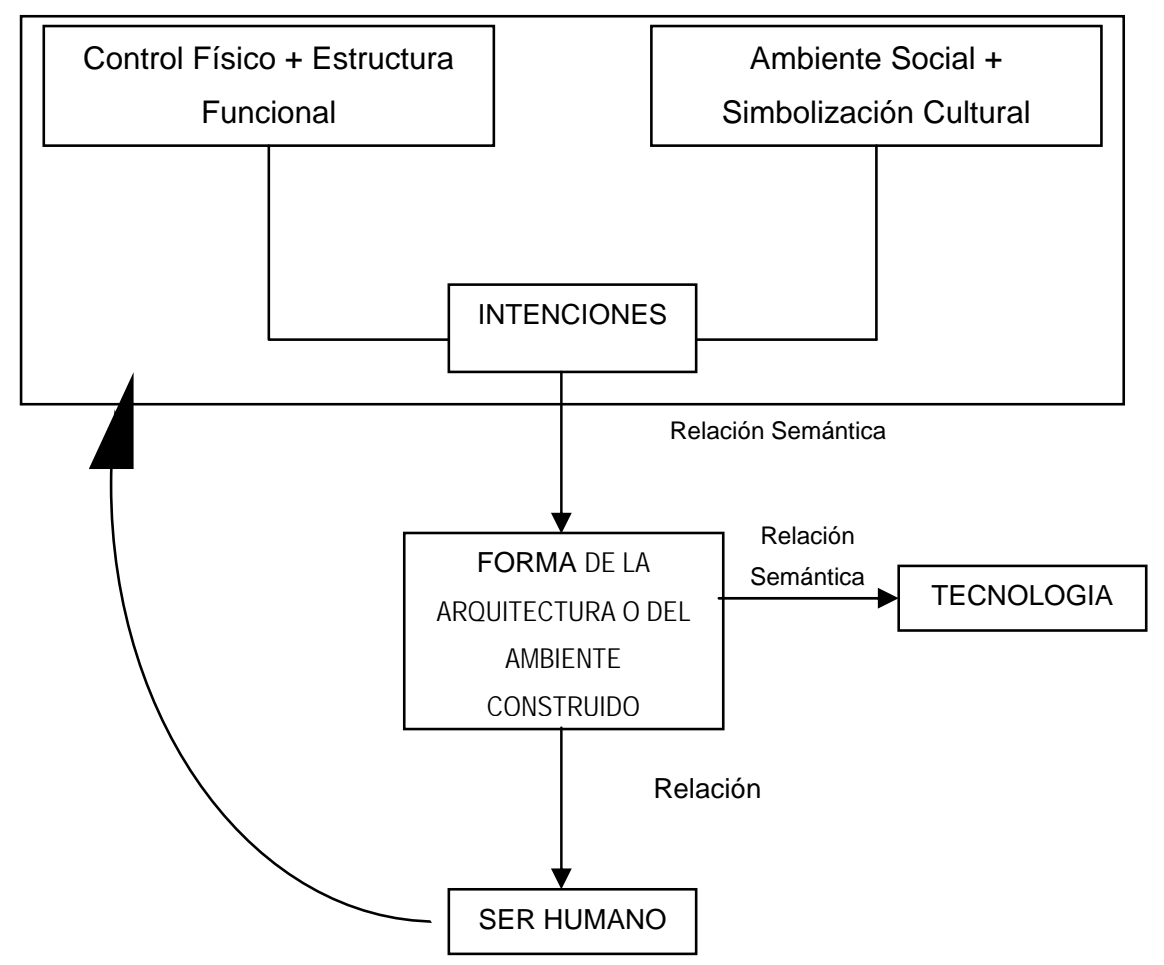

Fig.08. Esquema diseñado por Hohmann-Vogrin para mostrar las interrelaciones entre el ambiente construido, el ser humano y las intenciones que impulsaron al ambiente construido.

Según la teoria semiótica de Umberto Eco (Eco 1972), las estructuras se interpretan a manera de los objetivos intermediarios, que concretizan los sistemas coherentes de las intenciones; "la arquitectura controla el ambiente con tal de hacer posible tanto la interacción como la colaboración". Este control toma varias formas. El mas elemental se expresa a manera de protección del ser humano (contra la lluvia, el viento, el frió, el calor, los insectos, sus enemigos y demás), "control físico". Otro aspecto del "ambiente físico" es la participación de los edificios en la acción humana (su "estructura 
funcional"). Las acciones, no obstante, son determinadas socialmente. Los edificios, por lo tanto, manifiestan implícitamente un significado social; con eso los edificios constituyen un "ambiente social".

La arquitectura, finalmente, representa un "objeto cultural", que puede aplicarse a conceptos religiosos o cosmológicos; aunado al aspecto social, esta "simbolización cultural" constituye el "ambiente simbólico" (Norberg-Schulz 1970, 112-113).

Existe una "relación pragmática" entre el ser humano y su "ambiente construido", y también existe una "relación semántica" entre el "ambiente construido" con las intenciones arriba mencionadas. ¿Como puede la forma expresar el contenido? Primeramente existe la posibilidad de una clara intención mediante la "convención" y, segundo, mediante las similitudes estructurales; de allí la imperiosa necesidad de contar con mapas exactos y croquis, para poder reconocer el patrón especifico establecido en ciertos complejos arquitectónicos. Es importante para la interpretación del ambiente construido (de diseño urbano y arquitectura) el reconocimiento de dos condicionantes:

1- El espacio no se experimenta en forma continua, sino descontinúa, delimitado de manera diferente en cada lado, y

2- Tanto el espacio como el tiempo presumen de ser integrados de manera indivisible.

Resulta interesante que los elementos masivos, que forman los límites espaciales, enfatizan la simetría, por lo menos en lo nominal. Los ejes o líneas centrales inducidos por aquella simetría no se emplean con tal de organizar los otros elementos de masa, no crean 
así un espacio simétricamente ordenado sino que las líneas centrales alcanzan una función, con tal de ordenar u organizar de un modo diferente el espacio construido. Estos ejes, puesto que se perciben como líneas rectas virtualmente trazadas, pueden constituir la base de un elemento arquitectónico opuesto o pueden tal vez atravesar el punto medio de algún otro elemento. Con este sistema, de ordenar a lo largo de las líneas rectas o de alinear, resulta una operación básica, flexible en el sentido de la relación significativa dentro del ambiente construido.

En relación a la segunda condicionante la autora expone que en la alineación de los elementos resulta muy apropiada la ordenación de fases constructivas sucesivas. Con eso se produce, y se explican, las agrupaciones en los centros mayas. Una construcción nueva, o la nueva fachada de un edificio existente, pueden organizarse con relación a los alineamientos arquitectónicos, también existentes. De manera que el paso del tiempo se representa mediante las transformaciones en el ambiente creado. El alineamiento como recurso o estrategia, también resulta recomendable con tal de arraigar algunos edificios dentro de su aplicación cósmica. Así es que el alineamiento de edificios en relación al sol naciente o poniente, o de otros elementos entre las entidades celestes, también parecen reforzar la correlación del edificio en algún día significativo dentro del ciclo respectivo. Para poder alinear un edificio nuevo hacia edificios existentes o eventos cósmicos, se necesita ubicarla adecuadamente dentro de la continuidad del tiempo y del espacio; por tanto, el paso del tiempo queda inscrito dentro del ambiente construido.

La visión del mundo del maya antiguo, se hace patente en el "ambiente construido", expresado espacialmente en las siguientes tendencias: 
1- Similitudes estructurales entre grupos-patio con los centros elaborados, estos se relacionan con el entorno natural, además de su imagen del mundo,

2- Las diferencias limítrofes en plazas y patios hacen hincapié en la discontinuidad del espacio expresado a través de las varias características del espacio,

3- Alineamientos de edificios y monumentos se relacionan con el paisaje natural o con edificios existentes

4- Alineamientos de edificios y monumentos se relacionan con los eventos cósmicos, por lo tanto los arraigan en el tiempo.

\subsubsection{Metodología aplicada en Petén}

Ya se menciono anteriormente que el concepto de los arquitectos Hohmann y Hohmann-Vogrin, de separar diferentes elementos de la composición arquitectónica (de mayor a menor) fue modelo para esta investigación. Para el estudio del cuadrante noreste se incorporo un nuevo componente llamado: "Primer nivel de análisis". En este estrato se estudia la posición de los yacimientos mayas en relación con el paisaje circundante. Se hace referencia a la relación semántica entre un centro urbano y otros, con intención de una correspondencia de comunicación visual.

Al segundo nivel de investigación lo llamamos "elementos urbanos". En este caso se tipifican los elementos que forman el tejido urbano. El estudio se ordena en los dos componentes hacedores del espacio construido. Primero analizamos el espacio libre o vacío con sus elementos (plazas, patios y otros). Luego se estudian los espacios sólidos (edificios-masa), entre estos están: los edificios verticales, los edificios horizontales, los grupos de edificios y sus combinaciones, (grupos de cuatro edificios, de tres edificios, de dos, y otros). 
El tercer grupo de elementos investigados se refiere a las superficies del espacio construido. Aquí se estudia por ejemplo, las fachadas, superficie de muros, techos y otros elementos de las edificaciones prehispánicas. El cuarto y quinto nivel del estudio lo conforman los sistemas constructivos y los materiales empleados.

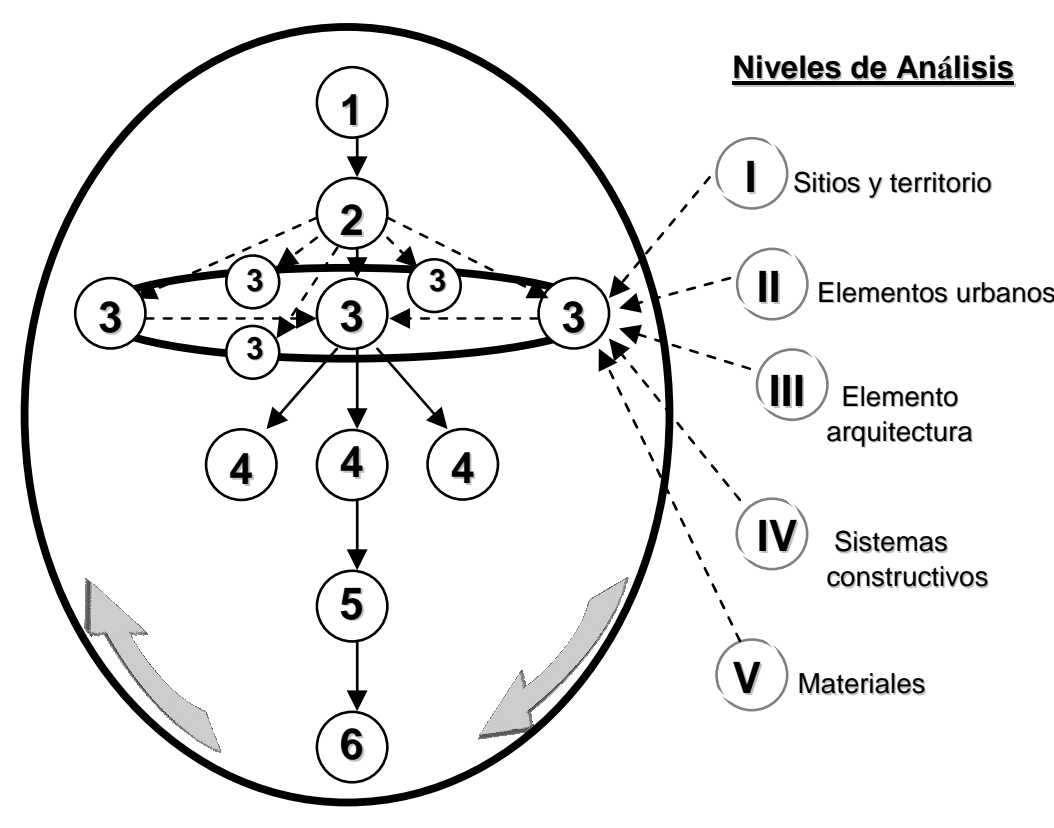

Simbología

1 Territorio seleccionado

4 Intervenciones de conservación
5 Conjuntos seleccionados

2 Objetos documentados

3 Investigación realizada

6 Estrategia

Fig.09. Apartado 3, Investigación. Composición arquitectónica

Estos últimos niveles de detalle son muy difíciles de sistematizar. Esto se debe a la enorme diferencia entre los datos posibles de obtener en las visitas de campo y en la literatura existente. En muchos de estos sitios arqueológicos no existe arquitectura visible o datos previos de 
sondeos arqueológicos. Por lo que es imposible hacer estudios de detalle. Por el contrario en pocos sitios como Tikal o Nakum abundan los detalles para estudiar los sistemas constructivos y los materiales. Esta diferencia abismal, en las tablas resumen proyecta datos falsos, pues los sistemas constructivos no son representativos de la mayoría de los sitios de la muestra. Igual sucede con las relaciones entre el ambiente construido. Es indudable que hace falta aumentar el número de estudios de detalle en la región para tener un dato mas riguroso y valido para el noreste de Petén.

Un estudio del diseño específico de las edificaciones, en sus diferentes niveles y bajo diversos aspectos podría conducir a una más amplia percepción de la estructura formal. En el área maya solo se ha analizado un solo aspecto de la forma arquitectónica que es el aspecto del "estilo" (Marquina 1964, Pollock 1980, Andrews et al 1985 y otros). Se podría detectar mucho más, mediante el reconocimiento de patrones en la arquitectura maya. El concepto urbano no se reduce a la "pirámide" o el "templo" ni tampoco a ninguna casa aislada, sino primordialmente al "espacio creado" a consecuencia de aquellas entidades masivas. Los rostros de los edificios, o de las masas de los edificios, varían en relación a cada fachada según la disposición y función de la situación espacial que los rodea. Plazas, patios, terrazas, plataformas y calzadas, constituyen por consiguiente, la materia prima de la arquitectura maya. Hohmann-Vogrin agrega que pocas son las culturas en la historia de la humanidad que se dedican tan evidentemente a la función de la arquitectura en el sentido de la creación del espacio y, por lo tanto su análisis debe de examinar no sólo el contexto espacial específico de las edificaciones sino también el espacio contiguo creado por estos mismos edificios. 
En conjunto tenemos un sistema básico para identificar la estructura urbana y los elementos arquitectónicos que la conforman. Por ejemplo podemos saber la forma de las edificaciones dominantes y cuáles son sus condiciones y caracteres particulares que identifican a la región en estudio.

En relación a los datos disponibles necesarios para elaborar la investigación de la composición arquitectónica, (presentada en la segunda parte de este trabajo), ya referimos que se disponen 128 planos esquemáticos y también dijimos que la calidad de esta información grafica es precaria y por lo tanto no nos permite hacer estudios de detalle. Los resultados presentados en los capítulos 3 al 7 deben verse como un primer intento de sistematizar en la región maya estudios de composición urbana a escala regional. 


\section{RESULTADO DE INVESTIGACIONES}

La metodología empleada para la investigación sobre la composición arquitectónica se basa en el concepto diseñado por los arquitectos Hasso Hohmann y Annegrete Hohmann-Vogrin (1982, 1992,1995 1998, 2000b) y fue adaptado para este análisis espacial de los sitios mayas del noreste de Petén.

\subsection{LOS SITIOS Y SU POSICIÓN EN EL PAISAJE}

El primer nivel de análisis es la relación de los sitios arqueológicos con el paisaje circundante. Las características del terreno disponible para construir los espacios urbanos condiciona la posición de los sitios arqueológicos. Generalmente se ubican sobre terreno elevado fuera de las áreas inundables. Algunos sitios arqueológicos como Tikal, Uaxactún, El Zotz o Naranjo se localizan en terrenos elevados cerca de los pasos naturales; otros, como Nakum, Río Azul, Ucanal, a orilla de los ríos; otros sitios arqueológicos se ubican a orillas de lagos o lagunas como Yaxhá, Nichtunchich o Tayasal. Estas posiciones llevan a considerar un programado control sobre el paisaje, y los recursos naturales, considerando las vías de comunicación, accesos, puestos estratégicos de control, zonas productivas y otros. Los centros urbanos generalmente se adaptan a las condiciones naturales existentes y no se sujetan a esquemas urbanísticos matemáticos.

Para tener una idea de la densidad constructiva en la región del estudio mostramos los resultados de la investigación regional realizada en el "triángulo cultural" Yaxhá-Nakum-Naranjo. La investigación contó con tres objetivos: El primero, exploraciones en 
espacios entre sitios, con transectos diseñados entre: Yaxhá y Nakum, Yaxhá y Naranjo, Nakum y Tikal. Los resultados demostraron una densa ocupación entre los yacimientos mayas mayores, ya desde periodos tempranos del Preclásico Tardío. El segundo objetivo fue el estudio de rasgos humanos en los espacios de bajos o humedales en el área entre Tikal y el triángulo cultural. El tercer objetivo fue la investigación de los espacios con rasgos de actividad humana en la cuenca del río Holmul (Fialko 2005, 253-268). Todos los datos confirman una densidad alta de uso del suelo por espacio de más de mil años (300 a.C.- 850 d.C.). En conclusión, el territorio de 37160 hectáreas, que cubre la zona del triángulo cultural registro 4 sitios grandes, 10 sitios intermedios y cerca de 282 sitios menores (Plan Maestro 2007, 14). Estos datos pueden replicarse para otros sectores de los grandes humedales.

En relación al proceso de ocupación del noreste de Petén, "Los descubrimientos de la ultima década demuestran que desde el Preclásico Medio las ciudades mayas fueron concebidas alrededor de un punto central, considerado como el lugar que daba vida y movimiento a las cosas y a los hombres. Este concepto se reforzó aun mas durante el transcurso del Preclásico Tardío, cuando se integraron fuertemente los conceptos ideológicos, religiosos y políticos, quedando establecido el centro de las ciudades como el lugar de mayor prestigio, equivalente al paraje de la "abundancia inagotable"... Por eso, la arquitectura de vanguardia que exaltaba al rey y los poderes divinos fue edificada en estos lugares" (Valdés $2000,11)$. Valdés continua diciendo "La carrera por obtener prestigio había comenzado y la competencia estaba cuesta arriba. Las grandes ciudades del momento se enfrascaron en rivalizar una contra la otra en su ideal de llegar a convertirse en el centro del mundo, en el eje del cosmos y en el lugar favorecido por los dioses....". 
Es difícil establecer hasta donde llega el área urbana e inicia el área rural. Para este estudio comparativo es difícil de determinarlo pues la documentación recopilada y sistematizada se limita al área compacta y monumental, sin asegurar que puedan existir otros sectores monumentales vecinos al área ya registrada. En esta investigación se excluye el registro de las áreas habitacionales periféricas, ya que los restos tangibles de estos sectores urbanos son extremadamente difíciles de identificar en la selva y requieren de investigación arqueológica para buscar evidencias de plataformas de sustentación que identifiquen las bases de las viviendas. Además no hay muros ni bóvedas que requieran de atención preventiva ni restauración en estos sectores.

Uno de los principales objetivos de este estudio es identificar arquitectura monumental, para proponer medidas de conservación por lo que no es un estudio sobre asentamiento habitacional o de límites urbano-rural.

Resultados de la posición del sitio en el paisaje

Para ordenar el resultado de la investigación sobre los sitios y su posición en le paisaje, en el cuadro 3 (posición del sitio con le paisaje), se ha agrupado la muestra (128 sitios) en dos variables:

1- Sitios ubicados sobre colinas en cadena, escarpas o sitios, en colinas aisladas en medio de bajos o terrenos planos.

2- Sitios a orillas de cuerpos de agua: lagos, lagunas, ríos, bajos, islas y penínsulas.

Es común que la ubicación de un sitio coincida con dos o tres variables. Por ejemplo Yaxhá está sobre una colina en cadena, que al mismo tiempo es límite físico entre una cuenca y otra. Al sur, la 
ciudad es limitada por la laguna Yaxhá y al norte por un bajo o humedal. El sitio Naranjo se encuentra en una posición muy privilegiada en donde puede controlar tres segmentos de cuenca: al oeste, tiene el extremo este de la cuenca de Los Lagos; al este, el extremo norte de la cuenca Mopán; y al norte la cuenca media del Río Holmul; igualmente Tikal tiene una posición estratégica ubicada en una colina parte aguas, con grandes humedales al oeste y este que pueden conectarse con otros sistemas.

En otros sitios como Poza Maya modificaron el terreno natural para posesionarse del paisaje circundante de bajos. Aquí se construyo artificialmente todo el sector norte del yacimiento, con rellenos de más de $7 \mathrm{~m}$; a $400 \mathrm{~m}$ al sur se encuentra un cuerpo de agua en forma cuadrada de $200 \mathrm{~m}$ por $200 \mathrm{~m}$.

Los mayas además de modificar el terreno natural para adaptar sus construcciones (diques y rellenos artificiales) también usaron recurso naturales disponibles como los cortes pronunciados de topografía, las islas o las penínsulas. En este sentido el uso de las escarpas cortadas, fue una táctica utilizada, por lo que la estructura urbana se amolda a las cimas y lenguas de terreno en las orillas de los cortes geológicos (Kanajau, El Diablo, Ciudadela Naranjo, Laín Perdido, Witzná, Tzikintzakán, Juleque y Canchén). Estos sitios tienen la ventaja de poder controlar desde arriba amplios sectores de territorio.

\subsubsection{Indicadores de tamaño}

Varios autores han tomado diferentes criterios para dar una idea del tamaño y complejidad de los centros mayas. Sylvanus G. Morley fue el primero y utilizó como indicador de importancia la cantidad y calidad de monumentos con inscripciones jeroglíficas. En su criterio Morley considera: el área respectiva, el número de restos 
arquitectónicos, y el número y calidad de sus monumentos (Morley 1938, 48). Morley consideró un sitio de primer categoría (Tikal); cinco para la categoría dos (Uaxactún, Xultún, La Honradez, Nakum y Naranjo); seis para la categoría tres (Xmakabatún, Chochkitam, Ucanal, Yaxhá, Tayasal y Holmul); y seis sitios para la categoría cuatro (Uolantún, El Encanto, Chunhuitz, Motul, Ixlú y San Clemente). Otros autores emplearon complejos cálculos de población o contaron el número de edificaciones (Culbert et al. 1990, 103-121; Chase 1990, 149-166; Rice y Rice 1990, 123-148; Turner 1990, 301-324; Adams y Jones 1981, 301-322).

Herbert Wilhelmy (1989, 406-408) por ejemplo, se basa en cálculos de habitantes por sitio arqueológico más otros datos para centros de intercambio y población rural y clasifica las ciudades en: centros mayores, centros regionales, centros intermedios, pequeños centros y centros ceremoniales. Para el área de este estudio considera un centro mayor (Tikal); ocho centros regionales (Mirador, Naachtún, La Honradez, Xultún, Uaxactún, Nakum, Naranjo y Tayasal). Siete centros intermedios (Chochkitam, Xmakabatún, Holmul, Dos Aguadas, Yaxhá, Tzikintzakán, y Ucanal); y 24 centros pequeños (Wilhelmy 1989, Karte der Räumlichen Verteilung und Klassifikation der Zeremonialzentren).

\subsubsection{Indicador "espacios libres"}

Numero de plazas y patios

En este estudio si tomamos el indicador de "espacios libres" de plazas y patios, como elemento ordenador del tejido urbano, tenemos el siguiente resultado: 
- Un solo sitio sobrepasa más de 80 espacios de plazas y patios (Tikal).

- Tres sitios poseen más de 50 plazas y patios (Naachtún, La Honradez, Naranjo).

- Ocho sitios entrarían en una misma categoría: dos con más de 40 plazas y patios (Yaxhá y El Mirador), dos con más 30 plazas y patios (Uaxactún, Xultún,) y cuatro con más de 20 plazas y patios (Kinal, Chochkitam, Holmul y Nakum).

- Otro grupo, con 29 sitios, estaría entre el rango de más de 10 a más de 19 espacios de plazas y patios.

- 86 sitios estarían en el rango entre más de una a más de nueve espacios de plazas y patios. Estos últimos son considerados sitios pequeños (Planteles); sin embargo pueden tener hasta 9 "espacios libres" con edificaciones monumentales.

Las cuencas que poseen el mayor numero de sitios grandes (Reinados) se encuentran en la cuenca de Ixcán con 5 sitios, luego la cuenca de Holmul con 3 sitios y Tikal y Mirador con 2 sitios cada cuenca. El más grande de todos es Tikal con más de 100 espacios libres de plazas/patios. Las cuencas de Los Lagos y Mopán no poseen sitios grandes. En la cuenca de Los Lagos solo hay un sitio con más de 40 plazas/patios que se refiere a Yaxhá. Pero Yaxhá se encuentra en el límite de la cuenca Holmul y podría considerarse más ligado al territorio de los grandes humedales del norte que a la cuenca de Los Lagos. En la cuenca del río Mopán no se encuentra ningún sitio arqueológico que posea más de 20 espacios de plazas/patios. Es necesario recordar que ya mencionamos que las tabulaciones realizadas para este estudio se refieren a los resultados de los planos esquemáticos de las áreas centrales y compactas y que muy posiblemente habrán otros grupos de patios y plazas no 
registrados en la muestra; por eso nos referimos a mas de 20 plazas/patios, mas de 30 plazas/patios.

Esta clara diferencia en el tamaño de los sitios arqueológicos entre los diferentes territorios quizá se deba a que en las cuencas del norte (Área Tikal, cuenca Ixcán y Holmul) los asentamientos son agrupados y compactos en contraste con los grupos del sur (cuencas Los Lagos, Mopán) en donde los asentamientos son más dispersos. Otros estudios en la cuenca Mopán confirman este patrón de asentamiento disperso (Laporte 2001,137-162, Laporte y Mejía 2000).

\subsubsection{Indicador "elementos masa"}

\section{Numero de edificios}

Si tomamos el indicador relacionado con el número de edificios (elementos sólidos) tenemos la siguiente visión del territorio:

- Sitios que sobrepasan las 400 edificaciones, dos (Tikal y El Mirador).

- Sitios con mas de 120 edificaciones, dos (Naranjo y La Honradez).

- $\quad$ Sitos entre mas de 80 y 100 edificaciones, nueve.

- Sitios entre 20 a 39 edificaciones son los mayoritarios con $40.47 \%$.

- $\quad$ Sitios entre 1 y 19 edificaciones (39.67\%).

El mayor de todos es Tikal con más de 600 edificaciones y luego El Mirador con mas de 420. En seguida continúa Naranjo con más de 170 y La Honradez con más de 120 construcciones monumentales. Sitios con mas de 80 y 100 construcciones hay en la cuenca Mirador, tres (Nakbé, Naachtún y Tintal), en el área Tikal, uno (Uaxactún), en 
la cuenca Holmul tres (Yaxhá, Nakum y Xultún) y dos en la cuenca Ixcán (Kinal y Chochkitam).

La menor densidad de edificaciones se encuentra en la cuenca Mopán, aquí el 100\% esta en la categoría de entre 1 y 39 edificios por sitio arqueológico. Igual sucede en la cuenca de Los Lagos, el 91\% de los sitios aquí registrados se encuentran en el rango entre 1 y 39 edificios por sitio (32 sitios).

Al combinar los dos indicadores tenemos como resultado dos súper centros, uno en le área Tikal (Tikal) y uno en la cuenca Mirador (El Mirador). Centros muy grandes hay dos, uno en la cuenca Holmul (Naranjo) y uno en la cuenca Ixcán (La Honradez). Centros grandes hay nueve; en la cuenca Mirador tres (Nakbé, Naachtún y Tintal), en la cuenca Ixcán tres (Kinal, Chochkitam y Xultún), en la cuenca Holmul dos (Yaxhá y Nakum) y uno en el área Tikal (Uaxactún).

\subsubsection{Relaciones visuales}

Mencionamos anteriormente que, buena parte de los sitios arqueológicos toman posesión de puntos estratégicos, muchas veces estos puntos son cimas de colinas que permiten tener un control visual de su entorno. Aun hoy en día, en la selva continua, es posible observar las crestas cubiertas de vegetación de las edificaciones mas peraltadas. Por lo general en un radio de 25 kilómetros de un sitio mayor y otro u otros sitios de similar rango, existe una relación visual entre ellos. Esto supone una extensa red de comunicación rápida por todo el territorio. En el cuadro 3 (ver anexo 1) se registra la relación visual comprobada entre un sitio y otros.

Hay ocasiones en que por alguna razón un sitio mayor no se localiza en una posición elevada o con vista hacia otro $u$ otros yacimientos 
importantes. En este caso se construye, sobre la cima de las colinas cercanas, pequeños grupos de edificios (tipo ciudadelas). Con estas construcciones les fue posible la comunicación visual con otros sitios. Ejemplos de centros urbanos grandes con este control en la cima de los cerros cercanos se encuentran en: El Zotz, con el sitio El Diablo, en Nakum con una construcción sobre la colina cercana y en Naranjo con el pequeño sitio llamado Ciudadela Naranjo. En estos tres casos el área monumental se ubica al pie de los cerros o como Nakum a orilla del rió Holmul.

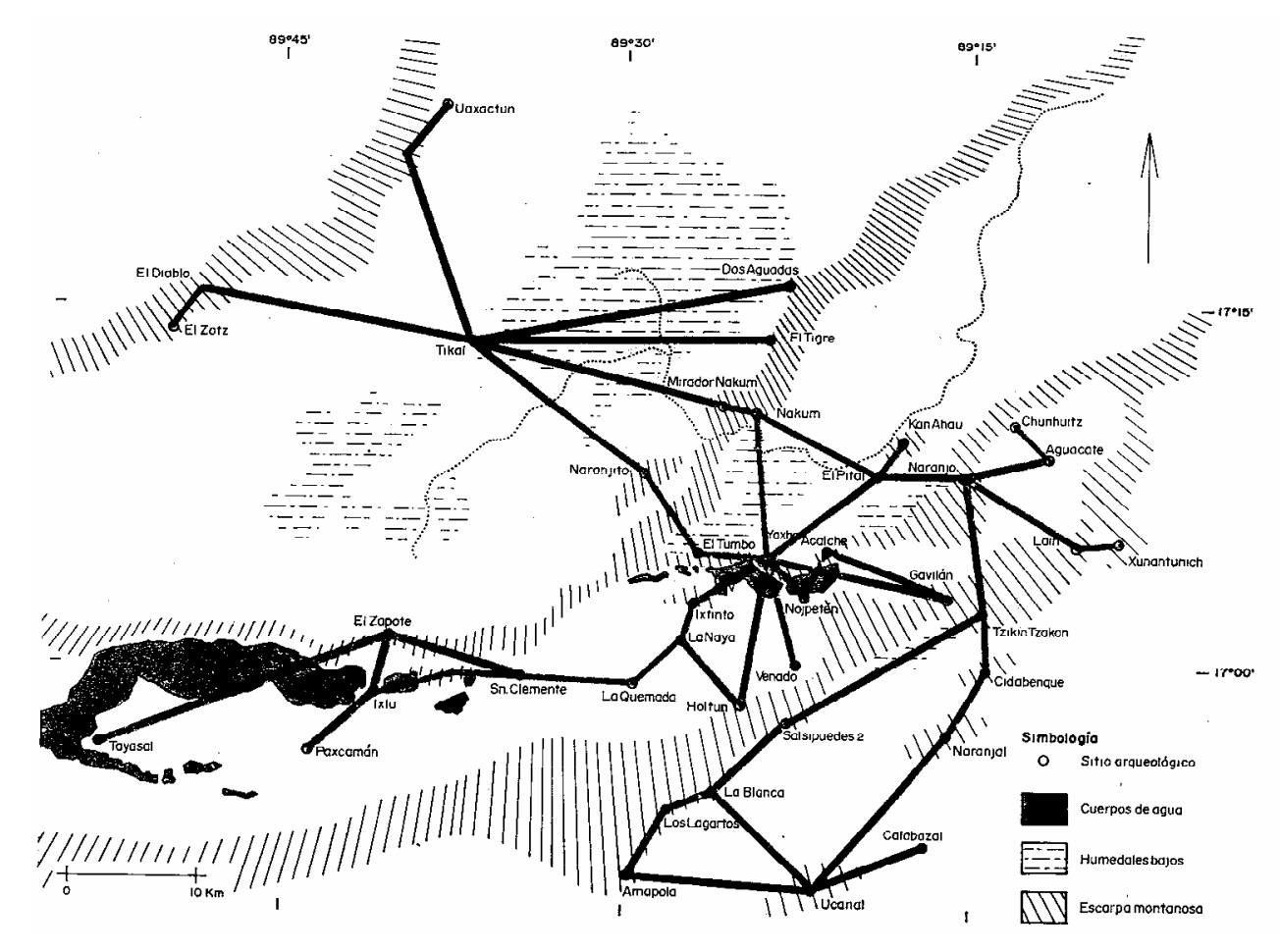

Fig. 10. Relaciones visuales entre Tikal y Yaxhá 
La relación visual y el dominio del paisaje llegan a excepcionales ejemplos en la cuenca Mirador. La característica general del terreno es más plana que el resto de las cuencas que conforman los grandes humedales (Área Tikal, cuenca Ixcán, y cuenca Holmul). En este territorio los mayas construyeron sobre elevaciones naturales sus propias colinas artificiales, formando monumentales construcciones, transformando así el paisaje. Ejemplos de estas construcciones monumentales se observan en los sitios: El Mirador, Nakbé, Tintal, Wakna, y Xulnal.

En principio el territorio del noreste con sus cuencas puede dividirse en dos paisajes. En el extremo noroeste, con la cuenca Mirador con un paisaje continuo y homogéneo entre colinas bajas y humedales, con drenaje hacia el oeste. Otro grupo lo forman: el área Tikal y las cuencas Ixcán y Holmul con colinas en cadena, escarpas, grandes humedales y ríos estacionarios (con drenaje hacia el este) Estos dos segmentos se pueden unir en uno llamado "los grandes humedales".

El segundo grupo, al sur, lo forman la cuenca de Los Lagos y la cuenca baja del rió Mopán. En este territorio predomina en el paisaje, al norte la escarpa que limita los dos grandes territorios, colinas aisladas y en cadena, humedales no tan grandes 14 lagunas, un lago y tres ríos permanentes.

Al comparar los diferentes paisajes, podemos decir que en la cuenca Mirador la ubicación recurrente fue en colinas en medio de bajos y a orilla de bajos con un solo ejemplo de un sitio en isla (Puerto Arturo). Solo dos sitios se ubican en colinas en cadenas situados en el extremo noreste de la cuenca (La Muralla y Naachtún). Al este, en el grupo de los grandes humedales y ríos estacionarios, se ubican sobre colinas en cadena 28 sitios, de ellos 7 se posicionan sobre 
escarpas que dominan los valles. La posición a orilla de bajos fue de 21 sitios y 10 a orilla de ríos estacionarios.

En el paisaje dominante del sur: En colinas en medio de bajos 36 sitios y 12 sobre colinas en cadena, de los cuales 9 se posesionan en escarpas que controlan las cuencas. A orillas de bajos inundables 15 sitios y 10 a orilla de ríos permanentes. En islas dos y en penínsulas tres.

La división del territorio en dos paisajes dominantes identifica diferentes tipos de composición urbana. Por ejemplo en la cuenca Mirador el elemento dominante son edificaciones dispersas con pocos ejemplos de centros urbanos concentrados y monumentales (Tintal, El Mirador, Nakbé, Wakna y Xulnal). Seguramente estas diferencias de composición o densidad urbana coinciden también, con el auge constructivo de diferentes épocas culturales. En la cuenca Mirador predomina el patrón del Preclásico Tardío, con edificios emblemáticos como los grandes grupos triádicos.

En toda el área del estudio prevalecen los edificios horizontales ya sea en composiciones dispersas o concentradas. Este patrón difiere un tanto en el segmento: Área Tikal, Ixcán y Holmul en donde el indicador principal son conjuntos de edificios más compactos y monumentales con múltiples tipos de edificios; esta sección forman una unidad compositiva común, propia del esplendor del periodo cultural del Clásico. En el periodo Clásico Tardío y Terminal se organiza el espacio a escala masiva y monumental con grupos de patios complejos de grandes dimensiones, no aparecen complejos de esa escala tan grande y monumental en los otros sectores del área de estudio. 
Los tipos representativos en la cuenca de Los Lagos y cuenca Mopán, no son tan monumentales y se encuentran sobre colinas cercanas unos de otros en conjuntos dispersos. En la cuenca de Los Lagos se combinan construcciones no tan monumentales del Clásico, con edificaciones características del periodo Posclásico, éstos últimos con adaptaciones al terreno natural para formar compactas terrazas niveladas. El esquema de solución urbana en este periodo, es totalmente distinto a las formas y proporciones espaciales del Clásico.

En la cuenca Mopán los conjuntos de edificios se organizan sobre colinas que dominan el paisaje. Una característica de esta cuenca es la construcción de diferentes conjuntos urbanos en diferentes cimas cercanas; algunas unidas por calzadas, otras sin aparente unión entre unas y otras. 
El siguiente nivel de análisis se refiere a los elementos urbanos. El panorama actual para su investigación tiene varias limitantes. En los planos esquemáticos que disponemos, se registran más de 4000 construcciones. Estas edificaciones se encuentran, la gran mayoría, en situación de "montículos" o sea que las edificaciones están cubiertas por humus, escombros y vegetación. Otro factor limitante es la falta de excavaciones arqueológicas y de estudios sobre la composición arquitectónica general en todo el territorio.

En la investigación se identificaron 34 elementos urbanos y mas de 87 combinaciones o variantes de estos tipos. Primero analizaremos los elementos geométricos y horizontales que generan espacios libres de plazas, terrazas y patios. Estos elementos, son planos, lisos y nivelados; su superficie sirve para reunir personas, permitir la circulación horizontal y mostrar edificios. Los límites de un espacio libre lo forman edificios o el mismo límite del piso. Los elementos, plazas y patios, tienen el mismo criterio de ordenar el espacio libre. Estos funcionan también como elementos de conexión con otras plazas y otros patios generando así, los elementos de comunicación horizontal entre grupos de edificios. Aquí hay que agregar, que la comunicación entre plaza y plaza, plaza patio, patio y patio, es apoyada por corredores, terrazas, y en ocasiones por pasillos que atraviesan edificios (Edificio D de Nakum). Una variante de espacio libre y de comunicación son las vías o calzadas.

Los centros urbanos generalmente se ubican sobre cimas de colinas, aprovechando el relieve topográfico para acentuar requerimientos culturales de estratigrafía social. En este caso la comunicación 
horizontal se complica con una serie de barreras verticales, formadas por plataformas de diferentes niveles. Las barreras verticales son resueltas por las escalinatas. Generalmente, las escalinatas se consideran como parte de los elementos compositivos de los "espacios libres" y apoyan a definir ejes visuales con las edificaciones. Las escalinatas no sólo son el medio para pasar de una plataforma a otra sino son parte del escenario teatral de las ciudades y marcan los ejes principales de las edificaciones.

Para formar espacios horizontales, amplios y nivelados se requiere del apoyo de las plataformas de nivelación. La plataforma es el principal elemento constructivo de los centros urbanos mayas. Este elemento básico de la arquitectura se forma con muros contrafuerte y materiales de relleno, formando bloques macizos con superficie horizontal plana o, más o menos plana. Dependiendo de sus dimensiones puede formar una plataforma de sustentación (plazas y patios) o un elemento de base para un edificio. Varias plataformas superpuestas pueden formar una base piramidal o plataforma escalonada, la cual puede o no tener una construcción superior. Varias plataformas superpuestas pueden alcanzar dimensiones monumentales y llegar a soportar varios edificios y patios, formando grupos de patios elevados (acrópolis).

El otro elemento generador de ciudades, son las edificaciones con espacios interiores, también llamados "elementos sólidos"; por representar masas sólidas en la estructura urbana. Los edificios son volúmenes construidos a base de muros y techos de piedra con el propósito de "usar" el espacio interior. Para ser un "elemento sólido" no es imprescindible contar con un espacio útil interior; una pirámide escalonada o una edificación para formar una cancha para el juego de pelota también son elementos sólidos. 
Algunos escenarios se forman al combinar los "elementos sólidos o elementos masa", con los "elementos espacios libres". La posición de los edificios está especialmente estudiada, aprovechando efectos de orientación, posición, relación plaza y edificio, relación entre un edificio y otro, u otros; también se aprovechan los efectos de luz y sombra, plástica aplicada a las fachadas de los edificios y el color para trasladar mensajes e impactar al observador.

Miguel Rivera Dorado dice que la escenografía es considerada como rasgo principal de su composición arquitectónica y menciona varios elementos empleados para acentuar este efecto teatral. Entre ellos están: el uso de plataformas elevadas, el uso de la perspectiva, la ornamentación en los edificios, la circulación con entrada y salidas preparadas, efecto de ascender o descender en las escalinatas. Otros elementos que enfatizan el carácter escénico son, ubicaciones especiales con impactos visuales, visión frontal y laterales, el movimiento de masas, complementos auditivos, acústica, los vestidos, adornos y movimientos corporales (Rivera Dorado 2007, 166-168).

A continuación presentamos los elementos urbanos identificados en la muestra, principiamos con los elementos básicos (elementos espacios libres y elementos sólidos) individuales o "sueltos", para luego continuar con combinaciones de tipos de construcciones hasta llegar a los complejos sistemas de grupos de patios y edificios. 


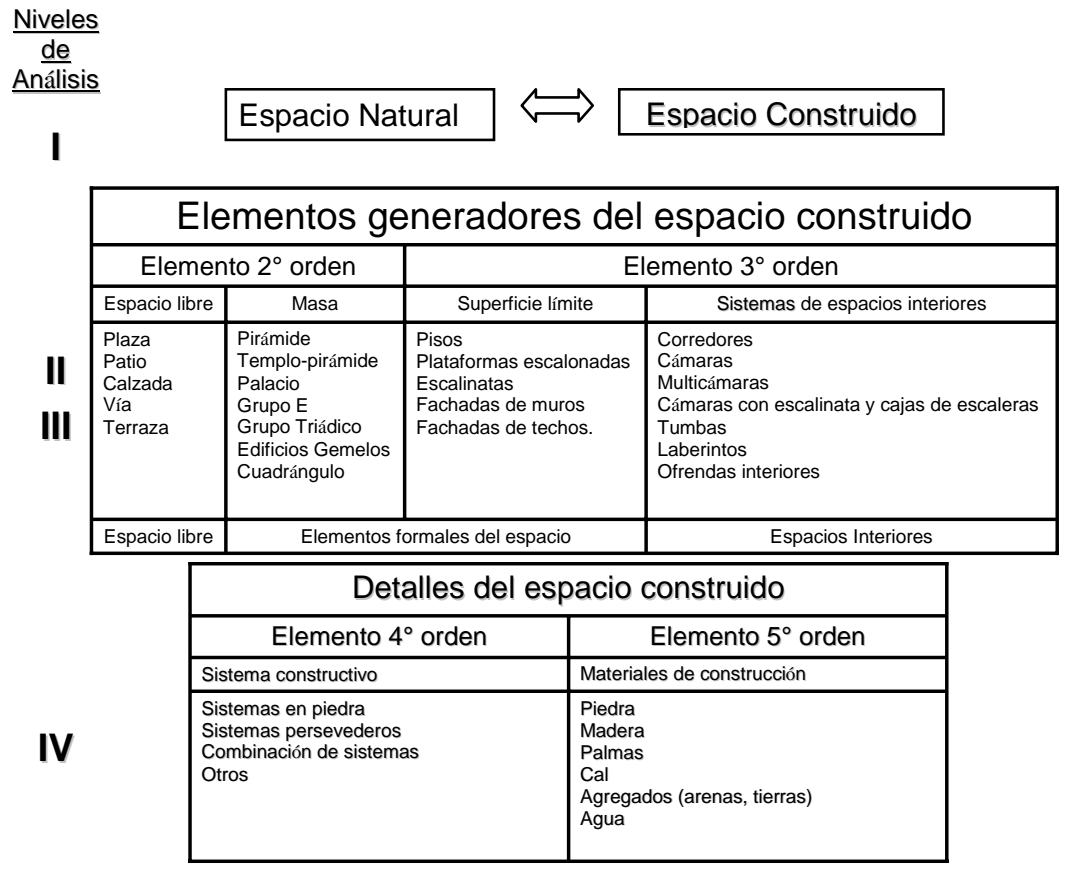

Fig. 11. Relación de elementos formales en cinco niveles de análisis

La figura 11 presenta un esquema de relación con los cinco niveles de análisis utilizados para la investigación. El primer nivel se ocupa de la relación entre el sitio y su ambiente natural. Los niveles II y III a los elementos generadores del espacio construido (elementos de 20 y 30 orden) y los niveles IV y $\mathrm{V}$ a los detalles de ese espacio construido (elementos de 40 y 50 orden). En las figuras 12, 13 y 14 se muestran en forma esbozada cada elemento identificado (niveles II y III) y en el anexo 1 los planos esquemáticos utilizados (plano esquemático por cuenca 2 al 7); además el cuadro 3 "elementos urbanos" registra los elementos identificados. 


\subsection{ESPACIOS LIBRES}

El primer elemento generador del espacio construido, se refiere al nivel II, "espacios libres". En este estudio distinguimos cinco elementos de espacios libres (plazas, patios, calzadas, vías y plataformas elevadas con espacio vacío) y 12 variaciones de estos elementos (ver figura 12). Para cada variante hay diversas combinaciones que incluyen otros términos como terrazas, corredores, pasillos, ampliaciones de plazas, ampliaciones de patios, y otros.

Los elementos plaza y patio son los principales generadores del espacio libre. Estos espacios se forma por una superficie horizontal geométrica y pavimentada de dimensiones más o menos amplias para las plazas y mas reducidas en los patios. Sobre esta superficie lisa se colocan edificios y se congregan personas. También sirve como vestíbulo de los edificios y como medio de circulación horizontal entre otros espacios abiertos de plazas y patios.

\subsubsection{Plazas}

En el análisis del "espacio construido" los elementos libres de plazas son un elemento base para ordenar la composición arquitectónica. La plaza es el centro de la ciudad también llamada "Gran Plaza", "Plaza Central" "Plaza Mayor" o "Plaza Principal". Alrededor de ésta se colocan los edificios representativos, como lo son los templos pirámide, las canchas de juego de pelota, la acrópolis y donde se realizan los principales rituales y ceremonias públicas. Las plazas son un elemento frecuente y necesario para ordenar los centros urbanos prehispánicos. Las plazas son el vestíbulo de las edificaciones y dependiendo del tipo de edificio (representativo o público) se dimensiona el espacio libre. Por ejemplo las dimensiones de algunas 
plazas son: La Honradez 100 por 75 m (en la Plaza Principal), Tikal 85 por 60 m (en la Gran Plaza), Nakum 80 por 60 m (en la Plaza Central), Topoxté 65 por 30 m (en la Plaza Principal) Yaxhá 180 por $50 \mathrm{~m}$ (Plaza E).

Si un edificio debe ser enfatizado (Palacio real, templo principal) entonces la plaza es el medio de mostrarlo. En algunas ocasiones, ciertos sectores de las plazas se extienden a los lados de los edificios importantes, formando "ampliaciones de plaza" o terrazas laterales (Plaza M de Yaxhá, Naranjito, Tzikintzakán, Quemada Corozal, La Blanca, Chunhuitz, Holtún, Nakum, Sufricaya, Holmul, Dos Aguadas, Xnakabatún, Río Azul, Manantial, Corozal, La Pita, Ramonalito, Bejucal, El Zotz, Nakbé, Xulnal, El Porvenir, La Ceibita). Estas ampliaciones o extensiones de plazas suceden con más frecuencia en la cercanía de los grupos de patios o acrópolis. Del espacio de las plazas se generan las calzadas o vías que completan el sistema de circulación de la ciudad.

\subsubsection{Plazas con monumentos}

\section{Estelas y altares}

Si una edificación es muy importante, sobre la plaza se incorporan elementos adicionales para acentuar la categoría del edificio (ver figura 12, 4.1.1.1).

Generalmente se puede identificar las plazas principales por la presencia de monumentos de piedra (estelas y altares). Estas plazas son el centro simbólico de la ciudad (el axis mundi). Las inscripciones en estos monumentos permiten reconstruir la historia del sitio y sus gobernantes y además posicionar el sitio en una cronología absoluta. 
Como resultado del desarrollo histórico de las ciudades, algunos centros urbanos tienen más de una plaza principal. Xultún tiene dos plazas principales, Naranjo tiene cuatro plazas con monumentos esculpidos y edificios monumentales. En Yaxhá, cuatro plazas reúnen los requisitos para ser una plaza principal. Ciudades donde es fácil identificar la plaza principal son: Tikal, La Honradez, Xmakabatún, Nakum, Chochkitam, San Clemente y Naranjito.

En centros urbanos sin evidencia de monumentos esculpidos en sus plazas, el "espacio libre" principal generalmente está cercano a una acrópolis, un grupo de patios, cuadrángulo, o grupos de edificios alargados dominante.

Dentro de la muestra estudiada 56 sitios tienen plazas con monumentos esculpidos en piedra monolítica con inscripciones jeroglíficas o lisas (44\% de los sitios). La cuenca Ixcán es la que mayor índice de plazas con monumentos (80\% de los sitios registrados), le sigue el área Tikal con un 73\% y cuenca Holmul con 50\%. La cuenca de Los Lagos y Mopán tienen respectivamente 34\% y $42 \%$. La cuenca Mirador es la de menor cantidad de ejemplos con un $25 \%$.

\subsubsection{Plazas con edificaciones}

Una variante del elemento plaza, son los espacios libres con edificaciones en medio (ver figura 12, 4.1.1.2). Estas construcciones generalmente son plataformas bajas, como especie de tarimas macizas para eventos. Además sirven para marcar ejes de relación con algún edificio. Esta función de marcar ejes o puntos focales en las plazas también la cumplen las estelas y altares. Ejemplos de estas construcciones podemos mencionar en: la Plaza de la Gran Pirámide de Tikal con la plataforma al centro de la Plaza Oeste 
(Edificio 5C-53). En la Plaza Central de Nakum hay dos edificaciones bajas y alargadas en el extremo sur de la plaza, frente a la gran base escalonada de la Acrópolis; También en Nakum una edificación baja se encuentra sobre la Plaza Norte frente al Edificio $X$. Este caso también se aplica a los patios, un ejemplo esta en Yaxhá en el cuadrante $12 \mathrm{C}$ se halla un grupo de edificaciones sobre una misma plataforma; al centro de este conjunto se ubica un edificio que fue excavado en la década de 1970 por Nicolas Hellmuth, otro ejemplo se encuentra en el Patio 1 de la Acrópolis de kinal.

Es muy raro que aparezcan edificaciones mayores en medio de la plaza, como sucede en el sitio arqueológico de Zapote Corozal (Quintana y Wurster 2001, 116).

En el periodo Posclásico hay varios ejemplos de construcciones en medio de espacios libres; en la Plaza Principal de Topoxté, frente a los edificios C y B, está una plataforma baja (Edificio J). Esta construcción forma un grupo típico, identificado por Tatiana Proskouriakoff en Mayapán (Proskouriakoff 1962). En la misma plaza se encontraron otras construcciones bajas: unas con forma de cruz, frente a los edificios G, E y D (protegidas ahora bajo el suelo de la plaza), otra alargada, en el extremo oeste, y al lado derecho del Edifico D, una serie de plataformas bajas con estelas y altares lisos. (Wurster 2000, 36-37).

Otros ejemplos se encuentran en: Tayasal, Sacpetén, Aguacate, Xultún (Grupo B), La Honradez, Ratón Pucteal, Jimbal, Ta-Aj, Corozal, Paxcamán, Naranjal y Camalote). En la muestra hay 22 sitios que tiene esta modalidad (17\%). La zona con mayor incidencia es la cuenca Ixcán (26\%) y la menor presencia para la cuenca Mopán (9.5\%). 
En principio, las canchas de juego de pelota en medio de plazas, como sucede en San Clemente y Naranjo, (referidos en el apartado "canchas de juego de pelota" 4.2.1.7), podrían coincidir también con esta categoría.

\subsubsection{Calzadas}

Las calzadas son elementos, "espacio libre", que se prolongan y se estrechan formando caminos pavimentados de comunicación entre un grupo de edificios y otro. Generalmente, este elemento se genera a partir de un espacio libre de plaza. Los límites laterales de las calzadas pueden tener pequeños muros llamados parapetos. Su posición en relación a los grupos de edificios que une es variable y generalmente cubre el espacio con terreno bajo e inundable, poco apropiado para construcciones monumentales. En otros casos ascienden colinas empinadas para llegar a grupos de edificios en la cima.

En este estudio dividimos las calzadas en cuatro variables: calzadas que se amoldan al terreno, calzadas horizontales, casos especiales y calzadas entre sitios.

\subsubsection{Calzadas inclinadas}

La mayoría de calzadas, se amoldan al terreno y suben o bajan siguiendo su topografía para cumplir su función de comunicación entre grupos de edificios (Chochkitam, Naranjo, Naranjito, Yaxhá, Tikal, La Honradez, Aguacate y otros).

Las calzadas no sólo cumplen la función urbana de comunicar un grupo de edificios con otro, sino también son un elemento escénico de la ciudad (ver figura 12, 4.1.2.1). Estos caminos son usados para acentuar edificios importantes. La calzada Tozzer de Tikal no necesita 
tener un ancho de 75 m para comunicar el área central de la Gran Plaza con el Templo IV. En este caso, la topografía ascendente hacia el edificio es aprovechada y refuerza el sentido ceremonial y la grandiosidad de este camino procesional.

Hay casos en que pareciera que la calzada es un camino de acceso hacia el centro urbano, como sucede con la Calzada Maudslay de Tikal. En este caso, el camino geométrico, que mide $60 \mathrm{~m}$ de ancho, inicia en un edificio (ahora como montículo) que cierra el espacio; posiblemente una puerta simbólica de entrada a un "lugar sagrado". Similar impresión dan las calzadas este y oeste de La Honradez. Ambos caminos tienen al inicio un edificio (o control de acceso), para luego ascender al centro de la ciudad. En este caso ambas vías ceremoniales al este (Calzada 3), y al oeste (Calzada 1) tienen $40 \mathrm{~m}$ de ancho. Un caso particular en Naranjo, la calzada que asciende el cerro hacia la Acrópolis Norte a mitad de camino tiene un descanso. Este paro en el acenso esta formado por una terraza alargada y horizontal (ortogonal a la calzada) con edificios bajos en sus extremos (este y oeste). Luego continúa la subida hacia el grupo de edificios en la cima.

\subsubsection{Calzadas horizontales}

Una versión especial son las calzadas que rellenan los terrenos de bajos (no apropiados para la construcción), con diques de contención. Con este procedimiento se logra "extender" el espacio horizontal de la plaza hacia otro grupo de edificios (ver figura 12, 4.1.2.2). Estas calzadas horizontales requieren enormes movimientos de relleno y condicionan, por la alteración a la topografía natural, la creación de estanques de agua en uno de los lados del dique-calzada. Impresionantes ejemplos de este tipo se encuentran en Yaxhá, Nakum y Uaxactún. 
La Calzada Blom en Yaxhá es el enlace entre el centro de la ciudad con el Grupo Maler al norte. Aquí, en lugar de bajar y seguir la topografía del terreno, se construyeron muros laterales, con más de $200 \mathrm{~m}$ de largo, para elevar el piso de la calzada al mismo nivel de las plazas. Otro ejemplo parecido es la calzada Perigny en Nakum, de más de $250 \mathrm{~m}$ de largo, y $26 \mathrm{~m}$ de ancho, que une el grupo de edificios al norte con los grupos de edificios al sur. El espacio de bajos intermedio, fue rellenado para tener un nivel similar a la Plaza Central (del Sector Sur). En la calzada, antes de llegar al Sector Norte, el piso horizontal se transforma en una rampa, que asciende 8 $\mathrm{m}$ al nivel del piso de la Plaza Norte. Este cambio de nivel al final de la calzada "dramatiza" el efecto de llegada o salida de un punto a otro. Similar es la calzada que une el Grupo A con el Grupo B de Uaxactún. Aquí el camino ceremonial sale al mismo nivel de la plaza del Grupo B, en dirección sur. Son claros los rellenos a ambos lados de la calzada para mantener el nivel del piso de la plaza B. Luego una rampa, con todo el ancho de la calzada $(80 \mathrm{~m})$, asciende $8 \mathrm{~m}$ para llegar a la parte aplanada del Grupo A. Aquí también se repite el efecto de acentuar con una rampa el acceso o salida de un grupo de edificios. Ejemplos similares de rampas inclinadas al final o salida de una calzada se encuentran en Xultún, Naranjo, Naranjito y El Pital.

\subsubsection{Casos especiales}

Hay situaciones particulares en que una calzada se "mezcla" con una plaza (ver figura 12, 4.1.2.3). La diferencia que marca los espacios son pequeñas rampas y los reducidos muros laterales; por ejemplo en la Plaza Este Baja de Naranjo. Similar detalle urbano se observa en El Zotz. El propósito seguramente era marcar la dirección del camino ceremonial entre la plaza. 
Una variante especial es la calzada en diagonal de Poza Maya. Aquí El camino ceremonial desciende en rampa en una esquina de la Plaza Sur, atraviesa el espacio libre de la plaza en forma diagonal (parapetos de barrera) y luego asciende en rampa en la esquina contraria hacia la Plaza Norte.

Otro caso atípico es la calzada en paralelo de Kinal. Esta calzada en lugar de unir grupos de edificios, corre a un lado de los principales edificios y espacios monumentales de la ciudad, incluyendo la plaza principal (a un nivel más bajo), como una terraza elevada alargada.

En el sitio El Pital hay dos calzadas que se juntan formando un ángulo de 90 grados. La razón de esta peculiaridad es librar una depresión topográfica entre dos cimas de colina con edificaciones.

En toda la muestra, sólo encontramos un caso, en que una calzada no conduce a otro grupo de edificios. Se trata de la "Calzada al Lago" en Yaxhá. Aquí el área central de la ciudad, ubicada en la parte alta de un cerro, tiene una vía de comunicación que desciende hasta la laguna o desde el agua se construyó un camino que asciende a la urbe (ver figura12, 4.1.2.3).

Yaxhá y Tikal tienen cinco ejemplos distintos de calzadas; Nakbé tiene cuatro, La Honradez tiene tres calzadas.

\subsubsection{Calzadas entre sitios}

Una modalidad especial son los caminos o calzadas que unen un centro poblado con otro $u$ otros, como sucede en la cuenca Mirador (ver figura 12, 4.1.2.4). Desde la ciudad de El Mirador salen varias calzadas regionales en distintas direcciones; una sale hacia el norte, 
tres salen hacia el oeste, y otras salen hacia el sur. Sólo la calzada entre El Mirador y Nakbé, de 13 kilómetros de largo, ha sido parcialmente investigada (Suasnávar 1994, 335-348).

En las cuencas de Holmul, Ixcán, Los Lagos, Mopán y en el área Tikal no se ha encontrado evidencia de calzadas que comuniquen dos o más yacimientos mayas. Probablemente la diferencia de la cuenca Mirador con el resto de las áreas de esta investigación sea que en las otras cuencas la vía principal de comunicación fueron los ríos y los cuerpos de agua. Estos "caminos rápidos", que ahora son ríos estacionarios pueden haber sido las vías de comunicación en los grandes humedales del este (área Tikal, cuenca Ixcán y cuenca Holmul). En la cuenca de Los Lagos está la red de cuerpos de agua, que se prolongan este-oeste por cerca de 90 kilómetros; y en la cuenca Mopán, tres ríos permanentes corren de sur a norte a lo largo del valle.

En total, 43 sitios arqueológicos de la muestra tienen calzadas (33.5 $\%$ ); con más de 65 ejemplos. La cuenca Ixcán tiene el mayor índice de calzadas con un $60 \%$. Luego continúan los sitios de la cuenca Mopán con 42.8\%; Mirador y Holmul tienen igual ponderación 33.3\% y por último la cuenca de Los Lagos con la menor incidencia de calzadas (17\%).

\subsubsection{Vías}

Dentro del tejido urbano se encuentra otro tipo de comunicaciones con dimensiones y función diferente a las calzadas. Estas vías son "calles" que separan un grupo de edificios de otro dentro de un mismo sector (ver figura 12, 4.1.3). Es decir no tienen el propósito de librar espacios no apropiados a las construcciones, sino más bien cumplen una función de circulación interna entre los edificios de un mismo 
grupo. Los mejores ejemplos se pueden observar en Yaxhá: la Vía 1 entre la Plaza A y la Acrópolis Este; y la Vía 6 entre la Acrópolis Sur y los grupos O y P. En Tikal hay una calle entre el sur del Palacio de los Murciélagos (5C-13) y los edificios al norte de la Plaza de la Gran Pirámide.

\subsubsection{Vías y grupos de edificios}

Una variante son las vías o "calles" que forman grupos de relación con edificios alargados y bajos como en las Vías 2, 3 y 4 que comunican los grupos I, J, K y L de Yaxhá (ver figura 12, 4.1.3.1). Es posible que estos espacios urbanos tengan relación con actividades de manufactura, mercado o cuarteles militares. Otros ejemplos similares se observan en: Naranjo, Ixtinto, Naachtún, Xultún, Manantial, La Línea, Balán Chac, Ixqueej, Juleque, y El Tumbo.

En la muestra 12 sitios (9.3\%) registran vías con 23 ejemplos.

\subsubsection{Patios}

El segundo gran elemento básico del espacio construido es el patio. (ver figura 12, 4.1.4) Este en otro nivel se ocupa de la organización de la composición arquitectónica de grupos de edificios mas bien alargados y de carácter privado, en relación a los espacios libres de plazas con un carácter de uso público y representativo. Además sus dimensiones son menores. Por ejemplo miden: La Honradez 30 por $22 \mathrm{~m}$ (en el grupo de patios principal), Tikal 31 por $20 \mathrm{~m}$ (en el Patio 2, de la Acrópolis Central), en Nakum 40 por 40 m (en el Patio 1 de la Acrópolis), Yaxhá 50 por 43 m (Acrópolis Este).

Los patios junto con las plazas, calzadas, rampas y escalinatas constituyen los elementos que articulan las ciudades prehispánicas. Estos elementos espaciales pueden crecer, como especie de 
"panales de abejas" (patios en cadena) formando complejos espacios urbanos llamados "grupos de patios".

Como mencionamos arriba en los patios, el volumen dominante son las construcciones tipo "edificio horizontal". Pero también hay combinaciones de otras construcciones como: baños de vapor, templos pirámide y composiciones de edificios como el grupo triádico. Es frecuente también que aparezcan patios "más privados", con barreras de ingreso, en los sectores de los grupos de edificios horizontales. En otros casos se agregan patios alargados o terrazas hacia la parte exterior; como terraza privada (Acrópolis Sur de Naranjito, cuadrángulo $F$ de Tikal, Acrópolis de Xmakabatún, Acrópolis de Nakum).

Una terraza es un espacio libre, mas largo que ancho, elevado, con tres lados "vacíos" o abiertos hacia el horizonte. El cuarto límite lo forma una edificación en el sentido longitudinal al espacio libre. La terraza sirve de vestíbulo y acceso a los espacios interiores del edificio. Una variante son las "ampliaciones de patios", en este caso en un sector del patio se extiende el espacio libre formando corredores, terrazas o patios secundarios en esquinas. (Patio 6 de la Acrópolis Central de Tikal. Patio 2, 7, 5 de la Acrópolis de Nakum, Patio 1 de la Acrópolis Sur de Yaxhá);

\subsubsection{Plataformas con espacios vacíos}

La característica de este elemento urbano es contar con una plataforma elevada que tiene espacios libres sin construcción alguna en su superficie horizontal (ver figura 12, 4.1.5). En otros casos sobre la superficie horizontal, se colocan edificios que no ocupan aparentemente "todo el espacio útil" de la plataforma elevada. Un ejemplo del primer caso se encuentra en el extremo norte de la plaza 
principal de Chochkitam Es una plataforma elevada de aproximadamente $30 \mathrm{~m}$ por $30 \mathrm{~m}$ y un alto de $10 \mathrm{~m}$ sin edificación aparente en su parte superior. Un ejemplo de construcciones elevadas con espacios vacíos se observa en el límite oeste del Grupo F de Tikal. Aquí se encuentra la plataforma 5E-1, que mide 115 $\mathrm{m}$ por $132 \mathrm{~m}$ y un alto de $7.5 \mathrm{~m}$ desde el piso de la Plaza Este. William R. Coe dice al respecto, "pese a una gran cantidad de excavaciones, la naturaleza y función de esta explanada permanece en uno de los mayores misterios arqueológicos de Tikal... Sin embargo las excavaciones practicadas sobre la plataforma no revelan nada más que montículos de relleno.... también puede suponerse que una ampliación de construcciones anteriores haya sido proyectada sin ser llevada a cabo". (Coe 1967, 72)

Otros ejemplos similares se encuentran en Xultún, la plaza sur (Edificio A-22) y la plaza norte (Edificio B-18); en Ucanal la plataforma norte (Edificio B-1 y B-2); en Nakum el Grupo Este (Merwin), Xmakabatún, Naranjo, La Sufricaya, Cival, y Nixtunchich.

La muestra cuenta con 19 ejemplos de esta característica urbana (14.8\% de la muestra). No se conoce ningún ejemplo en la cuenca Mirador; la cuenca Mopán tiene un 4.7\% y la mayor concentración se halla en el área Tikal (33.3\%) y la cuenca Holmul (20\%).

\subsection{ELEMENTOS SÓLIDOS}

El tercer elemento esencial en la composición arquitectónica son los espacios masa o elementos sólidos. Para describir los elementos sólidos los hemos dividido en dos grupos básicos, el primero para los edificios bajos y alargados, llamados aquí "edificios horizontales" y la segunda variante para los edificio en donde predomina la intención de elevar los mismos, llamados "edificio verticales". De estas dos 
tendencias formales, elevados y no elevados, se construyen los elementos sólidos de las ciudades prehispánicas. Hay que aclarar que al decir edificaciones bajas $u$ horizontales no nos referimos a construcciones de una altura corta o rebajada sino a una tendencia a alargar los edificios en lugar de elevarlos. Las proporciones en los edificios mayas son monumentales en las dos variables.

\subsubsection{Edificios horizontales}

Los edificios horizontales tienen generalmente forma rectangular. Este tipo básico está formado por uno o varios espacios interiores delimitados por pisos, muros, techos.

Los edificios horizontales tienen una base propia, formada por una plataforma de sustentación, que puede ser una simple grada, o plataformas escalonadas de varios metros de altura, con su propio sistema de escalinatas. En principio, la base propia de los edificios define si es un elemento sólido que tiene una tendencia horizontal o vertical. Un simple edifico alargado, elevado por una serie de plataformas escalonadas se puede convertir en un templo pirámide. El mismo edificio con una plataforma propia baja, por ejemplo una grada, puede convertirlo en un edificio "común" dentro de otros edificios similares en un patio.

La principal característica de los edificios horizontales es que el sistema de adición de espacios, puede "crecer" tanto en forma longitudinal como transversal y vertical, llegando a crear espacios interiores multi-cámaras (ver figura 12, 4.2.1).

La variante mas utilizada es de repetir el espacio interior en el eje longitudinal (hileras de celdas) formando edificios alargados. Estas edificaciones tienen la tendencia a utilizar todo el límite de los 
espacios libres (plazas y patios). La posición de los edificios horizontales o alargados generalmente es el extremo de uno, dos, tres o cuatro lados de una plaza o patio.

Una particularidad de estos elementos urbanos es que el acceso a los espacios interiores puede realizarse por uno, dos, tres o los cuatro lados del edificio. La forma más común es el acceso por una sola fachada del edificio. El número de accesos va de uno a más entradas. Los accesos de dos entradas son escasos, sólo se han encontrado ejemplos en el ala sur de La Blanca (Muñoz Cosme y Vidal Lorenzo 2007, 549-554); en la Acrópolis Central de Tikal; y en San Clemente. Las fachadas mas comunes tienen, tres, cinco y más entradas. Hay casos en que los edificios llegan a tener hasta 21 , accesos en una fachada.

Dentro de los edificios horizontales hay casos con accesos por dos fachadas (por diferentes patios), como el Edifico $L$ de Nakum. También hay edificios con accesos por tres lados como el Edificio $G$ de Nakum. El Edificio D de Nakum es el más "largo" del área de estudio, con $122 \mathrm{~m}$ (y $10 \mathrm{~m}$ de ancho), 38 espacios interiores y 39 diferentes accesos en tres de sus fachadas; en su fachada oeste, en lugar de tener un acceso a un espacio interior, tiene una escalinata de piedra que asciende al techo. Como ejemplo de edificios con accesos en sus cuatro fachadas están en Nakum en el Edificio $Y$ (Palacio Real), y en Tikal el Edificio 5D-65 (Palacio Maler) de la Acrópolis Central.

El crecimiento vertical de los edificios horizontales puede llegar hasta tres niveles. El ejemplo más conocido es el edificio de Cinco Pisos de la Acrópolis Central de Tikal. Este edificio documentado en 1895 por Teobert Maler, está formado en realidad por dos edificios separados. 
Un primer edificio con dos niveles (Edificio 5D-50) y otro edificio, ligeramente más atrás y a mayor altura, con tres niveles superpuestos (5D-52). Tikal tiene numerosos edificios en dos niveles, entre otros podemos mencionar: el Grupo de Las Ventanas o el Palacio de Los Murciélagos (5C-13), el Palacio Maler (5D-65) y el Palacio de Gran Garra de Jaguar del año 350 d.C. (5D-46). Este ultimo con una escalinata maciza interior. En Uaxactún, el palacio de dos niveles AXVIII también tiene una escalinata interior. En Nakum hay dos ejemplos de edificios con dos niveles: el Edificio $Z$ con 12 espacios interiores en el primer nivel y el Edificio N. En San Clemente, el Edificio III, del sector norte de los palacios, resultó ser un edificio alargado de $62 \mathrm{~m}$ con dos niveles superpuestos y 21 accesos en el primer nivel.

Otros indicios de edificios con dos niveles, todavía no investigados, se pueden estimar en las acrópolis de Kinal, Naranjo, Chochkitam, y posiblemente Xmakabatún.

Es común encontrar adentro de los edificios horizontales otros elementos arquitectónicos tales como: bancas de mampostería, nichos en las paredes, ventanas, agujeros en jambas, y otros elementos que tiene relación clara con la función de esos espacios.

No se puede olvidar ni desligar la estrecha relación que existe entre los espacios interiores y el espacio libre inmediato frente a ellos. Los patios eran empleados como vestíbulos y para la circulación entre un edificio alargado a otro. También en estos espacios abiertos existía un tipo de arquitectura móvil o perecedera hecha de madera y otros materiales que formaron parte del mismo conjunto.

Hay además, edificios horizontales de forma compleja como el Edifico $\mathrm{H}$ de Nakum El Edificio $\mathrm{H}$ es una secuencia de cámaras con 
pequeños patios interiores: aparentemente su forma particular fue ser un paso controlado y único acceso a la Acrópolis Central.

Una marcada condicionante en este tipo de edificaciones, seguramente por el uso frecuente de sus espacios, fue el constante cambio (ampliaciones, remodelaciones). Se agregan nuevos sectores al conjunto por lo que se cambian accesos, se abren pasillos, se quitan y ponen bancas y se separan los espacios interiores (tabiques).

Por regla general en las fachadas de las edificaciones, el plano del muro vertical o macizo domina sobre el vano o abertura en el muro. El Edificio III de San Clemente es un caso particular en donde el constante macizo-espacio abierto es manejado igual; otro caso similar es el Edifico 5C-44 de la Acrópolis Central de Tikal.

Los grupos de edificios horizontales aparecen, ya completamente construidos en piedra, en el Preclásico Tardío. En Uaxactún Juan Antonio Valdés realizó extensas investigaciones en palacios tempranos (Valdés 2000, 11-32). Juan Pedro Laporte, en su trabajo de tesis doctoral, estudió la evolución de un grupo residencial de élite del Clásico Temprano en un sector al sur de la Plaza de la Gran Pirámide de Tikal (Laporte 1986).

Los edificios horizontales son el elemento más abundante en los centros prehispánicos, prácticamente todos los sitios tienen varios ejemplos de esta categoría de edificaciones.

En este estudio se identificaron 14 variantes de edificios horizontales. Entre las particularidades de los edificios horizontales están los edificios representativos, los edificios alargados aislados y peraltados, 
los salones abiertos ó salones de columnas, los salones con pórtico, los edificios circulares y las edificaciones especiales como el baño de vapor y las canchas para el juego de pelota.

\subsubsection{Edificios representativos}

Este tipo constructivo se caracteriza por estar un edificio horizontal aislado en un lado de una plaza o patio. Generalmente es de grandes proporciones. El mejor ejemplo es el Edificio 1 de Tzikintzakán. Esta construcción tiene su propia plataforma y terraza elevada frente a la plaza, tiene dos espacios interiores corridos y, en el techo, una crestería; posee una sola fachada con tres accesos orientados hacia la plaza (ver figura 12, 4.2.1.1).

Otro ejemplo es el Edificio A-XVIII de Uaxactún. Aquí la construcción alargada de dos niveles tiene su propia plataforma elevada y sólo una fachada con tres accesos viendo hacia la plaza. En Tikal el Edificio 5D-65 (Palacio Maler) tiene estas características, aunque se encuentra confinado en un patio rodeado de edificios, éste está aislado en el extremo sur del Patio 2 (ver figura 12, 4.2.1.1). Tiene también una terraza al frente y es un edificio de dos niveles. Una característica común en estos tres ejemplos es la excelente calidad de su fábrica. Otros ejemplos de edificios representativos se encuentran en, Kinal, Cival, El Porvenir y La Muerta.

\subsubsection{Edificios aislados y peraltados}

Estos elementos urbanos son edificios alargados aislados de tamaño monumental que se colocan en uno de los extremos de una plaza y su característica es que son muy peraltados (ver figura 12, 4.2.1.2). Por su forma y tamaño destacan en el tejido urbano. Esta variante de los edificios horizontales aún no ha sido investigada y no presentan arquitectura expuesta. La muestra cuenta con ocho ejemplos, seis de 
ellos en la cuenca Holmul (Naranjito, Holmul, Pacayal, Witzná, El Carmen, El Danto) y dos en la cuenca Ixcán (Chochkitam y Manantial).

\subsubsection{Salones abiertos}

La solución espacial, de esta variante arquitectónica, es un tanto distinta y está referida a las edificaciones del período Posclásico (ver figura 12, 4.2.1.3). En estos casos, los techos son losas planas y la fachada principal está formada por hileras de columnas o pilares. Los salones abiertos también son conocidos como salones de columnas. En Topoxté hay 10 ejemplos de este tipo y en Sacpetén tres más.

Juan Antonio Valdés (Valdés y Fahsen 2003, 24), opina que éste tipo constructivo no debe de considerarse como elemento foráneo de Petén en el Posclásico, ya que en el Clásico Tardío se tienen evidencias de edificios con pilares de mampostería en su fachada. Ejemplos de estos se encuentran en: Edificios A-2 y A-4 de Uaxactún y en la Acrópolis Central de Tikal (Edificio 5C-44). Otro edificio de múltiples puertas es el llamado "mercado" de Tikal (Edificios E6-32 al E6-36). En San Clemente la fachada del Edificio III, del Clásico Terminal, tiene 21 accesos en hilera y 22 pilares o segmentos de muro.

Otro argumento a favor de la antigüedad de este sistema de construcciones es que durante el Período Clásico hay ejemplos del uso de techos planos; o combinaciones de techos planos y arranques de bóveda de mampostería como el "edificio de las pinturas" de San Bartolo. Otros usos de techos planos se emplean en los sistemas constructivos de las tumbas (Yaxhá, El Encanto), en los espacios interiores de las cresterías (Templo $\vee$ de Tikal), o en los espacios interiores de los templos (segunda cámara del Edificio 1 de Xultún). 


\subsubsection{Salones con pórtico}

Estos espacios son edificios horizontales que en una de sus fachadas tienen un tratamiento distinto. Son amplios espacios con paredes en tres lados y el cuarto lado abierto o pórtico (ver figura 12, 4.2.1.4). Para permitir el ingreso de suficiente luz al recinto el pórtico tiene como solución estructural ligeras columnas. Las paredes interiores pueden contener pintura mural. Para dar amplitud al espacio interior, los techos tienen solución diferente. Aquí se utilizan losas planas ó combinación de arranque de bóveda de mampostería y losa plana de madera o madera y palma.

El primer ejemplo de un edifico con pórtico fue descubierto por el Instituto Carnegie de Washington en el Edificio B-XIII de Uaxactún. En la fachada este hay una amplia abertura hacia un patio privado y en el piso de la cámara huellas de columnas. La famosa pintura mural estaba en la pared contraria a la apertura. Con el tiempo la pintura se desintegró totalmente; ahora solo queda una copia realizada por Antonio Tejeda, en el Museo Nacional de Antropología y Etnología de la ciudad capital. En el Patio 2 de la Acrópolis Central de Tikal el Edificio 5D-118 tiene una forma atípica en el conjunto; posiblemente haya sido un salón con pórtico o al menos una fachada con columnas de madera con un acceso de $5 \mathrm{~m}$ de ancho. Otro espacio similar fue encontrado adentro del Edificio I de La Sufricaya, con pintura en los muros. Un posible ejemplo de un salón con pórtico, es el palacio real de Uaxactún, descrito por Juan Antonio Valdés para un grupo de edificios del Clásico Temprano (Valdés 2000,17-18). En este caso, tres edificios están unidos para formar el palacio (Edificio Sub.-5, Edificio Sub.-2-C y Sub.-4). El edificio de en medio (Sub. 2-C) tiene un espacio rectangular abierto con siete agujeros de postes en el piso, en frente al patio. Valdes dice que los agujeros en el piso 
corroboran la existencia de una techumbre tipo rancho (o podría ser la estructura de una losa plana).

El edificio de las Pinturas de San Bartolo tiene la combinación de arranque de techo de mampostería y techo plano de madera y su espacio libre interior mide $4 \mathrm{~m}$ de ancho. Este es un caso especial ya que no tiene el espacio abierto al frente (pórtico) y la pintura se encuentra en el paramento del techo.

Los ejemplos de Uaxactún, La Sufricaya y San Bartolo, están fechados para etapas tempranas, entre el final del Preclásico Tardío y el Clásico Temprano.

Otros edificios horizontales

\subsubsection{Edificios circulares}

En esta categoría se agrupan los edificios con forma circular, semicircular o de forma oval. Las muestras de este tipo constructivo se encuentran en las excavaciones de edificios de épocas del Preclásico Medio y Tardío (ver figura 12, 4.2.1.5). Estas construcciones aisladas corresponden a plataformas de edificios. El caso más conocido es el documentado en la primeras fases del grupo A-V de Uaxactún y el único expuesto en la región por las trincheras de excavación dejadas abiertas por el Instituto Carnegie de Washington. Todos los demás ejemplos han sido enterrados de nuevo.

Juan Antonio Valdés escribe que en el Preclásico Medio, en el Grupo E de Uaxactún, se erigieron plataformas circulares. También dice que en el Preclásico Tardío se construyeron en el Grupo H (H Sub.-1), en el Grupo A de Uaxactún, en Nakbé y la Acrópolis Norte de Tikal 
(Valdés 1992, 19). Igualmente el Altar A-Sub-9 de Uaxactún es una construcción circular (Valdés, Fahsen y Escobedo 1999, 28-29). Hasta el momento sólo se ha detectado un ejemplo de edificio circular en Nakum y se refiere a un edificio parcialmente investigado con una base circular en el extremo suroeste de la Plaza Central.

Un caso extraño, no investigado, es una especie de plataforma de medio círculo de $0.40 \mathrm{~m}$ de altura sobre una construcción en el sitio Jimbal. Este tipo de edificación es difícil de identificar sin el apoyo de excavaciones arqueológicas, razón por la cual se eliminó de la presentación resumen de elementos urbanos en el cuadro 4.

\subsubsection{Baños de vapor}

Este tipo de edificación tiene características particulares bien identificadas. Los pocos casos analizados en el noreste de Petén, son edificios aislados; con un solo espacio interior y "accesorios" característicos como: bancas interiores de mampostería en forma de $\mathrm{U}$, espacio para el hogar, un acceso reducido con dintel de piedra y un pequeño agujero en el techo (respiradero). El mejor ejemplo se encuentra en el Patio 9 de la Acrópolis de Nakum Ver figura 12, 4.2.1.6). Este edificio mide $7 \mathrm{~m}$ por $7.3 \mathrm{~m}$. En este caso el techo abovedado es de cuatro lados. Las cuatro pendientes inclinadas del techo permiten tener un espacio interior más amplio.

En Tikal se conocen dos ejemplos de baño de vapor, uno en el Grupo F, y otro en la Zona Norte. Seguramente en la región hay más edificios de este tipo que requieren del apoyo de excavaciones arqueológicas para su localización; por esta razón no está representado en las tablas resumen del cuadro 4. 


\subsubsection{Cancha para el juego de pelota}

Este elemento urbano es formado por dos caras o fachadas de edificios parecidos y paralelos. Las edificaciones son más o menos de similares dimensiones y forman dos límites del espacio para el juego de pelota (ver figura 12, 4.2.1.7). Las superficies de juego se componen de muros verticales y muros inclinados (elementos sólidos) combinados con el espacio del piso (elemento libre). Generalmente orientados norte-sur. Una excepción es Jimbal, en donde la orientación de la cancha es este-oeste.

En la muestra se identificaron nueve variables. Los espacios para el juego de pelota, generalmente se localizan cerca de la plaza con monumentos esculpidos (estelas y altares), en los extremos de las plazas o forman parte de uno de los límites de la misma. Hay dos casos de una cancha para el juego de pelota en posición dominante sobre una plaza (San Clemente y el Juego de Pelota Oeste de Naranjo). En otros casos se ubican en posición subordinada, más abajo del nivel de la plaza principal (Xultún, Nakum, San Clemente, Ixtinto). Otra posibilidad es su ubicación en los espacios cercanos a calzadas (Naranjito, Tikal, Nakbé, Naranjo, Nakum, El Zotz).

Por lo general, los límites del espacio de juego norte-sur son libres ("abiertos"). En ocasiones tienen en un extremo (norte o sur) un edificio que marca uno de los topes del área de juego (Poza Maya, Juego de Pelota Este de Naranjo). En otros casos, dos edificios aislados forman los límites norte y sur del espacio libre para el juego de pelota (Nakum). Otra posibilidad registrada es que, uno de los edificios que forma la cancha esté adosado a otra edificación (La Honradez, Jimbal, Ucanal, Tikal). 
En San Clemente el Juego de Pelota Este tiene una cancha tipo doble $\mathrm{T}$, con todos los extremos límites bien definidos, este es un caso atípico para la región.

En un sitio hay una cancha para el juego de pelota triple (Tikal). En dos sitios una cancha doble (La Honradez y Xultún), y cuatro sitios tienen dos distintas canchas para el juego de pelota (Tikal, Yaxhá, Nakum, Naranjo y San Clemente).

Una característica local es que hasta ahora, en el espacio de las canchas de juego de pelota, no se han encontrado monumentos de piedra esculpidos con escritura. Solamente en Naranjo se han encontrado dos fragmentos de un disco de piedra con inscripciones.

La cancha para el juego de pelota es uno de los elementos urbanos más antiguos en el área de estudio (ejemplos desde el Preclásico Medio) y tiene una connotación ritual-religiosa. Rivera Dorado dice que los juegos de pelota son rasgos de Xibalbá "un rasgo del cosmos antes de la creación del sol" constituye un "ingrediente mitológico básico por su relevancia cosmográfica", nos indica claramente que el espacio donde se ubica "trasciende las funciones propias de una ciudad administrativa y política para adquirir significaciones religiosas". El juego de pelota constituía "fundamentalmente una representación del camino hacia el inframundo y un rito relacionado con la mitología cosmológica" constituyéndose en un portal, en una entrada hacia el "otro mundo" (Rivera Dorado 2001, 90, 132).

Este elemento urbano está registrado en 48 sitios de la muestra y representa un $37.5 \%$. La mayor concentración se encuentra en las cuencas Holmul e Ixcán (60\% y 53.3\%). En el área Tikal y cuenca Mirador (33\%); y en las cuencas Los Lagos y Mopán (25.7\% y 19\%). 


\subsubsection{Grupos de edificios no elevados}

Marshall Becker estudió en Tikal diferentes formas de ubicación de edificios en los espacios libres (Becker 1986, 7-20). Becker identificó 8 tipos "Plan Plaza". Los tipos Plan Plaza 2 al 5 se refieren a grupos de dos a más edificaciones horizontales alrededor de espacios libres grandes o pequeños. Entre esta organización está un tipo de plaza con el edificio dominante al este (Plan Plaza 2). Ejemplos de grupos de edificios horizontales en patios y plazas en Tikal (5E-2 y 3, 5E-16 y $17,5 E-113$ y 114, 6E-25 y 26), en Uaxactún (B-9 y B-25). En forma de "L": en Tikal (3C-11 y 12), en La Honradez (A-4 y A-5), en Yaxhá (en el cuadrante B-11). Estos tipos de espacio urbano se encuentran por lo general en los alrededores de los edificios monumentales.

Combinaciones de tres edificios horizontales se encuentran en todos los sitios (ver figura 12, 4.2.1.8). Ejemplos típicos de Tikal son (5D-7, 8 y 9, 5E-105, 106 y 107). Las construcciones están en forma de "U", con el edificio dominante en un extremo y dos edificios laterales parecidos a sus lados. Este patrón se observa en los sitios La Perra, Riberona, Ahau Na, Naranjo y otros.

Si se colocan edificios horizontales en los cuatro límites de un espacio libre se forma un cuadrángulo. Ejemplos de cuadrángulos en Tikal (5E-44, 45, 46 y 47; 5E-75, 76, 77 y 78; 7C-25, 26, 27 y 28; 3B-26, 27, 28 y 29), Xultún (A 59-60), La Honradez (A-61, 62 y 63), El Susto Mirador, Paxcamán, El Gavilán, Dos Hermanas, Salsipuedes y El Zotz. La ubicación de estos elementos urbanos se encuentra por lo general cerca de la plaza principal, o forma parte de uno de los límites de la plaza.

En ocasiones, en los sitios no monumentales, estos grupos de edificios horizontales se ubican en la parte más alta del terreno y son 
el elemento urbano dominante: La Pita, San Máximo, Temblor, Las Ventanas, El Carmen, Yalain, Cordoncillo Corozal, Huech, Nima Wits, La Perra, Lalila, Ixqueej, Akalche, Noj Petén, El Gavilan, Ta-Aj Corozal.

\subsubsection{Grupos de edificios elevados}

La misma distribución de edificios horizontales alrededor de un espacio libre, se repite; pero, en este caso la base de sustentación del grupo esta elevado (ver figura 12, 4.2.1.9). Por regla general ocupan uno de los lados de las plazas y representan áreas administrativas y de vivienda importante, con una fachada distintiva hacia la plaza principal. La característica de este "grupo elevado" es que alrededor de un patio (un espacio libre) se organizan los edificios o "elementos sólidos" en distintas formas y posiciones. El patio central, puede tener extensiones del patio, pasillos o patios secundarios en las esquinas. Habitualmente el frente de los edificios da hacia el patio (interior del grupo) y las fachadas exteriores son lisas $\sin$ aberturas.

En ocasiones los cuadrángulos tienen terrazas exteriores en alguno de sus lados, como sucede en el Grupo F de Tikal y Naranjito (Acrópolis Sur). Además en las esquinas se pueden formar pequeños espacios libres dejados entre dos edificios horizontales que se aproximan perpendicularmente al límite de la plataforma elevada. Estos espacios son llamados patios secundarios en esquina.

Grupo de dos edificios horizontales elevados: En este caso dos edificios alargados son el elemento dominante. Ejemplos en esta posición, se encuentran en Naranjito, San Bartolo (palacio Tigrillo), Manantial y Cordoncillo Corozal. Dos edificios horizontales elevados no son tan comunes en el área de estudio. Una variable es dos 
edificios horizontales formando una "L" (Edificio 5D-105 y Edificio 5D107 de Tikal). Similares ejemplos se encuentran en El Porvenir, Holmul, Zapote, Motul, Huech, y Chunhuitz.

En los grupos de tres edificios horizontales elevados el lado sin construcciones es el ingreso común (al patio interior). Los edificios forman una "U", un ejemplo es el Palacio de los Murciélagos en Tikal (edificios 5C-11, 5C-12 y 5C-13). Ejemplos similares se encuentran en El Mirador, Nakbé, Uaxactún (Grupo F), El Pital, San Máximo, Ramonal, Bejucal, Quemada Corozal, Corozal Torre, Trinidad, San Clemente, Río Azul, Holmul, Cival, Naranjito, y El Carmen.

Grupo de cuatro edificios horizontales elevados: Los cuadrángulos se definen por ser un patio que contiene en sus límites cuatro edificios horizontales, todos elevados por una plataforma de sustentación, que los separa del resto del tejido urbano. El rasgo común de este tipo de edificaciones es que las fachadas son cerradas hacia el exterior y sólo un frente principal posee el único acceso al cuadrángulo. Ejemplos de este tipo están en: el Grupo F (5E-1 y 4E- 45, 47 y 48) de Tikal, Ramonalito, Dos Aguadas, Naranjito, Ixtinto (con cuatro cuadrángulos), El Mango, Naachtún, Witzná y Naranjo.

Los grupos de "edificios horizontales elevados" se encuentran en 65 sitios de la muestra (50.7\%). El área Tikal y cuenca Ixcán tienen el mayor índice $(66.6 \%$ y 60\%). Las cuencas Los Lagos, Mopán y Holmul (57\%, $47.6 \%$ y $46.6 \%)$ y la cuenca Mirador un (16.6\%).

\subsubsection{Edificios verticales}

La característica básica de este elemento urbano son su marcado acento vertical, esta condición obligada se logra sobreponiendo diferentes plataformas escalonadas una sobre otra. De este tipo hay 
dos variables: una, son los edificios pirámide sin construcción superior y la otra los edificios verticales con construcción superior, llamados templo pirámide (ver figura 12, 4.2.2). Primero describimos los edificios verticales aislados y luego sus diferentes combinaciones.

\subsubsection{Pirámide sin construcción superior}

Estas construcciones, hechas de sucesiones de plataformas escalonadas, se caracterizan por no tener en la parte superior de la pirámide un edifico con espacio interior. Otra condición es que se ubican dentro del tejido urbano en forma aislada con dos formas de posición (ver figura 12, 4.2.2.1):

1- Una es la pirámide colocada en medio de una plaza. Esta pirámide forma con otro edificio un tipo de espacio urbano ya caracterizado que describiremos más adelante (grupos E, véase 4.2.4.1).

2- La otra posición de pirámides sin construcción superior, forman también parte de otro grupo identificado (Pirámides gemelas, véase 4.2.3.1 y 4.2.4.3). En este caso son dos pirámides iguales colocada en dos extremos de una plaza. Estas pirámides, escalonadas, tienen escalinatas en sus cuatro fachadas.

\subsubsection{Pirámide con construcción superior}

Los templos pirámide son elementos urbanos formados por una construcción sobre una base escalonada con "espacio interior útil" (ver figura 12, 4.2.2.2). Son simétricos, aislados y frontales, estando colocados frente a las plazas. Su eje principal es acentuado por una escalinata ceremonial que comunica la plaza con el templo elevado. La "pirámide", generalmente tiene tres, siete o más plataformas escalonadas superpuestas. 
A diferencia de los edificios horizontales, el espacio interior de los templo pirámide, sólo puede "crecer" en un sentido transversal a su eje frontal y con riguroso orden. El "templo" tiene uno ó tres vanos de acceso en su fachada principal, no hay accesos laterales o posteriores. El espacio interior del templo propiamente dicho está formado por una, dos ó tres cámaras interiores que crecen en profundidad en relación a su eje transversal. Generalmente a nivel del techo y su crestería se concentra la escultura aplicada. Así se acentúa la vista del espectador hacia arriba.

Generalmente frente a los templos pirámide se colocan monumentos esculpidos en piedra (estelas y altares), que acentúan el eje dominante del edificio y pueden dar información sobre el contexto histórico del edificio, el monumento y el gobernante quien ordenó la obra.

Los templo pirámide aislados tienen diferentes características, en este estudio podemos mencionar tres formas características:

1- Templo pirámide tradicional: El más famoso de todos, es el Templo I o "Gran Jaguar"; varios autores han descrito detalladamente este edificio, y es el principal representante del "Estilo Petén" (Stierlin 1964, 139-140; Gendrop 1984, 14-19; Vidal Lorenzo y Muñoz Cosme 1997). Su posición aislada frente a una plaza, las plataformas escalonadas, la escalinata ceremonial y el templo superior son el principal indicador de esta variante.

Dependiendo de la época hay diferentes características constructivas para la base piramidal; como plataformas escalonadas con remetimientos de muros, salientes de muros (llamados faldones), 
esquinas redondeadas o esquinas remetidas, molduras tipo entrecalles, monumentales mascarones y otros.

Las construcciones superiores también varían, según el periodo constructivo. Estos espacios interiores van desde edificaciones perecederas ya desaparecidas, a construcciones con techos de piedra y torres crestería, ó techos planos de madera y cemento de cal, ya desaparecidas (Edificio C de Topoxté).

Igual sucede con la circulación vertical, algunos templos pirámide poseen escalinatas remetidas o escalinatas adosadas; escalinatas con y sin alfarda; y en la época Posclásica escalinatas con alfarda y dados como el Edificio C de Topoxté (Noriega 1995). De estas características constructivas hay multitud de combinaciones y casos especiales que no son tratados en este estudio.

En el Clásico, el templo pirámide $U$ en Nakum es el edificio más parecido a las clásicas proporciones del emblemático Templo I de Tikal; también en El Zotz hay dos templos pirámides similares, con las mismas topología. Este elemento urbano puede aparecer repetido como sucede en Tikal, con los seis templos pirámide o "templos mayores" del Clásico Tardío. Este grupo "marca" los ejes principales en la ciudad y le dan el carácter particular al sitio. Por ejemplo, el límite oeste es flanqueado por el gigantesco Templo IV, la construcción más grande del periodo Clásico. Otros edificios templo pirámides parecidas se encuentran en Xultún, El Zotz, Manantial, La Línea, El Danto y Yaxhá).

2- Templos pirámide con construcción adosada al frente: La forma y posición es similar a la descrita anteriormente pero, la característica dominante de esta variable es un agregado frente (adosado) a la 
escalinata ceremonial del edificio (ver figura 12, 4.2.2.2-2). Este caso es diferente a los "dados" superiores que tienen algunos templos pirámide en su escalinata monumental; como sucede en el Edificio 1 de Xultún y el Templo II de Tikal.

Otra variante que aparece, hasta el momento solo en Tikal, son los edificios templo pirámide con una especie de nicho o altar, a media altura de la escalinata (Edificio 5E-38, Edificio 5D-82).

Las edificaciones, que presentan esta construcción adosada en la fachada principal, no han sido investigadas y tienen fuerte destrucción por el saqueo. Están registrados 17 casos (El Zotz, Wakna, Naachtún, Corozal, El Encanto, Manantial).

3- Templos pirámide con terraza a media altura: En este caso los templos pirámide tienen en el frente principal una terraza que se extiende a todo lo ancho de su fachada (ver figura 12, 4.2.2.2.-3). Esta terraza se encuentra a menos de un tercio de la altura de la pirámide escalonada. Como si fuera un vestíbulo elevado frente al edificio. En algunos casos la terraza está libre, en otros se agregan edificios menores en las esquinas frontales. En ocasiones sobre la terraza los edificios agregados tienen un solo acceso viendo hacia el edificio principal. En otros casos estos edificios de menor tamaño miran hacia el centro de la plaza elevada (en posición encontrada) y forman un grupo caracterizado más adelante como grupo triádico (véase 4.2.4.3). Ejemplos de Templos pirámide con terraza en frente pueden verse en: Tikal (zona Norte), Holtún, El Mirador, Wakna, Manantial, Xmakabatún, Naranjo e Ixlú.

Templos pirámide aislados se registran en 87 sitios de la muestra (67.9\%). La mayor densidad de este elemento se encuentra en la 
cuenca Ixcán (80\%) y área Tikal (73.3 \%). La cuenca Holmul tiene el (68.5\%); Las cuencas Mirador y Los Lagos (66.6\%) y la cuenca Mopán (57.1\%).

\subsubsection{Combinaciones de edificios verticales}

En este acápite presentamos los grupos de combinaciones de edificios verticales. La condición de estos se mantiene igual: posición aislada, viendo hacia la plaza. Su particularidad es formar grupos de edificios.

\subsubsection{Templos pirámides gemelas}

La característica principal de esta variante es que son dobles o gemelos (ver figura 12, 4.2.3.1). Este tipo de construcciones son colocados uno al lado del otro frente a una plaza. Un ejemplo de esta variable se encuentra al sur de la plaza principal de San Clemente (Edificios XIV y XV). Otros ejemplos de dos edificios similares frente a una plaza se observan en: Manantial, Motul, La Línea, Juleque, y La Amapola.

Una variante de edificios pirámide gemelos son las dos plataformas escalonadas sin construcción superior formando un grupo tipificado como "grupo de pirámides gemelas" explicado mas adelante (véase 4.2.4.3).

En la muestra se identificaron 9 sitios con este tipo constructivo (7. 0 $\%)$.

\subsubsection{Templos pirámides en hilera}

En esta variante los templos pirámide son colocados en fila, en un extremo de una plaza (ver figura 12, 4.2.3.2). Mantienen su condición de elemento aislado y las características que lo identifican como 
templo pirámide. Juntos forman los grupos en hilera. El más conocido, es la Plaza de Los Siete Templos de Tikal, con los siete templos pirámide en fila que forman el límite este de la plaza. Una posición similar tienen los edificios al sur del Mundo Perdido (6D-2 al 6D-7). Otros ejemplos de esta variante se pueden observar en la Plaza B de Yaxhá; los edificios alineados al oeste de la plaza de El Zotz; y los tres edificios en hilera en el sector este de la acrópolis de Chochkitam

Una modificación del tipo "edificio en hilera" sucede en Río Azul. Aquí se encuentra un templo pirámide dominante y central, con terraza a media altura que se prolonga a ambos lados (tipo "T"); sobre esta terraza se posicionan cuatro edificios templo pirámide (dos a cada lado) todos en situación aislada y con la fachada viendo hacia la misma plaza, Edificios A1 al A5 (ver figura 12, 4.2.3.2-1).

\subsubsection{Grupos de templos pirámide}

Un grupo especial de edificios, templo pirámide, es el conjunto de la Acrópolis Norte de Tikal, con mas de 10 edificios similares, formando grupos triádicos y grupos en hilera (ver figura 12, 4.2.3.3). Aquí, las bases escalonadas de algunos edificios no son de dimensiones monumentales. Esta variable de espacio urbano es un caso particular de Tikal.

Un caso especial de grupos de templo pirámide, sucede cuando se coloca un templo pirámide adelante de otro. Esta condición particular ocurre en los sitios Ramonalito y Las Cubetitas (ver figura 12, 4.2.3.3.-1). En principio se trata de un templo pirámide sobre una plataforma con un patio elevado o terraza; frente a esta construcción se "mete" un edificio vertical, el cual es rodeado por tres lados por la anterior edificación. 


\subsection{Edificios horizontales y verticales}

En este apartado agrupamos a diferentes combinaciones de edificios horizontales con edificios verticales sobre un mismo espacio libre (plaza o patio).

\subsubsection{Grupos E}

Los grupos E deben su nombre al primer "grupo de observación solar" identificado por Frans Blom (Blom 1926) en Uaxactún (Edificio E-VII Sub.). Tienen otros nombres como "grupo astronómico", "Complejos de Conmemoración Astronómica" (CCA), "Complejos de Ritual Público" (CRP), y como "Grupos con un edificio aislado al oeste y uno alargado al este" (Quintana y Wurster 2001, 144).

Los grupos $\mathrm{E}$ se forman con un edificio vertical aislado sobre una plaza, en posición central y otro edificio alargado ubicado en el límite este de esa misma plaza (ver figura 12, 4.2.4.1). Lo más frecuente son los edificios tipo pirámide al centro sin edificio superior y con escalinatas a los cuatro lados. Sobre el edificio alargado se sobreponen tres edificaciones en hilera, uno al centro y dos a los lados. Estos elementos marcan, en relación con el edificio aislado al centro de la plaza, las posiciones solares de equinoccios y solsticios.

El concepto de uso del espacio urbano es distinto al mencionado anteriormente en le apartado 4.1.1.2 (plaza con edificio en medio). Pues aunque el edificio pirámide se ubica al centro de una plaza, su dimensión monumental, "rompe" el espacio libre de la plaza. El edificio central, crea relación con segmentos de la plaza, en donde la correlación con el espacio libre al este tiene el principal valor. 
El edificio alargado al este puede llegar a medir hasta $200 \mathrm{~m}$ de largo en Wakna. Otros ejemplos miden: en Yaxhá 180 m, Tikal 130 m, Naranjo 130 m, La Providencia 113 m.

Por lo general, el patrón urbano, es completado con monumentos esculpidos de piedra (estelas y altares) en la plaza. Los límites norte y sur de la plaza pueden estar delimitados por edificios alargados parecidos (Dos Aguadas, Yaxhá, y Quemada Corozal). En otros casos hay un edificio "intruso" en el conjunto, como el edificio norte en la Plaza Central de Naranjo. El límite oeste de la plaza es por lo general poco determinante.

La ubicación de los grupos $\mathrm{E}$ en relación al tejido urbano parece ser de posición dominante en el centro de la urbe y permite suponer que fue empleado como elemento generador del ordenamiento ortogonal de sucesivos espacios urbanos en la ciudad (Naranjo, Yaxhá, Dos Aguadas, Cival). Es posible, sobre todo el edificio alargado al este, al "marcar" el recorrido del sol, tuviera una aplicación practica para el ordenamiento y alineación norte-sur dominante de las ciudades mayas. La mayoría de los centros mayas del estudio, con y sin grupos E, tienen una desviación similar de 4 a 5 grados de norte al este, (Topoxté, Yaxhá, Nakum y Naranjo), en Tikal en 1960, 645' (Carr y Hazard 1961, 3).

Los grupos $\mathrm{E}$ aparecen desde época muy temprana, al final del Preclásico Medio 600 a 400 a.C. en Tikal (Laporte y Fialko, 1995, 4748) y Nakbé (Hansen 2000, 55). Pocos centros urbanos mayas tienen dos diferentes Grupos E: en Uaxactún (E-7 con E-1, E-2 y E3, y D-4 con D-2), Yok'Ol Wits, Dos Hermanas, Ucanal y posiblemente Yaxhá. 
Los grupos E, son lugares de observación al sol en su paso por la tierra y por lo tanto son espacios urbanos asociados al culto solar. La posición simbólica de los edificios mayas dentro del tejido urbano es mencionado por Hohmann-Vogrin "el recorrido del sol y los astros con entradas y salidas en el horizonte fue seguido con puntos fijos formando posición de relación de edificios, así se materializa la idea de tiempo y espacio en las ciudades" (Hohmann-Vogrin 2000a, 200).

Sitios que poseen este tipo de edificaciones son 46 (35.9\% de la muestra). En la cuenca Ixcán no se ha identificado ningún tipo E. La mayor incidencia de este elemento urbano se encuentra en la cuenca Mopán con (57\%). El área Tikal y las cuencas Mirador y Holmul con (40\%, 41.6\% y 43.3\%); la cuenca de Los Lagos (28.5\%).

En la cuenca Mopán, de los 21 sitios registrados en el corpus, 12 tienen este tipo constructivo. Las investigaciones del Atlas Arqueológico de Guatemala, para esta misma zona, ha identificado a los grupos E como indicador de rango urbano local (Laporte 2001, 137-162; Laporte y Mejía 2000).

\subsubsection{Grupos Triádicos}

Los grupos triádicos se forman con tres edificios independientes sobre una misma plataforma, en posición encontrada; es decir cada uno de ellos mira al centro del mismo espacio libre (plaza o patio), produciendo una tensión espacial triádica (ver figura 12, 4.2.4.2). Generalmente hay un edificio dominante y dos edificios subordinados similares a ambos lados. El cuarto límite del espacio libre, está abierto y es el acceso común al grupo.

En contadas ocasiones los tres edificios son iguales (Uaxactún A-V); lo común es que el edificio dominante es distinto a los dos edificios 
subordinados (Edificios $\mathrm{N}$ y $\mathrm{E}$ de Nakum). También hay casos en que los tres edificios son distintos como sucede con los templos pirámide I, II y 5D-33 de la Gran Plaza de Tikal.

Este elemento urbano tiene una larga tradición en el área del estudio, con representantes de distintas épocas culturales. La persistencia de este elemento urbano por más de 1200 años es un distintivo urbano de la región; por esa razón los ordenamos en tres categorías: grupos triádicos con edificio dominante monumental, grupos triádicos en grupos de patios y grupos triádico en plaza.

1- Grupo triádico con edificio dominante monumental: En este caso, nos referimos a los grupos triádicos monumentales en el centro urbano El Mirador (ver figura 12, 4.2.4.2-1). El edificio dominante crece tanto que permite tener "terrazas triádicas" a diferentes alturas. (Los Monos, La Danta). También sucede que, debido a las dimensiones monumentales, el espacio libre (patio) se alarga y se pierde la escala de relación entre los dos edificios subordinados y el edificio dominante. Estos grupos son el signo distintivo de la cuenca Mirador (Preclásico Tardío). El grupo más famoso y el más alto es La Danta, con $72 \mathrm{~m}$ de altura y una base de $500 \mathrm{~m}$ por $350 \mathrm{~m}$.

Una variante hasta ahora sólo identificada en la cuenca Mirador, son los grupos triádicos en forma de "T". En este caso los dos edificios subordinados se alejan del edificio dominante (más grande), formando un patio triádico alargado (Edificio 34 de El Mirador y el grupo triádico de Wakna). En la cuenca Holmul en la Plaza Este del Sector Sur de Nakum, el Edificio $V$, tiene en planta la misma forma en "T". Quizás este edificio Clásico de Nakum fue también un edificio triádico; el edificio dominante es claro y la terraza alargada enfrente 
también, sólo faltan los dos edificios subordinados en los extremos del patio alargado.

2- Grupo triádico en grupos de patios: En los grupos triádicos del período Clásico, el edificio dominante no adquiere dimensiones tan monumentales como en la cuenca Mirador y el espacio libre frente a los edificios en posición triádica es de proporción más bien cuadrada (ver figura 12, 4.2.4.2-2). Los edificios que forman este grupo por lo general son construcciones tipo templo con un acceso y una cámara interior. En ocasiones la construcción dominante tiene más de dos espacios interiores. Un caso especial es el Edificio $\mathrm{N}$ de Nakum; aquí el edificio dominante es una construcción multi-cámara con varios espacios interiores incluyendo bancas de mampostería.

La posición de los grupos triádicos varía con la época cultural y las cuencas. Para el Preclásico Tardío, en la cuenca Mirador, los grupos triádicos son claros indicadores del límite urbano monumental de las ciudades. Para el período Clásico y en el área Tikal, cuenca Ixcán y cuenca Holmul, los grupos triádicos de los períodos iniciales (Preclásico Tardío, Clásico Temprano), son cubiertas por otras edificaciones.

Está comprobado que algunos de estos elementos urbanos pasan de ser un grupo triádico a un grupo de palacios, como el Grupo A-V de Uaxactún. La evolución de este complejo, es un clásico en la historia de la arquitectura maya; ejemplificado magistralmente por los dibujos de Tatiana Proskouriakoff (1946, 115-129). Igual sucede con el grupo triádico de Nakum, debajo de la Acrópolis Central; y en Tikal, debajo de la Acrópolis Norte. 
Los grupos triádicos del Clásico Tardío y Clásico Terminal se ubican dentro de los "grupos de patios", por lo general en un extremo de estos grupos de palacios (Nakum y La Honradez). En Naranjo ocupan posiciones frente a las plazas (Plaza Oeste Baja, Plaza Este Baja y la Plaza Este Alta).

El Mirador y Nakbé cuentan con cuatro ejemplos cada uno, Naachtún con dos ejemplos. Naranjo tiene tres ejemplos; Nakum con dos ejemplos visibles y uno más dentro de la Acrópolis Central (Preclásico).

Los grupos triádicos están representados en 14 sitios (14\% de la muestra). En la cuenca Mopán no se ha identificado ningún grupo triádico. En la cuencas Los Lagos (5.7\%). Los índices mas altos se encuentran en las cuencas Mirador y Holmul (50\%) y (66.6\%); en el área Tikal y cuenca Ixcán (20\%) y (13.3\%).

3- Grupo triádico en plazas: Esta variante de relación triádica monumental se desarrolla en las plazas. En tres extremos de una plaza se colocan tres edificios verticales que marcan la relación "encontrada" característica para los grupos triádicos (ver figura 12, 4.2.4.2-3). Estos espectaculares grupos triádicos se encuentran en: la Gran Plaza de Tikal, con la relación espacial triádica entre los edificios: Templo I, Templo II y el Templo 5C-33 de la Acrópolis Norte, (destruido "científicamente" en la década de 1960). Otros ejemplos son la Plaza Central de Nakum con los edificios A, B y C; en la Acrópolis Norte de Yaxhá; y el más monumental de todos es el Grupo Triádico Este, en la Plaza Este Alta de Naranjo. 
4.2.4.3

En este apartado describimos dos tipos distintos conformados por cuatro elementos urbanos que forman un grupo particular sobre un solo espacio libre:

1- Grupo de pirámides gemelas: La mayoría de estos grupos están sobre grandes plataformas elevadas y cuadradas. Sobre la extensa plaza se colocan cuatro edificios; dos con forma de pirámide escalonada en los extremos este y oeste (descritos en el apartado 4.2.2.1), un edificio en el extremo norte, llamado "recinto sagrado" y un edificio alargado en el extremo sur. En resumen el conjunto se forma con dos edificios horizontales diferentes y dos edificios verticales iguales (ver figura 12, 4.2.4.3-1).

En Tikal, estos elementos urbanos se ubican cerca o adosados a los sistemas de calzadas. En Yaxhá el grupo de pirámides gemelas se construyo sobre una plataforma artificial elevada de $100 \mathrm{~m}$ por $100 \mathrm{~m}$ de lado. Se supone que este tipo constructivo tiene relación conmemorativa de 20 años y son construcciones del Clásico Tardío (Coe 1967, 78).

La plaza puede tener monumentos de piedra esculpida, altares y estelas lisas o con inscripciones jeroglíficas. El recinto al norte es sin techo y tiene al centro un altar y una estela. Este elemento urbano tiene aproximadamente $20 \mathrm{~m}$ por $10 \mathrm{~m}$ rodeado por un muro y un único acceso hacía la plaza con una abertura en forma de arco maya.

En Yaxhá el arqueólogo Ramírez Baldizón en 2004 (manuscrito en biblioteca del PRONAT), se comprobó que el edifico alargado al sur no necesariamente debe de contar con nueve accesos como lo 
sugiere Coe (1967, 78). Posibles construcciones de complejos de pirámides gemelas aparecen en Uolantún, Sacpetén e Ixlú. Tikal tiene siete ejemplos de este tipo y Yaxhá uno.

2- Otras combinaciones de edificios: Hay un caso particular de cuatro edificios sobre una misma plataforma elevada, donde tres extremos del patio son ocupados por edificios horizontales y el cuarto lado por un edificio vertical (ver figura 12, 4.2.4.3-2). Esta variante en principio es un cuadrángulo con templo pirámide, pues por lo general sólo contiene un patio interior, terrazas o patios secundarios en las esquinas. La diferencia es que el edificio dominante con su acentuada verticalidad rompe visualmente el concepto de un elemento cuatripartito. Ejemplos, La Acrópolis Este de Yaxhá, Acrópolis Norte de Naranjito y el patio elevado de Dos Aguadas.

\subsection{GRUPOS DE PATIOS}

En este apartado analizamos los grupos de patios, por ser éstos los elementos urbanos más complejos. Aquí se integran en un sólo conjunto la mayoría de los tipos de edificios identificados en este trabajo.

La muestra se divide en dos: El primero (23 sitios) se refiere a grupos de patios con edificios verticales y el segundo (53 sitios) a los grupos de patios sin edificios piramidales.

Grupo de patios con templo pirámide: Estos edificios muy verticales se encuentran en diferentes posiciones y están unidos a edificios horizontales formando especies de torreones (no aislados). En esta variable hay cuatro posiciones para ubicar los "edificios verticales". Estas posiciones son: templo pirámide en un lado de un patio, templo 
pirámide en medio de un patio, templo pirámide en la esquina de un patio y conjuntos irregulares.

1- Templo pirámide en un lado del patio, esta variante lo forman tres lados del patio con edificios alargados, y en el cuarto lado un edificio templo pirámide. Un ejemplo es el Edificio E del Patio 1 de la Acrópolis de Nakum. Este edificio fue, primero un edificio horizontal que luego se transformo en un edificio vertical y después en un grupo triádico elevado; También en la base piramidal del mismo edificio, se agregaron edificios alargados a ambos lados de la escalinata ceremonial. Sin embargo el elemento vertical del edificio no se ha perdido; este factor dominante marca el eje direccional y define la característica principal de este grupo.

2- Templo pirámide en medio del patio (en posición aislada), rodeado por edificios horizontales. De este tipo hay tres ejemplos, uno en la Acrópolis Sur de Tikal, otro en la Acrópolis Sur de Yaxhá, y podría haber un tercer caso en Witzná.

3- Templos pirámide en esquina. Estos se encuentran en los grupos de patios de Xultún, Manantial y La Honradez. Aquí sobresalen los edificios verticales, como torreones unidos a edificios alargados.

4- Casos no comunes como en el grupo de patios no elevado al norte de Chochkitam, aquí dos edificios verticales son colocados al final de dos edificios alargados. Otro ejemplo es un templo pirámide al oeste de la Acrópolis de Kinal. Aparentemente este grupo de patios creció y destruyó el espacio original de la plaza frente a este edificio y lo integró al conjunto de la Acrópolis.

Grupo de patios sin templo pirámide: Esta variante es la más común. El edificio dominante es el palacio real. Este edificio está en la 
posición más restringida del conjunto, rodeado por patios, edificios horizontales y terrazas. Aquí se percibe el carácter de proteger el edificio principal y algunos de ellos ya fueron descritos anteriormente. Ejemplos, Xmakabatún, Naachtún, El Porvenir, Uaxactún (Grupo AV), Tikal, (Acrópolis Central), Temblor, El Encanto, La Línea, El PerúHolmul, Chanchich, Naranjito (Acrópolis sur), El Carmen, El Danto, Balam Chac, Tayasal, Yalain, La Naya, El Venado, Nima Wits, Ucanal, La Blanca, Dos Hermanas, La Amapola y Chilonché.

Algunos grupos de patios no tienen plataformas elevadas tan espectaculares. Estos grupos de patios, se caracterizan porque los edificios y sus patios se encuentran en posición elevada con relación a los edificios circundantes, aunque la diferencia de elevación no sea tan monumental. (Quemada Corozal, Cival, Buenos Aires o Motul).

Los grupos de patios también se pueden clasificar por estar elevados o no levados.

\subsubsection{Grupos de patios elevados (Acrópolis)}

El termino "acrópolis" es una palabra griega que significa "ciudad alta" o fortaleza. En la región de estudio otros autores han llamado "acrópolis" a diferentes grupos de edificaciones que por su poca altura no corresponden con la definición tradicional griega, ni son fortalezas. La siguiente definición coincide en mayor parte con la formulada por George F. Andrews (1975, 67-71): En la arquitectura maya se emplea el término "acrópolis" para describir grupos de edificios, incluyendo los tipos definidos anteriormente como edificios horizontales, edificios verticales, patios, patios secundarios 0 extensiones de patios, terrazas, pasillos y otros, que están unidos por diferentes elementos libres (más de un patio) en diferentes niveles, todos sobre una sola plataforma elevada que separa claramente este 
elemento urbano del resto de la ciudad. Para ser un grupo de patios elevado se requiere que al menos el conjunto este formado por dos o mas patios.

En los extremos del grupo de patios elevados (acrópolis), la mayoría de los edificios tienen su fachada viendo a los patios interiores; por afuera se forman largos lienzos de muros elevados que dan la apariencia de una fortaleza (por ejemplo Nakum, Chochkitam, Kinal, Xmakabatún). El mensaje al observador es claro, son áreas restringidas, muy privadas y resguardadas, del resto del tejido urbano.

Dentro de estos complejos se encuentra la residencia principal o palacio del gobernante y su corte. Generalmente este recinto real es el más protegido y privado del complejo. En algunos casos ocupa la posición más elevada del conjunto; incluso mucho más alto que los templo pirámide (Nakum, Chochkitam, Xmakabatún, Naranjo). Las acrópolis normalmente están ligadas a una plaza monumental. Por la plaza es el acceso principal a la acrópolis y los patios subsecuentes son los espacios de transición entre las actividades públicas del gobernante con las actividades privadas con su familia.

Identificamos dos variables de grupos de patios elevados. La primera se refiere a los grupos de patios que ascienden marcadamente hacia un objetivo principal (el recinto real) y la segunda variante, a los grupos de patios elevados en donde esa tendencia a subir y marcar un punto determinado (edificio principal) no es tan clara.

Describimos ahora algunos grupos de patios elevados o acrópolis, que presentan la tendencia de subir y marcar al edificio principal. Estas edificaciones son características de los periodos culturales de 
finales del Clásico Tardío y el Clásico Terminal, las proporciones que llegan a tener son monumentales:

1- Acrópolis de Nakum: (ver figura 13, 4.3.1-1), la acrópolis tiene una base de $180 \mathrm{~m}$ por $150 \mathrm{~m}$ por lado. Cuenta con 13 patios, 33 edificios diversos y más de 162 espacios interiores; Telma Tobar (Tobar 2006, 225-325, Tobar y González 2007). Aquí el Edificio D es el elemento de contacto entre el grupo de patios elevados y la Plaza Central. La fachada representativa del Edificio $D$ tiene tres escalinatas monumentales y una impresionante fachada de $122 \mathrm{~m}$ de largo con 21 accesos. El Patio 1 es el primer contacto con el espacio interior de la Acrópolis, con edificios representativos como el Edificio $E$ y el Edificio $G$ (con dos relieves con cautivos a ambos lados de la escalinata). Luego inicia una serie de barreras y restricciones para continuar a los otros patios de la Acrópolis. En la esquina sur oeste del Patio 1, se encuentra el Edificio $\mathrm{H}$. Este edificio es un verdadero laberinto de espacios creados para restringir y controlar el paso hacia la Acrópolis Central. El único acceso a la Acrópolis Central es por un edificio de cinco puertas (fachada norte) que luego se transforma en tres (fachada sur) para llegar al Patio 6 y el Edificio $Y$. El Edificio $Y$ es el punto más alto e importante de toda la ciudad. En otro sector de la Acrópolis (Patio 9) se encuentra entre otros edificios un Baño de vapor.

2- Acrópolis de Chochkitam: (ver figura 13, 4.3.1-2), este grupo de patios elevados tiene una base de 140 por $130 \mathrm{~m}$ y 13 patios. En un sector elevado varios edificios representativos tipo templo pirámide en hilera y una cancha para juego de pelota forma el primer espacio; luego, a un nivel más alto tres patios en cadena rodeados de edificios horizontales crean un segundo nivel de edificaciones. A mayor altura, otro patio constituye el vestíbulo al grupo principal. El edificio 
dominante se distingue por su doble altura. Este edificio está rodeado, a un nivel mucho mas bajo, por tres patios hundidos como si fuera un foso defensivo.

3- Acrópolis de Xmakabatún: (ver figura 13, 4.3.1-3), la acrópolis ocupa un espacio aproximado de 145 por $75 \mathrm{~m}$, con seis patios y dos terrazas. Al parecer el primer patio no presenta edificios representativos; sólo está compuesto de edificios alargados. Luego continúan otros patios más elevados con terrazas laterales hacia el sur. Después y a un nivel más alto se llega al área del edificio principal con varios patios adosados con edificios alargados, pasillos y terrazas.

4- Acrópolis de Kinal (ver figura 13, 4.3.1-4), este grupo de patios elevados tiene una base de $110 \mathrm{~m}$ por $175 \mathrm{~m}$, con 14 patios y dos terrazas. El primer patio interior tiene un edificio representativo (templo pirámide en esquina) y una plataforma baja al centro del patio. Luego continúan varios patios de menores dimensiones, rodeados de edificios alargados. El edificio principal, más alto, está precedido por un patio elevado en su fachada norte y una cadena de tres patios elevados en su fachada sur.

Una característica urbana es que lo grupos de patios elevados se encuentran al sur de una plaza con monumentos esculpidos. En Nakum la Acrópolis se encuentra al sur de la Plaza Central; igual sucede con los grupos de patios de Kinal, Chochkitam, Xmakabatún. Una excepción es la Acrópolis de Naranjo localizada al oeste de la Plaza Central, con monumentos esculpidos; aunque al sur también tiene un extenso espacio libre (Plaza Oeste Alta), pero sin estelas o altares. 
En la segunda variable el grupo de patios tiene una misma base elevada, pero el efecto marcado de patios a diferentes alturas ascendiendo hacia un patio principal no sucede. En la Acrópolis Central de Tikal y la Acrópolis Sur de Yaxhá la altura de los distintos patios se conserva más o menos. También se alternan o no edificios verticales tipo templo pirámide con los edificios alargados. El espacio del edificio principal no es tan marcado en estos grupos de patios elevados:

5- Acrópolis Central de Tikal: (ver figura 13, 4.3.1-5), este grupo de patios cuenta con una base irregular elevada de $200 \mathrm{~m}$ por $75 \mathrm{~m}$, con más de 46 edificaciones, seis patios y nueve terrazas.

6- Acrópolis Sur de Yaxhá: (ver figura 13, 4.3.1-6), la acrópolis cuenta con una base en forma de "L" de 170 m por 125 m, seis patios, tres terrazas y cerca de 30 edificaciones.

Los grupos de patios marcan un espacio importante en la ciudad; al parecer son construcciones monumentales tardías en la secuencia cultural del Clásico, pero sobre edificios del Preclásico. Por ejemplo dentro de la Acrópolis Central de Nakum se encuentra un grupo triádico del Preclásico Tardío, lo que demuestra la predilección de uso del mismo espacio por cientos de años. Igual sucede debajo de la Acrópolis Norte de Tikal con edificios del Preclásico Temprano (Coe 1967, 41)

Algunos centros urbanos mayores tienen más de un grupo de patios elevados: Yaxhá cuenta con cuatro (tres de ellos según esta clasificación no deberían llamarse acrópolis); Tikal, Holmul y Naranjo con tres grupos de patios elevados; La Línea, Chochkitam y Naranjito con dos grupos. 
Un elemento común en los grupos de patios, son los pasillos abovedados. Elemento empleado para comunicarse internamente entre diferentes patios (Kinal, Naranjo, Nakum, El Danto, Xmakabatún, Naranjito, San Clemente, Holmul). En otros casos la comunicación interna entre los patios, se realiza atravesando los edificios (Edificios H y L de Nakum); en La Blanca, el Edificio 6J2 (cámara 3) funciono como comunicación entre dos espacios libres; pasillo que fue clausurado por los mismos mayas.

Sitios que cuentan con grupo de patios elevados, se registran 28 (21.8\%). En la cuenca Mirador no se ha identificado este tipo constructivo. El mayor índice de grupos de patios elevados se encuentra en la cuenca Holmul (43.3\%) y un 26.6\% para el área Tikal y la cuenca Ixcán. Las cuencas Los Lagos y Mopán tienen (11.42\% y $14.3 \%)$.

\subsubsection{Grupos de patios no elevados}

Aparte de la elevación, que no sucede en estos casos, todos los elementos que forman un grupo de patios coinciden con la definición de grupo de patios elevados ("acrópolis"). Dentro de los ejemplos más claros están:

1- El grupo de patios de La Honradez (ver figura 13, 4.3.2-1), este grupo tiene una superficie de $200 \mathrm{~m}$ por $80 \mathrm{~m}$, seis patios y varias terrazas rodeadas por edificios horizontales, tres templos pirámide y un grupo triádico. Su posición en el tejido urbano está al sur de la plaza principal. En la parte de atrás del grupo de patios con edificaciones monumentales se ubican otros grupos de cuadrángulos y patios con edificios horizontales. 
2- Similar condición sucede en Xultun (ver figura 13, 4.3.2-2), el área de grupo de patios mide $240 \mathrm{~m}$ por $100 \mathrm{~m}$, nueve patios rodeados de edificios horizontales, tres templos pirámide en esquina, un cuadrángulo y varias terrazas. Atrás del grupo monumental, una serie de cuadrángulos bajos conectados unos con otros continúan extendiéndose hacia el sur.

3- En Uaxactún el Grupo A-V (ver figura 13, 4.3.2-3), es un grupo de patios no elevado que mide $75 \mathrm{~m}$ por $60 \mathrm{~m}$, este elemento urbano está formado por cuatro patios rodeados de edificios horizontales. En este caso el núcleo del grupo fue varias veces rellenado, cubriendo edificios anteriores, hasta formar un grupo alto de palacios alargados, rodeado por edificios horizontales en tres de sus lados. Este proceso de superposiciones constructivas fue documentado en dibujos por Tatiana Proskouriakoff.

4- Chochkitam, grupo de patios norte (ver figura 13, 4.3.2-4), este sector fue descubierto por el equipo de documentación en 1999 y mide $95 \mathrm{~m}$ por $90 \mathrm{~m}$. El grupo presenta una mezcla de edificios alargados, siete patios y tres edificios verticales, uno rodeado de patios y dos localizados en la punta de un edifico alargado.

5- Aguacate, grupo de patios norte (ver figura 13, 4.3.2-5), este sector fue descubierto en el año 2003 y se encuentra sobre una colina cercana alejado del centro conocido unos $150 \mathrm{~m}$. Mide $103 \mathrm{~m}$ por $100 \mathrm{~m}$. El grupo presenta edificios verticales (no tan elevados) y edificios alargados distribuidos en ocho patios, dos de ellos del tipo secundario en esquina.

6- El Manantial (ver figura 13, 4.3.2-6), el grupo de patios también se localiza al sur de la plaza principal, esta formado por edificios 
verticales y edificios alargados ordenados en siete patios. Mide 140 $\mathrm{m}$ por $60 \mathrm{~m}$.

7- El Zotz (ver figura 13, 4.3.2-7), el grupo de patios se ubica al norte de la plaza principal, en un extremo tiene un edificio vertical, el resto son edificios alargados ordenados en cuatro patios y varias terrazas. Mide $120 \mathrm{~m}$ por $60 \mathrm{~m}$.

Otros grupos de patios, Naachtún, El Porvenir, Ramonalito, Temblor, El Encanto, El Perú-Holmul, Witzná, Chanchich, El Carmen, El Danto, El Pital, Balam Chac, Motul, Tayasal, Ixlú, Yalain, La Naya, El Venado, Nima Wits, Dos Hermanas, Camalote y La Amapola.

Sitios que poseen grupos de patios no elevados, 21 (16.4\%). La cuenca Ixcán tiene la mayor cantidad de este elemento urbano (60\%); el área Tikal y la cuenca Mirador (20\% y 25\%). Las cuencas Holmul, Los Lagos y Mopán tienen (10\%), (5.7\% y 4.75\%).

Existen varios casos de grupos de edificios llamados "acrópolis" que no precisamente cumplen todos los criterios descritos anteriormente. Ejemplos en Yaxhá, en la parte más elevada de la ciudad se encuentra la "Acrópolis Este". Este espacio elevado sería un "Grupo de cuatro edificios distintos" según nuestra definición, porque es de sólo un patio, con extensiones en las esquinas. Igual ocurre en la Acrópolis Norte y la Acrópolis Noreste del mismo sitio. La Acrópolis Norte de Tikal es un caso atípico en la composición urbana de la región. 


\subsubsection{Depósitos de agua}

Los depósitos de agua dentro de las ciudades prehispánicas son resueltos de distintas formas. Los más conocidos son los estanques de Tikal. Esta ciudad tiene depósitos de agua construidos en los lados norte y sur del área central. Las aguadas artificiales se lograron construyendo diques en los encaños naturales vecinos. Sobre los diques construyeron segmentos de calzadas o pasos entre un sector y otro de la ciudad (ver figura 14, 4.4.1).

El mismo sistema es empleado en Uaxactún. Aquí se construyó un muro de retención de grandes dimensiones para tapar un encaño natural. Sobre el dique se construyó una calzada que une los grupos A y $B$ de la ciudad. Ejemplo parecido se encuentran en Yaxhá (Calzada Blom) y en El Pital, aquí la calzada que forma el embalse se junta con otra calzada formando un ángulo aproximado de $90^{\circ}$. En Naranjo la Aguada Este recibe el drenaje de las colinas vecinas al sector noreste de la ciudad. En este caso el muro o dique que contiene el agua del estanque es una extensa plaza nivelada (Plaza Este Baja); seguramente debajo de esta superficie habrá drenajes para trasladar el exceso de agua de nuevo al encaño que continúa en el extremo sur de la plaza. Otros ejemplos de modificaciones monumentales del terreno natural se observan en el dique circular de La Honradez. En este caso, la reserva de agua se encuentra afuera del centro, a los pies del cerro principal.

Todas las ciudades tienen reservas de agua. Estos depósitos son colocados cerca de los edificios en terrenos bajos u hondonadas en donde se aprovecha la topografía para formar los depósitos. Tikal tiene, en su espacio cercano, nueve de estos reservorios. 
En Xulnal, en la parte sur del centro urbano se construyó un terraplén para contener un estanque de agua. Este sistema se combina con un canal que se dirige al bajo. Sitios como La Ceibita, y Tintal tienen dispersos depósitos de agua entre las edificaciones. En Tintal se combinan los depósitos de agua con canales. En Nakum, en el espacio contiguo a la Acrópolis, se modificó el curso del río para formar una especie de estanque o puerto fluvial. Un caso especial es el depósito de agua de Poza Maya, aquí se formó en el bajo un cuadrado de aproximadamente $200 \mathrm{~m}$ por $200 \mathrm{~m}$ a los pies del centro urbano (en parte elevado artificialmente). Es posible que este gran depósito tenga otras funciones relacionadas con el manejo de cultivos.

Otro ejemplo es el estanque recién descubierto, al sur del grupo de patios elevados de La Blanca. En la misma cuenca Mopán, el sitio Calabazal tiene una depresión que podría ser una pileta o estanque prehispánico en la plaza principal.

La mayoría de los sitios registrados tiene evidencia de cuerpos de agua cercanos (ríos, bajos, lagunas y lagos) naturales o modificados; en el cuadro 4 solamente se mencionan algunos de ellos. En 31 sitios de la muestra se identifica este elemento (24.2\%). La cuenca Mirador tiene el mayor índice con (58.3\%). El área Tikal y las cuencas Ixcán, Holmul y Mopán (20\%, 20\%, 30\% y 23.8\%). La cuenca Los Lagos tiene el menor índice con (11.4\%).

\subsubsection{Chultunes}

Son espacios cavados en la roca caliza para diferentes usos. Estos elementos forman espacios interiores de uno, dos o más cámaras. En la isla de Topoxté se documentó un chultún con 12 espacios interiores (Hermes y Calderón, en Wurster 2000, 66-74). Entre los 
elementos tallados se encuentran especies de vestíbulos, nichos, agujeros pequeños, respiraderos, gradas, plataformas y bocas de acceso con su tapadera de piedra. Los Chultunes se clasifican por su forma en planta (elonga, de trébol, de ocho ó forma circular o semicircular); ó por su sección (calceiforme, semiesférica doble, forma de botella, campaniforme, cuadrangular y semiesférica) (Calderón y Hermes 2005,124).

La arqueóloga Zoila Calderón ha investigado estos elementos con ejemplos de uso desde el período Preclásico Medio hasta el Posclásico. (Zoila Calderón, comunicación personal 2006). Este elemento está presente en la mayoría de los sitios y se indican en los planos esquemáticos y en los informes individuales, no están cuantificados en el cuadro 4.

\subsubsection{Terraplenes}

Constituyen modificaciones al terreno que se realizan al rededor o cerca de los centros urbanos. Generalmente no rodean totalmente al sitio. Están sólo en sectores que requieren la modificación del terreno para defensa, para crear espacios nuevos, para almacenar agua o proteger sectores de inundaciones. Ejemplos pueden observarse en El Mirador. Aquí los terraplenes cubren parcialmente el sector oeste de la urbe, con construcciones que tuvieron un alto aproximado de 4 m (Hansen 1998, 87). El sitio Xulnal también tiene terraplenes en el sector oeste. Como un caso diferente existen una especie de muros defensivos colocados sobre plataformas en el sector sur de Cival, en la cuenca Holmul (Estrada-Belli et al. 2004, 73-83).

Otro ejemplo, son los camellones de tierra en la parte oeste, norte y sureste de Tikal, bastante alejados del centro urbano (Martínez et al. 2004,659-664; Webster et al. 2006,695-703). Aquí el material sacado 
de la fosa cavada es colocado en un lado de la excavación formando un lomo de tierra artificial más elevado. Los ejemplos mencionados para El Mirador, Tikal y Cival pertenecen a construcciones del período Preclásico Tardío y principios del Clásico Temprano (ver figura 14, 4.4.3).

\subsubsection{Fosas y canales}

Las fosas son canales cavados en el terreno con el propósito de formar una barrera. En la cuenca Mirador, recientes investigaciones en el sitio Tintal (Hansen et al. 2006, 683-694), han identificado canales en el sector llamado "Complejo Mano de León". Esta parte de Tintal está separada por tres lados (oeste, sur y este) por vías de agua que drenan al bajo situado en la parte norte del complejo. Similar solución urbana ocurre en Xulnal. Aquí, un sector del sitio arqueológico, es separado del resto por un terraplén en la parte oeste y un canal en la parte sur y este. Luego el canal desciende hacia el bajo, al norte del grupo de edificaciones (ver figura 14, 4.4.4).

Otro ejemplo es un canal excavado en el bajo muy cerca de la orilla oeste de Naranjo (Grupo A, con la Plaza Oeste Baja). El canal corre a lo largo de $250 \mathrm{~m}$ y termina al sur en la "Aguada Oeste". Por este terreno de bajos la ciudad de Naranjo se comunicaba con el río Holmul. Puede pensarse que sobre el lomo de tierra del foso se completó un sistema de defensa con empalizadas de madera (Quintana y Wurster 2004, 152, 169).

En sitios del período Posclásico hay dos ejemplos claros de fosas o canales, uno en el límite norte del sitio Sacpetén, en el espacio más angosto de la península, y otro en el sector este del sitio Nixtunchich en el Lago Petén Itzá. Una variante son las modificaciones de salidas de ríos; un caso sería el extremo sur de la isla Topoxté, en donde el 
río Ixtinto en su recorrido final, hace un quiebre de 90 grados para salir (entre dos islas) a la laguna Yaxhá. Otros ejemplos fueron investigados por Don S. Rice (1997, 533-544) en la cercanía del sitio arqueológico Ixlú.

En la Laguna Macanche, muy cerca de Yalain, en el extremo noreste de la laguna, se encuentra el sitio "Muralla de León". Este sitio fue investigado parcialmente por el Proyecto Maya-Colonial (Rice y Rice et al. 1997, 503-504). El equipo de campo visitó Muralla de León en el año 2001, pero por la vegetación, el saqueo y la destrucción masiva de las edificaciones no se pudo elaborar un plano esquemático del sitio, ni se pudo constatar la evidencia de construcciones defensivas.

En el cuadro 4, están registrados 10 sitios con construcciones de este tipo (terraplenes, fosas y canales), representando un $7.8 \%$ de la muestra. La cuenca Mirador tiene el mayor índice con (25\%). El área tikal (6.6\%) y las cuencas Ixcán, Holmul, Los Lagos y Mopán con $(6.6 \%, 10 \%, 2.8 \%$ y $4.75 \%)$.

\subsubsection{Pasillos abovedados}

Los pasillos abovedados son un elemento de comunicación para pasar de un espacio a otro, o para llegar a un espacio interior (ver figura 14, 4.4.5). En Holmul se conocen dos ejemplos, uno de ellos es un pasaje escondido entre el muro para pasar de una cámara a otra en el Edificio I del Grupo I (Quintana y Wurster 2001, 79); el otro forma un pasillo "boca de entrada" de una fachada zoomorfa (Grupo III) que es la entrada a un espacio interior. Similar elemento se encuentra en Tikal, con un pasadizo, en forma de L, en el Grupo G; aquí la entrada es al mismo tiempo parte de un mascaron-fachada y el túnel llega a un patio interior. En la acrópolis de Kinal un pasaje abovedado pasa debajo de un patio elevado comunicando dos patios 
a menor altura. En las Acrópolis Central de Naranjo, un pasadizo abovedado comunica el patio norte con el patio este. En el grupo de palacios de San Clemente un pasillo abovedado comunica el Patio Bajo con la Plaza Principal; en este caso la comunicación entre los dos espacios abiertos es a través de dos cámaras y un pasillo (remodelaciones del Clásico Terminal). Otros ejemplos de este elemento se encuentran en: Xmakabatún, El Zotz, Naranjito y El Danto.

En 11 sitios existen pasillos abovedados (8.59\%). Seguramente tendremos más información o datos de este elemento a medida que se profundice el proceso de investigación arqueológica en los grupos de patios.

\subsubsection{Tumbas}

Este tipo de espacio tiene poca o ninguna relación con los elementos urbanos y de uso en las urbes mayas, pero sí tienen relación simbólica con la posición de los centros urbanos. "Los muertos se entierran en el espacio del grupo, así los antepasados toman parte del grupo y permanecen en la identidad que imprimen" (HohmannVogrin 1992, 154). Este elemento constructivo está por lo general bien conservado debajo de las edificaciones. Son espacios rectangulares preparados para servir de recinto funerario. Los hay cavados en la roca madre, dentro de los rellenos de las construcciones o combinaciones de ambos. Los arqueólogos encuentran en sus investigaciones abundantes entierros. Los que aquí presentamos tienen más relación con el espacio mortuorio y los elementos que lo forman. 


\subsubsection{Tumbas excavadas}

Por lo general las tumbas se encuentran bajo el nivel del suelo natural o sea excavada en la roca madre. Por esta condición los depredadores las llaman "tumbas roqueadas". Para encontrarlas, los saqueadores perforan los edificios por medio de túneles y pozos de excavación. A veces convierten el interior de un edificio en un laberinto de túneles, causando derrumbes internos y el colapso de los edificios, como sucedió en el edificio principal del sitio Chunhuitz. En el sitio El Encanto los buscadores de tesoros encontraron en el interior de un templo pirámide, tres niveles de tumbas. Las tumbas 2 y 3 fueron cavadas en la roca madre. Aquí los espacios simulan cámaras con bóvedas de piedra tallada incluyendo espacios de vestíbulos cavados, pasillos con bóveda de medio cañón y simulación de piedras tapa. Los interiores fueron estucados y pintados con franjas de color naranja, rojo y gris (ver figura 14, 4.4.6.1).

Otras tumbas excavadas en la roca son las encontradas en Río Azul. En este caso su ubicación no estaba debajo de un edificio sino bajo enormes terrazas elevadas. La cámara mortuoria tiene franjas de color pintada en sus paredes, figuras e inscripciones pintadas y nichos cavados (Tumba 1, encontrada por saqueadores). Otros ejemplos con pintura son las Tumbas 19 y 12. En Topoxté la Tumba 49 fue encontrada debajo del Edificio $A$; en ese caso se modifico un antiguo chultún como recinto mortuorio (Hermes, en Wurster 2000, 127-143).

\subsubsection{Tumbas mixtas}

La tumba 116 es la más famosa de la región; fue encontrada dentro del Templo I de Tikal. El espacio mortuorio fue preparado cavando en la roca caliza un espacio de $4.75 \mathrm{~m}$ por $3.2 \mathrm{~m}$ y $5.25 \mathrm{~m}$ de 
profundidad. Luego con bloques de piedra de aproximadamente 0.20 $\mathrm{m}$ de grosor se levantaron los muros de la cámara mortuoria. El espacio entre el muro (fachaleta) y la roca madre fue rellenado con mezcla. La planta es rectangular y del lado izquierdo una grada sube para contener el espacio donde se colocó el cuerpo del gobernante. En el espacio más bajo se encontró vasijas y otros objetos. El techo fue construido con una bóveda en saledizo (bóveda de cuatro lados) con tres filas de pasadores de madera a diferente altura.

En la investigación del edificio 216 de Yaxhá, en el túnel de excavación este-oeste en la base de la pirámide escalonada, aproximadamente al centro de la pirámide, se encontró un espacio interior. La planta es rectangular orientada norte-sur; las paredes longitudinales están estucadas y tienen una banda saliente. A una altura de $1.90 \mathrm{~m}$ el espacio interior tuvo un techo plano de vigas de madera con un tejido que formó una cubierta con ofrendas de cinabrio. Sobre este techo plano se construyó una bóveda en saledizo con siete piedras tapa (Hermes, Noriega y Calderón 1997, 276-280).

En ocasiones durante los trabajos de investigación, aparecen tumbas de fabricación rápida, como la encontrada en abril del año 2006, en el interior del Edificio IV de San Clemente. En este edificio del Clásico Tardío, que estaba en esa época en remodelaciones; por alguna razón, un personaje muere y un espacio en proceso de relleno es preparado como cámara mortuoria. En este caso se aprovecha el piso y el canto de una banca para formar dos lados de la tumba. A $0.60 \mathrm{~m}$ de la banca se construye un muro y a $0.60 \mathrm{~m}$ de altura se colocan bloques de piedras en saledizo y encima siete piedras tapa. Luego continuaron con el relleno de la Cámara 3. 
En una trinchera en el centro del grupo triádico de La Honradez los saqueadores cortaron dos tumbas colocadas en el relleno de la base de sustentación. El corte permitió ver los llamados "campos magnéticos" alrededor del espacio preparado para el entierro; el techo fue construido en forma rudimentaria con gruesas lajas de piedra en saledizo. Los campos magnéticos son capas de pequeñas lascas de pedernal formando un espacio "mágico" alrededor del recinto. La tumba documentada en Chunhuitz tiene también el mismo campo con cientos de pedazos de pedernal. Lamentablemente los buscadores de tesoros conocen este secreto y al encontrarlos refuerzan sus labores con saña.

Un caso especial es la tumba saqueada en el edificio Triádico de Wakna. Este recinto funerario se encuentra sobre una terraza elevada en la base del edificio dominante. Lo interesante aquí es el detalle de la cámara mortuoria con una bóveda formada por dos filas de siete gruesos bloques de piedra tallada colocados en diagonal uno contra otro formando una "A"; Hansen la llama "tumba pentagonal" y hace referencia a una tumba parecida ubicada en la Acrópolis Norte de Tikal (Hansen 1998 ,88).

En el área de estudio se han registrado tumbas en 18 sitios (Río Azul, El Porvenir, Juleque, Tikal, La Perra, Ahau-Na, Corozal Torre, San Clemente, Topoxté, Naranjo, Chunhuitz, La Naya, Witzná, Yaxhá, Nakum, Wakna, El Susto Mirador y El Encanto). Esta forma constructiva no está considerada en el cuadro 4 de elementos urbanos. 
4.1 .1

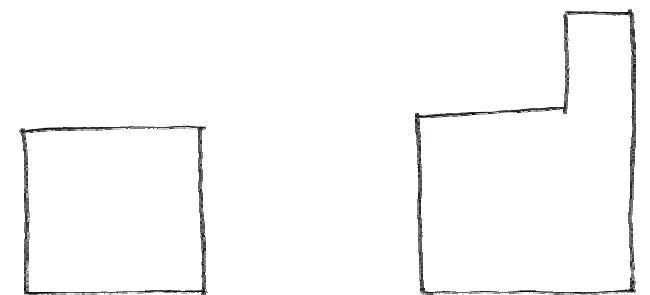

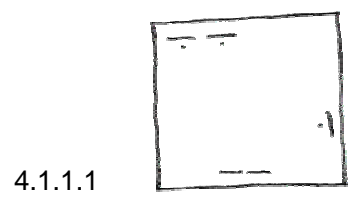

$1.1 .1 .2 \square$
$\square \square$
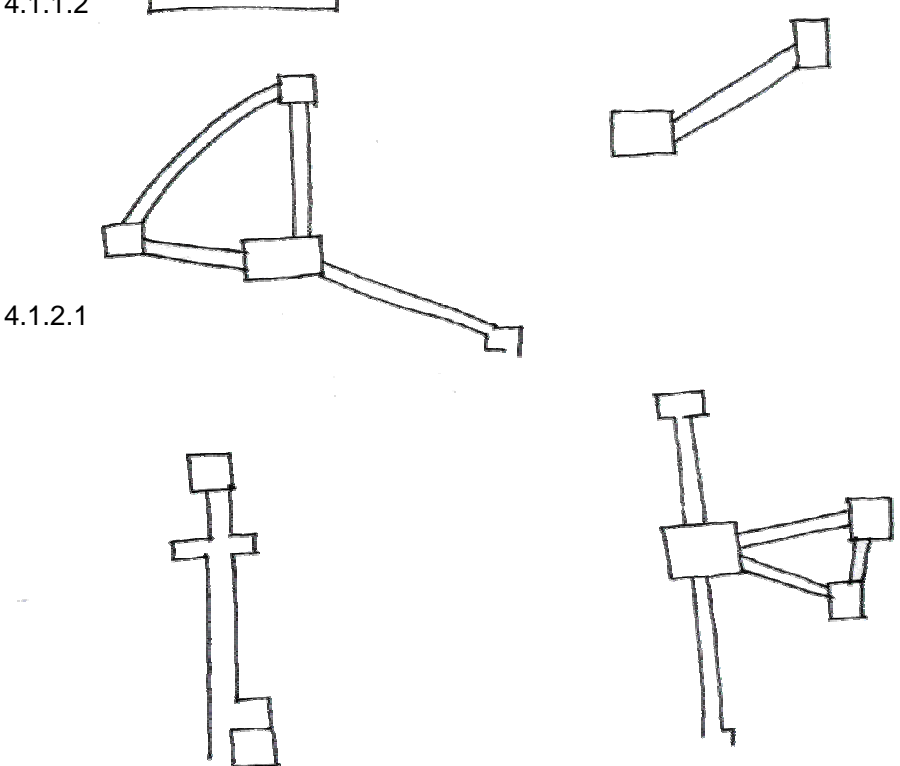

Fig. 12. Formas esquemáticas de los elementos generadores del espacio construido. 


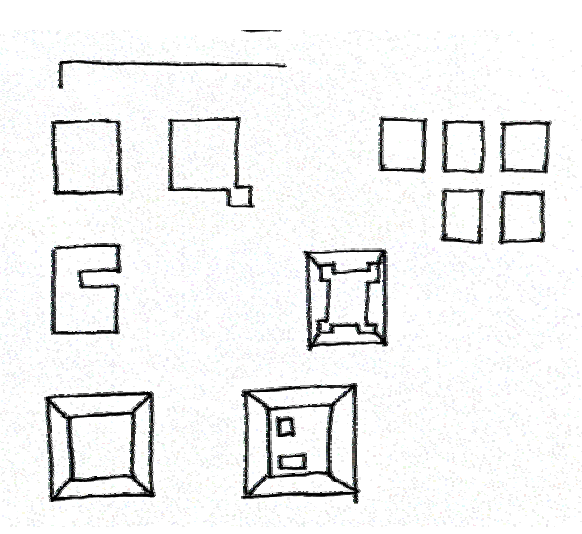

Fig. 12. Formas esquemáticas de los elementos generadores del espacio construido. 


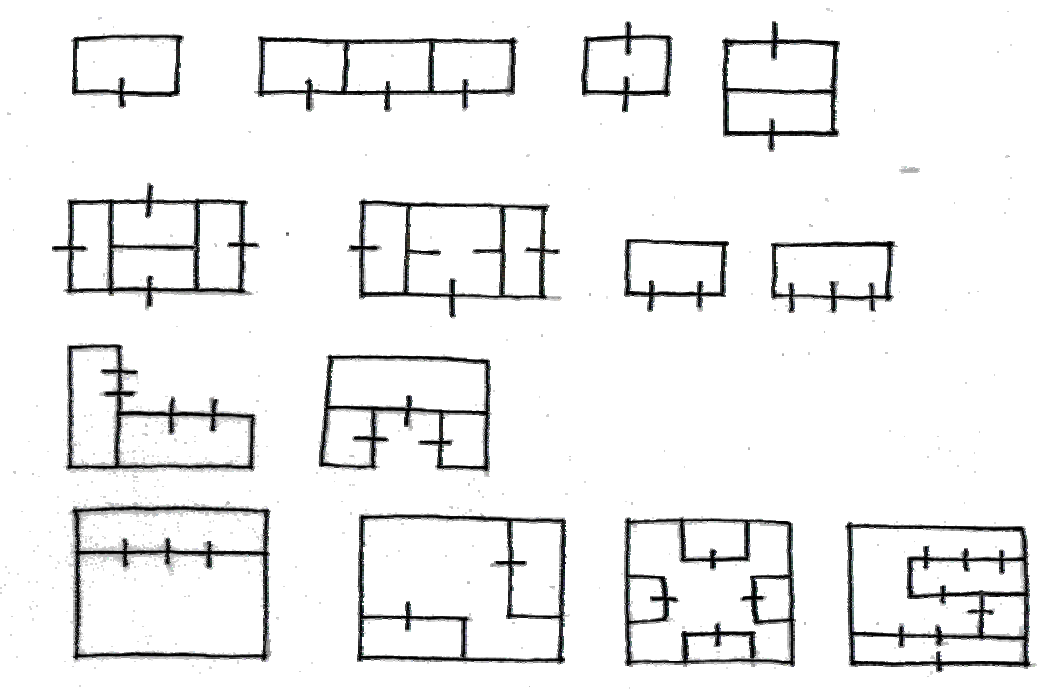

4.2.1
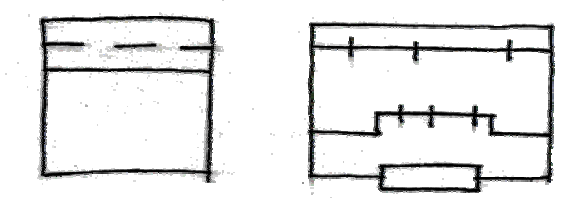

4.2.1.1
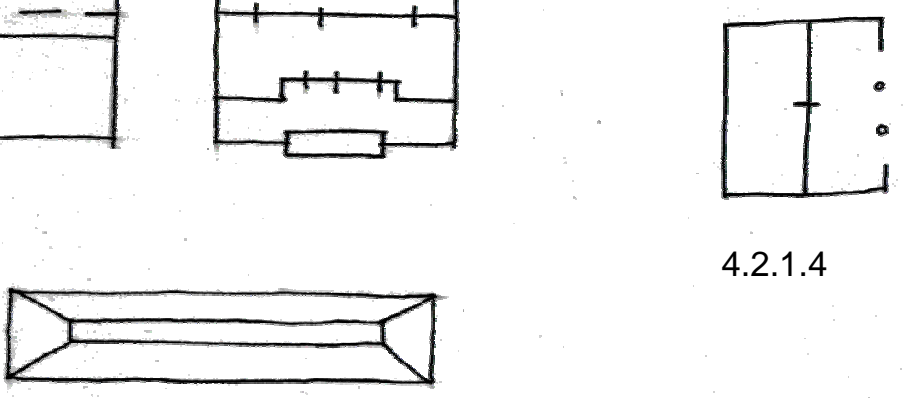

4.2.1.2

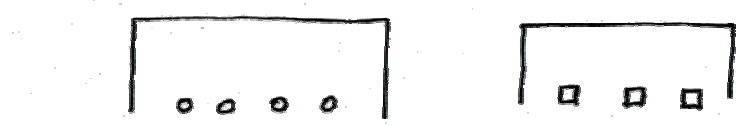

4.2.1.3

Fig. 12. Formas esquemáticas de los elementos generadores del espacio construido 


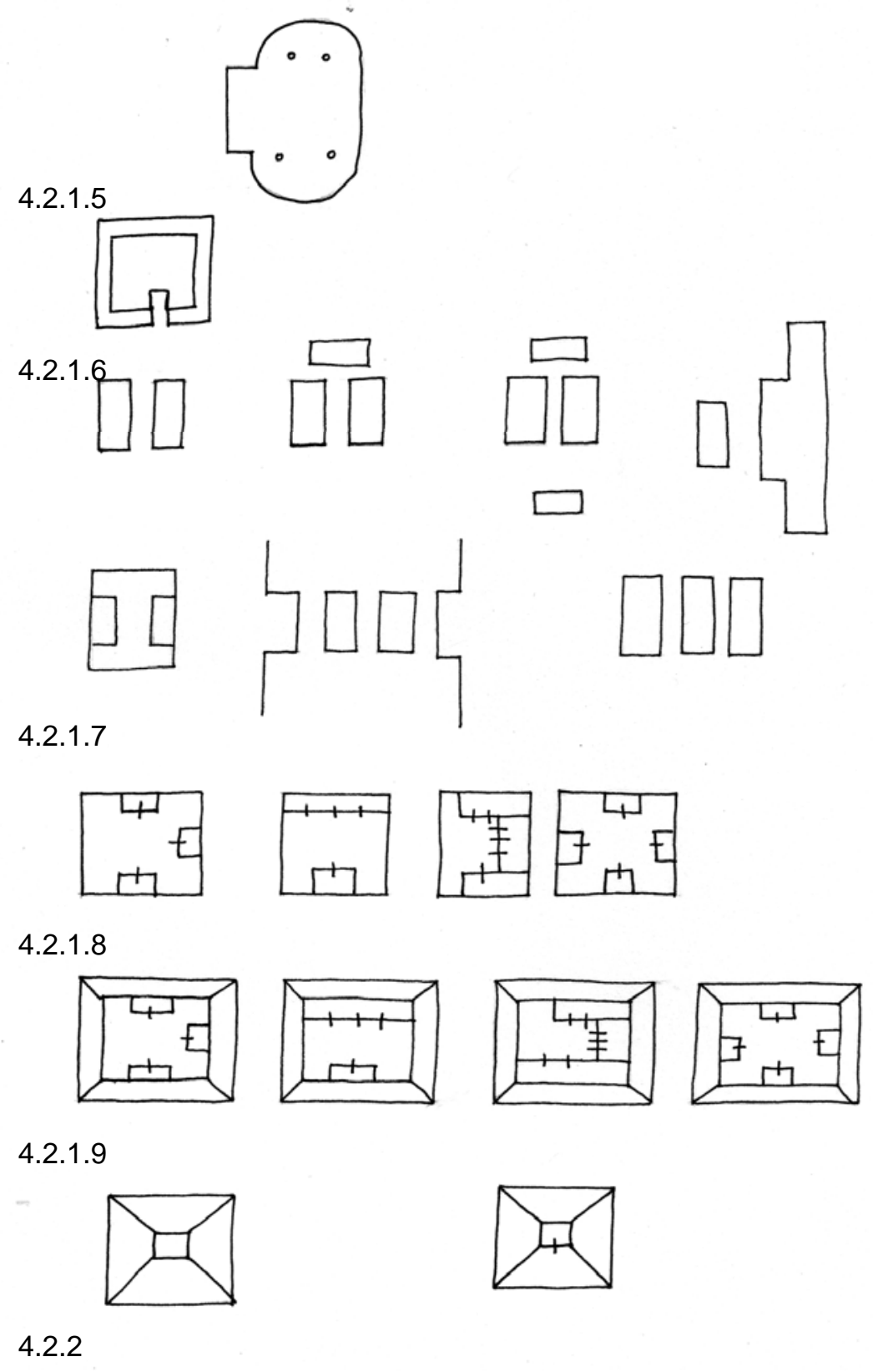

Fig. 12. Formas esquemáticas de los elementos generadores del espacio construido. 


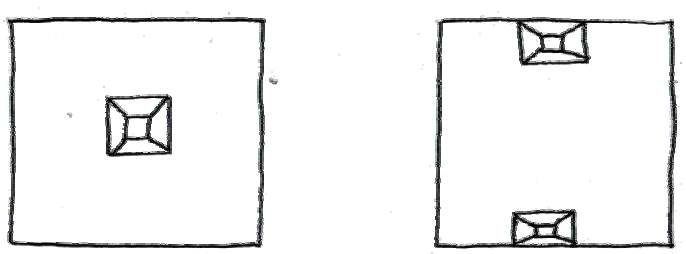

4.2.2.1

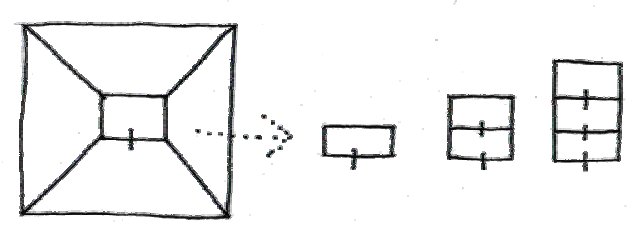

4.2.2.2

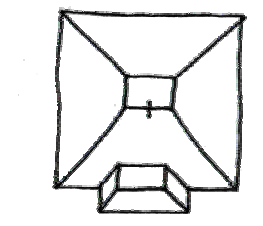

4.2.2.2-2
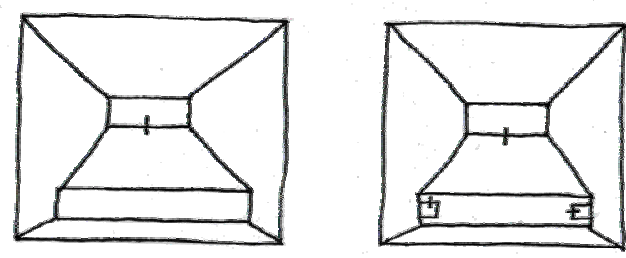

4.2.2.2-3

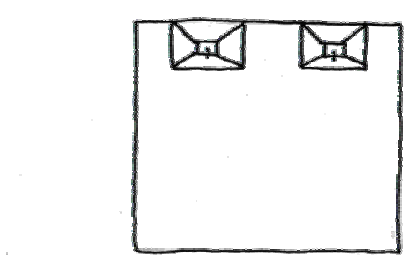

4.2.3.1

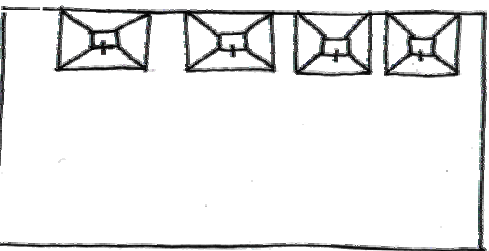

4.2.3.2

Fig. 12. Formas esquemáticas de los elementos generadores del espacio construido. 


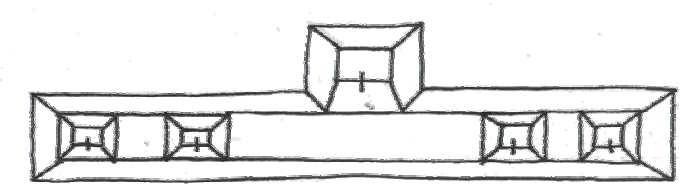

4.2.3.2-1
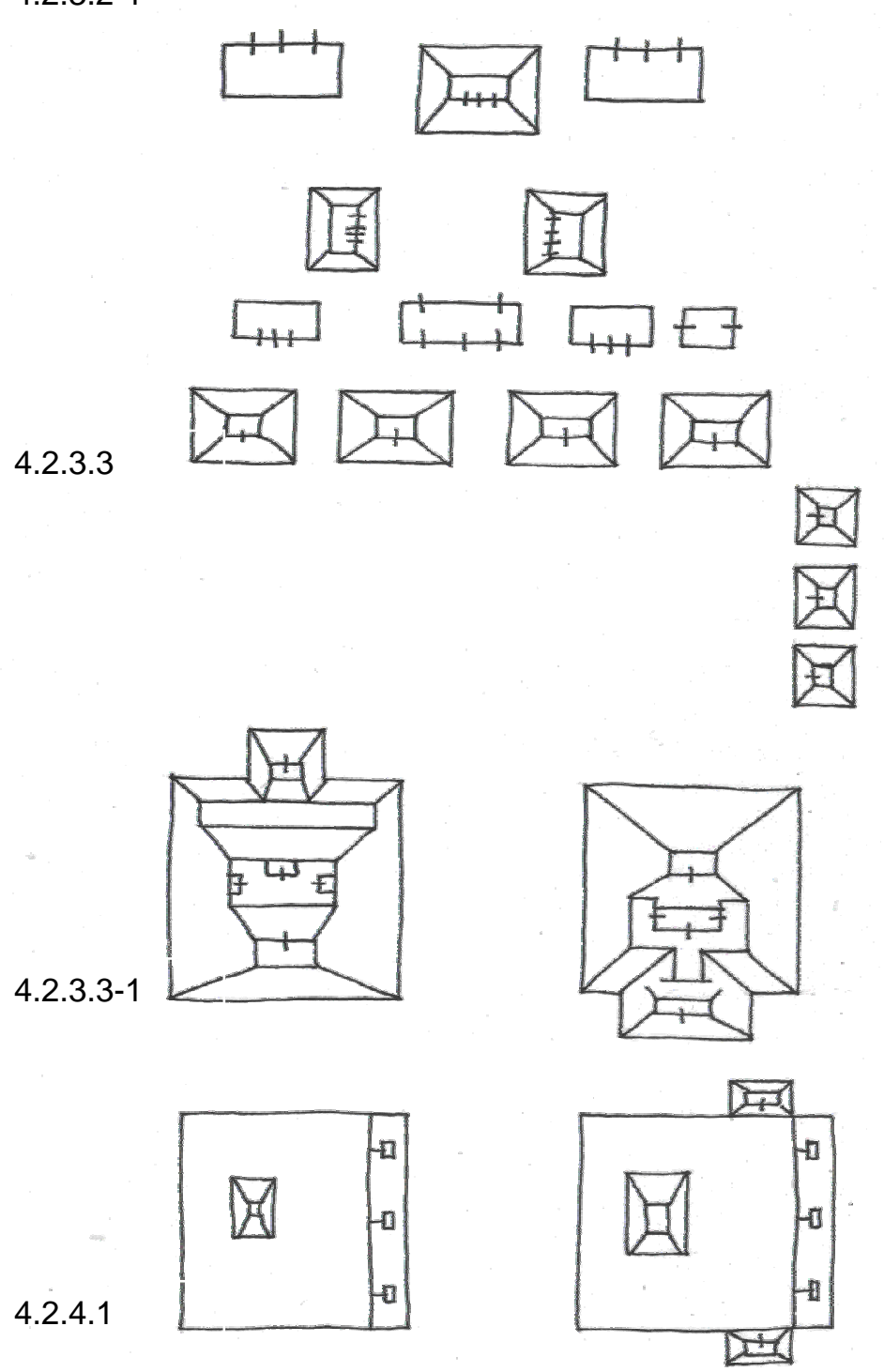

Fig. 12. Formas esquemáticas de los elementos generadores del espacio construido. 


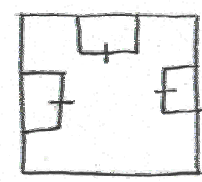

4.2.4.2
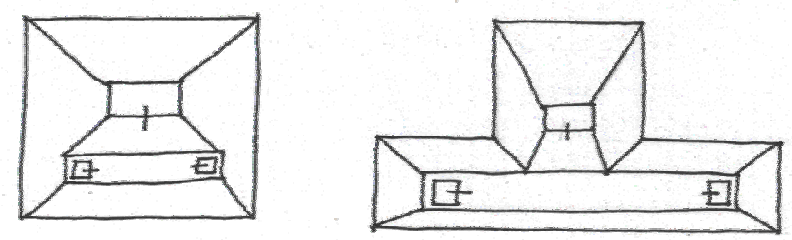

4.2.4.2-1
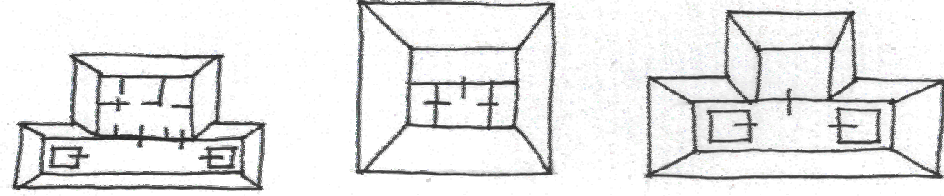

4.2.4.2-2
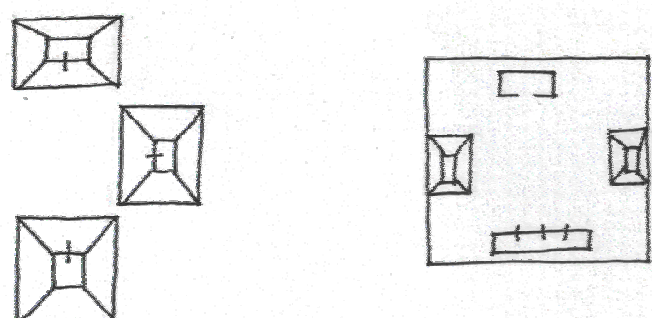

4.2.4.2-3

4.2.4.3-1

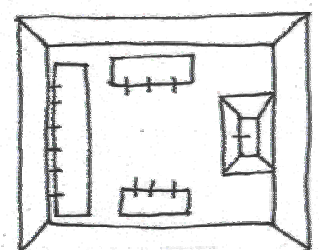

4.2.4.3-2

Fig. 12. Formas esquemáticas de los elementos generadores del espacio construido. 


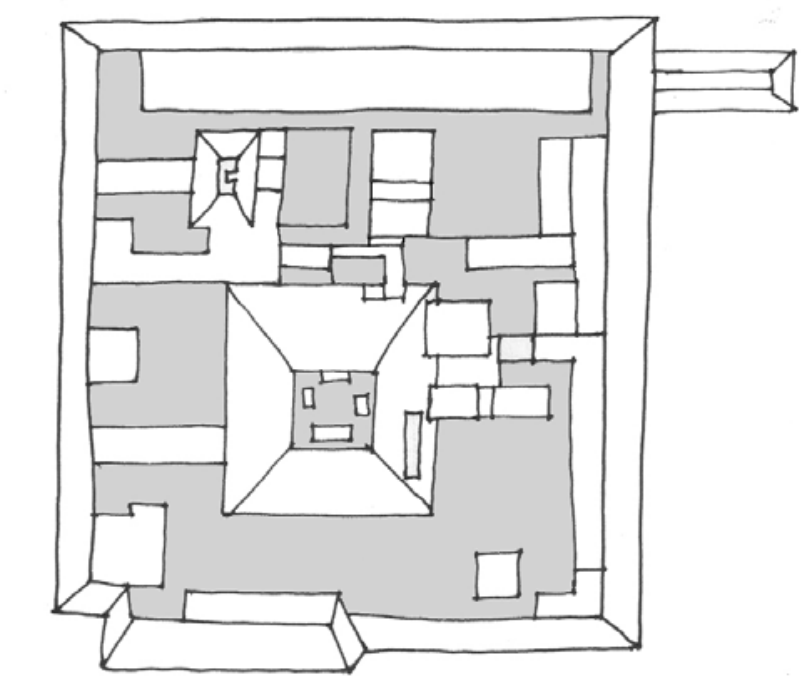

4.3.1-1

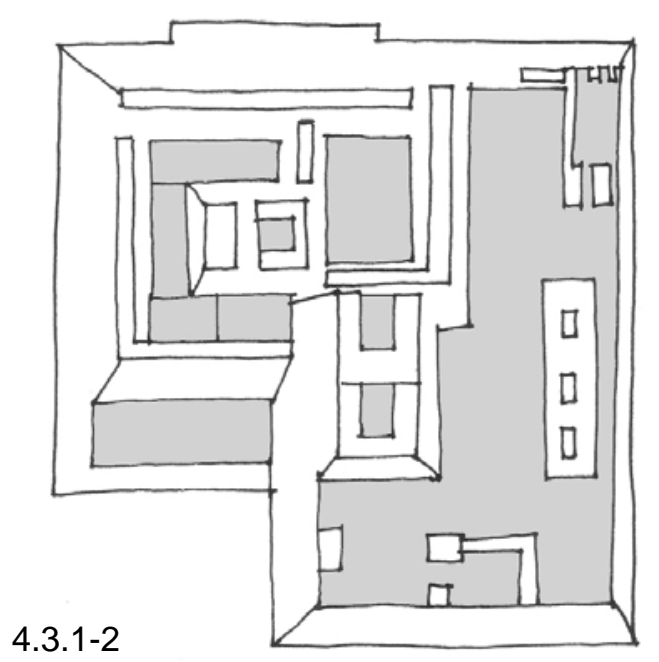

Fig. 13. Grupos de patios 

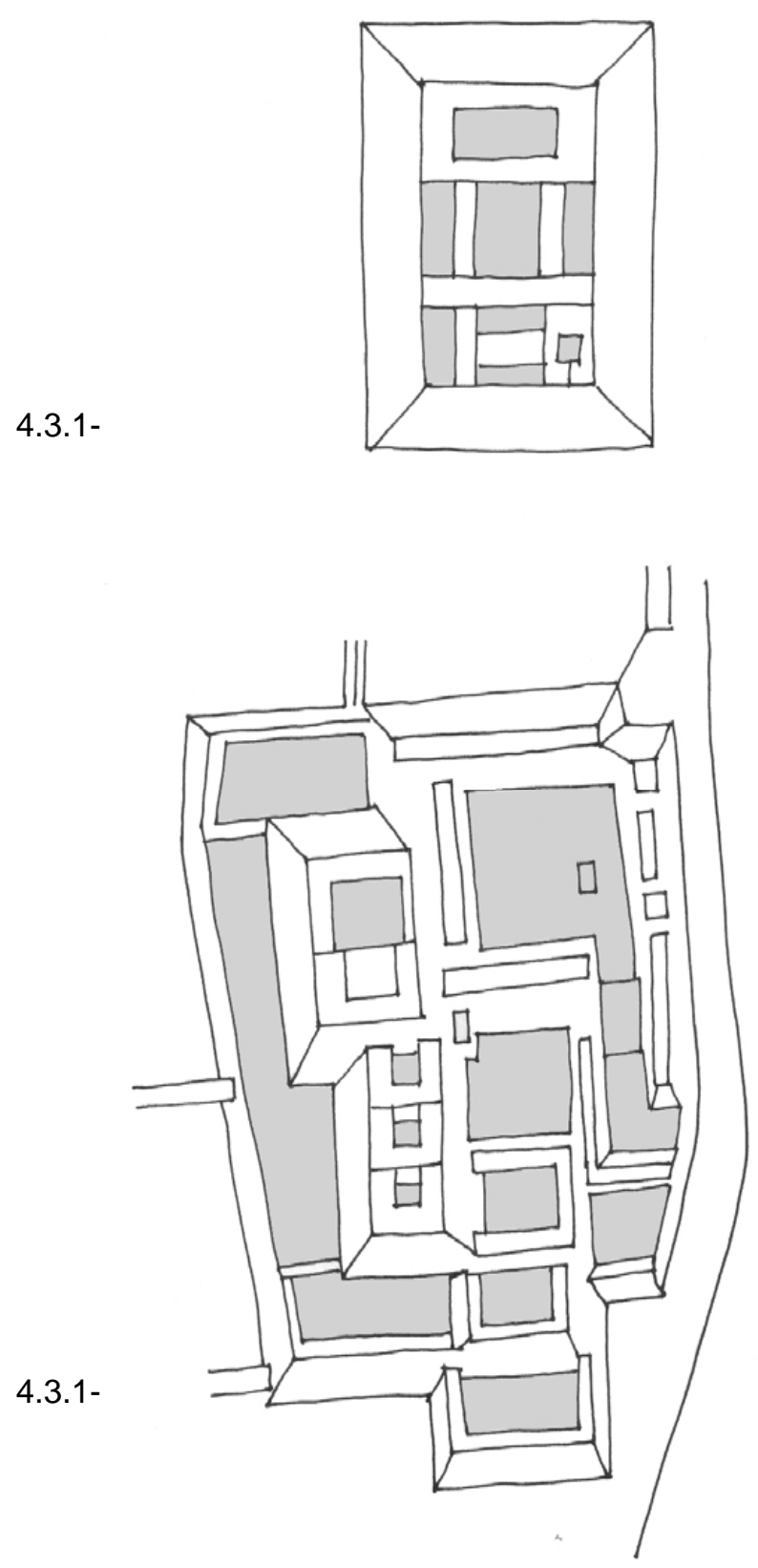

Fig. 13. Grupos de patios 


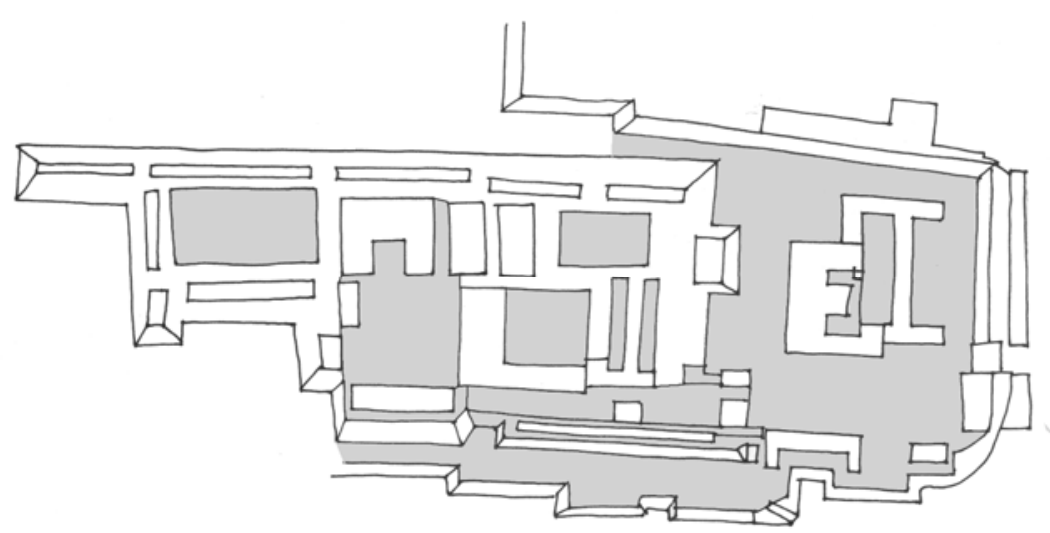

4.3.1-5

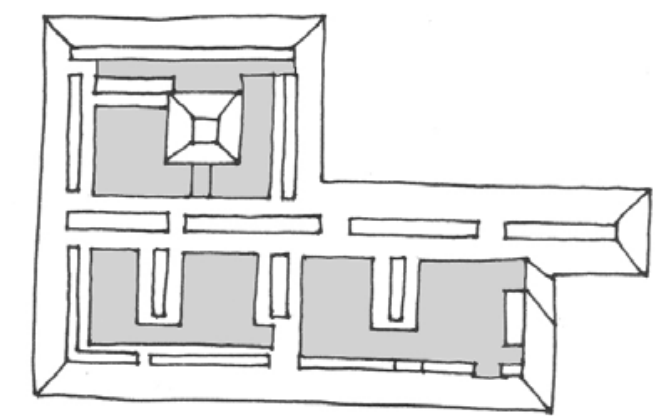

4.3.1-6

Fig. 13. Grupos de patios. 


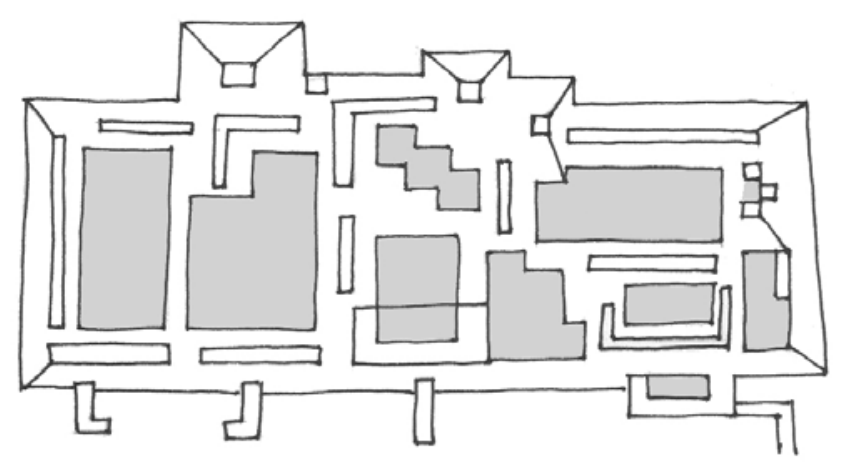

4.3.2-1

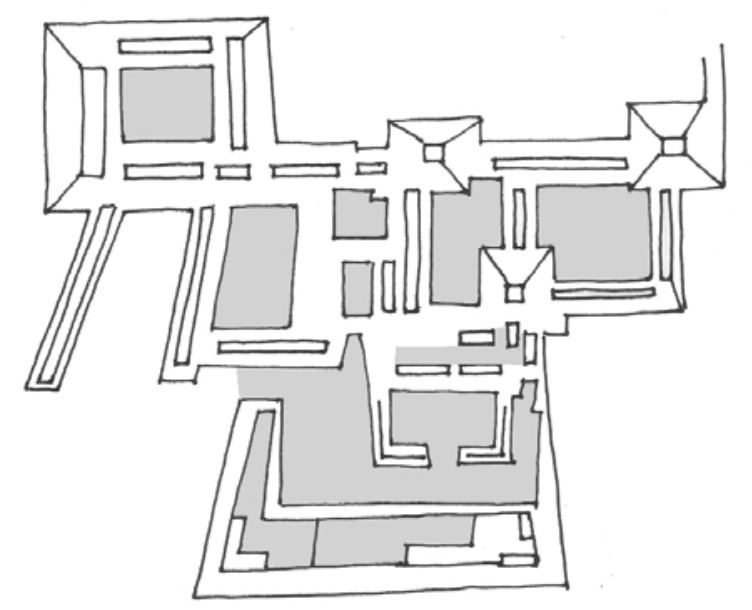

4.3.2-2

Fig. 13. Grupos de patios. 


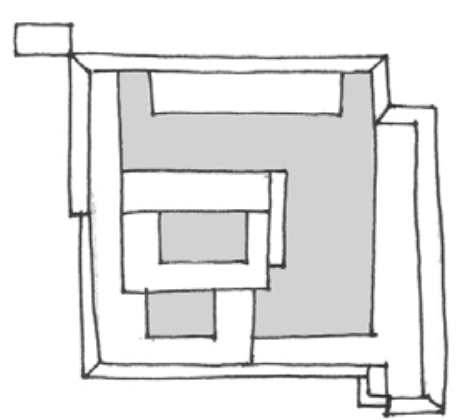

4.3.2-3

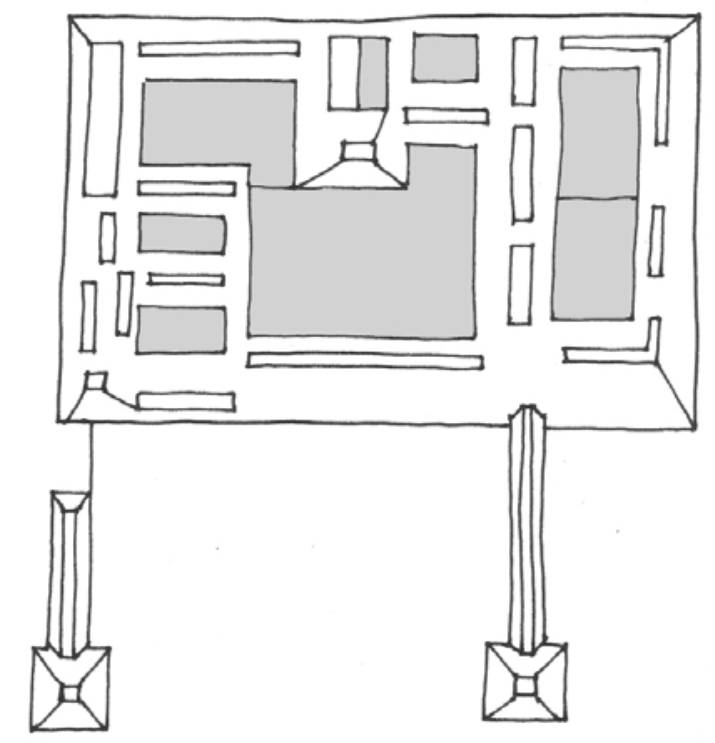

4.3.2-4

Fig. 13. Grupos de patios 

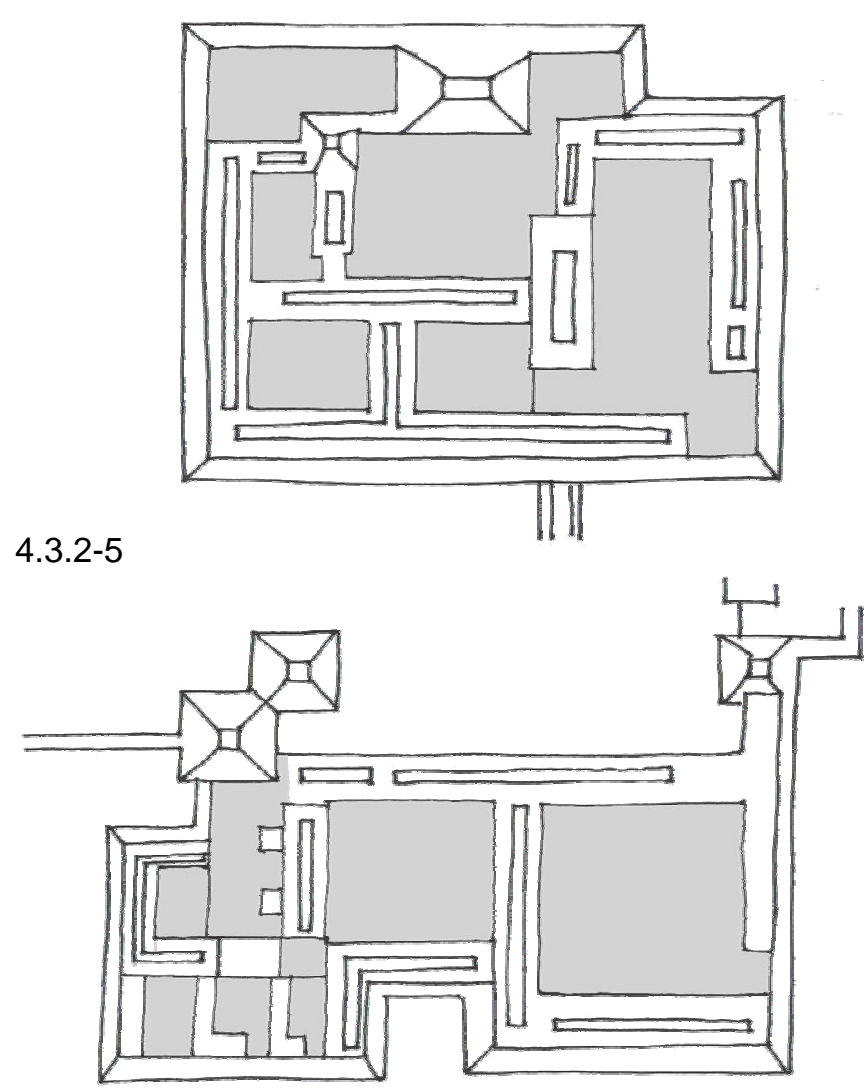

4.3.2-3-6

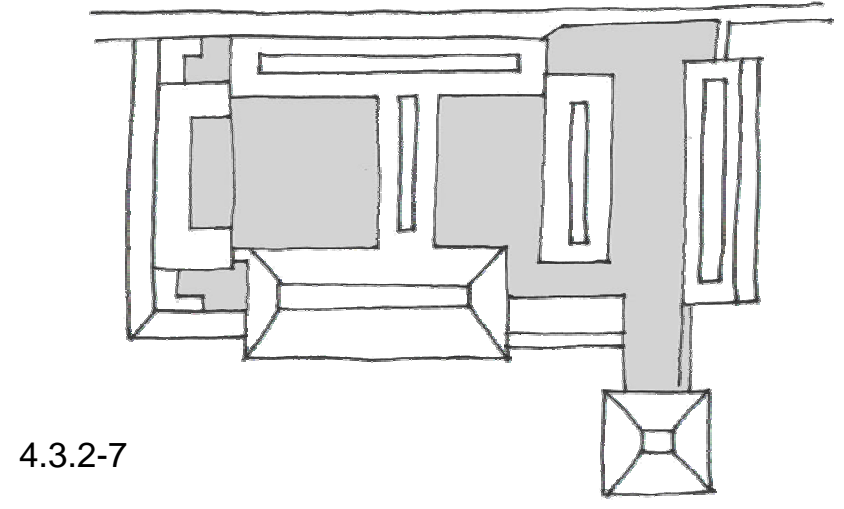

Fig. 13. Grupos de patios. 

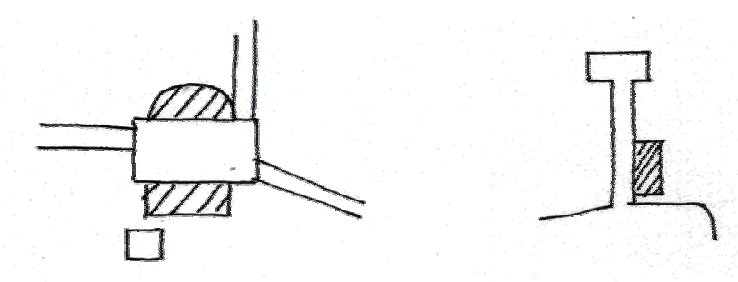

4.4.1
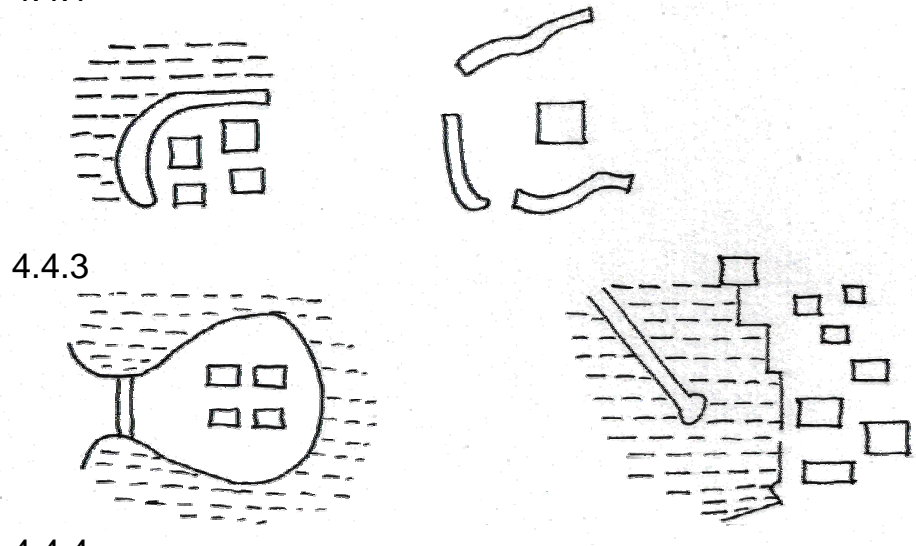

4.4.4

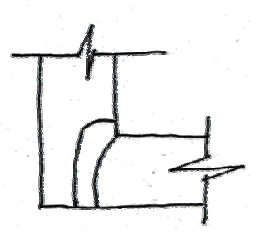

4.45
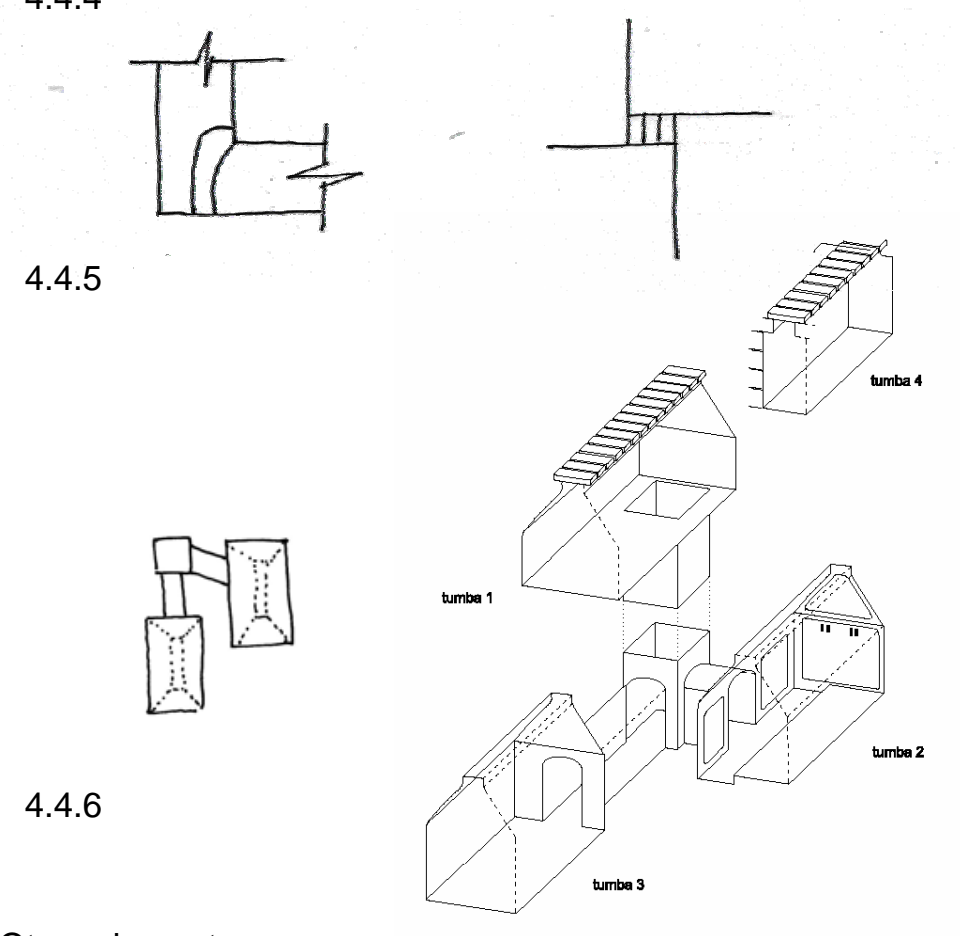

Fig. 14. Otros elementos 


\subsection{Consideraciones y relaciones}

En el caso del estudio de las relaciones planteadas por la Dra. Hohmann-Vogrin (apartado 2.4.2.2); en este trabajo solamente se esbozan algunos ejemplos percibidos en los recorridos de campo. Como se dijo anteriormente, el nivel de las excavaciones arqueológicas y la calidad de los planos de detalle son muy escasos y no permiten realizar este tipo de análisis compositivo. En la región del estudio, solo hay dos sectores de edificios con suficiente investigación, liberación de escombros y restauración para poder hacer un estudio de relaciones con ejes, mitades de edificios y otros indicadores mencionados por Hohmann-Vogrin. Los dos casos son la Acrópolis de Nakum y la Acrópolis Central de Tikal, con mas de 40 edificios investigados, liberados y restaurados.

En relación al lugar sagrado y a la superposición de capas de edificios unos sobre otros se logro establecer que fue una práctica constante en la región. Con interminables demandas de materiales y fuerza de trabajo para realizar eternos proyectos de revitalización urbana. Quizá esta región sea una de las zonas con mayor densidad constructiva en toda el área maya. Para los arquitectos mayas era común la superposición de edificios, uno sobre el otro empleando el efecto de "muñeca rusa". Al respecto Wolfgang W. Wurster menciona, "que los edificios son constituidos por grandes masas, con el tiempo estas masas sirvieron de base para otros edificios más grandes. Esto tiene la ventaja de tener una masa ya preparada para hacer un edificio más grande. Los elementos decorativos no son destruidos sino cubiertos cuidadosamente por el nuevo edificio, situación ideal para los arqueólogos. Como la muñeca rusa, que dentro de una hay otra y otra, esto conlleva a que generalmente el edificio más antiguo esté mejor conservado..." (Wurster 1992, 108). Los espacios sagrados son reforzados con nuevos edificios superponiendo 
construcciones y teniendo en mente la idea de tener a los antepasados presentes.

Este principio fue una práctica común durante todo el tiempo de ocupación prehispánica. Por ejemplo en la plaza principal de Topoxté se identificaron 10 estadios constructivos: Los primeros edificios datan del período Preclásico Medio (600-300 a.C.), el segundo y tercer estadio constructivo fue fechado para la época Protoclásica (200-300 d.C.), dos estadios más para el Clásico Temprano (350-650 d.C.), dos para el Clásico Tardío (650-800 d.C.), y las tres últimas fases de construcción pertenecen al Posclásico (1200-1450 d.C.) (Hermes, en Wurster 2000, 58-63). Similar proceso de superposiciones se han documentado en la Acrópolis Norte de Tikal, con 12 diferentes etapas constructivas (Coe 1990).

En Nakum se investigó en detalle el proceso evolutivo de los Edificios E y $\mathrm{N}$ de la Acrópolis (Hermes 2002, 277-285), y el Edificio 216 de Yaxhá (Hermes, Noriega y Calderón 1997, 261-268).

No necesariamente un grupo de edificios o un edifico debe de pasar por estos largos procesos de cambios constructivos. En Topoxté hay un ejemplo con el Edificio A, cercano a la plaza principal; aquí, por alguna razón que se desconoce, el proceso de crecimiento por superposición se para en el Clásico Tardío (séptimo estadio constructivo), Luego en el Posclásico la construcción de aproximadamente $17 \mathrm{~m}$ de alto no fue reutilizada y permaneció desmantelada por espacio de 600 años en medio de los cambios en las plazas y edificaciones vecinas (etapas 8 al 10). Otro ejemplo de un proceso constructivo que es abortado, es el Grupo $\mathrm{H}$ de Uaxactún, con edificios representativos monumentales con toda la parafernalia del Preclásico Tardío. Este grupo fue abandonado y sepultado 
alrededor del año 250 d.C. en el inicio del Clásico Temprano (Valdés, Fahsen y Escobedo 1999, 15-21).

En relación al principio de la arquitectura en servicio a la religión y a representaciones personales de los gobernantes y su grupo; Linda Schele dijo, "en la arquitectura se refleja la forma y el espacio de los elementos del cosmos con el objetivo de lograr un espacio sagrado en donde el pueblo, reyes y nobles tienen acceso a la terrible fuerza del más allá" (Schele 1992, 203). Al respecto, Wolfgang W. Wurster expresa "El hasta ahora esquema de los cuerpos constructivos de volumen y plazas que forman la arquitectura de los espacios exteriores, no sólo es un resultado estético sino una concepción de su universo y su principal significado es el equilibrio de las fuerzas naturales y sobrenaturales (buenas y malas) basados en complicados sistemas de ritos, simbolismos y dioses...." (Wurster 2000, 108). Al mismo tiempo estos edificios eran la representación física- símbolo material del poder de los gobernantes-semidioses. Los cuales toman posición en el tejido urbano y fueron utilizados como medios para demostrar su relación con los dioses y los poderes sobrenaturales.

Miguel Rivera Dorado enfatiza en que "la traza urbana y las formas de las ciudades mayas...obedecen al deseo de organizar el espacio con el propósito eminentemente escenografito que reforzara, mediante las representaciones ceremoniales, la identidad política-religiosa de las gentes" (Rivera Dorado 2007, 162), Mas adelante nos dice “...Y no solamente creo en la función teatral del espacio definido por el perímetro de las plazas o los patios sino que en la ciudad se pueden percibir innegables recorridos escenografitos que llevan por y entre los conjuntos arquitectónicos, Las fachadas de las construcciones son autenticas -portadas- que presentan el edificio y sugieren su 
importancia, su función y su significado, y por ende su adscripción social" ( Rivera Dorado 2007, 163).

La correspondencia entre edificios dominantes de las urbes es referenciada por ejes direccionales que marcan su relación especial. Por ejemplo en Naranjo se enfatiza en marcar el recorrido de una vía procesional, oeste-este hacia un edifico que simboliza la montaña sagrada (Templo Mayor del Grupo Triádico Este).

También son utilizadas las triangulaciones de puntos focales, como sucede en Naranjo, con la relación entre el Templo Mayor del Grupo Triádico Este, el palacio real de la Acrópolis Central y la Acrópolis Norte. En Tikal hay una correspondencia visual entre el palacio de la Acrópolis Sur (con vista panorámica de 360 grados) la Gran Plaza y el Templo IV. Por otro lado el efecto de cierre visual de un eje de la ciudad, con vías procesionales y edificios dominantes o simbólicos, es similar entre el Templo IV de Tikal y el grupo Triádico Este de Naranjo. En Yaxhá la triangulación de puntos focales se relaciona entre el templo pirámide de la Acrópolis Este, el edificio dominante del grupo triádico de la Acrópolis Norte y la pirámide aislada del grupo E.

En Nakum solo, el palacio principal (Edificio Y) de la Acrópolis Central es el punto verde (centro) con vista panorámica de 360 grados que domina todo el paisaje urbano a sus pies.

En cada apartado de los capítulos 3 y 4 se presentan las conclusiones para cada elemento de la composición arquitectónica. En términos generales, se identificaron diversas características locales tales como: 
- la definición de dos paisajes característicos para la región. Un paisaje común para la cuenca Mirador Ixcán, Holmul y área Tikal y otro para las cuencas del sector sur (Los Lagos y Mopán).

- Cada paisaje coincide con características de composición urbana, densidad de edificaciones y otros valores que permiten establecer sectores de influencia o alcance en cuanto a determinado tipo de composición arquitectónica. Por ejemplo: en la cuenca Ixcán no se han registrado los grupos $\mathrm{E}$.

- En las cuencas, área Tikal, Ixcán y Holmul es notorio el papel dominante de los grupos de patios monumentales del Clásico con múltiples variantes y combinaciones identificadas (Kinal, Chochkitam, La honradez, Xultún, Nakum, El Zotz y muchas mas) que imprimen en el tejido urbano un sentido de grandiosidad y poder del grupo elite.

- Una característica local es la larga tradición de emplear diferentes variantes de grupos triádicos (desde el Preclásico Tardío al Clásico Terminal) en las cuencas área Tikal, Ixcán, Mirador y Holmul.

- La identificación de elementos dominantes de edificios horizontales, con variantes y ejemplos en toda la muestra. Las diferentes combinaciones de edificios verticales y las distintas posibilidades de combinaciones entre edificios horizontales y verticales.

- Importante fue la identificación de nuevos tipos de elementos, anteriormente no reconocidos en la literatura, como los edificios aislados y peraltados y los salones con pórtico.

- También es significativa la identificación de las variantes locales para las calzadas, y las canchas para el juego de pelota, que juntos enriquecen el conocimiento de la composición arquitectónica en el noreste de Petén. 
Hace falta continuar con las investigaciones en este campo para establecer con mayor propiedad, los elementos locales de la composición arquitectónica del noreste de Petén. Además hace falta comparar estos resultados con las regiones vecinas. Sobre todo en el norte con: la cuenca de Calakmul, el Petén Campechano y el área vecina de Belice.

En esta investigación se planteo en un principio limitar el área al noreste de Petén y los 128 sitios de la muestra. Un futuro trabajo deberá realizar, con los resultados aquí presentados la investigación comparativa de una zona más extensa; que indudablemente darán respuestas que enriquecerán poco a poco el conocimiento de las tierras bajas mayas centrales. Los resultados presentados en esta investigación deben tomarse como una buena muestra de la calidad y cantidad del patrimonio maya construido en la región, que amerita continuar con el estudio sistemático de su composición urbana y sus elementos de arquitectura.

La metodología empleada, permite trabajar el tema de la "composición arquitectónica" en diferentes niveles. Este sistema pude ser utilizado, discutido y mejorado por otros estudios similares. También pretende mostrar un campo no explotado en Guatemala. Las escuelas de arquitectura y otras disciplinas académicas tienen en el tema del urbanismo y la arquitectura maya un rico campo por explorar, en donde también hay necesidad de nuevos aportes. 


\section{ELEMENTOS DE ARQUITECTURA}

El tercer nivel de análisis, se refiere al estudio de los elementos de arquitectura visible. En este capítulo nos referiremos al estudio de las superficies de los elementos sólidos. No se incluyen datos sobre la superficie de pisos y escalinatas ya que por lo general estos elementos se encuentran ocultos por el escombro o el humus acumulado sobre los edificios abandonados. En el cuadro 5 (elementos de arquitectura visible), se presentan los resultados de este nivel distribuidos en 13 variables y en la figura 15 se muestra, en forma esbozada, los elementos de arquitectura mas característicos del noreste de Petén.

\subsection{SUPERFICIE DE MUROS}

Los muros son definidos como elementos verticales que limitan el espacio. La superficie exterior forma parte de la fachada de las edificaciones y su cara es un rasgo especial de identificación de los elementos sólidos (barreras o focos visuales de la estructura urbana). La superficie de los muros exteriores por lo general es lisa con un acabado de estuco y pintura. Este recubrimiento se encuentra en la actualidad desprendido, dañado o totalmente desaparecido.

En el cuadro 5 se anotan los muros expuestos, identificando características como: aberturas de puertas y ventanas que atraviesan los muros, ventanas simuladas, y otros detalles. Para los muros interiores se anotan datos sobre: nichos y agujeros, dinteles y otros detalles visibles. A su vez se apuntan datos sobre el estado de conservación de las superficies visibles, información que es analizada en la tercera parte de este documento. 


\subsubsection{Muros exteriores}

Los muros exteriores mejor conservados y de mayor dimensión se encuentran en Tikal (Acrópolis Norte, Acrópolis Central, Palacio de los Murciélagos, Grupo Norte, Grupo G, Grupo Barringer); Kinal (Acrópolis); Naranjo (Acrópolis Central y Acrópolis Oeste); Chochkitam (grupo del Palacio); Nakum (Acrópolis, Edificio A, Edificio U); La Blanca (grupo de patios); Tzikintzakán (Edificio 1); Naachtún (Grupo E, Grupo triádico, Edificio XXXIX), y San Clemente (Patio Alto, Patio Bajo y Los Templos Pirámide Gemelos).

El muro posterior del palacio de Chochkitam es uno de los más grandes del área en estudio, y requiere urgente atención. En el Edificio XXXIX de Naachtún, son visibles dos caras de muro exterior con bloques de piedra formando diseño. Este tipo de acabado en los muros es atípico para el área de estudio.

Otros sitios con muros expuestos son, Yaxhá (Edificio 216), Corozal Torre (Edificio 1), Naranjito (Acrópolis Norte), Río Azul (Edifico A-1 y A2), San Máximo (Edificio 1), El Mirador (edificio 34 y el grupo La Danta), La Muerta (Edificios A1 y A2), San Bartolo (Edificio de las Pinturas y la Ventana), Las Ventanas (Edificio 1) y Nakbé (grupo códice)

Los sitios que presentan muros expuesto son, 42 (32.8\%). La mayor concentración se encuentra en el área Tikal (60\%) y las cuencas Mirador, Ixcán y Holmul (41.6\%, 40\% y 30\%). La menor exposición de muros está en las cuencas de Los Lagos y Mopán (17.1\% y 14.28\%).

Una característica de las fachadas en edificios verticales tipo templo pirámide son los remetimientos de los lienzos de muro. Viéndolos en planta, las entradas y salidas del muro coinciden con los muros 
interiores que separan en forma transversal las cámaras. En otros casos los muros laterales disminuyen rítmicamente, coincidiendo también con los cambios de los espacios interiores. La Acrópolis Norte de Tikal está llena de este tipo de tratamiento de muros laterales. Esta modalidad también se emplea en los llamados "templos mayores" de Tikal (Templo I, II, III, IV, V y VI). El juego de entradas y salidas de los muros de fachada, acentúan efectos de sombra y luz, y resalta un sentido de verticalidad en el edificio. Otros ejemplos de este tratamiento de fachadas se observan en Holmul, Chochkitam, La Honradez, Río Azul, El Zotz, Uaxactún y Naachtún. La fachada posterior del Edificio A-XVIII de Uaxactún es un ejemplo clásico del juego de entradas, salidas y agujeros en los muros.

Ejemplos tempranos de este tratamiento en los muros exteriores fueron identificados por Juan Antonio Valdés (1992, 16-31) en Uaxactún en edificios del Preclásico Tardío (Edificio H Sub.-2, H Sub.4 y 5). Es notorio que este juego de entradas y salidas de muros laterales en las fachadas de los edificios no es común en Yaxhá y Nakum.

En Nakum, el Edificio $N$ tiene en sus esquinas unas pequeñas salientes que simulan pilares. El Edificio $X$ en el sector norte, es el único edificio visible que presenta entradas y salidas en su fachada lateral.

Los paramentos de muros interiores también tienen un recubrimiento con aplanados a base de cal y pintura. Algunas paredes tienen además otras aplicaciones tipo pinturas murales como en San Bartolo, La Sufricaya, ó como la tuvo el Edifico B-XIII de Uaxactún. Hay que aclarar que las famosas pinturas de San Bartolo no se ubican en la superficie vertical del muro interior sino se encuentran en 
el paramento del techo. En otras paredes interiores se aplican franjas de colores naranja, amarillo ó rojo (Chochkitam, Chilonché, PerúHolmul, El Encanto). Otros muros interiores son completamente pintados de color como el negro, rojo o crema (Nakum, Tikal).

Otro elemento que se emplea en los paramentos, con mayor frecuencia en los muros interiores de los edificios, son los grafitos o incisiones en los muros, bancas y pisos. Para mayor información sobre el tema de grafitos se puede consultar para Tikal: las obras de Trik y Kampen (1983), Orrego y Larios (1983); para Nakum: Tozzer (1913, 162), y Hermes et al. (2002b, 123-132); sobre La Blanca las publicaciones de Muñoz Cosme y Vidal Lorenzo (2005, 2006); y Uaxactún (Ricketson y Ricketson 1937).

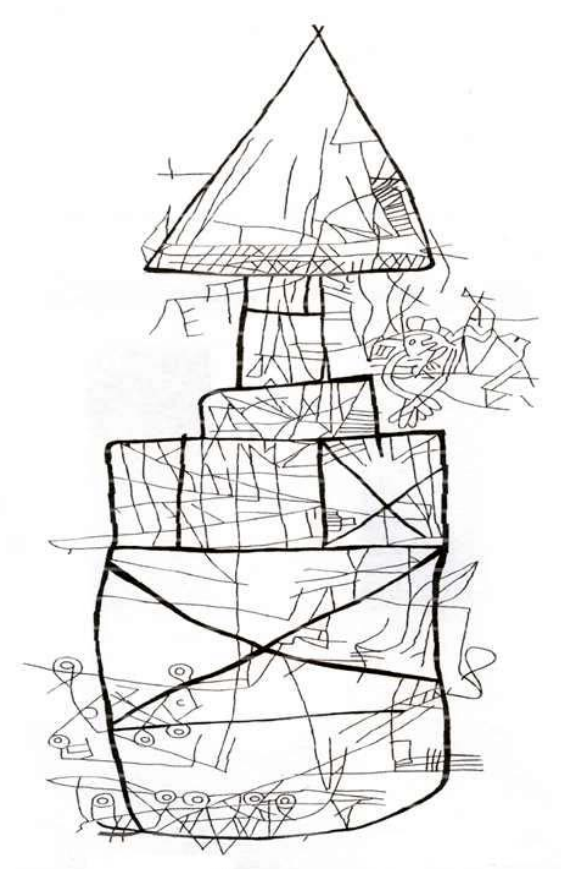

Fig. 15. Grafito en pared del Edificio Y, Acrópolis Central, Nakum 
La superficie de los muros tiene diferentes elementos como aberturas en muros (puertas, ventanas, perforaciones menores), remetimientos, molduras, cornisas y proporciones que identifican una particularidad local.

\subsubsection{Puertas}

Los muros tienen aberturas o "puertas" (vanos) para permitir el acceso al espacio interior. La mayoría de los ingresos a las edificaciones ha sido destruida por el tiempo. Aquí influye el sistema constructivo empleado (en la mayoría de los casos madera dura) para solucionar estructuralmente las aberturas en los muros. Solamente escasos ejemplos de accesos con dinteles originales de madera se conservan en Tikal (Templo V, Acrópolis Central), Nakum (Edificio X), Tzikintzakán (Edificio 1), La Honradez (grupo triádico) y Chochkitam (Edificio XV). En los últimos dos sitios en avanzado deterioro. En el Edificio XV de Chochkitam, el dintel de madera original ya no tiene posibilidades de cumplir su función estructural, pues sólo queda una pequeña cáscara de pocos milímetros de espesor.

Juan Antonio Valdés hace referencia a la importancia de las aberturas de las puertas. Valdés separa un tipo de edificios alargados con un basamento de poca altura llamado "Palacios Escénicos" o "Palacios de Representación" (Valdés 2000, 22-23). La característica de estos edificios es el ancho de la puerta. Este es de mayor dimensión para permitir ver el espacio interior. Estas aberturas se colocan al centro del edificio, en el espacio interior hay una banca o trono en donde el personaje principal, sentado sobre la banca, puede observar y ser observado por las personas que se congregan frente al edificio. Ejemplos de este tipo constructivo se tienen en San Clemente 
(Edificio I, Edificio II y III), en Tikal el Edificio 5D-49, y La Blanca (Edificio 6J1).

En San Clemente el promedio del ancho de los vanos de los edificios I y || es de 2.07 y $2.21 \mathrm{~m}$, y sus accesos laterales (dos) miden un promedio de $1.68 \mathrm{~m}$ cada uno. El Edificio III, con 21 accesos; el vano central tiene una dimensión mayor $(2.17 \mathrm{~m})$ a las puertas laterales (1.16 m); además, en la pared opuesta al acceso principal existe una banca.

Es común que las fachadas de los edificios tengan el acceso central más grande. Ejemplos en Nakum: Edificio D, el acceso central mide $2.33 \mathrm{~m}$ y es un pasillo hacia el Patio 1, las puertas laterales tienen un promedio de 1.29 a 1.69 m; en el Edificio $\mathrm{N}$, el acceso central tiene $2.48 \mathrm{~m}$, los accesos laterales $1.02 \mathrm{~m}$ cada uno. El Edificio $\mathrm{A}$, al centro mide 2.04 y los lados $1.70 \mathrm{~m}$ cada uno. En Yaxhá el Edificio 218, el acceso central mide $2.33 \mathrm{~m}$, los accesos laterales miden entre $1.00 \mathrm{a}$ $1.43 \mathrm{~m}$ de ancho; en el Edificio 216 el acceso central mide $2.40 \mathrm{~m}$ y los laterales $1.00 \mathrm{~m}$.

En La Blanca los accesos del Edificio 6J2, miden en promedio 1.70 $\mathrm{m}$; solo en la cámara 3 , que es el pasillo monumental al patio norte, el acceso mide $2.97 \mathrm{~m}$ de ancho. En las modificaciones posteriores, este pasillo fue clausurado.

En Tzikintazkan la entrada central de la segunda cámara del edificio mide $2.40 \mathrm{~m}$ y en Holmul el Edificio A del Grupo I mide 2.80 m. En Tikal los acceso de la Acrópolis Central, tienen un promedio $1.00 \mathrm{~m}$; pero en los Templos Mayores son mayores, Templo III 3.00 m; Templo IV $2.40 \mathrm{~m}$ y los templo I, V y II $2.00 \mathrm{~m}$ cada uno. 
El promedio general de los anchos de puertas en la región es de 1.00 $\mathrm{m}$ a $1.60 \mathrm{~m}$ y el grueso de los muros de fachada de $1.00 \mathrm{~m}$ a $1.50 \mathrm{~m}$.

Similar condición ocurre en los edificios del periodo Posclásico; en Topoxté en el Edificio $C$, el acceso central y los dos accesos laterales miden $1.00 \mathrm{~m}$ cada uno. Tres entradas iguales $(1.00 \mathrm{~m})$ tienen los dos edificios $\mathrm{G}$ y $\mathrm{E}$; el Edificio $\mathrm{D}$ tiene al centro $4.50 \mathrm{~m}$ de ancho y los accesos laterales miden $0.80 \mathrm{~m}$ cada uno. En este caso el acceso central debió tener elementos verticales intermedios (de madera) para cubrir esta abertura.

En la muestra 28 sitios tienen evidencia de accesos (21.8\%). El área Tikal, Ixcán y Holmul tienen el mayor índice con (46.6\% y 33.3\%) (25\%); y la menor presencia se encuentra en las cuencas Los Lagos y Mopán (8.5\% y 9.5\%).

\subsubsection{Ventanas}

Un caso particular de aberturas en los muros son las ventanas. Este elemento atraviesa todo el muro. La parte estructural es resuelta como si fuera una puerta, es decir con piezas de madera o piedra en la parte superior de la abertura. Ejemplos pueden verse en varios edificios de Tikal (5D-65, 5D63, 5D-49, 5C-13 y otros). En el Edificio A XVIII de Uaxactún, hay un orificio parecido a una ventana en un espacio interior. El Edificio $\mathrm{C}$ de Topoxté tiene una versión del Posclásico para aberturas en muros (Wurster 2000, 296-310).

Una variante local es la ventana redonda de Nakum. En este caso, simplemente se cavó un agujero en el muro y luego se acondicionó el espacio vacío con recubrimiento de estuco y pintura (Edifico $\mathrm{N}$, Cámara 3). 
En la muestra cuatro sitios reportan ventanas (3.12\%); la mayoría de ejemplos se encuentran en el área Tikal.

\subsubsection{Ventanas simuladas}

Una característica especial de las fachadas son las "ventanas simuladas" que se colocan en los muros laterales y a veces en el muro trasero de los edificios. Estas ventanas simuladas consisten en rectángulos tallados en el muro, sin atravesarlo, más largos que altos que simulan una abertura o ventana. Generalmente en los recuadros laterales, una incisión más profunda en el muro realza el efecto de sombra de este elemento. Hay que aclarar que en algunos edificios este detalle se encuentra a nivel del muro del techo (Edificio Merwin de Holmul, Edificio A-2 de Río Azul). Ejemplos de ventanas simuladas se encuentran en ocho sitios documentados (6.2\%): Tikal, El Zotz, Uaxactún, Naachtún, Holmul, Río Azul, La Honradez y Chochkitam

Por el momento no se ha identificado este tipo de elemento en sitios de la cuenca de Los Lagos y la cuenca Mopán. Quizá sea éste un indicador de un límite específico en los detalles constructivos del área en estudio, o simplemente una falta de investigación arqueológica en estos sectores.

\subsubsection{Perforaciones}

Los muros pueden tener otro tipo de aberturas menores como agujeros o perforaciones de aproximadamente $0.10 \mathrm{~m}$ por $0.10 \mathrm{~m}$ que atraviesan todo el grueso del muro. Aparecen en algunos lienzos de muro colocados rítmicamente; unos abajo, a nivel del piso interior y que podrían funcionar como desagüe; otros se ubican a una altura media del muro, que podrían servir de ventilación; y otros cerca de la parte final del muro vertical, que también podrían funcionar como ventilación. Otra posible utilización, sería para fijar andamios de 
madera que se armaban periódicamente para dar mantenimiento a las superficies (reparación de estucos, pintura y otros). Ejemplos de edificios con muros con perforaciones se encuentran en Yaxhá (Edificio 216), Tikal (edificios en la Acrópolis Norte y Central, Los templos Mayores), Chochkitam (Edificio XV), Uaxactún (Edificio A$\mathrm{XVIII).} \mathrm{Este} \mathrm{tipo} \mathrm{de} \mathrm{detalle} \mathrm{no} \mathrm{es} \mathrm{común} \mathrm{en} \mathrm{los} \mathrm{edificios} \mathrm{de} \mathrm{Nakum.}$

Un caso especial de perforaciones en las paredes exteriores de Tikal, es una fila de agujeros pequeños de $0.05 \mathrm{~m}$ de diámetro y $0.50 \mathrm{~m}$ de profundidad; la fila de agujeros esta debajo de la cornisa superior del muro y al centro de la fachada sobre el acceso principal de los edificios: Palacio Maler y Templo V. Al parecer estos orificios en hilera (en el Templo $V$ con 28 perforaciones) servían para introducir una estructura perecedera que sirvió de base para una cubierta, a manera de toldo ó para sujetar un adorno temporal.

\subsubsection{Nichos}

Los muros interiores en ocasiones tienen espacios remetidos rectangulares llamados nichos, que no atraviesan todo el muro. Estos nichos pudieron servir para colocar o guardar objetos. Hay cámaras que tienen hasta tres nichos, uno en cada lado del paramento interior, (Edificio VII de San Clemente). También hay paredes con nichos y manos pintadas de rojo a ambos lados del agujero (Edificio VII de San Clemente). La cámara 3 del edificio 6J-1 de La Blanca tiene dos nichos en su pared norte y sur. Otros ejemplos se encuentran en Tikal (varios edificios de la Acrópolis Central), Holmul, Tzikintzakán, Nakum y otros. Ejemplos de perforaciones y nichos en muros Posclásicos fueron documentados por Wolfgang $\mathrm{W}$. Wurster en Topoxté (Wurster 2000, 296-310). 


\subsubsection{Otras perforaciones}

Hay otro tipo de perforaciones, de aproximadamente $0.10 \mathrm{~m}$ por 0.10 $\mathrm{m}$ que no atraviesan el muro, ubicados en diferentes partes de los paramentos. Algunos de ellos tienen señales de desgaste en los muros, seguramente por el uso constante de los mismos. Se supone que en ellos se introducen elementos de madera para formar un tipo de estructura (mobiliario). Otros agujeros cercanos a las puertas, tuvieron que ver con el sistema de cerramiento interior o exterior de las cámaras. Hasso Hohmann ha estudiado estos agujeros y presenta varios posibles usos (Hohmann 1998, 143). Un detalle de agujeros y perforaciones en los muros del Edificio 216 de Yaxhá fueron documentados por Hermes, Noriega y Calderón (Hermes et al. 1997, 271-273)

\subsubsection{Aberturas excavadas}

En Nakum hay varios ejemplos de abrir espacios en los muros; similar a lo mencionado para la ventana circular de Nakum (acápite 5.1.3). Un ejemplo se encuentra en la pared intermedia (entre dos cámaras) del Edificio A. Al parecer el muro fue vaciado para contar con más espacio útil. Para lograrlo, tallaron el muro sin preocuparse de insertar elementos estructurales para la transmisión de esfuerzos al suelo. Es decir, no se le colocaron vigas de madera, sino que excavaron el muro, dándole forma de medio arco. Se confió todo el esfuerzo estructural a la masa cementante del relleno. Luego de abierto el agujero se aplicó una capa de repello y pintura.

Igual solución se utilizó en el Edificio Y. Este edificio está formado por ocho cámaras (tres espacios con acceso sur, tres espacios con acceso al norte y dos cámaras en los extremos este y oeste); En algún momento se decidió remodelar el uso interno del edificio y 
hacer una comunicación entre las cámaras intermedias de la fachada longitudinal; la solución fue abrir en el muro de carga intermedio un pasillo cavado en la pared con una forma de medio arco; otra vez, sin elementos estructurales adicionales, sólo se confió en la calidad de la masa cementante monolítica del relleno.

Otra muestra de una abertura cavada en el muro y con forma de medio arco se encuentra en el palacio de El Danto, al noreste de Nakum. Algo parecido sucede en una puerta abierta posteriormente en el Edificio $\mathrm{N}$ de Nakum (cámara 2), y en el Edificio A-XVIII de Uaxactún (puerta cavada en muro tabique en la segunda cámara).

\subsection{BANCAS Y ESCALINATAS}

Construcciones de mampostería fija que se incorporan en los sistemas de espacios interiores. Otro tipo de bienes muebles no fijos, que debieron existir en estos espacios interiores, han desaparecido.

\subsubsection{Bancas}

Los muros interiores sirven también para limitar bancas de mampostería y escalinatas interiores. Las bancas macizas son construidas principalmente en los grupos de edificios horizontales (tipo palacio) y tienen múltiples tamaños. Los hay de forma rectangular, en forma de "L" $y$ " $U$ ".

En otros casos ocupan todo el espacio interior. Ejemplos de esta última variante se encuentran en el Edificio 6J1 de La Blanca. En Nakum, en el Edificio Q sucede lo mismo en una cámara; también con escalones de acceso. Otras bancas que cubren todo el espacio interior, se encuentran en el Edificio $\mathrm{N}$ de Nakum (una en el edificio sur del grupo triádico, segundo piso y dos cámaras laterales del primer piso). 
Telma Tobar en su análisis espacial de la Acrópolis de Nakum registró 41 bancas. La autora considera que por lo menos deberían de aparecer otras 16 bancas en el resto de las construcciones no investigadas de la Acrópolis (Tobar 2006, 225-325).

Estos elementos también son llamados tronos y algunos tienen uno o dos brazos laterales en los extremos de las bancas. En ocasiones cerca de la banca, en las paredes hay nichos (Edificio IV de San Clemente, Palacio Maler de la Acrópolis Central de Tikal). Las bancas más espectaculares en el área del estudio aparecieron recientemente en las excavaciones de La Blanca. Estas bancas tienen una dimensión máxima de $6.70 \mathrm{~m}$ de largo por $2.10 \mathrm{~m}$ de ancho en el Edificio 6J2, cámaras 1, 2, y 4 (Muñoz Cosme y Vidal Lorenzo 2006).

Las bancas cambian de posición conforme al uso de los espacios interiores. En Nakum hay evidencia de modificaciones de bancas en los edificios $F$ e $Y$. En el Edificio $F$, en un periodo constructivo se cambio el acceso del Edificio $F$ (se cerro la puerta del Patio 13 y se abrió una en el Patio 2). En la pared interior, frente al vano con la puerta sellada (fachada norte), se construyó una banca. El otro ejemplo es en el Edificio $\mathrm{Y}$; justo con las remodelaciones del pasillo cavado en el muro intermedio del edificio, dos bancas laterales de la cámara central (norte) fueron demolidas.

Evidencia de bancas hay desde el Clásico Temprano, aproximadamente en el año 450 d.C. (Valdés 2000, 20). Su uso se prolonga hasta el Posclásico (1450 d.C.); en los espacios interiores de los edificios E y G de Topoxté (Wurster 2000, 296-310).

En 16 sitios hay presencia de bancas y nichos (12.5\%) la mayor incidencia se encuentra en el área Tikal. Los datos de este elemento 
son relativos pues la mayoría de ejemplos son de Tikal, sitio arqueológico con mayor intensidad de investigación arqueológica y restauración; condición que no sucede en los otros sitios arqueológicos de la muestra.

\subsubsection{Escalinatas interiores}

Hasta ahora sólo se conocen seis ejemplos de escalinatas interiores: en Tikal en el palacio 5D-46; en Uaxactún en el Edificio A-XVIII; en San Clemente en el Edificio IV y una escalinata de menor dimensión en el interior del Edificio $\mathrm{N}$ de Nakum (en el pasillo entre las cámaras 2 y 3). Otra escalinata en el interior del palacio de Chilonché y un extraño caso dentro de un saqueo en Susto Mirador (Quintana 2004, 104). Seguramente el registro de escalinatas interiores aumentará con las investigaciones en otras edificaciones del tipo edificios alargados.

Escalinatas exteriores que ascienden a los techos o niveles superiores de los edificios horizontales, pueden observarse en: Tikal (Palacio Maler, Palacio de las Ventanas, Edificio 5D-52 de la Acrópolis Central), en Nakum en los Edificios $\mathrm{D}$ y $\mathrm{H}$.

Aparte de las escalinatas exteriores, mencionadas arriba; otros elementos de comunicación vertical sirven para acceder a las plataformas individuales de las edificaciones horizontales. Estas pueden ser un simple escalón o sistemas de escalinatas en diferentes diseños. Por ejemplo con dado central, con o sin alfardas, remetida o adosada. En los sistemas de plataformas escalonadas, con escalinatas representativas, incluso con bloques de piedra tallada con figuras (Naranjo y San Clemente) o paneles esculpidos asociados (Edificio $G$ de Nakum). Además hay escalinatas secundarias o de mantenimiento (en Tikal, Templo I, II, 5C-54). 
Para ordenar nuestro registro de elementos de arquitectura hemos dividido el techo en tres partes: una para el paramento exterior, otra para el paramento interior y la tercera para las construcciones encima del mismo techo.

\subsubsection{Paramento exterior}

Por techo exterior, entendemos la porción del muro que continúa a partir de una cornisa en saledizo que limita y separa el paramento vertical del muro y el techo. Esta cara expuesta está generalmente limitada arriba y abajo por cornisas salidas a manera de bandas horizontales. En ocasiones la banda superior no aparece; el espacio entre las dos bandas puede estar ligeramente inclinado para adentro o continuar vertical. El alto de este elemento del techo, también llamado friso, depende de qué tan peraltada sea la bóveda interior.

En el muro exterior del techo se concentra la mayor aplicación de ornamentos y símbolos de los edificios, a veces con diseños en alto relieve por todo el paramento del techo. Otros techos tienen figuras completas como los frisos del Edificio $\mathrm{N}$ de Nakum (un panel con un ave, y otro con un cocodrilo, un ave y un pez). En otros casos se representan caras de "monstruos". Estos mascarones por lo general son figuras frontales sin quijada, puestos sobre los vanos de los accesos. En otros casos, se colocan en las esquinas y sobre ellos figuras humanas sentadas. Ejemplos de ellos en, Torre Corozal (Edificio 1), Nakum (Edificio E, anterior), y en El Pital (Edificio I Sub. I). Según Juan Antonio Valdés, el primer registro de un friso con escultura modelada en estuco aparece en el muro posterior del Edificio H Sub.2 del periodo Preclásico Tardío de Uaxactún (Valdés 1992, 23). 
En las fachadas de los edificios del periodo Clásico, la constante local son muros verticales lisos, estucados y pintados sin decoración y techos con abundante arte aplicado. En este sector de la fachada se aplican figuras en estuco modelado o mascarones que marcan los accesos o esquinas de los edificios.

Prevalece, en la parte de los muros verticales de la fachada, el paramento macizo en relación a pocas aberturas (puertas); estos paramentos macizos, como vimos anteriormente, en las fachadas laterales y posteriores pueden tener remetimientos de muros, formando entradas y salidas que también se marcan en la zona del techo (ver figura 15).

\subsubsection{Paramento interior}

Los paramentos interiores del techo son realizados por dos muros en saledizo formando bóvedas de aproximación. De este tipo de techo hay, dependiendo del periodo constructivo en el Clásico, varias formas constructivas. Un elemento especial del techo es la bóveda de cuatro lados. Este tipo se emplea en áreas en donde se requiere más espacio interior, como el baño de vapor de Nakum. Una versión de techo de cuatro lados "simulados" se emplea como solución de esquinas en intersecciones de edificios como en La Blanca, Naranjito y Holmul.

En la publicación "Ciudades Mayas del noreste de Petén", se presentó un registro de 24 diferentes secciones de bóvedas (Quintana y Wurster 2001, 156-157). En el año 2006 Luis Guardado documentó 24 tipos de bóveda en el Sector Sur de Nakum (Guardado 2006, 332-458). En estos catálogos se muestra la gran variedad de soluciones locales. 
Algunas bóvedas conservan pintura en sus paramentos, como la ya mencionada de San Bartolo. En los restos de bóveda de San Clemente (Edificios I y II) se encontraron manos pintadas de rojo (negativo y positivo) similares a las de Tikal.

En la muestra hay 42 sitios con evidencia de paramentos interiores (32.8\%). La mayor concentración se encuentra en las cuencas Ixcán, Tikal y Holmul $(53.3 \%, 41.6 \%$ y $33.3 \%)$. Hay que precisar que el cuadro 5, relaciona sitios con evidencia de techos (bóvedas); lo cual es muy diferente a comparar cantidad de paramentos interiores en cada sitio. En este último caso Tikal y Nakum son los principales representantes de este elemento.

\subsubsection{Pasadores de madera}

Los pasadores de madera son elementos que fueron empleados en el proceso de levantado de los techos; éstos quedaron posteriormente ahogados en los muros e integrados como elemento del espacio interior. Pudieron ser usados como accesorio para colgar objetos o como tarimas. Además entre los pasadores de madera se pueden colocar tablones temporales para realizar reparaciones del estuco o pintura del techo. Puede haber varias posibilidades: pasadores en parejas, aislados, a diferentes alturas, tallados con decoración. En otros casos, por requerimientos especiales, no se emplearon pasadores de madera, como sucede en la bóveda del Baño de Vapor de Nakum. Aquí se debió contar con una tarima o formaleta de madera para armar la bóveda de cuatro lados del techo.

Pasadores originales se conservan en: Tikal, Nakum, Kinal, Witzná, Naranjo. 
Las cresterías son construcciones adicionales sobre el techo. Por ejemplo en Tikal llegan a alcanzar $12.30 \mathrm{~m}$ de altura (Templo V). Sobre el Edificio A en Nakum se levantan tres torres de $4.60 \mathrm{~m}$ de alto. Un caso especial es la crestería del Edificio I de La Muralla, formada por nueve torres unidas por ocho espacios vacíos o pasadores de aire de $17 \mathrm{~m}$ de largo y $5 \mathrm{~m}$ de alto. Las torres están decoradas con escultura en alto relieve que incluye figuras humanas; en muy mal estado de conservación (Quintana y Wurster 2001, 3233).

Otro ejemplo de crestería se encuentra en el Edificio A-2 de Río Azul. Esta torre tiene espacios para ingresar al interior, mide $5 \mathrm{~m}$ de largo y $5 \mathrm{~m}$ de alto. En la fachada tiene una especie de balcón, quizá para poner estandartes o dar "efectos especiales" como humo o sonidos producidos en el interior de la crestería (Quintana y Wurster 2001, 6263). Un caso similar se estudio en la Plaza de Los Siete Templos de Tikal. En el techo del Edificio 5D-91; se encuentra una crestería particular formada por cinco espacios interiores abovedados (con cuatro ventanas o pasadores de aire cada uno, pequeñas puertas laterales y 10 máscaras de $2 \mathrm{~m}$ de alto); estos espacios interiores, se pudieron haber usado como cajas de resonancia o incensarios gigantes (Oswaldo Gómez, comunicación personal 2006).

Un caso difícil de aclarar, es el segundo nivel del Edificio $Y$ de Nakum; sobre el primer nivel se construyó un espacio interior de 2.50 $\mathrm{m}$ de ancho por el largo del edificio. Este espacio tiene una sola puerta en el eje longitudinal (fachada norte) y una banca colocada frente al acceso. No hay ningún indicio de escalinatas de piedra para subir a este espacio. Este edificio es diferente a los palacios con dos niveles del Clásico Temprano y el Clásico Tardío (A-XVIII de 
Uaxactún y la Acrópolis Central de Tikal). Es posible que este nivel sobre el Edificio $Y$ sea una especie de reminiscencia de los palacios de dos niveles de épocas anteriores. Por lo tanto el Edificio $Y$, como el palacio principal de la ciudad, tiene un segundo nivel; pero con uso muy restringido y mas empleado como remate monumental (crestería) del palacio Clásico Terminal mas importante. Algo similar podría suceder con el supuesto segundo nivel del Edificio G, de la misma Acrópolis de Nakum. Fuera del área del estudio en Yaxchilán, hay edificios que tienen simulados en los paramentos del techo puertas, para dar una impresión de dos niveles.

Un caso particular de crestería integrada al espacio interior, se encuentra en edificios de La Honradez (Edificio VII) y Chochkitam (Edificio XV). En estos casos, en la fachada exterior, parece que el techo y la torre conservan los mismos parámetros de definición del espacio; pero en el interior no hay separación entre el espacio del muro vertical, el techo y la crestería. Todos conforman un sólo elemento que se prolonga desde el arranque del piso de la cámara hasta el final de la crestería. De esta forma la cámara del Grupo de Tres Torres de La Honradez tiene más de $8 \mathrm{~m}$ de altura (Quintana y Wurster 2001, 72-75).

En otros edificios sólo quedan los arranques de crestería, entre ellos están: El Edificio E de Nakum, el Edificio I de Tzikintzakán, los Edificios II y VI de Xultún, el Edificios 216 de Yaxhá, Edificios I de El Zotz , un edificio en El Susto, y otro en el Susto Mirador.

En las cresterías se concentra la ornamentación de los edificios. Éstas, junto con los juegos de espacios vacíos entre las torres y los pasadores de aire forman un elemento dominante en las fachadas de los edificios. En ocasiones además de figuras humanas y máscaras 
de monstruos se incluyen textos, como en la parte trasera de la crestería del Templo VI de Tikal, o en los muros laterales del Edificio A- 2 de Río Azul.

En 12 sitios hay ornamentación en los techos (9.37\%) y 17 sitios tiene evidencia de crestería (13.2\%). En este elemento también las ciudades de Tikal y Nakum, por contar con mayor arquitectura expuesta documentada, tienen la mayor densidad. La cuenca Ixcán tiene el mayor índice de cresterías. Las cuencas de Los Lagos y Mopán (5.7\%) y (4.7\%).

La cuantificación y comparaciones por sitio y cuenca de este capitulo esta presentada en el cuadro 5. Como se aclara en el texto, los indicadores de arquitectura visible son muy relativos, por la condición actual de los sitios arqueológicos (no investigados, en escombros, humus, vegetación). Sin embargo se ha identificado, por ejemplo en Naachtún un paramento atípico para el área del estudio, se han reconocido mas de 24 diferentes formas de bóvedas.

Como determinante para la arquitectura del periodo Clásica, son las fachadas con paredes lisas y techos con abundante decoración; también predomina la composición de las fachadas con más espacio de muros y pocos accesos y la preferencia de marcar el acceso central. Otra particularidad es el tratamiento de los muros laterales y traseros con remetimientos y ventanas simuladas.

Una peculiaridad de la zona son los diferentes tipos de cresterías tanto en edificios horizontales como verticales, con diferentes soluciones y posible uso adicional para "efectos especiales". Para el Preclásico, con edificios sin techos de piedra, la escultura aplicada, los elementos focales y de información, en la arquitectura se 
colocaron en las plataformas escalonadas (grandes mascarones). Ya se menciono que en esta parte de las construcciones, se incorporan diferentes tipos de soluciones en las esquinas y otros detalles como bandas o remetimientos horizontales, que luego siguen aplicándose y modificándose en los siguientes periodos culturales, como una tradición local. Sobre las superficies de los elementos (espacios libres y elementos sólidos) de éste nivel 3, se integran todas las artes aplicadas como la pintura, color, escultura, escritura, que informan sobre la función, importancia o el poder mágico de las construcciones. 


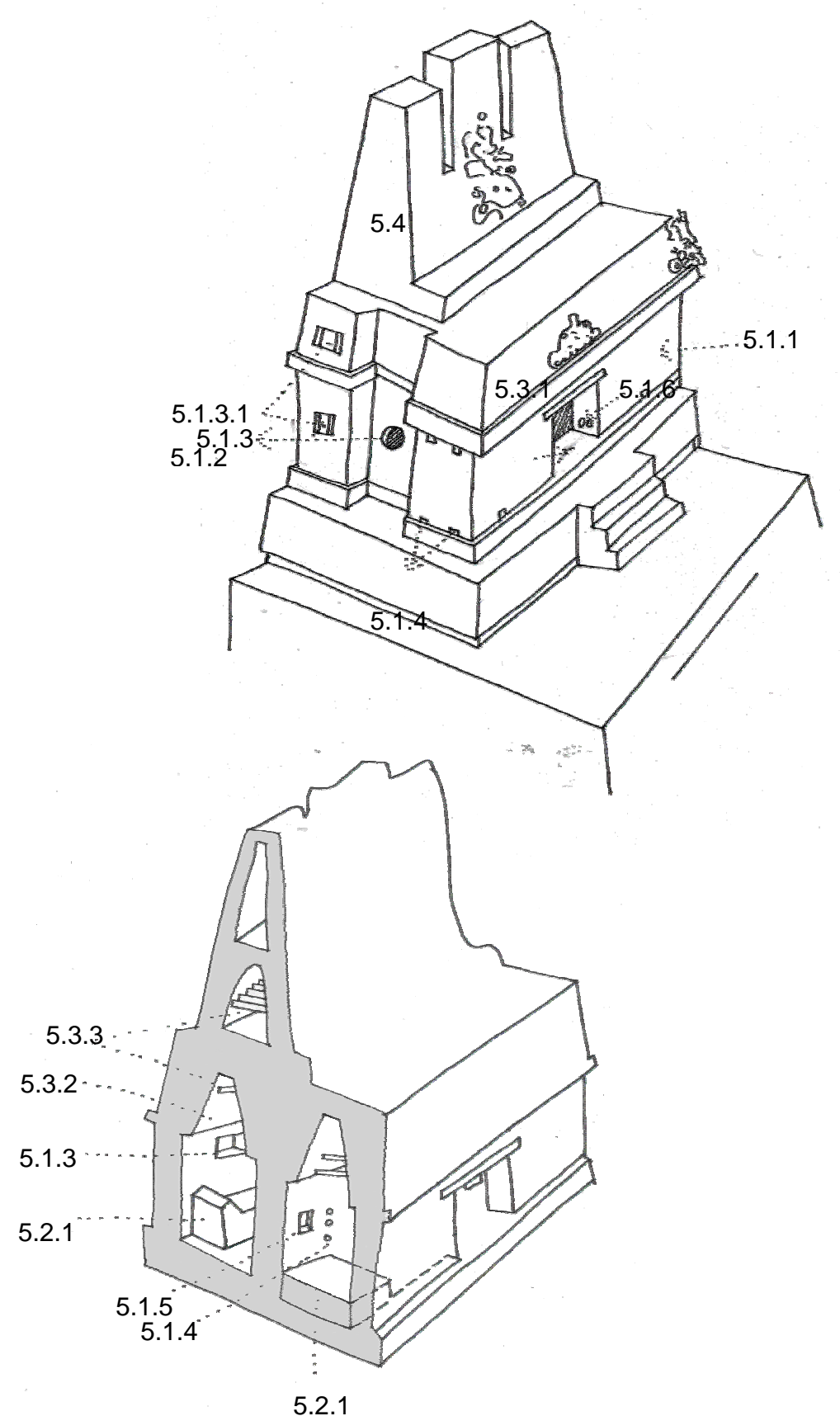

Fig. 16. Elementos de arquitectura identificados. 


\section{ELEMENTOS CONSTRUCTIVOS}

El cuarto nivel del análisis del espacio construido se refiere a los elementos constructivos. Las técnicas constructivas mayas, a lo largo de su evolución tecnológica, van desde las primeras construcciones de tierra apisonada a los diferentes tipos de edificaciones empleando bloques de piedra tallada y mezcla para las paredes y los techos.

Henri Stierlin analizó la evolución de la arquitectura maya en base a la choza o rancho que actualmente siguen construyendo en el mismo territorio; empleando los mismos materiales y formas de hace más de 2000 años. En el rancho se encuentran los elementos espaciales básicos que se repiten a lo largo de la evolución de la arquitectura maya. Se mantiene la relación ancho-largo-alto, relación aberturas y muros, muros y techos, ranchos-patios y ranchos-ranchos (Stierlin 1964, 93-94).

En principio, el maya necesitó un espacio libre de vegetación para poder construir en un área relativamente menos húmeda y segura sus edificios. Necesitó además nivelar el terreno y asegurar que el agua de lluvia no entre en los edificios. Así se formaron los elementos básicos del espacio maya: el edificio (elemento sólido o masa), el patio o el espacio que rodea a las construcciones (elemento espacio libre) y la plataforma, que es el elemento con el cual logran acondicionar el terreno. La arquitectura maya evolucionó con estos tres elementos básicos pasando de una concepción funcional a transformarse en una arquitectura monumental y simbólica. 
El sistema constructivo de los "espacios interiores" (paredes y techos) no evoluciona paralelamente con las plataformas, su sistema se mantiene sin cambios de materiales (madera y palma) por muchos cientos de años. Por esta razón las plataformas y sus elementos verticales de comunicación (escalinatas) se convierten en el principal instrumento generador de la concepción arquitectónico-urbana, plenamente desarrollado y explotado ya en el Preclásico Tardío. Para esta época ya existen monumentales ciudades como El Mirador. En El Mirador contrastan gigantescas plataformas escalonadas, plazas, patios y calzadas de piedra estucada y pintada con los edificios de madera y palma convencionales.

En los edificios, por lo general, el principio del espacio interior básico de los ranchos se mantiene (proporción largo, ancho y alto) y lo que cambia son los materiales: de madera y palma se pasa a bloques de piedra tallada, mezcla y relleno. Esto ocurrió a finales de Preclásico Terminal y principios del Clásico. Para soportar el nuevo sistema constructivo, las paredes aumentan de tamaño. Los espacios interiores tienen una forma básica rectangular alargada, como consecuencia de las limitaciones estructurales empleadas para el sistema techo-bóveda de piedra. El eje longitudinal continúa siendo el más importante. Los edificios aumentan de tamaño utilizando el método de repetición del espacio básico del rancho sobre sus ejes longitudinales, transversales y verticales descritos anteriormente (apartado 4.2.1. y 4.2.2).

Los constructores mayas, en sus edificaciones monumentales en piedra, no emplearon sistemas de anclaje entre un muro y otro, entre un muro y el piso, o entre un muro y el techo. En principio el concepto constructivo era utilizar diversas capas (plataforma, muro, techo) superpuestos y simplemente apoyados; solamente separados por 
finas capas de nivelación (pisos constructivos); la estabilidad de las construcciones se lograba con el peso. De allí sus restricciones estructurales para los espacios interiores. El sistema funciona porque existe un cementante de unión, hecho a base de la cal, que amarra todos los elementos constructivos y en principio forma una sola masa monolítica.

Gaspar Muñoz Cosme y Cristina Vidal Lorenzo definen un sistema constructivo como "Un conjunto funcional y ordenado de elementos constructivos que forman una unidad completa y autónoma en que puede dividirse un edificio" (Muñoz Cosme y Vidal Lorenzo 2004, 763). Gaspar Muñoz, presenta una detallada descripción de los sistemas constructivos prehispánicos en, Introducción a la Arquitectura Maya (Muñoz Cosme 2006c, 89-93).

Gaspar Muñoz Cosme menciona que "los mayas utilizaron un repertorio limitado de sistemas constructivos y se supone que esto se debe a que los mayas poseían una cultura lítica que no tuvo herramientas metálicas ni utilizo el metal para la construcción. Tampoco llegaron a diseñar sistemas que permitieran un aprovechamiento mayor de las capacidades mecánicas de la piedra, como podría haber sido el empleo de un arco con piedra clave". (Muñoz Cosme 2006c, 89)

Instrumentos: Entre las herramientas se encuentran instrumentos de pedernal, obsidiana y otras piedras duras empleadas para hacer cortes en los bloques de piedra caliza (hachas y cinceles); conocieron las plomadas de piedra, asimismo usaron objetos fabricados de hueso, conchas; emplearon artefactos de madera para hacer palancas y cuñas. Usaron el fuego, la arena y el agua como elementos abrasivos. Emplearon vasijas de cerámica para transportar 
agua, rodos de madera para trasladar objetos pesados. Emplearon rampas, andamios de madera y escalinatas de construcción para subir materiales. De la corteza de los árboles obtuvieron lazos, cables y redes. También usaron una especie de tripié para movilizar objetos pesados. Estos tripiés fueron construidos por tres vigas de madera en forma de pirámide que se sujetan en la parte alta; en este punto se agrega otra pieza horizontal amarrada en la parte media. En un extremo se amarra el objeto a trasladar y en el otro lado se hace palanca para elevarlo, girarlo y ponerlo en el lugar deseado (comunicación personal de Jacinto Rosado Lanza, maestro de Tikal).

La forma constructiva de los edificios monumentales se inicia con una base plana y horizontal conformada por la superficie de una plataforma de sustentación. Sobre esta superficie se desplanta otra u otras plataformas (escalonadas) individual para cada edificación. Luego, si es el caso, se coloca encima otros elementos constructivos (muros y techos) para formar los espacios interiores.

Por referirnos a los edificios monumentales construidos en piedra, en este trabajo los sistemas constructivos con materiales perecederos no son considerados y nos concentraremos en los sistemas básicos (plataformas, muros y techos) en piedra. La intención es conocer mejor los sistemas de construcción empleados en los edificios de la muestra y poder proponer intervenciones de rescate y restauración sobre éstos mismos elementos de arquitectura. Continuando con el esquema de análisis describimos aquí, las formas constructivas de las plataformas, muros y techos; esta vez desde la óptica de su construcción como portante de los elementos formales del espacio construido. 


\subsection{PLATAFORMAS}

La plataforma es el principal elemento constructivo de las edificaciones mayas ya que en ella se desarrolla la tecnología constructiva en piedra. Inicia en el Preclásico con las primeras plataformas de nivelación con tierra apisonada utilizando posteriormente la piedra como muro de retención. Luego evolucionó el uso de la mezcla como elemento de cohesión de los conglomerados de piedra. Primero fue el lodo y luego la cal como el principal elemento cementante. Posteriormente y a manera de proteger los materiales de construcción de la intemperie, se utilizó en el recubrimiento de todas las partes expuestas con capas fina de pasta de cal (estuco) y pintura.

La evolución de las plataformas permite desarrollar el manejo de los espacios libres que rodea y organiza a los edificios. La forma escalonada de las plataformas superpuestas una sobre otra permitía un mejor control de la escorrentía ya que en la región tropical las lluvias son abundantes. Esta solución, en grandes escalones, es la respuesta general a la condición climática particular del área maya. Los remetimientos constantes de plataformas cada vez más pequeñas, formando escalones, permitían también controlar los esfuerzos del empuje de los rellenos, logrando que esta forma pudiese repetirse muchas veces.

Cada plataforma superpuesta es tratada como un elemento independiente y simplemente colocado. La plataforma pasa de un carácter funcional en el rancho maya a ser un elemento distintivo en la composición de los centros urbanos mayas. Las plataformas toman función de carácter simbólico religioso; por ejemplo, la superposición de plataformas escalonadas en 1, 3, 5, 7, 9 cuerpos. 
Para lograr una superficie plana, los constructores mayas primero quitaban todo el humus del suelo y lo pelaban hasta dejar expuesta la roca caliza; de allí iniciaban los trabajos de tallado, nivelado o relleno para preparar su espacio geométrico. Si se requería más espacio horizontal, entonces se construían muros contrafuertes en las posiciones deseadas para ampliar el área.

En las plataformas se emplean muros contrafuertes para el levantado de los límites verticales. Los paramentos son lo suficiente gruesos para sostener los empujes laterales del relleno y por lo general son construidos en talud. La altura promedio de estas plataformas no sobrepasa los cuatro metros; aunque hay plataformas de mas de 7.60 m de alto (Uaxactún grupo $\mathrm{H}$, en Valdés 1992, 19).

Para los rellenos de las plataformas se tenía mucho cuidado; investigadores como Juan Antonio Valdés, Richard Hansen y Donald Forsyth han analizado diferentes tipos de relleno. Valdés se refiere a los rellenos Preclásicos en el grupo $\mathrm{H}$ de Uaxactún; en el Edificio $\mathrm{H}$ Sub.2 del año 500-300 a.C., "estadio 3.... el relleno es compacto pero no completamente sólido... luego, a partir del estadio 4 los rellenos son completamente sólidos con arcilla negra de los bajos mezclado con grandes piedras" (Valdés 1992,18). Igual sistema de cajas interiores fue documentado en la destrucción científica de la pirámide A-I de Uaxactún, realizada por Robert Smith en 1931.

En la región de la cuenca Mirador, Forsyth describe celdas de construcción, encontradas en edificios Preclásicos de Nakbé. (Edificio 49, grupo Triádico del Preclásico Tardío) "Estas celdas consisten de paredes hechas de piedras toscas que forman un corral cuadrado o rectangular, dentro del cual se echaron piedras, argamasa y relleno. Al estar las celdas llenas, se les niveló y se construyó una nueva 
serie de celdas en una posición horizontal diferente, evitando así una fisura en el interior del edificio". Luego describe el interior del Edificio 27 (edificio al norte del grupo E de Nakbé del Preclásico Medio) y dice que "el relleno es variable y extremadamente suelto, sin argamasa, otras partes con piedrín sin argamasa o si hay argamasa es muy floja; lo que sugiere que se utilizo cualquier material disponible para llenar las celdas". Forsyth anota la diferencia de relleno entre las dos edificaciones y concluye que el sistema de celdas de construcción para erigir la plataforma basal del Edificio 49 es de mejor calidad, "indicando un reflejo de perfeccionamiento de las técnicas constructivas" (Forsyth 1993, 131-133).

Las cajuelas son construidas con bloques de piedra canteada con mezcla, importante era lograr una masa uniforme y compacta tipo monolítico. La forma de las cajuelas es arbitraria, un buen ejemplo se conoce por la documentación realizada por el Museo de la Universidad de Pensilvania, al demoler sistemáticamente varias plataformas escalonadas del Edificio 5D-33 en la Acrópolis Norte de Tikal. La forma irregular de estos muros interiores (cajuelas), se debe en parte a que preparan la nueva construcción y rodean otro edificio anterior. En este caso los muros de las celdas tienen forma de L, otras de U; la altura promedio fue de $2.10 \mathrm{~m}$ a $4.70 \mathrm{~m}$ (ver figura 16).

Registros de éstos sistemas de celdas se han documentado en el interior del templo I de Tikal, (túnel que atraviesa el edificio buscando la Tumba 116). En la investigación de la plataforma base del templo $\mathrm{V}$ de Tikal; el arqueólogo Oswaldo Gómez menciona que "la forma constructiva de la plataforma basal se logró por medio de un sistema de cajas, con muros megalíticos ataludados de $8.70 \mathrm{~m}$ norte-sur reforzada con muros verticales de contrafuertes a $4 \mathrm{~m}$ este-oeste y 
un relleno muy compacto con capas alternas de tierra y piedra" (Gómez 1998, 55).

El arqueólogo Bernard Hermes, al realizar pozos estratigráficos en la plaza A de Yaxhá encontró el mismo sistema de cajas para formar la plataforma elevada de $100 \mathrm{~m}$ por $100 \mathrm{~m}$ de la plaza. También Zoila Calderón al excavar un túnel dentro de la Acrópolis Central de Nakum, encontró secciones de muros que formaban parte del sistema de celdas que soportó el relleno de la gran plataforma de la Acrópolis.

Al terminar una plataforma se extendía un piso de estuco sobre la superficie que sellaba el sistema de celdas. Sobre la nueva superficie, se trazaba de nuevo otro diseño de muros formando cajas para construir otra plataforma de menor dimensión. Para los rellenos se utilizaba el material disponible empleando diferentes composiciones desde estratos integrados por pedazos de piedra caliza y una argamasa de cal pobre hasta otros rellenos con piedras de gran tamaño colocadas sin mezcla, o, en otros casos se emplea piedra de distinto tamaño con mezcla de mejor calidad. También podía ser, con gruesas capas de barro procedente de los bajos cercanos, gruesas capas de piedra suelta tipo piedrín sin mezcla confinada por pisos estucados y nivelados. En ocasiones el relleno es apresurado pues son volcados sin cuidar niveles, en otros casos es notorio el cuidado de la colocación del relleno. En la región de la Laguna Pucteal hay una variable interesante, la zona tiene abundantes afloraciones de piedra pedernal. Esta piedra se empleo en los rellenos de las edificaciones con poca mezcla o sin agregar argamasa de arcilla o cal. Como resultado las construcciones, al ser "destapadas" por los saqueadores se derrumban inmediatamente. En el sitio Las Cubetitas es el único ejemplo en donde los depredadores tuvieron que utilizar 
un sistema de puntales de madera para poder continuar con su destructiva tarea.

En los periodos Preclásico Tardío y el Clásico los muros contrafuerte de las plataformas suelen tener una inclinación entre 12 a 16 grados. Mientras que las plataformas del periodo Posclásico son casi verticales con 3 grados promedio de inclinación. En ambos casos los muros tienen piedras de anclaje con el relleno y como acabado una capa de mortero de cal y pintura.

En el Preclásico Tardío y el Clásico, son comunes las esquinas redondeadas o esquinas remetidas. En las esquinas los esfuerzos de transmisión de cargas al suelo son menores, por lo tanto les permitía recortarlas. En Tikal, Naachtún, Chochkitam, la Honradez y Uaxactún hay una variante que integra a tres plataformas escalonadas por medio de un talud liso o faldón intermedio que pasa por las tres plataformas. También son comunes las plataformas con molduras básales (remetimiento horizontal en la base de los paramentos) o entrecalle. Esta forma tipo aparece desde el Preclásico Medio en la cuenca Mirador (Hansen 2000, 57). Gaspar Muñoz Cosme, estudio este detalle y dice que en la construcción de los muros contrafuerte, la entrecalle permite corregir pequeños desperfectos de nivelación o de medidas en los levantados de las plataformas (Muñoz Cosme 1994, 523-535).

En el periodo Posclásico son más frecuentes las esquinas encontradas formando ángulos cercanos a los 90 grados. Los muros contrafuerte de este periodo generalmente tienen una banda horizontal salida en la parte superior; esta banda al juntarse con las alfardas de las escalinatas forma los dados característicos de la arquitectura Posclásica. 
Sobre la superficie exterior de las plataformas se adosan las escalinatas de construcción y finalmente de uso. También en algunas construcciones hay escalinatas secundarias en los muros contrafuertes que se amoldan a la inclinación de los muros. Estas servían para el mantenimiento constante de las grandes superficies (Templo I, Templo II, 5C-54).

Sobre las plataformas, en el periodo Preclásico se aplico la información y el programa ideológico de los gobernantes. La posición favorita fue a los lados de las escalinatas principales (ejes visuales); aquí se colocaron gigantescos mascarones. Ejemplos de este elemento de arquitectura se tienen en Uaxactún, visible por excavaciones arqueológicas (1927-37) en el Edificio E-7Sub. (en total deterioro). Tikal en la Acrópolis Norte, tiene ejemplos de mascarones (visible en un pozo de excavación en el Edificio 5D-33a) y otro muy deteriorado en la plataforma escalonada del Edificio 5D-22. Otros sitios con evidencia de mascarones están: El Mirador (Edificio 34, parcialmente descubierto y con una cubierta moderna), Nakbé (cubiertos por rellenos), Yaxhá (visible parcialmente por excavaciones arqueológicas, en 2007), Holtún (en un saqueo, con cubierta protectora), Nakum (en el interior de la Acrópolis, ya sellada), Chanchich (en saqueo, parcialmente protegida por relleno) y en Cival (en una trinchera de saqueo ampliada).

Actualmente el gran problema de las plataformas es que ceso el constante mantenimiento y con el tiempo y la agresión del ambiente se han desprendido los muros contrafuerte. Al faltar esta capa protectora, se inicia a deformar la superficie escalonada. Los grandes escalones iniciales se convierten en pendientes inclinadas continuas. Esta pendiente facilita la escorrentía y erosión del núcleo o relleno. En algunos casos la pérdida de volumen en las plataformas 
escalonadas es tan grande, que muros de edificios, que están sobre los límites de las plataformas, se desploman o se deslizan y caen resbalados hacía abajo. Una falla estructural de este tipo sucedió recientemente (década 1970) en una fachada del Templo C de Topoxté. Restos del muro de la fachada sur, se encuentra ahora en el piso; aquí el volumen que aseguraba la estabilidad del edificio superior falto, con la consecuente destrucción total de la fachada sur. Algo parecido puede suceder con la fachada sur del templo $\mathrm{V}$ de Tikal; la perdida de volumen en la plataforma escalonada, especialmente en esta fachada, es tan grande que pone en peligro la estabilidad del templo superior. 


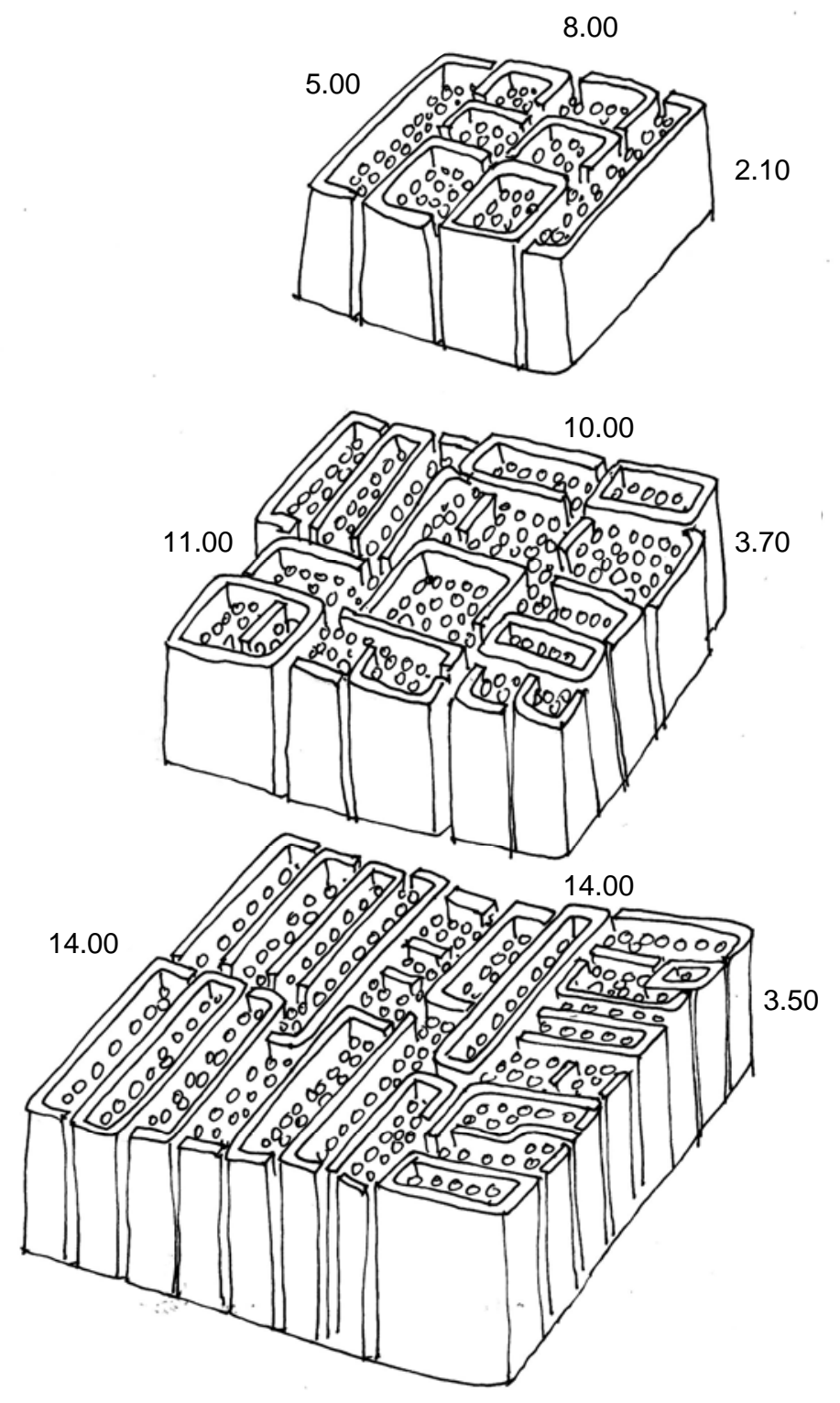

Fig. 17. Sistema de cajuelas en las plataformas escalonadas del Edificio 5D-33 primero del Clásico Tardío, Tikal 


\subsection{MUROS}

La primera definición de un espacio interior fue hecha de madera. El sistema constructivo fue basado en postes o columnas en las esquinas, más elementos horizontales y verticales que soportan los muros. En este caso las columnas son introducidas en el piso de la plataforma, o sea cimentados. La variante constructiva actual de este sistema, fue documentada por R. Wauchope (Wauchope 1938). En el área de estudio, tenemos pocos ejemplos visibles de este sistema constructivo; uno se encuentra en Uaxactún (plataforma $\mathrm{C}$ del grupo A-V) correspondiente al periodo Preclásico. Es una planta rectangular de aproximadamente $0.40 \mathrm{~m}$ de alto con esquinas redondeadas, con una saliente sobre el eje longitudinal, que marca el acceso al recinto interior. Sobre el piso estucado se marcan los agujeros de los cuatro postes principales.

De la madera se pasa a la piedra. Con los sistemas constructivos de muros en piedra, no se emplea anclajes o cimientos en las superficies horizontales. Los muros de carga se construyen en hileras paralelas. Para el área de estudio, la distancia del espacio interior libre entre dos muros longitudinales tiene como promedio entre $2.00 \mathrm{~m}$ a 2.80 $\mathrm{m}$. El espacio de aberturas para accesos (puertas) se solucionan con dinteles de madera o piedra. Los cerramientos en los extremos de los cañones de muros se construyen con tapaderas independientes en la misma forma constructiva. Si se deseaba dividir el espacio interior se construían muro tabiques de diferentes gruesos, sin función estructural. El no amarrar un muro con otro, es una tradición que llega hasta la época Posclásica. Un ejemplo de este sistema lo podemos ver en el muro intermedio del Edificio $C$ de Topoxté; esta pared esta ahora separada $0.14 \mathrm{~m}$ de la fachada norte por la deformación de esta ultima. 
Los muros generalmente están formados de tres partes, dos caras de revestimiento construido con piedra tallada de tamaño uniforme y un espacio intermedio entre las dos capas exteriores, juntos forman una masa homogénea de espesor promedio entre $1 \mathrm{~m}$ a $1.5 \mathrm{~m}$. En la descripción del edificios mas antiguos registrado en el área del estudio, (H Sub.-2 etapa 3, del Preclásico Tardío) de Uaxactun; Juan Antonio Valdés, anota la medida de los muros (0.90 $\mathrm{m}$ de grosor). Este muro antiguo estaba forrado por bloques de piedra tallada, cornisa con gota y un paramento de techo con figuras en estuco, todo pintado de rojo. Valdés mide también los espacios interiores (1.45 $\mathrm{m}$ y $1.58 \mathrm{~m}$ de ancho) y los espacios de puertas $(1.30 \mathrm{~m}$ de ancho y $1.30 \mathrm{~m}$ de alto). En el Edificio $\mathrm{H}$ Sub.-5 (del siguiente estadio 4), los muros tienen un grosor de $0.50 \mathrm{~m}$ y los espacios interiores miden $1.30 \mathrm{~m}$ y $0.82 \mathrm{~m}$. Los accesos a las cámaras miden de ancho $1.91 \mathrm{~m}$ y $1.27 \mathrm{~m}$ y de alto solo $1.12 \mathrm{~m}$ y $1.48 \mathrm{~m}$ (Valdés 2000, 16). Llama la atención el poco grosor de los muros en el Edificio H Sub.-5 y el alto de los accesos a las cámaras.

Richard Hansen basa el diagnostico de la arquitectura del Preclásico en la forma y tipo de los muro. El primer muro en la cuenca Mirador es del 900-600 a.C. (Preclásico Medio) y consiste en un muro vertical con piedra pequeña de dos metros de alto. Hansen define 10 indicadores diagnostico de arquitectura para el periodo Preclásico. También dice que la piedra de cornisa es diagnostico para edificios del Preclásico Tardío; muros con cornisa no aparecen antes del 250 a.C. (Hansen 1998).

Hay casos excepcionales, como los muros del templo $V$ de Tikal (Clásico Tardío), con $5 \mathrm{~m}$ y $9 \mathrm{~m}$ de espesor. Los edificio $\mathrm{G}$ y $\mathrm{R}$ de Nakum tienen $1.50 \mathrm{~m}$ y $1.75 \mathrm{~m}$ de grosor. Para los muros del periodo 
Posclásico en la Plaza Principal de Topoxté (estadio 9), el grueso varia entre $0.60 \mathrm{~m}$ a $0.80 \mathrm{~m}$ (edificios $\mathrm{C}, \mathrm{D}, \mathrm{E}, \mathrm{y} \mathrm{G}$ ).

En el levantado de los muros, las hileras de piedra son colocadas de manera organizada y a nivel. Por lo general se colocan los bloques de piedra de "soga" ( $0.60 \mathrm{~m}$ por $0.30 \mathrm{~m}$ por $0.20 \mathrm{~m}$ ) con rigidizantes de la misma piedra puestos de "punta" que se ensartan en el núcleo. Estos anclajes se colocan a distancias rítmicas. En el Clásico Terminal se eliminan los anclajes al núcleo y se colocan bloques de piedra tipo fachaleta con un grosor aproximado de $0.08 \mathrm{~m}$

Los formatos de bloques de piedra del Preclásico Tardío, en la cuenca Mirador tienen un promedio de 0.80 por $0.40 \mathrm{~m}$ por $0.38 \mathrm{~m}$ de grosor. Para el Preclásico Medio 0.90 por $0.40 \mathrm{~m}$ por $0.30 \mathrm{~m}$ de grosor (Hansen 1998). Los formatos de piedra tallada del Clásico Tardío en el área de Yaxhá-Nakum-Naranjo son de aproximadamente 0.60 por $0.40 \mathrm{~m}, 0.60$ por $0.30 \mathrm{~m}, 0.45$ por $0.15 \mathrm{~m}$ con un grosor entre $0.35,0.20$, y $0.18 \mathrm{~m}$ El formato en muros del periodo Posclásico de Topoxté tienen: 0.64 por $0.36 \mathrm{~m} ; 0.73$ por $0.51 \mathrm{~m}$ o 0.36 por $0.22 \mathrm{~m}$, con un grosores de $0.20 \mathrm{~m}$ a $0.08 \mathrm{~m}$.

Para formar la capa intermedia del muro se hace por fases de trabajo diario, hasta alcanzar la altura deseada. La forma de verter el relleno del núcleo tiene diferentes maneras; una es ir colocando las piedras con cuidado entre la mezcla, durante el proceso de levantado del muro; y el otro procedimiento es cuando el material mixto es vertido entre varios tamaños y formas conjuntamente con la argamasa sin cuidar la colocación de sus piezas. Independiente de la forma de fabricar el núcleo, estos rellenos con cemento de cal funcionan estructuralmente solos aun sin el revestimiento de piedra tallada. Esto sucede por el grueso del núcleo y la calidad del 
aglutinante. Las argamasas de arcilla (tierra), el cascajo de piedra y la cal logran perfeccionarse y se convierten en el principal elemento portante del muro. Las capas exteriores de piedra tallada se reducen de tamaño en el Clásico Terminal y llegan a tener espesores de 0.08 a $0.15 \mathrm{~m}$ y se olvida la antigua tradición de colocar piedras de punta para que entren en el relleno intermedio. Un ejemplo de la confianza que los mayas tenían en los relleno de los muros es visto en varios edificios de Nakum con aberturas posteriores en muros de carga (edificios $A, N$ e $Y$ ).

Una descripción de la forma constructiva de los muros en el área de Yaxhá, Nakum y Naranjo fue realizada entre 2001 y 2003 por el consultor José Alejandro Flores. Flores ejemplifica la construcción de los muros iniciando por la base o el zócalo. Aquí se emplean piedras mas grandes para formar la grada (plataforma de arranque) del muro con bloques de $0.30 \mathrm{~m}$ de alto; luego sobre él se colocan hileras de bloques uniformes y nivelados; la construcción del muro continúa hasta llegar a la altura de colocar la piedra de cornisa. En este nivel se coloca de nuevo una hilera de piedra grande ( $0.35 \mathrm{~m}$ de alto) que sale del rostro del muro inferior y divide la zona entre pared y techo del edificio. Las cornisas en esquinas llegan a tener dimensiones de $1.0 \mathrm{~m}$ por $1.0 \mathrm{~m}$ y $0.35 \mathrm{~m}$ de alto. Sobre la piedra de cornisa se levanta un nuevo muro, por lo general de un formato más pequeño, semejando a la proporción de un ladrillo (0.15 por $0.06 \mathrm{~m}$ y $0.18 \mathrm{~m}$ o $0.17 \mathrm{~m}$ de grosor). La parte del muro que da al espacio interior, se levanta en la misma forma, hasta llegar a una altura deseada, aquí una piedra salida, llamada línea de imposta o "sofito", marca el arranque del muro del techo. Hay casos en que el sofito no aparece y simplemente las piedras empiezan a salir de la vertical para formar el paramento del techo. 
Por lo general en las esquinas, la capa exterior del muro son bloques tallados, se amarra o entrelaza, colocando en una fila el primer bloque de punta, luego en la siguiente fila el primer bloque de soga, luego otra pieza de punta y otra de soga hasta llegar a la altura de la cornisa. Este tipo de tratamiento puede ser observada en: Nakum, Tikal, Torre Corozal, San Clemente, Yaxhá, Naranjo y Chochkitam.

En el periodo Posclásico se hacen combinaciones de muros de piedra con la parte superior de madera (postes de madera ensartadas en el muro de piedra). Un ejemplo documentado es el Edificio E de Nakum, en su estadio 8 (Wurster 2000, fig.33).

El criterio de no cimentar los muros y la forma de construirlos (en tres capas) determinó, con el tiempo de cientos de años, que los elementos se separaran. Esta separación es una de las causas de su estado de conservación actual. Los muros se desprenden por fallas en el piso, el techo, o por presiones provocadas por vegetación sobre los muros. Estas causas ocasionan separación de las capas de construcción, hundimientos, desplomes, fisuras, grietas y otros. Esto sumado a la perdida de volúmenes en las plataformas escalonadas constituye hoy los principales problemas de estabilidad en los edificios.

Grandes tramos de muro sin su capa protectora de piedra tallada se encuentran en proceso de desintegración, ejemplos de esto se muestran en: Nakum, parte posterior del Edificio A, parte posterior del Edificio Q, edificios de Chochkitam, La Honradez, Kinal, El Zotz, Holmul, Xultún, Naachtún y otros. 


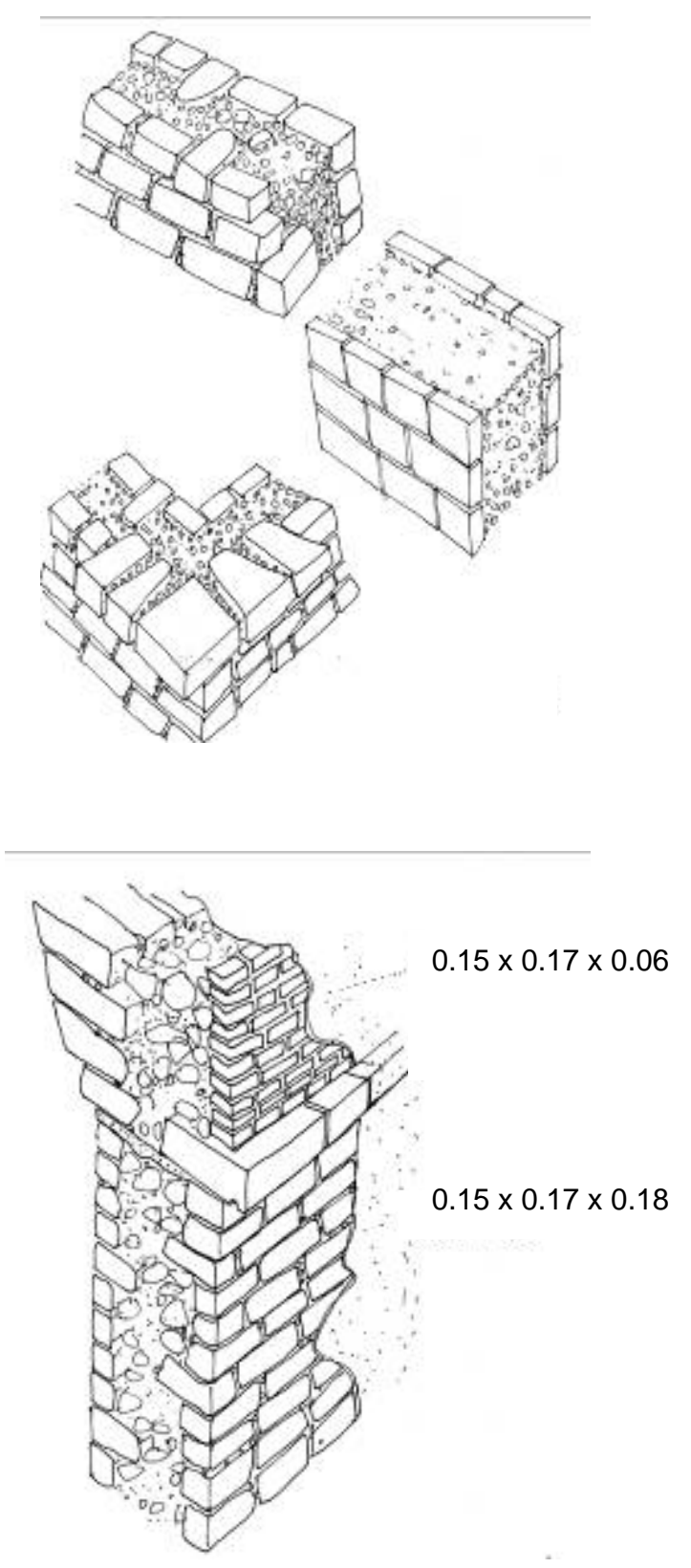

Fig. 18. Detalles de sistemas constructivos en muros

202 


\subsection{TECHOS}

Al llegar los muros de piedra, de un edificio con espacio interior, a un nivel determinado se aplica un piso de nivelación que sirve de base para el desplante de los muros del techo. En ocasiones el arranque es marcado por una fila de piedras salidas (aproximadamente de 0.08. $\mathrm{m}$ a $0.12 \mathrm{~m}$ ) formando una grada llamada sofito o línea de imposta. El muro del techo, en su cara interior, tiene una inclinación hacía adentro de aproximadamente 17 grados, formando un prisma llamado bóveda en saledizo o bóveda de aproximación. El paramento interior del techo se construye con piedras que salen de la vertical hasta casi llegar a juntarse con su muro homólogo enfrente a él. Sobre la última piedra en saledizo, se coloca una piedra llamada "piedra tapa". Y sobre ésta más piedras y mezcla para formar el volumen del techo. Los muros del techo funcionan como una prolongación del muro inferior y son estructuralmente estables e independientes.

El paramento interior del techo se construye de varias formas; la más antigua es con piedra irregular usando o no sofitos para definir el arranque del muro en saledizo, colocando luego un acabado grueso de mezcla para corregir las diferencias del levantado. En el Clásico los bloques de piedra son tallados con mayor precisión y con formatos uniformes. En el Clásico Tardío y Terminal, las piedras de bóveda son diseñadas (en planta) en forma de un trapecio. Estos bloques se colocan en el muro en forma salida con la parte más ancha hacia el espacio de la cámara. La parte más angosta queda confinada en el núcleo del muro. Al colocar dos piedras de este formato, una contigua a la otra, queda en la planta un espacio vació triangular, en donde penetra bien la mezcla cementante de cal. Además con ésta forma se ahorraba volumen de piedra. El formato de bloques en reducción 
(hacia el interior del muro) se utilizo también para formar las piedras de cornisa de los paramentos exteriores de los edificios.

Ejemplos de cornisas se han registrado desde el Preclásico Tardío. Algunos edificios en la parte inferior de las piedras de cornisa tienen un ribete tallado llamado "gota". Ejemplos de este elemento se encuentran en: El Mirador, Naranjo San Bartolo, Uaxactún, Holmul y El Pital.

Un elemento estructural que condicionó la durabilidad de los techos, fue el sistema de soporte de los muros, en los espacios en donde se encuentran las aberturas para el acceso. El sistema adintelado, por lo general está formado por vigas de madera (de aproximadamente 0.15 a $0.25 \mathrm{~m}$ de grosor), colocados en filas formando "camas" a lo largo del grosor de los muros. Esta técnica permitía la transmisión de esfuerzos a los muros laterales de mampostería. Aunque se escogió madera dura, como el palo de tinto (Campechanium platymiscium) o chicozapote (Manilkara zapota) éstos elementos perdieron con el tiempo su capacidad de carga y provocaron el colapso de esa parte del techo. A veces estos dinteles de madrera eran tallados con figuras y escritura, situación que propicio el robo de los mismos. Ejemplos de daños por perdida de dinteles se observan en los templos mayores de Tikal (ya restaurados), en el acceso principal del Edificio $\mathrm{N}$ de Nakum (también restaurado) y en el Edificio A 2 de Rió Azul, Templo 1 de El Zotz y otros.

Sobre los techos se desplantan nuevos muros que forman celdas en forma de torres (cresterías). En el techo las cajuelas o celdas de construcción son vacías, en este caso para liberar peso a la construcción. Estos elementos arquitectónicos por lo general se ubican sobre los muros posteriores de las cámaras, dejando una 
especie de terraza al frente. Esta porción del techo, con el abandono y el tiempo, fue un espacio propicio para almacenar vegetación y propicio el crecimiento de árboles. Esta terraza frontal y el sistema dintelado de los accesos, condiciono el derrumbé del primer espacio interior (cámara) de muchos edificios; ejemplos de ello están: el Edificio A de Nakum, el Edificio 216 de Yaxhá, el Edificio I de Tzikintzakán, los Edificios I y II de Xultún, el Edificio XV de Chochkitam, el Edificio A-XVIII, A-X de Uaxactún y muchos otros más.

Para las construcciones del periodo Posclásico; los cambios constructivos de los techos y los detalles de fachadas con columnas o pilares empleando elementos de madera causaron grandes daños. En esta época los espacios interiores pueden llegar a tener anchos mayores, porque el sistema constructivo del techo es distinto. En este periodo el sistema más común para edificios monumentales, son las losas planas. Los techos planos fueron construidos con hileras de vigas de madera, pegadas unos con otros; colocados sobre los muros de carga o sistemas de columnas o pilares (Noriega 1995, 29-251). Sobre la fila de vigas de madera se coloco una gruesa capa de cemento de cal para impermeabilizar la losa y formar el volumen deseado. Para detalles constructivos en edificios Posclásicos de Topoxté ver (Wurster 2000, 296-310).

El uso de losas planas se utilizó también en edificios del período Clásico, ejemplos se encuentra en: el cerramiento del techo de la segunda cámara del Edificio I de Xultún; en este edificio se hallan aún las huellas de las vigas de madera. Igual sucede en el interior de la crestería del Templo V de Tikal (Quintana y Noriega 1992, 52-76), en la tumba en el interior del Edificio 216 de Yaxhá y en el Edificio de Las Pinturas Sub. 1 en San Bartolo. 
Alejandro Flores elaboro tres informes, no publicados, de consultoría sobre formas de intervención de restauración en Topoxté, Yaxhá y Nakum, y procedimientos de intervención de restauración y monitoreo de edificaciones intervenidas en Yaxhá-Nakum-Naranjo (Flores 2001, 2002, 2003 en manuscritos, biblioteca del PRONAT). Otros proyectos de investigación y restauración, en el área de estudio, han realizado trabajos parecidos. Entre ellos la Misión Española ha desarrollado desde 1992 varios "estudios especiales" en Tikal y La Blanca; en Tikal hay dos publicaciones sobre el tema, uno para el Templo III (Coarsa 1999), y otro con el análisis de varios edificios (Valdés et al 1999). En el área de la cuenca Mirador, el Proyecto Regional de Investigación Arqueológica en el Norte de Petén Guatemala (PRIANPEG) también tiene investigaciones sobre los sistemas constructivos y los materiales utilizados.

Un aspecto a considerar en el estado de conservación de los edificios es conocer los procesos de relleno y preparado de edificios anteriores para soportar, encima, edificios nuevos. En el proceso de rellenado de edificios se seguía diferentes criterios. En primer lugar, el edificio era ritualmente matado. Se realizaban ceremonias de cierre con ofrendas y rituales, en ocasiones el edificio era pintado de blanco antes de ser rellenado. En lo posible, los elementos escultóricos eran respetados y cubiertos cuidadosamente con finas capas de arena o arcilla para no dañarlos. En otros casos, se definía un nivel predeterminado, entonces todo lo que estuviera arriba de esa altura era arrasado. Un ejemplo de este procedimiento se encuentra en el interior de la Acrópolis Central de Nakum, aquí el grupo triádico del Preclásico Tardío con sus plataformas y mascarones fue cortado a altura de la frente del mascaron. A ese nivel se colocó un grueso piso de nivelación para levantar un nuevo edificio. La parte mutilada quedó rellenada y los restos de mascarones fueron protegidos por una capa 
de arcilla bien apisonada. En el caso de edificios con cámaras puede suceder que las piedras de caballete (o piedras tapa) sean levantadas para rellenar cuidadosamente el interior (Naranjito y Perú-Holmul) o el techo completo es quitado y rellenado todo el espacio interior $(\mathrm{H}-\mathrm{Sub}$ 2 de Uaxactún, en Valdés 1992, 18).

Otra condicionante que determina el estado de conservación de las edificaciones prehispánicas es el tiempo que llevan expuestas a los procesos de meteorización los elementos constructivos (piedra, mezclas, rellenos, maderas) y el abandono histórico, dejando al edificio a merced de la selva tropical, el clima y el saqueo. 

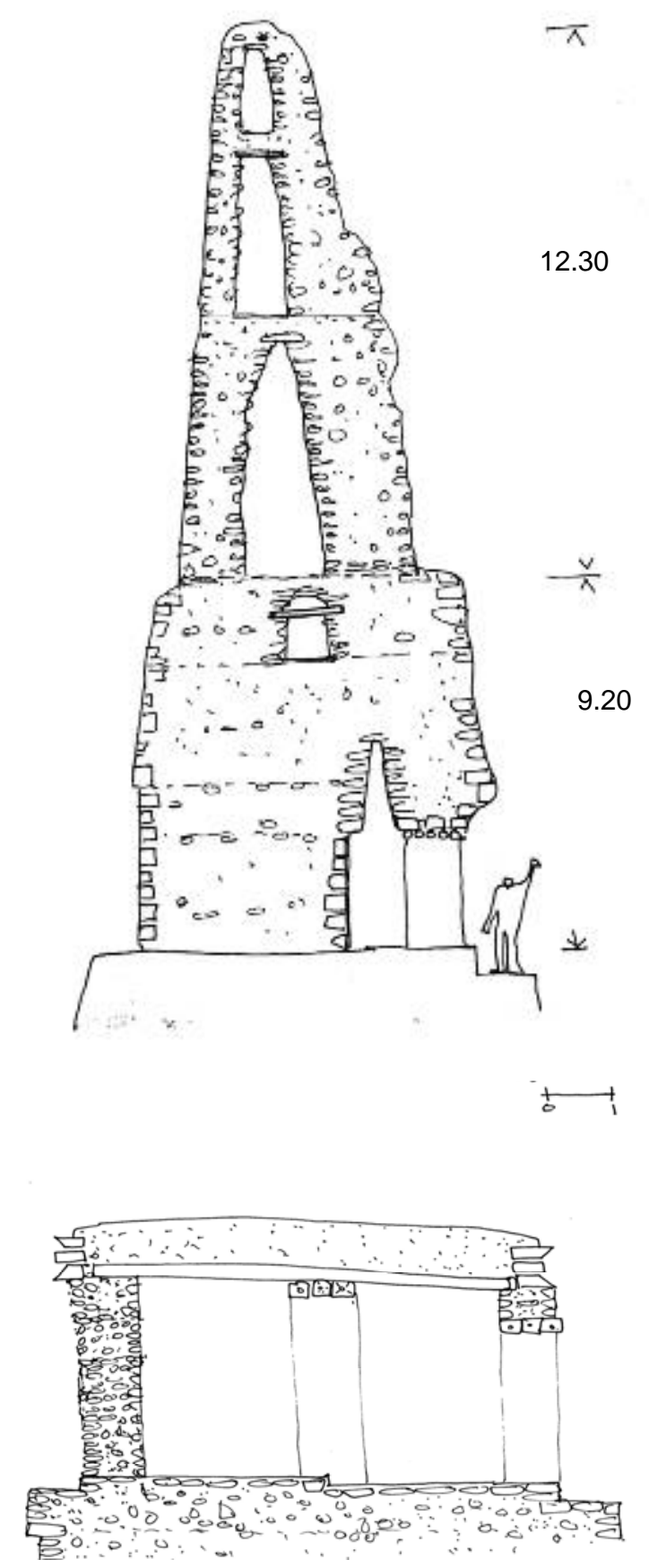

Fig. 19. Sistemas constructivos de techos

208 


\section{MATERIALES}

El quinto nivel de análisis corresponde a los materiales empleados en la construcción de los edificios. Una condición para la vasta construcción monumental en piedra de la región, por espacio de cerca de mil doscientos años sin interrupción, se debe en parte a mucha fuerza humana de trabajo y abundantes bancos de materiales. Prácticamente todo el suelo del área de estudio es un gigantesco banco de piedra caliza. Material que permitió hacer millones de bloques de piedra para sus muros y techos. También, gracias a la abundancia de piedra caliza, la producción de grandes cantidades de cal y mezclas cementantes fue posible. La cal producida se utilizada en los recubrimientos de todas las superficies de las edificaciones. Este elemento jugó un importante papel en la conservación de las construcciones prehispánicas. La capa protectora era hecha con una pasta basada en cal y arena fina, que se aplicaba sobre la superficie de pisos, muros, escalinatas, bancas y techos. Grupos de personas se ocupaban en la producción de las mezclas para la construcción y el mantenimiento periódico de las superficies de los espacios urbanos. Aquí cabe preguntarse ¿a qué costo ecológico llevó a la región este procedimiento de conservación y construcción masiva? Los recursos de madera en la región también debieron ser abundantes para soportar la rigurosa exigencia constructiva de los gobernantes. Miles de toneladas de leña se han de haber hecho humo en la quema de la piedra caliza para producir el necesario y requerido polvo para preparar sus mezclas. En este capitulo nos referiremos a la piedra, la cal, la madera y los agregados. 


\subsection{PIEDRA}

Se menciono en el capitulo 1 que la región noreste de Petén está localizada sobre la plataforma de Yucatán. El suelo esta formado por capas horizontales de rocas sedimentarias con depósitos marinos de yeso, caliza blanca suave, dolomitas yesosas, margas y arcillas yesosas del paleoceno-eoceno. Las rocas empleadas como material de construcción en el área de estudio son compuestos básicamente de carbonato de calcio y magnesio, considerados de forma muy general como rocas calizas. Este material abunda en la zona, es de fácil extracción y cuando está recién expuesto a la intemperie (alta concentración de humedad) es de fácil manejo. Ahora los maestros restauradores identifican empíricamente cuatro tipos de piedra caliza: piedra muy suave o piedra podrida (sascab), piedra suave de color blanco, piedra dura y piedra de fuego. La de consistencia más suave se emplea como agregado a las mezclas. La segunda categoría (caliza suave) se utiliza para formar bloques de piedra para la construcción. La piedra dura es empleada para la quema de cal y como material de relleno (piedra de embono). La cuarta categoría, piedra de fuego es usada como material de relleno en las construcciones; a los albañiles no les gusta emplear la piedra de fuego pues es más resistente y difícil de trabajar. En la escala de Mohs la piedra caliza tiene una dureza de 2.5 a 3.

Además de la piedra caliza, en el área de estudio hay abundantes bancos de pedernal. Roca sedimentaria construida por sílice amorfa con una dureza en escala de Mohs de 7 (dureza mayor a la obsidiana). Esta roca se utilizo para elaborar herramientas, armas, adornos y como relleno de núcleos de basamentos (como sucede en la región de la laguna Pucteal en la cuenca del río Holmul). Se supone que está roca dura fue comercializada por los mayas y fue uno de los productos de exportación de la zona. Se estima que Tikal 
fue un centro de manufacturación de pedernal, o al menos controló la producción de esta roca en la región (alrededor de Tikal se han encontrado abundantes yacimientos de pedernal).

Otras piedras como la obsidiana (dureza en escala de Mohs de 5 a 5.5) eran importadas desde otras regiones. La obsidiana se empleó profusamente para fabricar herramientas, armas, amuletos $y$ adornos. También el jade, la jadeita y la nefrita (jade tiene en la escala de dureza de Mohs 6) fue importado y empleado como armas, amuletos y adornos de la elite. Otras piedras de origen ígneo fueron importadas como basalto, granito, diorita para la producción de metates, manos de moler, cinceles y otros instrumentos. Los mayas usaron también objetos de hueso, conchas y artefactos de madera.

En el área del estudio se han realizado varios análisis específicos sobre las características particulares de la piedra caliza y su comportamiento en la selva tropical. Entre los trabajos más completos están los realizados en Tikal (por AECI en el Templo I, y el trabajo del equipo dirigido por Juan Antonio Valdés); en la cuenca Mirador (Hansen y su equipo) y en Yaxhá, Nakum, Naranjo por las consultorías dirigidas por Alejandro Flores.

En Tikal los trabajos fueron realizados por la Agencia Española de Cooperación Internacional (AECI). Los estudios estuvieron a cargo del profesor de Petrología y Mineralogía de la Universidad Politécnica de Madrid, José María García de Miguel quien realizó la caracterización de los materiales del Templo I de Tikal (García de Miguel 1992); también es muy completo el estudio realizado en 1999 por expertos de la Universidad de San Carlos en Tikal (Valdés et al 2001). En la cuenca Mirador el equipo de PRIANPEG realizó varios estudios sobre materiales constructivos: En la temporada de campo 
1993, en el sitio Nakbé (Woods y Titmus 1994, 349-356) estudiaron el proceso de reproducir bloques de piedra empleando herramientas de pedernal, simulando los procesos prehispánicos de excavar los bancos de material y extraer los bloques (piedras promedio $0.75 \mathrm{~m}$ por $0.50 \mathrm{~m}$ ). El experimento reportó que es necesario 34 horas hombre por bloque de piedra canteada. Los autores concluyen que el procedimiento de elaborar bloques es relativamente corto y la dificultad principal eran la obtención de buena calidad de piedra y las irregularidades de los bancos de materiales. En 1996 y 1998 se estudiaron siete canteras en Nakbé (Titmus y Woods 2002, 207221); los autores hacen mención a los cambios del paisaje por la extensa extracción de materiales para producir bloques de piedra; a veces a orillas de los edificios que se extienden cientos de metros en distintas direcciones. De sus estudios consideran que una persona puede extraer y cantear de 2 a 3 bloques de dimensiones promedio entre 0.90 por $0.48 \mathrm{~m}$ y $0.39 \mathrm{~m}$ de grosor a 0.50 por $0.33 \mathrm{~m}$ y $0.43 \mathrm{~m}$ de grosor por semana.

Una idea del impacto causado por la extracción de piedra en los sitios arqueológicos es visible en el plano topográfico de Tikal. Robert F. Carr y James E. Hazard documentaron cientos de canteras dentro del área urbana de Tikal (Carr y Hazard 1961, 12). En Naranjo al sur del grupo Triádico Este, se encuentran grandes canteras con cortes verticales de más de $2 \mathrm{~m}$; en algunos sectores parecen haber creado especie de calles para extraer grandes bloques de piedra. Igual en Yaxhá, en el lado norte de la Calzada Lincoln, en donde todavía se observan cortes en la roca natural de grandes proporciones.

En la región de Yaxhá, se realizaron pruebas de resistencia y composición química de la piedra. Los trabajos se realizaron en el año 2001 en: Holtún, Yaxhá, Nakum, La Blanca y Tzikintzakán; el 
estudio fue efectuado por el Centro de Investigaciones de Ingeniería, facultad de Ingeniería, Universidad de San Carlos (Informe LAB.01702). En el estudio se determinó que la selección de la piedra cortada en bloques debe observarse el seguir la veta de la piedra (como se sigue la veta de la madera), y de esa forma aprovechar mayor comportamiento de trabajo estructural. Se cuentan con resultados de la composición de la piedra en cuanto al carbonato de calcio, y sílice y las pruebas de su capacidad de resistencia practicada en los mismos (documentos en biblioteca del PRONAT, oficinas centrales).

\subsection{CAL}

De la quema de piedra caliza se produce un polvo que al ser disuelto en agua y otros agregados se convierte en una mezcla cementante muy resistente. Con una pasta preparada a partir de cal se pegaban los bloques de piedra formando masa homogénea. En principio el procesó parte de la roca caliza (carbonato de calcio), la cual calentada a temperaturas entre 900 a 1000 grados centígrados, comienza a transformarse en un polvo de cal conocido como oxido de cal o cal viva. Luego continúa la etapa llamada apagado de cal o cal muerta (hidróxido de calcio) para después estar lista para almacenarse o usarse. La cal muerta se mezcla con agua y agregados para producir volumen y para reducir los resquebrajamientos o fracturas causadas por la contracción del producto final cuando se seca y se cura. Mientras la mezcla se cura, el dióxido de carbono en la atmósfera reacciona con el hidróxido de calcio para producir carbonato de calcio y el agua después se evapora. El producto final completa un ciclo que comienza y termina con carbonato de calcio. La cal sé emplea también para preparar mortero y enlucidos. 
Investigaciones de los pisos Preclásicos de El Mirador, Nakbé y Wakna (Hansen 1994, 376) indicaron un cambio en la calidad y cantidad de las capas de estuco durante el Preclásico. Hansen menciona que en el Preclásico Medio se construían pisos solo con capas delgadas de sascab (roca calcárea suave como arena), sin hacer el proceso de quema de la piedra. Al mismo tiempo que se preparaban pisos de estuco de un grosor mínimo de $0.02 \mathrm{~m}$ a $0.05 \mathrm{~m}$ de espesor. Hansen los compara con piso del periodo Preclásico Tardío de $0.18 \mathrm{~m}$. Iguales observaciones hace con los mascarones de El Mirador (Hansen 1994, 376). En el Preclásico Medio los mascarones tenían una base de piedra tallada a la cual se le aplicaba una capa delgada de estuco, en contraste con los mascarones del Preclásico Tardío, los cuales recibieron una capa de estuco de hasta $0.25 \mathrm{~m}$ de espesor. Luego menciona que, aproximadamente después del año 100 d.C. los pisos se construyen de nuevo más delgados y de menor calidad.

En las excavaciones en el interior de la Acrópolis Central de Nakum, Zoila Calderón dice que los pisos Preclásicos se encuentran bien conservados con un promedio de $0.05 \mathrm{~m}$ a $0.08 \mathrm{~m}$ de grosor. Los pisos de transición entre el Preclásico Tardío y el Protoclásico llegan a tener $0.12 \mathrm{~m}$ a $0.15 \mathrm{~m}$ de grosor. Para el Clásico Terminal los pisos tuvieron ente $0.03 \mathrm{~m}$ a $0.05 \mathrm{~m}$ de grosor. En las últimas remodelaciones (Edificio 13, Edificio 65 y Edificio $M$ ) tienen un recubrimiento de estuco muy fino. Por ejemplo en el Edificio 65, el piso interior tiene de $0.02 \mathrm{~m}$ a $0.01 \mathrm{~m}$ de grosor (Zoila Calderón, comunicación personal 2007).

En el año 1998 investigadores del proyecto PRIANPEG realizaron estudios sobre producción de cal en seis tipos distintos de hornos tradicionales con madera húmeda y al aire libre; otro experimento 
uso un horno tipo "colonial" en San Benito. Los hornos actuales "tipo colonial" se construyen cavando en la roca tres lados y levantando el cuarto lado con piedra canteada que forma la parte frontal con el acceso. Los experimentos dieron resultados sobre rendimiento y cantidad de madera necesaria (Schreiner 2001, 405-418). En 1998 personal del proyecto PRIANPEG analizó en el laboratorio 80 muestras de repello, estuco y mortero de edificios del Preclásico Medio, Preclásico Tardío y Clásico Tardío investigando sus diferentes técnicas de composición y aplicación (Hansen y Rodríguez 2002, 203-206). El estudio determina varios tipos de cal, con selección cuidadosa del tamaño del grano en los estucos utilizados en distintas partes, los más finos eran empleados en escultura aplicada a los edificios (mascarones).

El Proyecto Nacional Tikal tiene cuatro hornos con paredes excavadas en la roca tipo "horno colonial" en Yaxhá, Nakum, Tikal y Uaxactún, con estudios de rendimiento en manuscritos no publicados (biblioteca del PRONAT en oficina central de la capital). En el año 2006, Óscar Orlando Quixchan, maestro de obras de San Clemente, realizó un estudio sobre el costo de producir la cal en los hornos de Yaxhá y Nakum, comparado con la compra convencional de sacos de cal de 50 libras en el mercado. El resultado fue que la propia producción de cal es mucho más cara comparada con el precio de la bolsa fabricada en forma industriales (relación Q40.60 contra Q26.00 en el mercado). Para trabajos especiales, como resanes de estucos y otros trabajos finos en Yaxhá se cuenta con depósitos especiales de cal con varios años de preparación. Una quema de cal produce aproximadamente 320 sacos de cal de 50 libras, y requiere de 6 trabajadores por 14 días de trabajo. Este personal realiza: el abastecimiento de leña para la quema y la piedra para quemar (4400 unidades promedio). El personal también se ocupa del armado de la 
piedra en el horno y permanece tres días y dos noches continúas abasteciendo de leña al fuego durante la quema. Luego se ocupan del retiro de la piedra del horno y su depósito en las piletas de hidratación.

Estudios sobre la preparación de los substratos y la composición de los pigmentos aplicados en edificios del periodo Clásico Tardío y Terminal, han sido realizados en paramentos de edificios de La Blanca, el Edificio 218 de Yaxhá y el edificio $G$ de Nakum (Doménech Carbo y Vásquez de Agredos Pascual 2005,127-137; 2006,139-161). Las investigadoras hicieron pruebas y análisis de laboratorio de los materiales portantes de la pintura, pigmentos, arcillas, resinas, gomas y otros compuestos para la fabricación de pinturas y su aplicación a los muros. También el mismo equipo estudio la composición de los pavimentos en diversos sectores excavados de La Blanca (Piles Selma y Saiz Mauleon 2005, 139-161). Otros trabajos en la región relacionados con la preparación de la superficie se realizan en La Sufricaya, con pintura mural del Clásico Temprano en el Edificio 1 (Foley 2005, 216-217), y en San Bartolo, con las pinturas murales del Edifico Sub. I del Preclásico Tardío (Hurst 2005, 639-640). Los expertos para los murales de San Bartolo identificaron cinco etapas para desarrollar el mural; desde el preparado de la superficie, el trazado de las figuras hasta la pintura aplicada.

Juan Antonio Valdés indica que los primeros muros con pintura se reportan en el Periodo Preclásico Tardío (Edificio H Sub.-2 de Uaxactun). Los mascarones eran pintados de color rojo, negro y crema. En menor escala se empleaba el color amarillo, ocre, verde, rosado, gris y naranja (Valdés 1992, 28). En Tikal otro ejemplo de pintura mural del Clásico Temprano fue descubierto, a ocho metros debajo de la superficie actual, en la plataforma Sub-39 del grupo 6C- 
XVI. El mural representa a jugadores de pelota con colores negro, naranja, amarillo, rojo, bajo fondo blanco. Las figuras están paradas y distribuidas a los lados de una escalinata pintada de blanco y franjas rojas. Un antecedente de destrucción total de pintura sobre una pared preparada, existió en el Edificio BXIII de Uaxactún. En un espacio con pórtico abierto estuvo una pintura mural con figuras y escritura de $3 \mathrm{~m}$ por $1.2 \mathrm{~m}$ con vivos colores (rojo, naranja, amarillo, negro y gris) de excepcional calidad. Este mural fue descubierto en 1937; ahora hasta la superficie base del muro esta perdida. Solo queda una copia a escala original de Antonio Tejeda.

En 1999 se realizó un estudio en donde se considero el análisis físico-químico y mecánico de varios elementos constructivos de Tikal (9 edificios). Se analizaron muestras de piedra de muro, mezcla de sillería, estuco y roca de cantera; con caracterización geológica, evaluación de composición de las muestras y otros estudios (Valdés et al 1999). Mencionamos anteriormente que en el año 2001 José Alejandro Flores y el Centro de Investigaciones de Ingeniería de la Facultad de Ingeniería de la Universidad de San Carlos de Guatemala, realizaron dos diferentes análisis de muestras (piedra y mezclas originales, con canteras y mezclas usadas ahora en la restauración). Se quería comparar la calidad actual con la prehispánica. Es curioso que algunos resultados dieran prueba que en la mezcla se empleo solo polvo de piedra caliza sin pasar por los procesos químicos de la quema en horno e hidratación. Datos similares han sido mencionados por Hansen en la cuenca Mirador (Hansen 1994, 376). Quizás es posible que los constructores mayas utilizaran una clase de piedra caliza pulverizada para ahorrar el proceso de quema en horno e hidratación en mezclas de poca calidad. Realizando todo el proceso para las mezclas en donde se 
requería alta disposición (estucos). Condición que evitaría el uso excesivo de leña para las quemas.

\subsection{MADERA}

La madera puede utilizarse en muros, dinteles o cubiertas. También en andamios y mobiliario. Este elemento estuvo presente y en abundancia en la región noreste de Petén y apoyo a la masiva construcción de la zona. De los terrenos no inundables se extraían maderas nobles como cedro y caoba para el mobiliario y árboles duros como el chicozapote, empleado en la construcción de dinteles en los edificios. De los terrenos inundables palos de tinto utilizado para colorantes y como madera dura en las construcciones. De las lianas o bejucos se obtenían los lazos y redes para transportar materiales y amarrar andamios o construcciones perecederas. De las plantas de algodón hicieron tejidos que se emplearon en toldos y arquitectura provisional para los patios y plazas.

Ya se mencionó que los elementos agregados de este material en las construcciones monumentales en piedra fue, con el tiempo, un factor de inestabilidad estructural, al fallar las vigas de madera de los dinteles en los accesos a las cámaras y en los techos planos.

En el capitulo resultados del programa patrimonio natural de Miguel Flores y Ximena Leiva (en Wurster 2000, 280-289) se describen los diferentes ecosistemas de la región de Yaxhá, Nakum y Naranjo, con perfiles del sistema del bosque, listados de especies arbóreas que dan una idea de la variedad de madera que dispusieron los constructores antiguos. 
Los constructores mayas emplearon los materiales cercanos a sus edificaciones utilizando generalmente la tierra de los humedales cercanos como material de relleno (margas yesosas y arcillas), en ocasiones el uso de este material era tan abundante, como sucede en los rellenos de la Plaza Este Baja de Naranjo, que en la actualidad, esos espacios urbanos, tienen una vegetación característica de los terrenos bajos o humedales (bosques de corozo).

Los constructores prehispánicos también empleaban como material de relleno todo lo que no servia, como objetos de cerámica rotos, desperdicios de herramienta lítica, restos de alimentos (huesos) e incluso los mismos edificios de sus antepasados eran preparados como masa para nuevas construcciones. Para arena, tierra o áridos se empleaban bancos naturales llamados sascaberas. En la actualidad se utiliza este sascab y el material de escombro reciclado para los trabajos de restauración. El escombro sobe los edificios se separa en tres partes: piedras grandes, piedras pequeñas y tierra mezclada con piedra pulverizada y humus, este material es tamizado en cernidores para tener un grano homogéneo apropiado para la mezcla.

Otro elemento importante es el agua, los constructores mayas, como los trabajadores que reparan ahora sus edificaciones deben contar con suficiente abastecimiento de este liquido, sin el no es posible hacer las mezclas para unir los elementos de construcción. Hoy en día el abastecimiento de agua es uno de los principales problemas para intervenir edificios en las cuencas de Mirador, Ixcán, Holmul y el área Tikal. Hay sitios como Kinal, con edificios monumentales y grandes complejos de acrópolis en donde no hay recursos de agua cerca. Incluso no hay agua para mantener a dos vigilantes 
permanentes todo el año. En 2006, durante los siete meses que se trabajó en San Clemente se tuvo que contar con personal y vehículos diarios para trasladar en toneles el agua a 5 kilómetros del centro urbano.

Una buena referencia para describir el proceso de acomodo y desintegración en las superficies de las edificaciones mayas es referido por Gaspar Muñoz Cosme, citando el informe de García de Miguel "...La pirámide del Gran Jaguar en Guatemala, encalada periódicamente y mantenida por la civilización Maya que la construyó, sufrió un fuerte ataque biológico en el ambiente tropical en que se ubica una vez desaparecida la citada civilización. Desde entonces se estableció un equilibrio natural con el entorno, donde el asentamiento de vida sobre el monumento, por un lado fue deteriorando lentamente la edificación, mientras que por otro lado ha venido preservando de la acción física y química de las lluvias torrenciales y los cambios de temperatura. Desde su deforestación para ser mostrada y estudiada, la insolación diaria y las precipitaciones han provocado la perdida parcial de la cubierta biológica de la piedra y su rápida disolución, acelerando el proceso degradativo" (García de Miguel, en Muñoz Cosme 2003, 376-377). Por otro lado, otros autores dicen "debe enfatizarse que el principal agente de deterioro de los materiales consolidados en los edificios históricos, lo constituyen la fuerza del intemperismo y en el caso de Tikal se nota que el viento, el sol y la lluvia causan efectos profundos. El proceso de deterioro esta asociado a la inclusión de agua en la estructura a través de sus poros o de micro fisuras. Los materiales calcáreos utilizados en los edificios de Tikal son de baja resistencia en tensión y por lo tanto propensos al agrietamiento por esfuerzos de tensión superficial generados por grados de humedad variable en periodos cortos (efecto Iluvia, sol, lluvia característico de las regiones 
tropicales); esto genera contracción y dilatación, propagando los agrietamientos fácilmente hacia el interior. Esto genera el movimiento de agua por capilaridad, lo que propicia un mecanismo crítico para la edificación. En general las continuas evaporaciones y absorciones de agua salobre, promueven la deposición de otros materiales que cristalizan y atacan químicamente la roca, el mortero y el revestimiento estucado" (Valdés et al 1999, 69).

Resumen: Los capítulos 3 al 7, son parte del apartado 3 de la metodología (investigaciones en los espacios construidos). En cada nivel de análisis se dan resultados para cada apartado. Como resumen tenemos una investigación del espacio construido prehispánico, la forma, algunas relaciones de edificios, algunas técnicas constructivas, y ciertas condiciones de los materiales locales. Estos datos nos permiten conocer y aplicar este conocimiento en las tareas de conservación del patrimonio edificado. En una visión mayor, los resultados aquí presentados permiten programar nuevos planteamientos de investigación científica sobre el espacio construido maya. 

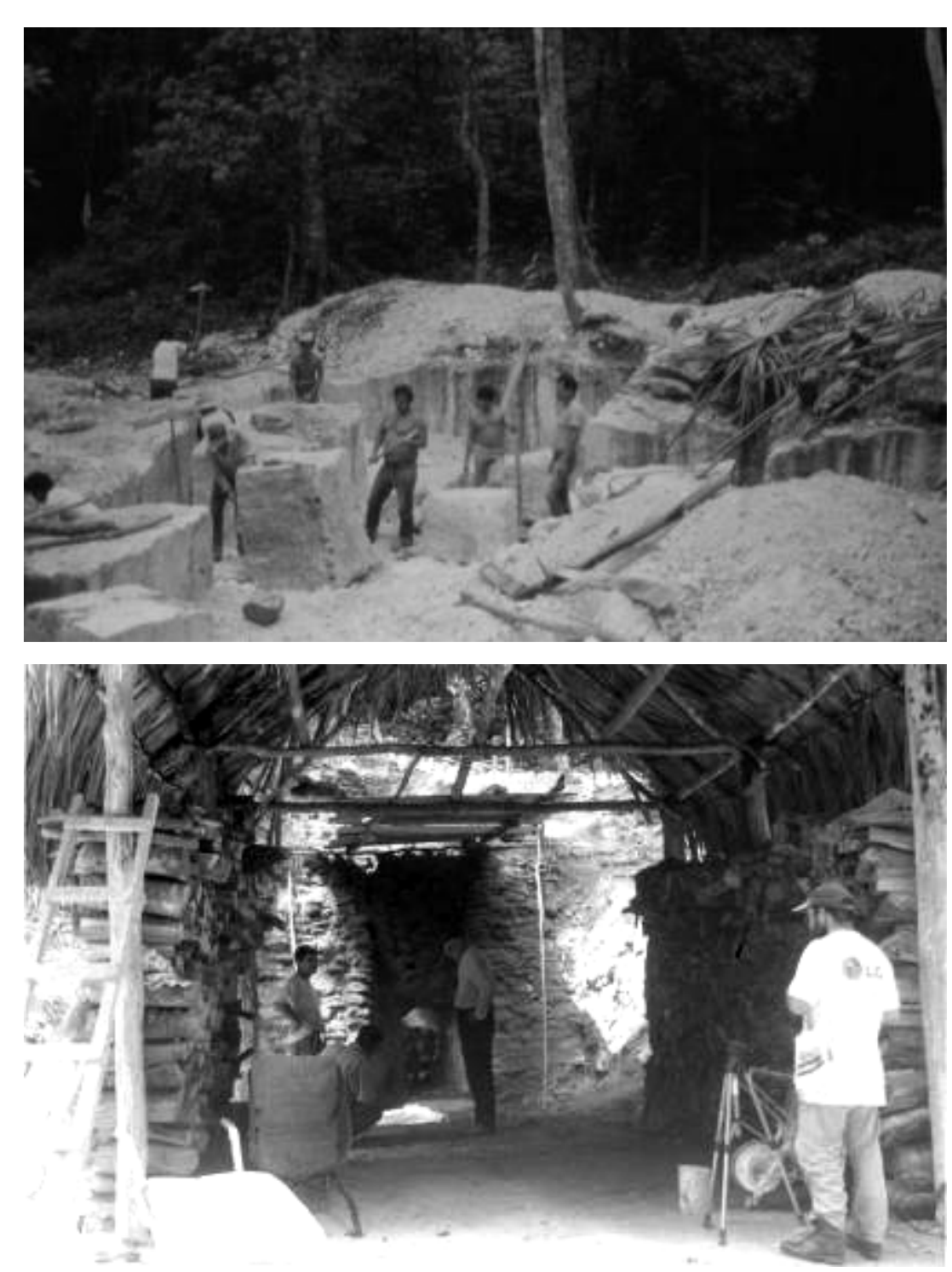

Fig. 20. Materiales de construcción, cantera y calera de Nakum 


\section{RESULTADO DE INTERVENCIONES}

Un aspecto importante en el planteamiento de este estudio fue el conocer el estado de conservación del patrimonio maya monumental. En la metodología (capitulo 2) esbozamos los conceptos y principios para elaborar esta investigación.

En este capitulo presentamos los antecedentes de intervenciones en los edificios mayas construidos en piedra. Estas acciones pueden ser ilegales, como la depredación o proyectos de inversión legalizados.

Otro apartado comenta las acciones de intervención durante el período 1987 a agosto 2006. Luego se explica la metodología diseñada para las intervenciones en el área del triángulo cultural Yaxha-Nakum-Naranjo, ahora muestra palpable de un resultado de intervención, conservación, uso y disfrute cultural.

\subsection{SAQUEO ARQUEOLÓGICO}

En los últimos 50 años se ha incrementado la actividad depredadora de objetos mayas. Por décadas los buscadores de tesoros han "abierto" las edificaciones mayas cubiertas por el tiempo, escombros y vegetación. Los saqueadores rompen muros, abren pisos y bancas, taladran los rellenos macizos de las plataformas, perforan techos, quitan escalinatas y monumentos esculpidos en piedra. El propósito es encontrar objetos culturales (cerámica policromada, piezas de jade, obsidiana, huesos tallados, escritura y otros objetos) para ser vendidos de forma ilegal en el mercado nacional e internacional de obras de arte. 
La falta de conocimiento sobre el valor real del patrimonio maya y el abandono en que se encuentra la gran mayoría de sitios arqueológicos en la región y el país, propician que bandas organizadas de buscadores de tesoros dañen al patrimonio cultural prehispánico.

Para el área del estudio el interés por culturas perdidas se remonta a mediados del siglo XIX. En esta época los bienes patrimoniales mayas eran tratados como cosas extrañas o "curiosidades"; influidos por los descubrimientos y expolios de otras grandes culturas en otros continentes. En esas épocas se negaba su ascendencia local y se argumentaban teorías fantásticas como Atlantis y otros.

El gobernador de Petén Modesto Méndez (1848), fue el primero en perforar muros y movilizar monumentos de piedra con el propósito de encontrar "curiosidades". La búsqueda de tesoros escondidos entre los edificios prehispánicos, fue el objetivo de personajes que viajaron por la selva de Petén. Uno de ellos fue J.W. Boddam, quien en 1875, extrae un fragmento del dintel 3 del Templo I de Tikal; ahora en el Museo Británico de Londres. En 1876, Gustav Bernoulli ordena la extracción de un dintel del Templo IV de Tikal; ahora en Basilea. Otros exploradores como H. J. Spinden, J Carmichael, o T. Gann buscan en las ruinas perdidas de Petén objetos de valor comercial. Gann escribe en su libro "ciudades Mayas" (Gann 1928, 216-217) un capitulo titulado "Tikal y la búsqueda del templo del tesoro". Secuelas de estos buscadores encontró Franz Blom (1928) al visitar el sitio de Chochkitam, Blom describe, por primera vez, los saqueos encontrados en los edificios e informa que, según sus guías, estas agresiones tenían cerca de 20 años de haberse realizado (Morley 1938, 460). A partir de la década de 1960, se incrementa el expolio del patrimonio local. En principio este aumento de agresiones se debe 
a tres factores. El primero es que los objetos mayas de la región, son reconocidos internacionalmente como obras de arte de primera calidad. El segundo fue el final del "Proyecto Tikal" del Museo de la Universidad de Pensilvania (1969); con el despido de cientos de trabajadores con experiencia en excavación y el tercer factor, la aparición de la Empresa Nacional de Fomento y Desarrollo Económico de Petén FYDEP (1956); con su política de cambios fundamentales en el departamento.

En 1970 el Ministerio de Educación Publica, publicó la monografía oficial del departamento (Sosa 1970, 488-493), En dicho texto, en uno de los capítulos se repite la leyenda del "templo del tesoro", hablando sobre la supuesta existencia de lingotes de oro enterrados en la región noreste del departamento.

El Petén tuvo una gran tradición en la producción de monumentos (estelas y altares) tallados en piedra. Solo para la región del noreste de Petén Morley contabilizó 325. Los monumentos esculpidos tienen información histórica local; revelan acontecimientos importantes de las ciudades y sus gobernantes. Además los monumentos fueron trabajados con gran calidad y técnica artística. De ellos la mayoría están ahora fuera de Petén. Unos pocos monumentos esculpidos yacen en su lugar original, muy deteriorados, medio enterrados entre los escombros de las ciudades en ruinas. Otros están desaparecidos, en museos y colecciones privadas, guardados en bodegas o se destruyeron en el afán de reducirlos en partes para facilitar su transporte fuera del departamento. Para cortar los monumentos de piedra se emplearon sierras, taladros especiales y fuego. La época más terrible para los monumentos esculpidos en piedra fue en las décadas de 1970 y 1980. En 1972 Karl Meyer (Meyer 1972, pp. 3537) denuncia el saqueo intensivo en 28 ciudades mayas de Petén. 
Piezas que aparecen luego en: New York, Houston, Los Ángeles, Forth Worth, Mineapolis, Cleveland, Denver, Colonia y otras ciudades. En esos tiempos, varios autores denuncian el vandalismo en Petén: Clemency Coggins (1969, 1970, 1972, 1992) Ian Graham (1986a), Karl Herbert Mayer $(1977,1980,1987)$, Miguel Valencia $(1985,1988)$, Joya Hairs (1973) Luis Lujan Muñoz (1974), Jorge Lujan Muñoz (1965) y otros.

Con el tiempo la actividad de saqueo arqueológico se diversifica agrediendo todo tipo de edificios. Para las décadas de 1970 y 1980 grupos enteros de vecinos se dedicaban al saqueo; fue tanto el auge de esta actividad ilegal que apareció un grupo de personas que se dedico a asaltar a los saqueadores. Los depredadores al verse afectados se organizaron con armas para protegerse de los asaltantes. Poco después con la guerra interna en Petén, las bandas de saqueadores disminuyeron. En la década de 1980, las personas que andaban por la selva sin justificación alguna eran reclutadas por los guerrilleros. En esa época algunos sitios arqueológicos fueron utilizados como bases de campamentos. Entre ello Xultún, y San Bartolo. Estos sitios quedaban en la línea de recorrido de las fracciones guerrilleras. Otro caso parecido (fuera del área de estudio) fue Piedras Negras. Todavía en el año 2001 se encontraba en ese sitio los restos de un poblado revolucionario que fue atacado varias veces con bombardeos.

A partir de las décadas de 1980 y 1990; se incorpora al expolio de la cultura maya, el saqueo de tumbas reales. Ejemplos dolorosos son las famosas tumbas de Río Azul (1983). En las últimas décadas, ya no solo se agreden edificios monumentales sino que los saqueadores destruyen los edificios menores y grupos de edificios alargados en busca de talleres de cerámica pintada y otras piezas valiosas en el 
mercado internacional de arte. Las dimensiones del saqueo llegan a extremos tan grandes como en el complejo "Mano de León" de Tintal (cuenca Mirador); en donde se contaron 2154 aberturas en los edificios (Hansen et al 2006, 686). Las edificaciones parecen ser cortadas en partes por el excesivo esfuerzo de los saqueadores. A veces la búsqueda es tan intensa que prácticamente "vacían" las construcciones. Estas nuevas agresiones al patrimonio son dejadas "abiertas", aumentando así la inestabilidad y el peligro de colapso en los edificios prehispánicos.

La tragedia es que muchos de los objetos robados, además de presentar bellas composiciones estéticas de excelente calidad técnica, también llevan consigo escritura o sea documentación histórica. Por tal razón el daño causado al ser extraído sin documentación, la escritura pierde contexto dejando historias cortadas. Uno de los caminos para conocer el pasado maya es leer su mensaje escrito, estos mensajes están siendo destruidos por el tiempo y en las últimas décadas por bandas de saqueadores. Las acciones de los gobiernos de turno no han podido frenar este riesgo al patrimonio prehispánico, que es un fenómeno regional y mundial.

\subsubsection{Intentos para detener el saqueo}

Intentos para evitar la depredación del patrimonio cultural y natural inician en 1882 con la comisión de límites para establecer las fronteras del departamento con el vecino país de México. Leyes generales para proteger el patrimonio cultual del país se registran desde 1893. Fuera del área del estudio mencionamos algunos acontecimientos importantes como: 1893 Ley protectora de Gumarkaj, en Quiche (luego de usar sus piedras talladas para construcciones modernas); 1894 se establece la primer oficina de inspección de monumentos arqueológicos, y la ley específica sobre protección y 
conservación (decreto 479). En 1921 Ley declaratoria de Quirigua, en Izabal (como pertenencia de la Nación); 1933 Ley reglamentaria del museo de arqueología. En 1946 creación del Instituto de Antropología e Historia (IDAEH); 1947 Ley de protección y conservación de los monumentos y objetos arqueológicos históricos y típicos (decreto 425); 1955 declaratoria Parque Nacional Tikal; 1964 Ley protectora de Kaminal Juyú, en la ciudad capital (para ese entonces destruida en mas del 90 \%); 1970 creación de zonas y monumentos arqueológicos históricos y artísticos de los periodos prehispánicos e hispánicos.

La primera oficina con sentido de atención a los edificios patrimonio de Guatemala aparece después del terremoto de 1976. En esa época y con apoyo internacional se crea la unidad para la recuperación del patrimonio edificado dañado por el terremoto (URPAC, luego PROCORBIC).

UNESCO Guatemala realizó una colección de leyes sobre la protección del patrimonio cultural (UNESCO 2006); en esta recopilación se incluyen los principales convenios internacionales sobre el comercio ilícito de bienes culturales y otros temas sobre patrimonio suscritos por Guatemala.

Un riesgo al patrimonio prehispánico es la falta de consistencia del mismo con las autoridades y los pobladores actuales; de allí el abandono en que se encuentran y la condición de emergencia o peligro general de perdida de patrimonio en todo el departamento del Petén. El mismo desconocimiento del valor real presente y futuro del patrimonio prehispánico provoca que vecinos depreden sus restos tangibles. Sobre los restos de ciudades mayas se realizan asentamientos, se queman sus espacios urbanos para siembras, se parten por caminos nuevos y otros. En referencia a sitios 
arqueológicos "partidos" por nuevas vías de comunicación están: Salsipuedes 1, Naranjal, El Sombrero, Ramonal, La Pita, El Pilar, Naranjo, Trinidad, Aguacate, Chochkitam, Laguna Perdida, Buenos Aires, Dos Hermanas, Balamtún y otros. Sitios arqueológicos que están dentro de tejidos poblados nuevos: Uaxactún, Colonia Itzá, isla de Flores, Tayasal, Paxcaman, Yalain, Yo'Ol Wits, La Amapola, Lain Perdido, Ixlú, Holtún y otros.

"El problema del saqueo arqueológico en Guatemala no es solo un problema sucedido en remotas selvas; es un fenómeno que ataca la razón de ser de la arqueología y de los arqueólogos: la esencia del hombre desaparecido por medio de sus obras materiales, es también una negación de nuestra historia, es por fin una vergüenza nacional en un país que pretende y se enorgullece de contar con una de las civilizaciones más relevantes de toda la humanidad. Pero ese drama no es desde ningún punto de vista insubsanable, se necesitan leyes para reducirlo, es cierto, pero no tendrían razón de ser ni de existir tales leyes si todos los guatemaltecos nos convirtiéramos en guardianes e inspectores de ese patrimonio que es parte consubstancial de lo que somos" (Valencia 1988).

En relación a la toma de conciencia del valor cultural del patrimonio maya, una forma de "convencer" a los actuales pobladores de su importancia es realizando proyectos de inversión (ejecución) enseñando así a los nuevos vecinos que los vestigios culturales son medios de identidad, desarrollo local y que deben protegerse, usarse y disfrutarse.

Los proyectos de investigación arqueológica no se interesan por el daño causado a los edificios por los saqueos. Un ejemplo que ilustra esta condición sucedió con el robo de tumbas en Río Azul (década de 
1980). El alarmante saqueo con aberturas gigantes en los edificios de la ciudad motivó a que se realizara un proyecto extranjero en el sitio. El Proyecto Río Azul, investigó y documento las tumbas saqueadas y descubrió otras. Se realizaron ruidosas publicaciones en revistas como National Geographic; pero el proyecto no hizo nada por atender los edificios saqueados en peligro de colapso. Esos edificios continúan hoy en día "abiertos" sin atención y en grave peligro de colapso (Grazioso et al 2007).

\subsubsection{Cantidad de saqueos}

En el cuadro 6 (Registro de saqueos en edificios), se presenta los datos sobre el saqueo. La dimensión del saqueo asciende a más de 6000 depredaciones registradas en los planos esquemáticos. La tabla incluye un espacio para observaciones en donde se hacen comentarios y comparaciones. Por ejemplo se incorporan los datos de documentación de saqueos de otros proyectos, o se dan comentarios como: continúan los saqueos en los edificios a pesar de haber vigilancia; como en Río Azul (Grazioso et al. 2007, 673-682). También se comentan acciones extrañas como ocurre en el área del sitio Holmul, en donde un saqueo pequeño de pronto aparece más grande mostrando vestigios de arquitectura del Preclásico, y otros casos.

Desde 1987 se consideró que los saqueos podrían ser un indicador del estado de conservación de los edificios, en relación al peligro de desintegrarse por las agresiones recientes en él. Los grados de depredación se dividieron en tres categorías: "muy saqueado", "saqueado" y "poco saqueado". Ahora se incorporan dos categorías nuevas que indican las acciones realizadas para mitigar el daño en las construcciones. Estas acciones son: "saqueo parcialmente documentado y rellenado"; y "saqueo totalmente documentado y rellenado". En el año 1995, inició esta actividad, con el registro 
sistemático y relleno de depredaciones en edificios. Los trabajos comenzaron en el sitio Poza Maya. Para el año 2006 se habían atendido 28 sitios con más de 848 rellenos de saqueos. Con esta medida se quiere reducir en parte el daño causado por aberturas expuestas en las construcciones.

Los daños más frecuentes son filtración de agua al núcleo del edificio, derrumbes, pérdida de cohesión de las partes constructivas y otros. Las acciones de relleno de saqueos en edificios son considerados como medidas de conservación "pura". Este tipo de trabajo muchas veces no tiene otro fin más que el de proteger y volver a formar masas homogéneas en las edificaciones, sin el propósito de luego presentarlas a un público.

El cuadro 7 (indicadores de saqueo) muestra las prioridades de atención a la depredación. Como resultado del análisis regional se detectó que en 14 sitios hace falta realizar acciones "muy urgente"; la zona de mayor prioridad es la cuenca Ixcán (Río Azul, Kinal, Chochkitam, Xmakabatún, La Honradez y Xultún); la segunda prioridad es para la cuenca Mirador (La Muralla, Naachtún y Tintal). El área Tikal (El Zotz y El Diablo) y la cuenca Holmul (Holmul y Witzná) comparten la prioridad 3; y las cuencas Los Lagos y Mopán les corresponde las prioridades 5 y 4 . La cuenca de Los Lagos tiene la menor prioridad en la región noreste, debido a que en esta zona se ha realizado la mayoría de acciones de documentación y relleno de saqueos, también cuenta con buena parte de edificios rescatados o restaurados. 

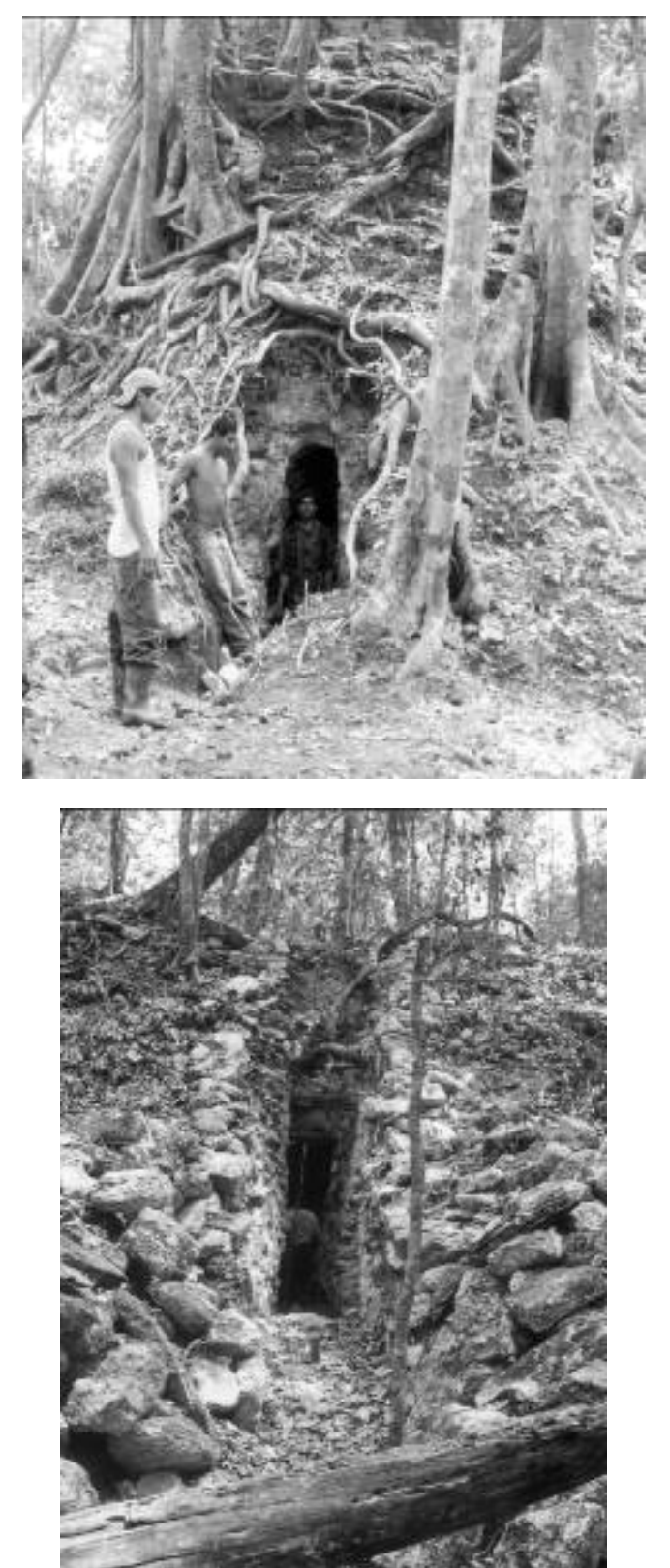

Fig. 21. Daños en edificios causados por saqueo 


\subsection{OTROS FACTORES}

La falta de conocimiento sobre el valor real del patrimonio maya y el estado de abandono de los sitios arqueológicos en la región y el país, propician el saqueo arqueológico. Estos mismos factores, también favorecen el deterioro físico de los monumentos. En este caso la no intervención del Estado, con acciones de rescate y mantenimiento básico, causan la pérdida de la sustancia tangible de las edificaciones. Recordemos también que la condición actual de las ciudades prehispánicas y sus monumentos edificados tiene categoría de "ruina arqueológica". Los elementos que lo conforman están desarticulados, sin sus superficies protectoras de estuco y techos, en simbiosis con la vegetación exuberante de la selva tropical.

Entre los factores naturales que influyen en la conservación del patrimonio edificado maya podemos mencionar: inundaciones, huracanes, terremotos, erupción de volcanes, incendios y otros. En relación a amenazas por sismo, en el año 2002 se registraron daños comprobados en edificios prehispánicos de Topoxté, Yaxhá y Nakum. La causa fue un sismo frente a las costas de Honduras. (Quintana, Noriega y Galindo 2002). Antecedente de daños por sismo (terremoto de 1976) se muestra en el Edificio 1 del sitio Tzikintzakán (cuenca Mopán). En Tikal, los antiguos maestros se recuerdan de daños menores en sus edificios (Jacinto Rosado Lanza, comunicación personal).

Otro riesgo al patrimonio edificado maya son los incendios naturales o incendios provocados por el ser humano. En épocas prehispánicas hay evidencia de sectores de ciudades quemados por conflictos internos. Hoy en día la selva se quema constantemente para realizar cultivos o siembra de pasto para ganado. Los incendios causan irreparables daños sobre todo en monumentos esculpidos en piedra. 
Los grabados de las estelas o altares explotan por el calor del fuego, perdiéndose valiosa información para siempre. Ejemplos hay por todo Petén (La Corona, Naranjo, varias veces en Motul, Huacutal, La Montura, Calzada Mopán, Naranjal, Camalote, y otros).

La vegetación tropical sin control sobre los edificios mayas es una amenaza latente en los sitios arqueológicos y ha determinado la pérdida de un gran porcentaje de su tejido arquitectónico. Árboles de más de $30 \mathrm{~m}$ crecen sobre los edificios mayas sin control, estos al caer (por diversas causas) traen consigo elementos constructivos, perdiéndose así substancia original de los edificios. Este tema especifico es tratado mas adelante en el apartado 10.3 (control de vegetación).

Una condición natural sobre el patrimonio edificado maya, es el irreversible deterioro del material pétreo. La meteorización o el intemperismo es una alteración de los materiales rocosos expuestos al aire, la humedad y al efecto de la materia orgánica; proceso del cual sólo se podría retardar la desintegración natural de los materiales con medidas preventivas o correctivas, que no se realizan. En principio los agentes de detererioro son físicos, químicos y biológicos. Además debe agregarse el componente de antigüedad de las construcciones.

Los agentes físicos se dividen en movimientos mecánicos exteriores y movimientos mecánicos interiores; en el primer grupo estaría el hombre con su incapacidad operativa para conservar los edificios abandonados. El vandalismo con los buscadores de tesoros mayas y sus acciones ilegales, la falta de educación de los visitantes quienes rallan las superficies de los monumentos y caminan sobre superficies originales sin cuidado. También son riesgo al patrimonio edificado, las 
acciones propias de las técnicas de investigación arqueológica y de intervención en los edificios.

En otro nivel estarían los nidos de animales dentro de los edificios (termitas y otros), el movimiento oscilatorio (viento) y presión de los árboles sobre los edificios; otro agente físico es el clima con su acción disgregante por contacto de las superficies sin protección, con la lluvia y el lavado de los materiales y la tensión térmica causada por la insolación, aire, luz y los cambios de temperatura sol-lluvia-sol característica de las regiones tropicales. Entre los movimientos mecánicos internos se consideran los esfuerzos producidos en los bloques de piedra caliza por la transformación de sales en cristales.

En los agentes químicos se toman en cuenta los movimientos del agua dentro de los muros de piedra. Los desprendimientos de Co. de la vegetación y la composición química del suelo (oxidaciónreducción) y la consecuente acción de sales y ácidos que ascienden por la humedad a los muros por capilaridad y otos agentes como el $\mathrm{PH}$ del agua.

Entre los agentes biológicos está la vegetación: árboles de gran tamaño, arbustos y plantas vasculares que extraen nutrientes de los muros y techos de piedra que los soportan. Aquí se consideran los hongos, mohos, musgos, líquenes que se adhieren a las superficies y por su proceso de expansión y dilatación causan daños mecánicos en las paredes. En otros casos causan el impedimento de la respiración o la extracción de nutrientes de los muros portantes. Otro agente biológico son los organismos vivos o sus productos residuales de descomposición (excremento de aves y mamíferos) que realizan ataque físico químico de bacterias. En resumen estos elementos del 
deterioro, junto con la acción o no acción del hombre determinan el estado de conservación del patrimonio edificado del área del estudio.

\subsection{INTERVENCIONES EN EDIFICIOS}

Ya se mencionó que la primera intervención registrada en Petén se remonta al descubrimiento oficial de Tikal, en 1848. Entre 1881-1882 el ingles Alfred Percival Maudslay ordenó cortar los árboles sobre los principales edificios de Tikal; el propósito fue poder limpiar de vegetación los edificios y tomar las primeras fotografías. Entre 18951904 el Alemán-Austriaco Teoberto Maler realizó la segunda tala de árboles sobre los edificios de Tikal y tomó nuevas fotografías. En 1909, en su segundo viaje, el francés Maurice de Perigni, ordeno la tala de árboles sobre los edificios del Sector Sur de Nakum; en 1910 llega al mismo sitio, la octava expedición del museo Peabody con Alfred M. Tozzer y Raimond E. Merwin, quienes realizaron otra masiva tala de árboles, para tomar fotos panorámicas. Estas acciones sobre los edificios de Tikal y Nakum, si bien produjeron fabulosas fotografías y planos de los grupos de edificios; luego del corto trabajo de campo, las ruinas arqueológicas fueron dejadas abandonadas sin ninguna medida de protección. La vegetación sobre los edificios permitía de alguna manera mantener un microclima estable que fue alterado con el corte masivo de árboles.

En 1912 Merwin, realizó la primera investigación arqueológica en el área de estudio, al excavar en el Edificio B del grupo II de Holmul. Merwin descubre por primera vez que dentro de un edificio se encuentran otros edificios más tempranos. El edificio "Merwin" se encuentra hasta ahora "destapado" y en grave peligro de colapso. Este descubrimiento, un edifico encima de otro, es corroborado poco después por las destructivas excavaciones del instituto Carnegie de Washington en Uaxactún. 
8.3.1 UAXACTÚN 1927-1937

En 1914 se descubre Uaxactún, 13 años después inicia allí un extenso proyecto de investigación arqueológica del instituto Carnegie de Washington (1927-1937). Al mismo tiempo fuera del área del estudio, la misma institución realizo otro proyecto paralelo en Chichen Itzá. Los dos con conceptos distintos, para Chichen Itzá se considero la restauración y el uso de la ruina; para Uaxactún no y por lo tanto era válido investigar extensivamente sin preocuparse por la destrucción provocada por la excavación científica. Con este criterio las trincheras de investigación, con más de $4 \mathrm{~m}$ de ancho, escogieron los "mejores" ejemplares de edificios con arquitectura expuesta. Edificios que fueron vaciados o destruidos sistemáticamente. Como resultado se tiene: esplendidos cortes estratigráficos publicados de grupos de edificios, una correlación de la cerámica con la arquitectura que todavía sigue vigente, fabulosos dibujos de reconstrucción de diferentes fases constructivas y un montón de escombros de edificios tirados en las plazas alrededor de las excavaciones. Famosos fueron los trabajos en el grupo $\mathrm{E}$ con la pirámide aislada en medio de la plaza (E-VII Sub.); pirámide que fue pelada, destapada y dejada expuesta con sus fachadas estucadas y pintadas con grandes mascarones del Preclásico.

En el grupo A de Uaxactún la misma institución vació el complejo A-V, con el famoso grupo triádico convertido en acrópolis (12 capas constructivas). Muy cerca se realizó el vaciado del edificio pirámide A1, destruida fase por fase. Esta curiosidad "científica" fue considerada por Daniel Schávelzon como el caso más notable de arqueología destructiva en toda Mesoamerica (Schávelzon 1990a, 120). También fue famosa la pintura mural del Edificio B-XIII ahora totalmente desintegrada. (Ricketson y Ricketson 1937), (Smith R. 1937 y 1955). 
8.3.2 Proyecto Tikal (1956-1969)

Desde 1937 investigadores como Edwin Shook, Ledyard Smith y E. O. Pollock, buscaban un sitio en Petén para realizar otro proyecto de investigación. A causa de la segunda guerra mundial este proyecto fue retrasado hasta 1956, fecha en que inicia el "Proyecto Tikal" del Museo de la Universidad de Pensilvania (1956-1969). Desde 1951 se realizaron preparativos para echar andar el nuevo proyecto, se construye una pista aérea y en 1955 se declara un área protegida, de 24 kilómetros por 24 kilómetros, como Parque Nacional Tikal. En realidad los trabajos de campo inician en 1957; veinte años después de Uaxactún, las condiciones de "desarrollo" en la región ya habían cambiado un tanto y también las normas internacionales de UNESCO estaban publicándose. El concepto de este proyecto considero además de la investigación, la preparación de ciertos sectores de la ciudad para que fuera expuesta al turismo. El primer director fue Edwin Shook (1956-1961); Shook trabajó antes en Copán. Luego fue director William R. Coe. Para realizar los trabajos de investigación y habilitación del área arqueológica se diseñó un plan de caminos vehiculares internos y fachadas o sectores de fachadas que debían prepararse para el turista.

Los caminos atravesaron espacios de plazas y calzadas que llegaban hasta la Gran Plaza; luego con la demanda de visitantes, se amplio la red y se abrió literalmente un nuevo camino por atrás de la Acrópolis Norte, aquí se demolieron parte de edificios ( 5C-37 y 5C-39) para facilitar el acceso de vehículos a la Plaza Oeste. Plaza que fue considerada como "estacionamiento principal". La primer parada, del recorrido en vehiculo, correspondía a la Plaza de las Pirámides Gemelas (grupo Q). 
Los trabajos de restauración de la arquitectura de Tikal estuvieron a cargo, primero por Aubrey Trik 1959- 1964 (quien trabajo antes en Copán y Zaculeu) y luego por Jorge Guillemín (trabajo ante en Mixco Viejo e Iximché). La política a seguir es clara al escribir William R. Coe "La preparación de los edificios explorados en Tikal reviste dos formas. La más común ha sido la consolidación, por medio de la cual la antigua mampostería es reforzada para impedir el progreso del deterioro. Las restauraciones han sido practicadas también; por este método se fabrican bloque de mampostería nueva para sustituir a los antiguos y dar a la obra la apariencia de lo original. Muchas veces se combinan las dos técnicas en la misma estructura pero tratando siempre de mantener el efecto de ruina con el agregado de tener la precisión que sólo la reparación puede dar" (Coe 1965, 27).

En resumen las intervenciones del Proyecto Tikal se dividieron en dos partes, uno para el área central y otra para investigaciones en la periferia de la urbe. Ambas tratadas con el mismo criterio. En las afueras del centro, en donde no estaba previsto el paso de turistas, los edificios de menores dimensiones (como el área de los actuales comedores), fueron atravesados por trincheras de investigación; que luego fueron dejadas abiertas. Los restos de estos edificios desarticulados, fueron rellenados posteriormente entre los años 1987 y 1990.

\subsubsection{Grupo Q}

En 1959 se iniciaron los preparativos para la intervención de edificios en Tikal. El programa de restauración de Aubrey Trik, inicia en la primera parada diseñada para el circuito en vehículos. Aquí se consideran tres edificios del complejo $\mathrm{Q}$. La primera fue la Pirámide Gemela 4E-36, formada por cinco plataformas escalonadas, sin espacio interior en la parte superior y cuatro escalinatas, una a cada 
lado. El circuito turístico considero parar al centro de la plaza. Por esta razón el Edificio 4E-36 fue liberado de toda su vegetación, se realizo una investigación arqueológica y luego se reconstruyó, con piedra nueva, la fachada oeste y parte de las fachadas norte y sur; esto con el propósito de dar "volumen aparente" al edificio y favorecer el ángulo escogido para las fotografías de los turistas.

El recubrimiento con piedra nueva en la pirámide 4E-36 colapsó al poco rato; al respecto Guillemin escribe: "al reconstruirse el frente de la pirámide este, la fachada se derrumbó (lluvia); en ausencia de Trik se había descuidado la limpieza del núcleo y su debida interpenetración con la parte reconstruida" (Guillemin 1968, 119). Para la reparación de la reconstrucción se trajeron albañiles de Alta Verapaz (comunicación personal de Jacinto Rosado Lanza).

Con el mismo criterio se restauró al sur del conjunto arquitectónico el Edificio 4E-37. Este edificio es una construcción alargada con nueve accesos en su fachada norte (hacia el punto de vista diseñado en el recorrido turístico de Tikal). Aquí se eliminó la vegetación y se consolidaron los muros a altura de los escombros originales, sin llegar a la reconstrucción total.

El tercer objetivo se localizo al norte del grupo (Edificio 4D-39). Este edificio corresponde a un muro perimetral sin techo con un acceso en la fachada sur (punto de vista del diseño de recorrido). En este caso se eliminó la vegetación, se vació el espacio interior y se reconstruyó parcialmente el muro sur, parte de los muros laterales (este y oeste) y el arco de acceso al recinto interior (nuevo). El cuarto edificio del grupo, el Edificio 4E-38 fue dejado con vegetación tal y como fue encontrado. Adicionalmente Jorge Guillemin, entre 1958 y 1959, 
recompuso los monumentos esculpidos en piedra frente al edificio $4 \mathrm{E}$ -36 y la estela dentro del recinto sagrado 4D-39.

\subsubsection{Gran Plaza}

En la intervención de los edificios que conforman la Gran Plaza, Aubrey Trik empleo diferentes criterios de restauración. El recorrido turístico en vehiculo (inicialmente fue un carretón jalado por un tractor) debió parar al centro de la Gran Plaza; y de allí tener las vistas de los edificios. Como primera medida se elimino toda la vegetación sobre los edificios circundantes y la plaza. Trik resuelve para el Templo I restaurar parcialmente la fachada oeste con una reconstrucción total de las nueve plataformas escalonadas al lado norte de la fachada; "alargándose" (para dar volumen a la toma fotográfica) a un pequeño tramo de la fachada norte (esquina noroeste). Del lado sur de la fachada oeste, solo reconstruye las primeras dos plataformas escalonadas y consolida el resto de las siete plataformas siguientes. La escalinata ceremonial, al centro, fue consolidada en una fase constructiva anterior; solamente las cinco primeras escalinatas de la fase final fueron reconstruidas. En la fachada sur solo se prolonga una parte de la reconstrucción de la primera plataforma escalonada. La fachada este y sus esquinas no fueron intervenidos por Trik.

En la parte superior del Templo I, en el espacio construido sobre la plataforma piramidal (templo) se realizaron consolidaciones menores, ya que estaba en mejor estado de conservación; en este sector se pusieron de nuevo los dinteles (concreto armado), se reparó la crestería y el techo, y se reconstruyeron las gradas del basamento del templo. Para poder acceder al templo, se coloco sobre las gradas consolidadas (de la fase anterior) una cadena metálica. Al respecto Schávelzon dice que la cadena para facilitar la subida al público 
produjo, el trafico de turistas, un deterioro tal que para 1975 ya era necesario volverla a reconstruir" (Schávelzon 1990a, 162). Dicha cadena fue quitada en 1988, argumentando el daño al edificio (la parte consolidada) y el peligro que había para las personas que subían hasta el templo, sobre todo en la época de lluvia era extremadamente peligroso.

La técnica para investigar el Templo I fue a través de túneles. Extrayendo los materiales por medio de vagones y rieles montados sobre la escalinata de la plataforma escalonada. Entre 1957 y 1964 se realizaron: Sobre el eje este-oeste del edificio un túnel atravesando todo el edificio, (túnel 19), otros túneles menores en las plataformas No. 5 y No. 8; un túnel de exploración en la fachada sur; varios túneles al norte de la escalinata, donde se encontró la tumba 116 (1962). Las acciones en el templo I fueron concluidas en 1964.

En la plataforma escalonada del Templo II, Trik emplea la reconstrucción total de la fachada este (incluyendo la escalinata ceremonial) y toda la fachada norte, incluyendo un sistema de escalinatas secundarias. Esto permitía tomar excelentes fotografías del edifico desde la primer terraza de la Acrópolis Norte. Después de la actuación del "Proyecto Tikal" se continúo con la reconstrucción parcial de la fachada oeste y la fachada sur. A pesar de que el edificio cuenta con una escalinata reconstruida para acceder al recinto superior (1962) ahora se cuenta con una escalinata de madera (fachada sur). El recinto superior fue tratado igual al Templo I; con la reconstrucción del acceso y la reposición de nuevos dinteles de concreto armado.

En las temporadas de 1964 a 1969 se realizaron intensos trabajos de restauración y reconstrucción a cargo de Jorge Guillemin. En cuanto 
a intervención, la obra de mayor envergadura fue la Acrópolis Norte. Aquí se tomó dos vías de trabajo: por un lado, la limpieza de escombro y restauración de los edificios exteriores, y por otro, la realización de un corte de más de $150 \mathrm{~m}$ de largo por casi $4 \mathrm{~m}$ de ancho para conocer con detalle su historia. Por supuesto, este corte arrojo información de inestimable valor para la arqueología, e incluso permitió descubrir ejemplos únicos de arquitectura del periodo Preclásico; pero desde el punto de vista de la conservación fue negativo.

Los trabajos realizados en los Edificios 5D-20, 22, 23, 25, 26, 32 y 34 fueron de consolidación en algunos casos (Edificios 5D 34 y 5D-25), de reconstrucción en la mayoría. Entre los Edificio 5D-34 y 33 y 5D-33 y 32 se simularon dos mascarones gigantes. Los tres templos ubicados al este del conjunto, al igual que los Edificios 5D-24 y 5D35, fueron dejados sin explorar. La política general de reconstrucción fue la misma que para todo el sitio; solo se volvieron a rehacer taludes, escaleras y muros hasta las alturas originales y nunca más allá de ellas. Hoy en día es difícil saber con precisión, si no es con fotografías tomadas durante los trabajos, o anteriores, qué es nuevo y que antiguo.

El problema más grave originado por este trabajo lo representó la intervención en la Pirámide 5D-33, la más alta en la Acrópolis Norte, y la cual fue demolida casi en su totalidad para liberar diferentes fases constructivas anteriores. La demolición de este edificio modifico sensiblemente la imagen de la Gran Plaza, tal como era en el Clásico Tardío. El Edificio 5D-33, el Templo I y el Templo II tenían una relación triádica en la Gran Plaza; Al demolerse el Edificio 5D-33 se perdió esta visión tripartita del centro principal de Tikal. 
El desmantelamiento del Edificio 5D-33, presenta la oportunidad de conocer el criterio de intervención en la Acrópolis Norte. Los múltiples túneles de investigación dentro del Edificio 5D-33 mostraron varios edificios interiores con grandes mascarones en buen estado de conservación. También encontraron ricas tumbas y una estela enterada ceremonialmente (estela 31). Por otro lado el edificio del Clásico Tardío (5D-33-1 ${ }^{\mathrm{a}}$ ) no estaba tan bien conservado como los Templos 1 y 2. Esta situación llevo al "Proyecto Tikal" a demoler parcialmente el edificio. Así exponía las edificaciones anteriores al visitante y utilizaba el material demolido del templo pirámide para rellenar la gran trinchera norte-sur, al lado oeste del edificio.

El proyecto de desmantelamiento fue aprobado por director del IDAEH (Carlos Samayoa Chinchilla). Los argumentos a favor de la destrucción del templo pirámide los justifica Jorge Guillemin en un documento entregado al IDAEH en 1964. Entre otros argumentos dice "el Proyecto Tikal no puede dejar, después de excavar, una cosa peligrosa y fea; además el Edificio 5D-33 no puede volverse a su forma de montículo sin provocar daños a lo ya restaurado a su alrededor" (Guillemin 1964). El principal adversario de esta actuación fue el Dr. Heinrich Berlín, quien acusa a los autores de la demolición de "falta de sentido de responsabilidad" (Berlín 1967, 241-244). Sobre lo acontecido Marcelino González Cano dice "La impresión visual de la Acrópolis Norte no es tan agradable como se pensó, para los que conocimos la armoniosa sucesión de volúmenes de los templos 32 , 33, 34 y 35 en su estado después de los trabajos de limpieza, sentimos que se rompió el espacio concebido, posiblemente para grandes ceremonias, ya no corresponde con la grandiosidad del sitio; muchos visitantes no se explican la existencia de un edificio bajo entre los maravillosos edificios verticales que buscan el espacio infinito. Indudablemente el equilibrio de volúmenes se rompió y 
ningún trabajo de restauración se lo podrá devolver" (González Cano 1973, 147). Marcelino González menciona otros problema no resuelto consistió en "la adecuada conservación de los trabajos en estuco, encontrados más o menos en buenas condiciones tales como los mascarones de las fachadas de varios templos, por ejemplo: 5D-222nd, 5D-33-2nd; tableros con escenas ceremoniales como 5D-44, los cuales fueron expuestos al aire libre y por efecto de calor, viento, alteración del equilibrio de humedad se han desintegrado alarmantemente (González Cano 1973, 134).

Además de lo referido anteriormente en la Acrópolis Norte se reconstruyo totalmente la primera escalinata monumental (primera terraza) y se levantaron los monumentos esculpidos en piedra (estelas), tanto en la primera terraza como frente a la escalinata reconstruida.

\subsubsection{Acrópolis Central}

El otro gran conjunto de construcciones que se intervino fue la Acrópolis Central, compuesta por 42 edificios formando un grupo de patios. En general la política seguida fue similar: se consolidaron algunos edificios y partes de las plataformas de sustentación de los edificios, se reconstruyeron varios y se dejó sin explorar una parte del conjunto; para mostrar los diferentes aspectos de los edificios antes y después de las intervenciones.

Intervenciones alrededor de patios: Patio 2 (Edificios 5D-59, 60, 61, $62,63,65,66,118$ y 120$)$, Patio 4 (5D-51, 122, 49, 50 y 52) y el Patio 6 (5D-44, 46, 48, 49, 53, 54, 126, 128 y137), un Edificio adosado en la esquina noreste frente al juego de pelota de la Plaza Este. Algunas consolidaciones de muros adicionales en los patios 1, 3 y 5 . Más de 24 edificios fueron reconstruidos en forma parcial o total, pero 
siempre respetando las alturas de muros y los fragmentos de bóvedas. Por lo general se procedió a revestir los muros que habían perdido las piedras del exterior, a rehacer las cornisas, dinteles repuestos y las escalinatas de acceso. Jorge Guillemin dice que "obviamente la tendencia ha sido de restaurar edificios visibles y relacionados en el foco ceremonial. Una meta primordial de la labor de restauración y reconstrucción arqueológica es esencialmente la misma que da de la museográfica, que es hacer accesible el pasado de la manera más directa y comprensible" (Guillemin 1968, 121).

\subsubsection{Otras intervenciones}

En la Gran Plaza se restauro parcialmente la cancha para el juego de pelota (5D-74). Al este de la Gran Plaza el Edificio 5E-38, los restos de un baño de vapor en la Plaza F y el Edificio 6F-27 (Templo VI). Al oeste la parte superior de los templos III y IV con la restitución de dinteles de concreto armado y reconstrucción y consolidación de los techos.

Jorge F. Guillemin dice que "El responsable debe tomar disposiciones en los aspectos técnicos y estéticos, reconstruir o no reconstruir es a menudo la pregunta, se evitara la reconstrucción completa. La restauración no debería dejar la impresión que se detuvo la construcción, sino que se detuvo la destrucción, que es distinto. La labor tenderá a reconstituir las grandes líneas de la arquitectura y hacerla comprensible tanto para el simple visitante como para el especialista. No solo se tratará de emplear la técnica y el estilo original, también procurará de quedar discreta, sin por ello, evitar de disimular la obra restaurada" (Guillemin 1968, 121).

Luego Guillemin continua diciendo, "Una meta primordial de la labor de restauración y reconstrucción arqueológica es esencialmente la 
misma que la de la museológica, que es hacer accesible el pasado de la manera más directa y comprensible, o sea abrir puertas de la cultura para todos”. Guillemin hace referencia al maíz, y dice “¿No, se está repitiendo aquí la historia de la vieja Ixmukané cuando ve renacer la mata de maíz en señal de resurrección de los héroes civilizadores del Xibalbá? Ese mismo regocijo que experimentó la abuelita Ixmukane ante el revivir de su mata de maíz lo compartimos al ver levantarse de sus ruinas los grandes templos y palacios, un simple hecho material talvez, pero una promesa del revivir espiritual de una gran cultura. No fue tan tímido Voltaire al decir -Conservar y restaurar resulta casi tan bello como hacer-?" (Guillemin 1968, 121).

En el Proyecto Tikal (1956-1969) varios estudiantes, profesionales y técnicos extranjeros y nacionales hicieron sus prácticas, y se entreno a más de 900 trabajadores operativos en tareas de excavación arqueológica, abertura de túneles, trincheras, pozos, y otros. Además se enseño a intervenir y presentar edificios. Así se formo lo que los mismos trabajadores llamaron "la escuela Pensilvania". Éstos jóvenes con el tiempo se volvieron encargados de grupo y fueron jefes que continuaron con los mismos criterios impartidos por el "Proyecto Tikal" aun después de su cierre en 1969.

\subsubsection{Administración Parque Nacional Tikal}

(1969-1979)

La continuación de las actuaciones en edificios de Tikal sigue con el Proyecto Arqueológico-Administración Parque Nacional Tikal. Los responsables de los trabajos (Rudy Larios Villalta y Miguel Orrego) venían de los equipos formados por el anterior proyecto, continuando con el mismo criterio de intervención en edificios. 
En este período se realizan intervenciones en el Edificio 5D-91 en la Plaza de los Siete Templos y en dos grupos con arquitectura expuesta llamados palacio de las Ventanas o Murciélagos (5C-13) y palacio de Las Acanaladuras (grupo G). Solamente los trabajos realizados en el grupo $G$ fueron publicados (Orrego y Larios 1983). Para dar un ejemplo de los procedimientos empleados, en el grupo G, los túneles de investigación dentro de los edificios se dejaron abiertos con el pretexto de exhibir al turismo grafitos y etapas constructivas anteriores; incluso tuvo un tiempo instalación eléctrica montada sobre las paredes con estuco. Buena parte de los escombros y desechos de los trabajos de esa temporada aún se encuentran al lado de los palacios; condición que altera los espacios libres de las plazas y terrazas vecinas. Esta actuación refleja un poco el concepto del Proyecto Tikal de actuar sólo en partes de edificios y no tratar el espacio urbano; en este caso los "espacios libres" como parte de los edificios. Igual sucede con el escombro dejado al lado oeste del Edificio 5C-13;

Otro ejemplo de esta idea disgregada del espacio urbano, son los caminos vehiculares ubicados dentro del tejido urbano sobre las vías ceremoniales y las plazas. El paso de vehículos con turistas por los espacios de Tikal fueron prohibidos en el año 1987.

En Tikal, la visión disgregada del espacio urbano continúa hasta la fecha. Hasta ahora no hay un solo caso de espacio libre de una calzada a pesar de que este elemento es un rasgo distintivo de la gran ciudad; otro ejemplo son los espacios de pirámides gemelas, Tikal tiene varios, pero en ninguno se percibe el espacio urbano de este grupo de edificios como grupo. Las personas caminan por estos espacios sin percibir la tensión espacial de estos elementos. El guión planteado por el Proyecto Tikal a finales de 1957 prevalece. 
En 1972 se publica el primer plan maestro de Tikal, El documento alaba la actuación del Mueso de la Universidad de Pensilvana. "Las técnicas, métodos y estilo de la consolidación y restauración iniciados por la Universidad de Pensilvana debe ser continuado" (Plan maestro 1972, 142). El objetivo del plan dice: "consolidar selectivamente, algunas de las características de las estructuras mayas para que los visitantes comprendan la naturaleza de la estructura original de Tikal" (Plan Maestro 1972, 40). Se propone entre otros "reconstruir cuatro casas mayas, buscar la tumba dentro del templo IV...La mayoría de Templos Mayores, están o fueron edificados sobre tumbas de personajes importantes. Se ha propuesto localizar, excavar y reconstruir dichas tumbas para una interpretación de exhibición in situ"... (Plan maestro 1972, 211) El plan aconseja también quitar toda la vegetación sobre el templo IV y reconstruir la fachada este y la escalinata. Estos pocos ejemplos dan una idea de la continuación del criterio de la "escuela de Pensilvana".

\subsubsection{Proyecto Nacional Tikal}

En este estudio hacemos una diferencia entre dos etapas del Proyecto Nacional Tikal (PRONAT). La primera corresponde a las actuaciones efectuadas entre los años 1979 a 1986 y la segunda a las realizadas entre los años 1987 agosto 2006.

\subsubsection{Tikal (1980-1985)}

En 1979 se formula el Proyecto Nacional Tikal (PRONAT). Este proyecto (1980-1985) estuvo bajo la administración del Ministerio de Comunicaciones, Transportes y Obras Publicas y su director fue Juan Pedro Laporte. La primera etapa de este proyecto de inversión inicia con excavaciones en la Plaza de la Gran Pirámide mas conocida, desde esa época, como el "Mundo Perdido". El objetivo principal era abrir nuevos sectores de Tikal al turismo. Para esa época se hablaba 
de descargar el área de la Gran Plaza ya agobiada por un creciente número de visitantes y vehículos.

La construcción de servicios y más infraestructura dentro del parque, incluso con hoteles estimulo la visita a Tikal. Ya para esta época el esquema de recorridos en vehiculo iniciaba a colapsar, sobre todo en épocas de vacaciones. El interior de la ciudad se convertía en una fila de vehículos compitiendo por llegar a la Plaza Oeste u otros estacionamientos habilitados (Grupo F, al sur del Templo IV, Templo VI y otros).

En el llamado Mundo Perdido, se intervinieron 13 edificios: la Gran Pirámide (5C-54), el Edificio Talud Tablero (5C-49), la Plataforma Central ( 5C-53), Edificio en "U" o Herradura (5C-45, 46 y 47), el Palacio Mayor (5D-77), el Templo de las Calaveras (5D-87), Templo de las Mascarones (5D-86), Templo del Gran Muro (5D-84), Templo del Gran Friso (5D-82) y las plataformas 5D-88 y 5D-89). El criterio de restauración fue el mismo utilizado por el Museo de la Universidad de Pensilvania (Proyecto Tikal).

Un ejemplo del método empleado es el Edificio 5C-54 de $32 \mathrm{~m}$ de altura; luego de eliminar toda la vegetación del edificio, se consolidó y restauró la fachada oeste y parte de la fachada norte (ángulo diseñado para la toma fotográfica). En este mismo edificio los investigadores a través de kilómetros de túneles identificaron 5 etapas constructivas interiores. El más antiguo (5C-24 Sub-2B) del año 700 a 300 a.C. Los túneles atravesaron el edificio en tres diferentes niveles; también tres túneles (llamados túneles de ascenso) siguieron construcciones anteriores. Luego de la investigación los túneles no se rellenaron. El resultado posterior fue el derrumbe de la fachada este de la Gran Pirámide (1984). Millones de quetzales, y cerca de cinco años de trabajo, fue necesario para reparar la Gran Pirámide. Entre 
1982 y 1984 varios artículos de prensa con entrevistas a los responsables del proyecto fueron publicados y recopilados luego en un documento (García Urea 1987).

A partir del año 1983 el PRONAT se extiende a otros sectores de Tikal (Grupo 6B-II y Zona Norte) y a Uaxactún. Las investigaciones de campo llegan hasta mediados de 1985. En 1985 el Instituto de Antropología e Historia recupera su autoridad en Tikal.

Entre mayo de 1985 y diciembre de 1987 los trabajos de Tikal y Uaxactún quedaron en manos de los maestros encargados. Los antiguos trabajadores del Proyecto Tikal, continuaron con más de 700 trabajadores operativos. Personajes como: Don Jacinto Rosado Lanza (don Chinto), Don Sóstenes Durán Rosado, Pompeyo Castellanos, Francisco Ochaeta, Viviano Monterroso, Francisco Alvarado, Cristino Flores y otros, fueron los protagonistas de las intervenciones en los edificios de Tikal y Uaxactún. En esta época se formaron nuevos jóvenes como futuros maestros: Orlando Quixchán, Enrique Monterroso hijo, Antonio Morales y otros. Muchos de ellos continuaron en la segunda parte del Proyecto Nacional Tikal (1987agosto 2006).

La tradición de la escuela Pensilvania, con más de 50 años, continúa con pocos cambios hasta estas épocas. Por ejemplo ahora la tercera generación de maestros de obras ya no acostumbra desmontar un muro desplomado para volverlo a construir a plomo o seguir una raíz incrustada desarmando los muros. En pleno siglo XXI hay ejemplos recientes del criterio empleado por el Museo de la Universidad de Pensilvania (Templo $\vee$ de Tikal). 
Antes de 1983 en toda el área del estudio, sólo se intervenían edificios en Tikal. En el resto del territorio, con excepción de unos trabajos de emergencia en Nakum (apuntalamiento de accesos a la segunda cámara del Edificio $A$ ), no se realizó ningún trabajo de conservación de edificios. Todo el territorio del noreste estaba sin atención.

Por aparte, proyectos de investigación arqueológica había en Yaxhá (Hellmuth entre los años 1970-1974) y posteriormente Río Azul (Adams, entre 1983 y1987) y Mirador (con Dahlin en1978, Matheny y otros) que no tenían en su concepto realizar intervenciones de restauración, rescate o habilitación de los sitios. En Yaxhá el proyecto de Nicolás Hellmuth tomó la idea de los caminos para vehículos de Tikal abriendo brechas entre la vegetación para pasar de un sector a otro de la ciudad.

\subsubsection{Uaxactún (1983-1985)}

Fue en 1983 que por primera vez, personal de Tikal, sale fuera de los límites del Parque Nacional. En esta oportunidad desde 1982 se preparaba Uaxactún para realizar excavaciones arqueológicas. El PRONAT restauro 10 edificios: cuatro en el grupo A (II, III, XII y XVII). Un Edificio en el grupo B (XIII) y cinco Edificios en el grupo E (I, II, III, VIII, y X). Algunos de ellos fueron intervenidos en forma parcial (A-III) $y$ otros en forma completa atendiendo las prioridades de rescatar arquitectura expuesta en peligro. El doctor Juan Antonio Valdés, describe los trabajos de restauración realizados en esa temporada en el libro "El periodo Clásico en Uaxactún, Guatemala" (Valdés 2005, 205-216). En el texto Valdés relata la precaria condición del sitio a su llegada en 1982. Las áreas liberadas de vegetación por el Instituto Carnegie, en la década de 1930, habían sido invadidas de nuevo. Además la gran cantidad de trincheras y túneles dejados abiertos 
habían causado enormes daños en los edificios. Por ejemplo menciona que los Edificios A-XVIII y E-X estaban a punto de colapso, con árboles sobre los edificios, derrumbes y grietas en muros y techos.

Valdés describe varios criterios de intervención, por ejemplo se considera que aunque se tenia abundante información grafica de antes y después de los trabajos del Instituto Carnegie de Washington; un criterio fue de consolidar los elementos arquitectónicos existentes a la llegada del PRONAT en 1982. Aunque existía evidencia de muros en fotografías, si estos habían caído en el lapso de actuación de los dos proyectos, casi 50 años, este no se reconstruía. Si era necesario completar el sistema estructural de los techos (Edificios AXVIII, B-XIII y E-X) estos eran restituidos con piedra nueva; se recolocaron nuevos dinteles de piedra y travesaños de madera en las bóvedas (chicozapote).

El objetivo principal fue evitar la entrada de agua de lluvia a los espacios interiores. Para el Edificio A-XVIII, Valdés escribe en relación a la restitución de pasadores de madera en las bóvedas y otros datos particulares del edificio (Valdés 2005, 208). Otro criterio común fue desmontar secciones de muros, numerando los bloques de piedra, para eliminar raíces incrustadas para luego armarlos de nuevo. En las mezclas se usó además de arena y cal, pequeños porcentajes de cemento. Se rellenaron algunas de las trincheras dejadas abiertas por el Instituto Carnegie (A-II, B-XIII, Plataforma E$X V I$ ) y un pozo de excavación central en el Edificio A-III. Se rellenaron dos agujeros de postes en el cuarto 7 (las pinturas) del Edificio B-XIII. Los pisos de varios edificios fueron reconstruidos, dándoles inclinación para evacuar el agua de lluvia. Este procedimiento se extendió también hacia los alrededores de los muros exteriores, con 
el propósito de evacuar rápido el agua fuera de los edificios. También se "remarcó" la cornisa de los Edificios B-XIII y E-X, este último con gota.

Otro criterio fue que en muchos basamentos de edificios intervenidos, luego de su consolidación y recuperación de volúmenes, fueron luego enterrados y se planto vegetación baja para su conservación. En otros casos luego de la investigación y consolidación los edificios fueron rellenados (A-VI, VII y VIII). En otros se dejaron expuestos y sugeridos diferentes etapas constructivas (basamento del Edificio EII); en este edificio también se restituyó el muro norte el cual había sido destruido por el Instituto Carnegie. "En el Edificio E-VIII con dos diferentes etapas constructivas... se decidió mostrar secciones de ambas etapas, principalmente al poniente, para que el espectador pueda observar claramente las diferencias entre los edificios y el estado de destrucción en que muchas veces son encontrados los edificios por los arqueólogos" (Valdés 2005, 215). 
En esta fase, la nueva dirección del PRONAT decidió hacer una evaluación regional sobre el estado de conservación de los edificios en el área vecina al Parque Nacional Tikal y la región noreste del departamento.

Mientras se planteaba un esquema más amplio de atención al patrimonio edificado, en Tikal se elaboraron consideraciones generales para la clasificación de daños y medidas urgentes de conservación y protección de la ciudad. Para Tikal se describen las principales medidas de intervención en 26 grupos de edificios (Siller y Quintana 1989, 55-62). Como una medida de conservación al espacio urbano de Tikal, en abril de 1987 se clausuro el paso de vehículos dentro del área abierta al público; poco después se canceló el uso de la pista de aterrizaje aéreo dentro del parque (Quintana y Siller 1989, 48-49). El trabajo en los edificios monumentales, durante 1987-1991, consistieron fundamentalmente en reparaciones de anteriores intervenciones.

El nuevo criterio de intervención no congenió del todo con el método empleado por el Museo de la Universidad de Pensilvania. Los maestros de obras se resistían a hacer cambios en el sistema así que la decisión fue "divide et impera"; un fuerte grupo de personal se traslado a Uaxactún, otro a las dependencias del IDAEH en Petén (vigilantes de sitios arqueológicos del departamento de Monumentos Prehispánico) y otro al área de Yaxhá, Nakum y Naranjo. Para 1992 en Tikal permaneció un reducido grupo de trabajadores que atendieron específicamente los proyectos de intervención (contrapartida nacional) con la Agencia Española de Cooperación 
Internacional (AECI): Templo I, Templo $\mathrm{V}$ y finalmente la plaza de Los Siete Templos.

La actuación en Uaxactún (1987-1991) continúo con las mejoras del campamento y el horno para hacer cal. Luego se trabajo en los sectores D, E, B y A. Paralelamente, se hicieron trabajos similares en el área de Yaxhá, Nakum Naranjo con mejora de campamentos, hornos de cal y atención preventiva en edificios en peligro. Los resultados de estas actuaciones son presentados más adelante.

El resultado del primer recorrido (1987) en la región noreste del departamento fue publicado en 1989. “..Debido a la magnitud de los daños encontrados, que sobrepasan los recursos económicos y técnicos de Guatemala. Es necesario tener una panorámica general de la situación real de los sitios arqueológicos y localizar entre ellos los de una mayor necesidad de intervención para tratar de garantizar su preservación" (Siller y Quintana 1989, 53). Estos recorridos sirvieron de base para la elaboración de un primer plan regional que estableció prioridades de intervención en edificios en peligro de colapso. Después se creó un "Programa de Rescate", formado por un equipo de trabajadores de Tikal. Este equipo atendió trabajos de conservación preventiva en varios edificios en peligro; mediante esta acción se consolidaron provisionalmente, ya en 1987 y 1988, edificios en Nakum, Yaxhá, Uaxactún, Naranjo, EL Zotz y Topoxté.

Con la primera visión regional se llegó a la conclusión de que debe considerarse de urgencia el rescate de sitios arqueológicos en Petén y realizar acciones que los liberen de su estado de abandono y destrucción. Siendo consecuente con este principio; desde 1987 el PRONAT ha registrado el deterioro en los sitios mayas del noreste del Petén. Dichos informes confirman que la fuerza destructora de la 
selva, el clima tropical y principalmente las acciones del hombre, por abandono o sobre todo por saqueos ilegales han creado las condiciones para que estos vestigios estén en peligro de perderse. Esta realidad requiere con urgencia proyectos de rescate del patrimonio edificado.

Como primera medida se planteó conocer la dimensión y el estado actual de los edificios patrimonio cultural de la región, luego la formulación de una metodología de atención adecuada a la realidad actual. En términos generales damos en este capítulo una visión rápida de los procedimientos y acciones realizadas durante la etapa del estudio. Más adelante explicamos con mayor detalle cada fase del procedimiento de intervención.

Por regla general los edificios que antes no habían recibido ningún tratamiento de conservación ahora requieren intensas intervenciones. Un ejemplo para ilustrar esta situación general es el caso del Edificio C de Topoxté: las fotografías de principios de 1900 muestran el edificio en relativo buen estado de conservación (Maler 1908, lám 14), otros autores tomaron las mismas fotos en 1933 y 1960 que muestran y señalan, por ejemplo en la esquina noreste del edificio un joven árbol de ramón, que 20 años después fue el causante del colapso total de esa parte del edificio. Este tipo de daño a tiempo se hubiera podido reparar fácilmente (quitar el palo de ramón antes de que creciera). Sin embargo, el abandono, la vegetación descontrolada y los saqueadores causaron, alrededor de los años 1970, la pérdida total de la fachada sur del edificio. En esta fecha la fachada se deslizó completamente. Ahora quedan las partes que no se cayeron entonces, como testigos de un importante edificio Posclásico de Petén. De este edificio existe documentación desde 1831 (Galindo 1834, 570); sin embargo hasta 1987, 156 años después, nadie había 
realizado algún intento de rescate. La historia del Edifico $\mathrm{C}$ es un ejemplo típico de la actitud científica dominante en los últimos cien años, cuando fondos financieros para rescate y conservación de la arquitectura no fueron considerados en los presupuestos de investigación arqueológica.

El propósito de las intervenciones es atender en lo posible a los edificios con arquitectura visible en peligro de colapso. Se realizan las acciones necesarias para estabilizar sus elementos constructivos. En algunos casos cubriéndolos de nuevo y en otros restaurando sus plataformas, muros y techos; evitando así la desintegración del patrimonio tangible de la región. A su vez en un proceso más amplio los edificios "restaurados" son y serán los focos de un uso social de las ciudades mayas rescatadas. Los edificios restaurados dentro de la ciudad forman el nuevo circuito de visitas al sitio y en si son la base y razón del turismo en la región. Los edificios restaurados junto con las plazas, patios, calzadas y monumentos forman en conjunto la visión urbana de la ciudad que permiten entender, comprender y disfrutar los logros arquitectónicos y urbanos de sus constructores.

En la selva, las condiciones ambientales, transforman rápidamente los trabajos nuevos en aparentes trabajos antiguos (originales). Un principio es no engañar al espectador ni a nadie, haciéndoles creer que los edificios intervenidos son todos perfectamente mantenidos en el tiempo sin ayuda del hombre moderno. Por el contrario el espectador debe leer en los edificios nuestro trabajo y los especialistas visualizar con detalle en que momento y en que parte del edificio hay una integración, una restitución de volúmenes, una reparación de grietas en muros, en donde se colocan elementos estructurales nuevos, en donde se restituye una bóveda, etc. 
La conservación de ruinas mayas y su mantenimiento puede convertirse en una fuente duradera de trabajo para las comunidades vecinas a un sitio arqueológico. El creciente turismo cultural a Petén puede aportar ingresos a la economía de la zona si se logra crear un sistema de parques nacionales que conserve el patrimonio natural y cultural, con sus bosques tropicales y sus ciudades mayas y lo hagan accesible a visitantes bajo planes maestros de manejo. Las intervenciones en los edificios son necesarias para mitigar y detener la pérdida de sus elementos constructivos.

A continuación nos referimos a las principales acciones de intervención, en diferentes sitios, atendidos por el proyecto de inversión PRONAT, mas tarde Proyecto Protección de Sitios Arqueológicos en Peten (PROSIAPETEN).

\subsection{UAXACTÚN, 1987-1991}

Los trabajos se concentraron en el sector A de la ciudad; se liberaron cientos de metros cúbicos de escombros, dejados por el Instituto Carnegie de Washington (1927-1937) en la Plaza Principal. En el grupo A-V se rellenaron las trincheras monumentales en los ejes de investigación. Las aberturas tenían más de $4 \mathrm{~m}$ de ancho. Aquí se empleo el material de escombros mezclado con argamasa de cal. La superficie reconstruida quedo remetida, unos centímetros, del resto de las edificaciones dejadas en pie y la textura final fue de piedra sin forma. Los restos de edificios separados por las trincheras fueron consolidados con bloques de piedra sin tallar. Se reforzaron las bases de varios edificios con restitución de volúmenes nuevos, también empleando piedras sin acabado. La investigación dejada abierta por el instituto Carnegie dejó un problema de conservación de pedazos de edificios y de interpretación de más de 10 diferentes fases constructivas dejadas expuestas. Por ejemplo hoy aparecen las 
esquinas de los Templos A, B y C pero el templo en sí ya no existe (demolido por la trinchera de investigación). Igual sucede con el Edificio $L$ solo quedan sus esquinas norte y sur, y así sucesivamente con el resto de edificios del grupo. Las trincheras del instituto Carnegie al norte, este y oeste fueron rellenadas completamente. En la trinchera del eje sur solo se consolidó las paredes laterales, para permitir el acceso al "corazón" del grupo.

Un edificio horizontal en el límite norte del palacio mostraba diferentes espacios interiores y arranques de muros originales. La falta de mantenimiento estaba destruyendo los pisos y estucos originales, razón por la cual todo el edificio fue de nuevo tapado formando un volumen (montículo). Esta acción de volver en "montículo" un edificio, para su conservación, fue realizada en 1989. Igual solución se dio a la continuación de la trinchera oeste-este, en dirección hacia el Patio Este. En este sector se rellenaron saqueos recientes en la cercanía del Edificio A-XV.

Para apoyar la interpretación de este sector, partido en cuatro partes y vaciado por las investigaciones del Instituto Carnegie, se construyó un mirador panorámico, empleando la misma posición de la perspectiva realizada por Tatiana Proskouriakoff. Este mirador fue demolido en 1997 por falta de mantenimiento.

En el sector B se realizó la remoción de escombros dejados por el instituto Carnegie de Washington. En el Edificio B-XIII se repararon daños ocasionados por caída de árboles sobre el edificio. La unidad de Flora y Fauna determinó que el $70 \%$ de los árboles en el sector $A$ y $B$, estaban enfermos. En el Edificio B-XII luego de consolidar muros y restos de una bóveda, fue de nuevo rellenado y convertido en "montículo". En el sector D se efectuó una documentación y relleno de 
saqueos. En el sector $E$ se proporcionó mantenimiento a los edificios restaurados en la primera etapa del PRONAT (Edificios E-X, VIII, III, II y I). En el Edificio E-VII Sub. se propuso construir una cubierta protectora; pero las autoridades del IDAEH no lo permitieron; aduciendo que se alejaría el turismo si se tapaba el edificio expuesto desde la década de 1930. El deterioro de las superficies de este edificio son alarmantes; en 1974 Edwin Schook trató de protegerlo haciendo reparaciones de las superficies y controló la vegetación sobre el edificio abandonado. En la década 1980, Luis Greñas se preocupó por el deterioró de las superficie del famoso edificio, en esa época se le aplicó substancias químicas para preservar los estucos. Esta acción no se volvió a repetir, razón por la cual su efecto se perdió rápidamente.

Se intentó delimitar la expansión del poblado en medio del sitio arqueológico y se realizaron mejoras en el campamento del IDAEH, el cual debió convertirse en un museo local. Una subdirectora del IDAEH dio el campamento en concesión a una ONG norteamericana.

También se crearon áreas de estacionamiento (sector B y E) para evitar que los vehículos ingresaran hasta determinado espacio del área arqueológica. En los últimos años sólo se realizaron visitas esporádicas a Uaxactún. En el año 1999 el INGUAT construyó en los grupo B y E, espacios techados modernos para el turismo. En el grupo B, la construcción colapsó en el año 2002. En el año 2004 el Parque Nacional Tikal restituyó los techos ( $\mathrm{B}$ y E) con nuevas cubiertas de palma (guano).

Desde Uaxactún se realizaron acciones de rescate en el Edificio 1 de El Zotz (1989-1991). En este edificio se restituyeron dos dinteles de madera, recién extraídos por actividades de saqueo. Se rellenaron las 
depredaciones principales y las cámaras para dar más unidad a la edificación; también se construyó una cubierta protectora (madera y palma) la cual se destruyó al poco tiempo. Así mismo se desintegró el rancho oficina-dormitorio construido por Sóstenes Durán Rosado. El campamento del PRONAT en Uaxactún sirvió de base para múltiples recorridos de identificación de daños en los edificios en las cuencas Ixcán y Holmul.

\subsection{TIKAL 1987-1992}

Como se mencionó anteriormente la actividad principal del proyecto de inversión PRONAT, en la segunda fase, se ocupo más de la atención de centros urbanos vecinos a Tikal. En Tikal quedo un reducido contingente de trabajadores que formaron parte, como contra partida nacional, en proyectos de inversión de la cooperación internacional.

\subsubsection{Templo V}

Intervenciones en la crestería del Templo V ,1987 - 1989.

Durante la actuación del Museo de la Universidad de Pensilvania, el Templo $\vee$ fue poco atendido. En los otros cinco templos la vegetación de sus cresterías fue eliminada en su totalidad y se hicieron restauraciones y reconstrucciones (Templos I, II, III, IV y VI). Pareciera ser que el Templo $V$, especialmente por su entorno lleno de vegetación, fue dejado como muestra de cómo se integró la vegetación a la arquitectura y al paisaje de Tikal. Algo parecido sucedió a la Acrópolis Sur vecina del Templo $\mathrm{V}$, la cual también se dejó sin intervención alguna; y contrastan con la deforestación causada en la Acrópolis Central, Gran Plaza y Acrópolis Norte.

Por más de 140 años, permaneció abierto un agujero que atravesó, en forma vertical, la crestería del templo $\vee$. Por este agujero penetro 
la lluvia al interior de la crestería y el templo. También por años, cientos de visitantes se ingeniaron la forma de escalar el agujero hasta llegar a la cúspide de la crestería. En la guía de Tikal el autor incita al visitante a escalar el pozo a través de la crestería para poder observar, "uno de los panoramas más maravillosos de Tikal; luego agrega el autor, abrigando sin embargo la duda de si las escaleras que sirvieron para trepar aguantarán el viaje de regreso" (Coe 1967, 91). Tal sugestión, determinó incalculables daños en el interior de la crestería, pues los visitantes introdujeron todo tipo de objetos para escalar, perforaron agujeros en las paredes, quemaron con fuego los repellos interiores y destruyeron porciones de muros, piedras tapa y pisos originales, con tal de ver la espectacular vista en la cima del edificio.

Debido a los daños causados, en marzo de 1987, se construyó una cubierta provisional de madera y guano (palma) sobre el agujero de la crestería. Se construyó un andamio hasta la cúspide del edificio para permitir llegar hasta el techo de la crestería. Se documentaron los espacios interiores para posteriormente rellenar y sellar los espacios del caballete y pisos rotos por el agujero (con nueva piedra canteada y morteros de cal). También se reconstruyó el techo del último espacio interior (con bloques de piedra tallada nuevos de formato parecida a los bloques desaparecidos).

En la única cámara del templo se rellenó el agujero producido en el muro posterior (con bloques de piedra canteada irregular) la intervención es marcada por los bloques sisados, en constaste con el acabado liso y estucado de la superficie original. Tambien se relleno el agujero en la fachada norte del templo, realizado por el personal de Modesto Méndez en 1848. Los trabajos de intervención concluyeron en 1991(Quintana y Noriega 1992). 
Este mismo edificio fue objeto de otra intervención "Proyecto Templo V" de la Agencia Española de Cooperación Internacional, (19952003).

Los trabajos de la AECI se concentraron en parte de la fachada norte y la escalinata ceremonial. En este sector se eliminó toda la vegetación, en la plataforma escalonada se restituyo el volumen perdido con nuevos formatos de bloques de piedra, simulando la forma original. Los primeros escalones de la escalinata monumental, fueron reconstruidos, el resto tuvo diferentes tratamientos, las alfardas fueron convertidas en volúmenes. No se consideraron los problemas de estabilidad de la base piramidal que sostiene el templo. Especialmente la alarmante pérdida de volúmenes en la base de la pirámide escalonada, en su fachada sur. La actuación del PRONAT, en este proyecto fue el proporcionar 57 trabajadores operativos como contrapartida nacional.

\subsubsection{Templo I}

Plan de intervención 1992-1996: A principios de 1978, en el Templo I se hacían reparaciones en el techo para evitar la filtración de agua de lluvia. En 1991 se elaboró una primera versión del Plan de conservación y restauración del Templo I (Quintana 1995, 3-13); dicho plan fue adoptado por el gobierno Español y los trabajos iniciaron en el año 1992. Este plan considero una intervención integral del edificio. Un concepto distinto a los realizados hasta el momento en Tikal. Para el Templo I se contempló realizar tareas de:

1- Recuperación de volúmenes interiores; aquí se realizó un estudio de ingeniería estructural con el ingeniero Roberto Solís Hegel, y cuyo dictamen avaló el no relleno de los túneles realizados por el Museo de la Universidad de Pensilvania. 
2- Se realizaron acciones en la plataforma de nivelación entre la Gran Plaza y la Plaza Este; se corrigió el drenaje de la Gran Plaza al liberarse el pasadizo entre la fachada norte del Templo I y la Acrópolis Norte.

3- en la base piramidal y el templo se resanaron con inyecciones de cal las grietas y fisuras, se hicieron adherencia de elementos originales desprendidos y restitución de elementos volumétricos que ayudaron a la estabilidad del edificio. (No se realizó, el plan de impermeabilización propuesto con una lechada de lejía, el cual tuvo fuerte oposición).

4- Un especialista en restauración Miguel Ángel Núñez Villanueva realizó el resane de estucos en el interior del templo y además se colocó una barrera transparente en el acceso al recinto interior para evitar el paso de aves.

El proyecto de inversión inicio en mayo de 1992, contó con el apoyo de la $\mathrm{AECl}$, programa de Preservación del Patrimonio Cultural de Ibero América, El segundo arquitecto director, Gaspar Muñoz Cosme continuo, en 1993, con los trabajos propuestos y otros adicionales hasta completar su intervención en julio de1996.

Publicaciones sobre los trabajos de intervención en el Templo I (Muñoz Cosme y Quintana 1996, 335-342). (Vidal Lorenzo y Muños Cosme 1997), (Muñoz Cosme 1997b, 20-29), (Muñoz Cosme 2003).

\subsubsection{Otros edificios}

Intervenidos en Tikal, 1987- 1992

Plaza de la Gran Pirámide: Continuación de reparaciones iniciadas en la Gran Pirámide (excavaciones anteriores 1982-1984, primera fase de PRONAT). Aquí se debieron de realizar rellenos de grietas y un sistema de siete "grapas-vigas" al lado este de la Gran Pirámide (5C- 
54) para contener el colapso de toda la pirámide con varios derrumbes y años de estar reparando la fachada este y norte.

Acrópolis Norte y Acrópolis Central: En estos dos grupos de edificios se continuó con reparaciones iniciadas en intervenciones anteriores. Se repararon hundimientos en el piso, atrás del Edificio 5D-33, causados por el reacomodo de rellenos y túneles abierto por las excavaciones del Museo de la Universidad de Pensilvania; las grietas en muros y filtraciones de agua fueron atendidas en diversos edificios de la Acrópolis Central; en el Edificio 5D-52 de tres pisos se libero del sobrepeso (escombro) el último nivel.

En otros sectores se realizaron reparaciones en muros y techos (palacio de las Ventanas) y tres edificios del sector Norte (3D-46, 45 y 44). También se efectuaron cubiertas en edificios con estucos $6 B$ II en el sector sur del Mundo Perdido. Por el visible deterioro de los estucos y la falta de vigilancia en este sector, en el año 1991 se elimino la cubierta y se tapo (relleno) todo el edificio.

\subsection{TOPOXTÉ 1987- 1996}

Topoxte presenta arquitectura expuesta del siglo 15 d.C. (Posclásico). Los trabajos de conservación iniciaron en el Edifico C, (1987) con una serie de medidas preventivas que consistieron en apuntalamiento de muros, en especial la fachada norte, desplomada y en peligro de colapso. En este edificio se elimino la vegetación y se construyo al rededor un andamio y una cubierta protectora, de madera y palma diseñada para permitir el paso del aire y bastante luz en el interior. Luego continúo el trabajo de liberación de escombros, investigación arqueológica, documentación y relleno de saqueos. A partir de 1991 iniciaron las acciones permanentes que concluyeron a finales de 1994 con la conservación duradera del Edificio. El procedimiento 
empleado fue publicado en la memoria del Instituto Arqueológico Alemán-KAVA (Noriega 1995, 229-258). Paralelo a la conservación del Edificio $C$ se realizaron trabajos en los Edificios $D, E$ y $G$ que definen la Plaza Principal. Las acciones consistieron en: Liberación de escombros alrededor y adentro de los edificios, consolidación de varias plataformas bajas (con estelas y altares) y una escalinata entre Ios Edificios C y D. Los muros expuestos fueron consolidados, las grietas fueron reparadas, se construyeron fajas nuevas de muro sobre las paredes originales (superficie de sacrificio); sobre los pisos se aplico una nueva capa de tierra apisonada con mezcla; igual tratamiento tuvieron las bancas de los Edificios E y G.

Para la presentación y conservación final de la Plaza Principal se consideraron tres criterios. 1- Los Edificios C y G se mantienen con techos protectores, 2- el Edificio E, consolidado con la misma técnica de conservación permanece sin cubierta protectora, y 3- El Edificio D después de las investigación arqueológica y la consolidación de muros, fue rellenado. En medio de este edificio permanecieron dos árboles para procurar una sombra controlada; dichos árboles fueron eliminados en el año 2002 ya que causaron daños internos a los elementos constructivos enterrados. Periódicamente se monitorea las intervenciones realizadas en la isla, es notorio que los muros protegidos con las cubiertas protectoras permanentes (Edificios $\mathrm{C} y$ G) tienen menos alteraciones visibles a los muros expuestos al sol y la lluvia; estos últimos tienen cambios de coloración en su superficie, dependiendo de la temporada, si es época de lluvias los muros toman un color entre verde y negro mientras que los muros con cubierta protectora se mantienen sin fuertes cambios de coloración.

Además de la intervención en los edificios de la Plaza Principal se realizaron trabajos de consolidación de muros expuestos en toda la 
isla y se recuperaron volúmenes en los taludes que rodean la Plaza Principal, esto para consolidar su forma. Los trabajos generales de conservación terminaron en diciembre de 1996 con la inauguración de un pequeño centro de visitantes con información sobre la isla.

En 1992 se publicó el primer informe con un plano topográfico (Wurster1992, 261-302). Después varios informes en los Simposios de Arqueología Guatemalteca y en el año 2000 la monografía de la Isla con la contribución de 14 autores (Wurster 2000). En mayo del año 2001 se presentó el mismo libro en una mesa redonda organizada por Asociación Tikal.

En el año 2005 por tres meses y a requerimiento de la Presidencia de la Republica el Programa SURVIVOR tomo la isla de Topoxte (realita show de una cadena televisiva...). En esta acción se quitaron las cubiertas permanentes de los Edificios G y C, dichos techos (tubería de metal y techo de palma) fueron restituidos, luego del programa televisivo, con un nuevo diseño

\subsection{YAXHÁ}

9.4.1 Acrópolis Este

Edificio 216

En el año 1987, al iniciarse los primeros trabajos preventivos, el templo pirámide 216 se encontraba convertido en una colina llena de vegetación. La cámara frontal del templo estaba completamente llena de tierra y escombros. Al espacio posterior se ingresaba a nivel del techo. La pared posterior del templo tenía un saqueo de $1.5 \mathrm{~m}$ de diámetro y junto con las dos fachadas laterales, al norte y sur, permanecieron visibles desde la época de su abandono. En 1987 se iniciaron los trabajos con tres medidas: 1- Corte selectivo de árboles que por su peso y el movimiento provocado por el viento ponían en 
riesgo elementos arquitectónicos, 2-. Apuntalamiento de arquitectura en peligro, incluyendo el saqueo reciente en la fachada este, y 3 Construcción de una cubierta protectora sobre el templo. Los trabajos de conservación duradera se orientaron inicialmente a asegurar la estabilidad estructural de los elementos arquitectónicos. En el año 1990 se cerró con bloques de piedra sin tallar y mezcla el agujero que atravesaba el muro de la fachada este. Los trabajos nuevos tienen un pequeño remetimiento para marcar el área del saqueo rellenado. Por el interior (segunda cámara), se restituyeron algunos bloques originales de la bóveda, encontrados en el escombro. Esta integración se diferencia del resto del paramento de la bóveda porque los bloques puestos de nuevo tienen sisada la mezcla de unión en contraste con el resto estucado del techo. De esta manera se recuperó la cohesión necesaria del muro para soportar el sistema abovedado del techo. En 1991 se realizaron otros trabajos de conservación combinados con la investigación arqueológica y el dibujo detallado de la arquitectura.

La secuencia consistió en: liberación de escombros del recinto y el material depositado alrededor de los muros y plataformas del templo. El trabajo se inició en la parte exterior del edificio, liberando el piso de la última plataforma de la pirámide (terraza) y lo que aún se conservaba de las escalinatas. Se consolidaron los muros originales. Después se vació la cámara interior. Allí aparecieron más piedras de bóveda y bloques de muros derrumbados. Para realizar los trabajos en la cima de la pirámide escalonada se construyó una torre de andamio con más de $30 \mathrm{~m}$ de altura, (esquina noreste). La cubierta protectora colocada en 1987 fue modificada cuatro veces para poder adaptarse a los avances de los trabajos. La última fase de la cubierta fue construida con tubería de metal y techo de palma. Luego de terminados los trabajos de investigación y restauración en el templo 
se eliminó la cubierta protectora temporal. Previamente los muros expuestos fueron tratados con una nueva capa de piedra sin tallar y mezcla, (superficie de sacrificio). Los muros estucados de la segunda cámara fueron consolidados; estos muros han sido intervenidos en varias oportunidades, los trabajos principales los realizó Miguel Ángel Núñez Villanueva, experto del equipo de $A E C l$, que entrenó al personal de Yaxhá durante su contribución en la restauración del Templo I de Tikal. (Núñez Villanueva 1996)

No se reintegró el sistema abovedado del techo ni se repusieron dinteles de madera. En la parte exterior del techo se sellaron las grietas, se corrigió la escorrentía del agua de lluvia a unos muros previamente preparados y se restauró el arranque de la crestería sin agregar nuevas piedras a los muros. El piso original de las cámaras fue protegido con capas de tierra apisonada y mezcla; los escalones originales de acceso al templo fueron cubiertos por una nueva capa de piedras laja y mezcla para soportar el paso de los visitantes.

En este edificio se estableció desde un principio que el acceso al nivel del templo, en la cima de la pirámide, era un elemento símbolo de la ciudad. A nivel de la plataforma escalonada se consolidaron las secciones de muro expuestas en las cuatro fachadas; posteriormente se continúo con la restitución de volúmenes de las plataformas escalonadas hasta el año 2006. Estos trabajos se hacían por temporadas cortas durante la época de lluvia. En 1997 se publicó el primer informe sobre los trabajos en el Edificio 216 (Hermes, Noriega y Calderón 1997, 259-309).

En 1997 iniciaron los estudios y pruebas para procurar una recuperación de volúmenes en la base piramidal del edificio 216 de Yaxhá (fachada oeste); la idea era diseñar un nuevo método de 
intervención empleando el reciclaje del mismo escombro del edificio. Para el estudio se contrató al ingeniero estructural Hugo Galindo (estudios especiales) para que analizará la problemática de la pérdida de volumen y propusiera soluciones factibles. El proceso de restitución de volúmenes utilizando el mismo material original, en forma reciclada, con estabilizadores vegetales (refuerzos horizontales contra el deslizamiento), se experimentó por primera vez en 1998. (Noriega y Galindo 2001, 191-206). En 1998, 2001 y 2002 se solicitó el apoyo del Centro de Investigaciones de la Facultad de Ingeniería de la USAC (CII) para monitorear el nuevo método de reintegración de volúmenes. Los trabajos de prueba de materiales estuvieron a cargo del ingeniero Pablo De León y el arquitecto Alejandro Flores.

Este método se empleó en dos edificios del Grupo Maler (Edificio 4 y 6) pero fue destruido en el año 2002 por el Programa PDS-BID. Actualmente no se continúa con esta técnica ya que es cuestionada por el gremio de restauradores y arqueólogos. La intervención en la base piramidal del edificio 216 de Yaxhá lleva mas de diez años, continúa tan estable y sólida como en 1998; por lo que debería replantearse su aplicación en otros edificios, sobre todo en sectores aislados de difícil acceso. Un estudiante de ingeniería de la Universidad Técnica de Graz realizó su trabajo de tesis sobre este método con resultados positivos (Tourlutter 2002). A principios de 2005 el Banco de Desarrollo Alemán (KfW) envió una comisión de evaluación técnica para el cierre de la cooperación del gobierno Alemán. Esta comisión estuvo integrada por dos expertos del Instituto Arqueológico Alemán (KAAK) y una experta de la Universidad Técnica de Berlín; en su informe recomiendan continuar con dicho procedimiento. 


\subsubsection{Otros edificios}

Acrópolis Este: Edificio 218. A finales del año 2004 se inició la investigación arqueológica, luego en enero 2005, continuó, por etapas, la restauración que concluyó en el año 2007. El equipo responsable fue Raúl Noriega y Francine Valiente.

Plaza A: Plaza de las Pirámides Gemelas, en el año 2001, se investigó el edificio alargado en el extremo sur del grupo. Luego se consolidaron los restos de muros sin ninguna integración. El interior del edificio, que no tenía 9 accesos, fue rellenado de nuevo y se consolidó su plataforma base para marcar mejor el volumen del edificio. En el extremo norte del mismo grupo entre los años 2002 y 2003, se investigo el edificio norte. Aquí, luego de la investigación arqueológica y la liberación de escombros del patio interior y el muro perimetral, se consolidaron los muros en sus cuatro lados, el arco de acceso no se reconstruyó. Adicionalmente en la fachada norte (limite de la plaza elevada) se recuperaron los volúmenes de la plataforma de sustentación. En la liberación de escombros el arqueólogo responsable encontró abundante cantidad de piedras con diseños tallados en alto relieve, que correspondían a un friso decorado del muro perimetral; Las piedras decoradas no fueron recolocadas por que fue imposible determinar la altura del friso, así que fueron documentadas y enterradas de nuevo en un deposito especial cerca del edificio.

Acrópolis Sur: Patio 2, en este grupo de edificios existía un saqueo a nivel del techo de un edificio horizontal con bóveda expuesta por el vandalismo. Luego de documentar el espacio interior se relleno y se clausuro el saqueo. En este grupo permanecieron expuestos dos secciones de muros que no fueron intervenidos. 
Yaxhá a pesar de ser un sitio grande no presentaba más arquitectura expuesta, que la ya descrita. Por años se concentraron los esfuerzos en trabajar los espacios urbanos de la ciudad. Se intervino el espacio de las calzadas y vías, se realizaron cubiertas protectoras sobre los monumentos esculpidos en piedra (techos de madera y palma). En la ultima fase de la cooperación alemana (medida complementaria 2006) se produjeron replicas de cuatro estelas.

\subsubsection{Intervenciones PDS-BID}

En el año 1998, un nuevo financiamiento (préstamo BID), inició su primera etapa de actuación en Yaxhá (noviembre 1998-mayo2000). En esta fase se acondicionó un nuevo acceso para este proyecto de inversión, se construyeron bodegas y se amplió el campamento. Los trabajos se concentraron en el sector norte de la ciudad. En esta parte no existía evidencia de arquitectura visible; pero las autoridades superiores, con visión hacia el turismo, ordenaron más edificios restaurados. Así que se planificó "destapar" edificaciones en el grupo Maler, Calzada Blom y Acrópolis Norte. El concepto inicial era restituir volúmenes perdidos con el mismo proceso empleado en la base piramidal del Edificio 216 (reciclado de escombros y fibras vegetales horizontales como estabilizadores). En el Grupo Maler se intervinieron dos edificios pequeños ( 2 y 3 ) que fueron trabajados como volúmenes geométricos. En los edificios de mayor volumen (Edificio $4 \mathrm{y}$ plataformas del Edificio 6) se utilizo el método de reciclaje de escombros diseñado para el Edificio 216 (demolido luego con dictamen favorable de consultor contratado por el programa BIDPDS). En la Acrópolis Norte se trabajó, con el mismo sistema, la recuperación del volumen en la terraza oeste del Edificio 142 (no destruida y en buen estado de conservación). En la fachada sur del mismo edificio, se restituyeron volúmenes del lado este (destruidos en la fase siguiente del programa BID-PDS). En la parte superior del 
mismo Edificio 142 se empleo un sistema distinto; aquí se utilizo piedra pequeña sin tallar para permitir el paso de personas a la cima (vista panorámica). Desde la cúspide del Templo 216 se divisa esta parte alta del Edificio 142 formando un eje visual que permite dar idea de la dimensión urbana de la ciudad.

En la segunda fase del préstamo (2003-mayo 2007), el programa PDS-BID contrató varias firmas privadas para que continuara los trabajos de intervención en Yaxhá, tanto en restauración como en la construcción de infraestructura turística (servicios sanitarios, muelles escalinatas y otros). Los trabajos de restitución de volúmenes, hechos en la primera fase, fueron quitados y vueltos hacer con piedra y mezcla. Los trabajos de "destapar" más arquitectura se extendieron a otros sectores de la ciudad. El criterio usado fue mostrar arquitectura, así que se reconstruyeron fachadas nuevas en 15 edificios: en el grupo Maler, 3 edificios; en la Acrópolis Norte, 5 edificios. En este grupo se dejo expuesta una escalinata y una fase constructiva anterior (con un mascaron) con cubierta temporal de madera y palma. Además se reconstruyó dos segmentos de plataforma del basamento de la Acrópolis

Otros trabajos de reconstrucción de fachadas para el turista: Acrópolis Sur dos sectores de edificios; en el Juego de Pelota 1 ( dos edificios), en la Plaza C, (Edificio 40), en la Plaza B (un edificio), en el grupo al oeste de la Plaza R (un edificio, una plataforma y la base de la plataforma en la esquina sureste). También se intervinieron los muros contrafuerte de la calzada Blom incluyendo unas gradas en el muro contrafuerte oeste. 


\subsection{NAKUM 1987- 2007}

Entre 1987 y 1991 se realizaron acciones preventivas en varios edificios. Las medidas consistieron en: control de vegetación, construcción de cubiertas protectoras (ocho en total) y apuntalamiento en 35 muros y 4 bóvedas. Además se realizaron: corrección de escorrentías, relleno de saqueos y documentación gráfica y fotográfica. En 1991 Marvin Fuentes elaboró un informe técnico sobre el estado de conservación de siete edificios en peligro, A, V, C, N, E, U, y 104 (Fuentes 1991, manuscritos en la Biblioteca del PRONAT).

En el año 2002 colaboraron dos arquitectos voluntarios, Marcus Schald con documentación de arquitectura en la Acrópolis y el dibujo de etapas constructivas de los Edificios N y E; y Xavier Ruchti con una simulación en computadora de la parte sur de la ciudad. En el mismo año se publicó el nuevo plano topográfico de Nakum con una descripción de la arquitectura y una síntesis de su evolución cultural (Quintana y Wurster 2002, 243-275). En el año 2006 se presento la tesis "Análisis de la arquitectura expuesta del sitio prehispánico Nakum" en la Facultad de Arquitectura de la Universidad de San Carlos (Méndez, Tobar, Guardado y Gonzáles, 2006).

La ciudad se divide en dos sectores uno al sur y otro al norte, unidos por una calzada en diagonal de $250 \mathrm{~m}$ de largo. Los trabajos de rescate se concentraron en la parte sur, por ser este el grupo de edificios con mayor arquitectura visible en peligro. Los sondeos de arqueología y reconocimiento de áreas vecinas se realizaron en toda la ciudad. 


\subsubsection{Plaza Central}

Edificio A: Desde 1988 se realizaron medidas preventivas; su estabilidad estructural estaba tan frágil que en 1984 personal del Parque Nacional Tikal llegó a Nakum para apuntalar los dos accesos laterales en forma de medio círculo del templo. Las acciones realizadas fueron: construcción de una cubierta provisional sobre todo el edificio, eliminación de vegetación, apuntalamiento de muros y techos y el relleno de saqueo en el muro noreste de la segunda cámara. En 1989 el templo tuvo un derrumbe (lado sur), quedando en el aire la crestería. Desde Tikal se trasladaron de emergencia tubería galvanizada para reforzar el andamio de madera. En esa época se formó una comisión técnica interinstitucional para plantear alternativas de estabilización para este y otros edificios de Nakum También opinaron diferentes ingenieros estructurales, que fueron invitados. En 1995 iniciaron los trabajos de intervención duradera, un nuevo andamio, de tubería galvanizada fue construida para cargar la crestería y liberar el espacio inferior para realizar los trabajos de intervención.

Se optó por rellenar con material de piedra y mezcla los dos ingresos laterales (el acceso sur ya colapsado); los trabajos tuvieron el cuidado de crear una capa intermedia de plástico entre el muro nuevo y los restos originales aun con estuco. Esto con el propósito de marcar la intervención moderna, acción que es totalmente reversible. En el acceso central se reconstruyó la porción de muro colapsado y se restituyó de nuevo los dinteles de madera (1996). Las vigas originales de madera desaparecieron antes de las fotografías de principios del siglo $X X$. El criterio de intervención, después del colapso parcial, fue restituir en lo posible la mayor cantidad de masa a los muros del edificio para ayudar a cargar las torres de la crestería. En la crestería se revisaron los espacios vacíos interiores, se cerraron 
los espacios quebrados y se consolidaron los muros desprendidos. La plataforma escalonada que sostiene al templo no presentó muros expuestos, por lo que solamente fue parcialmente investigada por el programa de arqueología. En la fachada posterior se incrustaron piedras claves en las filas inferiores de la piedra fachaleta, con el propósito de sostener las hileras superiores; buena parte de estas piedras fachaleta se han desprendido dejando en el relleno del muro su huella.

Edificio C: Este edificio tiene una base piramidal escalonada muy peraltada con fuerte perdida de volumen, los muros del templo superior se encuentran colapsados y los pocos restos de muro están agrietados y en peligro. Al frente, en la parte superior de la escalinata ceremonial aun quedan escalones de piedra en posición original. Esta evidencia arquitectónica se aseguró con andamios en 1989. En el año 2004 se liberó de escombros la cámara, se realizó documentación detallada de muros y un pozo de sondeo en el piso del templo. Frente a la fachada se documentó y consolidó la Estela C (ver informe anual de Arqueología en Nakum 2004).

En el extremo sur de la Plaza Central se consolidaron dos plataformas alargadas y bajas frente a las escalinatas laterales del Edificio D, Los trabajos consistieron, luego de la investigación arqueológica, en la consolidación de los muros, y posterior relleno con capas de tierra apisonada más la colocación de plantas rastreras. Posteriormente (2007) se realizó una investigaciones en la esquina suroeste de la Plaza Central, identificando una cancha para el juego de pelota y en el extremo suroeste un edificio con planta semicircular. La mayoría de las estelas y altares lisos de la plaza, fueron desde 1990 tratados y enterrados. 


\subsubsection{Plaza Este}

Edificio V: En 1988 se construyó un techo protector, apuntalamientos de muros de la cámara superior y la base piramidal. En planta el Edificio $V$ tiene una forma de " $T$ " con una terraza alargada enfrente. En este edificio el principal problema fueron dos grietas verticales que partían el edificio en cuatro partes. Luego de los estudios de suelos se detectó que dichas fracturas fueron causadas por asentamientos diferenciales del suelo. La parte norte del edificio fue construida sobre un terreno ganado al bajo, mientras que la parte sur sobre un lecho de roca caliza. El criterio de restauración considero mantener las dos partes separadas con un relleno de mezcla de cal que permitiera en caso de nuevos asentamientos separarse de nuevo en la parte restaurada. Este edificio también tenía agujeros de saqueo en los muros. Se respetó la deformación en el piso del edificio (lado norte se hundió $0.25 \mathrm{~m}$ ) y se consolidó el arranque de la bóveda de piedra. Se rellenaron tres saqueos (1994-1995) en la base posterior del edificio. Luego de consolidar los muros y el resto de la bóveda del recinto se eliminó la cubierta protectora. Quedan visibles las costuras de las grietas, en algunos sectores de hasta $0.20 \mathrm{~m}$ de abertura. Las intervenciones permanentes se realizaron a partir de 1998 y terminaron en 1999. La base y los laterales del edificio no presentan arquitectura expuesta por lo que solo fueron investigados por el equipo de arqueología.

\subsubsection{Plaza Sureste}

Edificio U: Este edificio presenta partes de muros originales en el templo, en las plataformas escalonadas y en los muros laterales de la escalinata ceremonial. En el año 2001 se realizó un control de vegetación sobre el templo superior y la base piramidal escalonada. En el año 2004 se vació el escombro del templo con una documentación detallada y sondeos arqueológicos. Hace falta la 
consolidación de muros y recuperar el volumen perdido en la base del templo. Frente al edificio se realizó un pozo estratigráfico, atrás de la Estela U.

\subsubsection{Acrópolis}

La Acrópolis de Nakum contiene la mayor cantidad de edificios con arquitectura visible. Los edificios se ordenan alrededor de 13 patios interiores, pasillos y terrazas. Los trabajos preventivos iniciaron en 1988 en los Edificios N, E y el baño de vapor con cubiertas protectoras y apuntalamiento de secciones de muro en toda el área de la Acrópolis. También se realizaron rellenos emergentes de saqueos (solo piedra sin mezcla) y protección de piedras-fachaleta desprendidas (apuntalamientos con bloques de piedra sin mezcla o puntales de madera).

\subsubsection{Patio 1}

Edificio E: Este edificio es tipo triádico, formado por tres edificios, uno dominante y dos secundarios. Los trabajos preventivos iniciaron en el área del recinto elevado con una cubierta protectora. En el interior del edificio principal, los saqueadores abrieron en el piso un enorme agujero. Para extraer el material de relleno del piso rompieron el muro norte del edificio. Este saqueo destruyo también una banca adosada al muro este de la cámara; en 1998 se relleno el saqueo del piso y se restituyo el faltante de muro. Sobre el acceso al espacio interior se pusieron dinteles de madera nuevos, con el propósito de completar el sistema estructural de la bóveda; aquí también se colocaron los bloques de piedra faltantes del techo (la mayoría recuperados del escombro). Antes de terminar de cerrar el sistema del techo; un sismo (11 de julio de 1999) provocó la caída de la parte en restauración. Los daños fueron reparados de nuevo para dejar completo el techo (Noriega y Galindo 2001, 191-199 y Wurster 2001, 
201-206); de nuevo la parte integrada es reconocida por los bloques de piedra mostrando su mezcla de unión. En los dos edificios adosados (ya sin techo), se consolidaron los muros a la altura encontrada y se consolidó la escalinata en forma de $U$ que da acceso a los tres espacios interiores. En la parte superior del techo se encontró evidencia de arranque de muros de crestería; dichos arranques fueron consolidados en una fase posterior (2003).

Al pie de la pirámide escalonada se realizaron trabajos de consolidación e integración de muros en espacios adosados a la pirámide, a ambos lados de la escalinata ceremonial. En el año 2004 se destapó y consolidó un mascaron en la esquina de un edificio anterior (escultura en el friso del techo); luego de su documentación y consolidación fue rellenado y tapado. Los muros que conforman terrazas de acceso a los edificios alargados adosados, junto con dos escalinatas laterales, fueron restaurados y preparados para recibir el paso de visitantes.

Edificio D: En la fachada correspondiente al Patio 1 fueron consolidados los muros y la terraza corrida que forma el patio hundido. El acceso principal (pasillo) del Edificio D fue liberado de escombros y luego sus superficies consolidadas. Los restos de muros con estucos fueron restaurados y se colocó una cubierta provisional de madera, palma y plástico para cubrir provisionalmente el pasillo. Los espacios interiores de las cámaras, fueron parcialmente investigados y rellenados de nuevo con piedra sin mezcla; también los restos de bóveda fueron consolidados, incluyendo un pasillo en forma de zig-zag del lado oeste del edificio. Los grafitos encontrados en los muros fueron documentados y consolidados. 
EDIFICIO G: Las secciones con muros expuestos con bloques fachaleta fueron apuntalados en 1989. En 2004 se liberó la cámara este, con una reintegración del techo (bóveda y dinteles nuevos de madera); la razón fue procurar mayor protección a una banca y muros con restos de estuco y dibujos con pintura y carbón frente al acceso. Luego continuaron trabajos de consolidación de muros en la parte oeste y el frente (sur); en estos sectores no se liberó el espacio interior, solamente el equipo de arqueología realizó investigaciones y luego se rellenó de nuevo con escombros y piedra sin mezcla. La base escalonada de la fachada principal fue consolidada y restaurada. También se restauró la escalinata con dado central hacia el patio. A los lados de la escalinata aparecieron dos cautivos correspondientes a una edificación anterior (2005). La fachada posterior, en el nivel de la cornisa de arranque del techo, conservó restos de piedras talladas con diseño. Sobre el techo se encontró evidencia de una construcción que no fue posible comprobar si fue un segundo nivel o una crestería; en este sector solamente se realizaron consolidaciones de restos de muros y el techo (2006).

EDIFICIO H: En el extremo suroeste del Patio 1, se encuentra el Edificio H. Esta edificación corresponde a dos reducidos patios interiores con cámaras a su alrededor y pasillos. Por esta complicada circulación se accede al vestíbulo de la Acrópolis Central. En este edificio se realizaron investigaciones arqueológicas $(2000,2001)$ y consolidación de muros.

9.5.4.2 Patio 2

EDIFICIO F: Este edificio se encuentra en el extremo oeste de la plataforma escalonada de sustentación; por tal razón toda su fachada oeste se encontraba destruida. En este sector se realizaron trabajos de restitución de volúmenes desde la plataforma de sustentación. 
Luego de investigar los espacios interiores se rellenaron de nuevo, con escombro y piedra sin mezcla; el propósito fue dar volumen y sostener los pocos restos de techo (cámara 2). En la fachada norte, se consolido los restos de un mascaron (friso del techo). La restitución parcial del volumen del techo se terminó en el año 2004.

EDIFICIO I: En este edificio se consolidó la cámara este con restos de techo (bóveda) con grietas y en peligro de colapso. Este espacio interior es una especie de comunicación entre el Edificio $\mathrm{H}$ y el Patio 2. Los restos de muros visibles solo fueron consolidados, $\sin$ investigación arqueológica.

9.5.4.3 Patio 3

En este patio solo se realizaron consolidaciones de muros visibles del Edificio I (fachada sur).

\subsubsection{Patio 4}

EDIFICIO M: Solo se consolidaron los muros expuestos en la fachada sur incluyendo la cornisa del techo. En 1990 se rellenó en forma provisional un saqueo en la fachada oeste (hacia la plataforma de sustentación de la Acrópolis); luego en el año 2000 fue rellenado formalmente con piedra y mezcla. El espacio interior no ha sido investigado.

EDIFICIO L: Este edificio fue tratado sólo en el eje central, abriendo el pasillo de comunicación entre el Patio 4 con el Patio 5. Se sacó el escombro y luego se consolidaron los muros con restos de estuco. En secciones de los muros del pasillo abierto, fue necesario reintegrar partes de muro para contener el resto de la edificación sin investigar. Los muros visibles tanto en la fachada norte como sur (hacia el Patio 5) fueron consolidados marcando los accesos a las cámaras sin 
investigar. También se liberó de escombros los dos corredores elevados (norte y sur) que dan acceso a las cámaras del edificio; no se restauraron las gradas de acceso a la plataforma del edificio y se conservaron como montículo (rampa).

9.5.4.5 Patio 5

EDIFICIO N: Edificio triádico formado por 5 espacios interiores en dos niveles. Los trabajos iniciaron simultáneamente en la base del edificio, que es la esquina suroeste de la plataforma escalonada de sustentación de la Acrópolis. Se liberó de escombros y la escalinata (fachada este) fue restaurada parcialmente con el dado central y una superficie de sacrificio para permitir el acceso a la parte alta (grupo triádico). Similar intervención se realizó en las otras tres fachadas. El edificio triádico dominante; tuvo una cubierta provisional de madera y palma frente al acceso principal (ver acceso colapsado en figura 24). Las acciones de excavación (1998) se alternaron con el vaciado de cámaras y los trabajos de restauración.

En el edificio triádico principal se restituyeron los dinteles de madera y se construyó de nuevo un muro faltante para cargar el techo. Sobre el techo se aplicó una capa protectora de lajas de piedra y mezcla de cal. Igual se recuperó el espacio de muros para colocar dinteles de madera en los dos espacios interiores del primer nivel (los dinteles de chicozapote fueron cortados y preparados con seis años de antelación). En los dos espacios interiores del grupo triádico (norte y sur) solamente se consolidaron los muros tal y como se encontraron. En el año 2004 se completó la restitución de la fachada principal. En este caso se construyó una armazón de madera en forma de bóveda maya para reintegrar el espacio interior perdido; en el espacio exterior se colocaron capas de piedra sin tallar y mezcla para unificar visualmente la fachada. Los trabajos concluyeron en febrero 2005. 
Edificio O: Se consolidaron muros expuestos en la esquina oeste del edificio. Luego de los trabajos se rellenó la cámara. Frente a la fachada norte se liberó el escombro para dar volumen al Patio 5.

EDIFICIO P: El edificio fue parcialmente investigado y se consolidaron en el año 2007 los muros de las fachadas norte, este y sur.

\subsubsection{Patio 6}

El Patio 6 es el espacio de vestíbulo para el Edificio Y, a 20 metros por encima del resto de patios de la Acrópolis. Este sector fue investigado en los años 2003, 2004.

EDIFICIO Y: En el año 2004 se iniciaron los trabajos con la liberación de los espacios interiores; en las cuatro fachadas del edificio. En la fachada norte se construyó una cubierta provisional de palma. En el espacio de las cámaras se documentaron distintas modificaciones interiores, como un pasillo de comunicación entre la cámara central norte y sur, construido en una etapa posterior. Este sector era el más dañado y en el año 2007 fue consolidado y rellenado (cámaras y pasillo). Esta medida fue tomada para poder crear una base sólida para el nivel superior. Sobre estas modificaciones prehispánicas se encuentra un segundo nivel con una banca y una puerta escénica al centro, viendo hacia el norte. Para este piso no hay evidencias de una escalinata de acceso.

\subsubsection{Patio 7}

EDIFICIO Z: Este edificio está formado por dos pisos de cámaras en hilera sobre el costado este de la plataforma de sustentación de la Acrópolis Central. En los años 2003 y 2006 se consolidaron muros y terrazas del edificio. Se consolidaron los muros contrafuerte y las paredes expuestas de escombros. En el primer piso, los espacios 
interiores en hilera, luego de consolidado los muros se rellenaron de piedra sin mezcla y en el segundo nivel se restauró la plataforma base de la fila de cámaras, sobre todo se reforzaron los muros transversales (contrafuertes).

EDIFICIO Q: En los años 2005 y 2007 se trabajó en la restauración de los muros del edificio alargado. En la fachada este (limite de la plataforma escalonada de sustentación de la Acrópolis) se realizaron grandes trabajos de recuperación de volúmenes. En los muros de las cámaras de la fachada oeste (hacia el patio) se consolidaron y repararon grietas, se marcaron los accesos a las cámaras y se liberó de escombros los espacios interiores y la terraza (parte horizontal de la plataforma del edificio) hacia el patio.

EDIFICIOS AL NORTE: El límite norte del Patio 7 esta formado por dos edificios alargados sin techo y una escalinata en medio de los dos edificios. En el año 1999 se consolidaron los muros de la fachada norte, este y sur. Los espacios interiores fueron rellenados de nuevo. Por detrás de estos edificios se restauró un pasillo elevado que pasa hacia el Patio 9 (2001).

\subsubsection{Patio 8}

De reducidas dimensiones rodeado de construcciones en tres lados (norte, oeste y sur), con muros lisos que corresponden a fachadas posteriores y un basamento elevado al oeste (restaurado 2002). En la esquina noreste hay un edificio alargado, de una cámara, que fue investigado parcialmente y rellenado de nuevo en 1997. La fachada este del patio corresponde al extremo norte del Edificio $\mathrm{Q}$. 
9.5.4.9 Patio 9

BAÑO DE VAPOR: Este edificio conserva el único techo de cuatro lados original en todo el sitio. En 1988 se eliminó la vegetación sobre el edificio y se construyó inmediatamente una cubierta protectora provisional (madera y palma) el objetivo fue liberar del peso al techo, ya que únicamente la cáscara interior sostenía la bóveda El equipo de arqueología realizó las investigaciones alrededor del edificio y en el saqueo interior. El equipo de restauración reafirmó el techo con bloques de piedra nueva, encima de la cáscara original, (una de las tres capas que conforman el techo), sin llegar a la reconstrucción total (2000-2001).

EDIFICIO R: En el año 2003 se consolidaron los muros y bóvedas escalonadas del edificio. La cámara norte fue investigada por Tozzer y Merwin; dicho espacio interior se conservó sin escombros y con una cubierta provisional (madera y palma); las otras dos cámaras fueron investigadas parcialmente (2001), sin remover el escombro y luego los accesos fueron tapados con piedra sin mezcla. Los restos originales del techo fueron consolidados; también se reintegro parte del techo para definir el edificio y la terraza elevada hacia el patio fue liberada de escombros y la escalinata conservada en forma de rampa monticulada. Los trabajos de restauración concluyeron en el año 2004. El edificio adosado por atrás fue solamente investigado y luego conservado en forma de montículo.

EDIFICIO S: La fachada sur, corresponde a la parte de atrás del edificio, el cual es liso y sin aberturas; el muro fue consolidado para liberar de escombros un pasillo (entre los Edificios R y S) hacia la Plaza Sureste. 
EDIFICIOS AL OESTE: En el año 2005 se investigaron los edificios del límite oeste del patio. En este sector solamente se consolidaron muros y se habilitó un pasillo interno (por un edificio) hacia el Patio11.

\subsubsection{Patio 10}

EDIFICIO S: Investigación, documentación y restauración de muros en el año 2004; en 2005 se continuaron los trabajos en la esquina noreste, la cual contenía restos de un friso a nivel de cornisa del techo, luego de la investigación la esquina fue tapada de nuevo. El espacio interior no fue investigado.

EDIFICIO D: (tramo correspondiente al Patio 10). En el extremo norte del patio, se investigo y se consolidaron muros visibles dentro del escombro del edificio. Se conserva como montículo al igual que el Edificio T (lado este) y los dos edificios al lado oeste del patio. Estos dos edificios fueron intensamente investigados posteriormente por un proyecto Polaco.

\subsubsection{Patio 11}

En el año 2005 se vació el espacio del patio apareciendo muros en los cuatro extremos. Al este se consolido un muro sin aberturas. Al sur un edificio adosado a la plataforma escalonada de la Acrópolis Central con acceso, banca, restos de bóveda y pintura mural. Al norte se consolidaron los muros de un edificio con abertura hacia una terraza con vista al patio hundido (Patio 1). Por este mismo edificio se pasa al Patio 9. Al oeste se consolidó la plataforma de sustentación del Edificio G. Por la esquina suroeste se supone esta un acceso hacia el Patio 12 
9.5.4.12 Patio 12

Este sector esta formado por la fachada trasera del Edificio $G$ y el acceso monumental hacia la Acrópolis Central. Solamente se ha consolidado el muro sur del Edificio G, con restos de figuras esculpidas a nivel de la cornisa del techo. No se ha investigado aún el escombro sobre este patio.

9.5.4.13 Patio 13

Este espacio lo forma la esquina noroeste de la Acrópolis. Los limites, al norte y oeste están abiertos (terraza en esquina). Al este la fachada del Edificio D con una escalinata de piedra, exterior (al techo); consolidada y rellenada. El límite sur esta definido por la fachada posterior del Edificio F. Enfrente a este muro se encuentra los cimientos de otro edificio.

\subsection{NARANJO}

En Naranjo no se realizaron trabajos de restauración de arquitectura. Solamente se han trataron secciones con muros expuestos con medidas de conservación preventiva; como control de vegetación, cubiertas temporales de protección y apuntalamiento de elementos, en seis sectores de la ciudad.

\subsection{OTROS DEL TRIÁNGULO CULTURAL}

En este acápite agrupamos los trabajos de intervención de edificios en sitios arqueológicos dentro del área del nuevo Parque Nacional Yaxhá-Nakum-Naranjo.

\subsubsection{Poza Maya}

En 1992 se inicio la documentación de saqueos en el sitio (35 depredaciones). Luego continúo la investigación arqueológica y el posterior relleno de los saqueos. La arquitectura expuesta por las 
trincheras de saqueo fueron rellenadas. En el patio norte (edificio al este), se consolidaron dos trincheras de saqueo para ser mostradas como ejemplos de daños causados por la depredación.

\subsubsection{Pochitoca}

En 1994 se documentaron los saqueos (20 depredaciones) y en 1995 se realizó la investigación y el relleno de los mismos. No se dejó visible ningún elemento de arquitectura.

\subsubsection{Naranjito}

En el año 2003 se realizaron tareas de relleno de saqueos y conservación de arquitectura. El sitio fue parcialmente investigado en 1996, se rellenaron todos los saqueos, se limpió el patio central y las dos acrópolis. En la Acrópolis Norte se relleno la trinchera monumental en el templo pirámide principal; aquí también se remediaron las bases de los muros y se repararon las grietas del techo, aún con restos de bóveda. El sector de la Acrópolis Sur cuenta con varios muros expuestos que requieren atención preventiva. Los trabajos de relleno de los túneles y trincheras de depredación representaron el movimiento de 2413 m cúbicos de relleno.

\subsubsection{El Pital}

Al igual que en los sitios Poza Maya y Pochitoca se preparó el sitio arqueológico con documentación de saqueos, investigación y relleno de la arquitectura expuesta. Como una medida de conservación preventiva la arquitectura consolidada fue tapada de nuevo en espera de condiciones más favorables para su presentación, dentro del nuevo parque (Quintana 2007, 91-92). 


\subsubsection{Otros sitios}

Varios sitios menores dentro del parque fueron tratados con el mismo criterio explicado anteriormente para Poza Maya y El Pital. Los pocos edificios con restos de arquitectura expuesta fueron documentados y rellenados en El Tigre, El Carmen, La Perra, El Tumbo y otros.

\subsection{ALREDEDOR DEL TRIÁNGULO CULTURAL}

En este acápite agrupamos los trabajos de intervención de edificios en sitios arqueológicos alrededor del nuevo Parque Nacional YaxháNakum-Naranjo.

\subsubsection{La Blanca}

Sitio con arquitectura visible monitoreado desde 1994 con trabajos de apuntalamiento y documentación de arquitectura, investigación y relleno de saqueos. En el año 2004 inicio un proyecto de investigación y restauración con la Universidad de Valencia, Universidad Politécnica de Valencia y la Universidad de San Carlos. En el año 2007 inicio la restauración de los edificios del patio principal (ver en bibliografía, publicaciones de Gaspar Muñoz Cosme y Cristina Vidal Lorenzo sobre el proyecto La Blanca).

\subsubsection{Tzikintzakán}

El sitio tiene un edificio horizontal representativo con arquitectura expuesta en peligro, que no ha podido ser atendido; solamente se han realizado trabajos de control de vegetación y una documentación detallada de su arquitectura. El edificio es monitoreado desde 1987 y los muros en peligro están apuntalados desde 1995.

\subsubsection{Corozal Torre}

En el año 2003 se realizó la investigación y el relleno de un túnel de saqueo que atravesaba el edificio principal, con arquitectura expuesta 
en peligro. Luego en el año 2004 se restituyó un dintel en la fachada del mismo edificio, se reparó una grieta vertical, se consolidó el techo (con un friso con figuras esculpidas) y se recalzó la base de la torre con piedra nueva.

\subsubsection{San Clemente}

En 1992 se elaboró su primera ficha técnica con un plano esquemático, registro de saqueos y la arquitectura visible en peligro de colapso. El sitio fue monitoreado a partir el año 1995. En el año 1996 iniciaron acciones preventivas con un control de vegetación y un inventario de vegetación. En los años 1996 y 1997 se realizaron intervenciones preventivas en la arquitectura.

En el año 2006 se intervinieron seis edificios de sector norte (el palacio). Se restituyeron las bases de varios muros y se recuperó parte del volumen perdido en la plataforma de sustentación (esquina noroeste). Se repararon grietas en muros y techos; se restituyeron, en seis sectores, los dinteles perdidos de madera y se reconstruyeron los segmentos de bóveda perdida. Las terrazas y pasillos frente a los edificios intervenidos fueron liberados de escombros y las escalinatas se trataron como rampas monticuladas. Los muros estucados fueron consolidados, los pisos y bancas protegidos con capas de arena apisonada. En el año 2007 se restauraron dos edificios (templos pirámide) más en el sector sur del sitio arqueológico.

\subsubsection{Otros edificios}

Continuando con el mismo criterio de conservación preventiva de edificios, se trabajaron con acciones de control de vegetación, documentación y relleno de saqueos, consolidación de la arquitectura expuesta y su posterior "tapado" para su preservación en los sitios: 
Quemada Corozal, Zapote Corozal, La Naya, Ixtinto, El Venado, El Sombrero, Holtún, Cordoncillo Corozal, y otros.

\subsection{PRIORIDADES DE INTERVENCION}

La muestra cuenta con aproximadamente 4000 edificios identificados. En este corpus alrededor de 1500 edificaciones tienen algún rasgo visible de arquitectura expuesta. La gran mayoría causada por la actividad de saqueos. Para ordenar las prioridades de intervención dividimos la muestra disponible en tres partes.

1- El primer grupo corresponde a los edificios sin arquitectura expuesta en peligro, en donde la mayoría de edificaciones se encuentran en forma de "montículos". Este grupo representa el 62\% de las edificaciones. La arquitectura expuesta es reciente producida por la actividad de saqueo; pero por el momento su situación no presenta riesgo de perder elementos importantes.

2- En el segundo grupo la mayoría de edificaciones están cubiertas en forma de montículo, pero aparecen algunos edificios con partes de arquitectura visible en peligro de colapso. Entre los elementos visibles están: secciones de muros, cornisas, parte de techos y otras superficies que constituye un $38 \%$ de la muestra. En este grupo también aumenta la exposición de arquitectura debido a las constantes intervenciones "ilegales" de saqueo que "destapan" los edificios.

3- El tercer estado de presentación del patrimonio edificado, es un segmento que pertenece al grupo de edificaciones con arquitectura expuesta en peligro. Este segmento recientemente (a partir de 1959), ha tenido algún tipo de intervención de "conservación" y representa el $4.20 \%$ de los edificios identificados (168 edificios). Estas 
intervenciones "legales" en los edificios, pueden ser totales o parciales, buenas o malas, necesarias o innecesarias.

La investigación ha identificado, aproximadamente unas 240 edificaciones que tiene arquitectura expuesta visible de importancia o en peligro de colapso. De estas 168 se encuentran con algún grado de intervenciones y 72 edificios requieren con urgencia atención de rescate. El conocimiento actual, muy parcial de estos elementos arquitectónicos visibles, es sin embargo el universo de trabajo actual

Este patrimonio expuesto se encuentra en diferentes grados de exposición. Esta condición se debe a tres factores:

- Edificios destapados por razones científicas o políticas como los edificios de Yaxhá del programa PDS-BID.

- Edificios destapados por el vandalismo (saqueo arqueológico).

- Edificios expuestos desde su abandono. Este caso representa a los edificios que por razones especiales siempre estuvieron expuestos con arquitectura visible; por ejemplo las cresterías de los Templos Mayores de Tikal (ya restaurados), o tres fachadas del Edificio 216 de Yaxhá (ya restaurado), la crestería-torre de la Muralla, las tres torres triádicas de La Honradez, el Edificio XV de Chochkitam y otros.

Este último grupo de edificios expuestos deberían de ser la prioridad de atención actual. 

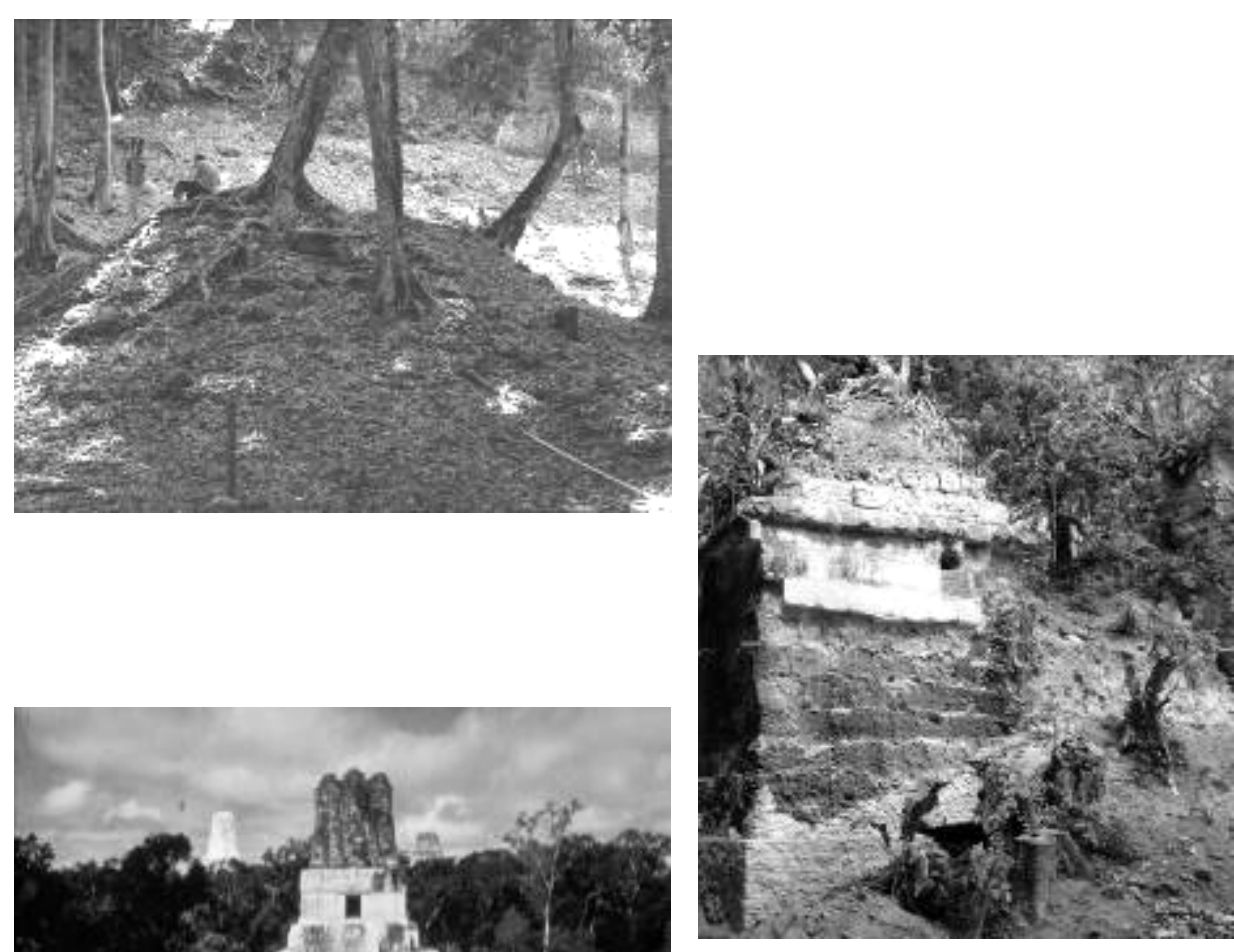

Fig. 22. Tres estados de presentación del patrimonio edificado, a) montículo, sin arquitectura visible, b) edificio con arquitectura parcialmente descubierta (Edificio $P$ de Nakum), c) edificio restaurado, reconstruido (Templo II de Tikal). 
Para definir los grados de intervención necesaria, los elementos de arquitectura expuesta se dividen en cinco niveles y cuatro prioridades. El primer nivel representa a los edificios emblemáticos de valor excepcional y único que se encuentran en peligro de colapso. Estos son edificios o grupos de edificios vitales para la historia de la arquitectura de las tierras bajas mayas. De esta categoría se identificaron 36 edificios en 12 sitios arqueológicos. Se supone que dentro de la condición actual de montículo en que se encuentran la mayoría de edificios habrá otros ejemplos singulares que requerirán atención futura. Mientras se averigua, los 36 edificios identificados deberían de ser el objetivo principal de la acción de recuperación de la memoria tangible maya.

En la estrategia diseñada para el territorio en la prioridad uno o "muy importante" se consideran 18 sitios estratégicos. En este criterio no solamente se consideran los sitios con arquitectura expuesta $y$ excepcional que debe rescatarse ( $A$, arquitectura muy urgente), sino también se incluyen sitios que no tienen arquitectura visible o en peligro, pero por su posición entre los "paquetes de sitios" del diseño de planificación regional son importantes para activar el patrimonio cultural en determinados sectores del territorio (ver capitulo 12).

El segundo grupo (B, arquitectura urgente) lo forman los sitios con edificios o grupos de edificios con arquitectura monumental expuesta y en peligro, consta de 13 edificios en 7 sitios. La prioridad 20 "importante" para la estrategia regional son 11 sitios. En el tercer nivel (C, arquitectura poco urgente) la evidencia de arquitectura expuesta es menor y requiere intervenciones puntuales de rescate, son 24 edificios en 22 sitios. Este nivel tiene prioridad 3 en donde la principal acción sería intervenciones preventivas. En la estrategia regional se identificaron 26 sitios que corresponden a este grado de intervención. 
El cuarto nivel ( $D$, sin arquitectura en peligro) son elementos de arquitectura parcialmente expuestos y aislados que requieren atención preventiva y monitoreo en 77 sitios.

La quinta categoría ( $E$, arquitectura ya restaurada) se refiere a los edificios ya intervenidos o "fuera de peligro". Aquí se incluyen los edificios en proceso de restauración en toda la zona del noreste del departamento, con más de 154 edificaciones, que desde 1959, con diferentes métodos y objetivos, han sido intervenidos y persisten ahora total o parcialmente expuestos.

Las actuaciones realizadas sobre las edificaciones en los últimos 49 años (1959-2008); junto con los edificios identificados como: muy urgentes, urgentes, poco urgentes deberían ser el tema de atención del patrimonio edificado monumental del noreste de Petén. Estos edificios requieren un plan y una metodología de atención en el corto, mediano y largo plazo. 
Los procesos de intervención en un sitio arqueológico tienen diferentes fines u objetivos y diferentes escalas de resultados.

El apartado 3 permite formular la base para las acciones de intervención en el patrimonio edificado. Ya mencionamos los métodos de investigación para obtener resultados sobre el espacio construido y su condición actual. Podemos agregar, también, en el campo de arqueología la matriz diseñada en este trabajo. Este campo considera cuatro escalas o niveles de actuación. Un primero llamado "arqueología regional" el cual se encarga de la investigación macro entre sitios, arqueología en áreas de humedales, cauces de ríos y otros.

El segundo campo se encarga de la investigación en sitios arqueológicos grandes y en apoyar las intervenciones de restauración; incluyendo, investigaciones en los alrededores del área monumental, y otros. El tercer campo se refiere a sitios arqueológicos abandonados, llamado "arqueología de rescate"; y un cuarto apartado llamado "estudios especiales". Este cubre otros aspectos científicos necesarios para obtener un conocimiento general de la cultural maya en la región de estudio. Cada campo de actuación alcanza un grado distinto de conocimiento $\mathrm{y}$, en conjunto, forman el sustento científico para entender o interpretar el pasado cultural de la región. Tiene como objetivo la obtención de resultados de investigaciones y, por lo tanto, es el marco científico del modelo general.

El conocimiento adquirido, permite en el apartado 4 hacer intervenciones de conservación en los edificios-objeto seleccionado y es el tema del presente capitulo. 
En todos los edificios seleccionados se realizan actividades preventivas. Luego según su posición en le esquema del plan regional se ejecutan otras intervenciones (edificio-objeto no estratégicos, edificios-objeto no tan estratégicos y los estratégicos). También se mencionó que los tres niveles de intervención, se realizan bajo tres diferentes visiones:

- El primer grupo lo forman los sitios estratégicos (tercera etapa de intervención). Aquí deben realizarse las intervenciones necesarias para que el trabajo además de garantizar la estabilidad del o los edificios, genere identidad, orgullo en la población local y beneficios económicos a través del turismo; es decir restauración para el uso del recurso patrimonial, ejemplos de esta visión son: Topoxté, Yaxhá y Nakum Estos sitios seleccionados son los elementos patrimoniales edificados que "soportan" y representan al patrimonio prehispánico del conjunto "triángulo cultural".

- La segunda visión del programa es "preparar" los edificios con arquitectura visible en peligro para que se "conserven"; no para el uso y disfrute actual, sino como grandes reservas de identidad cultural que se "congelan" para un futuro cercano o lejano (segunda etapa de intervención). Cuando el Estado tenga más presupuesto, cuando el público sea más "educado" y exija calidad y no imitaciones o reconstrucciones, cuando la tecnología de conservación sea más avanzada, podrán ser "descongelados" estos recursos preservados para iniciar una etapa de representación con calidad.

- La tercera visión es una posición intermedia, en donde los objetos a rescatar no son sitios tan espectaculares como Tikal o Yaxhá, pero si poseen arquitectura visible en peligro de colapso y son "estratégicos" para las zonas aledañas y si se intervienen pueden apoyar al desarrollo humano de su localidad (etapa 2 ó 3 de intervención). Estos sitios intermedios junto con los sitios mayores pueden combinarse con las comunidades vecinas en circuitos culturales y así 
participar, sostener las inversiones y esfuerzos del programa por recuperar el patrimonio prehispánico y sus edificios en peligro. Ejemplos de esta condición intermedia son los sitios San Clemente, Corozal Torre, La Blanca y otros.

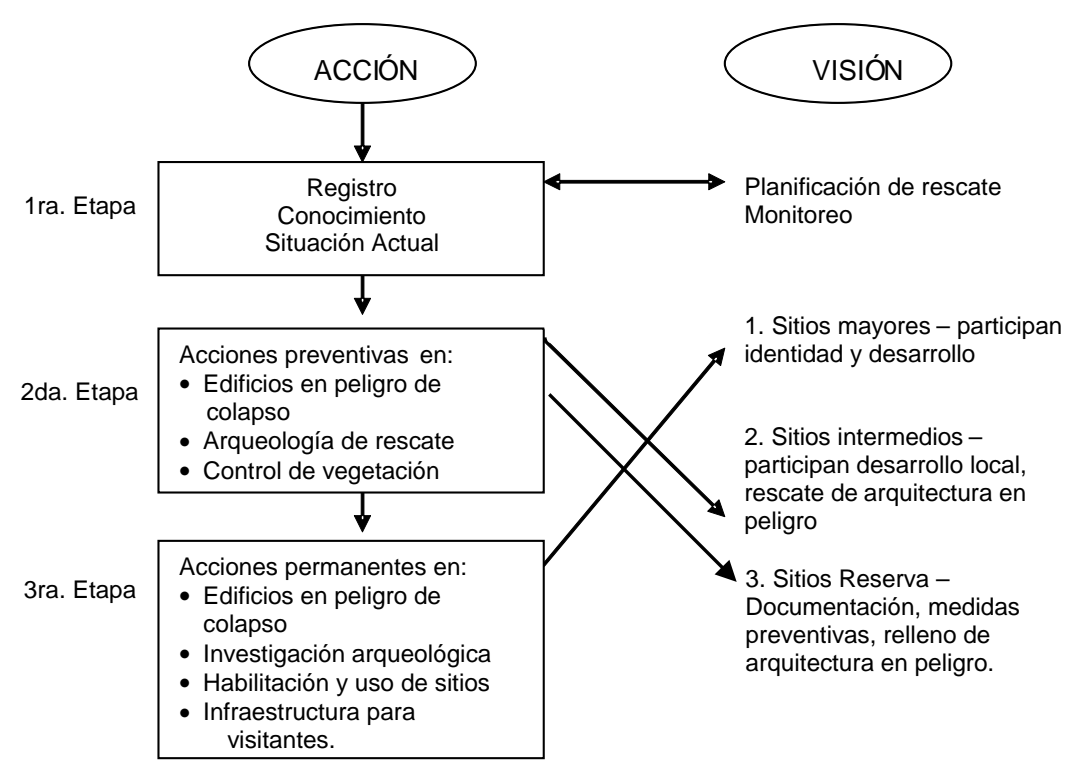

Fig. 23. Concepto, acciones y visiones de conservación

Las tres visiones de intervención, corresponden al apartado 4 del modelo general y pretenden abarcar las prioridades actuales de las edificaciones de la región noreste del departamento. El diseño da atención a los edificios identificados como estratégicos, otros edificios no tan estratégicos y otros poco estratégicos, pero que requieren atención por parte del Estado.

El mecanismo técnico para realizar intervenciones cortas dirigidas a consolidar principalmente la arquitectura visible en peligro de colapso, cuenta con tres etapas de acción. En una forma muy resumida, la primera etapa se refiere a la acción de identificar y registrar los bienes 
patrimoniales con edificios en peligro de colapso. La segunda etapa, atiende a esos edificios identificados con medidas preventivas; y en la tercera fase, los edificios con arquitectura en peligro, "estratégicos" son atendidos con acciones duraderas. Cada etapa va aumentando el grado de intervención y complejidad del trabajo, y en conjunto forman un esquema mayor del patrimonio edificado rescatado.

\subsection{Recorridos}

\section{Primera etapa}

El primer paso se refiere a los recorridos en la región del estudio, (para este caso el noreste del departamento) para identificar y documentar el recurso cultural tangible. Estas acciones ocasionan poca intervención física en los monumentos, mas bien son actividades de reconocimiento y clasificación del patrimonio edificado para programar sucesivas acciones de intervención. Información que permite poder planificar acciones de rescate y conservación.

El procedimiento para realizar los recorridos requiere: personal entrenado en elaboración de planos esquemáticos, guías conocedores de la selva, informantes y equipo (vehículo $4 \times 4$, motos de cuatro ruedas, casas de campaña, lonas, lazos, herramientas, medicinas y otros) y un técnico responsable que elabora la ficha técnica.

El objetivo es hacer un informe escrito y grafico de la condición actual del bien cultural. El documento elaborado debe incluir un plano esquemático que indique la conformación urbana del sitio y ubique en él las edificaciones con arquitectura expuesta en peligro, los saqueos y otros elementos culturales y naturales dominantes. 
Mientras se programan los fondos para la segunda etapa, en casos de inminente peligro, se realizan cubiertas protectoras empleando el material local (palma, madera y lianas para sujetar la estructura). En esta fase no se realiza un control de vegetación en plazas, patios ni edificios, solamente se permite liberar ramas de algún árbol con el propósito de tomar vistas fotográficas.

Las acciones de "recorridos" duran de uno a seis días y se visitan de uno a ocho sitios por campaña. Al año se efectúan de 3 a 8 campañas. Como producto se elabora un informe anual. En el informe anual se incorporan todas las acciones y fichas técnicas individuales ya procesadas. Las fichas técnicas incluyen el texto comprimido de las diferentes visitas realizadas en el año, planos y fotografías. Si hay alguna emergencia como: invasores en el área arqueológica, cortes ilegales de madera dentro del sitio o la inminente pérdida de un elemento arquitectónico, se informa a la autoridad competente.

\subsubsection{Ficha técnica}

La ficha resumen contiene 13 secciones que se llenan en el campo; luego se procesa la información en la oficina. El texto inicia con el número de catálogo, luego el nombre del sitio. Aquí se incluyen otros nombres que identifican al mismo lugar. En principio se respeta los nombres ya publicados. Luego continua con la fecha de la inspección y el responsable de la comisión; se agregan los integrantes, el equipo utilizado y datos sobre el acceso referido, en tiempo y en kilómetros, a un punto de salida; la condición de los caminos y si hay cambios en el entorno vegetal cercano a los sitios arqueológicos. Luego los datos de posición geográfica.

Los aspectos técnicos, como las intervenciones (si hubiera) se anotan en otra sección de la ficha técnica, así como datos sobre la condición 
de los edificios, si posee arquitectura visible; se cuantifican los saqueos en los edificios y se colocan gráficamente en el plano de registro. También se anotan observaciones, tales como sitio abandonado, hay muros con pintura, bóvedas, hay dinteles de madera originales y otros datos como invasiones cercanas, destrucción reciente del bosque y otros; luego una descripción rápida de la composición urbana del sitio con datos como: posee plazas con estelas, cancha para el juego de pelota, grupos E, numero de acrópolis, baño de vapor y otros tipos de edificaciones previamente identificadas. Después se anotan datos sobre publicaciones, manuscritos, informes de laboratorio y otros datos de referencia sobre el sitio. Finalmente por medio de isométricos y un plano esquemático se da una idea del volumen y la composición urbana. También se agregan algunas fotografías.

Planos esquemáticos: los planos son dibujados en papel y lápiz a una escala aproximada 1:200 y 1:400. Para ajustar la escala del plano se elige una plaza o patio la cual es medida con una cinta métrica de 50 m; luego el personal entrenado recorre los "montículos", unos arriba y otros abajo, indicando al técnico si existen saqueos o arquitectura visible. El técnico anota en el plano, con una simbología, la información proporcionada por los asistentes. Este personal guía al técnico en la elaboración del plano y le informa de los hallazgos dentro de los saqueos: presencia de tumbas, restos de cerámica, objetos tallados en piedra, edificios aislados, presencia de chultunes, canteras, etc. La elaboración de un plano esquemático puede durar de dos a tres horas de trabajo. Luego el técnico, en la oficina, hace un borrador final y el encargado de dibujo lo traslada a tinta en papel calco. Todos tienen la misma escala, el norte hacia arriba y la misma simbología. 


\subsubsection{Fichas resumen}

En las fichas resumen se clasifican y actualizan anualmente los aspectos más relevantes que interesan al patrimonio construido del área del estudio En ese sentido se toma en consideración los siguientes elementos de comparación: Posición del sito con el paisaje, rasgos urbanos, elementos de arquitectura, registro de saqueos en edificios, indicador edificios en peligro, indicador saqueos en edificios, actividades prioritarias (indicadores edificios con arquitectura y saqueos en edificios). Con esta información ordenada por niveles de análisis se pueden hacer propuestas de investigación o de medidas de intervención.

\subsection{ACCIONES PREVENTIVAS}

\section{Segunda etapa}

Una vez seleccionados y priorizados los edificios-objetos a intervenir. Como primera medida para preparar los sitios a una actividad de rescate, se envía a un encargado con 6 a 12 personas para realizar tareas de limpieza en los espacios libres y la construcción de un campamento provisional. Luego llega el personal técnico de arqueología con sus trabajadores de apoyo para realizar dos acciones: 1) documentación y relleno de saqueos, y 2) pozos de sondeo estratigráfico en área de plazas y patios. Esta es la primera tarea de la segunda fase de intervención.

Con la información recuperada por el equipo de arqueología de rescate se prepara una base de datos para conocer en forma preliminar la complejidad cultural del sitio-objetivo. Durante la estadía en los sitios se realiza apuntalamiento preventivo de muros y bóvedas, construcción de cubiertas protectoras y el relleno de los saqueos investigados y los pozos de sondeo realizados. Con esta información se pueden formular proyectos de intervención más a 
detalle y propuestas de restauración permanente (tercera etapa de intervenciones de rescate).

\subsubsection{Campamentos}

Una de las primeras acciones que se realizan antes de armar un campamento es tratar de acondicionar el camino o vereda lo mejor posible para llegar lo más cerca del lugar de trabajo. Para ese caso los encargados recorren el terreno buscando antiguos caminos de madereros (llamados wines) para desmontarlos y utilizarlos de nuevo. Si no es posible el personal debe caminar a diario largas jornadas para llegar a los objetivos de trabajo.

Para el personal técnico se construyen techos protectores de madera y palma, madera y plástico o madera y lámina galvanizada para colocar adentro carpas plásticas. El personal operativo prepara techos protectores de madera y palma o madera y plástico o lona plástica para ubicar debajo sus camas y hamacas. Aparte se hacen otras construcciones provisionales para cocinas y, más apartado, el área de servicios (letrinas) y duchas. Por otro lado se construye una bodega y una oficina de personal; estas construcciones, cuando el trabajo es corto, son simples lonas o techos de madera y palma.

Cuando se emplean techos protectores de madera y palma de guano (Sabal morrisiana), la palma es colocada en la forma llamada "enguane chiclero" ya que su colocación es diferente a un "enguanado normal". Las palmas son puestas más esparcidas y su duración es menor (de uno a tres años), un rancho con un "enguanado normal" puede llegar a durar 15 años. A la orilla de los techos protectores se excavan zanjas para desviar la escorrentía producida por la lluvia. En el campamento hay un régimen estricto de control de basura, uso de cal en las letrinas; si no hay agua cercana, 
este elemento es racionado a un bote al día por persona (cocina y aseo). En ocasiones se utiliza un generador portátil para iluminar por unas horas el campamento, así el personal técnico puede avanzar en sus notas de campo. Este generador se emplea en la investigación de saqueos (túneles) que son muy extensos. Por ejemplo en Naranjo había túneles de $30 \mathrm{~m}$ de largo. Es importante contar con al menos un vehículo $4 \times 4$ o una moto de cuatro ruedas para que en caso de una emergencia, el trabajador pueda ser trasladado de inmediato al hospital más cercano. A veces los campamentos provisionales se encuentran a tres días de recorrido a pie del poblado más cercano (80 kilómetros). Antes de contar con motos de cuatro ruedas el personal transportaba el equipo, materiales y alimentos en mulas de carga.

\subsubsection{Documentación de saqueos}

Quizá esta sea la tarea más difícil ya que es virtualmente imposible evitar que las bandas de saqueadores sigan excavando ilegalmente. Por un lado el Estado no cuenta con suficiente personal para tener una "policía cultural". Tampoco es posible colocar vigilancia permanente en cada sitio y para la documentación y relleno de esta gran cantidad de agujeros, recién abiertos, se requiere tiempo y personal. El trabajo es lento y voluminosos, por ejemplo en el sitio Naranjo, en 107 saqueos rellenados en el año 2003 se empleo un volumen aproximado de $2500 \mathrm{~m}^{3}$ de material; en Naranjito $240 \mathrm{~m}^{3}$ (2003), en Corozal Torre $420 \mathrm{~m}^{3}$ (2003), en Quemada Corozal 170 $\mathrm{m}^{3}$ (2004), en El Pital $455 \mathrm{~m}^{3}$ (2005) y en San Clemente $2000 \mathrm{~m}^{3}$ (2006).

Las depredaciones registradas en las fichas técnicas son atendidos por arqueólogos y sus asistentes (un arqueólogo y cuatro a seis parejas de excavadores) mas dibujantes. El trabajo consiste en 
limpiar o raspar una cara del túnel o trinchera de saqueo para realizar un dibujo en planta y sección de la depredación; luego se hacen pequeños registros adicionales para obtener material cultural. Se recupera el material arqueológico abandonado por los saqueadores, éste más el material recuperado técnicamente es trasladado al laboratorio para su proceso de limpieza y análisis. Posteriormente las trincheras y túneles de saqueo son rellenados con el mismo material de escombro. En ocasiones frente al saqueo se realiza un pozo estratigráfico con el fin de completar la información del edificio con su espacio libre de patio o plaza.

\subsubsection{Pozos de sondeo}

Esta actividad es una acción complementaria que junto con la documentación y relleno de saqueos da la primera visión de la complejidad cultural del sitio. Por lo general en sitios intermedios (El Pital, San Clemente y otros) se realizan entre 10 y 20 pozos estratigráficos en plazas, patios y calzadas; en sitios mayores más de 100 (Yaxhá, Nakum y otros). El propósito es asegurar junto con la información obtenida de los saqueos y las intervenciones en edificios, el conocimiento científico del sitio. Los pozos son escogidos al azar y tienen una dimensión de $1 \mathrm{~m}$ a $1.5 \mathrm{~m}$ por lado con una profundidad variable hasta llegar a la roca madre. El promedio de profundidad de los pozos estratigráficos oscilan entre 0.70 y $1.50 \mathrm{~m}$. En ocasiones especiales se pueden registrar terrenos artificiales rellenados por los mayas de más de $6 \mathrm{~m}$ de profundidad. El material recuperado es procesado en el laboratorio. Luego de la toma de datos, el dibujo y la fotografía los pozos son de nuevo rellenados con el mismo material excavado.

Los dibujos de pozos estratigráficos, saqueos y material cultural: se realiza en obra en papel y lápiz, luego se traslada en calco y tinta, las 
escalas más comunes son 1:20, 1:50. El material cultural es dibujado en escala 1:1 o 1:5, 1:10.

\subsubsection{Plano de situación}

A diferencia del plano esquemático inicial, el cual se basa en la experiencia del técnico y su personal, en este nivel el plano es mejorado con mediciones con brújula y cinta métrica. El plano luego es dibujado en escala 1:20 o 1:50 en papel calco. En este nuevo plano se ubican los pozos estratigráficos realizados, los saqueos rellenados y otros trabajos efectuados como chultunes investigados, edificios con medidas preventivas y otros.

Para realizar el plano se coloca arbitrariamente un banco de marca en una plaza o patio dominante y de allí salen las mediciones, en ocasiones se usa el aparato teodolito. El trabajo es generalmente realizado por el arqueólogo o el arquitecto residente. La representación grafica empleada en este plano es el método tradicional local el cual consiste en mostrar los edificios en forma geométrica, como pirámides truncadas. En una fase posterior se realiza un nuevo plano mas preciso con curvas de nivel y observación solar. Por lo general en esta etapa se realizan uno o dos cortes maestros por todo el sitio arqueológico o por el sector o sectores trabajados.

\subsection{CONTROL DE VEGETACIÓN}

Un proceso importante que debería ser tratado en forma permanente, como medida de conservación preventiva, es el control de vegetación.

Los bosques tropicales son producto de altas temperaturas, alta humedad y alta precipitación pluvial. La caracterización de la selva actual es en su mayoría sucesiones secundarias de algunos cientos 
de años. Como indicadores tenemos tres ejemplos en el Parque Nacional Tikal,

- El árbol más antiguo (en 1992) es una Caoba de aproximadamente 300 años

- En una hectárea puede haber entre 40 y 150 diversas clases de árboles

- Si consideramos la antigüedad de las edificaciones mayas (300 ${ }^{\mathrm{a}} \mathrm{C}$. en adelante hasta el siglo XVII), sobre un mismo espacio cuadrado es posible que de 7 a 15 generaciones de árboles nacieron, crecieron y murieron sobre un mismo lugar.

La estructura del bosque esta determinada por diferentes niveles de altura de los árboles y la estratificación de la vida biológica. Predominan los árboles emergentes o gigantes que pueden llegar hasta $50 \mathrm{~m}$ de alto como la Ceiba (Ceiba pentandra), la Caoba (Swietenia macrophilla), el Cedro (Cederla mexicana) y otros. Continúan los árboles intermedios con alturas de 15 a $20 \mathrm{~m}$ como el Ramón (Brosimum alicastrum), el Zapote (Achras sapota) y otros. Luego los árboles bajos de $15 \mathrm{~m}$ de alto como el Escobo (Crysophila argentea), el Guano (Sabal morrisiana), y otros. Por ultimo la vegetación baja de arbustos.

Por razones culturales, cerca de los sitios arqueológicos abundan los árboles de Ramón, Caoba, Cedro, Chicozapote (Manilkara zapota) y otros que fueron cultivados por los mayas. El caso del Ramón es particular pues es una especie que abunda, crece rápido y sus raíces se extienden horizontalmente causando daños a los edificios prehispánicos.

Las semillas son transportadas por el aire a superficies horizontales de los edificios abandonados; las plataformas escalonadas son 
lugares ideales y propician un rápido crecimiento de vegetación ya que su posición elevada favorece la entrada de luz solar.

El control de vegetación inicia con el corte selectivo del bosque bajo (maleza) en los espacios de plazas y patios. Esta acción permite trabajar con mayor seguridad en el área ya que por lo general aparecen entre siete, o más serpientes venenosas en cada limpia. Por otro lado, permite tomar fotografías, facilita la elaboración del plano de situación y a visualizar el espacio urbano del sitio. Luego continúa el corte selectivo de árboles sobre edificios con arquitectura visible en peligro.

Hay árboles que están muy integrados al edificio, si se eliminan, pueden causar otro tipo de daños si no se intervienen rápidamente. Por tal razón si no se puede garantizar su intervención arquitectónica, solamente se eliminan algunas ramas para evitar peso y la acción oscilatoria del paso del viento. Las raíces de los árboles penetran en las capas constructivas de muros y techos causando deformaciones.

Además al caer un árbol trae consigo elementos estructurales de los edificios causando nuevas perdidas y daños. En el proceso de control de vegetación cada árbol cortado es registrado en una tabla llamada "Inventario de vegetación", que contiene información sobre: especie, diámetro en centímetros a un metro de altura; como indicador del estado de salud se dan datos sobre si el árbol esta muerto o enfermo, tronco verde y otros datos. Con esta información puede obtenerse la caracterización dominante en el sitio y hacer comparaciones con otros. Por ejemplo: se ha comprobado que la especie Brosimum Alicastrum (Ramón Blanco) es el árbol dominante en San Clemente 69.7\%, La Blanca 56.3\%, La Naya $73.77 \%$, Pochitoca 60.3\%. 
La importancia de esta actividad es que al continuarse con la limpia selectiva se efectúa una "conservación preventiva del sitio". El personal está entrenado para eliminar futuros árboles de rápido crecimiento (como el ramón blanco) y que luego ocasiona nuevos daños a los edificios. Este procedimiento es más económico (control de vegetación) que hacer posteriormente trabajos de recuperación y restauración de edificios dañados por la acción de las raíces o el peso de los árboles.

En ocasiones el corte de árboles sobre edificios es sumamente complicado ya que los muros y bóvedas que lo soportan están en precarias condiciones de estabilidad. Para estos casos es necesario contar con personal muy entrenado. Estos expertos deben escalar los árboles, luego subir con lazos la motosierra y hacer primero cortes de ramas y luego cortes de secciones del tronco. Para evitar el contacto con el edificio tratado, el encargado diseña un sistema de lazos entre los árboles vecinos para que cada pieza cortada pase en forma de columpio a otro árbol vecino y luego bajado por el personal asistente hasta el suelo.

El material vegetal cortado es reciclado; cuando es posible se envía en camión a las caleras para ser empleado como combustible en la producción de cal. También se usa para la construcción de los campamentos temporales, en leña para los trabajadores, en estructura temporal para cubiertas y apuntalamientos, en andamios temporales, en tablones y tablas para albañilería, muebles rústicos como: mesas y bancos, la construcción de cajas de madera para hacer bateas de mezcla o para almacenar agua.

En una etapa posterior es posible que el personal encargado del monitoreo de vegetación trasplante árboles grandes a sectores que 
han quedado con agujeros dentro del área arqueológica. Los expertos reconocen especies de árboles que pueden ser cortados y sin raíz ser plantados y brotar de nuevo: Jabín (Piscidia piscipula), Madre Cacao (Gliricida sepium), Chacal (Bursera simaruba) y otros.

Gaspar Muñoz Cosme investigo, en su trabajo de tesis doctoral, las ventajas e inconvenientes de emplear los árboles como elementos de protección a las fachadas de los edificios. Muñoz Cosme menciona, "que entre las principales causas de la degradación mas intensa de la piedra caliza figuraba la exposición a la hidratación por el agua de lluvia y a las rápidas desecaciones por alcanzar temperaturas muy altas por la insolación directa. De ello se deducía que las partes del edificio que permanecían en zonas umbrías y protegidas de la lluvia eran mas estables." Muñoz Cosme realizo una primera selección de árboles locales de Tikal atendiendo ocho aspectos. Como resultado de ello se identificaron 30 especies de las cuales se recomendaron 10 (Muñoz Cosme 2003, 384-386).

\subsection{PERSONAL, TIEMPO Y LOGÍSTICA}

Se ha comprobado que el equipo humano que realiza estas tareas de intervención preventiva en la selva debería de estar formados por 20 a 30 trabajadores operativos, uno o do arqueólogos y un responsable. El equipo lo forma: un encargado de personal y logística, un bodeguero-enfermero, cocinero, conductores y personal de apoyo. Este grupo esta formado por: albañiles, ayudante de albañil, excavadores, ayudante de excavadores, dibujantes. Para seleccionar al personal es indispensable que sean grupos homogéneos y bien entrenados en el trabajo de rescate ya que el esfuerzo de trabajo continuo y en condiciones precarias causa a menudo situaciones tensas entre los trabajadores. El responsable debe conciliar las acciones de los grupos de trabajo (restauradores y 
arqueólogos) por lo que el equipo debe estar bien informado de los objetivos, metas comprometidas y la ruta crítica del programa para poder apoyarse unos a otros.

El tiempo para realizar una acción de rescate varía entre dos y cuatro planes (meses) de 20 días de trabajo; tiempo que debe ser aplicado en la temporada anual seca. Un caso especial fue San Clemente, por ser un plan de entrenamiento; las acciones duraron seis meses de trabajo en campo, con un personal formado por dos grupos (aproximadamente 63 personas). Por las condiciones precarias en campamentos temporales, al personal se le permite laborar más de las ocho horas reglamentarias.

La experiencia de campo, hacen plantear que para futuras acciones de rescate se proponga un esquema de trabajo intenso por no más de 15 días, con un período de descanso de 5 a 6 días para luego realizar otra jornada de 15 días. La experiencia dice que el personal, en estas condiciones, responde mejor al esquema de dar tareas por trato, que al riguroso horario de oficina de 8 horas. En el Programa de Rescate el tiempo laborado se mide por horas trabajadas y no por días trabajados con un máximo de horas de trabajo por plan. También debe considerarse que si el objetivo de intervención es muy lejano de poblados, los bloques de trabajo deberían de ser de 20 a 30 días intensivos (dos en uno) por 8 a 12 días de descanso y en un plazo máximo de dos "entradas" por año. Esto se propone para evitar gastos excesivos de transporte hacia el interior de la selva.

Generalmente uno o dos vehículos $4 \times 4$ abastecen de materiales y lo necesario para el trabajo, también se podría contar con motos de cuatro ruedas. En ocasiones, como ya hemos indicado ocurren accidentes (mordeduras de serpientes, cortaduras con machete, 
caída de ramas sobre personas etc.) que deben ser evacuados inmediatamente hacia el hospital más cercano.

A veces la falta de agua para el uso del personal y los trabajos de intervención (relleno de saqueos, relleno de pozos estratigráficos, intervención de rescate en edificios), es un problema que debe resolver el encargado del grupo. El factor agua debe ser estudiado con antelación a una intervención (fase 2 ó 3) ya que la falta de este elemento puede hacer fracasar u ocasionan grandes gastos en el traslado a la obra. Para el rescate de edificios con arquitectura en peligro sin agua cerca, el equipo planificador debe considerar, con años de antelación, las formas para abastecerse de ese líquido para sus trabajos. Una posibilidad es preparar recolectores de plástico diseñados para que se llenen en época de lluvia y se use el agua en la época seca.

Para el caso de intervenciones de rescate en sitios vecinos a comunidades, debe entrenarse al personal técnico y operativo en la comunicación y acercamiento con las comunidades vecinas. El encargado debe identificar a los líderes comunitarios para informarle del objetivo del proyecto, así como entablar relaciones con los señores alcaldes auxiliares, vecinos y maestros. En ocasiones son oportunos los partidos de fútbol y la participación en ceremonias sagradas y las ferias locales.

\subsection{ARQUEOLOGÍA DE RESCATE Y RESTAURACIÓN}

Ya se explicó anteriormente que el objetivo principal es preservar los elementos tangibles de las construcciones prehispánicas expuestas a las condiciones de abandono y pillaje cultural. También se ha mencionado que una etapa previa identifica a estos objetivos y se realizan acciones preventivas en ellos, tales como: apuntalamientos y 
cubiertas protectoras provisionales. En una segunda fase estos edificios-objetivo son atendidos en dos aspectos simultáneos: a, arqueología de rescate y b, intervenciones de restauración.

Primero el grupo de arqueología de rescate, inicia la liberación de escombros de los espacios interiores o alrededor de los elementos arquitectónicos expuestos. El trabajo de liberación se realiza con excavadores y sus ayudantes bajo la supervisión del arqueólogo. El procedimiento de excavación se realiza con piochines a través de calas o trincheras de aproximación. El equipo de dibujo documenta tanto la situación antes de excavar, para luego incorporar los resultados de la liberación. El material recuperado es dividido en dos partes:

- El material arqueológico como cerámica, lítica, huesos y otros, son procesados con un sistema de operaciones, sub-operaciones y lotes, analizado posteriormente en el laboratorio y

-Segundo, el material de construcción con bloques de piedras talladas de muros, cornisas y bóvedas es ordenado, clasificado y colocado cerca de la obra; esto se realiza para poder hacer posteriores reintegraciones en los edificios.

A veces aparecen bloques de piedra con tallado, que pertenecen a los decorados de los techos; por lo general este material no puede ser reintegrado en su posición "in situ" debido a que estos paramentos de la construcción generalmente están muy destruidos o ya no existen. En estos casos el material recuperado es inventariado, dibujado y vuelto a enterrar en el mismo edificio o en depósitos especiales. Todos los procesos son registrados en el plano general del sitio, en la bitácora y en los informes de arqueología. 
El restaurador junto con el arqueólogo avanza simultáneamente, algunas veces empleando el escombro como andamio para reparar muros, sobre todo las superficies superior. Estos segmentos de muro reciben una nueva capa de piedra sin tallar llamada "superficie de sacrificio". Una vez consolidada la parte alta de los muros o techos, los arqueólogos continúan con el vaciado de las cámaras. El equipo de arqueología se detiene en el nivel de piso del edificio, realizando pequeños registros arqueológicos para corroborar pisos anteriores y recuperar material cultural para su análisis. En esta etapa no se permite realizar investigaciones adicionales (aparte de los saqueos) en los edificios con el propósito de localizar etapas constructivas anteriores o tumbas reales.

No se permite realizan "túneles de investigación" dentro de los edificios. En casos especiales se realizan pozos de un metro por un metro para asegurar un dato importante. En ocasiones se prosigue un túnel de saqueo para obtener más información o se ubican pozos de sondeo en lugares claves con el propósito de obtener además de lo esperado (niveles hacia la roca madre) otros datos de interés; por ejemplo un pozo que se amplía en trinchera para estudiar las fases constructivas de plataformas escalonadas que soportan un grupo de edificios con arquitectura expuesta en peligro.

El restaurador interviene los edificios con arquitectura expuesta con el propósito de estabilizar en lo posible la construcción. Se reparan grietas en los muros y bóvedas, se reintegran espacios perdidos por excavaciones de saqueo. Muchas veces esto se realiza en muros o bóvedas que fueron "rotos" en búsqueda de "tesoros". Para asegurar la estabilidad estructural se hacen pequeños y grandes trabajos de restitución de volúmenes en las plataformas escalonadas que sustentan a los edificios con arquitectura expuesta. Generalmente se 
restituyen volúmenes perdidos en la base de muros (recalzado) con el objetivo de asegurar la estabilidad de los paramentos constructivos. Todos los agujeros causados por saqueo son documentados y rellenados con el mismo material que dejaron los saqueadores a sus lados.

En casos urgentes y especiales (poco tiempo, escaso personal o presupuesto) se realizan rellenos provisionales de saqueos. En este procedimiento se emplean las mismas piedras desencajadas (extraídas por los saqueadores) pero no se usa mezcla de unión entre cada bloque. El objetivo es "tapar los accesos" para que no penetren personas (dañen las paredes interiores), no ingresen animales (aves, murciélagos) y evitar el ingreso de agua de lluvia al interior. Estas acciones preventivas son corregidas posteriormente con un plan establecido de rescate: por ejemplo en el sitio San Clemente, los primeros trabajos se realizaron en 1996 y los trabajos formales tardaron 10 años en realizarse.

En otros casos, cuando el edificio o sitio arqueológico presenta grandes dificultades de acceso y su posición no es estratégica ni importante en el futuro cercano (según la visión regional), el procedimiento de intervención es: primero el equipo de investigación arqueológica de rescate procede con los pozos estratigráficos y la documentación de saqueos. El equipo de restauración consolida los restos de muros o techos, para luego cubrir toda la arquitectura expuesta. Este fue el criterio empleado en sitios como: Pochitoca, El Carmen, La Perra, El Pital, Kanajau y otros. Este esquema de administrar el patrimonio cultural no significa que se "tapan" y se abandonan, sino se debe continuar el monitoreo y el correspondiente y periódico control de la vegetación. Estos sitios pueden ser visitados por turistas ya que es posible leer el espacio urbano y en el 
momento requerido estos "tapones preventivos" pueden ser de nuevo expuestos y continuar con la tercera etapa del programa, hasta llegar a la fase de uso del patrimonio (apartados 5 y 6 ).

Otro criterio de administración o manejo de los sitios arqueológicos es el esquema de incorporar sitios intermedios cercanos a sitios mayores ya habilitados o cercanos a poblados actuales; como sucedió en: Poza Maya, Corozal Torre, Quemada Corozal, San Clemente y Naranjito. Estas intervenciones pueden integrarse en un plan de uso del patrimonio y comunidades vecinas.

El tercer grupo de sitios arqueológicos, corresponde a los sitiosestratégicos. En este diseño de administración del patrimonio cultural los procesos de rescate y habilitación llegan a los apartados 5 y 6 de la metodología. Y cuentan con otro tipo de trabajos adicionales. En este esquema están los sitios de Yaxhá, Topoxté, Nakum, Naranjo, Tikal y Uaxactún.

Como se dijo anteriormente en el tema de conservación de los edificios con arquitectura expuesta, ocurren diferentes niveles de intervención comprende desde el relleno de la arquitectura visible, la limpieza de escombros, restitución de volúmenes perdidos, reintegración de elementos estructurales faltantes (dinteles de madera), reintegración de elementos de la fabrica perdidos por saqueo (muros y bóvedas), reparación de grietas y fisuras causados por el abandono y la vegetación, el tiempo o el saqueo; resane de estucos, grafitos, bancas, pisos y escalinatas.

A falta del techo encima de los muros o bóvedas incompletas, se plantean cubiertas protectoras temporales o permanentes con diferentes sistemas constructivos: techos de madera y palma, techos 
con estructura de madera y cubierta de piedra (Edificio $\mathrm{N}$ de Nakum) o reintegración total en piedra.

El criterio de utilizar cubiertas temporales causa problemas de mantenimiento ya que el material más común es madera y palma. Este elemento preventivo se deteriora rápidamente y es necesario estar monitoreándolo y cambiándole piezas para mantener su función de protección. Por otro lado, estéticamente los ranchos de palma sobre los edificios, no son la solución ideal para la visión del conjunto urbano.

Aunque la segunda etapa se denomine "acciones preventivas", la experiencia recomienda realizar acciones un tanto más permanentes que preventivas. La razón es que las intervenciones temporales como el relleno de saqueos, solo empleando tapones de piedra sin mezcla; o cubiertas de madera y plástico para suplir los techos perdidos, son poco durables. Otro factor a considerar es la lejanía y el difícil acceso de algunos sitios con arquitectura en peligro. Otro indicador importante es que los equipos de mantenimiento no pueden ser asegurados todo el tiempo. Por las razones expuestas arriba las intervenciones deben ser un "tanto más agresivas" previendo la posible falta de monitoreos y acciones futuras de conservación. Recordemos que los procesos de conservación no se realizan en los últimos 100 años y por lo tanto una acción preventiva no realizada en tiempo se convierte en una causa mayor de daños que incluso provocan el colapso de sus elementos constructivos.

\subsection{INTERVENCIONES PARA USO FRECUENTE}

Siguiendo el concepto diseñado, en un nuevo estrato de atención, los edificios-objetivo seleccionados continúan en el proceso con mayor grado de intervención en los apartados 5 y 6 de la metodología. 
En este nivel la intervención además de asegurar la estabilidad de los edificios se incorpora la variable de ser utilizado como elemento de identificación cultural con su espacio urbano que representa. Un caso de intervención "preparada" para recibir visitantes fue el templo pirámide 216, en la Acrópolis Este de Yaxhá. En este edificio las gradas originales de acceso al espacio interior fueron cubiertas por una nueva capa de piedra (superficie de sacrificio) para asegurar la conservación de las escalinatas originales. Igual los muros originales de la fachada oeste, fueron protegidos con hiladas de capas de sacrificio, pero se subió el nivel del muro en dos sectores (no necesarios para la conservación) con el propósito de evitar que el visitante pueda escalar los muros para llegar al techo. En la fachada norte de la base piramidal se construyo una escalinata de madera, simplemente apoyada a los restos de las plataformas escalonadas, para permitir el acceso de personas a la parte superior. Dicha escalinata fue posteriormente modificada por otro proyecto de habilitación en Yaxhá (PDS-BID).

En Nakum el circuito diseñado para el recorrido dentro de la Acrópolis también tiene las superficies originales preparadas para el paso de visitantes. En este caso las escalinatas originales del Edificio $\mathrm{N}$ fueron cubiertas por nuevas piedras para permitir el acceso a la parte alta con los tres edificios triádicos. En otros casos las escalinatas monumentales son cubiertas con taludes, formados con tierra apisonada, para proteger así los deteriorados restos originales; ejemplos en Nakum: escalinatas de los Edificios D, L, A, E, R y otros.

Todos los pisos originales expuestos son cubiertos por capas de tierra cernida y apisonada; y en los techos restaurados se aplica una capa de piedra laja y mezcla a manera de sello. Este procedimiento sirve también para dirigir a puntos determinados la salida del agua de 
lluvia. En los muros con estuco son consolidadas las capas desprendidas, si un muro con estuco original permanece en la intemperie se trata de restituir en la parte superior elementos de cornisa para proteger la pared, o son parcialmente rellenados como se realizo en el Edificio D de Nakum. En todo caso, las superficies con estuco son documentadas, restauradas y monitoreadas.

Para proteger las superficies originales de bancas de mampostería, se colocan sobre ellas tablones simplemente apoyados para proteger las superficies y los cantos de las bancas o se les aplica una capa de arena fina apisonada. Otra técnica para permitir observar el espacio pero no el acceso de personas, consiste en colocar barreras (de madera) en los accesos a los espacios interiores. En los recorridos diseñados se colocan gradas nuevas de madera y barandas para dirigir a los visitantes.

\subsubsection{Acciones en arqueología}

Aparte de los trabajos propios de la arqueología de rescate; comentados anteriormente (documentación y relleno de saqueos, pozos estratigráficos en plazas y patios y apoyo a los trabajos de restauración) en este estrato (apartado 5 del concepto general), el trabajo arqueológico se extiende y abarca otros aspectos científicos. En este rango, el trabajo arqueológico se ocupa por ejemplo de investigación de etapas anteriores de construcción; se realizan túneles de investigación y estudios arqueológicos específicos tales como: investigación de calzadas, chultunes, grupos habitacionales periféricos, canales y otros. También el equipo de arqueología se encarga conjuntamente con el personal de laboratorio a realizar las labores de conservación de las superficies de muros con restos de estuco. 


\subsubsection{Infraestructura}

En esta etapa que corresponde a preparar el objeto-estratégico para un uso social (apartado 5); se considera la construcción de instalaciones más formales para el mantenimiento y administración del sitio arqueológico con: bodegas, laboratorios, talleres, áreas de oficina, dormitorios para el personal de funcionamiento, incluyendo mejores áreas de servicio. Se considera el uso de energía solar y manejo de desechos; también se apoya la elaboración de instrumentos de manejo tales como: planes maestros, planes operativos, convenios y otros aspectos legales como la creación de zonas de protección restringida, como en el triángulo cultural YaxháNakum-Naranjo, ahora convertido en una zona núcleo, Parque Nacional (2003).

Como se dijo anteriormente, el principio de atención al patrimonio edificado se circunscribe a los edificios o grupos de edificios con arquitectura en peligro. Estos edificios-objetivo intervenidos o por intervenir se convierten en las metas de inversión que luego representan a los sitio arqueológico. En esta fase se diseña un circuito de visita o interpretación el sitio. El guión se base en los edificios-objetivo identificados y preparados; dejando partes del área arqueológica, como reservas, o sea fuera de las rutas de visita. Esto al menos durante se supera la fase de emergencia regional; reflejada en los resultados del estado de conservación del patrimonio cultural del noreste de Petén presentados en los siguientes capítulos.

En esta etapa de intervención en los edificios-objetivo, las acciones de restauración se "enlazan" con otras disciplinas como la arquitectura del paisaje y trabajos de infraestructura turística. Aquí se realizan tareas como: mejora de accesos, construcción de áreas de acampe, casas de descanso, servicios sanitarios, pequeñas salas de 
introducción del sitio para apoyar la interpretación. En esta fase se pueden realizar modelos a escala, modulaciones virtuales en 3D, réplicas de monumentos esculpidos en piedra, tablas informativas y otros.

\subsubsection{Documentación gráfica}

La diferencia (calidades) en las distintas etapas de acción de la metodología, puede ilustrarse bien con la documentación gráfica. En la primera etapa basta un plano esquemático. En el segundo se exige mayor exactitud con planos levantados con brújula y cinta métrica; y en al tercera etapa se requiere de un equipo topográfico que realiza un plano completo con cuadrantes a cada $100 \mathrm{~m}$ y curvas de nivel a cada metro. Además en la etapa 3 se realiza una observación solar para determinar el ángulo de desviación entre el norte magnético y astronómico.

Para el caso de Yaxhá-Nakum-Naranjo, el primer plano topográfico con esta calidad fue realizado en 1990 en Topoxté con ocho hectáreas medidas y dibujadas, luego Yaxhá en 1998-1999 con 60 hectáreas. El tercer plano fue Nakum en 2001 con 36 hectáreas y el cuarto plano Naranjo en el año 2002 con 70 hectáreas. La medición se realiza con teodolitos de alta precisión, todas las lecturas de todas las estaciones son calculadas y dibujadas en el campo. La escala de los planos finales es dibujada a 1:250 luego son reducidos a 1:500 y después publicados en 1:1000 ó 1:2000. La publicación de todos estos planos topográficos fue apoyada y financiada por el Instituto Alemán de Arqueología DAI-KAAK en Bonn (anteriormente KAVA).

Por lo general se requiere una planta de conjunto, cortes transversales y longitudinales generales, plantas, elevaciones y detalles por edificio y por operación arqueológica. La escala de 
dibujo en campo es de 1:20 y 1:50. En el campo lleva un registro gráfico en dos grupos de planos separados: el primero registra los procesos llevados a cabo por el equipo de arqueología y en otro las de restauración. Luego esta información básica es pasada directamente a las computadoras (auto Cad). En el ordenador se realiza la integración de los datos, que nos permiten como resultado, poder realizar el análisis espacial, vistas isométricas y modulaciones virtuales en $3 \mathrm{D}$. 

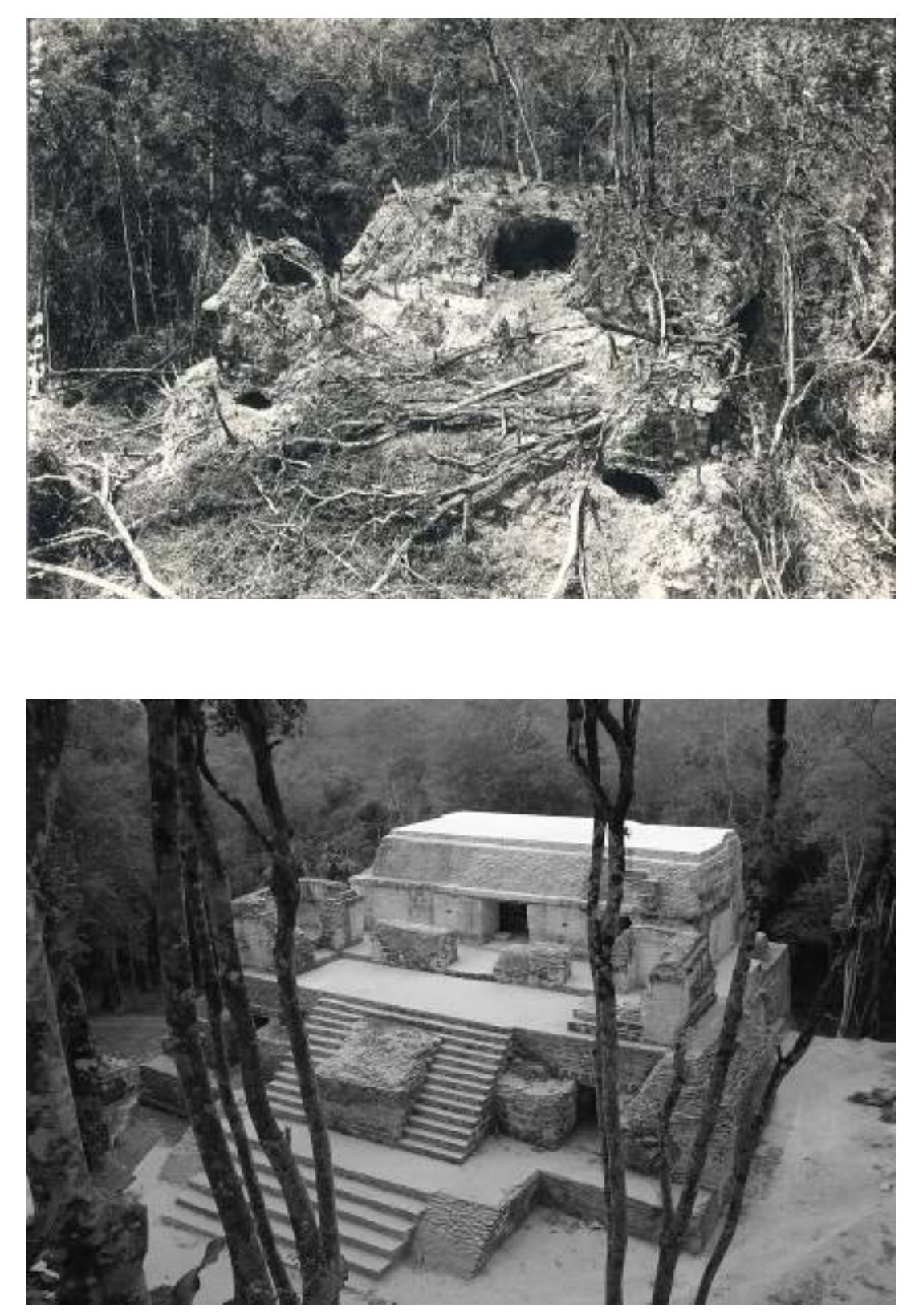

Fig. 24. Edificio N, Nakum, fotografía de 1910 Tozzer, y 2000 Noriega 


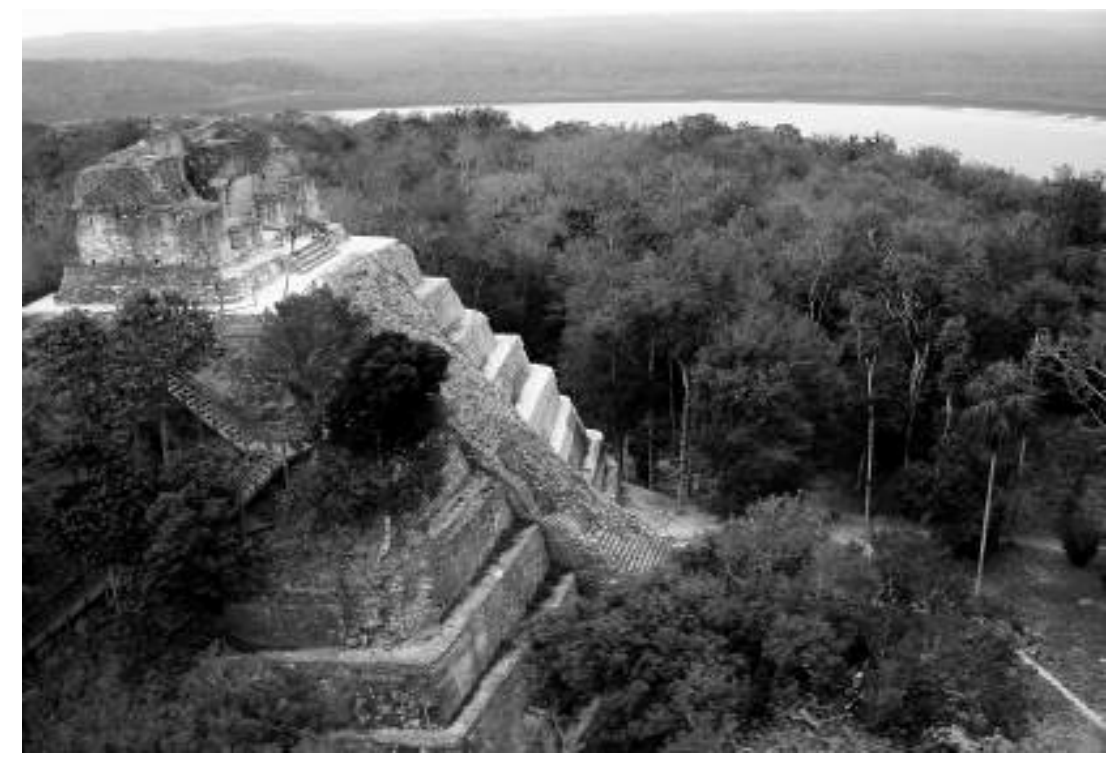

Fig. 25. Edificio 216 de Yaxhá, fotografía Noriega

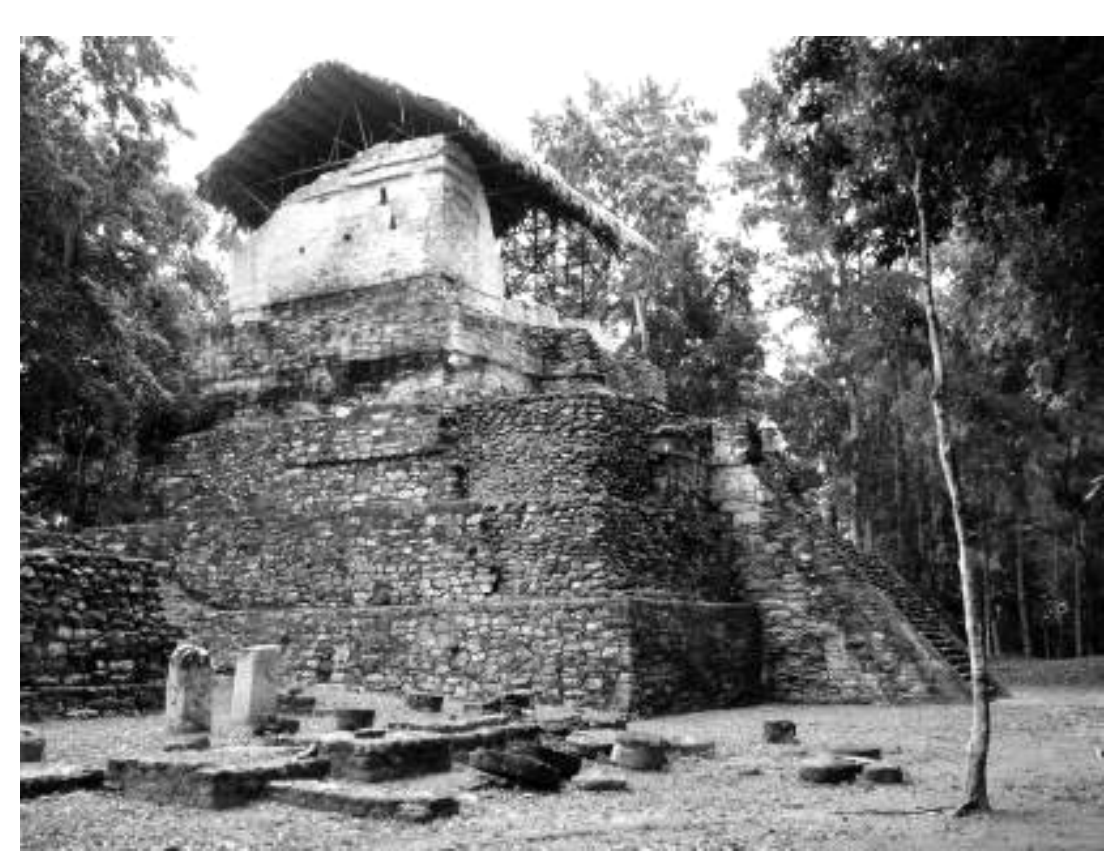

Fig. 26. Edificio C de Topoxté, fotografía Noriega 


\section{PRESENTACIÓN Y USO DEL PATRIMONIO CULTURAL}

En este capítulo presentamos con más detalle dos ejemplos de intervención. El primero es el sitio San Clemente, el cual se intervino en tiempo reducido (seis meses en el año 2006) pero con resultados abundantes. El segundo ejemplo son los sitios de Yaxhá, Nakum y Naranjo, en donde con múltiples acciones y actividades se llegó a "crear" un nuevo parque nacional (2003).

\subsection{SAN CLEMENTE}

En la historia reciente de San Clemente no había antecedentes de investigación arqueológica, razón por la cual se planteó realizar una acción de arqueología de rescate, además de intervenciones permanentes en edificios con arquitectura en peligro.

San Clemente es un sitio intermedio en la cuenca de Los Lagos a mitad del camino entre la ciudad de Flores y el nuevo Parque Nacional Yaxhá-Nakum-Naranjo. El sitio está formado por tres sectores: al norte, dos patios con edificios alargados, un área central con una plaza rodeada de edificios con monumentos esculpidos en piedra (estelas y altares), y una cancha para el juego de pelota en posición central. Al sur, dos edificios templo-pirámide, otros edificios largados, dos plazas adosadas y otro espacio para el juego de pelota.

San Clemente fue visitado desde 1992 y tuvo varios períodos de acciones preventivas, pero no fue hasta el año 2006 que se obtuvieron fondos adicionales (donación del gobierno Alemán) para realiza actividades permanentes. 
Dentro del plan de trabajo se ordenaron las actividades en siete partes: logística y campamento provisional, documentación y relleno de saqueos, pozos estratigráficos, investigación de chultunes, laboratorio arqueológico, liberación de escombros en edificios (liberación de arquitectura) y restauración.

Logística y campamento: El primer grupo que llegó a San Clemente fue el equipo de logística. Este personal tuvo diferentes responsabilidades: fue el encargado de construir el campamento temporal (957.8 $\mathrm{m}^{2}$ con lámina de zinc, madera, lonas plásticas). Este grupo también reparó a mano el último tramo del camino de acceso al sitio (3.3 kilómetros) y fue el responsable de suministrar los materiales a los frentes de trabajo: agua, piedra, mezclas, andamios, etc. El equipo de logística se ocupó además de la administración y limpieza del campamento provisional, de la oficina, bodega, conductores, suministro, vehículos, equipo, enfermería, carpintería, cocina, limpieza de letrinas, basura, área de dormitorio de técnicos y operativos.

Durante el trabajo en campo se atendieron a más de 300 alumnos de las comunidades vecinas (Zapote, Naranjo, La Democracia, Aguadas Nuevas y el Ramonal), se realizó una ceremonia sagrada y los vecinos se organizaron en una asociación para apoyar al sitio arqueológico. El encargado de logística también es responsable de realizar el inventario de vegetación y el corte selectivo de árboles sobre edificios.

Documentación y relleno de saqueos: En las fichas de registro de San Clemente se identificaron 46 depredaciones, algunas de las cuales se rellenaron en forma temporal en 1996 y 1997. En cuatro temporadas (febrero-mayo), se documentó y rellenó 25 saqueos del sector norte. 
En esta actividad se empleó un personal promedio de 11 trabajadores y un arqueólogo responsable. Se elaboró una ficha técnica para documentar el trabajo; cada saqueo siguió el mismo procedimiento sistemático de: limpieza, pequeños registros adicionales, dibujo y relleno.

Pozos estratigráficos: Para la investigación arqueológica en pozos de sondeo se seleccionó al azar, 14 puntos en plazas y patios; esta actividad duró tres temporadas (febrero-abril) con un personal promedio de cuatro personas y un arqueólogo responsable. En esta actividad se empleó la misma ficha técnica y el mismo procedimiento descrito arriba.

Investigación de chultunes: Aunque el sitio arqueológico San Clemente cuenta con más de 8 chultunes, solamente se investigaron dos. La actividad duró media temporada de campo (10 días), se emplearon cuatro personas y un arqueólogo responsable. El procedimiento fue: limpieza de escombros, obtención de material arqueológico, dibujo y tapado del acceso.

Laboratorio arqueológico: En el campamento provisional, se construyó el espacio para laboratorio, con estructura de madera y cubierta de plástico $\left(15 \mathrm{~m}^{2}\right)$. En este mismo espacio se construyeron dos anaqueles de madera rústica para almacenar el material recuperado, una mesa de trabajo para ocho personas y varios cernidores para el secado de la cerámica. En este espacio laboraron por cinco temporadas de campo, tres trabajadores y una arqueóloga responsable. Este equipo preparó, seleccionó, analizó y procesó el material cultural recuperado de las actividades de: documentación y relleno de saqueos, pozos estratigráficos, chultunes, vaciado de cámaras y espacios con arquitectura visible. En resumen se 
procesaron más de 50,000 piezas culturales. Los resultados fueron presentados en un documento final (manuscrito en la biblioteca del PRONAT). Además el equipo de arqueología de rescate se encargó de realizar las acciones preventivas en muros expuestos con estucos.

Restauración: Los trabajos de restauración se concentraron en el sector norte (Edificios I, II, III, IV, VII y XXIV). Los restantes edificios con arquitectura visible en peligro (2) del sector sur, fueron restaurados en la temporada de 2007. El apoyo del equipo de arqueología de rescate consistió en la liberación de escombros de las fachadas y espacios interiores. La liberación de escombros fue en algunos casos total y en otros parcial. El equipo contó con 12 trabajadores promedio y un arqueólogo responsable, la actividad duró cinco temporadas. El método para liberación de escombros fue combinado con el equipo de restauración, trabajando alternamente y por etapas sucesivas de trabajo. En la mayoría de los casos el escombro servía de andamio para consolidar, primero las terminales de los muros y los techos. El volumen total estimado de material removido fuera del área arqueológica es de 2300 m cúbicos. Para esta acción se contó con apoyo de personal de restauración, logística y un camión de volteo. Gran parte del escombro fue tamizado y vuelto a usar como agregado en las mezclas.

Los criterios generales de conservación fueron; para el Patio Alto (Edificios I y II), asegurar la preservación de los muros posteriores con amenaza de colapso (por pérdida de volumen en la plataforma de sustentación). La prioridad incluyó también el recalzado de los propios muros de los edificios, aquí se restituyeron $59 \mathrm{~m}^{3}$ de volumen perdido. Posteriormente se repararon grietas en los muros transversales y se aplicó a todo lo largo de los muros expuestos, una nueva superficie de piedra sin tallar y mezcla para su protección a la 
intemperie. Los espacios interiores (6 cámaras) no fueron liberadas totalmente de su escombro; tampoco las escalinatas de acceso a los dos edificios intervenidos fueron restauradas. Ahora se presentan como un volumen en forma de talud realizado con lodo apisonado.

En el Patio Bajo (Edificios IV, XXIV y VII), la investigación arqueológica en los saqueos en el edifico al norte (Edificio IV), dieron información de una compleja serie de modificaciones realizadas por los propios habitantes prehispánicos, incluyendo una escalinata interior, no conocida anteriormente, y el agregado de tres espacios abovedados en tres de sus lados. Los espacios interiores con bóveda y saqueos del lado norte fueron documentados y rellenados. Al sur, el espacio abovedado de la escalinata fue restaurado parcialmente. En el lado oeste y sur del Patio Bajo (Edificio XXIV y Edificio VII) se consolidaron muros y techos expuestos; y se restituyó un dintel de madera.

En la documentación recopilada de la Plaza Principal (Edificio III), no se tenía información sobre una segunda fachada, prácticamente destruida y cubierta por el escombro. Esta nueva fachada apareció al liberarse el edificio para realizar las consolidaciones de muros expuestos. De la última fachada, solo se recuperó una serie de arranques de muros o pilares que limitan los accesos al espacio interior (22 pilares). Los trabajos de intervención consistieron en restituir 4 dinteles de madera colapsados en cuatro diferentes accesos, restitución de volúmenes de techos perdidos sobre los accesos a los espacios interiores, reparación de banquetas y bancas, consolidación de muros, incluyendo la escalinata monumental del Edificio III (conservada como talud inclinado cubierto de lodo apisonado). En las intervenciones en los seis edificios trabajó un 
promedio de 28 personas y dos responsables. El volumen de intervención es de aproximadamente 700 m cúbicos.

El equipo de dibujo estuvo formado por seis personas (tres dibujantes y tres ayudantes) y un responsable. Su trabajo, por seis temporadas de campo, fue documentar en primer lugar la condición previa y las acciones realizadas (110 dibujos en papel y lápiz a escala 1:20 y 1:50).

En términos generales las acciones de arqueología de rescate ocuparon el $30 \%$ del presupuesto. La acción de restauración el $37.5 \%$ del presupuesto y finalmente las acciones de logística (construcción campamento, administración, alimentación, transporte, combustible, medicina, vehículos, varios) ocupó un 32.5\%. Esta relación de acciones produjo en seis meses un abundante trabajo de rescate. Se combinaron los elementos científicos y técnicos esenciales para ser un trabajo sostenido y sostenible, modelo que puede replicarse en otros sitios arqueológicos. (El costo total de la inversión fue de 1.2 millones de quetzales (equivalente a Euros 120 000 o US \$ 164 000). El 63.66\% corresponde a la contrapartida nacional, pago de trabajadores operativos y el $36.34 \%$ para el pago de técnicos, equipo, materiales y suministros (fondo de donación, medida complementaria $\mathrm{KfW}$ ).

Este esquema de acciones de conservación y uso de sectores de sitios arqueológicos con arquitectura en peligro, como el ejercicio realizado en San Clemente, demuestra que es posible hacer intervenciones de rescate, cortos y de impacto directo a la cultura y a la sociedad vecina. 

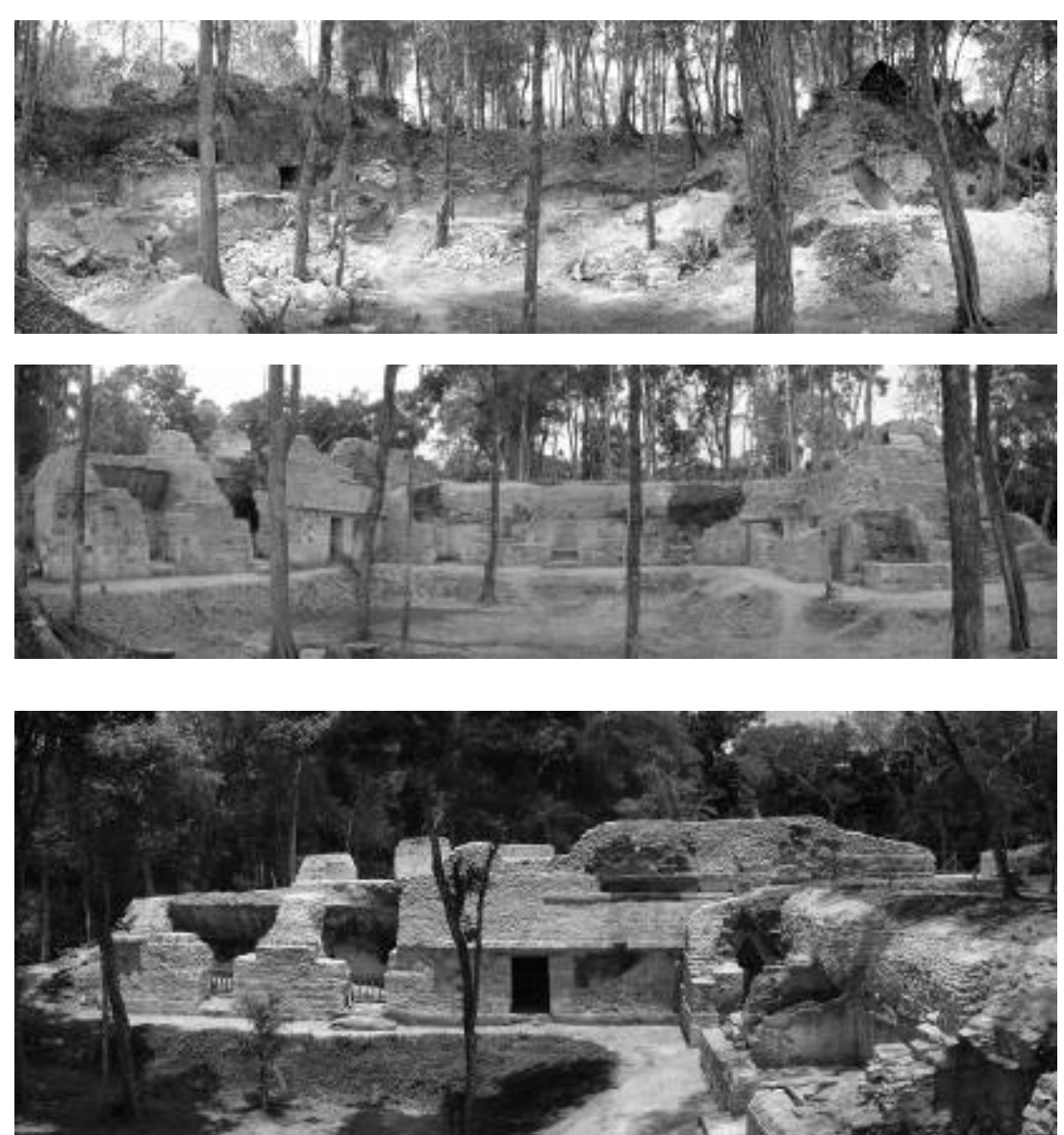

Fig. 27. Área del palacio de San Clemente, fotografías Noriega

\subsection{TRIÁNGULO CULTURAL YAXHÁ-NAKUM-NARANJO}

El proceso de rescate, activación, conservación y uso en el área del Triángulo Cultural inició con un recorrido (1987) para identificar edificios con arquitectura en peligro (apartado 2 de la metodología). Antes sólo había un puesto de vigilancia en Yaxhá, Nakum y Naranjo. No se realizaba ninguna otra actividad más que contar con presencia (vigilantes), para evitar saqueos, y una escasa labor de 
chapeo en algunas plazas. La llegada a los sitios era difícil y solo podía entrarse en vehículo de doble tracción pocos meses al año (época seca). El valor del recurso cultural no era considerado, se realizaban cacerías en el área arqueológica; de la laguna salían toneles llenos de pescados y tortugas, y los militares hacían sus prácticas de guerra encima de los edificios.

Esta condición cambio con la llegada del proyecto de inversión de Tikal (PRONAT) en 1989. Desde esa fecha se trabajó continuamente en rescatar y preparar el espacio cultural y natural del llamando triángulo cultural. Se mejoraron los campamentos y los caminos de acceso, se realizaron investigaciones de diferentes campos (arqueología regional, entre sitios, cuencas y arqueología de rescate y otros). También se realizaron trabajos de rescate y restauración de edificios en peligro, relleno de saqueos, investigaciones de flora y fauna y otros estudios especiales. Se habilitaron sectores de las ciudades para ser visitados, con infraestructura y servicios para el turismo.

En el año 1991 se incorpora, al territorio del triángulo cultural, el Consejo Nacional de Áreas Protegidas (CONAP). Por razón legal establecida en la Ley de Áreas Protegidas, decreto 4-89 y La ley de creación de la Reserva de La Biosfera Maya (RBM), decreto 5-90, el CONAP administra y resguarda el área de Yaxhá-Nakum-Naranjo. Junto con CONAP se logró el cambio de categoría legal del territorio que pasó de una zona de usos múltiples a una zona híbrida llamada "Monumento cultural y natural" que luego se transformó en zona núcleo, máxima categoría de protección legal (decreto 5-2003 publicado el 19 de diciembre de 2003). 
El proceso de rescate e incorporaciones cubrió los 6 apartados de la metodología. Acá se trabajó en documentos especiales de manejo, monitoreo, administración, uso público y otros que permiten ahora al nuevo Parque Nacional ser un elemento de desarrollo y modelo de conservación a nivel local, regional y nacional. Su esquema es novedoso pues es el primer parque en Guatemala que sus límites físicos no corresponden a una figura geométrica, decidida en una oficina y es una administración compartida entre CONAP, región VIII y la Dirección General del Patrimonio Cultural y Natural del Ministerio de Cultura y Deportes.

El proceso de cambio duró 11 años. El proyecto de inversión dio trabajo continuo a más de 300 trabajadores operativos, cerca de 60 técnicos y profesionales; y más de 50 voluntarios fueron entrenados. Todas las actividades realizadas (octubre1989-agosto 2006) tuvieron un costo de 77 millones de quetzales, equivalente a unos 7.7 millones de euros (la cooperación Alemana aportó el 36.8 \% de esta suma).

Un logro adicional fue la creación de todo un programa de funcionamiento para el nuevo parque. El Parque Nacional YaxháNakum-Naranjo ya está posicionado en los programas de turismo de Guatemala y forma parte de los atractivos de Petén. Actualmente es el segundo lugar más visitado después de Tikal. Además de Parque Nacional es un sitio Ramsar (No. 1599) y uno de los lugares dentro de la RBM que comprende tres diferentes tipos de humedales, lagunas temporales, sistemas kársticos y turberas (plan maestro 2006-2010, 13-14).

Los resultados del proyecto de inversión en el triángulo cultural no se restringieron al terreno (zona núcleo) del parque (37000 hectáreas), sino atendieron también aspectos estratégicos fuera del él. 
Al sur, el área de influencia se extiende a unos 11 kilómetros incluyendo a 12 comunidades como: el Zapote, Aguadas Nuevas, Las Viñas, La Máquina, caserío Yaxhá, y otras hasta la comunidad de la Pólvora (15000 familias). Las actividades fuera del parque se concentraron en acciones de rescate de sitios con arquitectura cercanos a poblados (La Blanca, Corozal Torre, San Clemente y otros)

El plan maestro del parque (2006-2010) contempla en sus primeras estrategias priorizadas: Promover la declaratoria del parque como patrimonio mundial ante la UNESCO (prioridad 1). Fortalecer el Plan de Prevenciones (control y vigilancia, prioridad 2). Promover el desarrollo de empresas turísticas comunitarias de servicios (guías, alimentación, venta de artesanías, tiendas y otros, prioridad 3) y otras más (plan maestro 2006-2010, 183-185).

En el año 2007 el parque generó ingresos por Q 863,160 quetzales (86,316 Euros) por concepto de entrada al parque con un registro de 12,843 visitantes. En el mismo tiempo el Parque Nacional Tikal generó, por el cobro de ingreso al parque, más de 10 millones de quetzales (1 millón de Euros).

Los resultados de conservación, habilitación y presentación de los patrimonios cultural y natural en el triángulo cultural Yaxhá-NakumNaranjo demuestran que es posible convertir y activar áreas con potencial cultural estratégico en polos de desarrollo cultural y natural local, de importancia nacional y mundial. Las lecciones aprendidas en la activación del triángulo cultural pueden ser replicadas en otros conjuntos estratégicos de la región en estudio. 


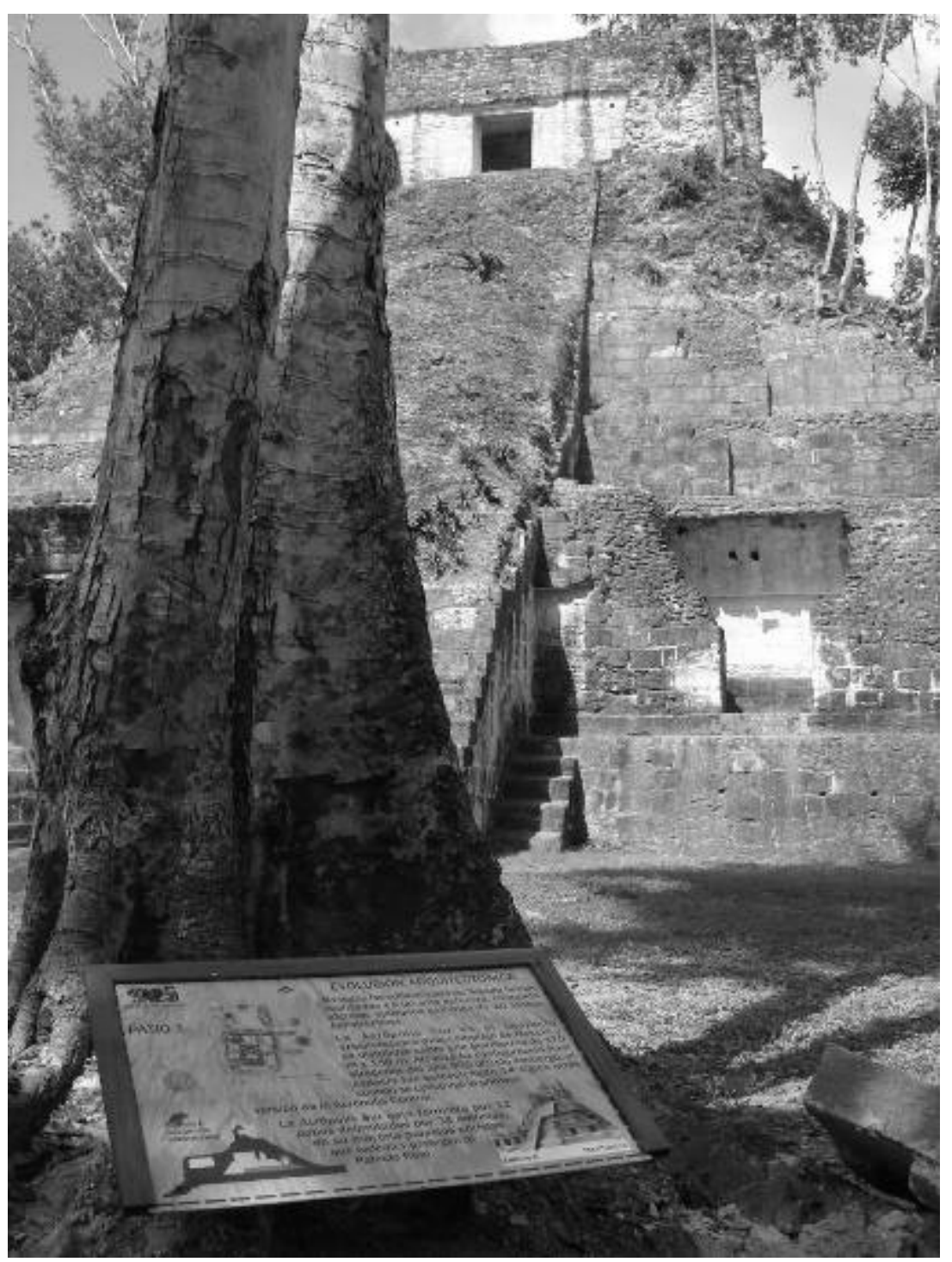

Fig. 28. Infraestructura turística en Nakum, cartel informativo del Edificio $E$, fotografía Noriega. 


\section{CONDICIONES Y POSIBILIDADES}

Todos los estudios, trabajos y comparaciones anteriores nos han dado como resultado una visión general del conocimiento sobre las condiciones y posibilidades del patrimonio monumental edificado maya. Ahora presentamos a manera de resumen para cada cuenca, los principales indicadores culturales, incluyendo otras variables potenciales como, la condición legal del territorio, la identificación de poblados, campamentos y zonas importantes por su posición geográfica estratégica en cuanto a la interconexión de sitios, los recursos naturales, la belleza del paisaje y la comunicación vial de la región. Todos ellos considerados como elementos potenciales y estratégicos para rescatar y desarrollar el noreste del departamento.

\subsection{DESCRIPCION POR CUENCAS}

Las condiciones y posibilidades son presentadas primero en forma separada para formar luego una visión integrada y una propuesta de activación, conservación y desarrollo. Para estructurar la estrategia los recursos potenciales se denominan "conjuntos". Un conjunto es la integración de dos o más sitios estratégicos en un paquete. Este conjunto forma un vínculo de bienes culturales y naturales. Por ejemplo el triángulo cultural Yaxhá-Nakum-Naranjo es un conjunto formado por 4 sitios mayores, varios sitios intermedios y muchos sitios menores. Cada conjunto es trabajado como una unidad; varios conjuntos forman "bloques" y diversos bloques y conjuntos forman una estrategia regional.

\subsubsection{Cuenca Mirador}

La cuenca Mirador cuenta con una muestra de 12 sitios, un súper centro (El Mirador) y tres grandes (Nakbé, Naachtún y Tintal). Dos 
sitios tienen arquitectura visible en peligro de colapso (La Muralla y Naachtún), y nueve edificios identificados como prioritarios o muy urgentes (cuadro 8). En la visión regional la cuenca tiene una ponderación con prioridad 2 (cuadro 9).

En esta parte del territorio trabaja desde 1989 un proyecto regional, llamado "Proyecto Regional de Investigación Arqueológica en el Norte de Petén Guatemala" (PRIANPEG), que luego cambió de nombre a "Proyecto Cuenca Mirador". La condición general en la cuenca continúa "estable". La presencia del Proyecto Cuenca Mirador es notoria. Este Proyecto regional considera los trabajos de documentación de saqueos, el rescate y restauración de edificios con arquitectura visible en peligro. En el tema de intervención de edificios en El Mirador, en el año 2003, fue colocada una cubierta protectora permanente sobre el Edifico 34 en el Grupo Tigre, y parte de un mascaron fue parcialmente tratado (Hansen et al. 2005, 59-73), y continúan acciones en el grupo de edificios llamado La Danta. A pocos kilómetros al sur de El Mirador, se encuentra el sitio La Muerta, con restos de arquitectura del Clásico Tardío. En este sitio también se han realizado trabajos de documentación, investigación arqueológica y consolidación parcial de edificios con arquitectura visible en peligro (Suyuc et al. 2005, 75-90). Por la cercanía con El Mirador e importancia de sus edificaciones es importante integrar este sitio a un uso turístico. Desde 1993 se cuenta con campamentos y vigilancia en El Mirador y Nakbé, más recientemente en La Florida y Xulnal (El Burro). Desde 2004 se realiza un programa de mapeo de sitios al sur de El Mirador con nuevos planos de Xulnal, Tintal, El Mirador, Nakbé, Wakna, El Porvenir, La Ceibita y otros. La población clave para el manejo del área es Carmelita. De ese poblado salen las veredas a pie y en mula para llegar al Parque Nacional Mirador. Todos los recorridos por la cuenca atraviesan un sin número de sitios menores 
con múltiples edificios saqueados. El punto apropiado de conexión con otros grupos estratégicos y otras regiones es el sitio Nakbé. Desde Nakbé se puede llegar a La Muralla y luego a Naachtún.

Naachtún es el otro punto estratégico con 8 edificios en peligro que requieren atención urgente. En el año 2003 inició la investigación arqueológica del sitio (University of Calgary) proyecto que desde 2006 ya no continuó con acciones de campo. El Grupo E es el más completo y posiblemente el mejor ejemplo de este tipo constructivo en toda las "tierras bajas mayas". Naachtún posee otros sectores con arquitectura monumental en peligro que son fundamentales para la historia de la arquitectura maya. De Naachtún existe un camino antiguo para vehículos que llega a la estación biológica de Dos Lagunas. Esta estación pertenece a la Universidad San Carlos (USAC) a cargo del Centro de Estudios Conservacionistas (CECON). Este es un buen punto para la administración y control de la zona. De Dos Lagunas se puede llegar al camino hacia Uaxactún, o continuar en dirección este hasta llegar al campamento de Ixcán Río (Río Azul).

\subsection{2 Área Tikal}

En el área Tikal, la muestra cuenta con 15 sitios, un súper grande (Tikal) y un grande (Uaxactún). Tiene la mayor cantidad de antecedentes de intervención con 96 edificios preparados para ser visitados (Tikal 85 y Uaxactún 11 edificios). La prioridad son 3 edificios muy urgentes en el sitio El Zotz (cuadro 8). En la visión regional esta cuenca tiene prioridad 3 (cuadro 9).

En 1959 el Museo de la Universidad de Pensilvania inició, en Tikal, el proceso de presentación de edificios mayas. Los trabajos de investigación e intervención en edificios continúan hasta la fecha. En 1983 Tikal extendió su radio de atención a Uaxactún. En los 
alrededores de Uaxactún se encuentran varios sitios con arquitectura expuesta por el saqueo que requieren atención preventiva, entre ellos están, Jimbal, Ramonalito, San Máximo y La Pita. Dentro del Parque Nacional Tikal (zona núcleo) es necesario realizar acciones de rescate en El Encanto y otros sitios abandonados.

El objetivo de rescate se encuentra en El Zotz, al oeste de Tikal. El sitio arqueológico El Zotz está dentro del biotopo San Miguel la Palotada-Zotz (zona núcleo), bajo la administración del CECON.

Sobre una montaña al pie de El Zotz se encuentra El Diablo, sitio sin arquitectura expuesta, pero con fuertes saqueos; por lo inclinado de la pendiente en la cima del cerro la erosión y el deterioro son alarmantes. Recientemente en El Zotz, se hacen cortas investigaciones arqueológicas en saqueos y se mejora el plano general del sitio (Houston et al. 2007, 333-347).

La comunidad de Cruce Dos Aguadas es la población estratégica. También es valiosa la estación biológica del CECON. Cerca de este campamento hay un corte natural donde habitan miles de murciélagos. Desde la cima del sitio El Diablo se aprecia una impresionante vista panorámica de selva con la silueta de los templos de Tikal.

Desde la comunidad Dos Aguadas se pueden organizar recorridos a sitios arqueológicos fuera del biotopo como Juleque y Canchén, con excelentes vistas de la cuenca del río San Pedro.

\subsubsection{Cuenca Ixcán}

La muestra cuenta con 15 sitios, uno muy grande (La Honradez) y tres grandes (Kinal, Chochkitam y Xultún). A nivel regional tiene la 
máxima prioridad (cuadro 9). En este sector hay tres conjuntos de sitios estratégicos con urgencia de intervención, y 14 edificios en peligro de colapso. El primero lo forman los sitios arqueológicos Río Azul y Kinal en el Parque Nacional Río Azul (zona núcleo). Los otros dos están en la Zona de Usos Múltiples de la Reserva de Biosfera Maya (ZUM-RBM). Uno es el Triángulo Ixcán (Chochkitam-La Honradez-Xmakabatún) y el tercer objetivo es Xultún-Uaxactún.

El primer conjunto es "Río Azul y Kinal", tiene cinco edificios en peligro identificados como prioritarios. En Río Azul, lo más urgente es el rescate de los Edificios A-1 al A-5 y las tumbas encontradas en la década de 1980. En Kinal la prioridad de intervención se encuentra en la acrópolis y dos edificios templo pirámide. Estos sitios fueron parte de un proyecto regional llamado Río Azul (Adams 1990, 1986). En los años 2005 y 2008 miembros del proyecto Río Azul retornaron al sitio arqueológico, informando sobre el precario estado de conservación de los edificios, las tumbas y el aumento del saqueo en la zona (Grazioso et al. 2006, 673-682). En el año 2007 el CONAP abrió un camino antiguo entre Kinal y el campamento La Lagunita, vía que facilita los recorridos por la zona.

El segundo conjunto lo forman tres sitios, Chochkitam, La Honradez, y Xmakabatún (Triángulo Ixcán), con seis edificios prioritarios. Ninguna de estas tres ciudades monumentales ha sido científicamente investigada. Los planos esquemáticos de los tres sitios fueron actualizados y publicados en 2001 (Quintana y Wurster 2001, 68-75).

El tercer objetivo es Xultún, sitio monumental sin investigación arqueológica, con tres edificios con arquitectura visible en peligro de colapso (Edificios I, II y VI). En el año 2002 se encontraron pinturas murales en un sitio al noreste de Xultún; acontecimiento que motivó a 
crear el proyecto San Bartolo. Las pinturas resultaron ser espectaculares ejemplos de arte Preclásico (Taube, Saturno y Stuart 2004, 871-881). Ahora el "Proyecto Arqueológico Regional San Bartolo" continúa y realiza trabajos de investigación y conservación en los edificios intervenidos y tiene un programa regional llamado "Intersitios entre San Bartolo y Xultún" (Urquizú y Saturno 2004, 629635; 2006, 649-657; Saturno y Urquizú 2005, 283-290). Estos dos sitios junto con Uaxactún forman un conjunto estratégico.

Antiguamente el acceso a Xultún se realizaba sólo por el poblado de Uaxactún. En el año 2001 las concesiones forestales comunitarias abrieron nuevos caminos. Este camino transformó el esquema de comunicación vehicular de la zona (ZUM-RBM). La nueva vía, que atraviesa el Corredor Biología, hace posible llegar en vehículo a Xultún por el camino El Caoba-Dos Aguadas o por Melchor de Mencos.

Para el conjunto Río Azul y Kinal el campamento Ixcán (dentro del Parque Nacional) es el punto estratégico para atender los dos sitios arqueológicos. A Ixcán se llega por el camino de Uaxactún pasando por el campamento El Cedro o por el camino de Melchor de Mencos a Río Azul, pasando por Kinal, Chochkitam, La Lagunita.

Para el Triángulo Ixcán el punto estratégico es el campamento "La Lagunita", estación central del grupo de concesionarios forestales comunitarios "Laborantes del Bosque". Los tres sitios arqueológicos, se encuentran en distintas concesiones forestales. Chochkitam cuenta con el acceso más fácil y es monitoreado periódicamente por personal del campamento La Lagunita.

Para La Honradez hay que caminar por espacio de dos horas, y para Xmakabatún existe un camino antiguo (trocopas) sin uso que pasa 
muy cerca del sitio. Otro sitio cercano es La Línea, sin arquitectura visible en peligro.

Al sur del Triángulo Ixcán está el conjunto "Pucteal" con los sitios, El Susto, El Susto Mirador, Ratón Pucteal y Las Cubetitas, cercanos al campamento de concesionarios forestales comunitarios "Custosel" ubicado en la laguna "Pucteal". Este conjunto puede ser importante para realizar trabajos combinados de rescate, conservación de la naturaleza y turismo con los señores concesionarios forestales comunitarios.

\subsubsection{Cuenca Holmul}

La zona cuenta con una muestra de 30 sitios, uno muy grande (Naranjo) y dos grandes (Yaxhá y Nakum) con 3 edificios en peligro muy urgentes en el sitio Holmul (cuadro 8). A nivel regional tiene prioridad 3 (cuadro 9). La cuenca posee dos conjuntos prioritarios; uno lo forma la parte norte del Parque Nacional Yaxhá-NakumNaranjo (zona núcleo), y otro el conjunto Holmul-Yaloch (ZUM-RBM).

En la parte correspondiente al triángulo cultural, los sitios, Nakum, Naranjo, Pochitoca, Poza Maya, El Carmen, Kanajau, El Pital Naranjito y otros ya fueron o están en proceso de investigación, rescate y conservación. En Nakum se trabajaron 26 edificios con arquitectura expuesta y en Naranjo los seis sectores con arquitectura visible cuentan con medidas preventivas. En Naranjo el campamento arqueológico fue reforzado y cuenta con personal de funcionamiento permanente.

En el segundo conjunto estratégico "Holmul-Yaloch" el sitio Holmul tiene tres sectores con edificios en peligro (Grupo I, Grupo II y Grupo III). A partir del año 2000 un proyecto de investigación arqueológica 
regional trabaja en la zona (Estrada Belli et al. 2006, 639-647), con excavaciones en los sitios vecinos de La Sufricaya, Cival y El PerúHolmul. El objetivo de este proyecto arqueológico es encontrar y aclarar evidencias del Clásico Temprano sin considerar restauración o conservación de edificios con arquitectura en peligro. Por esta condición, la arquitectura continúa amenazada y sin atención. El acceso se hace por la ruta principal Melchor de Mencos-Yaloch. La estación estratégica es el campamento de concesionarios forestales comunitarios en la laguna de Yaloch.

Entre Nakum y Holmul hay un camino que pasa cerca de los sitios Dos Aguadas, El Danto y Witzná; todos ellos con arquitectura expuesta que requieren atención preventiva. La comunidad de Melchor de Mencos y los campamentos de concesionarios forestales comunitarios son los elementos estratégicos de este sector.

\subsubsection{Cuenca de Los Lagos}

La muestra cuenta con 35 sitios; sin ningún edificio en peligro muy urgente (cuadro 8). A nivel regional tiene la más baja ponderación 5 (cuadro 9). La razón es que los edificios muy urgentes (Yaxhá y Topoxté) ya fueron atendidos.

Los trabajos de restauración en Topoxté iniciaron en 1989 y concluyeron en 1996, presentando ejemplos de la arquitectura Posclásica.

En Yaxhá los trabajos preventivos iniciaron en 1988. A partir del año 1999 inició otro proyecto de inversión llamado "Programa de Desarrollo Sostenible" (Préstamo PDS-BID). El financiamiento fue a través del Banco Interamericano de Desarrollo (BID), con sede en 
Washington. Con este fondo se intervinieron 13 edificios y dos plataformas con el criterio de preparar fachadas para el turismo.

Por ser Yaxhá, la principal entrada del nuevo Parque Nacional (2003), se realizaron diversos trabajos de infraestructura tales como: la construcción de módulos de interpretación en Yaxhá y Nakum. Además se construyeron todas las instalaciones para la administración y funcionamiento del nuevo parque. El préstamo del BID financió también áreas de descanso, servicios sanitarios, caminamientos y muelles en Yaxhá y Topoxté.

Al sur y fuera del Parque Nacional Yaxhá-Nakum-Naranjo se trabajó en dos de los tres sitios arqueológicos identificados con arquitectura visible en peligro. En el año 2004 se intervino en el sitio Corozal Torre (Matute y Noriega 2005, 137-144) y en el año 2006 en el sitio San Clemente (Quintana 2007b, 17-19). San Clemente y Corozal Torre forman un circuito estratégico con las comunidades vecinas de Zapote, Naranjo, La Democracia, Aguadas Nuevas y Ramonal. Este conjunto es prioritario por estar cerca de comunidades y acceso rápido a la principal red vial de Flores-Melchor de Mencos. En los alrededores se encuentran otros sitios más como: Zapote Corozal, Quemada Corozal, Cordoncillo Corozal, Huech, Nima Wuits, Ta-Aj Corozal, La Naya e Ixtinto que se pueden integrar en un circuito de uso cultural y comunidades.

En el extremo oeste de la Cuenca de Los Lagos, está el área central con la concentración de poblados alrededor del lago Petén Itzá. Los sitios más estratégicos son tres. Todos sin arquitectura visible y sin peligro de colapso. El primero es Motul, cerca de la comunidad de San José, en el extremo oeste del lago Petén Itzá. El segundo es Tayasal, frente a la isla de Flores y el centro urbano actual más 
grande del departamento (Flores, Santa Elena, San Benito). El tercer sitio estratégico es Ixlú, en el lado este del lago Petén Itzá.

La rivera norte del lago Petén Itzá tiene potencial para ser un futuro corredor turístico, de recreación y servicios. El área central de FloresSanta Elena-San Benito tiene importancia para infraestructura, servicios y administración de los recursos culturales, naturales, educación y turismo del departamento.

\subsubsection{Cuenca Mopán}

La cuenca cuenta con 21 sitios y 5 edificios muy urgentes (cuadro 8). A nivel de la región tiene prioridad 4 (cuadro 9). El área de estudio abarca sólo el segmento norte de la cuenca Mopán. Esta parte es conocida como la cuenca baja del río Mopán. Aquí hay tres sitios con arquitectura visible en peligro.

El primero es Tzikintzakán. El Edificio 1 es un ejemplo de la destrucción reciente del patrimonio edificado. En fotografías de la década 1970 (Quintana y Wurster 2001, 132-134), la segunda cámara del edificio se encontraba completa; poco después por falta de mantenimiento la bóveda colapsó. Ahora los muros del Edificio 1 se encuentran apuntalados en espera de su rescate.

El segundo sitio estratégico es La Blanca. A partir del año 2004 dos Universidades Españolas (Universidad de Valencia y Universidad Politécnica de Valencia) y la Universidad de San Carlos, iniciaron un proyecto multidisciplinario de investigación arqueológica, restauración y desarrollo comunitario. El tercer sitio con arquitectura expuesta y en peligro es Chilonché. La Blanca y Chilonché forman un conjunto estratégico en la parte suroeste de la cuenca. 
Al centro del valle se encuentra el sitio Ucanal. Ucanal fue el centro rector del área durante el período Clásico; no tiene arquitectura expuesta en peligro, pero está parcialmente investigado (Laporte y Mejía 2002) y cuenta con vigilancia permanente. Además tiene un área natural protegida a orillas del río Mopán.

Desde Ucanal se pueden comunicar otros sitios arqueológicos cercanos, tales como: Dos Hermanas, Yok'Ol Wits, Naranjal y otros, formando un circuito de sitios, ríos y comunidades, hasta llegar a Melchor de Mencos (Quintana, 2006a, 150-157).

Melchor de Mencos es la cabecera municipal y el acceso de turismo que circula por la península de Yucatán y Belice. Desde Melchor de Mencos se pueden organizar recorridos hacia el norte (HolmulYaloch); hacia el distrito del Cayo en Belice o hacia el sur con el circuito Buenos Aires-Camalote y La Blanca, Chilonché, Tzikintzakán. El potencial de esta cuenca es la combinación de sitios arqueológicos, con la naturaleza, ríos, fácil comunicación vial y las comunidades actuales.

\subsection{CONJUNTOS ESTRATEGICOS}

En el área de estudio hay 168 edificios "preparados" o en proceso de restauración. La gran mayoría se encuentran en Tikal y Uaxactún (con 96 edificios), y la región del triángulo cultural Yaxhá-NakumNaranjo (con 58 edificios).

Las prioridades de atención al patrimonio edificado resultaron ser 78 edificios (34 muy urgentes, 20 urgentes y 24 poco urgentes). La mayoría de prioridades se encuentran en la cuenca Ixcán y la cuenca Mirador. Estos valores deben ser tomados en cuenta para diseñar una estrategia regional de desarrollo; en donde uno de los objetivos 
sea atender la situación de emergencia del recurso cultural edificado en la región del estudio. Los cuadros 7, 8 y 9 dan cuenta de esta condición actual.

La calidad, cantidad y variedad de soluciones espaciales con arquitectura monumental que ofrece la región es excepcional, digna de ser inscrita en UNESCO. Aquí se puede recorrer en un espacio territorial relativamente corto, toda la evolución cultural de los mayas. Desde el principio, con espectaculares ciudades del Preclásico, como en El Mirador y Nakbé. Disfrutar de verdaderos hitos de arquitectura Clásica en Uaxactún, Tikal, Nakum, La Honradez, Xultún, Chochkitam. Pasar por el esplendor del Posclásico, con la arquitectura de la isla de Topoxté, hasta llegar al último baluarte independiente maya en Tayasal, conquistado por la fuerza en 1697. Es un recorrido por más de dos mil quinientos años, aun palpable y enriquecido por los pobladores actuales y sus tradiciones. Adicionalmente la cobertura actual de selva continúa con ecosistemas sorprendentes de igual importancia nacional y mundial aumentan el potencial estratégico de la región noreste de Petén. Ahora las ciudades mayas en su condición actual de ruina arqueológica, son presentadas como documentos históricos de ese gran pasado. Esta herencia debe ser atendida con calidad, sabiduría y autenticidad, a sabiendas de que el verdadero valor de este patrimonio edificado y su contexto cultural es válido mientras conserve su calidad de documento histórico respetado.

Ya mencionamos que la "visión" ordena a los recursos culturales identificados en conjuntos de bienes estratégicos. En estos conjuntos se deben de diseñar proyectos de inversión para activarlos. Esto siguiendo el modelo empleado para el triángulo cultural YaxháNakum-Naranjo. El plan incorpora a los actuales pobladores y a los 
recursos naturales en su nueva condición legal del uso del suelo. Con estas condiciones se dividió el territorio en grupos de proyectos de inversión. Estas tres variables nos permiten formar paquetes de conjuntos llamados "bloques". Varios bloques y conjuntos llegan a formar un plan estratégico regional.

1- Proyectos de inversión para las zonas de uso restringido y de máxima protección legal (zona núcleo) en los parques nacionales y biotopos.

2- En zonas de uso controlado y de categoría ZUM-RBM, en los corredores biológicos y las concesiones forestales comunitarias e industriales.

3- En zonas de amortiguamiento de la RBM, terrenos privados o municipales, y poblados.

\subsubsection{Zonas restringidas}

En este apartado se desarrolla una estrategia para las zonas de máxima protección legal. La categoría se genera con el Parque Nacional Tikal (1955). En el año 1989 aparecen nuevas zonas restringidas en el límite norte (Parque Nacional Mirador- Río Azul y el Biotopo Dos Lagunas), y vecino a Tikal el biotopo San Miguel la Palotada-Zotz. En el año 2003 surge el Parque Nacional YaxháNakum-Naranjo.

El primer paquete estratégico se denomina "Bloque de conservación y turismo cultural y natural" (Bloque 1) tan bien llamado "Gran Tikal". El bloque está formado por una barrera de tres zonas núcleo (parques nacionales Tikal, Yaxhá-Nakum-Naranjo, y el biotopo El Zotz. Todos ellos forman un cordón este - oeste de 69 kilómetros de largo y una superficie protegida de 1340 kilómetros cuadrados. Este Bloque 1 (Gran Tikal) es el más avanzado y presenta espectaculares 
vestigios culturales y naturales, entre los que sobresale Tikal (parque desde 1955), ahora reforzado al este, por el nuevo parque YaxháNakum-Naranjo (2003). Para completar esta estrategia hace falta inversiones en el sector oeste, en el Biotopo El Zotz.

El segundo paquete lo forma el grupo de zonas núcleo creados en 1989, llamado en este estudio Bloque 3 (Parque Nacional Mirador-Río Azul y biotopo Dos Lagunas). Para el Bloque 3, su importancia estratégica es "conectarse" con otros parques o zonas similares de protección con los vecinos de México y Belice. En este sector aún hace falta trabajos de restauración urgente para poder activar el bloque. Es una de las prioridades identificadas en este estudio. También es importante la conectividad entre los bloques 1 y 3 (corredor Biológico), elemento que no está considerado como prioritario por las autoridades responsables (Conap). La ley (decreto 5-90) no los identifica como zona especial sino como una parte más de la zona de Usos Múltiples. Condición que es aprovechada para extraer madera y abrir caminos en su espacio protegido. Existe un interés regional de asegurar la interconexión de corredores naturales en Centroamérica. Este sería el potencial principal de este segmento.

Dentro del Bloque 3 la primera prioridad cultural está en evitar la caída o colapso de edificios monumentales con arquitectura en peligro en tres sectores: Al oeste y cerca de Nakbé (Parque Nacional Mirador), el sitio La Muralla. Al centro (dentro del Biotopo dos lagunas) el sitio Naachtún; y al este el conjunto Río Azul-Kinal. Los rasgos arquitectónicos de estos sitios con edificios en peligro son verdaderos piezas maestras de la civilización maya y se encuentran en gran peligro de colapso. 
Dentro del mismo Bloque 3 se encuentra el sitio El Mirador; significativo realmente, pero con ponderación (importancia de atención) menor a los sitios mencionados anteriormente. En el sitio El Mirador los trabajos prioritarios o de peligro de colapso en edificios ya está solucionado, gracias a la intervención oportuna de un proyecto de inversión; lo mismo sucede con Nakbé. Sin embargo los indicadores le dan mayor ponderación al sitio Nakbé que al sitio El Mirador.

Según la filosofía de esta investigación la primera condición que debe ser resuelta es evitar que el patrimonio expuesto en peligro no se pierda. Luego de solventada esta fase de emergencia, muy bien pueden caber otros intereses de investigación y búsqueda de claves que respondan a interesantísimas preguntas sin respuesta actual. ¿Por qué colapsó El Mirador? Esta es una pregunta clásica y excitante de investigar. Pero un plan debe ser consecuente y sistemático. Si conservamos ahora, otras generaciones tendrían otro panorama, no tan dramático como el actual, en donde se podrían satisfacer todo tipo de hipótesis apasionantes para investigar debajo de los edificios. Por el momento la estrategia de este estudio continúa insistiendo que primero debe superarse la etapa de emergencia general en la zona, o sea, atender a los 78 edificios que están en peligro.

\subsubsection{Zona central}

Este paquete se denomina "Bloque 2, administración, recreación e infraestructura". Este se localiza alrededor del lago Petén Itzá (28 kilómetros de largo) en el centro del departamento. En este Bloque 2 se integran varios conjuntos identificados alrededor del lago.

1- Rivera norte. En este segmento se debe promover su uso como corredor de recreo y turismo con infraestructura para atender al área 
central (mayor concentración de población y servicios) y a visitantes que entran y salen del Bloque 1 (Gran Tikal) y otros futuros conjuntos estratégicos del departamento.

Cabe mencionar que la visión divide al departamento en cuatro cuadrantes y todos ellos forman parte del área central. En este trabajo nos ocupamos únicamente del cuadrante noreste.

2- Parte sur oeste del lago. En este sector se localizan los centros poblados de Flores-Santa Elena-San Benito, San Andrés, San José y San Miguel. Aquí el objetivo sería fortalecer los servicios y la administración regional. Este sector no sólo concentra la mayor población del departamento, sino que también es el lugar en el que se encuentran las instituciones de gobierno, las universidades y escuelas de enseñanza media, bancos, hospitales, hoteles y el aeropuerto internacional.

La intención de la estrategia es conseguir que los atractivos del sector norte, este, oeste o sur del departamento dependan del área de servicios del centro. El propósito sería el generar un movimiento de usuarios en forma de zig-zag (entrar y salir) y de no recargar con infraestructura las zonas restringidas.

En el Bloque 2 debe concentrarse la administración de los recursos patrimoniales culturales y naturales. Deberá construirse la infraestructura necesaria para ser eficiente (oficinas, talleres, bodegas, equipos, servicios y otros). Por ejemplo, en este sector debería estar un museo regional con una visión macro y temática para todo el departamento y las tierras bajas centrales. En torno a este centro deberían estar preparados los guiones museográficos y museológicos para los cuatro cuadrantes. Así los visitantes de las 
subregiones podrían entrar y salir de las áreas de menor servicio al bloque ya diseñado para este fin.

3- Sitios arqueológicos estratégicos del área central. En este caso su prioridad en relación a los indicadores (saqueo en edificios y arquitectura visible en peligro) es baja; pero por su posición y cercanía al área principal de comunidades, debería considerase su incorporación. Los sitios identificados son: Motul, Ixlú y Tayasal. Además se cuenta con vestigios del patrimonio heredado de la colonia y la época republicana, aún visible en los poblados de: Flores, San Benito, San Andrés y San José.

12.2.3 Corredores de comunicación y poblados

La estrategia de este paquete es el integrar a los poblados actuales, el sistema vial y los sitios arqueológicos cercanos a las comunidades.

Las características de estos sitios arqueológicos no son tan monumentales si se comparan con los recursos ya preparados en el Bloque 1 (Gran Tikal). Pero sí pueden formar circuitos y tener dependencia de uso respecto a sitios emblemáticos o mayores como Tikal, Yaxhá, El Zotz. El potencial de este paquete está en las comunidades cercanas a los sitios y su fácil acceso vial. La red vial actual permite a algunas comunidades tener mejores servicios que otras más alejadas y podría aprovechar el flujo de turistas hacia los sitios mayores que pasan por sus comunidades.

1- Corredor Ixlú-Melchor de Mencos. Partiendo del Bloque 2 hacia el este, por la carretera de aproximadamente 70 kilómetros hasta llegar a la frontera con Belice. El plan identificó tres circuitos o tramos estratégicos

1.1- Ixlú-Remate y Macanché 
Este circuito lo conforman los poblado el Remate, Ixlú y Macanche con los sitios Ixlú y Sacpetén.

1.2- Naranjo, Zapote, Las Viñas y La Máquina

Este segmento involucra a los poblados de Naranjo, Zapote y Las Viñas, con el circuito San Clemente, Corozal Torre (ya activado); más otros seis sitios potenciales y otras aldeas vecinas. En este conjunto está además La Máquina con el acceso obligado al Parque Nacional Yaxhá-Nakum-Naranjo. Aquí el potencial es ser una estación intermedia de servicios al turista que se dirige por la ruta o se desvía hacia el Gran Tikal (Bloque 1). Alrededor de estos poblados hay varios sitios intermedios identificados que en un momento podrían ser activados (Holtún, Sufricaya, la Naya, El Venado y otros).

1.3- Bajo del Venado, la Pólvora, y Melchor de Mencos

El tercer circuito lo forma el tramo vial que desde la Máquina llega a la cabecera municipal de Melchor de Mencos. Acá el poblado estratégico es La Pólvora con el sitio Tzikintzakán. Melchor de Mencos es estratégico por su posición de frontera para continuar recorridos por Belice, hacia los grandes Humedales del norte, o hacia el sur en la cuenca del río Mopán. En este último segmento el sitio estratégico es La Blanca (en proceso de activación).

En este apartado de corredores de comunicación y poblados, el descrito anteriormente es el más atractivo. Hay otros dos segmentos en similar condición.

2- Corredor Ixlú-Caoba-Zocotzal. Del Bloque 2 hacia el Parque Nacional Tikal (Bloque 1). En este recorrido hay varios poblados recientes que se benefician de los turistas que Ilegan a Tikal. En los 
alrededores no se han identificado atractivos culturales potenciales para activar.

3- Corredor San José-Cruce Dos Aguadas-La Pasadita-Carmelita. Del Bloque 2 sale hacia el norte (Carmelita), en la cuenca Mirador (Bloque 3). A lo largo del camino no hay atractivos culturales estratégicos, y la vegetación está muy deteriorada. El poblado principal en este tramo es el Cruce Dos Aguadas. Este poblado es la puerta de acceso al Biotopo El Zotz (Gran Tikal, Bloque 1), hacia los grandes humedales del Mirador (al Norte) y hacia el oeste con la cuenca del río San Pedro.

Zonas degradadas y abandonadas pueden ser activadas a través de "circuitos" que intercalan sitios mayores e intermedios con poblados actuales. En cada circuito pueden incorporarse otros sitios o atractivos naturales importantes, formando así una cadena de mosaicos de posibilidades para sostener un turismo conectado con recursos auténticos y de calidad.

El recurso cultural es protegido cuando se hace parte de la conciencia de los actuales pobladores. Cuando la comunidad ve al recurso cultural como un medio para la obtención legal de bienes económicos por servicios y orgullo por ser el poseedor temporal de este invalorable tesoro cultural de la categoría patrimonio Mundial. Los limitantes actuales son la gran cantidad de sitios abandonados, la falta de estrategia y planificación, la depredación, el vandalismo y la falta de recursos humanos, financieros, educación y voluntad política para su rescate. 
12.2.4 Zonas en concesión

Desde 1990 el cuadrante noreste se divide en dos diferentes tipos de uso legal del suelo. Uno las zonas núcleo (Bloques 1 y 3); y la ZUMRBM, incluyendo el Corredor Biológico entre Tikal-Yaxhá con Río Azul (decreto 5-90). El otro son las zonas de usos múltiples (ZUM).

En el segmento oeste de esta zona están varios sitios parcialmente atendidos por el proyecto de inversión Cuenca Mirador. Desde el poblado Carmelita hay tres rutas posibles para llegar al Bloque 3. Las rutas son a pie o en mula, y dependiendo de cual se toma se pasa por sitios arqueológicos importantes con muchísimos saqueos abiertos, poca arquitectura visible en peligro y campamentos rústicos para pernoctar en el recorrido hacia el Bloque 3.

Al centro, por la ruta principal de vehículos (vía Uaxactún), no hay sitios o conjuntos valiosos identificados hasta llegar al Bloque 3. Ya dentro del bloque, se encuentra el sitio Manantial y la estación biológica de Dos Lagunas (CECON), y el campamento el Cedro (CONAP) que permiten llegar al sector este del Bloque 3 (Río Azul y Kinal).

La porción este contiene los principales conjuntos de edificios con arquitectura en peligro. Estos sitios se encuentran dentro de las áreas dadas en concesión forestal comunitaria. El conjunto llamado "Triángulo Ixcán" es el más importante y reúne tres sitios monumentales con abundante arquitectura en peligro de colapso; ninguno de ellos investigado arqueológicamente y con importancia fundamental para la historia de la región y las tierras bajas mayas. Los recursos estratégicos de este paquete "Chochkitam-XmakabatúnLa Honradez", al igual que Yaxhá-Nakum-Naranjo, serían lo ejes de activación de la zona. Cerca de ellos hay otros sitios importantes, 
como La Línea, que deberían de tratarse luego de consolidado el nuevo triángulo. Un conjunto estratégico cercano sería el grupo de sitios de la laguna Pucteal. Otro sería el conjunto Xultún-San Bartolo.

El potencial cultural de estos sitios se mezcla con la exuberante selva y el trabajo de los señores concesionarios forestales comunitarios.

Más al sur se encuentra otro conjunto importante llamado "HolmulYaloch" con similares condiciones a las descritas anteriormente.

El conjunto Parque Nacional Yaxhá-Nakum-Naranjo ocupa ya una posición importante en los grandes humedales y puede ser tomado como un modelo piloto para la región.

\subsection{ESTRATEGIA}

Los Bloques 1 (Gran Tikal), 2 (Zona Central), y 3 (Mirador-Río Azul) son los ejes de la estrategia, entre ellos debe ligarse las interconexiones necesarias para lograr sostener el plan y los proyectos de activación adentro y afuera de los bloques.

Ya mencionamos anteriormente que las condiciones de accesibilidad, cobertura de la selva y uso son distintos en el área sur y el área norte del cuadrante. Así se propone contar con un plan doble. Es decir una serie de proyectos de inversión que funcionen en las épocas secas con más trabajo en el Bloque 3 y conjuntos como el "Triángulo Ixcán"; y para la épocas de lluvia, una concentración de trabajos en los Bloques 1 y 2, los corredores de comunicación y poblados (sitios, poblados y sistema vial). Estos últimos son los conjuntos más flexibles de los elementos estratégicos del plan y es en donde habría mayor participación de la comunidad actual. 
De esta forma la logística funciona mejor; pues pensar en trabajar en época de lluvia en sitios como Xultún sería complicado, sin embargo, en época de lluvia en los proyectos de inversión del norte pueden efectuarse tareas de monitoreo, trasladándose el mayor personal a continuar tareas en el área sur.

En la figura 29 se ubican los conjuntos estratégicos identificados, y en el cuadro 10 "estrategia del plan" (principales programas y proyectos) se anotan las 16 principales actividades propuestas.

Los principales objetivos de atención son:

- Prioridad 1: dos en la cuenca Mirador, dos en área Tikal, tres en cuenca Ixcan, y dos en la cuenca Holmul

- Prioridad 2: uno en la cuenca Mirador, dos en la cuenca de Los Lagos, y una en la cuenca del río Mopán.

Al combinarse las prioridades de atención a edificios en peligro de colapso (cuadro 8 y cuadro 9) se establecen cuatro acciones prioritarias muy urgentes de rescate de arquitectura:

\section{Cuenca Mirador: La Muralla y Naachtún}

Cuenca Ixcán: Río Azul y Kinal

Cuenca Ixcán: Triángulo Ixcán

Cuenca Ixcán: Xultún

Estos cuatro elementos con la ponderación más alta, formarían la base (estructura) de abertura de la región norte. Siguiendo el esquema propuesto estas acciones deberían de combinarse para reforzar y formular nuevos conjuntos, siguiendo el modelo de YaxháNakum-Naranjo.

Muy cerca de la puntuación más alta hay tres sitios que resultaron con ponderación 1.5, uno de ellos fue el reforzar una estación 
turística en Nakbé. Proyecto que persigue consolidar la visión de los futuros conjuntos en el norte. Otro proyecto con puntuación 1.5 pretende consolidar el Bloque 1 con la integración del Biotopo El Zotz (y la restauración de sus edificios en peligro) al Gran Tikal.

El tercer grupo fue Holmul-Yaloch, el cual requiere un rescate urgente de arquitectura. Además si se estimula la restauración y el uso público en este conjunto, puede poco a poco convertirse en una parada estratégica para los conjuntos más al norte (Triángulo Ixcán, Río Azul-Kinal, y otros).

Sólo un conjunto tuvo ponderación 2 y corresponde al corredor de comunicación de Carmelita en el Bloque 3. Este conjunto es estratégico para la participación de la comunidad en el turismo y consolidar el territorio abajo del Parque Nacional Mirador (Bloque 3).

Seis proyectos de inversión propuestos tuvieron calificación 2.5. Dos de ellos corresponden a dos Parque Nacionales ya en funcionamiento del Bloque 1, "Gran Tikal" (Tikal y Yaxhá-Nakum-Naranjo). Aquí las prioridades de atención a los edificios en peligro ya fueron cubiertos y más bien se requiere fortalecer los programas de funcionamiento.

El conjunto Pucteal tiene ponderación 2.5 y estaría considerado con sus sitios intermedios como un circuito ligado al Triángulo Ixcán (con sitios mayores). Igual sucede con cuatro circuitos al sur de Yaxhá (parte suroeste del Bloque 1) en donde sitios intermedios ya rescatados o en proceso se combinan con los sitios mayores del triángulo cultural (clave 5-2) con tres circuitos cercanos a Yaxhá.

Algo similar sería con el sitio La Blanca; este proyecto inició como una extensión del radio de influencia al sur del Parque Nacional YaxháNakum-Naranjo. Está en proceso de activación con apoyo de la 
cooperación de España y debe ser él un generador de un nuevo conjunto estratégico en la zona.

Los proyectos en el Bloque 2 (zona central), tienen ponderación 2.5; en parte porque en este paquete no hay prioridades de rescate de arquitectura maya en peligro. Acá lo importante es la consolidación de las instituciones de gobierno para administrar el territorio, la conservación del paisaje urbano de la isla de Flores y otros recursos potenciales del área.

El proyecto de integración de la ciudad Melchor de Mencos con la cuenca baja del río Mopán recibió la más baja ponderación (3). Quizás porque en este sector tampoco hay arquitectura en peligro de colapso (aparte de Chilonché), que en el plan es visto como un apéndice de La Blanca. El potencial aquí son los poblados, los ríos y los sitios arqueológicos.

En todas las regiones del Mundo Maya los países y sus gobiernos locales se esfuerzan en captar la atención del turismo. Unos ofrecen sitios arqueológicos y playas, otros espectáculos de luz y sonido, o fastuosos museos temáticos o de sitio; algunos crean ambientes y zoológicos artificiales como parques eco-arqueológicos. La región noreste de Petén ofrece diversas formas de uso, disfrute cultural y natural auténtico y de calidad. Esta espectacular región si se lleva con un sistema, una filosofía y fondos suficientes, en 10 o 15 años podría ser el verdadero corazón del Mundo Maya. 


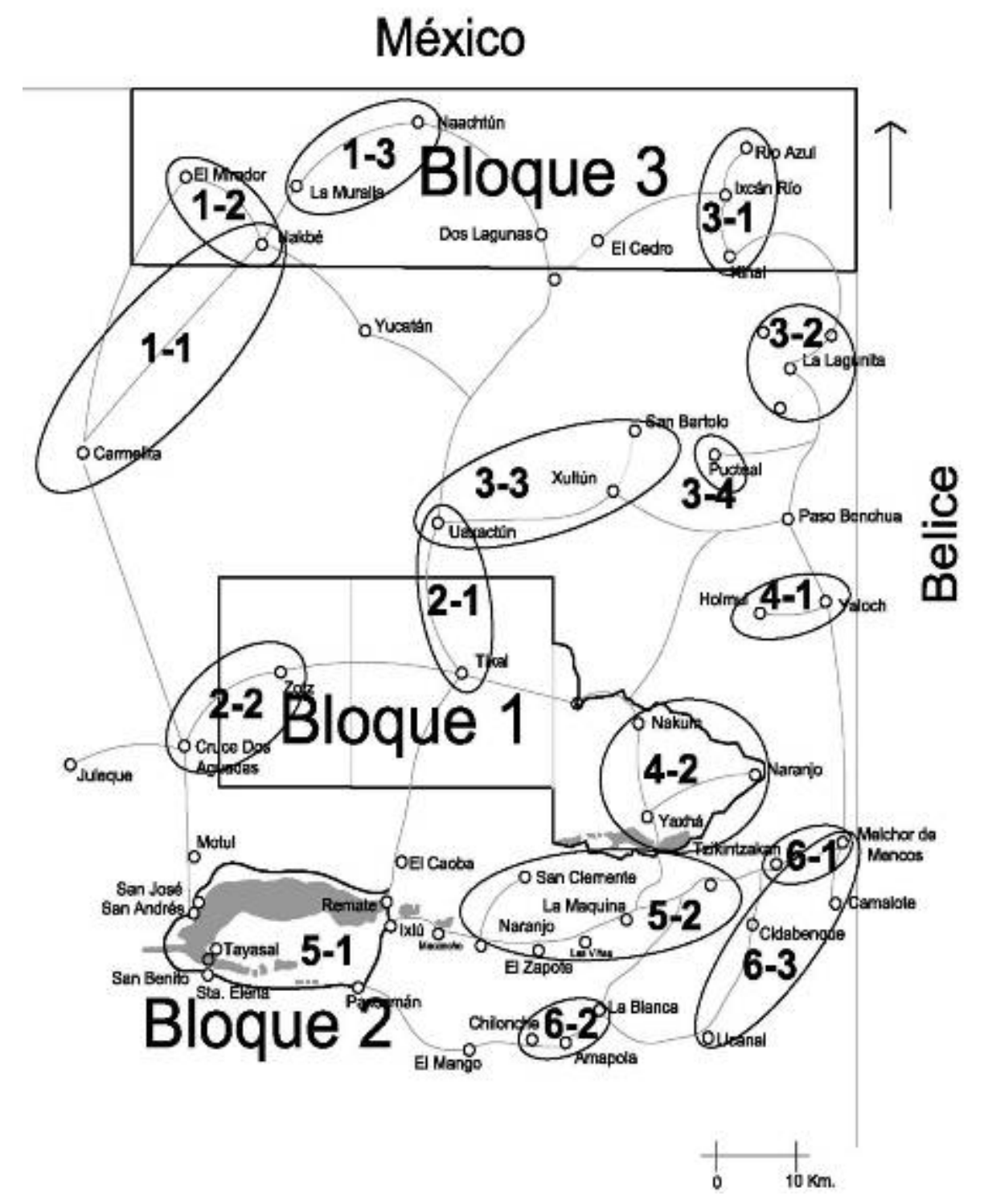

Fig. 29. La región noreste y los conjuntos estratégicos 
La primera conclusión del estudio confirmó que el potencial cultural del cuadrante noreste de Petén no es un patrimonio común, sino posee una condición excepcional, con monumentales ciudades y verdaderos hitos de la arquitectura maya. Patrimonio en condición de peligro de perderse, pero si se rescata a tiempo éste seria el mayor recurso cultural de Guatemala, con categoría patrimonio mundial de UNESCO.

El resto de las regiones de Petén también cuentan con gran cantidad de vestigios monumentales mayas, sin embargo, no con la concentración y las dimensiones del cuadrante noreste. Además en este territorio hay magistrales ejemplos visibles del urbanismo y la arquitectura maya de las tres principales épocas culturales (Preclásico, Clásico y Posclásico). A este recurso hay que sumarle la condición actual de selva continua y ser parte de la Reserva de la Biósfera Maya. Un potencial más para distinguir este territorio como muy particular. Las prioridades y objetivos de investigación y conservación de este gran conjunto patrimonial excepcional están planteadas en el capítulo 12 con una propuesta de estratégica regional

La metodología aplicada se extiende a todos los aspectos necesarios para este trabajo y se convierte en el sustento científico de los diferentes procesos y acciones realizadas y por realizar. El concepto abarca todos los niveles para llegar a conocer finalmente los elementos básicos de la composición arquitectónica, el estado de conservación del patrimonio monumental construido en piedra, y las medidas que deberían tomarse para su rescate y conservación. 
Los resultados de las investigaciones realizadas son presentados en tres grupos de conclusiones. El primero obedece a la pregunta ¿Cómo es el patrimonio edificado monumental construido en piedra?; en este caso se contó con una muestra de 128 sitios, con datos actualizados y comparables, que demostró la magnificencia de la composición arquitectónica y confirmó el precario estado de conservación de sus edificaciones.

Los resultados de la investigación en los espacios construidos dan una muestra de la gran cantidad de soluciones espaciales en la edificación de los espacios sagrados, portales mágicos, o lugares de la abundancia inagotable de los antiguos mayas. También tuvimos resultados de como estos centros urbanos se ubican en el paisaje. El estudio comprueba una selección de posiciones de los centros urbanos mayas para controlar su entorno y contar entre si con una relación visual. Esto como una forma de comunicación rápida en toda la región.

De la división inicial por cuencas naturales (6 cuencas) se llegó a dividir el paisaje en dos grandes grupos. Uno al norte (79\%) formado por cuatro cuencas llamada los "grande humedales" y otra al sur con dos cuencas (21\%). Cada una con sus diferencias naturales y culturales analizadas en la primera y segunda parte de este documento. Las características de ubicación y composición arquitectónica son comparadas en relación a estos paisajes, confirmando ya, en forma preliminar, ya diferencias internas en la composición arquitectónica de la región.

Para dar una idea del tamaño de los centros urbanos se tomaron dos indicadores; este método comprobó la alta concentración de centros urbanos monumentales en la región con dos súper centros urbanos 
(Tikal y El Mirador), dos centros muy grandes (Naranjo y La Honradez) y nueve centros grandes.

Los resultado presentados en la segunda parte, de este documento, confirman que la metodología empleada (cinco niveles de elementos del espacio construido) nos da respuesta sobre el espacio construido de los centros urbanos mayas y deja claro las limitaciones actuales para profundizar en este tipo de estudios. Situación que debe ser motivo de nuevos planteamientos y proyectos de inversión e investigación en el noreste de Petén. En la investigación sobre la composición urbana (segundo nivel), se logró identificar 34 elementos y cerca de 87 variantes. El estado actual de los sitios arqueológicos, en condición de ruina arqueológica, abandonados, cubiertos de escombros, humus, saqueos, vegetación y sin investigación, impide profundizar el estudio. En el proceso de análisis se tuvieron que eliminar de los cuadros resumen algunos elementos identificados, ya que no era posible asegurar su existencia, muy probable, en otros espacios similares. Esta limitante se agudiza al querer analizar los otros niveles (elementos de arquitectura, sistemas constructivos y materiales). Por ejemplo en el tercer nivel "elementos de arquitectura", la información de la muestra es limitada y contrasta grandemente con sectores ya investigados con abundante arquitectura expuesta. Esto sucede en la Acrópolis de Nakum y la Acrópolis Central de Tikal; con casi el 50\% de los edificios expuestos en toda la región del estudio. El contraste de estos dos grupos con otros sectores con la misma estructura compositiva, pero cubiertos por la vegetación, humus y escombros es enorme. Mas difícil aún son los niveles cuarto y quinto, pues al igual que en los casos anteriores los datos aquí presentados se basan en los pocos lugares visibles y trabajados, que no reflejan la condición mayoritaria de la muestra. Sin embargo esta investigación es la primera que se realiza con esta 
magnitud regional, y pretende ser una base sólida para registrar los elementos urbanos que identifican a la región noreste de Petén.

Una pregunta planteada a principio de este trabajo fue tratar de definir el Ilamado "estilo Petén", esta respuesta todavía no puede ser contestada científicamente. Si hemos conseguido una mayor información sobre las formas constructivas locales pero este tema deberá ser objeto de otro estudio.

Se pudo constatar que un instrumento estratégico en la construcción del espacio son las plataformas y sus superposiciones. Éstos y los espacios libres (plazas, patios y calzadas) tejen la estructura urbana. El otro componente son los edificios (horizontales y verticales); construcciones que son colocadas sobre plataformas diversas para marcar las relaciones urbanas de cada espacio construido.

En términos generales podríamos caracterizar a los edificios del Clásico de la siguiente forma:

- En los lienzos verticales de las fachadas predomina la masa lisa $\sin$ decoraciones sobre las aberturas (puertas).

- La simetría de las fachadas con acceso central dominante (más ancho).

- Los muros de las fachadas laterales y trasera, pueden tener remetimientos o salientes de paredes (efectos de sombra que acentúan verticalidad), a veces con ventanas simuladas.

- En los techos se concentra la información escultórica de los edificios; en dos partes, uno en lienzos horizontales (frisos) en donde se colocan esculturas en alto y bajo relieve, y otro en las cresterías (torres verticales). En algunos casos las cresterías pueden llegar a tener más de $12 \mathrm{~m}$ de altura. 
- Grupos triádicos. En el segmento de los grandes humedales, estos elementos urbanos evolucionan desde el Preclásico Tardío acompañando las superposiciones de los centros urbanos, uno sobre otros hasta llegar al Clásico Terminal con los templos pirámide triádicos en patios y los monumentales grupos triádicos en plazas, verdaderos sellos locales.

- Grandes acrópolis. Una característica particular de las cuencas, área Tikal, Ixcán y Holmul son los monumentales grupos de patios (elevados y no elevados) del Clásico Tardío y Terminal. Estos grupos de patios son verdaderos gigantes que dominan la estructura urbana. En estos grupos se encuentra la mayoría de variantes de edificios de la región y son, en si, especie de ciudadelas restringidas para los poderosos grupos de élite. En estos grupos se encuentra todo el esplendor posible en secuencias de patios a diferentes alturas. Una particularidad son los muros lisos de edificios colocados en los límites, formando verdaderas barreras físicas.

- Templos pirámide aislados en posición dominante frente a plazas principales. En la base piramidal con la superposición de plataformas escalonadas se muestran, según la época cultural, diferentes detalles constructivos (esquinas redondeadas, esquinas remetidas y otros). En el edificio en lo alto se presentan las proporciones, manejo de las superficies e información con estricto rigor.

Otras característica importantes, son dos elementos que acompañan la evolución urbana de los centros mayas; uno los grupos de edificios 
de conmemoración al sol (grupos E) y el otro, las canchas para el juego de pelota. Estos elementos son similares en otras regiones vecinas al área del estudio.

Una característica local identificada en dos sitios de la cuenca Ixcán son edificios que en la parte exterior cumplen con las disposiciones de proporción tradicional local: plataforma base, espacio vertical de paredes y techos (incluyendo la crestería), pero en el interior el espacio no se divide creando un recinto único sin divisiones.

Solamente en Naachtún se ubico un paramento de muro diferente a la generalidad, este muro tiene diseños en los bloques de piedra.

Otras características locales, están anotadas en la segunda parte de este documento. Para mayor propiedad en la descripción de las características locales deberán realizarse más estudios en este campo. Aquí damos una metodología para continuar con las investigaciones de la composición arquitectónica específica del noreste de Petén.

Otros recorridos, no anotados en la muestra de este trabajo, nos indican que la relación compositiva de la arquitectura del noreste de Petén se orienta más hacia el norte del departamento en los estados de Campeche y Quintana Roo y hacia el este, en Belice. La "relación" es mas fuerte que con los cuadrantes noroeste y sureste de Petén. Este es un tema que debe seguir investigándose. Seguramente estos estudios nuevos encontrarán muchas similitudes y otros elementos formales y compositivos que ayudarán a definir las barreras territoriales del estilo Petén o quizá, mejor dicho, de las tierras bajas centrales. 
El segundo grupo de conclusiones corresponden a las preguntas ¿Cómo está el patrimonio monumental construido en piedra? y ¿Qué hacer para conservar este numeroso patrimonio edificado?

La investigación sobre el estado de conservación del patrimonio edificado también ratificó la situación de emergencia en que se encuentra el patrimonio monumental maya. Se constató que hacen falta acciones rápidas de rescate para evitar la perdida de elementos tangibles expuestos y en peligro, y que el abandono institucional y el vandalismo continuo imperando en la región. Esta actividad ilegal, en los últimos 50 años, ha causado grandes daños al patrimonio edificado. En los registros actualizados sobre el saqueo se identificaron más de 5700 depredaciones. El territorio con mayor actividad ilícita es la cuenca Mirador (con trabajos muy urgentes en los sitios de La Muralla, Naachtún y Tintal), luego la cuenca Ixcán con la prioridad uno debido a que en este sector las depredaciones han afectado grandemente la estabilidad de las edificaciones (Río Azul, Kinal, Chochkitam, Xmakabatún, La Honradez y Xultún). En tercera prioridad están las cuencas de Holmul (Holmul y Witzná) y el área Tikal (El Zotz y El Diablo).

El escenario actual (con aproximadamente 4000 edificaciones registradas) determina que las medidas de conservación se dividan en tres tipos de acciones

- El primer grupo representa a los sitios arqueológicos con edificaciones sin arquitectura visible en peligro, o sea en condición de montículo, cubierto por escombros, humus y vegetación (62\% de los edificios identificados) Este grupo tiene arquitectura expuesta reciente por actividades de saqueo. Pero por el momento, su 
condición no presenta riesgos de perder elementos arquitectonicos importantes.

- El segundo grupo tiene la misma condición al primero, o sea la mayoría de las edificaciones se encuentran cubiertas, pero en algunos edificios aparece arquitectura expuesta o visible en peligro de colapso. Esta condición presenta secciones de arquitectura visible, por ejemplo segmentos de muros y techos. También en este grupo las bandas de saqueadores que buscan tesoros dentro de los edificios hacen túneles y trincheras de saqueos y ahora representan la condición de edificios con arquitectura visible en peligro (38\%). Esto significa que aproximadamente unos 1500 segmentos de superficie de edificaciones mayas requieren trabajos de rescate.

- El tercer grupo es parte del segundo y se refiere a las edificaciones ya intervenidas o en proceso de intervención realizadas entre 1959 y 2007 que representan un $11.2 \%$ de los edificios con arquitectura expuesta en peligro. (168 edificios). Este grupo presenta intervenciones totales o parciales, buenas y malas, necesarias 0 innecesarias. La gran mayoría se encuentran en el conjunto TikalUaxactún (96 edificios) y en el área del triángulo cultural YaxháNakum-Naranjo (con 58 edificios). A este grupo hay que agregar otros edificios importantes, ejemplos imprescindibles de la arquitectura local, que requieren atención inmediata. Entre las prioridades muy urgentes por atender se han identificado 34 edificios más con categoría muy urgente y 20 con categoría urgente. Estos edificios con arquitectura en peligro de colapso deberían ser las prioridades de intervención en le corto y mediano plazo.

Debe haber una estrategia general en donde se indique que, primero, se debe lograr la estabilidad de las edificaciones mayas en 
peligro de perderse, ya que es un patrimonio no renovable, y luego pasada la emergencia regional, atender otras ramas de la ciencia que podrían aclararnos aspectos que hacen falta conocer. Por ejemplo ¿por qué desaparece la actividad constructiva monumental de la zona en pleno esplendor cultural?, otro tema debería investigar y conocer mejor los sistemas constructivos y la forma de producir ciudades.

El tercer grupo de conclusiones responde a ¿Como se debe intervenir este patrimonio en peligro?

En este aspecto el estudio pretende sistematizar un proceso de conservación, adaptado a las condiciones actuales del noreste de Petén, (estado de emergencia). Esta propuesta está fundamentada en el trabajo realizado en 19 años en el campo y en los resultados de las investigaciones efectuadas. Para orientar las acciones físicas sobre los edificios monumentales mayas se diseñó un concepto de conservación particular para la región. La metodología considera un equipo multidisciplinario y muchas fases, visiones y acciones que han dado resultado válido para atender la condición actual del patrimonio monumental maya de la región. Los procedimientos aquí sugeridos han sido tratados en campo y se ha entrenado personal del Ministerio de Cultura y Deportes para continuar con la tarea.

Entre los factores que determinan el estado de conservación del patrimonio cultural prehispánico, está el vandalismo cultural. Estas agresiones aunadas a la antigüedad de las edificaciones, las condiciones climáticas, vegetación sin control, el abandono institucional y la actitud de los moradores actuales (Construyendo poblados sobre sitios arqueológicos, carreteras partiendo en dos sitios mayas o haciendo cultivos sobre los restos prehispánicos) 
determinan el precario estado de conservación de los monumentos y sitios mayas. Por lo tanto es necesario inculcar un sentido de urgencia para abordar la conservación del patrimonio edificado monumental maya en el noreste de Petén.

En la década de 1960 se planteó, por primera vez en el departamento, la idea de preparar fachadas de edificios mayas para ser expuestos al visitante. En términos muy generales esta idea de preparar superficies de edificios para impresionar al visitante, continúa hasta nuestros días y es una practica común en las regiones vecinas de México y Belice. .

Históricamente, la mayoría de los proyectos arqueológicos con permiso de trabajar en el Petén no consideran hacer trabajos de conservación en los edificios que investigan; sólo aisladas y recientes excepciones consideran realizar trabajos de rescate de edificios en peligro o se documentan y rellenan los saqueos.

Un caso diferente es el proyecto de inversión "Proyecto Nacional Tikal" (PRONAT) del Ministerio de Cultura y Deportes de Guatemala que tiene ya una larga tradición de trabajos de investigación y restauración en Petén. Este proyecto de inversión cuenta con más de 70 edificios intervenidos en: Tikal, Uaxactún, Topoxté, Yaxhá, Nakum, San Clemente, Naranjito, Poza Maya, Corozal Torre y otros. Ahora estos edificios restaurados y sus ciudades investigadas son un testimonio tangible ya preparado para recibir visitantes y procurar una economía local a través del turismo. Al mismo tiempo los sitios arqueológicos "habilitados" permiten procurar un sentido de identidad local. 
En el triángulo cultural se realizaron trabajo en gran escala. Aquí no fue aplicable el procedimiento de la "escuela Tikal" por eso se buscó una solución más integral y más adecuada al medio ambiente selvático, incorporando un sentido de visualización del espacio urbano. Este planteamiento se contrapone al "efecto sorpresa" empleado en Tikal, en donde sólo sectores de fachada son preparados para impactar al visitante.

El urbanismo se explica con la arquitectura del paisaje y el control de la vegetación sobre los edificios y las plazas y patios, de tal forma que los grandes rasgos son visibles para el visitante. También los edificios que requieren intervención no son tratados como fachadas sino en su conjunto o sea en forma integral. La razón obedece a buscar la estabilidad estructural del edificio y no a la búsqueda de tesoros escondidos en su interior.

En otro aspecto, uno de los logros más notorios fue haber preparado y activado el espacio conocido como triángulo cultural Yaxhá-NakumNaranjo. Este proyecto piloto convirtió un grupo de ciudades mayas en un Parque Nacional (2003). Parque que ahora participa en el desarrollo económico y cultural del departamento.

En relación a la toma de conciencia del valor cultural del patrimonio maya, una forma de convencer a los vecinos es realizando proyectos (ejecución) enseñando así a los nuevos pobladores que los vestigios culturales son importantes y que deben protegerse, usarse y disfrutarse. Ejemplos como San Clemente, en el marco del triángulo cultural Yaxhá-Nakum-Naranjo, impactan a las poblaciones vecinas y activan la conciencia local. Otros intentos de participación comunitaria se han realizado en El Remate, Uaxactún y La Máquina. Con pequeños esfuerzos deberían prepararse los sitios estratégicos 
en circuitos combinados (naturaleza, artesanías, gastronomía, arqueología) para un uso y disfrute local y como fuente de ingresos a través del turismo. El efecto positivo en el triángulo cultural YaxháNakum-Naranjo es palpable en los vecinos quienes, de repente, empiezan a tener interés en su entorno y ver que es posible obtener recursos económicos adicionales si se mantienen y presentan los sitios mayas; por eso es importante integrar, capacitar y educar a los pobladores vecinos. El manejo de las zonas arqueológicas puede ser una fuente de trabajo continua y gratificante.

No es válido hacer copias de fantasía para entretener a los turistas. El verdadero valor de los bienes culturales prehispánicos es su conservación duradera manteniendo su calidad histórica y no con falsificaciones de fachadas seudo mayas.

Hacen falta poner en marcha un plan estratégico que involucre todos los aspectos y prioridades de actuación en el corto, mediano y el largo plazo con más proyectos de inversión que investiguen y preparen al mismo tiempo los sitios estratégicos. Especial interés debe ponerse en los 16 proyectos de inversión identificados en este estudio.

En la búsqueda de un procedimiento de conservación que pueda aplicarse a la generalidad del recurso cultural del área de estudio, se comprobó que un control de la vegetación sobre los espacios construidos mayas es una forma de conservación preventiva, mucho más accesible a nuestra condición actual y a la gran tarea por realizar en todo el territorio. No requiere mayores inversiones y se puede realizar periódicamente con personal entrenado a un relativo bajo costo. Esta técnica aunada a los procedimientos diseñados para 
la arqueología de rescate y arquitectura preventiva pueden revertir en el corto y mediano plazo la condición de emergencia actual.

De nada sirve saber que el noreste de Petén tiene una condición patrimonial excepcional, si este bien no es parte de la conciencia actual de los guatemaltecos. La condición de ser un territorio retirado y sin poblados cercanos (la parte central y norte del cuadrante) con una "imagen" de ciudades mayas perdidas en la selva continua, puede ser el elemento de su conservación e incorporación actual como un territorio patrimonial especial. En este campo la conservación preventiva debería ser el primer eje de desarrollo para toda la región. El carácter de zona de difícil acceso debe mantenerse, la selva continua debe perpetuarse y declarar la zona como un territorio monumental "frágil" que no permite, por decir algo un turismo masivo, sino que debe manejarse como un territorio de experiencia personal y especializado, en donde las huellas históricas y autenticas de los mayas se presenten en simbiosis con la inmensa selva tropical.

El verdadero valor universal del patrimonio monumental maya en Petén, de categoría patrimonio de la humanidad de UNESCO, es conservar su calidad y autenticidad. El reto es incorporar este patrimonio con propiedad y sabiduría a la vida contemporánea y asegurar su continuidad futura.

En el Yaxhá-Nakum-Naranjo se realizaron trabajo en gran escala. Aquí no fue aplicable el procedimiento de la "escuela Tikal" por eso se busco una solución mas integral y mas adecuada al medio ambiente selvático, incorporando un sentido de visualización del espacio urbano. Este planteamiento se contrapone al "efecto sorpresa" empleado en Tikal, en donde solo sectores de fachada son 
preparados para impactar al visitante. El urbanismo se explica con la arquitectura del paisaje y el control de la vegetación sobre los edificios y las plazas y patios, de tal forma que los grandes rasgos son visibles para el visitante. También los edificios que requieren intervención no son tratados como fachadas sino en su conjunto o sea en forma integral. La razón obedece a buscar la estabilidad estructural del edificio y no a la búsqueda de tesoros escondidos en su interior, o satisfacer fachadas preparadas para políticos interesados en crear rápidos escenarios fantasiosos para el turismo.

En otro aspecto, uno de los logros mas notorios fue haber preparado y activado el espacio conocido como triángulo cultural Yaxhá-NakumNaranjo. Este proyecto piloto convirtió un grupo de ciudades mayas en un Parque Nacional (2003). Parque que ahora participa en el desarrollo económico y cultural del departamento.

En relación a la toma de conciencia del valor cultural del patrimonio maya, una forma de convencer a los vecinos es realizando proyectos (ejecución) enseñando así a los nuevos pobladores que los vestigios culturales son importantes y que deben protegerse, usarse y disfrutarse. Ejemplos como San Clemente en el marco del triángulo cultural Yaxhá-Nakum-Naranjo impactan a las poblaciones vecinas y activan la conciencia local. Otros intentos de participación comunitaria se han realizado en, El Remate, Uaxactún y La Máquina. Con pequeños esfuerzos deberían prepararse los sitios estratégicos en circuitos combinados (naturaleza, artesanías, comida, arqueología) para un uso y disfrute local y como fuente de ingresos a través del turismo. El efecto positivo en el triángulo cultural Yaxhá-NakumNaranjo es palpable en los vecinos, quienes de repente empiezan a tener interés en su entorno y ver que es posible obtener recursos 
económicos adicionales si se mantienen y presentan los sitios mayas.

No es válido hacer copias de fantasía para entretener a los turistas. El verdadero valor de los bienes culturales prehispánicos es su conservación duradera manteniendo su calidad histórica y no con falsificaciones de fachadas seudo mayas.

Hacen falta poner en marcha un plan estratégico que involucre todos los aspectos y prioridades de actuación en el corto, mediano y el largo plazo con más proyectos de inversión que investiguen y preparen al mismo tiempo los sitios estratégicos. Especial interés debe ponerse en los 16 proyectos de inversión identificados en este estudio.

En la búsqueda de un procedimiento de conservación que pueda aplicarse a la generalidad del recurso cultural del área de estudio, se comprobó que un control de la vegetación sobre los espacios construidos mayas es una forma de conservación preventiva, mucho más accesible a nuestra condición actual y a la gran tarea por realizar en todo el territorio. No requiere mayores inversiones y se puede realizar periódicamente con personal entrenado a un relativo bajo costo. Esta técnica aunada a los procedimientos diseñados para la arqueología de rescate y arquitectura preventiva pueden revertir en el corto y mediano plazo la condición de emergencia actual.

De nada sirve saber que el noreste de Petén tiene una condición patrimonial excepcional, si este bien no es parte de la conciencia actual de los guatemaltecos. La condición de ser un territorio retirado y sin poblados cercanos (la parte central y norte del cuadrante) con una "imagen" de ciudades mayas perdidas en la selva continua, puede ser el elemento de su conservación e incorporación actual como un territorio patrimonial especial. En este campo la 
conservación preventiva debería ser el primer eje de desarrollo para toda la región. El carácter de zona de difícil acceso debe mantenerse, la selva continua debe perpetuarse y declarar la zona como un territorio monumental "frágil" que no permite, por decir algo un turismo masivo, sino que debe manejarse como un espacio de experiencia personal y especializado, en donde las huellas históricas y autenticas de los mayas se presenten en simbiosis con la inmensa selva tropical.

El verdadero valor universal del patrimonio monumental maya en Petén, de categoría patrimonio de la humanidad de UNESCO, es conservar su calidad y autenticidad. El reto es incorporar este patrimonio con propiedad y sabiduría a la vida contemporánea y asegurar su continuidad futura. 
BIBLIOGRAFÍA

378 
2000 Plan Maestro 2006-2010, Parque Nacional Yaxha-NakumNaranjo

Consejo Nacional de áreas Protegidas, Ministerio de Cultura y Deportes, Dirección General del Patrimonio Cultural y Natural y The Nature Conservancy, Guatemala.

ACEVEDO, Renaldo y Ana Maria PAZ BONE

2005 Patrón de asentamiento en el Clásico Tardío, en: El Período Clásico en Uaxactun, Guatemala, arqueológica en el centro de Petén, Juan Antonio Valdés (ed.), pp.166-172, Instituto de Investigaciones Históricas, Antropológicas y Arqueológicas, Escuela de Historia, USAC, Guatemala.

ADAMS, Richard E. W.

1990 Archaeological Research at the Lowland Maya City of Río Azul, en: Latin American Antiquity, No. 1, pp. 23-41.

1986 Archaeologists Explore Guatemala: A Lost City of the Maya: Río Azul, en: National Geographic, Vol. 169, No. 4, pp. 420451, Washington. D.C.

ADAMS, Richard y Richard C. JONES

1981 Patrones espaciales y crecimiento del clásico maya, en: American Antiquity, Vol. 46, No. 2, pp. 301-322.

ANDREWS, George F.

1975 Maya Cities, placemaking and urbanization, University of Oklahoma Press: Norman, Oklahoma.

ANDREWS, George F., Paul GENDROP Y Juan Antonio SILLER

1985 Elementos arquitectonicos del Puuc floreciente, en: Cuadernos de Arquitectura Mesoamericana, No. 5, pp. 4750, UNAM, México D. F.

BAUER, Jeremy R, Ángel CASTILLO, Daniel LEONARDO, Mónica ANTILLÓN, Antolín VELÁSQUEZ, Jennifer M. JOHNSON y Joel ZOVAR.

2005 El pasado preclásico y monumental de la región de Holmul: resultados de las temporadas de campo 2003 y 2004 en Cival, Petén, en: XVIII Simposio de Investigaciones 
Arqueológicas en Guatemala, 2004, Juan Pedro Laporte, Bárbara Arroyo y Héctor L. Escobedo (eds.), pp. 201-213. Ministerio de Cultura y Deportes, Asociación Tikal y FAMSí, Guatemala.

BECKER Marshall, Joseph

1986 El patrón de asentamiento en Tikal, Guatemala y otros sitios mayas de las tierras bajas: implicaciones para el cambio cultural, en: Mayab, No. 2, pp. 7-20, Madrid.

BERLIN, Heinrich

1967 The destruction of structure 5D-33-1 ${ }^{\text {st }}$ at Tikal, en: American Antiquity, Vol. 32, No. 2, pp. 241-244.

1951 Breves estudios arqueológicos: El Petén, Guatemala en: Antropológia e Historia de Guatemala, vol III, No. 2, pp.1-8 Ministero de Educación, Guatemala.

BILOM, Frans

1926 El observatorio más antiguo del continente americano, en: Anales de la Sociedad de Geografia e Historia de Guatemala 2/3, pp. 335-338, Guatemala.

BULLARD, William R. Jr.

1960 Maya Settlement Pattern in North-eastern Petén, Guatemala, en: American Antiquity, Vol. 25, No. 3, pp. 355372.

CALDERÓN, Zoila y Bernard HERMES

2005 Chultunes en los alrededores de la laguna Yaxha, Peten, en: XVIII Simposio de Investigaciones Arqueológicas en Guatemala, 2004, Juan Pedro Laporte, Bárbara Arroyo y Héctor E. Mejía. (eds.), pp. 117-136, Ministerio de Cultura y Deporte, Asociación Tikal y FAMSI, Guatemala.

CARRASCOSA MOLINER, Begonia y Montserrat LASTRAS PÉREZ

2007 Conservación in situ. Revestimientos interiores de los edificios $6 \mathrm{~J} 1$ y $6 \mathrm{~J} 2$, en: La Blanca y su entorno. Cuadernos de arquitectura y arqueología maya, Cristina Vidal Lorenzo y Gaspar Muñoz Cosme (eds.), pp. 29-38, Agencia Española de Cooperación Internacional y Universidad Politécnica de Valencia, Valencia.

2006 Tratamiento de conservación y restauración del cuarto de los grafitos, en: La Blanca arquitectura y clasicismo, Gaspar 
Muñoz Cosme y Cristina Vidal Lorenzo (eds.), pp. 79-87, Ediciones Universidad Politécnica de Valencia, Valencia.

2005 La salvaguarda del Patrimonio Maya. Formación conservación y restauración, en: Actas del II Congresos Internacional de Patrimonio Cultural y Cooperación al Desarrollo, Gaspar Muñoz Cosme y Cristina Vidal Lorenzo (coros.), pp.143-153, editorial Universidad Politécnica de Valencia, Valencia.

CARR, Robert E. y James E. HAZARD

1961 Map of the Ruins of Tikal, Guatemala, en: Tikal Report 11, University Museum, University of Pennsylvania, Philadelphia.

CHASE, Arlene F

1990 Maya Archaeology and Population Estimates in the Maya Lowlands, en: Precolumbian Population History in The Maya Lowlands, Patrick Culbert y Don S. Rice (eds.), pp. 149-166, University of New Press, Albuquerque.

1983 A Contextual consideration of the Tayasal-Paxcaman zone el Petén, Guatemala, tesis de doctorado University Microfilms International, Ann Arbor, Michigan.

CHOCÓN, Jorge E., Heidy QUEZADA y Héctor MEJíA

1999 Acrópolis de El Chilonché: resultados de los sondeos y excavaciones, en: XII Simposio de Investigaciones Arqueológicas en Guatemala, 1998, Juan Pedro Laporte y Héctor L. Escobedo (eds.), pp. 301-326, Ministerio de Cultura y Deportes, Asociación Tikal, Guatemala.

CIUDAD RUIZ Andrés, María Josefa IGLESIAS PONCE DE LEON y María del Carmen MARTÍNEZ MARTíNEZ (eds.)

2001 Las Ciudades Mayas: El urbanismo en las sociedades antiguas, en: Sociedad Española de Estudios Mayas, Publicación No.6, Madrid.

COARSA

1999 Proyecto de restauración Templo III de Tikal, Informe final presentado por Corporación Arqueológica S. A. Guatemala.

COE, William

1990 Excavation in the Great Plaza, North Terrace and North Acropólis of Tikal, Tikal Report No.14, University Museum 
Monograph 61, University Museum,

Pennsylvania, Philadelphia.

1967 Tikal: A Handbook of the Ancient Maya Ruins. The University Museum, University of Pennsylvania, Philadelphia.

1965 Tikal: Ten Years of Study of a Maya Ruins in the Lowlands of Guatemala, en: Expeditions, Vol. 8, Nr. 4, pp. 5-56, The University Museum Magazine of Archaeology and Anthropology, University of Pennsylvania, Philadelphia.

COGGINS Clemency

1992 Tráfico de antigüedades y la respuesta de los Estados Unidos, en: Arqueología de Rescate, The Preservation Press pp. 74-79, Washington D.C.

1972 Archaeology and the Art Market, en: Science 21, pp. 263266.

1970 The Maya Scandal: How Thieves Strip Sites of Past Cultures, en: Smithsonian, pp.8-16

1969 Illicit Traffic of Pre-Columbian Antiquities, en: Art Journal, pp. 94- 98.

CULBERT, Patrick, Laura KOSAKOWSKY, Robert FRY y William HAVILAND

1990 The population of Tikal, Guatemala, Pre-Columbian Population History, en: The Maya Lowlands, Patrick Culbert y Don Rice (eds.), pp. 103-121. The University of New México Press, Alburquerque.

DOMENECH CARBÓ, María Teresa y María Luisa VÁSQUEZ DE ÀGREDOS PASCUAL

2006 Pigmentos, aglutinantes y estucos, composición químicaanalítica, en: La Blanca, arquitectura y clasicismo, Gaspar Muñoz Cosme y Cristina Vidal Lorenzo (eds.), pp. 129-148, Ediciones Universidad Politécnica de Valencia, Valencia.

2005 La caracterización química del color; en: La Blanca arqueología y desarrollo, Gaspar Muñoz Cosme y Cristina Vidal Lorenzo (eds.), pp. 127-138. Valencia.

ECO, Umberto

1972 Einführung in die Semiotik, Wilhelm Fink, München. 
ESTRADA-BELLI, Francisco, Jeremy BAUER, Michael CALLAGHAN, Nina NEIVENS, Antolín VELÁSQUEZ y Josué CALVO

2006 Las épocas tempranas en el área de Holmul, Peten, en: XIX Simposio de Investigaciones Arqueológicas en Guatemala 2005, Juan Pedro Laporte, Bárbara Arroyo y Héctor L. Escobedo (eds.), pp. 639-647, Ministerio de Cultura y Deportes, Asociación Tikal y Fundación Arqueológica del Nuevo Mundo, Guatemala.

ESTRADA-BELLI, Francisco y Jennifer FOLEY

2004 Arqueología e historia de enlaces geo-políticos: El clásico temprano en La Sufricaya, en: XVII Simposio de Investigaciones Arqueológicas en Guatemala, 2003, Juan Pedro Laporte, Bárbara Arroyo, Héctor L. Escobedo y Héctor E. Mejía (eds.), pp. 863-870. Ministerio de Cultura y Deportes y Asociación Tikal, Guatemala.

ESTRADA-BELLI, Francisco, Judith VALLE, Chris HEWITSON, Mark WOLF, Jeremy BAUER, Molly MORGAN, Juan Carlos PEREZ, James DOYLE, Edy BARRIOS, Ángel CHAVEZ, y Nina NEIVENS

2004 Teledetección, Patrón de asentamiento en Holmul, Peten en: XVII Simposio de Investigaciones Arqueológicas en Guatemala, 2003, Juan Pedro Laporte, Bárbara Arroyo, Héctor L. Escobedo y Héctor E. Mejía (eds.), pp.73-83, Ministerio de Cultura y Deportes y Asociación Tikal, Guatemala.

FIALKO, Vilma

2005 Diez años de investigaciones arqueológicas en la Cuenca del Río Holmul, Región Noreste de Peten, en: XVIII Simposio de Investigaciones Arqueológicas en Guatemala, 2004, Juan Pedro Laporte, Bárbara Arroyo y Héctor E. Mejía (eds.), pp. 253-268, Ministerio de Cultura y Deportes, Asociación Tikal y FAMSI, Guatemala.

FLORES, Miguel y Ximena LEIVA

2000 Resultados del patrimonio natural, en: El sitios maya de Topoxte, investigaciones en una isla del lago Yaxhá, Petén, Guatemala, Wolfgang Wurster (ed.) pp. 280-89, Materialien zur Allgemeinen und Vergleichenden Archäologie, 57, Mainz.

FOLEY, Jennifer

2005 En busca de la población del clásico temprano en La Sufricaya, Petén, en: XVIII Simposio de Investigaciones Arqueológicas en Guatemala, 2004, Juan Pedro Laporte, 
Bárbara Arroyo y Héctor E. Mejía (eds.), pp. 215-223, Ministerio de Cultura y Deportes, Asociación Tikal y Famsi, Guatemala.

FORD, Anabel

2003 Crecimiento de población y complejidad social: un examen de asentamiento y medio ambiente en las tierras bajas mayas centrales, en: Serie monografías CIRMA y Plumsock. Mesoamerican Studies XVIII, Antigua Guatemala.

FORSYTH, Donald W.

1993 La Arquitectura Preclásica de Nakbe: Un estudio comparativo de dos períodos, en: VI Simposio de Investigaciones Arqueológicas en Guatemala, 1992, Juan Pedro Laporte, Héctor L. Escobedo y Sandra Villagrán de Brady (eds.), pp. 131-141, Ministerio de Cultura y Deportes y Asociación Tikal, Guatemala.

FUENTES, Marvin

1991 Informe de edificios con arquitectura en peligro de Nakum, manuscrito en biblioteca del PRONAT, Guatemala.

GALINDO, Juan

1834 A Short Account of Some antiquities Discovered in the District of Petén, en Central America, in: Archaeologies or Miscellaneous Tracts Relating to Antiquity, Society of Antiquarians, 25, 570, London.

GANN, Thomas

1928 Maya cities, a Record of Explorations and Adventures in Middle America, New York.

GARCÍA UREA, Carlos

1987 Tikal: el Monumental Mundo Perdido, Guatemala

GARCÍA DE MIGUEL, José María

1992 La caracterización de los materiales del Templo I maya de Tikal (Guatemala), Informe para la agencia Española de Cooperación Internacional y el Instituto de antropología e Historia de Guatemala, Madrid.

GEBSSLER, August y Wolfgang EBERL (eds.)

1980 Schutz und Pflege von Baudenkmälern in der Bundesrepublik Deutschland, ein Handbuch, Kohlhammer, Köln. 
GENDROP, Paul

1984a La problemática de la conservación, en: Cuadernos de Arquitectura Mesoamericana, No. 3, pp. 1-3, UNAM, México D. F.

1984b Quince Ciudades Mayas, Colección de Arte 31, UNAM, México D. F.

GÓMEZ, Oswaldo

1998 Nuevas excavaciones en el Templo V, Tikal, en: XI Simposio de Investigaciones Arqueológicas en Guatemala 1997, Juan Pedro Laporte y Héctor L. Escobedo (eds.), pp. 55-70, Ministerio de Cultura y Deportes y Asociación Tikal, Guatemala.

GONZÁLEZ, Breitner Roely,

$2006 \quad$ Análisis de la Arquitectura Expuesta del Sitio Prehispánico Nakum, tesis de licenciatura, pp. 459-554, Área de Arquitectura, Facultad de Arquitectura, USAC, Guatemala.

GONZÁLEZ CANO, Marcelino

1976 Términos de referencia para el Parque Nacional Tikal, Instituto de Antropología e Historia, Guatemala.

1973 La restauración de los centros arqueológicos prehispánicos de Guatemala, un enfoque crítico, en: Anales de la Sociedad de Geografía e Historia de Guatemala, Tomo XVLVI, enero-diciembre 1973, No. 1 al 4, Guatemala.

GRAHAM, Ian

1986a Looters Rob Graves and History, en: National Geographic, Vol. 169, No.4, pp. 453-460, Washington D. C.

1986b Corpus of Maya Hieroglyphic Inscriptions, Vol. 5 part 3: Uaxactún, Peabody Museum of Archaeology and Ethnology, Harvard University, Cambridge, Massachusetts.

1980 Corpus of Maya Hieroglyphic Inscriptions, Vol. 2 part 3: Ixkún, Ucanal, Ixtutz, Naranjo, Peabody Museum of Archaeology and Ethnology, Harvard University, Cambridge, Massachusetts.

1978 Corpus of Maya Hieroglyphic Inscriptions, Vol. 2 part 2 Naranjo, Chunhuitz, Peabody Museum of Archaeology and Ethnology, Harvard University, Cambridge, Massachusetts. 
1975 Corpus of Maya Hieroglyphic Inscriptions, Vol. 2 part 1: Naranjo, Peabody Museum of Archaeology and Ethnology, Harvard University, Cambridge, Massachusetts.

1965 Tesoros arqueológicos del Petén al extranjero, en: El Imparcial, 17 de julio, Guatemala.

1963 Across the Petén to the Ruins of Machaquila, en: Expedition, pp. 2-10.

GRAHAM, lan y Richard D. HANSEN

1997 History of a Continent in Jeopardy, en, Looting in Latin America, pp.17-23, International Council of Museum, UNESCO.

GRAZIOSO, Liwy, T. Patrick CULBERT, Vilma FIALKO, Thomas SEVER y Carmen RAMOS

2001 Arqueología en el bajo La Justa, Petén, Guatemala, en: XIV Simposio de Investigaciones Arqueológicas en Guatemala, 2000, Juan Pedro Laporte, Ana Claudia de Suasnávar y Bárbara Arroyo (eds.), pp. 205-209, Ministerio de Cultura y Deportes y Asociación Tikal, Guatemala.

GRAZIOSO, Liwy, Fred VALDEZ, Norma GARCÍA, Karen PEREIRA y Carmen RAMOS

2006 Río Azul vuelto a visitar: Nuevas investigaciones y orígenes preclásicos, en: XIX Simposio de investigaciones Arqueológicas en Guatemala, 2005, Juan Pedro Laporte, Bárbara Arroyo y Héctor L. Escobedo (eds.), pp. 673-682, Ministerio de Cultura y Deportes, Asociación Tikal y Fundación Arqueológica del Nuevo Mundo, Guatemala.

GRUBE, Nikolai

2004 La Historia Dinastica de Naranjo, Petén, en: Beiträge zur Allgemeinen und Vergleichenden Archäologie, 24, pp. 195213, Mainz.

2001 Los mayas. Una civilización milenaria, (ed.), Könemann, Colonia.

2000 Monumentos esculpidos e inscripciones jeroglíficas en el triángulo Yaxhá-Nakum-Naranjo, en: El sitio Topoxte. Investigaciones en unai isala del lago Yaxhá, Petén, Guatemala, Wolfgang W. Wurster (ed.), Beiträge zur Allgemeinen und Vergleichenden Archäologie, 57, pp. 249268 Mainz. 
GRUBE, Nikolai y Simon MARTIN

2001 La historia dinastica de los mayas, en: Los Mayas. Una civilización milenaria, Nikolai Grube (ed.), pp. 149-171, Könemann, Colonia.

GUARDADO, Luis

2006 Análisis de la arquitectura expuesta del sitio prehispánico Nakum, tesis de licenciatura, pp. 332-458 Área de Arquitectura, Facultad de Arquitectura, USAC, Guatemala.

GUILLEMIN, Jorge F

1968 Notas sobre restauración en los sitios de Tikal e Iximché, Guatemala, en: XXVIII Internationale Amerikanisten Kongress, pp.119-121, Stüttgart-München.

1967 Tikal, desarrollo y función del centro ceremonial, en: Sociedad de Geografía e Historia de Guatemala, Guatemala.

1964 Documentos entregados al director del IDAEH, octubre, archivos del IDAEH, Guatemala.

HAIRS, Joya

1973 Operación Rescate: Guatemala's Ansewr to the Problems of Plundering of Anciente Maya Sites, en; Atti del XL Congreso Internazionale degli Americanisti, Roma-Genova, Vol. 1, pp.189-193, Genova.

HAMOND, Norman

1975 Lubaantún, A classic Maya Realm, en: Peadoby Museum Monographs, No.2, Cambridge, Massachussets.

HANSEN, Richard D.

2000a Continuity and Disjunction: the Pre-Classic Antecedents of Classic Maya Architecture, en: Function and Meaning in Classic Maya Architecture, Stephen D. Houston (ed.), pp. 49-122, Dumbarton Oaks, Washington, D.C.

2000b Las primeras ciudades, principios del urbanismo y formación de ciudades en las tierras bajas mayas, en: Los Mayas. Una civilización milenaria, Nikolai Grube (ed.), pp. 50-65, Könemann, Köln

1996 El Clásico Tardío del norte de Petén, en: Utz’ib, Vol. 2 No.1, pp. 1-15, Asociación Tikal, Guatemala. 
1994 Las dinámicas culturales y ambientales de los orígenes Mayas: estudios recientes del Sitio Arqueológico Nakbe, en: VII Simposio de Investigaciones Arqueológicas en Guatemala, 1993, Juan Pedro Laporte, Héctor L. Escobedo (eds.), pp. 369-387. Ministerio de Cultura y Deportes y Asociación Tikal, Guatemala.

1990 Excavations in the Tigre complex, El Mirador, Petén Guatemala. Papers of the New World, Archaeological Foundation, No. 62, Brigham Young University. Provo, Utah.

HANSEN, Richard D., Beatriz BALCÁRCEL, Edgar SUYUC, Héctor E. MEJÍA, Enrique HERNÁNDEZ, Gendry VALLE, Stanley P. GUENTER y Shannon NOVAK.

2006 Investigaciones arqueológicas en el sitio Tintal, Petén, en: XIX Simposio de Investigaciones Arqueológicas en Guatemala, 2005, Juan Pedro Laporte, Bárbara Arroyo y Héctor L. Escobedo (eds.), pp. 683-694 Ministerio de Cultura y Deportes, Asociación Tikal y Fundación Arqueológica del Nuevo Mundo, Guatemala.

HANSEN, Richard D., Enrique MONTERROSO TUN, Antonieta CAJAS, Adriana LINARES Y Carlos MORALES.

2005 Un katun de espera en el Mirador, Petén, sondeos y reexcavación de la estructura 34 del preclásico tardío, en: XVIII Simposio de Investigaciones Arqueológicas en Guatemala, 2004, Juan Pedro Laporte, Bárbara Arroyo y Héctor E. Mejía (eds.), pp. 59-73, Ministerio de Cultura y Deportes, Asociación Tikal y FAMSI, Guatemala.

HANSEN, Eric F. y Carlos RODRÍGUEZ NAVARRO

2002 Los comienzos de la tecnología de la cal en el mundo maya: innovación y continuidad desde el preclásico medio al clásico tardío en Nakbe, Petén, Guatemala, en: Simposio de investigaciones arqueológicas en Guatemala, 2001, Juan Pedro Laporte, Héctor Escobedo y Bárbara Arroyo (eds.), pp. 203-206, Ministerio de Cultura y Deportes y Asociación Tikal, Guatemala.

HELLMUTH, Nicholas M.

1993 A report for IDAEH on research accomplished at the Maya ruins of Yaxha, Peten, Guatemala, and Foundation for Latin American Anthropological Research, Cocoa. 
HERMES, Bernard

2002 Síntesis preliminar de la ocupación prehispánica en el área central de Nakum, Wolfgang W. (ed.), pp. 277-285, AVAMaterialien, 22, Mainz.

2000a Entierro 49, en: El sitio Maya de Topoxte, Investigaciones en una isla del lago Yaxha, Petén, Guatemala, W. Wurster (ed.), pp. 127-143, AVA- Materialien, 57, Mainz.

2000b Resumen de la secuencia constructiva, en: El sitio Maya de Topoxte, Investigaciones en una isla del lago Yaxha, Petén, Guatemala, W. Wurster (ed.), pp. 58-63, AVA- Materialien, 57, Mainz.

HERMES, Bernard, Justyna OLKO y Jaroslaw ZRALKA

2002 Entre el arte elitista y el arte popular: los graffiti de Nakum, Petén, Guatemala, Mexicon, Vol. XXIV, No. 6, pp. 123-132.

HERMES, Bernard y Zoila CALDERÓN

2000 Chultunes, en: El sitio Maya de Topoxte, Investigaciones en una isla del lago Yaxhá, Petén, Guatemala, Wolfgang W. Wurster (ed.), pp. 66-74, AVA-Materialien, 57, Mainz.

HERMES, Bernard, Raúl NORIEGA y Zoila CALDERÓN

1997 Investigaciones Arqueológicas y trabajos de conservación en el edificio 216 de Yaxhá, en: Beiträge zur Allgemeinen und Vergleichenden Archäologie, 17, pp. 257-309, Mainz.

HOHMANN Hasso

1998 A Maya Palace in Mexico: Structure IV at Becán, Campeche, Academic Publishers, Graz.

1995 Die Architektur der Sepulturas-Region von Cópan in Honduras, 2 Volumenes, Academic Publisher, Graz.

1979 Gewölbekonstruktionen in der Maya-Arkitektur, en: Mexicon Vol. I, No.3, pp. 33-36.

HOHMANN, Hasso y Annegrete VOGRIN

1982 Die Architektur von Copan (Honduras), Akademische Druck-u. Verlagsanstalt, Graz, Austria.

HOHMANN-VOGRIN, Annegrete

2000a Die Einheit von Raum und Zeit - die Architecktur der Maya en: Maya Gottkönige im Regenwald, Nikolai Grube (ed.), pp. 94-215, Könemann, Köln. 
2000b El espacio estructurado y la visión del mundo, en Arquitectura e ideologia de los antiguos Mayas, Memoria de la segunda Mesa Redonda de Palenque, Silvia Trejo ( ed.) pp.35-54, Conaculta- INAH, México D.F.

1992 Struktur und Bedeutung der Stadt. Ein architekturtheoretischer Versuch am Beispiel der voreuropäischen Kulturen Mesoamerikas, Habilitationsschrift, Fakultät für Architektur der Technischen Universität Graz, Graz.

HOUSTON, Stephen, Héctor ESCOBEDO, Zachary NELSON, Juan Carlos MELENDEZ, Fabiola QUIROA, Ana Lucía ARROYAVE y Rafael CAMBRANES.

2007 A la sombra de un gigante: Epigrafia y asentamiento de El Zotz, Peten, en: XX Simposio de Investigaciones Arqueologicas en Guatemala, 2006, Juan Pedro Laporte, Bárbara Arroyo y Héctor E. Mejía (eds.), pp. 333-347, Ministerio de Cultura y Deportes, Asociación Tikal y Fundación Arqueológica del Nuevo Mundo, Guatemala.

HURST, Heather

2005 San Bartolo, Petén: Técnicas de pintura mural de Preclásico Tardío, en: XVIII Simposio de Investigaciones Arqueológicas en Guatemala, 2004, Juan Pedro Laporte, Bárbara Arroyo y Héctor E. Mejía (eds.), pp. 639-646. Ministerio de Cultura y Deportes, Asociación Tikal y FAMSI, Guatemala.

JONES Christopher

1969 Twin-Pyramid. Group Pattern: A Classic Maya Architectura Assemblage at Tikal, Guatemala. Doctoral dissertation, Department of Anthropology, University of Pennsylvania, Philadelphia.

LANDA, Diego de

1990 Bericht aus Yucatán, en: Reclam-Verlag, Leipzig.

LAPORTE, Juan Pedro

2006 Trabajos no divulgados del Proyecto Nacional Tikal, Parte 4: Rescate en El Zotz, San José, Peten, en: XIX Simposio de Investigaciones Arqueológicas en Guatemala 2005, Juan Pedro Laporte, Bárbara Arroyo y Héctor E. Mejía (eds.), pp. 877-894, Ministerio de Cultura y Deportes, Asociación Tika y Fundación Arqueológica del Nuevo Mundo, Guatemala. 

Sur del Mundo Perdido, Tikal (Grupo 6D-II), en: XVI Simposio de Investigaciones Arqueológicas en Guatemala, 2003, Juan Pedro Laporte, Bárbara Arroyo, Héctor L. Escobedo y Héctor E. Mejía (eds.), pp. 637-657, Ministerio de Cultura y Deportes y Asociación Tikal, Guatemala.

2001 Dispersión y estructura de las ciudades del sureste de Petén, en Reconstruyendo las ciudades Mayas: El urbanismo en las sociedades antiguas, Andrés Ciudad Ruiz, Mario Humberto Ruz Sosa y María Josefa Iglesias Ponce de León (eds.), pp. 137-162, Sociedad Española de Estudios Mayas, Madrid.

1986 Alternativas del clásico temprano en la relación TikalTeotihuacan, Grupo 6 C -XVI, Tikal, Peten, Guatemala, tesis doctoral, inédita, UNAM, México.

LAPORTE, Juan Pedro y Vilma FIALKO.

1995 Reporte Arqueológico Mundo Perdido, Tikal, manuscrito inédito, IDAEH, Guatemala.

LAPORTE, Juan Pedro, Héctor E. MEJÍA y Jorge E. CHOCÓN

2003 La cuenca del río Chiquibul en Petén, Guatemala: su asentamiento prehispánico, en: Mexicon, Vol. XXV. No. 3, pp. 78-84.

LAPORTE, Juan Pedro y Héctor E. MEJÍA

2006 La cuenca baja del río Mopán: El asentamiento arqueológico en Guatemala y Belice, en: Mexicon, Vol. XXVIII, No.3 pp. 52-57.

2002 Ucanal: una ciudad del río Mopán en Petén, Guatemala, en: Utz'ib, Serie Reportes. Vol. 1, No. 2, Guatemala.

2001 Los sitios arqueológicos de la cuenca del Río Salsipuedes en el Sureste de Petén, Guatemala, en: Mexicon, Vol. XXIII, No. 3, pp. 65-72.

2000 Registro de sitios arqueológicos en el sureste de Petén, en: Atlas Arqueológico de Guatemala, Reporte No. 14. Ministerio de Cultura y Deportes y USAC, Guatemala. 
LAPORTE, Juan Pedro, Oswaldo GÓMEZ y Lilian A. CORZO

1999 La cuenca media del Río Mopán, Petén, Guatemala, su Desarrollo Arqueológico, en: Mexicon Vol. XXI. No. 2 pp. 33-38

LARIOS, Rudy y Miguel ORREGO

1997 Términos de Referencia para la Conservación de Tikal, Patrimonio de la Humanidad, en: proyecto de conservación, Tikal, etapa I, Crisarq Consult, Guatemala.

LOU, Brenda

2000 Recorridos en tierra firme, en: El sitio Maya de Topoxte. Investigaciones en una isla del lago Yaxhá, Petén, Guatemala, Wolfgang Wurster (ed.), pp. 74-76, AVAMaterialien, 57, Mainz.

LUJÁN MUÑOZ, Jorge

1965 Dos estelas mayas sustraídas de Guatemala: Su presencia en Nueva York, en: revista de la Universidad de San Carlos, LXVII, pp. 125-138, Guatemala.

LUJÁN MUÑOZ, Luis

1974 Algunos problemas sobre la protección de los bienes culturales de Guatemala, en: Antropología e Historia, Vol. XXI, No. 1-2, pp. 3-21, Guatemala.

LUNDELL, Cyrus L.

1934 Ruins of Polol and Other archaeological Discoveries in the Department of Petén, Guatemala, Carnegie Institution of Washington, 436, Contribution to American archaeology, No. 8, pp. 175-186, Washington.

MALDONADO CARDENAS, Rubén y Beatriz RESPETTO TIÓ

2002 La conservación del patrimonio arqueológico en las tierras bajas del área maya, en: Espacio Sagrado. Arquitectura Maya en la obra de Teoberto Maler, Ma. Luisa Vázquez de Agredos Pascual (comisaria), pp.140-151, Universidad de Valencia, Valencia.

MALER, Teobert

1975 Bauten de Maya. Aufgenommen in den Jahren 1886 bis 1905, en: Monumenta Americana, IV, Gerd Kutscher (ed.) Gebr. Mann. Berlin.

1911 Explorations in the Department of Petén, Guatemala, Tikal. Report of Explorations for the Museum. Memory Peabody 
Museum of American Archaeology and Ethnology, Harvard University, Vol. 5, No. 1, Cambridge, Massachusetts.

1908 Explorations in the Department of Petén, Guatemala and Adjacent Region: Topoxte; Yaxha; Benque Viejo; Naranjo, en: Peabody Museum, Harvard University, Memoirs, Vol. 4 No. 2, pp. 55-127, Cambridge, Massachusetts.

MARQUINA, Ignacio

1964 Arquitectura Prehispanica, en: Memorias del Instituto Nacional de Antropología e Historia, México D.F.

MARTIN, Simon y Nikolai GRUBE

2000 Chronicle of the Maya Kings and Queens, Deciphering the Dynasties of the Ancient Mayas, Thames \& Hudson, London.

MARTíNEZ, Horacio, David WEBSTER, Jay SILVERSTEIN, Timothy MURTHA, Kirk STAIGHT e Irinna MONTEPEQUE

2004 Reconocimiento en la periferia de Tikal: Los terraplenes norte, oeste y este, nuevas exploraciones y perspectivas, en: XVII Simposio de Investigaciones Arqueológicas en Guatemala, 2003, Juan Pedro Laporte Bárbara Arroyo, Héctor L. Escobedo y Héctor E. Mejía (eds.), pp. 659-664. Ministerio de Cultura y Deportes y Asociación Tikal, Guatemala.

MATUTE, Varinia y Raúl NORIEGA

2005 Rescate arqueológico y restauración en Corozal Torre y Naranjito, Petén, en: XVIII Simposio de Investigaciones Arqueológicas en, Guatemala 2004, Juan Pedro Laporte Bárbara Arroyo y Héctor E. Mejía (eds.), pp. 137-144. Ministerio de Cultura y Deportes, Asociación Tikal y FAMSI, Guatemala.

MAUDSLAY, Alfred Percival

1889-1902 Biología Centrali Americana: Archaeology, 5 Vols: R. H. Porter and Dulac and Co. London.

MAYER, Karl Herbert

2006 The Maya Ruins of La Línea, Peten, Guatemala, en: Mexicon, Vol. XXVIII, No. 4, pp. 66-68.

2003 Monumentos trasladados y destruidos de Naranjo, Petén, en: UTz'ib, Vol. 3, No 5, pp. 15-25. Guatemala. 
2000 Geplünderte Maya-Monumente aus La Naya, Peten Guatemala, en: Indiana, 16, pp. 159-184. Berlín.

1998 An inscribed Maya stela at La Montura (Kinin), Peten, Guatemala, en: Mexicon, Vol. XX, No. 1, pp. 5-6.

1995 Stela 1 from Balamtún, Peten, Guatemala, en: Mexicon, Vol. XVII, No. 4, pp. 62.

1993 Naranjo Stela 12 in Geneva, en: Mexicon, Vol. XV, No. 1, pp 6.

1993 Recent Destruction at San Clemente, Peten. In: Mexicon, Vol. XV, No.3, pp. 49-50

1987 Mexico: Three Maya Stelas Returned to Guatemala. In: Mexicon, Vol. IX, No. 2, pp. 29-30.

1985 Catálogo de Esculturas Mayas de Prodedencia Desconocida, en: Cuadernos de Arquitectura Mesoamericana, No. 5, pp. 94. México, D.F

1980 Monumentos Arqueológicos de la Cultura Maya, en: Boletín de la Escuela de Ciencias Antropológicas de la Universidad de Yucatán, Año 8, No. 43, pp. 70-72. Mérida.

1977 Kunstraub im Dschungel: Die Plünderung und Zerstörung der Maya-Ruinen in Mittelamerika, en: Universum, 32 Jahrgang, Heft 2, pp. 56-60. Horn-Wien.

MEJÍA, Héctor E.

1999 Asentamientos prehispánicos en la cuenca baja del río Mopán, Peten, Guatemala, Tesis de licenciatura, Área de Arqueología, Escuela de Historia, USAC, Guatemala.

MEJÍA, Héctor, Heidy QUEZADA y Jorge E. CHOCÓN

1998 Un limite político territorial en el sureste de Peten, en: $X$ Simposio de Investigaciones Arqueológicas en Guatemala, 1997, Juan Pedro Laporte y Héctor L. Escobedo (eds.), pp. 171-190, Ministerio de Cultura y Deportes, Asociación Tikal, Guatemala. 
MEJÍA, Héctor, Gendry VALLE, Francisco CASTAÑEDA y Enrique HERNANDEZ

2007 Sobreviviendo a la selva: Patrón de asentamiento en la Cuenca Mirador, en: XX Simposio de Investigaciones Arqueológicas en Guatemala, 2006, Juan Pedro Laporte, Bárbara Arroyo y Héctor E. Mejía (eds.), pp. 241-265, Ministerio de Cultura y Deportes, Asociación Tikal y Fundación Arqueológica del Nuevo Mundo, Guatemala.

MÉNDEZ, Michelle, Telma TOBAR, Luis GUARDADO y Breitner GONZÁLEZ

2006 Análisis de la arquitectura expuesta del sitio prehispánico Nakum, Tesis de licenciatura, Facultad de Arquitectura, USAC, Guatemala.

MÉNDEZ, Modesto

1955 Descubrimiento de las ruinas de Tikal. Informe de corregidor del Petén Modesto Méndez, de 6 de marzo de 1848. Antropología e Historia de Guatemala, Vol. 7, No. 1, pp. 3 - 7. Guatemala.

MEYER, Karl Herbert

1992 Saqueo del pasado: Historia del tráfico internacional ilegal de arte, Fondo de Cultura Economica, Mexico D.F.

MORIARTY, Mathew D.

2005 Entre el centro y la periferia en la tierra de los señores "IK". Investigaciones recientes en sitios satelites de Motul de San José, Petén, en: XVIII Simposio de Investigaciones Arqueológicas en Guatemala, 2004, Juan Pedro Laporte, Bárbara Arroyo y Héctor E. Mejía (eds.) pp. 453-466 Ministerio de Cultura y Deportes, Asociación Tikal y Fundación Arqueológica del Nuevo Mundo, Guatemala.

MORLEY, Sylvanus G

1937/38 The Inscriptions of Petén. Carnegie Institution of Washington, 219, Washington, D.C.

MORLEY, Sylvanus G. y George W. BRAINERD.

1983 The Ancient Maya. Revised by Robert J. Sharer: Fourth Edition. Stanford University Press, Stanford, California.

MUÑOZ COSME, Alfonso

2006 La Acrópolis, en: La Blanca Arquitectura y clasicismo, Gaspar Muñoz Cosme y Cristina Vidal Lorenzo (eds.), pp. 
1-78, Ediciones Universidad Politécnica de Valencia, Valencia.

1999 La arquitectura maya, en: Los mayas. Ciudades Milenarias de Guatemala, Gaspar Muñoz Cosme, Cristina Vidal Lorenzo y Juan Antonio Valdés Gómez (comisarios), pp. 43-49, Ministerio de Educación y Cultura, Generalitat Valenciana y Ayuntamiento de Zaragoza.

1990 Laberintos, pirámides y palacios. Las fases arquitectónicos de la ciudad de Oxkintok, en: Oxkintok 3, pp. 99-111, Misión arqueológica de España en México, Ministerio de Cultura, Madrid.

1989 La arquitectura de Oxkintok, en: Oxkintok 2, pp. 138-148 Misión arqueológica de España en México, Ministerio de Cultura, Madrid.

\section{MUÑOZ COSME, Gaspar}

2007 El Palacio de Oriente, en: La Blanca y su entorno. Cuadernos de arquitectura y arqueología maya, Cristina Vidal Lorenzo y Gaspar Muñoz Cosme (eds.), pp.21-28, Ediciones Universidad Politécnica de Valencia, Valencia.

2006a Estructura urbana y arquitectura en La Blanca, Peten, en: XIX Simposio de Investigaciones Arqueológicas en Guatemala, 2005, Juan Pedro Laporte, Bárbara Arroyo y Héctor E. Mejía (eds.), pp. 309-316, Ministerio de Cultura y Deportes, Asociación Tikal y Fundación Arqueológica del Nuevo Mundo, Guatemala.

2006b Proporción y Arquitectura, en: La Blanca, arquitectura y clasicismo, Gaspar Muñoz Cosme y Cristina Vidal Lorenzo (eds.), pp. 27-36. Ediciones Universidad Politécnica de Valencia, Valencia.

2006c Introducción a la arquitectura maya, Biblioteca TC, General de Ediciones de Arquitectura, Valencia.

2005a Tipologías y sistemas constructivos de la arquitectura Maya de Petén, en: XVIII Simposio de Investigaciones Arqueológicas en Guatemala 2004, Juan Pedro Laporte, Bárbara Arroyo y Héctor E. Mejía (eds.), pp. 609-613. Ministerio de Cultura y Deportes, Asociación Tikal y FAMSI Guatemala. 
2005b La arquitectura palaciega de La Blanca, en: La Blanca Arqueología y desarrollo, Gaspar Muñoz Cosme y Cristina Vidal Lorenzo (eds.), pp. 25-33, ediciones universidad Politécnica de Valencia, Valencia.

2003 La arquitectura maya. El Templo I de Tikal, Tesis Doctoral, Universidad Politécnica de Valencia, Valencia.

2002 Teoberto Maler, un pionero en el estudio de la arquitectura maya, en: Espacio Sagrado. Arquitectura Maya en la obra de Teoberto Maler, Ma. Luisa Vázquez de Agredos Pascual (comisaria), pp.92-101, Universidad de Valencia, Valencia.

1999 Las ciudades y el medio natural, en: Los Mayas. Ciudades Milenarias de Guatemala, Gaspar Muñoz Cosme, Cristina Vidal Lorenzo y Juan Antonio Valdés Gómez (comisarios), pp. 25-29 Iber Caja, Ministerio de Educación y Cultura, Generalita Valenciana y Ayuntamiento de Zaragoza.

1998 Resultados finales de la restauración del templo I de Tikal en: XI Simposio de Investigaciones arqueológicas en Guatemala, Juan Pedro Laporte y Héctor Escobedo (eds.), pp. 43-54, Ministerio de Cultura y Deportes y Asociación Tikal, Guatemala.

1997a La conservación de edificios de fábrica pétreas en Tikal, en Criterios de Intervención Arqueológica en Ciudades Mayas, Juan Antonio Valdés (ed.), pp. 53-61, Instituto de Antropología e Historia de Guatemala, Guatemala.

1997b La restauración del Templo I "Gran Jaguar" de Tika (Guatemala), Loggia, No.2, pp. 20-29, Universidad Politécnica de Valencia, Valencia.

1997c El Templo V: su arquitectura, en: $X$ Simposio de Investigaciones Arqueológicas en Guatemala, Juan Pedro Laporte y Héctor L. Escobedo (eds.), pp. 293-307, Ministerio de Cultura y Deportes y Asociación Tikal, Guatemala.

1994 La esquina retranqueada como solución arquitectónica de talud tablero, en: VIII Simposio de Investigaciones Arqueológicas en Guatemala, 1993, Juan Pedro Laporte y Héctor L. Escobedo (eds.), pp. 523-535, Ministerio de Cultura y Deportes y Asociación Tikal, Guatemala. 
MUÑOZ COSME, Gaspar y Cristina VIDAL LORENZO (eds.)

2007a Tipología palaciega de la acrópolis de La Blanca, Petén, en: $X X$ Simposio de Investigaciones Arqueológicas en Guatemala, 2006, Juan Pedro Laporte, Bárbara Arroyo y Héctor E. Mejía (eds.), pp. 549-554, Ministerio de Cultura y Deportes, Asociación Tikal y Fundación Arqueológica del Nuevo Mundo, Guatemala.

2007b Intervenciones autosostenibles sobre patrimonios culturales dispersos. El caso de La Blanca, Petén Guatemala, en. Actas del II Congreso Internacional de Patrimonio Cultural y Cooperación al Desarrollo, Gaspar Muñoz Cosme y cristina Vidal Lorenzo (eds.9, pp. 131-141, Ediciones Universidad Politécnica de Valencia, Valencia.

2006 La Blanca, arquitectura y clasicismo, (eds.), Ediciones Universidad Politécnica de Valencia, Valencia.

2005 La Blanca arqueología y desarrollo, (eds.), Ediciones Universidad de Valencia, Valencia.

2004 Análisis Comparativo de los diferentes sistemas constructivos en el área Maya, en: XVII Simposio de Investigaciones Arqueológicas en Guatemala, 2003, Juan Pedro Laporte, Bárbara Arroyo y Héctor E. Mejía (eds.), pp. 763-774, Ministerio de Cultura y Deportes, Asociación Tikal y FAMSI, Guatemala.

2003 Análisis comparativo de los diferentes sistemas constructivos en el área maya, en: XVII Simposio de Investigaciones arqueológicas en Guatemala, Juan Pedro Laporte y Héctor Escobedo (eds.), PP. 763-774 Ministerio de Cultura y Deportes y Asociación Tikal, Guatemala.

1998 Identificación del Templo $\mathrm{V}$ de Tikal en la descripción del Coronel Modesto Méndez de 1848, en: XI Simposio de Investigaciones Arqueológicas en Guatemala, Juan Pedro Laporte y Héctor Escobedo (eds.), pp. 9-19, Ministerio de Cultura y Deportes y Asociación Tikal, Guatemala.

MUÑOZ COSME, Gaspar, Andrés PEIRÓ, Victoria y Zacarias HERGUIDO ALAMAR

2006 Levantamiento arquitectónico del ala sur de la acrópolis, en: La Blanca. Arquitectura y clasicismo, Gaspar Muñoz Cosme y Cristina Vidal Lorenzo (eds.), pp. 46-64, Ediciones Universidad politécnica de Valencia, Valencia. 
MUÑOZ COSME, Gaspar, Cristina VIDAL LORENZO Y Juan Antonio VALDÉS GÓMEZ

1999 Los Mayas. Ciudades Milenarias de Guatemala, comisarios, Iber Caja, Ministerio de Educación y Cultura, Generalitat Valenciana y Ayuntamiento de Zaragoza.

MUNOZ COSME, Gaspar y Oscar QUINTANA SAMAYOA

1996 Intervenciones de restauración en el Templo I de Tikal, 1992-1994, en: IX Simposio de Investigaciones arqueológicas en Guatemala, Juan Pedro Laporte y Héctor Escobedo (eds.), pp. 335-342, Ministerio de Cultura y Deportes y Asociación Tikal, Guatemala.

NORBERG-SCHULTZ, Christian

1970 Logik der Baukunst, Berin-Frankfurt/ Mainz.

NORIEGA, Raú

1995 Templo C de Topoxté,en:Beiträge zur Allgemeinen und Vergleichenden Archäologie 15, pp. 229-258, Mainz.

NORIEGA, Raúl y Hugo GALINDO

2001 Proteccion de edificios Mayas por reposición de volúmenes, en: Beiträge zur Allgemeinen und Vergleichenden Archäologie, 21, pp. 191-199, Mainz.

NUÑEZ VILLANUEVA, Miguel Angel

1996 Informe de los trabajos realizados en los yacimientos arqueologicos en Yaxhá y Tikal, informe para la $\mathrm{AECl}$ e IDAEH, Madrid.

ORREGO, Miguel y Rudy LARIOS

1983 Reporte de las investigaciones arqueológicos en el Grupo 5E-II de Tikal, Instituto de Antropología e Historia Guatemala.

PERELLÓ ROSO, Ricardo

2005 Análisis del comportamiento estructural de los elementos históricos de fábrica. El caso de las estructuras de La Blanca, en: La Blanca. Arqueología y desarrollo, Gaspar Muñoz Cosme y Cristina Vidal Lorenzo (eds.), pp. 93-105, Ediciones Universidad Politécnica de Valencia, Valencia.

PERIGNY, Maurice de

1909 Villes mortes de l'Amérique Centrale. Le Tour du Monde, tomo 15, Paris. 
POLLOCK, Harry E. D.

1980 The Puuc. An Architectural Survey of the Hill Country of Yucatán and Northern Campeche, México, en: Memoirs of the Peabody Museum of Archaeology and Ethnology, Vol. 19, Harvard University, Cambridge, Massachusetts.

PROSKOURIAKOFF, Tatiana

1962 The Architecture of Mayapan; Yucatan, Mexico Part 1. Carnegie Institution of Washington, Washington, D.C.

1946 An Album of Maya Architecture. Carnegie Institution of Washington, Publication 558, Washington, D.C.

PULESTON, Dennis E.

1983 The Settlement Survey of Tikal, Tikal Report 13, University Museum, University of Pennsylvania, Philadelphia.

QUINTANA, Oscar

2007a Resultados de la cuarta fase del proyecto Triángulo Cultural Yaxha-Nakum-Naranjo, julio 2001-diciembre 2005, en: $X X$ Simposio de Investigaciones Arqueológicas en Guatemala, 2006. Juan Pedro Laporte Bárbara Arroyo y Héctor E. Mejía (eds.), pp. 137-145 Ministerio de Cultura y Deportes, Asociación Tikal y Fundación Arqueológica del Nuevo Mundo, Guatemala.

2007b Investigaciones en las Ruinas Mayas de San Clemente, Petén, Guatemala, en: Mexicon, Vol. XXIX, No. 1, pp. 1719.

2007c El sitio Maya El Pital en el noreste de Petén, Guatemala, en: Mexicon, Vol. XXIX, No. 4, pp. 91-92.

2006a El Proyecto La Blanca y el Plan Ruta Guayacán, en: La Blanca. Arquitectura y clasicismo, Gaspar Muñoz Cosme y Cristina Vidal Lorenzo (eds.), pp. 150-157, Ediciones Universidad Politécnica de Valencia, Valencia.

2006b El Proyecto San Clemente y el Plan Ruta Guayacán, en: Actas del II Congreso Internacional de Patrimonio Cultural y Cooperación al Desarrollo, Gaspar Muñoz Cosme y Cristina Vidal Lorenzo (coordinadores), pp. 101-112, Ediciones Universidad Politécnica de Valencia, Valencia. 
2005 La cuenca baja del rió Mopán, Petén, Guatemala y su patrimonio cultural maya, en: La Blanca, arqueología y desarrollo, Gaspar Muñoz Cosme y Cristina Vidal Lorenzo (eds.), pp. 17-23, Ediciones Universidad Politécnica de Valencia, Valencia.

2004 Programa de rescate en la región noreste del Petén, Guatemala; Nuevos registros en los alrededores de la Laguna Pucteal, en: Mexicon, Vol. XXVI, No. 5, pp. 102106.

2003 Planificación regional en el Triángulo Cultural YaxháNakum-Naranjo, en: Memoria de Cuarto congreso internacional de Mayistas, Mario Humberto Ruz, Maricela Ayala Falcón, Anna Luisa Izquierdo y de la Cueva, Ma. Del Carmen León Cázares, Tomas Pérez Suárez y Ma. Del Carmen Valverde Valdés (eds.), pp. 371-380, Universidad Nacional Autónoma de México, México.

2002 Resultados de la tercera fase del proyecto Triángulo cultural Yaxha-Nakum-Naranjo; octubre 1997-junio 2001, en: XV Simposio de Investigaciones Arqueológicas en Guatemala, 2001 Juan Pedro Laporte, Héctor L. Escobedo y Bárbara Arroyo (eds.), pp. 261-269, Ministerio de Cultura y Deportes, Asociación Tikal, Guatemala.

2001 Concepto para la intervención del recurso cultural prehispánico en el noreste de Petén, en: XIV Simposio de Investigaciones Arqueológicas de Guatemala, 2000, Juan Pedro Laporte, Ana Claudia de Suasnavar y Bárbara Arroyo (eds.), pp. 119-125, Ministerio de Cultura y Deportes y Asociación Tikal, Guatemala.

2000a Programa de Arquitectura, en: El Sitio Maya de Topoxte, investigaciones en una Isla del Lago Yaxha, Petén Guatemala, Wolfgang W. Wurster (ed.), pp. 24-28, AVAMaterialien, 57, Mainz.

2000b Concepto de desarrollo arqueológico y gestión cultural del noreste de Peten: 2000-2015, en: XIII simposio de Investigaciones arqueológicas en Guatemala 1999, Juan Pedro Laporte, Héctor L. Escobedo, Ana Claudia de Suasnavar y Bárbara Arroyo (eds.) pp. 411-418, Ministerio de Cultura y Deportes, Asociación Tikal, Guatemala. 
1999a Resultados de la segunda fase del proyecto Triángulo Cultural Yaxha-Nakum-Naranjo, octubre 1993-octubre 1997, en: XII Simposio de Investigaciones Arqueológicas en Guatemala 1998, Juan Pedro Laporte Bárbara Arroyo Héctor L. Escobedo y Héctor E. Mejía (eds.), pp.107-114, Ministerio de Cultura y Deportes y Asociación Tikal, Guatemala.

1999b El uso de los sitios arqueológicos y su incorporación a la vida contemporánea, en: Los Mayas. Ciudades Milenarias de Guatemala, Gaspar Muñoz Cosme, Cristina Vidal Lorenzo y Juan Antonio Valdés Gómez (comisarios), pp. 77-82, IberCaja, Ministerio de Educación y Cultura, Generalita Valenciana y Ayuntamiento de Zaragoza.

1997a Experiencia del Proyecto Nacional Tikal, en la intervención de edificios Mayas 1987-1995, en: Criterios de Intervención Arqueológica en Ciudades Mayas, Juan Antonio Valdés (ed.), pp. 29-40, Ministerio de Cultura y Deportes, Guatemala.

1997b Los elementos espaciales de Topoxte: un aporte al estudio de su arquitectura, en: Simposio de Investigaciones Arqueológicas en Guatemala 1996, Juan Pedro Laporte y Héctor L. Escobedo (eds.) pp. 275-281, Ministerio de Cultura y Deportes y Asociación Tikal, Guatemala.

1995 Plan de intervención del Templo 1 de Tikal, Petén, Guatemala, en: Cuadernos de Arquitectura Mesoamericana 29, pp. 3-13, UNAM, México.

QUINTANA, Oscar y Bernard HERMES

2002 Antecedentes del Programa de Restauración: Proyecto Nacional Tikal, en: Criterios, conceptos y modelos aplicados por los proyectos actuales en el campo de la restauración de estructuras prehispánicas, pp. 5-12. Asociación de Arqueólogos de Guatemala, Guatemala.

QUINTANA, Oscar, Hugo GALINDO y Raúl NORIEGA

2002 Daños por sismo en sitios Mayas de las tierras bajas del Petén, Guatemala, en: Mexicon, Vol. XXIV, No. 3, pp. 4244 
QUINTANA, Oscar y Raúl NORIEGA

2006 Tikal y sus vecinos: complejidad cultural en el Triángulo Yaxha-Nakum-Naranjo, en: XIX Simposio de Investigaciones Arqueológicas en Guatemala, Juan Pedro Laporte, Bárbara Arroyo y Héctor E. Mejía (eds.), pp. 303308, Ministerio de Cultura y Deportes, Asociación Tikal y Fundación Arqueológica del Nuevo Mundo, Guatemala.

1992 Intervenciones en el templo V de Tikal, Petén, Guatemala 1987-1991, en: Cuadernos de arquitectura mesoamericana, No. 20, pp. 53-76, UNAM, México D. F.

QUINTANA, Oscar, Víctor RIVERA y Juan Antonio SILLER

1991 Conclusiones de la primera mesa redonda sobre Tikal y la conservación del patrimonio Cultural y Natural en el Petén en: Cuadernos de Arquitectura Mesoamericana 14, pp. 5561, UNAM, México D. F.

QUINTANA; Oscar, Stefanie TEUFEL y Raúl NORIEGA

1999 The destruction of the archaeological site of Naranjo, Peten, Guatemala, en: Mexicon, Vol. XXI, No.1, pp.3-5

QUINTANA, Oscar y Juan Antonio Siller

1989 Documentación de acontecimientos históricos e investigaciones en Tikal, Guatemala, en: Cuadernos de arquitectura mesoamericana, No. 11, pp. 47-49, UNAM, México D. F.

QUINTANA, Oscar y Wolfgang W. WURSTER

2004 El plano del sitio Maya de Naranjo, Petén, Guatemala, en: Beiträge zur Allgemeinen und Vergleichenden Archäologie, 24, pp. 243-275, Mainz.

2002 Un nuevo plano del sitio de Nakum, Petén, Guatemala, en: Beiträge zur Allgemeinen und Vergleichenden Archäologie, 22, pp. 243-285, Mainz.

2001 Ciudades Mayas en el noreste de Peten, Guatemala, un estudio urbanístico comparativo, AVA-Materialien, 59, Mainz.

QUINTANA, Oscar, Wolfgang W. WURSTER y Bernard HERMES

2000 El plano del sitio maya de Yaxhá, Petén, Guatemala, en: Beiträge zur allgemeinen und Vergleichenden Archäologie, 20, pp. 261-286, Mainz. 
RAMÍREZ BALDIZÓN, Fredy

2004 Excavaciones y restauración en la plaza A de Yaxhá manuscrito inédito, biblioteca del PRONAT, Guatemala.

REESE-TAYLOR Kathryn, Peter MATHEWS, Marcelo ZAMORA, Martin RANGEL, Debra WALTER, Silvia ALVARADO, Ernesto ARREDONDO, Shaun MORTON, Roberta PARRY, Baudilio SALAZAR y Jeff SEIBERT

2005 Proyecto Arqueológico Naachtun: resultados preliminares de la primera temporada de campo 2004, en: XVIII Simposio de Investigaciones Arqueológicas en Guatemala, 2004, Juan Pedro Laporte, Bárbara Arroyo y Héctor E. Mejía (eds.), pp. 91-100. Ministerio de Cultura y Deportes, Asociación Tikal y Famsi, Guatemala.

REINDEL, Markus

1997 Xkipché. Eine Maya-Siedlung im nördlichen Yucatán, Mexiko, en: KAVA, Sonderdruck aus Beiträge zur Allgemeinen und Vergleichenden Archäologie, 17, pp. 177255, Mainz.

RICKETSON, Oliver G. y Edith B. RICKETSON

1937 Uaxactún, Guatemala, Group E, 1926-1931, Carnegie Institute of Washington, No. 477, Washington D.C.

RICE, Don S.

1997 Ingeniería Hidráulica en Petén Central, Guatemala, en: X Simposio de investigaciones arqueológicas en Guatemala, 1996, Juan Pedro Laporte y Héctor L. Escobedo (eds.), pp. 533-543, Ministerio de Cultura y Deportes y Asociación Tikal, Guatemala.

1976 Middle Pre-classic Maya settlement in the Central Maya Lowlands, en: Joural of Field Archaeology Vol.3, pp. 425445.

RICE, Don S., Prudence M. RICE, Grant D. JONES, Rómulo SÁNCHEZ POLO, Timothy PUGH, Anna McNAIR, Leslie CECIL y Hugo DRAKE.

1997 La segunda temporada de campo del proyecto Maya Colonial: nuevas evidencias, en: $x$ Simposio de Investigaciones Arqueológicas en Guatemala, 1996, Juan Pedro Laporte y Héctor Escobedo (eds.), pp. 499-512, Ministerio de Cultura y Deportes y Asociación Tikal, Guatemala. 
RICE, Don S. y Prudence M. RICE

1990 Population Size and population Change in the Central Peten Lakes Region, Guatemala, en: Precolumbian Population History in the Maya Lowlands, Patrick Culbert y Don S. Rice (eds.), pp. 123-148, University of New Mexico Press, Alburquerque.

RIVERA DORADO, Miguel

2007 Arquitectura y escenografía en la cultura maya antigua, en: La Blanca y su entorno. Cuadernos de arquitectura y arqueología maya, Cristina Vidal Lorenzo y Gaspar Muñoz Cosme (eds.), pp. 161-171, Edición Universidad Politécnica de Valencia, Valencia.

2006a El tenue resplandor del Postclásico petenero, en: La Blanca. Arquitectura y clasicismo, Gaspar Muñoz Cosme y Cristina Vidal Lorenzo (eds.), pp. 37-43, Edición Universidad Politécnica de Valencia, Valencia.

2006b El orden del desorden: La lógica del saqueo arqueológico, en: Actas del II Congreso Internacional de Patrimonio Cultural y Cooperación al Desarrollo, Gaspar Muñoz Cosme y Cristina Vidal Lorenzo (coordinadores), pp. 369-375, Ediciones Universidad Politécnica de Valencia, Valencia.

2002 Fulgor y extravagancia de la arqueología en tiempos deTeoberto Maler, en: Espacio Sagrado. Arquitectura Maya en la obra de Teoberto Maler, Ma. Luisa Vázquez de Agredos Pascual (comisaria), pp. 32-43, Universidad de Valencia, Valencia.

2001 La Ciudad Maya: un escenario sagrado, Editorial de la Universidad Complutense, Madrid.

1999 Puertas al otro mundo. Religión y ritos de los mayas, en: Los Mayas. Ciudades Milenarias de Guatemala, Gaspar Muñoz Cosme, Cristina Vidal Lorenzo y Juan Antonio Valdés Gómez (comisarios), pp. 51-56, IberCaja, Ministerio de Educación y Cultura, Generalita Valenciana y Ayuntamiento de Zaragoza.

1998a La arqueología maya a finales del milenio, en: La civilización Maya: descubrimientos recientes, Miguel Rivera Dorado (coord.), pp.9-36, Fundación Ramón Arece, Madrid. 
1998b La civilización y el estado en el norte de la península de Yucatán, en: La civilización Maya: descubrimientos recientes, Miguel Rivera Dorado (coord.), pp.125-153, Fundación Ramón Arece, Madrid.

1996 Los mayas de Oxkintok, Ministerio de Educación y Cultura, Madrid.

1995 Arquitectura, gobernantes y cosmología. Anotaciones sobre ideología maya en los cuadernos de Oxkintok, en: Revista Española de Antropología Americana, Vol.25, pp. 23-40, Madrid.

1986 La religión maya, Alianza Editorial, Madrid.

1982 Los mayas, una sociedad oriental, Editorial de la Universidad Compultense, Madrid.

RIVERA DORADO Miguel y Cristina VIDAL LORENZO

1992 Arqueología Americana, Editorial síntesis, Madrid.

RUNGGALDIER, Astrid

2004 Investigaciones preliminares en el conjunto Palaciego "Tigrillo", San Bartolo, en: XVII Simposio de Investigaciones Arqueológicas en Guatemala, 2003, Juan Pedro Laporte, Bárbara Arroyo, Héctor L. Escobedo y Héctor E. Mejía (eds.), pp. 621-628. Ministerio de Cultura y Deportes, Asociación Tikal, Guatemala.

SAPPER, Karl

1902 Mittelamerikanische Reisen und Studien aus den Jahren 1888 bis 1900, Vieweg, Braunschweig.

SATURNO, William

2006 The Dawn of Maya Gods and Kings, en: National Geographic, Vol. 209, No 1, pp. 68-77.

SATURNO, William A., David STUART y Karl TAUBE

2005 La identificación de las figuras del muro oeste de pinturas Sub-1, San Bartolo, Petén, en: XVIII Simposio de Investigaciones Arqueológicas, en Guatemala, 2004, Juan Pedro Laporte, Bárbara Arroyo y Héctor E. Mejía (eds.), pp. 647-655, Ministerio de Cultura y Deportes, Asociación Tikal y FAMSI, Guatemala. 
SATURNO, William A. y Mónica URQUIZÚ

2005 Proyecto Arqueológico Regional San Bartolo, Petén: Resultados de la tercera temporada de campo 2004, en: XVIII Simposio de Investigaciones Arqueológicas en Guatemala, 2004, Juan Pedro Laporte, Bárbara Arroyo y Héctor E. Mejía (eds.), pp. 283-290. Ministerio de Cultura y Deportes, Asociación Tikal y FAMSI, Guatemala.

SCHÁVELZON, Daniel

1990a La conservación del patrimonio cultural en América latina, Restauración de edificios prehispánicos en Mesoamerica: 1750-1980, Universidad de Buenos aires, Facultad de arquitectura, diseño y Urbanismo, Instituto de arte americano e investigaciones estéticas "Mario J. Buschazzo", Buenos Aires.

1990b Las ciudades Mayas, Historia de las teorías sobre su estructura urbana, editorial rescate, Buenos Aires.

1984 "La restauración como fenómeno social", en: Encuentro Nacional de Conservación, pp. 33-40, INAH, México.

SCHELE, Linda

1992 Religion und Weltsicht, en: Die Welt der Maya, Arne y Eva Eggebrecht (eds.), pp. 197-214, Philipp von Zabern, Mainz.

SCREINER Thomas

2001 Fabricacion de cal en Mesoamerica: Implicaciones para los mayas del Preclásico en Nakbé, Peten, en: XIV Simposio de Investigaciones Arqueológicas en Guatemala, Juan Pedro Laporte, Ana Caludia de suasnávar y Bárbara Arroyo (eds.), pp. 405-418, Ministerio de cultura y deportes y asociación tikal, Guatemala.

SHOOK, Edwin M

1964 Archaeological investigation at Tikal, Peten, Guatemala, en: $X X X V$ Congreso Internacional de Americanistas, Vol. 1, pp. 379-385, México.

1958 Field director's report: the 1956 and 1957 seasons, Tika report No.1, University of Pennsylvania Museum, Philadelphia. 
SILLER, Juan Antonio y Oscar QUINTANA

1989 Reconocimiento arquitectónico de sitios arqueológicos en Petén, en: Cuadernos de Arquitectura Mesoamericana 11 pp. 51-83, UNAM, México, D. F.

SMITH, Robert

1955 Ceramic sequence at Uaxactun, Guatemala, 2 Vols. MARI Publication 20, New Orleans.

1937 A Study of Structure A-1 Complex at Uaxactun, Petén Guatemala, en: Contributions to American Archaeology, No. 19 , pp. 189-231, Carnegie Institution of Washington, Washington D.C.

SOSA, José María

1970 Monografía del departamento de El Petén, segunda edición actualizada y notablemente aumentada, Colección Monografías 9, editorial José de Pineda Ibarra, Ministerio de Educación, Guatemala.

STEPHENS, John L.

1843 Incidents of Travel in Yucatan, 2 Vols. New York: Hamper. Reprinted by Dover, 1963.

STIERLIN, Henri

2001 Los Mayas, palacios y pirámides de la selva virgen, Taschen, Köln.

1964 Maya, Architektur der Welt, Office du Livre, Fribourg.

STUART, David

1985 The Yaxha Emblem Glyph as Yax-ha, en: Research Reports on Ancient Maya Writing, pp 1-6.

SUASNÁVAR, José S.

1994 Las calzadas de Nakbe en: XVII Simposio de Investigaciones Arqueológicas en Guatemala, 1993, Juan Pedro Laporte y Héctor Mejía, pp. 335-348, Ministerio de cultura y Deportes y Asociación Tikal, Guatemala.

SUYUC, Edgar, Beatriz BALCÁRCEL, Francisco LÓPEZ y Silvia ALVARADO

2005 Excavaciones en el Sitio La Muerta, Cuenca Mirador, Petén, en: XVIII Simposio de Investigaciones Arqueológicas en Guatemala, 2004, Juan Pedro Laporte, Bárbara Arroyo y 
Héctor E. Mejía (eds.), pp. 75-90. Ministerio de Cultura y Deportes, Asociación Tikal y FAMSI, Guatemala.

TAUBE, Karl, William SATURNO y David S. STUART

2004 Identificación mitológica de los personajes en el muro norte de la Pirámide de las Pinturas Sub-1, San Bartolo, Petén, en: XVII Simposio de Investigaciones Arqueológicas en Guatemala, 2003, Juan Pedro Laporte, Bárbara Arroyo, Héctor L. Escobedo y Héctor E. Mejía (eds.), pp. 871-881, Ministerio de Cultura y Deportes, Asociación Tikal, Guatemala.

TEUFEL, Stefanie

2000a Interpretación de artefactos del entierro 49, en: El sitio maya de Topoxte. Investigaciones en una isla del lago Yaxhá, Petén, Guatemala, Wolfgang W. Wurster (ed.), pp. 149-158, AVA-Materialien, 57, Mainz.

2000b Heiratsdiplomatie-Frauen am Königshof, en: Maya Gottkönige im Regenwald, Nikolai Grube, Eva Eggebrecht y Matthias Seidel (eds.), pp.172-173,Könemann, Köln.

200c Die Webkunst, en: Maya. Gottkönige im Regenwald, Nikola Grube, Eva Eggebrecht y Matthias Seidel (eds.), pp. 354355,Könemann, Köln.

TOBAR, Telma

2006 Análisis de la Arquitectura expuesta del sitio prehispánico Nakum, Tesis de licenciatura, pp. 225-325, área Arquitectura, Facultad de Arquitectura, USAC, Guatemala.

TOBAR, Telma y Breitner GONZÁLEZ

2007 La Acrópolis de Nakum: un análisis espacial y volumétrico, en: $X X$ Simposio de Investigaciones Arqueológicas en Guatemala, 2006, Juan Pedro Laporte, Bárbara Arroyo y Héctor E. Mejía (eds.), pp. 539-548, Ministerio de Cultura y Deportes, Asociación Tikal y Fundación Arqueológica del Nuevo Mundo, Guatemala.

TORLUTTER, ERIK

2002 Geotechnische Sicherungsmassnahmen zum Schutz von Bauwerkem der Maya-Kultur in Guatemala, Diplomarbeit, Institut fú Bodenmechanik und Grundbau der Technischen Universität Graz, Graz. 
TOZZER, Alfred M.

1913 A Preliminary Study of the Ruins of Nakum, Guatemala Memoirs of the Peabody Museum, Harvard University, Vol. 5, pp. 137-201. Peabody Museum of Harvard University, Cambridge.

TURNER, B.L.

1990 Population Reconstruction for the Central Maya Lowland 1000 BC to AD 1500, en: Precolumbian Population History in the Maya Lowlands, Patrick Culbert y Don Rice (eds.), pp. 301-324, The University of New México, Press.

TRIK Helen W. y Michael E. KAMPEN

1983 The Graffiti of Tikal, Tikal, en: Report No. 31, The University Museum, University of Pennsylvania, Philadelphia

TITMUS, Gene L. y James C. WOODS

2002 Un estudio arqueológico y experimental de las canteras antiguas de Nakbé, Petén, Guatemala, en: XV Simposio de Investigaciones Arqueológicas en Guatemala, Juan Pedro Laporte y Héctor L. Escobedo (eds.), pp. 207-221, Ministerio de Cultura y Deportes y Asociación Tikal, Guatemala.

UNESCO

2006 Compendio de leyes sobre la protección del patrimonio cultural guatemalteco, UNESCO Guatemala, Ministerio de Cultura y Deportes y Promuseum, Guatemala.

URQUIZÚ, Mónica y William A. SATURNO

2006 Resultados preliminares de la cuarta temporada de campo del Proyecto Arqueológico San Bartolo, en: XIX simposio de investigaciones arqueológicas en Guatemala, 2005, Juan Pedro Laporte, Bárbara Arroyo y Héctor E. Mejía (eds.), pp. 649-657, Ministerio de Cultura y Deportes, Asociación Tikal y Fundación Arqueológica del Nuevo Mundo, Guatemala.

2004 Proyecto arqueológico regional San Bartolo: Resultados de la segunda temporada de campo 2003, en XVII Simposio de Investigaciones Arqueológicas en Guatemala, 2003, Juan Pedro Laporte, Bárbara Arroyo, Héctor L. Escobedo y Héctor E. Mejía (eds.), pp. 629-635, Ministerio de Cultura y Deportes, Asociación Tikal, Guatemala. 
VALENCIA ARRIOLA, Miguel Santiago

1985 Anotaciones sobre depredación arqueológica en Guatemala. Versión revisada de la Ponencia Presentada en el 1 Coloquio Internacional de Mayistas, México.

1988 Depredación arqueológica en Guatemala, en: Anales de la Academia de Geografía e Historia de Guatemala No.61, pp. 219-231, Guatemala

VALDÉS GÓMEZ, Juan Antonio

2005 El período clásico en Uaxactún, Guatemala. Arqueología en el centro de Petén, Juan Antonio Valdés (ed.), Instituto de Investigaciones Históricas, Antropológicas y Arqueológicas, Escuela de Historia, USAC, Guatemala.

2000 El Resurgimiento de Palacios y Tronos en las cortes reales de las tierras bajas, en: Utz'ib, Vol. 2, No.2, pp. 11-32, Asociación Tikal, Guatemala.

1999 La vida cortesana en los palacios mayas, en: Los Mayas. Ciudades Milenarias de Guatemala, Gaspar Muñoz Cosme, Cristina Vidal Lorenzo y Juan Antonio Valdés Gómez (comisarios), pp. 31-35, IberCaja, Ministerio de Educación y Cultura, Generalita Valenciana y Ayuntamiento de Zaragoza.

1997 Criterios de intervención arqueológica en ciudades mayas Juan Antonio Valdés (ed.), Instituto de Antropología e Historia, Guatemala.

1992 El Crecimiento de la Civilización Maya del área central durante el Preclásico Tardío: una vista desde el Grupo $\mathrm{H}$ de Uaxactun, en: Utz'ib, Vol. 1, No. 2, pp. 16-31, Asociación Tikal, Guatemala.

VALDÉS GÓMEZ, Juan Antonio y Cristina VIDAL LORENZO

2007 Observaciones sobre el colapso y el periodo Clásico Temprano, en: La Blanca y su entorno. Cuadernos de arquitectura y arqueología maya, Cristina Vidal Lorenzo y Gaspar Muñoz Cosme (eds.), pp.173-179, Ediciones Universidad Politécnica de Valencia, Valencia.

VALDÉS GÓMEZ, Juan Antonio y Federico FAHSEN

2003 Desastre a la vista: El clásico Terminal en Tikal y Uaxactun, en: Utz'ib, Vol. 3, No. 4, pp. 13-30, Asociación Tikal, Guatemala. 
VALDÉS GÓMEZ, Juan Antonio, Federico FAHSEN y Héctor ESCOBEDO

1999 Reyes, Tumbas y Palacios, La Historia dinástica de Uaxactún, UNAM, Instituto de Antropología e Historia de Guatemala, México.

VALDÉZ GÓMEZ, Juan Antonio, Federico FAHSEN y Gaspar MUÑOZ COSME

1997 Estela 40 de Tikal. Hallazgo y lectura, Agencia Española de Cooperación Internacional e IDAEH, Guatemala.

VALDÉS GOMEZ. Juan Antonio, César Alfonso GARCÍA, Luis Francisco DE LEÓN, Pablo Christian DE LEÓN, Nelson CHANQUÍN y Juan Pablo HERRERA

1999 Aportes para la Restauración: análisis físico-químicos y mecánicos de la mampostería de Tikal, Informe Final proyecto 61-99, Consejo Nacional de Ciencia y Tecnología, Línea FODECYT, Instituto de Investigaciones Históricas, Antropológicas y Arqueológicas, escuela de Historia, Universidad de San Carlos de Guatemala y Centro de Investigaciones de la Facultad de Ingeniería, Universidad de San Carlos de Guatemala, Guatemala.

VIDAL LORENZO, Cristina

2006 La arqueología, en: La Blanca. Arquitectura y clasicismo, Gaspar Muñoz Cosme y Cristina Vidal Lorenzo (eds.), pp. 11-26, Edición Universidad Politécnica de Valencia, Valencia.

2005 Arte y arqueología, en: La Blanca, arqueología y desarrollo, Gaspar Muñoz Cosme y Cristina Vidal Lorenzo (eds.), pp. 11-26, Edición Universidad Politécnica de Valencia Valencia.

2002 Exploraciones de Teoberto Maler en Tikal, Guatemala, en: Espacio Sagrado. Arquitectura Maya en la obra de Teoberto Maler, Ma. Luisa Vázquez de Agredos Pascual (comisaria), pp.76-89, Universidad de Valencia, Valencia.

1999a El descubrimiento de las ciudades Milenarias de Guatemala, en: Los Mayas. Ciudades Milenarias de Guatemala, Gaspar Muñoz Cosme, Cristina Vidal Lorenzo y Juan Antonio Valdés Gómez (comisarios), pp. 19-29, IberCaja, Ministerio de Educación y Cultura, Generalita Valenciana y Ayuntamiento de Zaragoza. 
1999b La expresión artística maya a través de los objetos ceremoniales, en: Los Mayas. Ciudades Milenarias de Guatemala, Gaspar Muñoz Cosme, Cristina Vidal Lorenzo y Juan Antonio Valdés Gómez (comisarios), pp. 65-70, IberCaja, Ministerio de Educación y Cultura, Generalita Valenciana y Ayuntamiento de Zaragoza.

1999c Arte, arquitectura y arqueología ene. Grupo Ah Canul de la ciudad maya yucateca de Oxkintok, en: British Archaeological Reports, Internacional Series, No. 779, Oxford.

1998 Descubrimientos arqueológicos en la selva de Guatemala en: Las ciudades mayas: descubrimientos recientes, Migue Rivera Dorado (coord.), pp. 37-67, Fundación Areces, Madrid.

1997 Arquitectura maya: un enfoque para la clasificación estilística de los edificios del Norte de Yucatán, en: Ars Longa, No.7-8, pp. 15-31, Departamento de Historia del Arte, Universidad de Valencia, Valencia.

VIDAL LORENZO, Cristina y Gaspar MUÑOZ COSME.

2007a Proyecto La Blanca: temporada 2006, en: La Blanca y su entorno. Cuadernos de arquitectura y arqueología maya, Cristina Vidal Lorenzo y Gaspar Muñoz Cosme (eds.), pp.710, Edición Universidad Politécnica de Valencia, Valencia.

2007b La Blanca y su entorno. Cuadernos de arquitectura y arqueología maya, Cristina Vidal Lorenzo y Gaspar Muñoz Cosme (eds.), Edición Universidad Politécnica de Valencia, Valencia.

1997 Tikal El Gran Jaguar, Agencia Española de Cooperación Internacional y grupo Endesa, Madrid.

VIDAL LORENZO, Cristina y Juan Antonio VALDÉS GÓMEZ

2007 La huella arqueológica del abandono de los palacios de La Blanca, en: La Blanca y su entorno. Cuadernos de arquitectura y arqueología maya, Cristina Vidal Lorenzo y Gaspar Muñoz Cosme (eds.), pp.11-20, Edición Universidad Politécnica de Valencia, Valencia.

VIDAL LORENZO, Cristina y Osvaldo GÓMEZ

1997 Intervenciones arqueológicas en ciudades mayas, en: Criterios de intervención arqueológica en ciudades mayas, 
Juan Antonio Valdés (ed.), pp. 41-52, Instituto de Antropología e Historia, Guatemala.

VIDAL LORENZO, Cristina, Vilma FIALKO Y Stefanie TEUFEL

1996 Exploraciones arqueológicas en el corozal, área periférica de Tikal, en: IX Simposio de Investigaciones Arqueológicas en Guatemala, Juan Pedro Laporte y Héctor Escobedo (eds.), pp. 59-68, Ministerio de Cultura y Deportes y Asociación Tikal, Guatemala.

VON EUW Eric e Ian GRAHAM.

1984 Corpus of Maya Hieroglyphic Inscriptions, Vol.5, Part 3 Xultun, La Honradez, Uaxactun, Peabody Museum of Archaeology and Ethnology, Harvard University, Cambridge, Massachusetts.

WAUCHOPE, Robert

1938 Modern Maya Houses. A Study of their archaeological Significance, Carnegie Institution of Washington, 502, Washington D.C.

WEBSTER, David, Timothy MURTHA, Kirk STAIGHT, Horacio MARTINEZ, Richard TERRY, Rich L. BURNETT, Ryan V. SWEETWOOD, Walter ALVARADO, Irinna MONTEPEQUE y Jay SILVERSTEIN

2006 Nuevos trabajos e interpretaciones de los terraplenes de Tikal: segunda temporada de campo, en: XIX Simposio de Investigaciones Arqueológicas en Guatemala, 2005, Juan Pedro Laporte, Bárbara Arroyo y Héctor E. Mejía (eds.), pp. 695-703, Ministerio de Cultura y Deportes, Asociación Tikal y Fundación Arqueológica del Nuevo Mundo, Guatemala.

WILHELMY, Herbert

1989 Welt und Umwelt der Maya. Aufstieg und Untergang einer Hochkultur. Piper-Verlag, München.

WOODS, James C. y Gene L. TITMUS

1994 Piedra en piedra: perspectivas de la civilización maya a través de los estudios líticos, en: VII Simposio de Investigaciones Arqueológicas en Guatemala, Juan Pedro Laporte y Héctor L. Escobedo (eds.), pp. 349-356, Ministerio de Cultura y Deportes y asociación Tikal Guatemala. 
WURSTER, Wolfgang W.

2001 Denkmalpflege an massiven Maya-Pyramiden: Wiederherstellung von zerstörten Aussenböschungen durch Stampflehm mit Pflanzenarmierung, en: Beiträge zur Allgemeinden und Vergleichenden Archäologie, 21, pp. 201-206. Mainz.

2000 El sitio Maya de Topoxte; investigaciones en una isla de Lago Yaxhá, Petén, Guatemala, (ed.), en: AVA-Materialien, 57, Mainz.

1996 Expedition im tropischen Regenwald, en: Schliemanns Erben, Ein schüsseln archäologen unsere Zukunft?, Gisela Graichen y Michael Sieber (eds.), pp. 109-155, Philipp von Zabern, Mainz.

1992 Die Architectur der Maya, en: Die Welt der Maya, Arne y Eva Eggebrecht (eds.), pp. 107-138, Philipp von Zabern, Mainz.

1992 Maya-Architektur auf der Insel Topoxté im See von Yaxhá,Petén, Guatemala, pp. 261-302.AVA- Materialien 12, Mainz.

ZEA FLORES, Carlos Enrique

1998 Rescate, salvamento y recuperación arqueológica, Colección Obra Varia No. 22, Ministerio de Cultura y Deportes, editorial cultura, Guatemala. 
ANEXO 1

Figuras en cuadros 
CUADRO 1

SITIOS DE LA MUESTRA

\begin{tabular}{|c|l|}
\hline Nomenclatura & \multicolumn{1}{|c|}{$\begin{array}{c}\text { Sitio } \\
\text { Arqueológico }\end{array}$} \\
\hline \hline \multicolumn{2}{|c|}{ CUENCA MIRADOR } \\
\hline $1-001$ & El Mirador \\
\hline $1-002$ & Nakbé \\
\hline $1-003$ & La Muralla \\
\hline $1-004$ & Naachtún \\
\hline $1-005$ & Wakna \\
\hline $1-006$ & Tintal \\
\hline $1-007$ & La Florida \\
\hline $1-008$ & Xulnal \\
\hline $1-009$ & Puerto Arturo \\
\hline $1-010$ & La Ceibita \\
\hline $1-011$ & La Muerta \\
\hline $1-012$ & El Porvenir \\
\hline & \\
\hline
\end{tabular}

\begin{tabular}{|c|l|}
\hline Nomenclatura & \multicolumn{1}{|c|}{$\begin{array}{c}\text { Sitio } \\
\text { Arqueológico }\end{array}$} \\
\hline \hline \multicolumn{2}{|c|}{ ÁA TIKAL } \\
\hline $2-001$ & El Zotz \\
\hline $2-002$ & El Diablo \\
\hline $2-003$ & Bejucal \\
\hline $2-004$ & Uaxactún \\
\hline $2-005$ & Ramonalito \\
\hline $2-006$ & La Pita \\
\hline $2-007$ & San Máximo \\
\hline $2-008$ & Tikal \\
\hline $2-009$ & Corozal \\
\hline $2-010$ & Uolantún \\
\hline $2-011$ & Chalpate \\
\hline $2-012$ & Temblor \\
\hline $2-013$ & Jimbal \\
\hline $2-014$ & El Encanto \\
\hline $2-015$ & El Palmar \\
\hline
\end{tabular}


CUADRO 1

SITIOS DE LA MUESTRA

\begin{tabular}{|c|c|}
\hline Nomenclatura & $\begin{array}{c}\text { Sitio } \\
\text { Arqueológico }\end{array}$ \\
\hline \multicolumn{2}{|l|}{ CUENCA IXCÁN } \\
\hline 3-001 & Manantial \\
\hline 3-002 & Ramonal \\
\hline 3-003 & Xultún \\
\hline 3-004 & San Bartolo \\
\hline 3-005 & Río Azul \\
\hline 3-006 & Kinal \\
\hline 3-007 & Chochkitam \\
\hline $3-008$ & Xmakabatún \\
\hline 3-009 & La Honradez \\
\hline $3-010$ & Las Ventanas \\
\hline 3-011 & El Susto \\
\hline 3-012 & El Susto Mirador \\
\hline 3-013 & Ratón-Pucteal \\
\hline 3-014 & Las Cubetitas \\
\hline 3-015 & La Línea \\
\hline
\end{tabular}

\begin{tabular}{|c|l|}
\hline Nomenclatura & \multicolumn{1}{|c|}{$\begin{array}{c}\text { Sitio } \\
\text { Arqueológico }\end{array}$} \\
\hline CUENCA HOLMUL \\
\hline $4-001$ & Dos Aguadas \\
\hline $4-002$ & Holmul \\
\hline $4-003$ & Sufricaya \\
\hline $4-004$ & Cival \\
\hline $4-005$ & Jobal \\
\hline $4-006$ & Yaloch \\
\hline $4-007$ & Caracol \\
\hline $4-008$ & Pacayal \\
\hline $4-009$ & EI Perú - Holmul \\
\hline $4-010$ & Riverona \\
\hline $4-011$ & El Pilar \\
\hline $4-012$ & Witzná \\
\hline $4-013$ & Chanchich \\
\hline $4-014$ & Naranjo \\
\hline $4-015$ & Nakum \\
\hline $4-016$ & El Tigre \\
\hline $4-017$ & Naranjito \\
\hline $4-018$ & El Carmen \\
\hline $4-019$ & La Perra \\
\hline $4-020$ & Poza Maya \\
\hline $4-021$ & Pochitoca \\
\hline $4-022$ & Kanajau \\
\hline $4-023$ & Ciudadela Naranjo \\
\hline $4-024$ & El Danto \\
\hline $4-025$ & El Pital \\
\hline $4-026$ & Balam Chac \\
\hline $4-027$ & Lalila \\
\hline $4-028$ & Ixqueej \\
\hline $4-029$ & Ikilhá \\
\hline $4-030$ & Ahau - Na \\
\hline & \\
\hline
\end{tabular}


CUADRO 1

SITIOS DE LA MUESTRA

\begin{tabular}{|c|c|}
\hline Nomenclatura & Sitio Arqueológico \\
\hline \multicolumn{2}{|c|}{ CUENCA DE LOS LAGOS } \\
\hline 5-001 & Motul \\
\hline $5-002$ & Nixtunchich \\
\hline $5-003$ & Acte \\
\hline 5-004 & La Montura \\
\hline $5-005$ & Tayasal \\
\hline $5-006$ & Ixlú \\
\hline $5-007$ & Paxcamán \\
\hline $5-008$ & Sacpetén \\
\hline 5-009 & Yalain \\
\hline 5-010 & Zapote \\
\hline 5-011 & Corozal Torre \\
\hline 5-012 & Zapote Corozal \\
\hline $5-013$ & Quemada Corozal \\
\hline $5-014$ & San Clemente \\
\hline 5-015 & Cordoncillo Corozal \\
\hline 5-016 & Huech \\
\hline $5-017$ & La Naya \\
\hline $5-018$ & Ixtinto \\
\hline $5-019$ & Yaxhá \\
\hline $5-020$ & Topoxté \\
\hline 5-021 & Holtún \\
\hline 5-022 & El Sombrero \\
\hline $5-023$ & El Venado \\
\hline $5-024$ & El Gavilán \\
\hline $5-025$ & Ta-Aj Corozal \\
\hline $5-026$ & Nimá Wits \\
\hline $5-027$ & Huacutal \\
\hline $5-028$ & Trinidad \\
\hline $5-029$ & Balamtún \\
\hline $5-030$ & Canchén \\
\hline 5-031 & Juleque \\
\hline $5-032$ & El Tumbo \\
\hline $5-033$ & Akalche \\
\hline $5-034$ & El Ramonal \\
\hline $5-035$ & Noj - Petén \\
\hline
\end{tabular}

\begin{tabular}{|c|l|}
\hline Nomenclatura & \multicolumn{1}{|c|}{$\begin{array}{c}\text { Sitio } \\
\text { Arqueológico }\end{array}$} \\
\hline \multicolumn{2}{|c|}{ CUENCA Río MOPÁN } \\
\hline $6-001$ & Tzikintzakán \\
\hline $6-002$ & Chunhuitz \\
\hline $6-003$ & Aguacate \\
\hline $6-004$ & La Blanca \\
\hline $6-005$ & Buenos Aires \\
\hline $6-006$ & Ucanal \\
\hline $6-007$ & Blancasur \\
\hline $6-008$ & Lain Perdido \\
\hline $6-009$ & Las Zarcas \\
\hline $6-010$ & Yaltutú \\
\hline $6-011$ & Naranjal \\
\hline $6-012$ & Yok' Ol Wits \\
\hline $6-013$ & Calabazal \\
\hline $6-014$ & Salsipuedes 1 \\
\hline $6-015$ & Salsipuedes 2 \\
\hline $6-016$ & Dos Hermanas \\
\hline $6-017$ & Camalote \\
\hline $6-018$ & La Providencia \\
\hline $6-019$ & La Amapola \\
\hline $6-020$ & Chilonché \\
\hline $6-021$ & El Mango \\
\hline & \\
\hline
\end{tabular}


CUADRO 2

INTERVENCIÓN EN SITIOS ARQUEOLÓGICOS EN EL NORESTE DE PETÉN

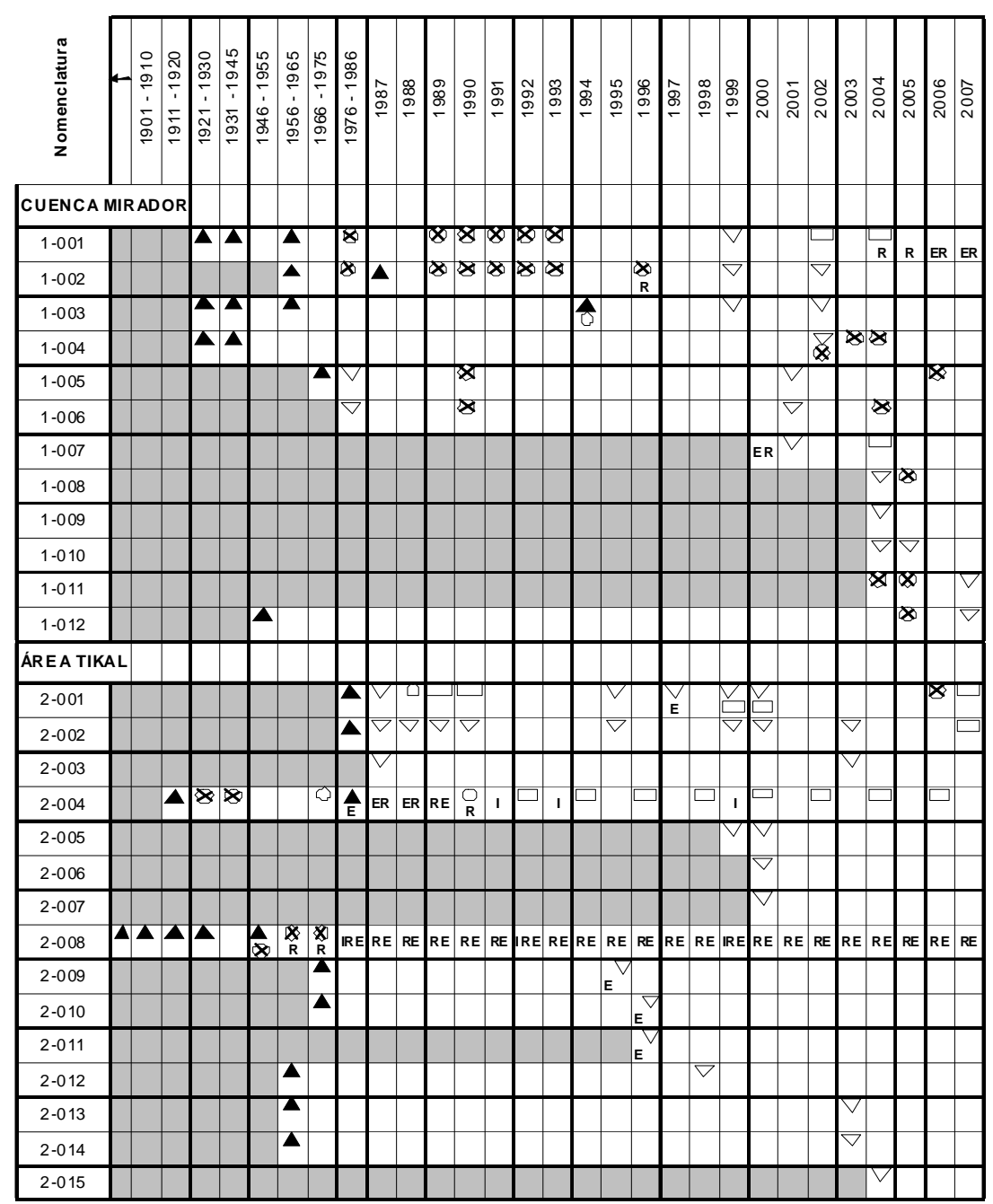

Expediciones - Documentación

\& Proyectos de Excavación

R Restauración-Conservación

Excavaciones

$\nabla$ Registro de Daños

Intervenciones de Rescate

Monitoreo

\begin{tabular}{|l|l|}
\hline 1 & Infraestructura Turística \\
\hline
\end{tabular}

A Atlas Arqueológico 
CUADRO 2

INTERVENCIÓN EN SITIOS ARQUEOLÓGICOS EN EL NORESTE DE PETÉN

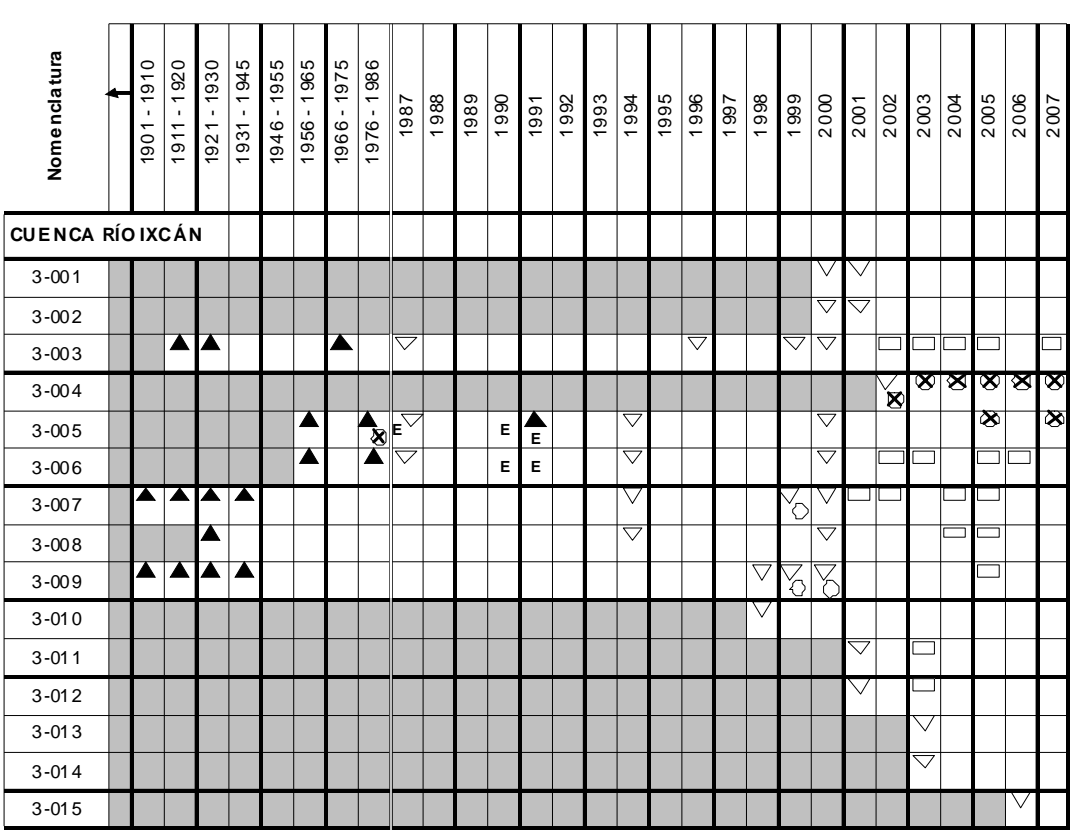

Expediciones - Documentación

Proyectos de Excavación

\begin{tabular}{|l|l|}
\hline R & Restauración-Conservación \\
\hline
\end{tabular}

\begin{tabular}{|l|l|}
\hline E & Rescavaciones \\
\hline$\nabla$ & Registo de Danos \\
\hline
\end{tabular}

DRegistro de Daños

Intervenciones de Rescate

Monitoreo

1 Infraestructura Turística

\begin{tabular}{|l|l|l}
\hline & Atlas Arqueológico \\
\hline
\end{tabular} 
CUADRO 2

INTERVENCIÓN EN SITIOS ARQUEOLÓGICOS EN EL NORESTE DE PETÉN

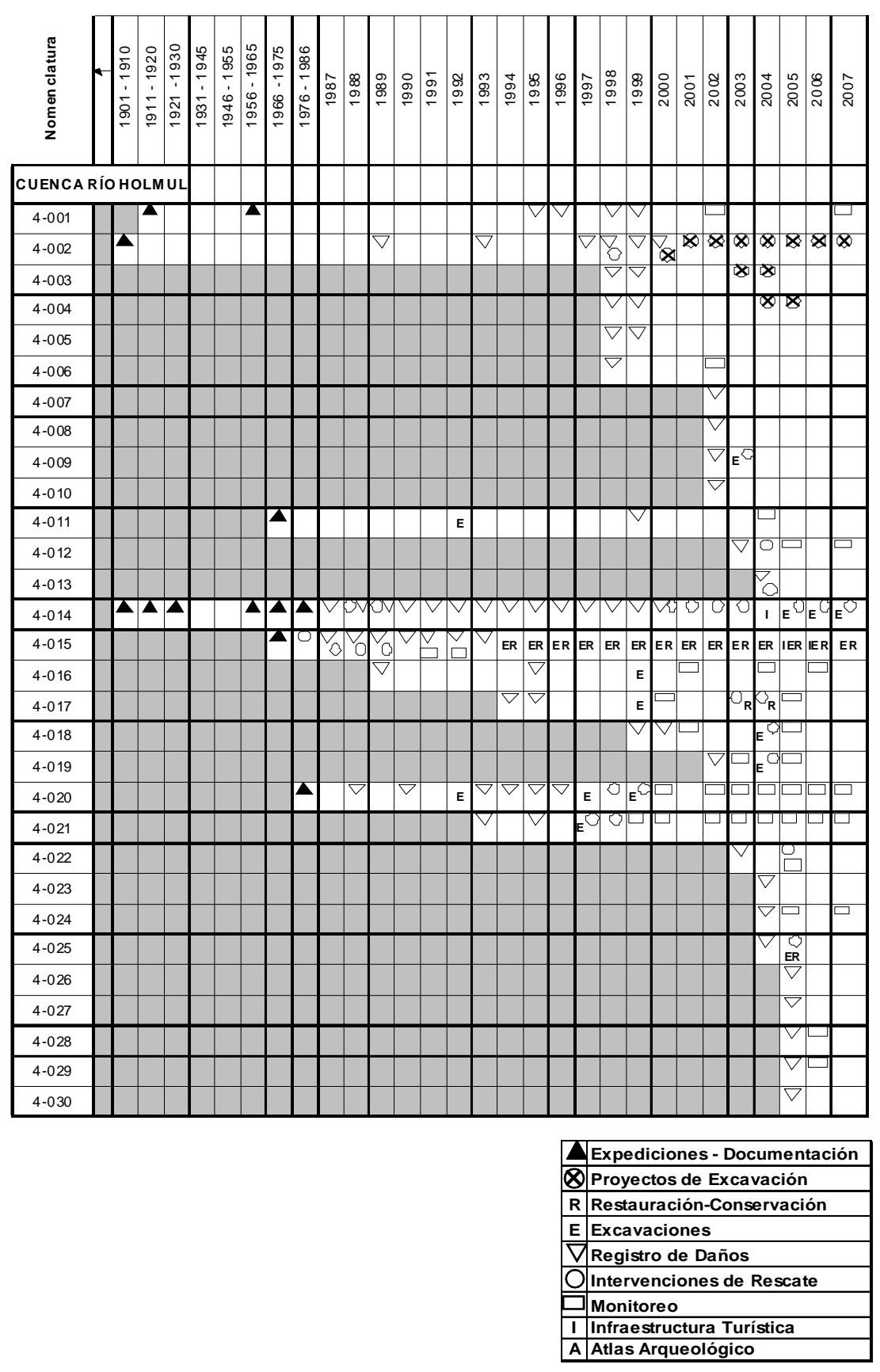


CUADRO 2

INTERVENCIÓN EN SITIOS ARQUEOLÓGICOS EN EL NORESTE DE PETÉN

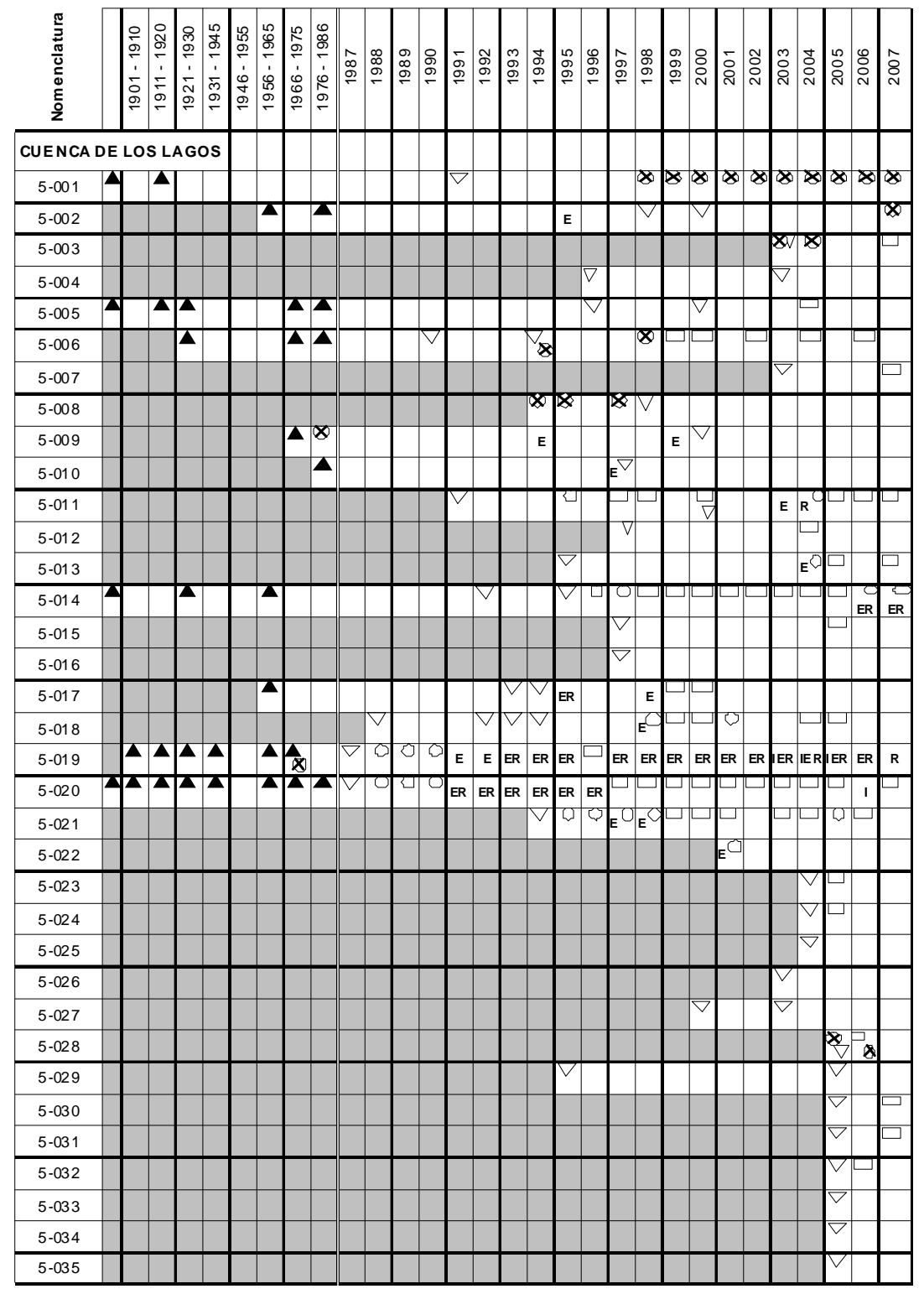


CUADRO 2

INTERVENCIÓN EN SITIOS ARQUEOLÓGICOS EN EL NORESTE DE PETÉN

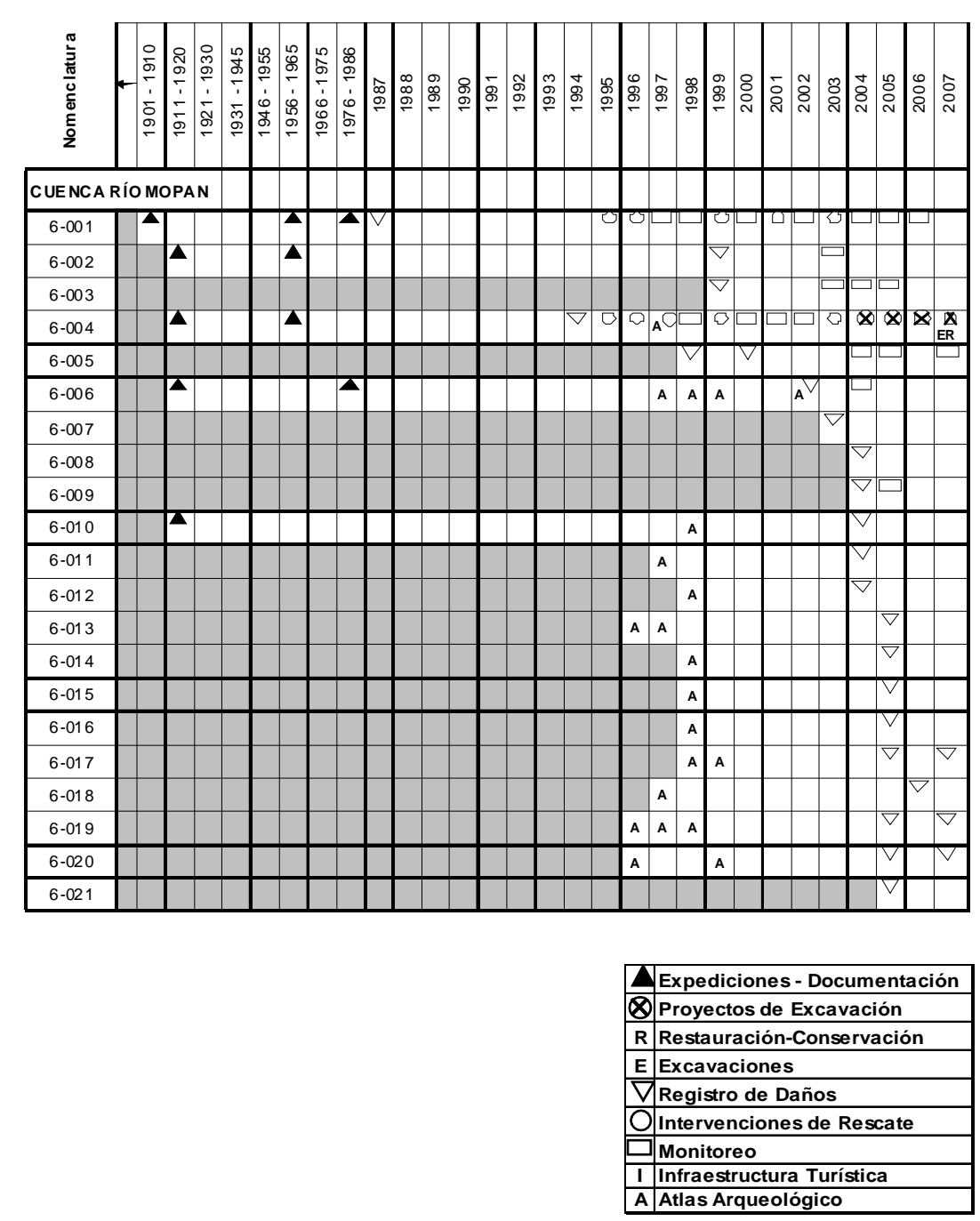


CUADRO 3

POSICIÓN DEL SITIO CON EL PAISAJE

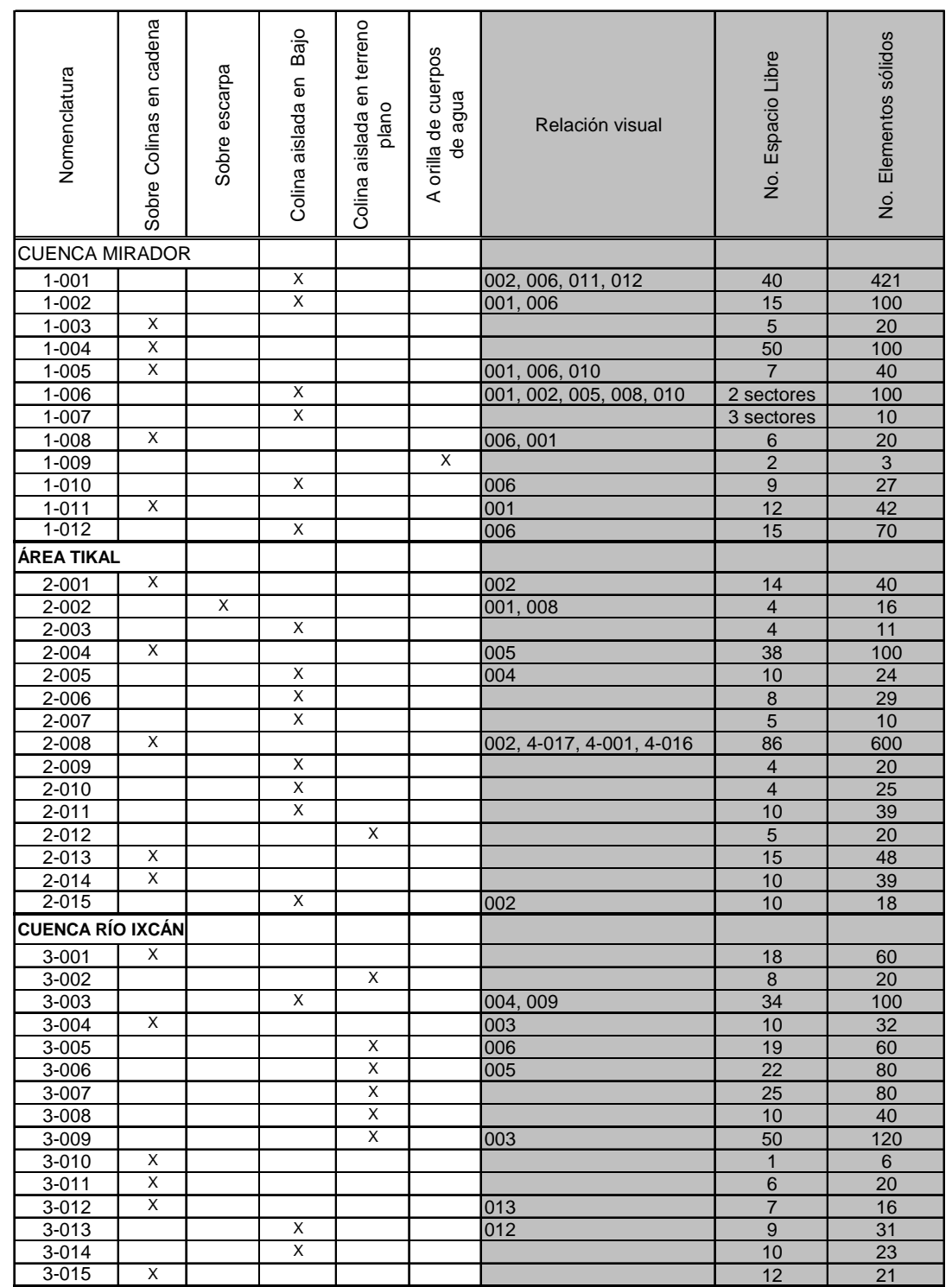


CUADRO 3

POSICIÓN DEL SITIO CON EL PAISAJE

\begin{tabular}{|c|c|c|c|c|c|c|c|c|}
\hline 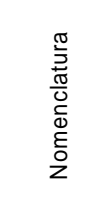 & 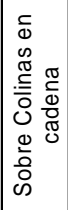 & 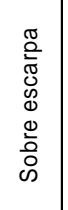 & 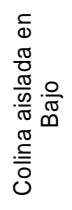 & 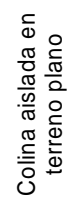 & 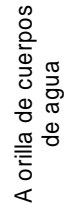 & Relación visual & 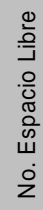 & 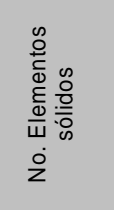 \\
\hline \multicolumn{9}{|c|}{ UUENCA RíO HOLMUL } \\
\hline 4-001 & $\mathrm{x}$ & & & & & 2-008 & 12 & 40 \\
\hline $\begin{array}{l}4-002 \\
-4003\end{array}$ & $x$ & & $x$ & & & & $\frac{25}{6}$ & $\frac{60}{20}$ \\
\hline 4-004 & $x$ & & & & & & $\frac{15}{15}$ & 35 \\
\hline $\begin{array}{l}4-005 \\
4-006\end{array}$ & & -5 & $x$ & & $x$ & & $\frac{6}{2}$ & $\frac{15}{6}$ \\
\hline 4-007 & $x$ & & & & & 010 & $\frac{2}{10}$ & 15 \\
\hline $\begin{array}{l}4-008 \\
-4009\end{array}$ & $x$ & 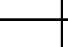 & $x$ & & & & $\frac{8}{8}$ & $\begin{array}{l}18 \\
28 \\
\end{array}$ \\
\hline $\begin{array}{ll}4-010 \\
-0.01\end{array}$ & $\frac{x}{x}$ & & & & & 007 & $\frac{3}{10}$ & 10 \\
\hline$\frac{4-011}{4-012}$ & & $x$ & & & & 013,004 & $\frac{16}{16}$ & 41 \\
\hline $\begin{array}{ll}4-013 \\
4-014\end{array}$ & $\bar{x}$ & & $x$ & & & $\begin{array}{l}012 \\
01236-0026-003\end{array}$ & $\frac{11}{50}$ & 23 \\
\hline$\frac{4-144}{4-015}$ & $\frac{x}{x}$ & & & & & & $\frac{30}{25}$ & $\frac{100}{100}$ \\
\hline 4 & $x$ & & & & & 2-008 & 10 & 18 \\
\hline $4-017$ & $\frac{x}{x}$ & -5 & & & & $\frac{2-008,019,5-032}{117}$ & $\frac{14}{12}$ & 36 \\
\hline $\begin{array}{l}4-018 \\
4-019\end{array}$ & $\frac{x}{x}$ & & & & & $5-179,021,025$ & $\frac{14}{4}$ & $\frac{40}{13}$ \\
\hline $4-020$ & & & $x$ & & & $221,028,025$ & 19 & 39 \\
\hline $4-021$ & $y$ & $x$ & $x$ & & -7 & 020,028 & & \\
\hline$\frac{4-202}{4-023}$ & $\lambda^{\prime}$ & $\frac{\hat{x}}{x}$ & & & $\lambda_{2}$ & $00,014,015$ & $\frac{9}{7}$ & $\frac{17}{22}$ \\
\hline $4-024$ & $x$ & & 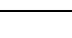 & & & & 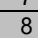 & \\
\hline $4-025$ & $x$ & & $y^{y}$ & & & & & 39 \\
\hline $\begin{array}{l}4-020 \\
4-027 \\
\end{array}$ & & & $\hat{x}$ & & & $0 \angle 1,0<2,014$ & & $\begin{array}{l}28 \\
11\end{array}$ \\
\hline $4-028$ & & & $\frac{x}{x}$ & & & $\frac{021,020}{0.620}$ & & 21 \\
\hline $\begin{array}{l}4-029 \\
4.030\end{array}$ & & & $\frac{x}{x}$ & & & & 5 & 14 \\
\hline
\end{tabular}


CUADRO 3

POSICIÓN DEL SITIO CON EL PAISAJE

\begin{tabular}{|c|c|c|c|c|c|c|c|c|}
\hline 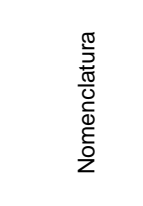 & 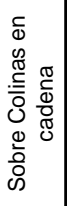 & 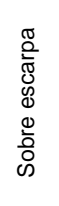 & 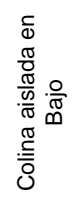 & 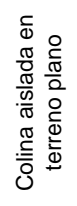 & 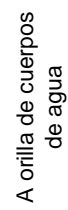 & Relación visual & 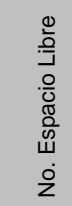 & 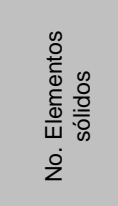 \\
\hline \multicolumn{9}{|c|}{ CUENCA DE LOS LAGOS } \\
\hline & & & & $x$ & & & 8 & 18 \\
\hline $\begin{array}{r}5-002 \\
5-003 \\
\end{array}$ & & & 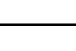 & $x$ & $\mathrm{x}$ & 005 & $\frac{12}{8}$ & \\
\hline $5-004$ & & & & $x$ & & 030,031 & 3 & $\frac{12}{9}$ \\
\hline 5-005 & $x$ & & & & $x$ & 002,028 & 10 & 34 \\
\hline $\begin{array}{l}5-006 \\
5-007\end{array}$ & 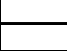 & & - & $\frac{x}{x}$ & $\frac{x}{x}$ & & $\frac{7}{9}$ & $\frac{24}{14}$ \\
\hline 5-008 & & & & & $x$ & & 5 & 39 \\
\hline $\begin{array}{l}5-009 \\
5-010 \\
\end{array}$ & $x$ & & - & & $x$ & 006,008 & $\begin{array}{l}3 \\
3 \\
\end{array}$ & $\begin{array}{l}14 \\
14 \\
\end{array}$ \\
\hline $5-011$ & & & & $x$ & & 013,012 & 5 & 16 \\
\hline $\begin{array}{l}5-512 \\
5-013 \\
\end{array}$ & - & & - & $\frac{x}{x}$ & & $\frac{011,013,014,017}{013}$ & $\begin{array}{l}6 \\
8 \\
\end{array}$ & $\frac{21}{26}$ \\
\hline $\begin{array}{ll}5-014 \\
5015\end{array}$ & $x$ & & & & & & 9 & \\
\hline $\begin{array}{l}5-5015 \\
5-016 \\
\end{array}$ & - & & & $\frac{x}{x}$ & & 013 & $\begin{array}{r}6 \\
7 \\
\end{array}$ & $\begin{array}{l}15 \\
28 \\
\end{array}$ \\
\hline $\begin{array}{l}5-017 \\
5010 \\
\end{array}$ & & & - & $x$ & & $013,018,021$ & 7 & 18 \\
\hline $\begin{array}{l}5-018 \\
5-019 \\
\end{array}$ & $\frac{x}{x}$ & & & & & $\frac{017,022,019,023}{018,020,021,022,032}$ & $\begin{array}{l}17 \\
40\end{array}$ & $\begin{array}{l}42 \\
100 \\
\end{array}$ \\
\hline $5-020$ & & & & $x$ & & & & \\
\hline 5-021 & $\frac{x}{x}$ & & 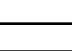 & 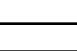 & 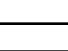 & $\frac{019,023,017,018}{0019,021}$ & $\frac{11}{5}$ & $\begin{array}{l}30 \\
15 \\
\end{array}$ \\
\hline 5-023 & $x$ & & & & & $019,021,017$ & 3 & 14 \\
\hline$\frac{5-024}{5-025}$ & - & & $\frac{x}{x}$ & & & $6-001,023$ & 3 & $\frac{12}{20}$ \\
\hline $\begin{aligned} 3-025 \\
5-026 \\
\end{aligned}$ & & & $x$ & & & $\begin{array}{ll}013,014 \\
013,011\end{array}$ & $\begin{array}{l}8 \\
7 \\
\end{array}$ & $\frac{20}{20}$ \\
\hline$\frac{5-027}{5-028}$ & $\frac{x}{x}$ & & & & $x$ & 005006 & $\frac{2}{11}$ & $\frac{3}{29}$ \\
\hline $\begin{aligned} 5-028 \\
5-029 \\
\end{aligned}$ & & 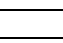 & & $x$ & & 000,000 & & $\frac{29}{10}$ \\
\hline$\frac{5-030}{5-3031}$ & - & $\frac{x}{x}$ & & & & 004,031 & $\begin{array}{l}3 \\
5 \\
\end{array}$ & $\begin{array}{r}7 \\
\end{array}$ \\
\hline $5-032$ & $x$ & & & & $x$ & $019,020,021$ & 5 & $\frac{10}{10}$ \\
\hline$\frac{5-033}{5-0.034}$ & $x$ & & & $x$ & $x$ & $0019,032,035$ & $\frac{4}{3}$ & $\frac{11}{8}$ \\
\hline & & & & & $x$ & & $\frac{3}{1}$ & $\begin{array}{l}8 \\
7 \\
\end{array}$ \\
\hline
\end{tabular}


CUADRO 3

POSICIÓN DEL SITIO CON EL PAISAJE

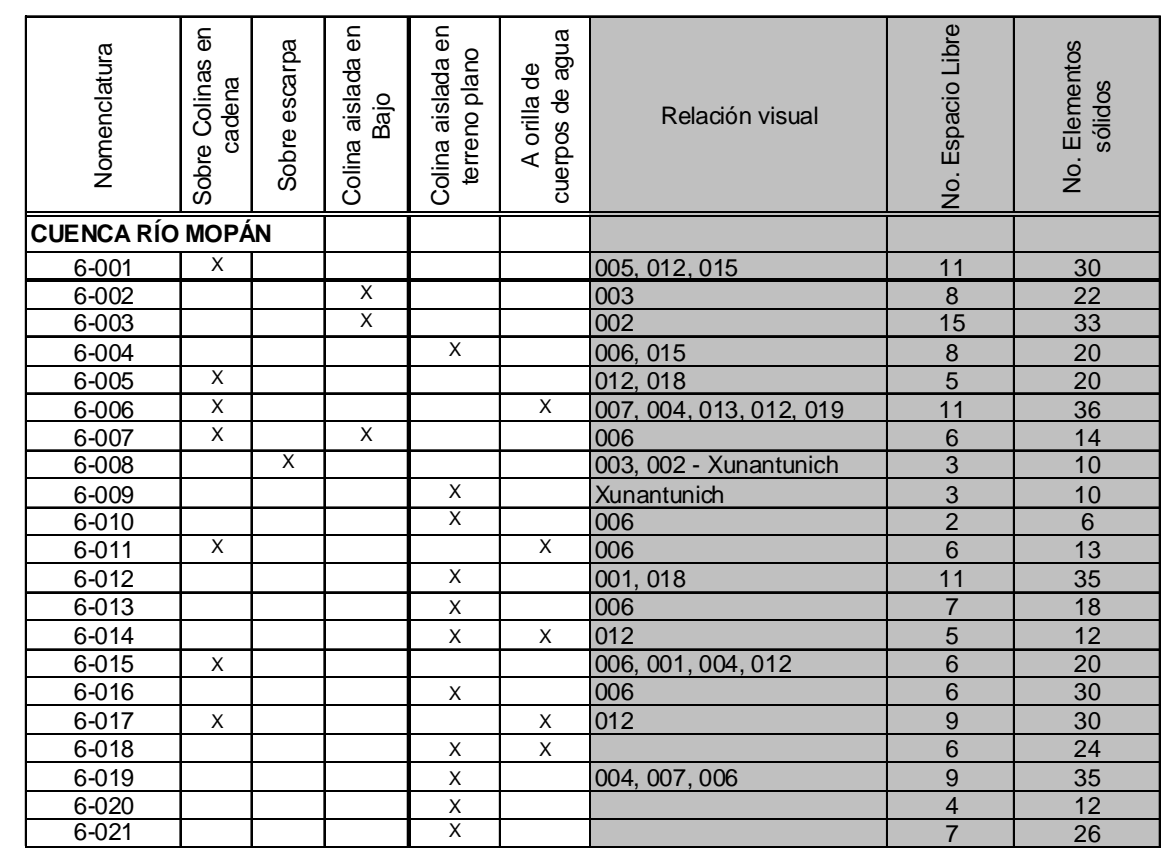


CUADRO 4

ELEMENTOS URBANOS

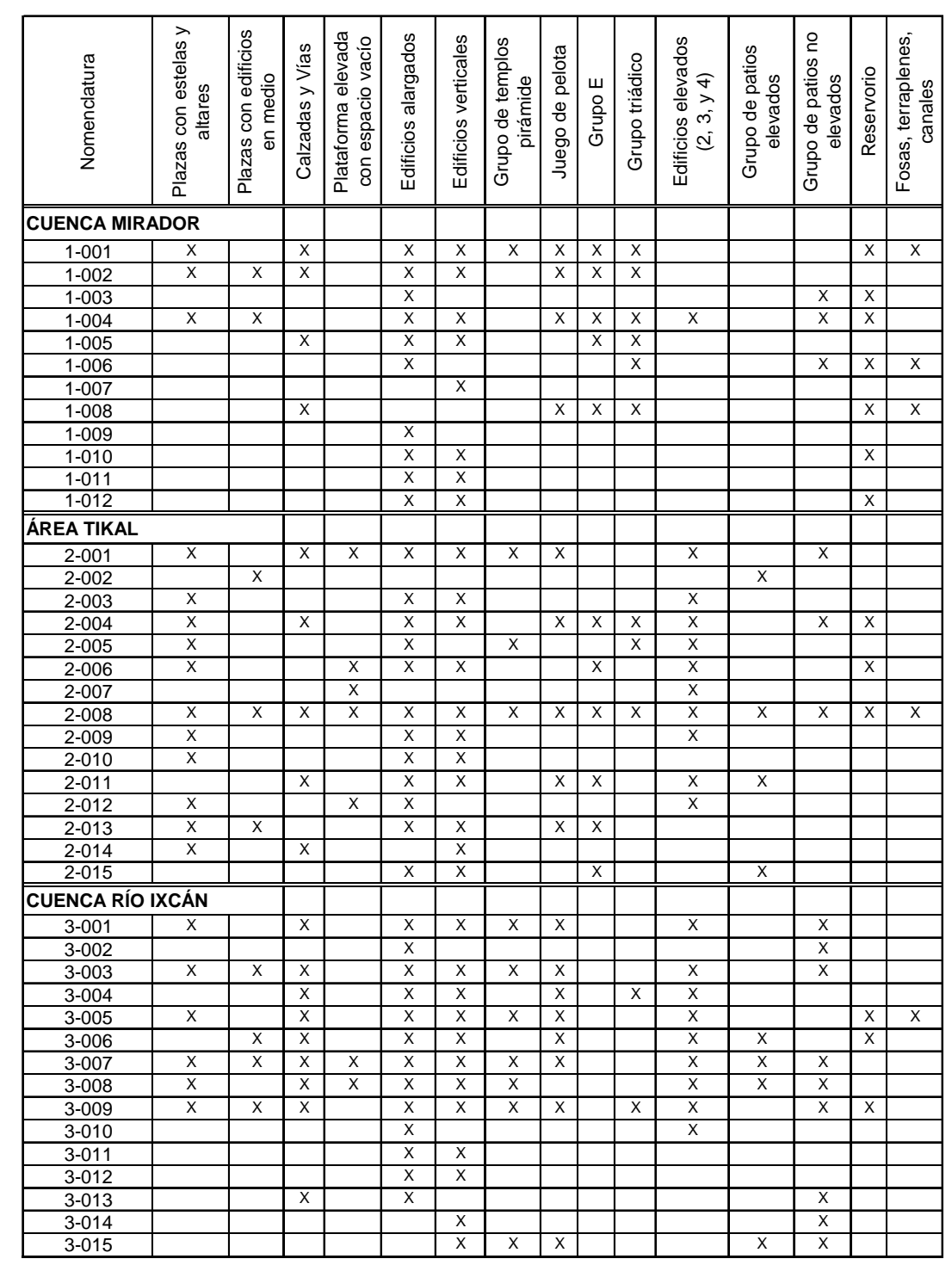


CUADRO 4

ELEMENTOS URBANOS

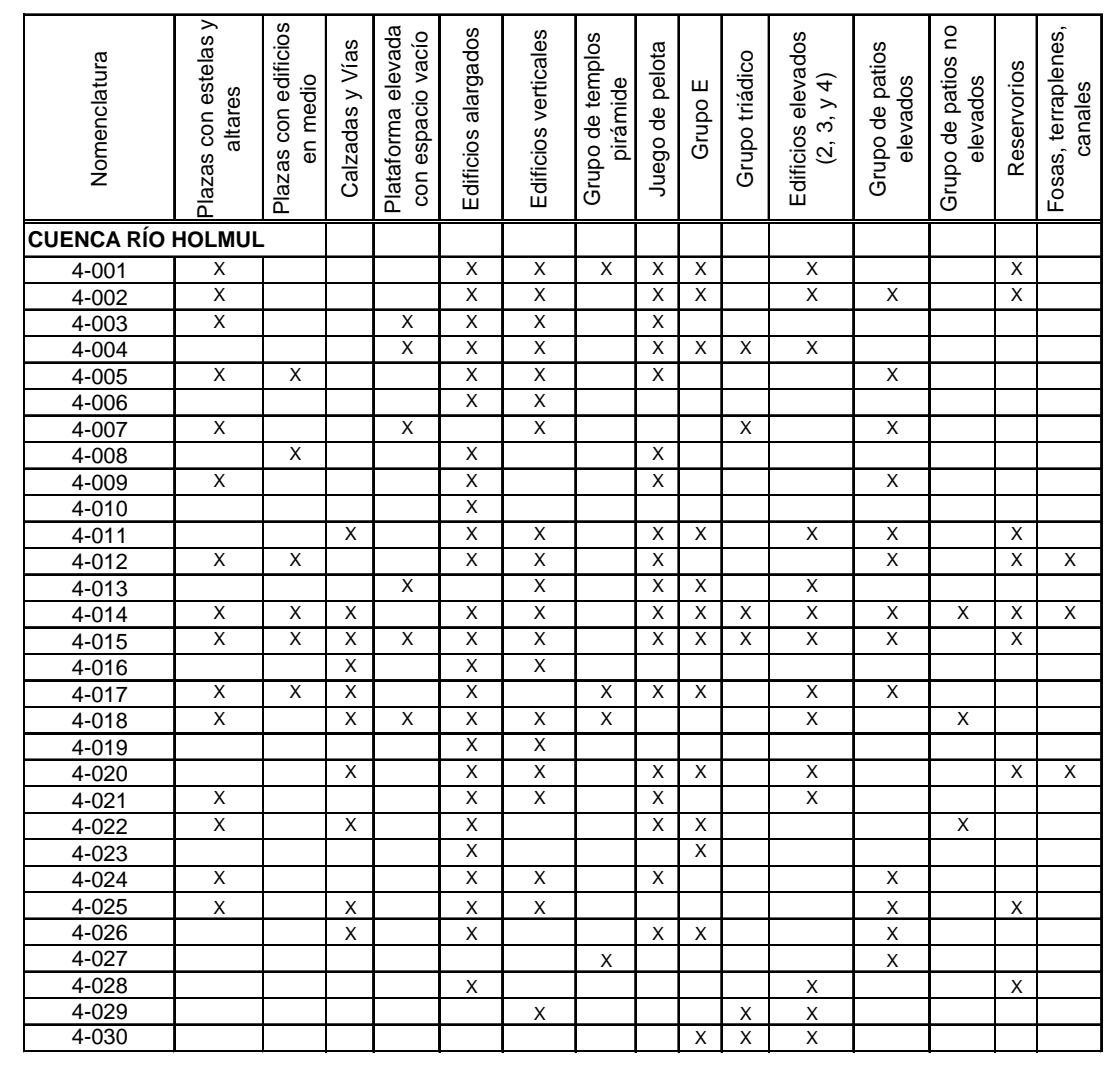


CUADRO 4

ELEMENTOS URBANOS

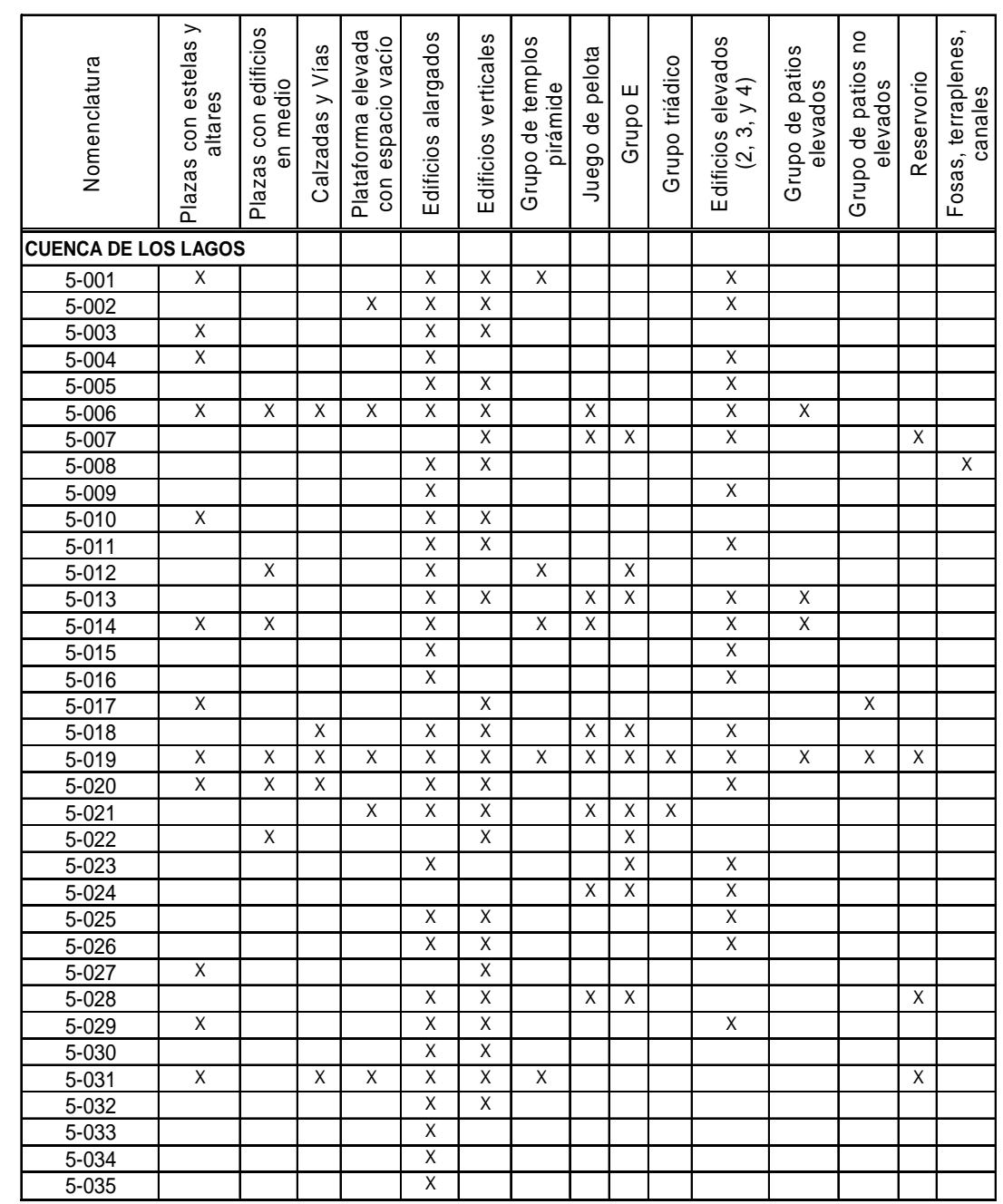


CUADRO 4

ELEMENTOS URBANOS

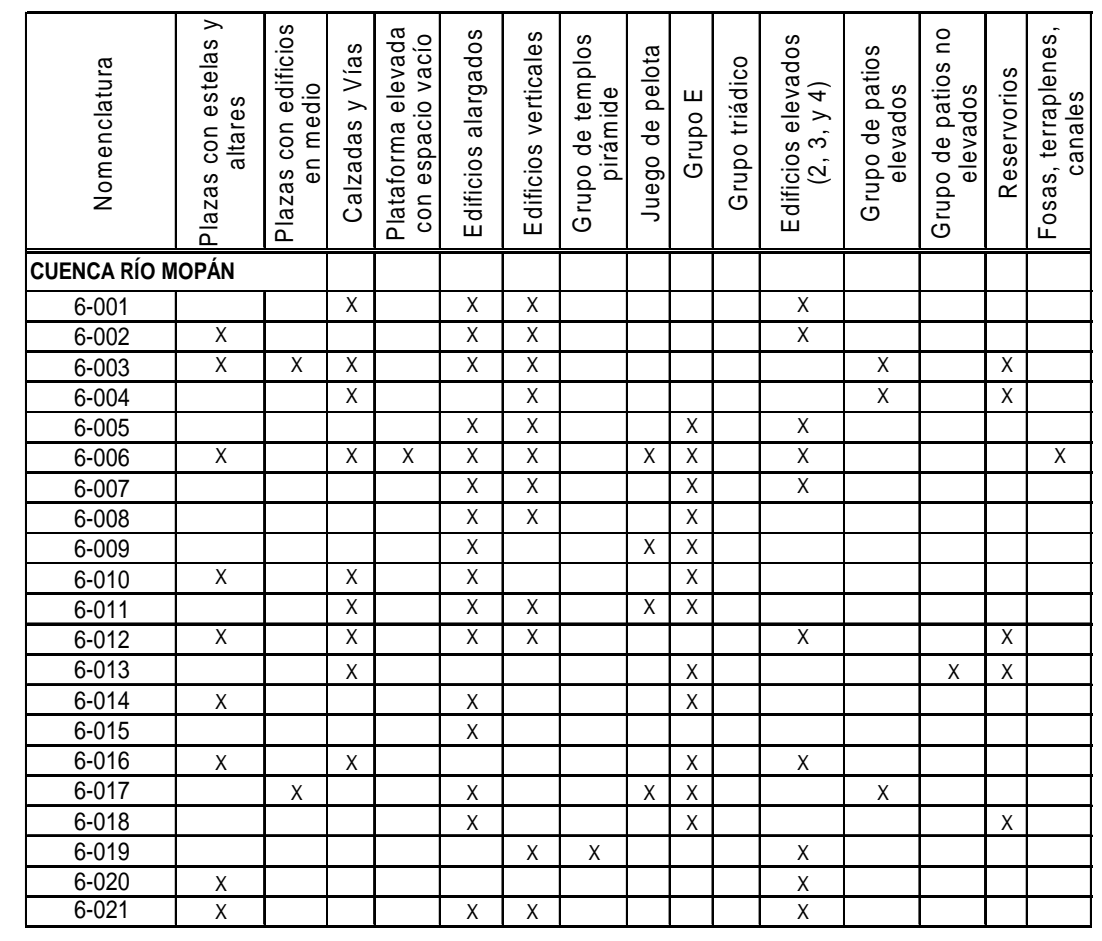


CUADRO 5

ELEMENTOS DE AROUITECTURA VISIBLE

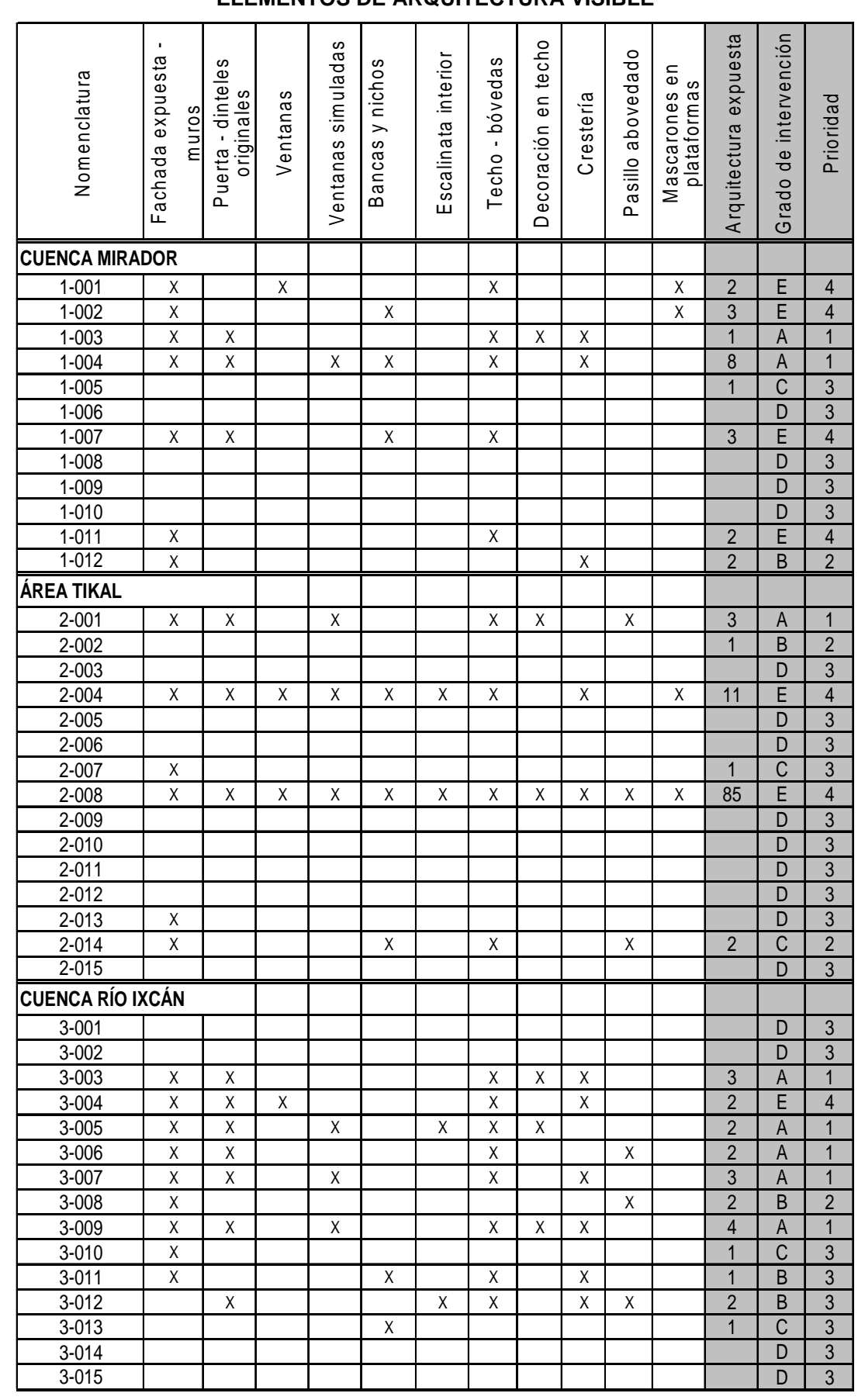


CUADRO 5

ELEMENTOS DE AROUITECTURA VISIBLE

\begin{tabular}{|c|c|c|c|c|c|c|c|c|c|c|c|c|c|c|}
\hline 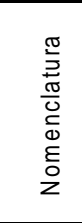 & 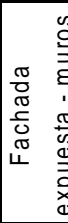 & 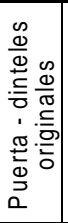 & 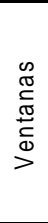 & 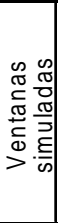 & 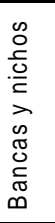 & 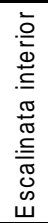 & $\begin{array}{l}0 \\
\frac{\pi}{0} \\
0 \\
0 \\
0 \\
\vdots \\
0 \\
0 \\
0 \\
0 \\
-\end{array}$ & 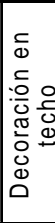 & 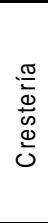 & $\begin{array}{l}0 \\
\frac{0}{\pi} \\
\frac{\pi}{0} \\
0 \\
0 \\
0 \\
0 \\
0 \\
0 \\
0 \\
\bar{N} \\
0 \\
0\end{array}$ & 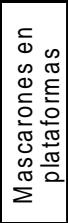 & 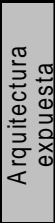 & 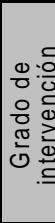 & 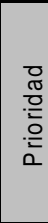 \\
\hline \multicolumn{15}{|c|}{ CUENCA RÍO HOLMUL } \\
\hline $4-001$ & & & & & & & $x$ & & & & & 2 & $B$ & 2 \\
\hline $4-002$ & $x$ & $x$ & & $x$ & $x$ & & $x$ & & & $x$ & & 3 & A & 1 \\
\hline $4-003$ & $\bar{x}$ & & & & & & & & & & & 1 & $\mathrm{C}$ & 3 \\
\hline $4-004$ & $\mathrm{x}$ & & & & $x$ & & & & & & $x$ & 1 & $\mathrm{C}$ & 3 \\
\hline $4-005$ & & & & & & & & & & & & 1 & $\mathrm{C}$ & 3 \\
\hline $4-006$ & & & & & & & & & & & & & $\mathrm{D}$ & 3 \\
\hline 4-007 & & & & & & & & & & & & & D & 3 \\
\hline $4-008$ & & & & & & & & & & & & & $\mathrm{D}$ & 3 \\
\hline $4-009$ & $x$ & $x$ & & & & & $x$ & & & & & 1 & $\mathrm{c}$ & $\frac{5}{3}$ \\
\hline $4-010$ & & & & & & & & & & & & & $\mathrm{D}$ & 3 \\
\hline 4-011 & & $x$ & & & $x$ & & $x$ & & & $x$ & & & $\mathrm{D}$ & 3 \\
\hline 4-012 & $x$ & $x$ & & & & $x$ & $x$ & & & & & 3 & $B$ & 2 \\
\hline $4-013$ & & & & & & & & & & & $\mathrm{x}$ & & $\mathrm{D}$ & 3 \\
\hline $4-014$ & $x$ & $x$ & & & & & $x$ & & & $x$ & $x$ & 3 & B & 3 \\
\hline 4-015 & $x$ & $x$ & & & $x$ & $x$ & $x$ & $\mathrm{x}$ & $x$ & & $x$ & 26 & $\mathrm{E}$ & 4 \\
\hline $4-016$ & & & & & & & & & & & & & $\mathrm{D}$ & 3 \\
\hline 4-017 & $x$ & $x$ & & & & & $x$ & & & $x$ & & 2 & $\mathrm{C}$ & 3 \\
\hline $4-018$ & & & & & & & & & & & & 2 & $\mathrm{C}$ & 3 \\
\hline $4-019$ & $x$ & & & & & & & & & & & & $\mathrm{D}$ & 3 \\
\hline $4-020$ & & $x$ & & & & & $x$ & & $x$ & & & 1 & $\mathrm{C}$ & 3 \\
\hline $4-021$ & & & & & & & & & & & & & $\mathrm{D}$ & 3 \\
\hline $4-022$ & & & & & & & & & & & & & $\mathrm{D}$ & 3 \\
\hline $4-023$ & & & & & & & & & & & & & D & 3 \\
\hline $4-024$ & $x$ & $x$ & & & & & $x$ & & & $x$ & & 2 & $\mathrm{~B}$ & 3 \\
\hline $4-025$ & $\mathrm{x}$ & $x$ & & & & & & $x$ & $x$ & & & 3 & $\mathrm{C}$ & 4 \\
\hline $4-026$ & & & & & & & & & & & & & $\mathrm{D}$ & $\frac{7}{4}$ \\
\hline $4-027$ & & & & & & & & & & & & & $\mathrm{D}$ & 3 \\
\hline $4-028$ & & & & & & & & & & & & & $\mathrm{D}$ & 3 \\
\hline $4-029$ & & & & & & & & & & & & & $\mathrm{D}$ & $\frac{5}{3}$ \\
\hline $4-030$ & & & & & & & & & & & & & $\mathrm{D}$ & 3 \\
\hline
\end{tabular}


CUADRO 5

ELEMENTOS DE AROUITECTURA VISIBLE

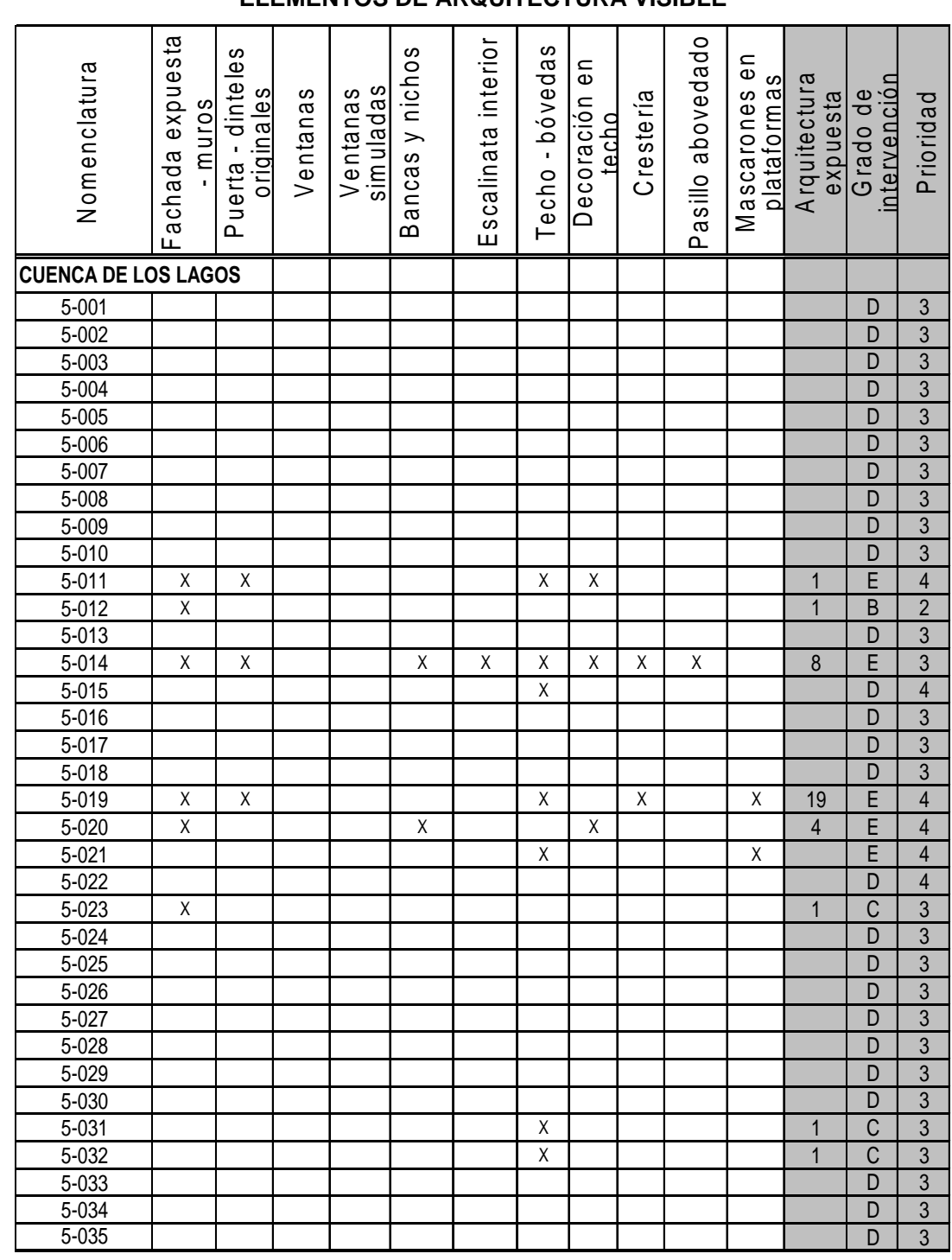


CUADRO 5

ELEMENTOS DE ARQUITECTURA VISIBLE

\begin{tabular}{|c|c|c|c|c|c|c|c|c|c|c|c|c|c|c|}
\hline 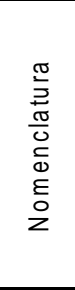 & 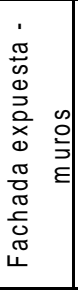 & 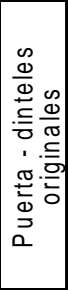 & 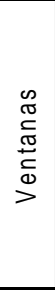 & 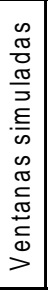 & 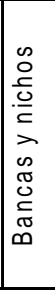 & 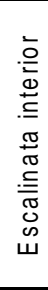 & 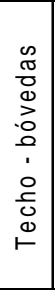 & 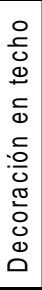 & 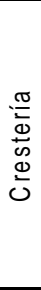 & $\begin{array}{l}0 \\
\frac{0}{0} \\
\frac{\pi}{0} \\
0 \\
0 \\
0 \\
0 \\
0 \\
0 \\
\overline{\bar{N}} \\
\pi \\
0\end{array}$ & 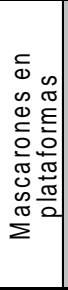 & 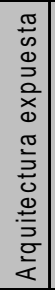 & 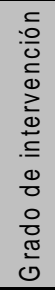 & $\begin{array}{l}\text { 음 } \\
\frac{\pi}{0} \\
\frac{0}{0}\end{array}$ \\
\hline \multicolumn{15}{|c|}{ CUENCA RÍO MOPÁN } \\
\hline 6-001 & $\mathrm{x}$ & $\mathrm{x}$ & & & & & $x$ & $x$ & $x$ & & & 1 & A & 1 \\
\hline $6-002$ & & & & & & & & & & & & 1 & $\mathrm{C}$ & 2 \\
\hline 6-003 & & & & & & & $x$ & & & & & 1 & $\mathrm{~B}$ & 2 \\
\hline $6-004$ & $x$ & & & & $x$ & & $x$ & & & & & 2 & $E$ & 4 \\
\hline $6-005$ & & & & & & & & & & & & & $\mathrm{D}$ & 3 \\
\hline $6-006$ & & & & & & & & & & & & & $\mathrm{D}$ & 3 \\
\hline 6-007 & & & & & & & & & & & & & $\mathrm{D}$ & 3 \\
\hline $6-008$ & & & & & & & & & & & & & $\mathrm{D}$ & 3 \\
\hline $6-009$ & & & & & & & & & & & & & $\mathrm{D}$ & 3 \\
\hline $6-010$ & & & & & & & & & & & & & $\mathrm{D}$ & 3 \\
\hline $6-011$ & & & & & & & & & & & & & $\mathrm{D}$ & 3 \\
\hline $6-012$ & & & & & & & & & & & & & $\mathrm{D}$ & 3 \\
\hline $6-013$ & & & & & & & & & & & & & $\mathrm{D}$ & 3 \\
\hline $6-014$ & & & & & & & & & & & & & $\mathrm{D}$ & 3 \\
\hline $6-015$ & & & & & & & & & & & & & $\mathrm{D}$ & 3 \\
\hline $6-016$ & & & & & & & & & & & & & $\mathrm{D}$ & 3 \\
\hline $6-017$ & $x$ & & & & & & & & & & & 1 & $\mathrm{C}$ & 3 \\
\hline $6-018$ & & & & & & & & & & & & & $\mathrm{D}$ & 3 \\
\hline $6-019$ & & & & & & & $x$ & & & & & 1 & $\mathrm{c}$ & 3 \\
\hline $6-020$ & $x$ & $x$ & & & $x$ & $x$ & $x$ & & & & & 4 & $A$ & 1 \\
\hline $6-021$ & & & & & & & & & & & & & $\mathrm{D}$ & 3 \\
\hline
\end{tabular}

Grado de Intervención

Prioridad

Muy urgente
Urgente
Poco urgente
Arquitectura en saqueo
Intervenido o en proceso

$\begin{array}{cl}1 & \text { Muy urgente } \\ 2 & \text { Importante } \\ 3 & \text { Acciones preventivas } \\ 4 & \text { Monitoreo }\end{array}$


CUADRO 6

REGISTRO DE SAQUEOS EN EDIFICIOS

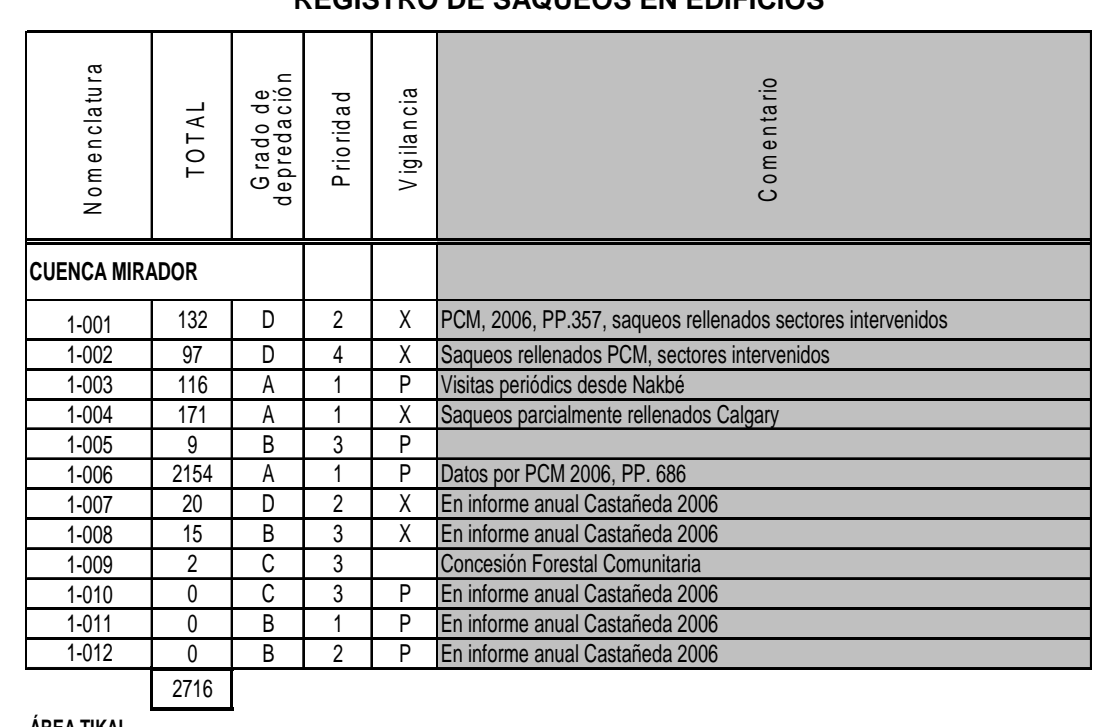

ÁREA TIKAL
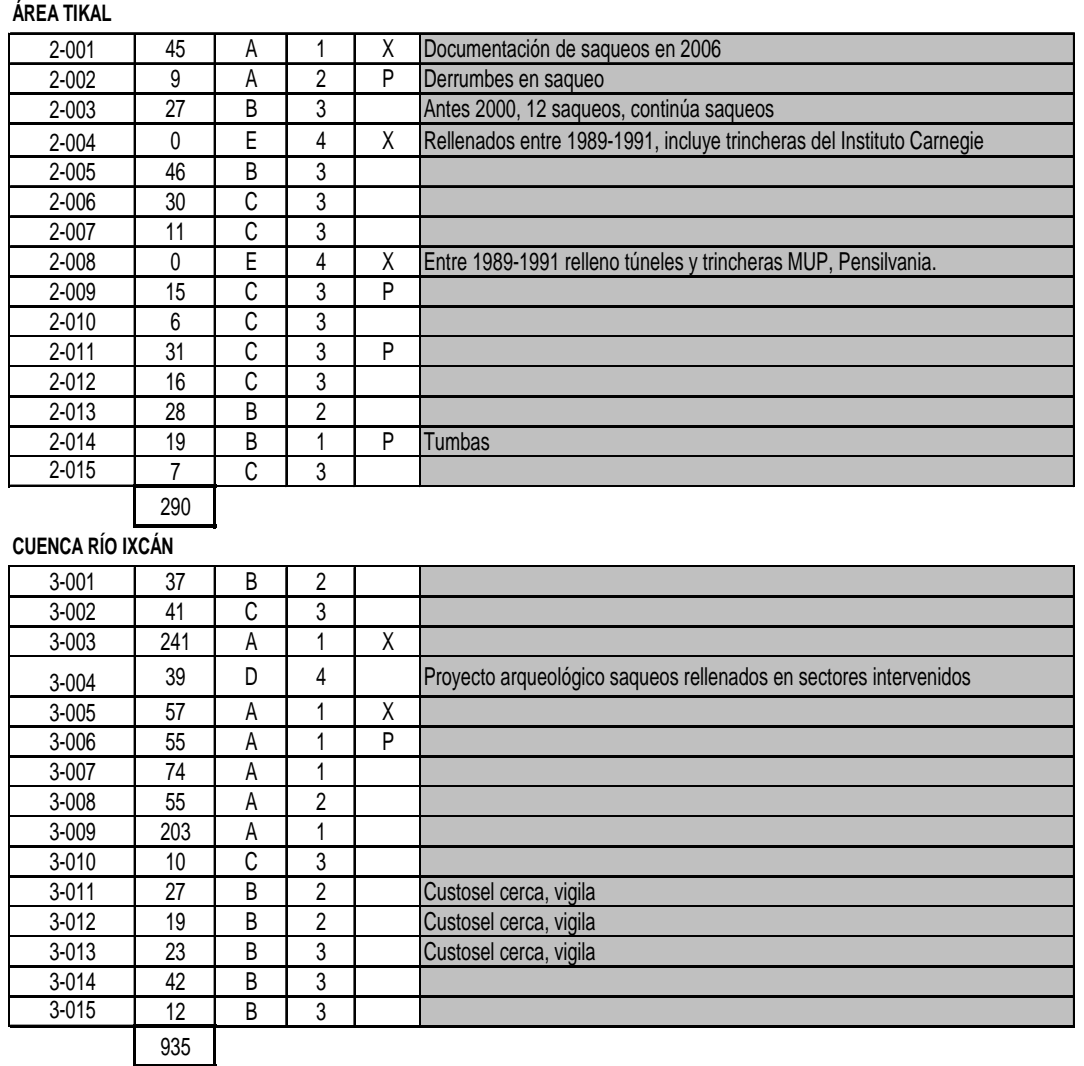
CUADRO 6

REGISTRO DE SAQUEOS EN EDIFICIOS

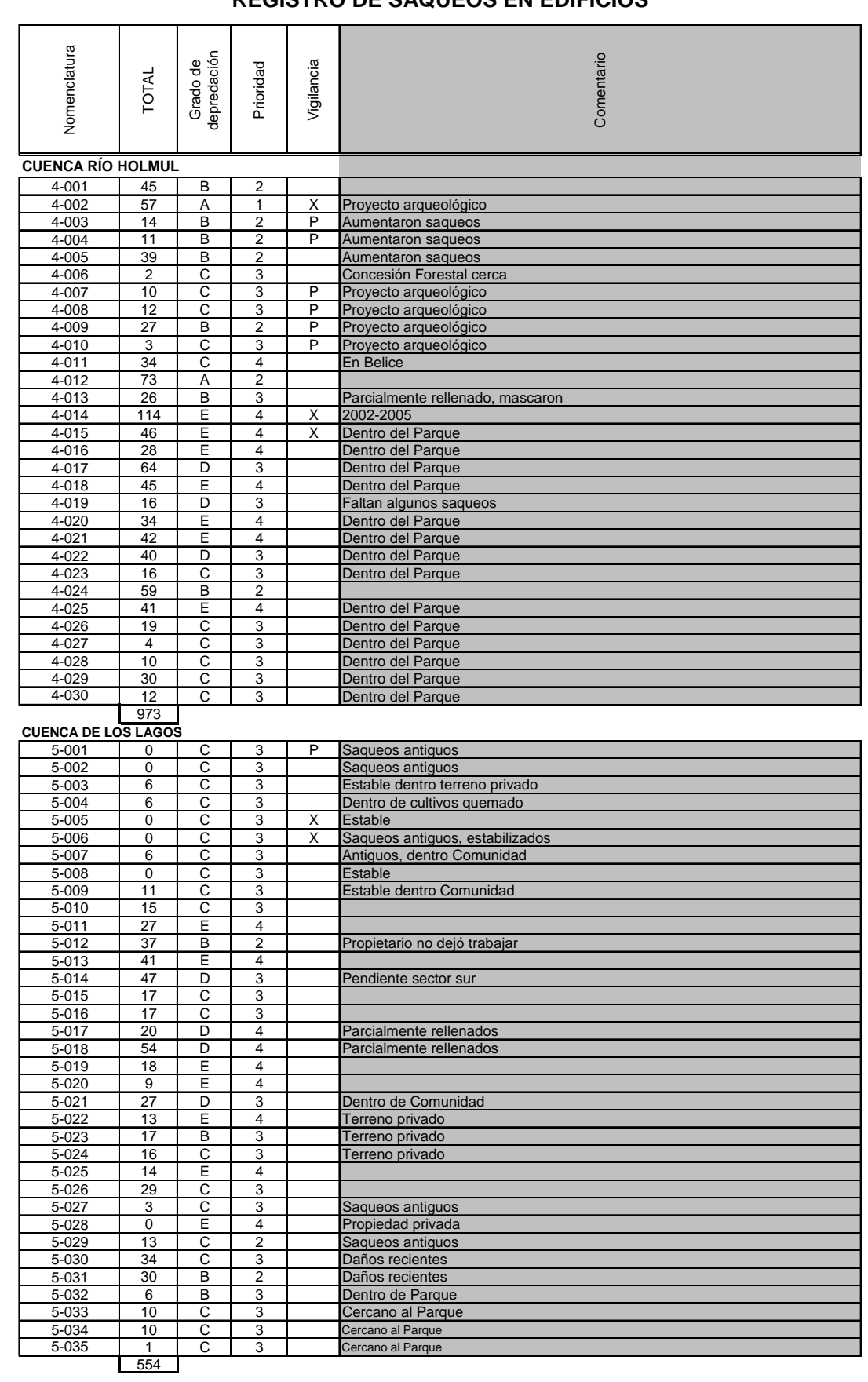


CUADRO 6

REGISTRO DE SAQUEOS EN EDIFICIOS

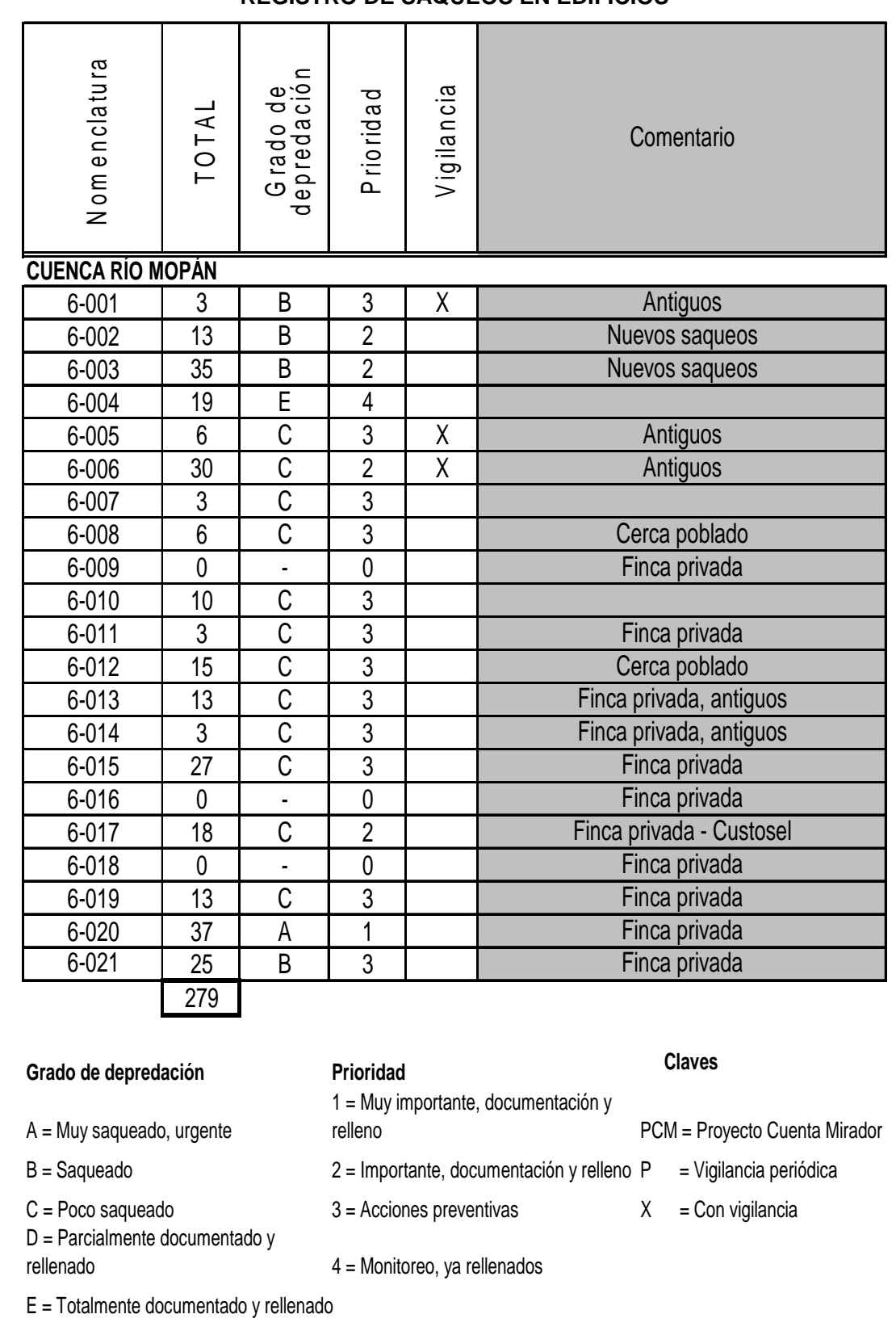


CUADRO 7

INDICADORES DE SAQUEOS

\begin{tabular}{|c|c|c|c|c|c|c|c|c|}
\hline \multirow{2}{*}{ CUENCA } & \multicolumn{5}{|c|}{$\begin{array}{c}\text { GRADO DE } \\
\text { DEPREDACIÓN }\end{array}$} & \multirow{2}{*}{$\begin{array}{l}\text { Prioridad por } \\
\text { sitios }\end{array}$} & \multirow{2}{*}{$\begin{array}{c}\text { Prioridad } \\
\text { por cuenca }\end{array}$} & \multirow{2}{*}{$\begin{array}{l}\text { Sitios rellenados o en } \\
\text { proceso }\end{array}$} \\
\hline & A & B & C & D & E & & & \\
\hline $\begin{array}{c}1 \\
\text { Mirador }\end{array}$ & 3 & 4 & 2 & 3 & 0 & $\begin{array}{l}\text { La Muralla } \\
\text { Naachtún } \\
\text { Tintal }\end{array}$ & 2 & $\begin{array}{l}\text { El Mirador } \\
\text { Nakbé } \\
\text { La Florida }\end{array}$ \\
\hline $\begin{array}{c}2 \\
\text { Tikal }\end{array}$ & 2 & 4 & 7 & 0 & 2 & $\begin{array}{l}\text { El Zotz } \\
\text { El Diablo }\end{array}$ & 3 & $\begin{array}{l}\text { Uaxactún } \\
\text { Tikal }\end{array}$ \\
\hline $\begin{array}{c}3 \\
\text { Río Ixcán }\end{array}$ & 6 & 6 & 2 & 1 & 0 & \begin{tabular}{|c|} 
Río Azul \\
Kinal-Chochkitam \\
Xmakabatún \\
La Honradez- \\
Xultún
\end{tabular} & 1 & San Bartolo \\
\hline $\begin{array}{c}4 \\
\text { Río Holmul }\end{array}$ & 2 & 7 & 11 & 3 & 7 & $\begin{array}{l}\text { Holmul } \\
\text { Witzná }\end{array}$ & 3 & $\begin{array}{l}\text { Naranjo, Nakum, El Carmen, El } \\
\text { Tigre, Kanajau, La Perra, Poza } \\
\text { Maya, Pochitoca }\end{array}$ \\
\hline $\begin{array}{c}5 \\
\text { Los Lagos }\end{array}$ & 0 & 4 & 20 & 2 & 9 & 0 & 5 & $\begin{array}{l}\text { Corozal Torre, Quemada } \\
\text { Corozal, San Clemente, La } \\
\text { Naya, Ixtinto, Yaxhá, Topoxté, } \\
\text { Holtún, El Sombrero, Ta-Ai } \\
\text { Corozal }\end{array}$ \\
\hline $\begin{array}{c}6 \\
\text { Río Mopán }\end{array}$ & 1 & 3 & 12 & 0 & 1 & Chilonché & 4 & La Blanca \\
\hline & 14 & 28 & 54 & 9 & 19 & & & \\
\hline
\end{tabular}

Grado de depredación:

$A=$ Muy saqueado, urgente

$B=$ Saqueado

$C=$ Poco saqueado

$D=$ Parcialmente documentado y rellenado

$\mathrm{E}=$ Totalmente documentado $\mathrm{y}$ rellenado 
CUADRO 8

INDICADORES DE EDIFICIOS EN PELIGRO

\begin{tabular}{|c|c|c|c|c|c|c|c|c|c|c|c|c|c|}
\hline \multirow{2}{*}{ CUENCA } & \multicolumn{10}{|c|}{ GRADO DE INTERVENCIÓN } & \multirow{2}{*}{$\begin{array}{c}\text { Sitios } \\
\text { prioritarios }\end{array}$} & \multirow{2}{*}{ Prioridad } & \multirow{2}{*}{$\begin{array}{l}\text { Sitios intervenidos o en } \\
\text { proceso y estratégicos }\end{array}$} \\
\hline & A & & & B & & c & & D & & $\mathrm{E}$ & & & \\
\hline $\begin{array}{c}1 \\
\text { Mirador }\end{array}$ & 2 & 9 & 1 & 2 & 1 & 1 & 4 & 0 & 4 & 10 & $\begin{array}{l}\text { La Muralla } \\
\text { Naachtún }\end{array}$ & 2 & $\begin{array}{c}\text { Mirador } \\
\text { Nakbé } \\
\text { La Muerta }\end{array}$ \\
\hline $\begin{array}{c}2 \\
\text { Tikal }\end{array}$ & 1 & 3 & 1 & 1 & 2 & 3 & 9 & 0 & 2 & 96 & El Zotz & 2 & $\begin{array}{l}\text { Uaxactún } \\
\text { Tikal }\end{array}$ \\
\hline $\begin{array}{c}3 \\
\text { Río Ixcán }\end{array}$ & 5 & 14 & 3 & 5 & 2 & 2 & $\mid 4$ & 0 & 1 & 2 & $\begin{array}{c}\text { Río Azul } \\
\text { Kinal- } \\
\text { Chochkitam } \\
\text { La Honradez } \\
\text { Xultún }\end{array}$ & 1 & San Bartolo \\
\hline $\begin{array}{c}4 \\
\text { Río } \\
\text { Holmul }\end{array}$ & 1 & 3 & 4 & 10 & 8 & 12 & $\mid 12$ & 0 & 8 & 26 & Holmul & 2 & $\begin{array}{l}\text { Nakum } \\
\text { Naranjo }\end{array}$ \\
\hline $\begin{array}{c}5 \\
\text { Los Lagos }\end{array}$ & 0 & 0 & 1 & 1 & 3 & 3 & $\mid 24$ & 0 & 4 & 32 & & 4 & $\begin{array}{c}\text { Yaxhá } \\
\text { Topoxté } \\
\text { Corozal Torre } \\
\text { San Clemente }\end{array}$ \\
\hline $\begin{array}{c}6 \\
\text { Río Mopán }\end{array}$ & 2 & 5 & 1 & 1 & 3 & 3 & $\mid 14$ & 0 & 1 & 2 & $\begin{array}{l}\text { Tzikintzakán } \\
\text { Chilonché }\end{array}$ & 3 & La Blanca \\
\hline
\end{tabular}

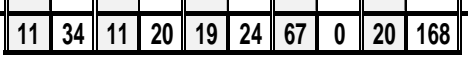

Grado de intervención:

$A=$ Muy urgente

$\square$ Sitio

$B=$ Urgente

$\square$ Edificio

$C=$ Poco urgente

$D=$ Arquitectura en saqueos

$E=$ Intervenido 0 en proceso 
CUADRO 9

PRIORIDADES DE INTERVENCIÓN

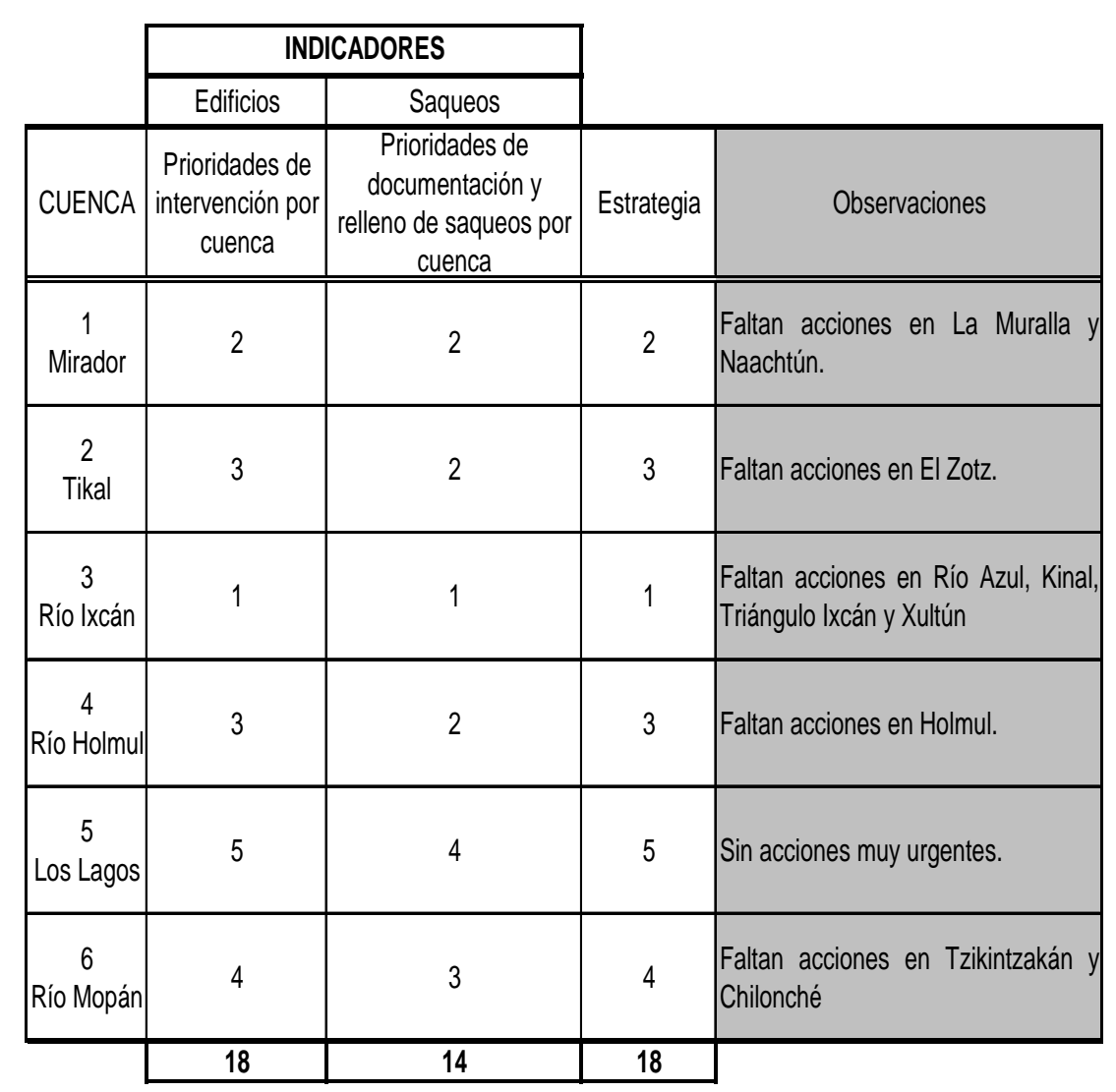


CUADRO 10

ESTRATEGIA DEL PLAN

PROGRAMAS Y PROYECTOS DE INVERSIÓN

\begin{tabular}{|c|c|c|c|c|c|c|}
\hline CONJUNTO & $\begin{array}{c}\text { ELEMENTO } \\
\text { ESTRATÉGICO }\end{array}$ & $\begin{array}{c}\text { PRIORIDAD } \\
\text { CUADRO } 7 \mathrm{Y} \\
8\end{array}$ & $\begin{array}{l}\text { USO DEL } \\
\text { SUELO }\end{array}$ & $\begin{array}{l}\text { PRIORIDAD } \\
\text { PLAN }\end{array}$ & ACTIVIDAD PRINCIPAL & TOTAL \\
\hline $1-1$ & $\begin{array}{c}\text { Carmelita } \\
\text { Florida } \\
\text { Wakna } \\
\text { El Burro } \\
\end{array}$ & 2 & $\begin{array}{c}\text { ZUM } \\
\text { Concesión } \\
\text { Forestal } \\
\text { Comunitaria } \\
\end{array}$ & 2 & $\begin{array}{l}\text { Ruta de conección con } \\
\text { Bloque } 3\end{array}$ & 2 \\
\hline $1-2$ & $\begin{array}{l}\text { Nakbé } \\
\text { El Mirador }\end{array}$ & 2 & $\begin{array}{l}\text { Núcleo } \\
\text { Bloque } 3\end{array}$ & 1 & $\begin{array}{l}\text { Estación turística en } \\
\text { Nakbé }\end{array}$ & 1.5 \\
\hline $1-3$ & $\begin{array}{l}\text { La Muralla } \\
\text { Naachtún }\end{array}$ & 1 & $\begin{array}{l}\text { Núcleo } \\
\text { Bloque } 3\end{array}$ & 1 & $\begin{array}{l}\text { Rescate arquitectura en } \\
\text { peligro. Consolidación } \\
\text { Bloque } 3 \\
\end{array}$ & 1 \\
\hline $2-1$ & $\begin{array}{c}\text { Tikal } \\
\text { Uaxactún }\end{array}$ & 4 & $\begin{array}{l}\text { Núcleo } \\
\text { Bloque 1+ } \\
\text { poblado }\end{array}$ & 1 & $\begin{array}{c}\text { Uso del recurso } \\
\text { preaparado } \\
\text { Estación turística en } \\
\text { Uaxactún. Promover } \\
\text { ampliación cobertura de } \\
\text { UNESCOO. } \\
\end{array}$ & 2.5 \\
\hline $2-2$ & El Zotz & 2 & $\begin{array}{l}\text { Núcleo } \\
\text { Bloque } 1\end{array}$ & 1 & $\begin{array}{l}\text { Rescate arq. en peligro } \\
\text { Activar Biotopo. } \\
\text { Consolidación Bloque } 1 .\end{array}$ & 1.5 \\
\hline $3-1$ & $\begin{array}{l}\text { Río Azul } \\
\text { Kinal }\end{array}$ & 1 & $\begin{array}{l}\text { Núcleo } \\
\text { Bloque } 3\end{array}$ & 1 & $\begin{array}{l}\text { Rescate arquitectura en } \\
\text { peligro. Consolidación } \\
\text { Bloque } 3\end{array}$ & 1 \\
\hline $3-2$ & $\begin{array}{l}\text { Triángulo } \\
\text { Ixcán }\end{array}$ & 1 & $\begin{array}{c}\text { ZUM } \\
\begin{array}{c}\text { Concesín Forestal } \\
\text { Comunitaria }\end{array} \\
\end{array}$ & 1 & $\begin{array}{l}\text { Rescate arq. en peligro } \\
\text { Estación turística } \\
\text { Activar Triángulo }\end{array}$ & 1 \\
\hline $3-3$ & Xultún & 1 & $\begin{array}{c}\text { zUM } \\
\begin{array}{c}\text { Concesion Forestal } \\
\text { Comunitaria }\end{array}\end{array}$ & 1 & \begin{tabular}{|} 
Rescate de arq. en peligro \\
Rescate Corredor \\
Biológico
\end{tabular} & 1 \\
\hline $3-4$ & Conjunto Pucteal & 3 & $\begin{array}{c}\text { ZUM } \\
\text { Concesión Forestal } \\
\text { Comunitaria }\end{array}$ & 2 & Rescate de arquitectura. & 2.5 \\
\hline $4-1$ & $\begin{array}{l}\text { Holmul } \\
\text { Yaloch }\end{array}$ & 2 & $\begin{array}{c}\text { ZUM } \\
\text { Concesion Forestal } \\
\text { comunitaria }\end{array}$ & 1 & $\begin{array}{l}\text { Rescate de arquitectura } \\
\text { Estación turística }\end{array}$ & 1.5 \\
\hline $4-2$ & $\begin{array}{l}\text { Triángulo } \\
\text { YNN }\end{array}$ & 4 & $\begin{array}{l}\text { Núcleo } \\
\text { Bloque } 1\end{array}$ & 1 & $\begin{array}{l}\text { Uso del recurso } \\
\text { preparado }\end{array}$ & 2.5 \\
\hline $5-1$ & $\begin{array}{l}\text { Alrededor del } \\
\text { Lago Petén Itzá }\end{array}$ & 4 & Bloque 2 & 1 & $\begin{array}{c}\text { Consolidación área } \\
\text { central } \\
\text { Infraestructura }\end{array}$ & 2.5 \\
\hline $5-2$ & $\begin{array}{c}\text { Circuitos cercanos } \\
\text { a Yaxháa }\end{array}$ & 4 & $\begin{array}{c}\text { Sitios - poblados } \\
\text { y red vial }\end{array}$ & 1 & $\begin{array}{c}\text { Integración circuitos San } \\
\text { Clemente - iniciar otros } \\
\text { (Holtún) }\end{array}$ & 2.5 \\
\hline $6-1$ & Tzikintzakán & 3 & $\begin{array}{c}\text { Sitios - poblados } \\
\text { y red vial }\end{array}$ & 2 & Rescate de arquitectura & 2.5 \\
\hline $6-2$ & La Blanca & 3 & $\begin{array}{c}\text { Sitios - poblados } \\
\text { y red vial }\end{array}$ & 2 & $\begin{array}{l}\text { Completar activación. } \\
\text { Conexión con Chilonché. }\end{array}$ & 2.5 \\
\hline $6-3$ & $\begin{array}{l}\text { Melchor - Ucanal } \\
\text { Camalote }\end{array}$ & 3 & $\begin{array}{c}\text { Sitios - poblados } \\
\text { y red vial }\end{array}$ & 3 & $\begin{array}{l}\text { Preparar sitios para } \\
\text { circuito }\end{array}$ & 3 \\
\hline
\end{tabular}

ZUM $=\quad$ Zona de Usos Mútitiples 
APENDICE

Figuras en planos 


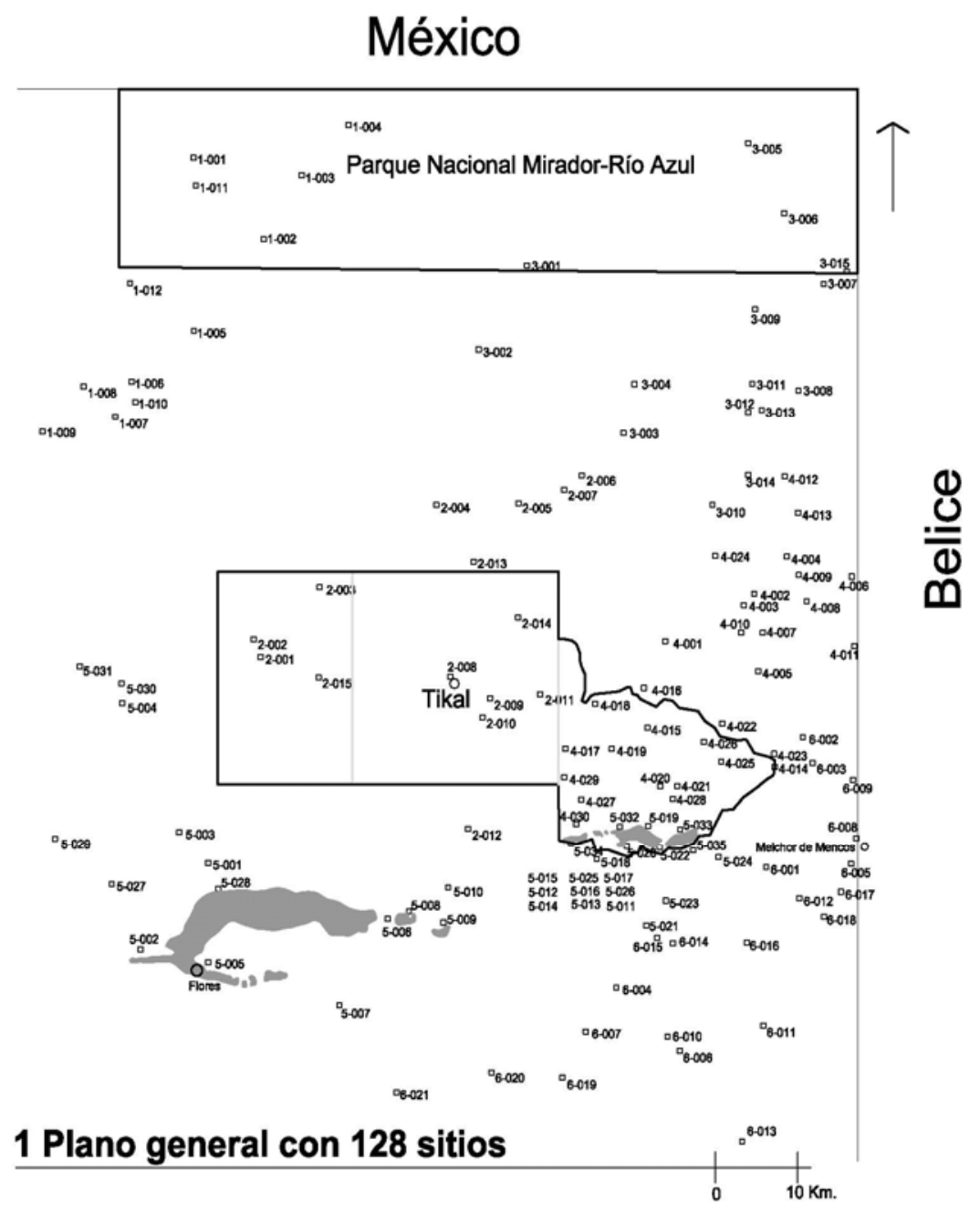


2. Planos esquemáticos CUENCA MIRADOR.
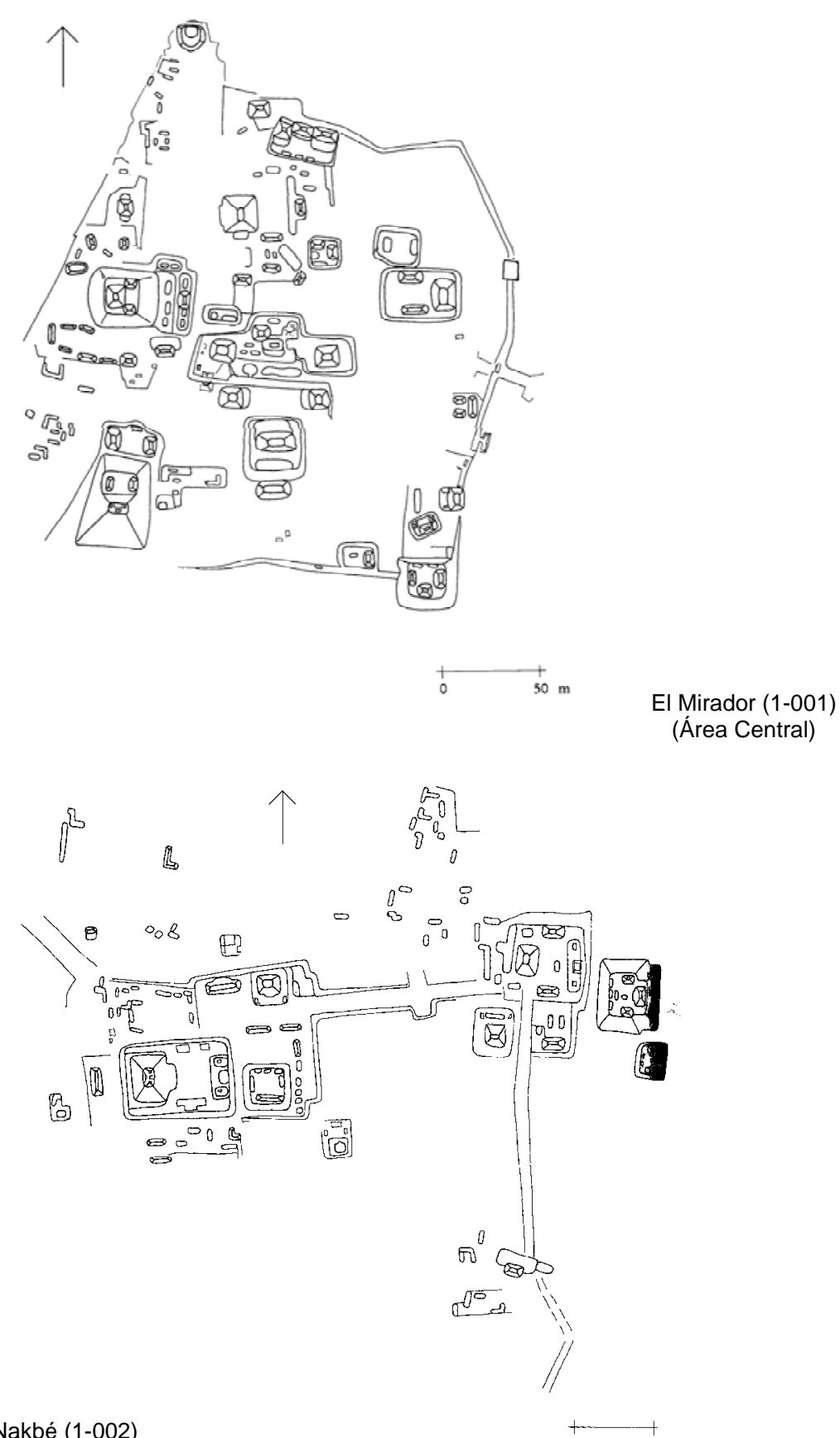


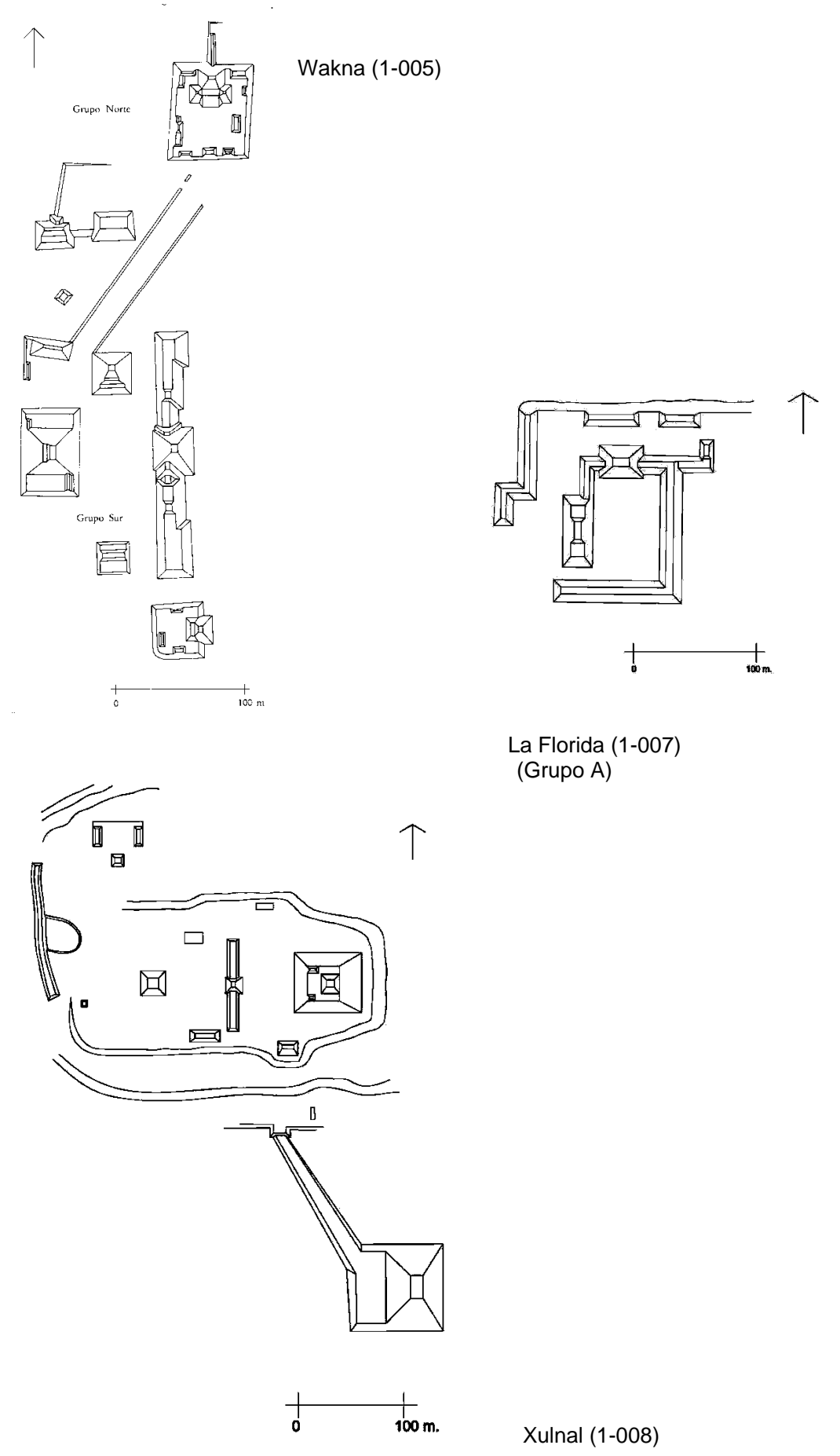




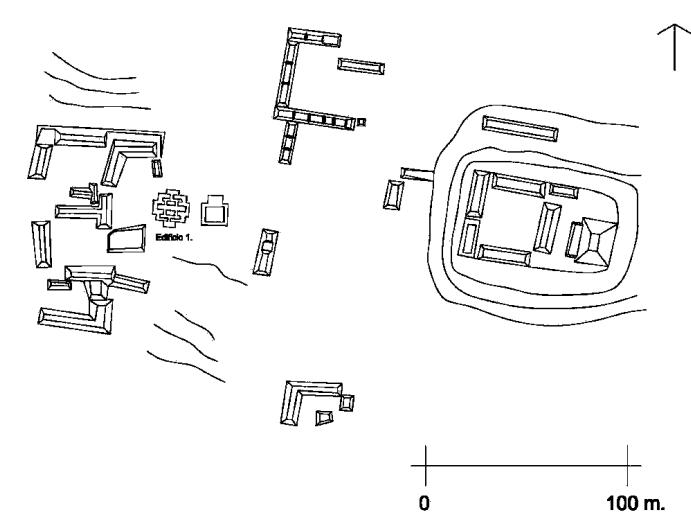

La Muerta (1-011)

(Un sector)

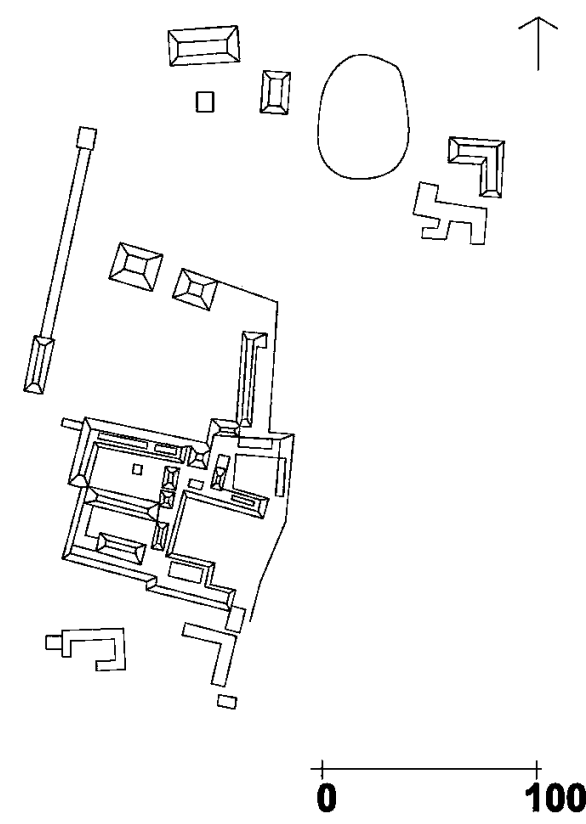

El Porvenir (1-012)

(Un sector) 
3 Planos esquemáticos ÁREA TIKAL.

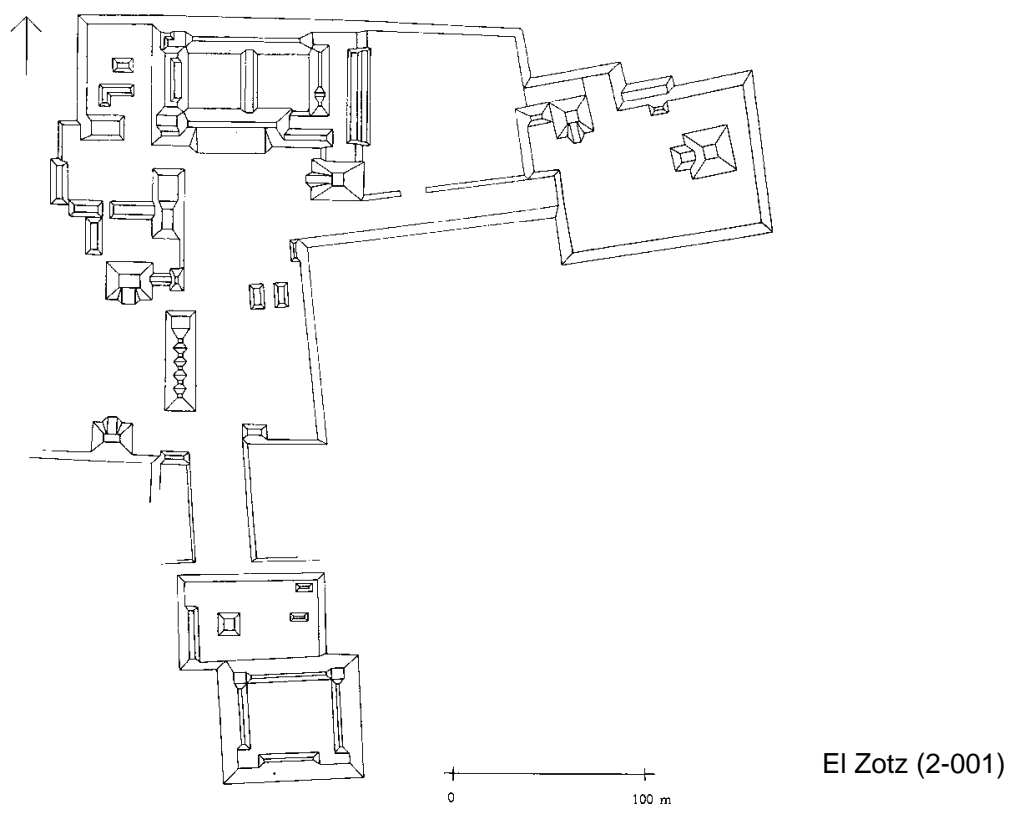

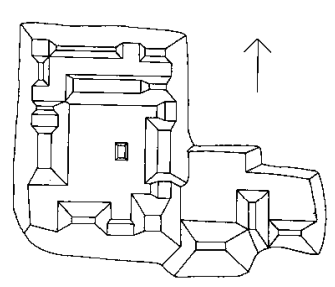

El Diablo (2-002)

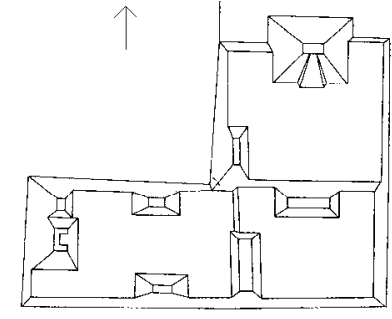

Bejucal (2-003) 

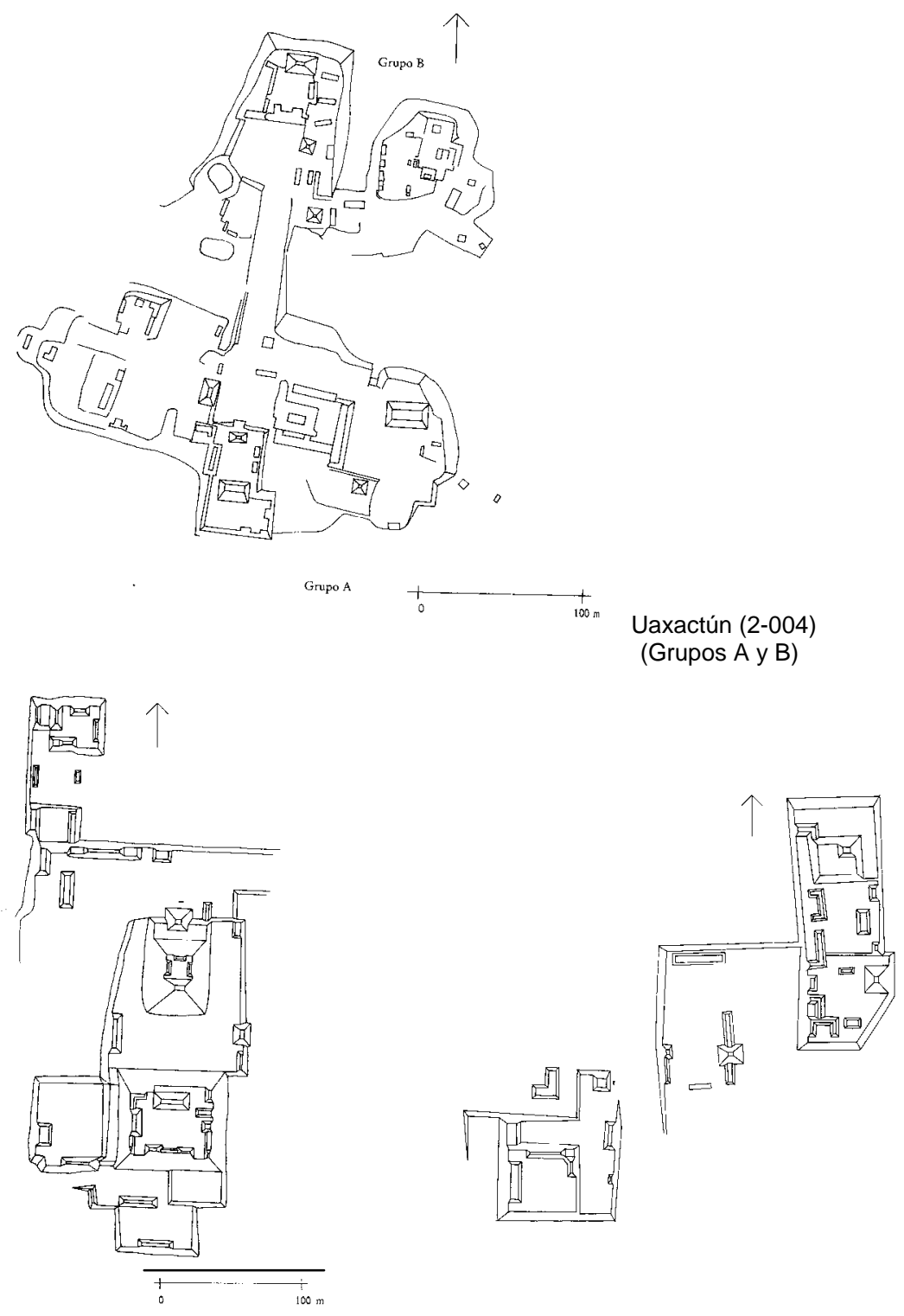

Ramonalito (2-005)

La Pita (2-006) 

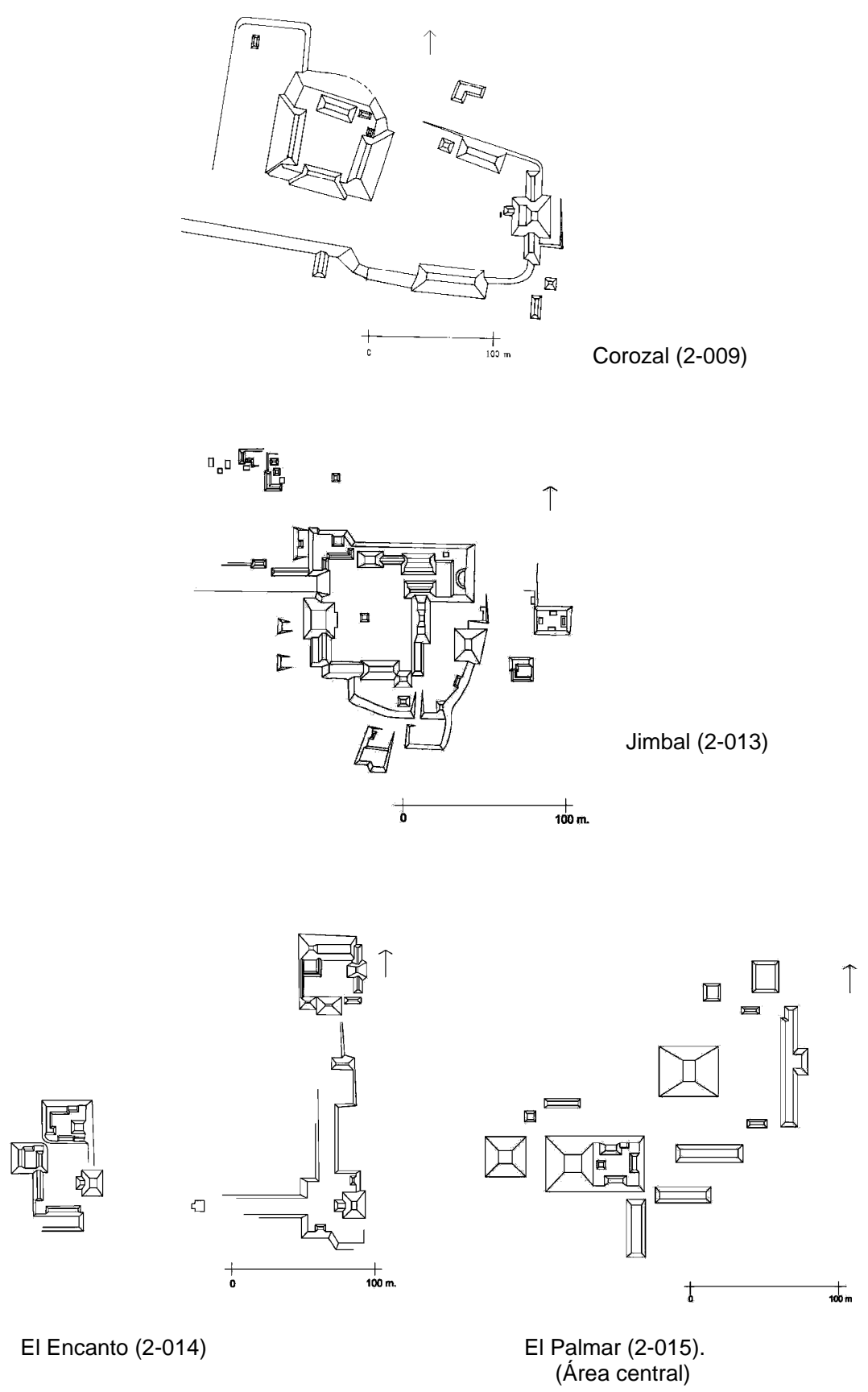
4 Planos esquemáticos CUENCA IXCÁN.
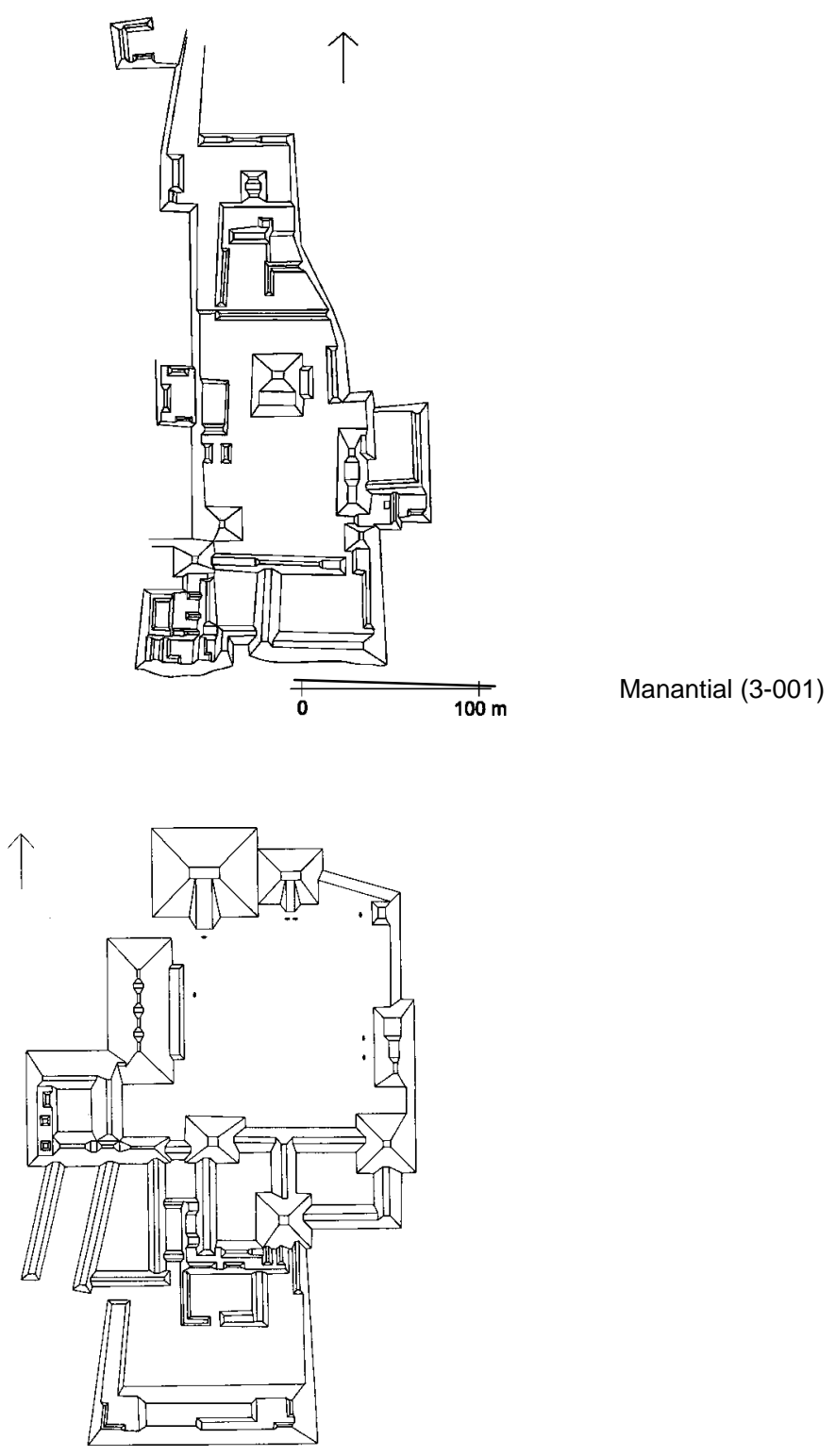

Xultún (3-003) 

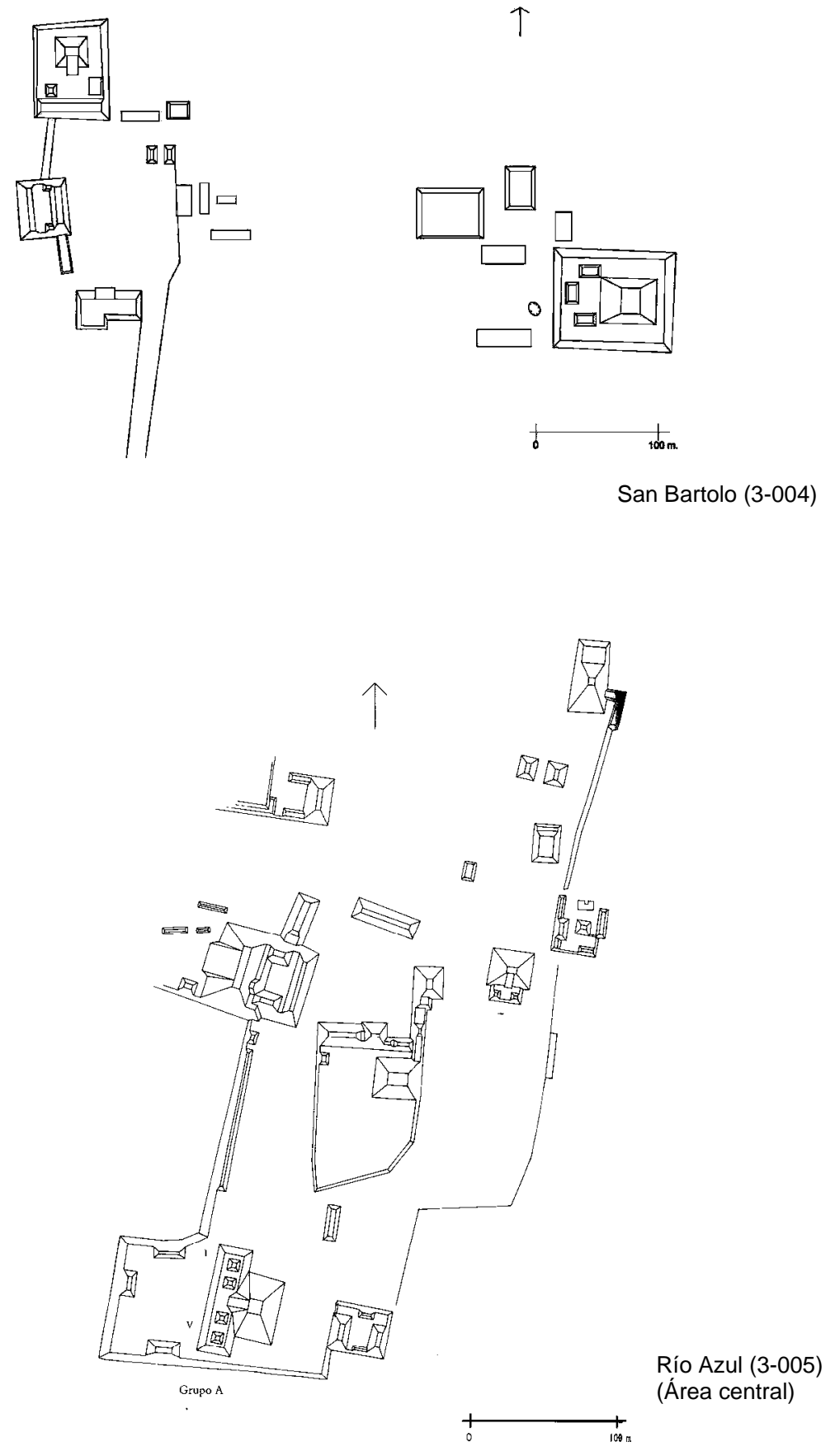

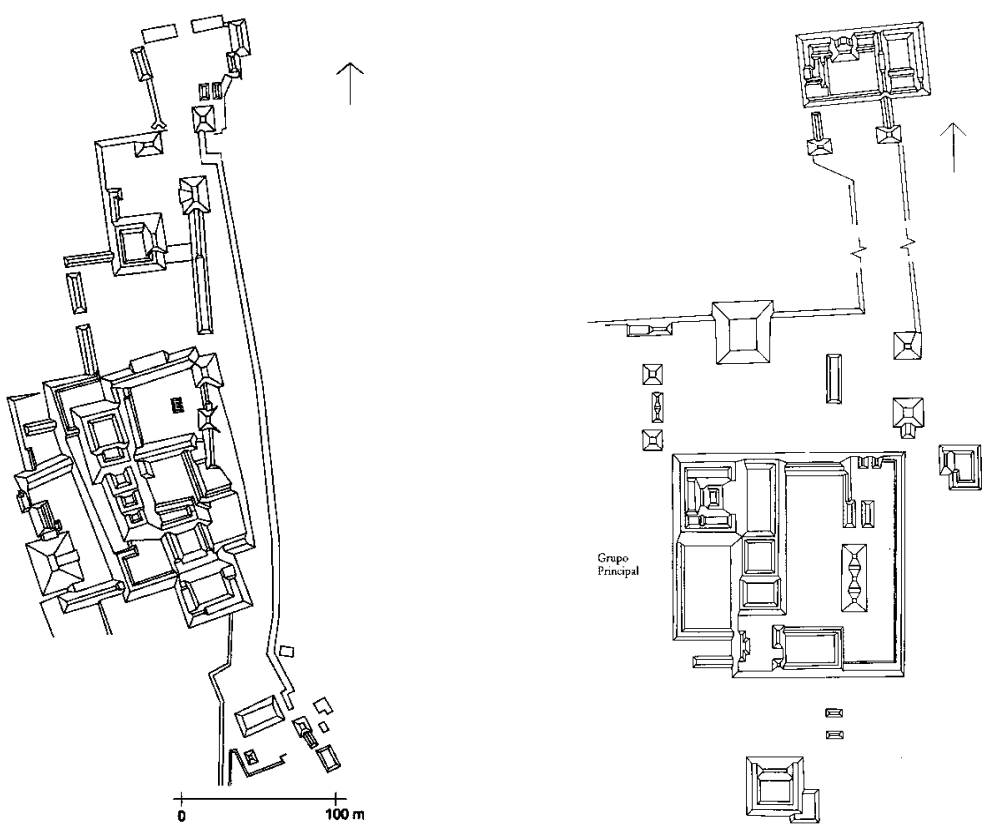

Kinal(3-006)

Chochkitam (3-007)
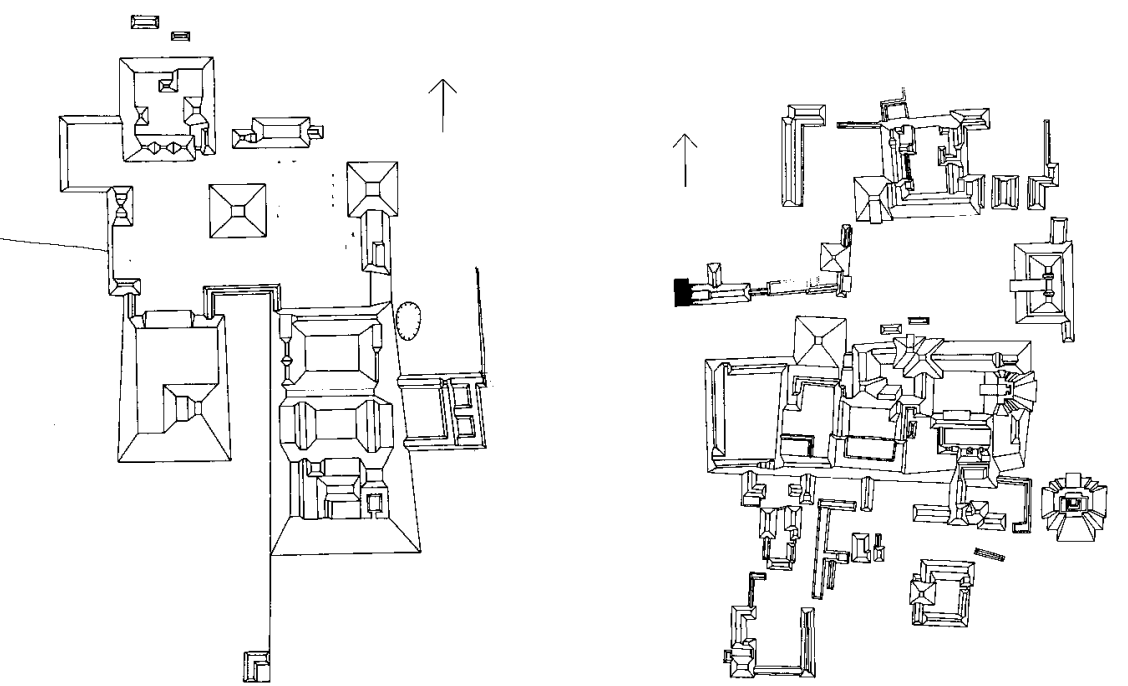

Xmakabatún (3-008)

La Honradez (3-009) 

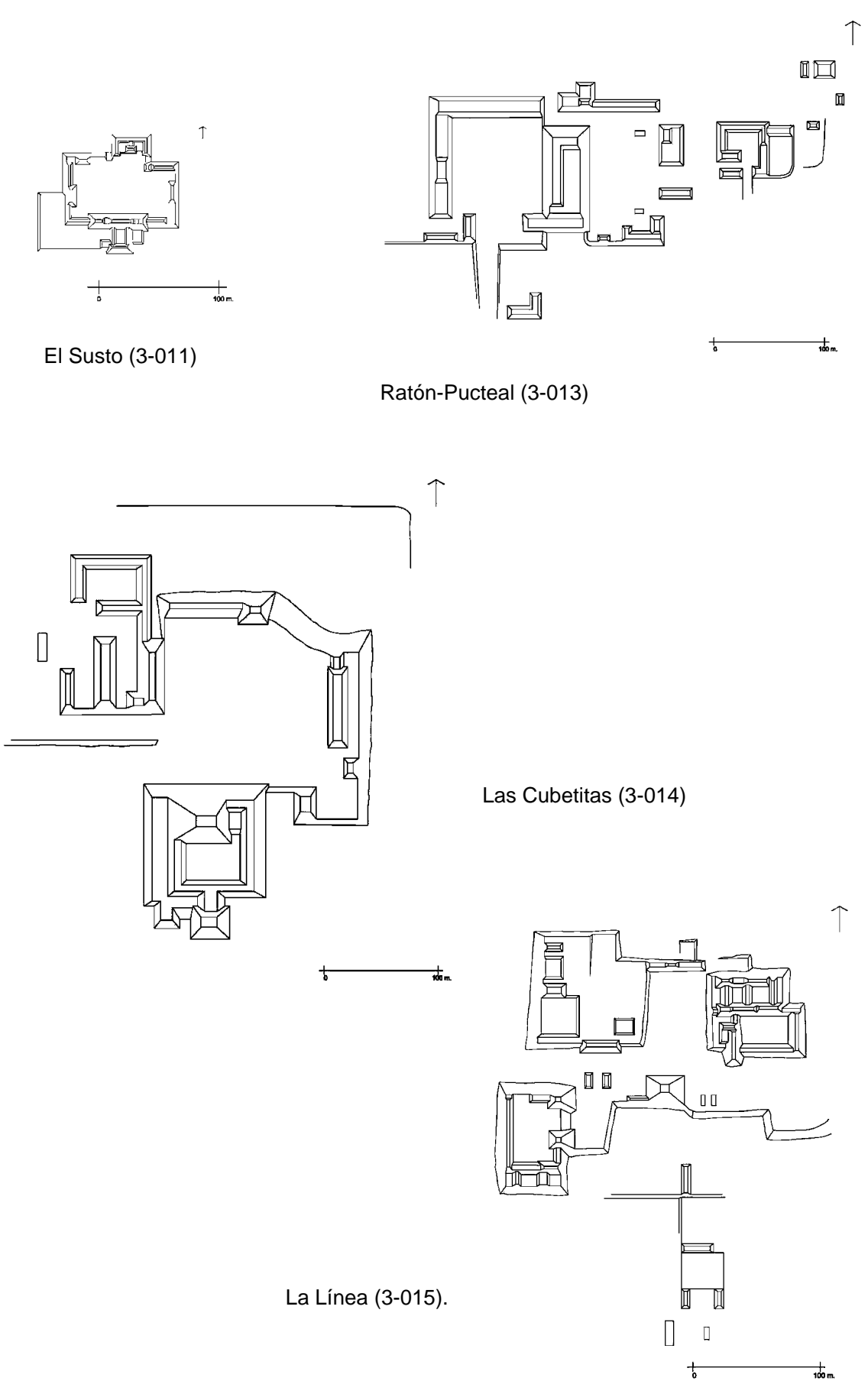
5 Planos esquemáticos CUENCA HOLMUL

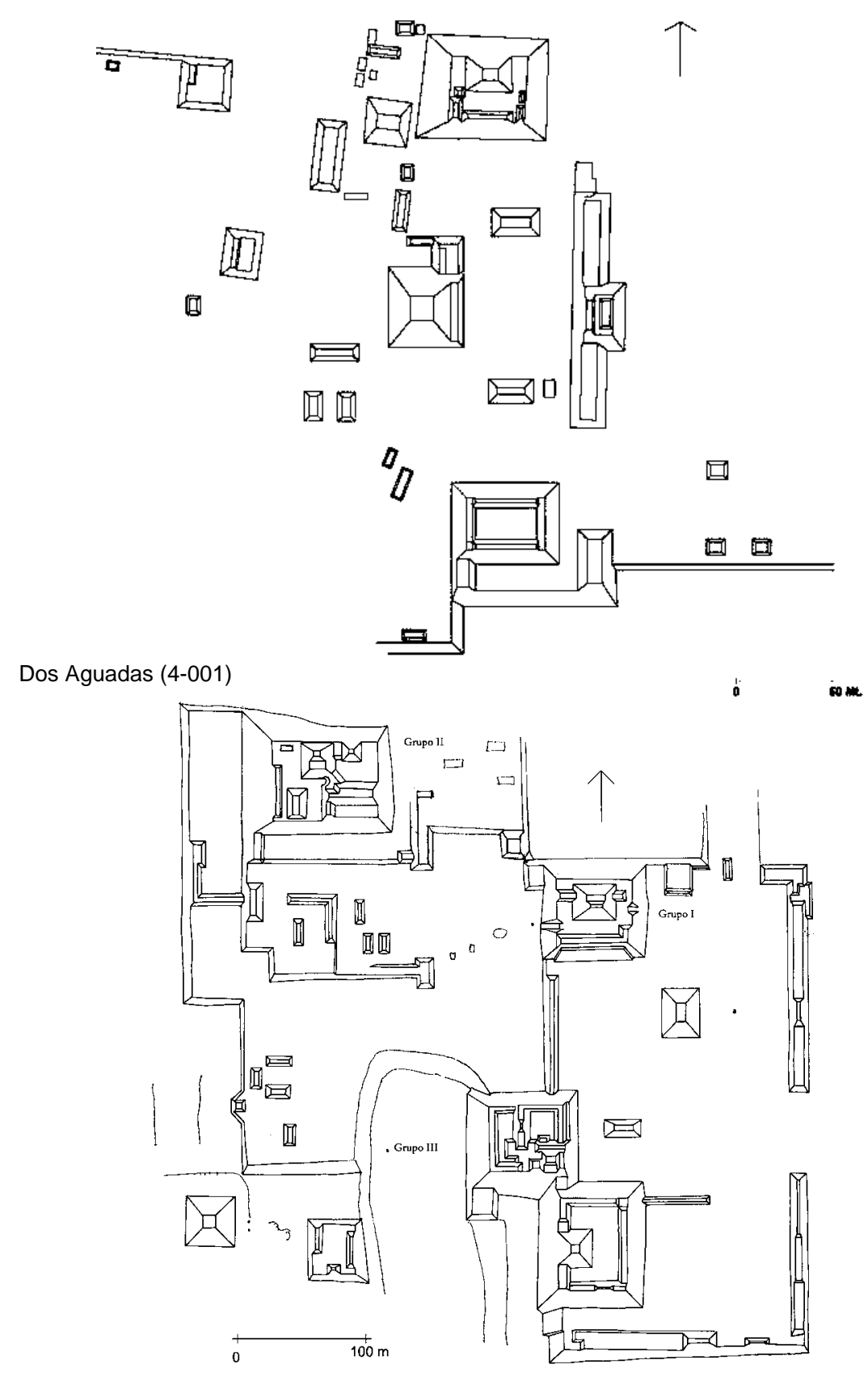

Holmul (4-002)

(Área central) 


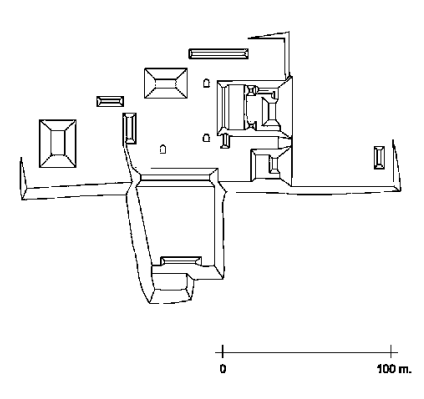

Caracol (4-007)

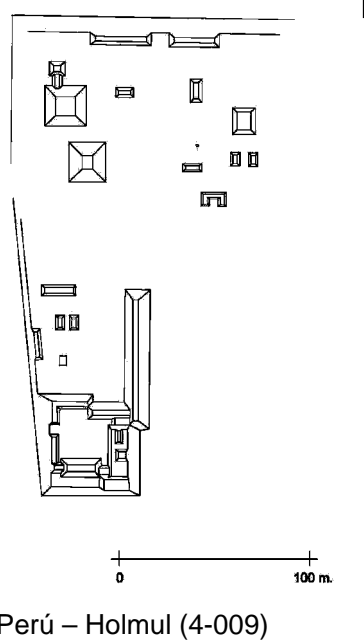

苨回

国

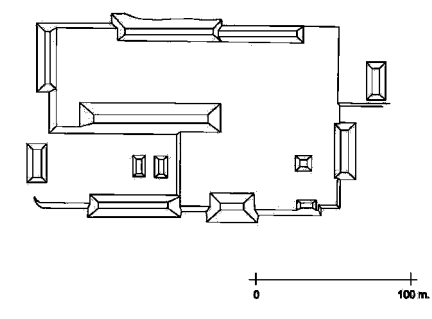

Pacayal (4-008)

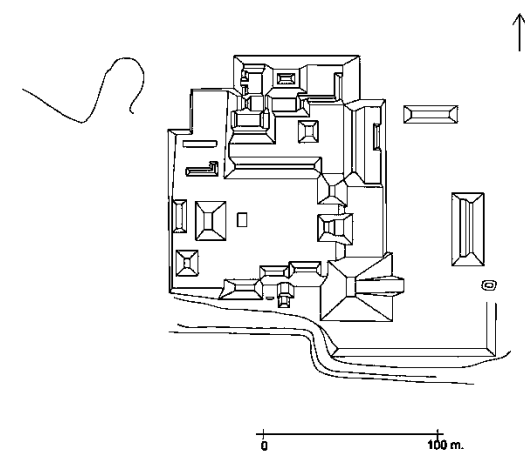

Witzná (4-012)

(Área central) 


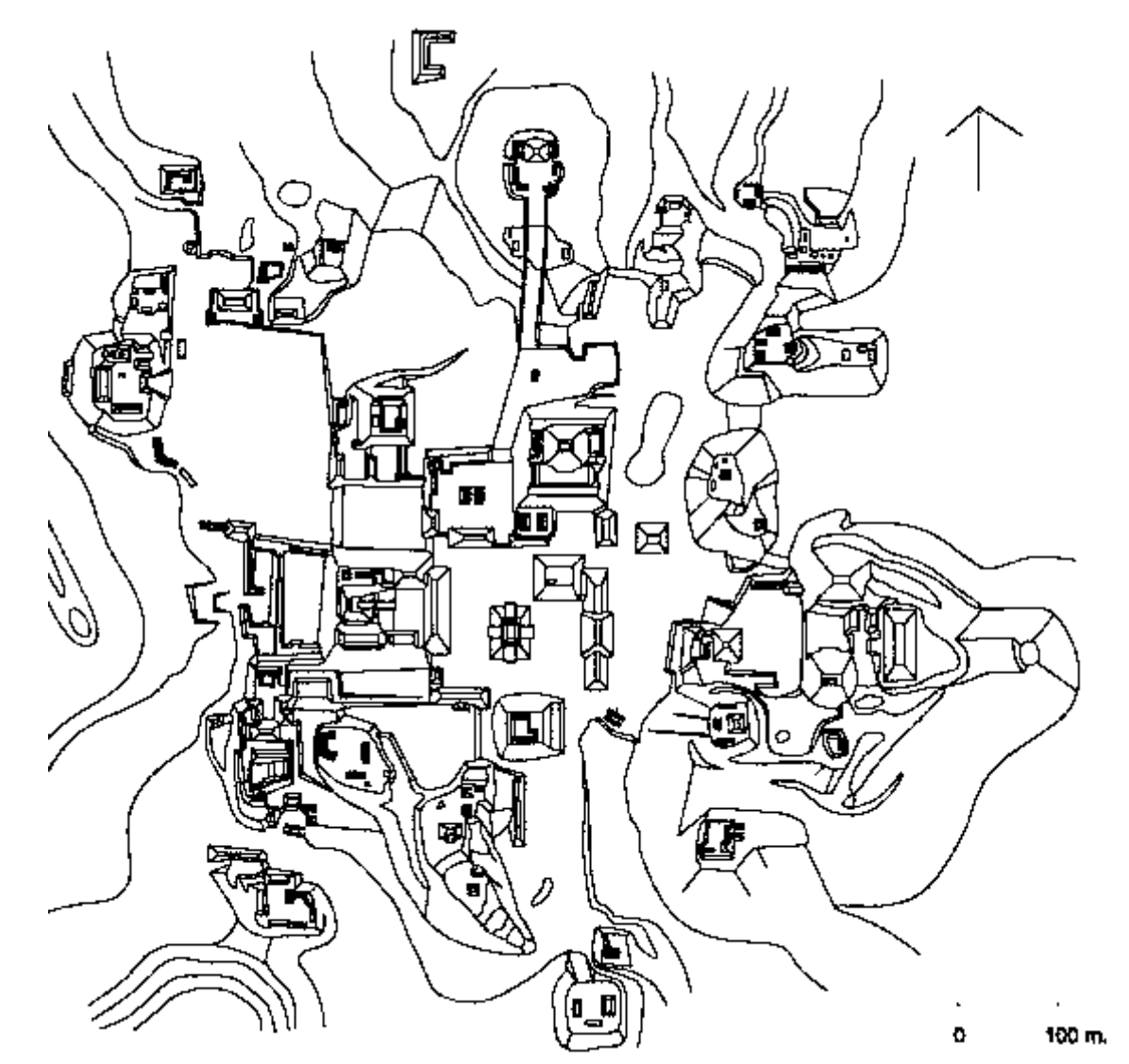

Naranjo (4-014) 


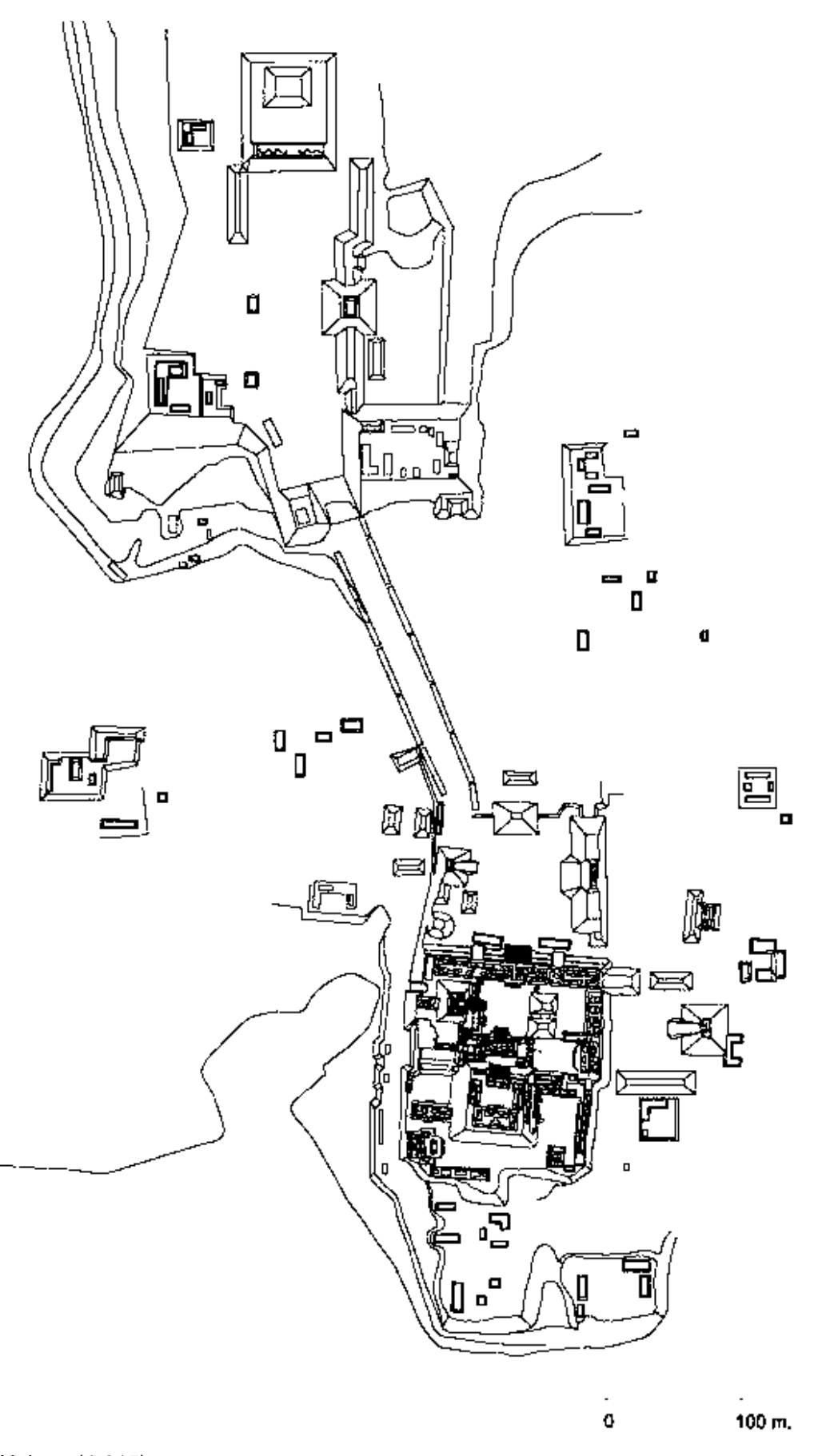

Nakum (4-015) 

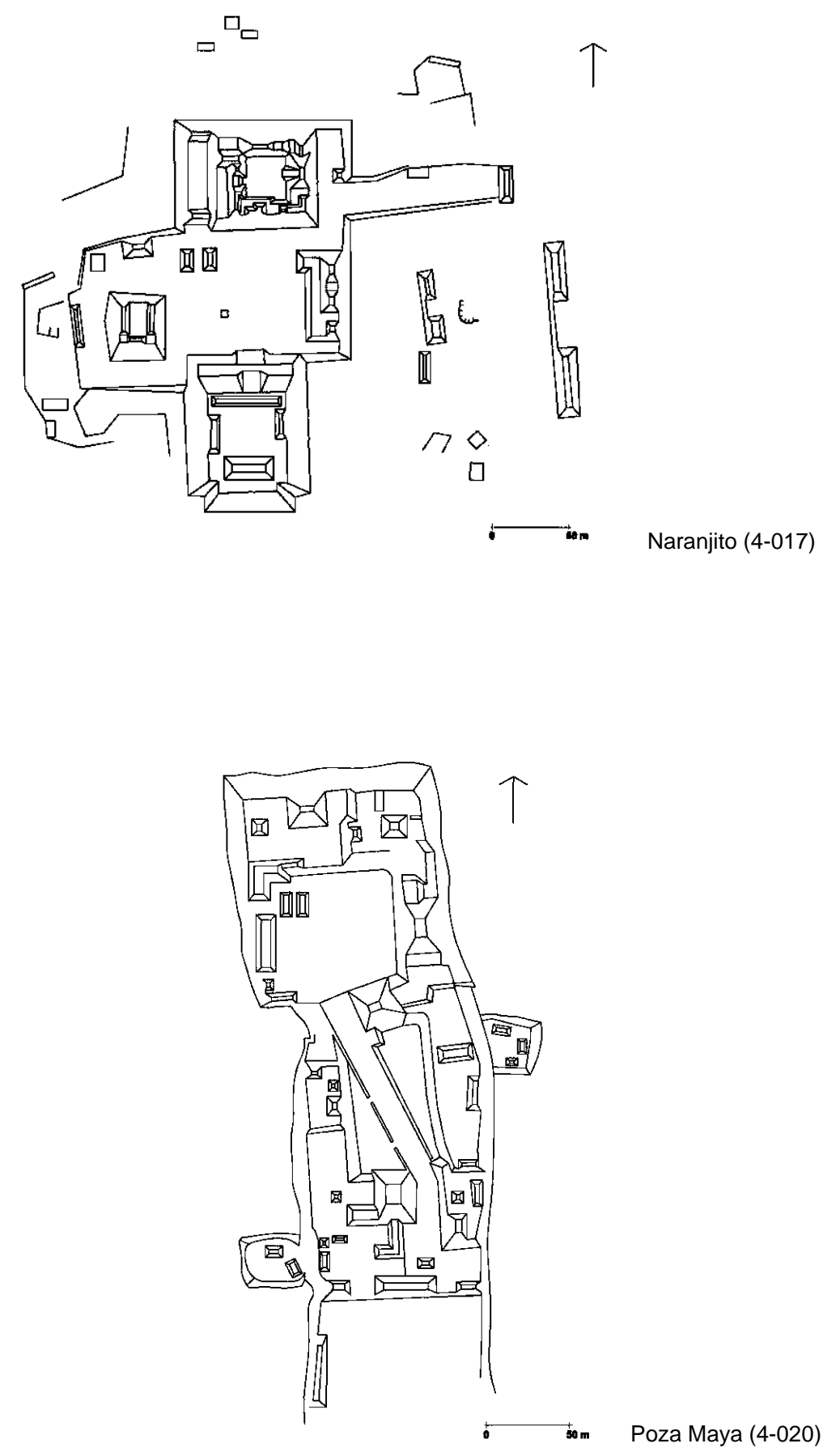

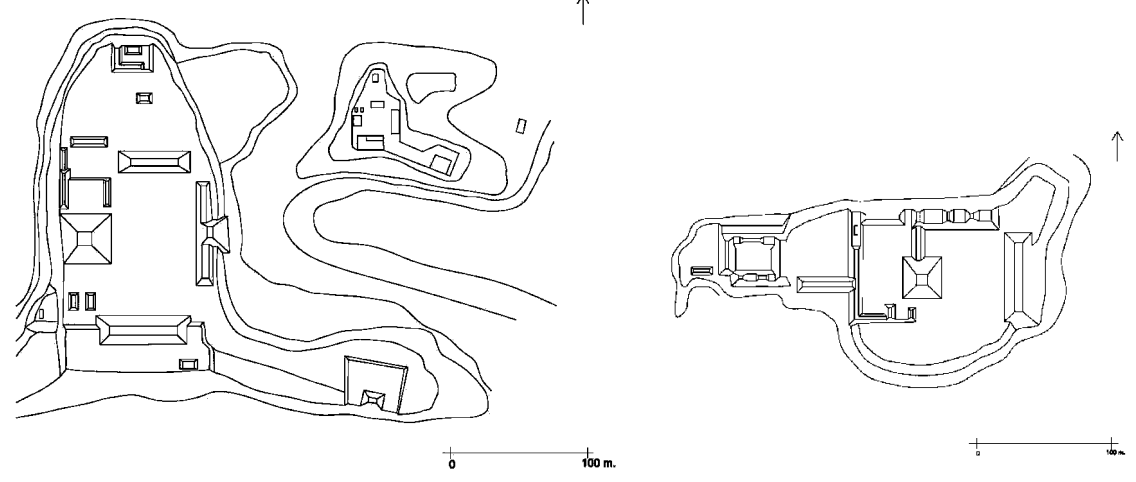

Kanajau (4-022)

Ciudadela Naranjo (4-023)
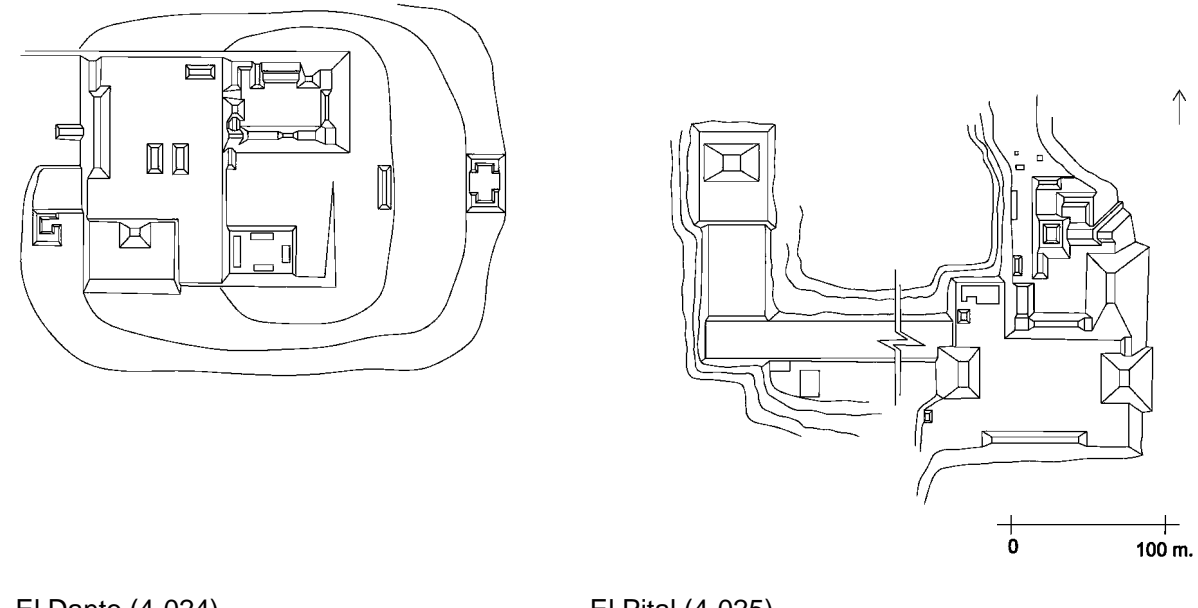

El Danto (4-024)

El Pital (4-025) 


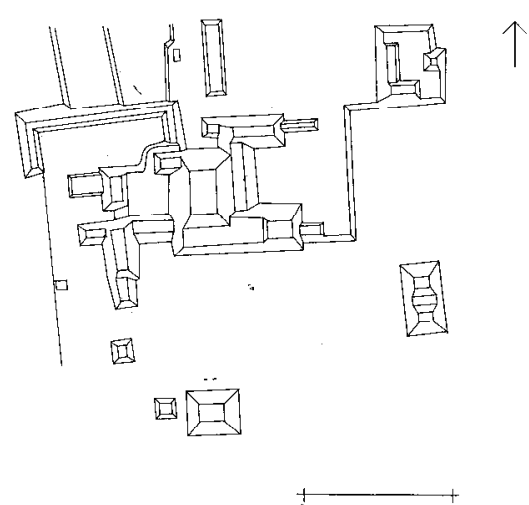

Motul (5-001)

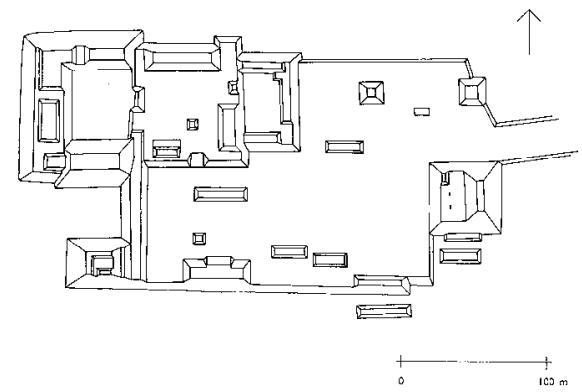

Ixlu (5-006)

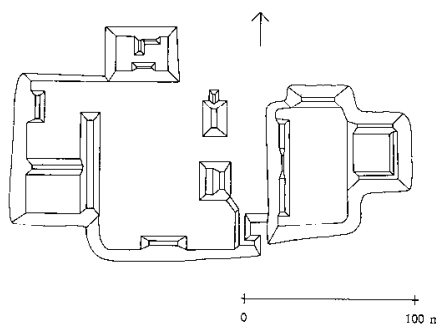

Corozal Torre (5-011)

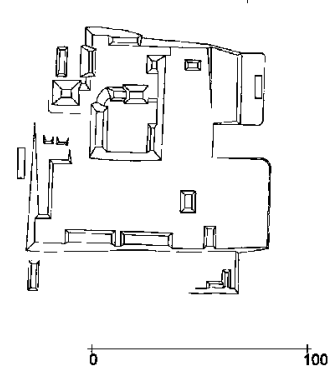

Acté (5-003)

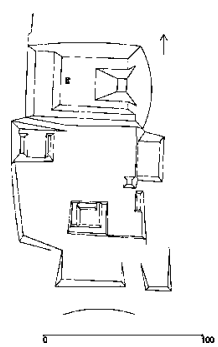

Paxcamán (5-007) (Grupo norte)

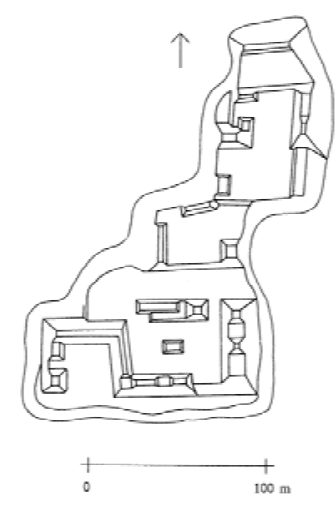

Zapote Corozal (5-012) 

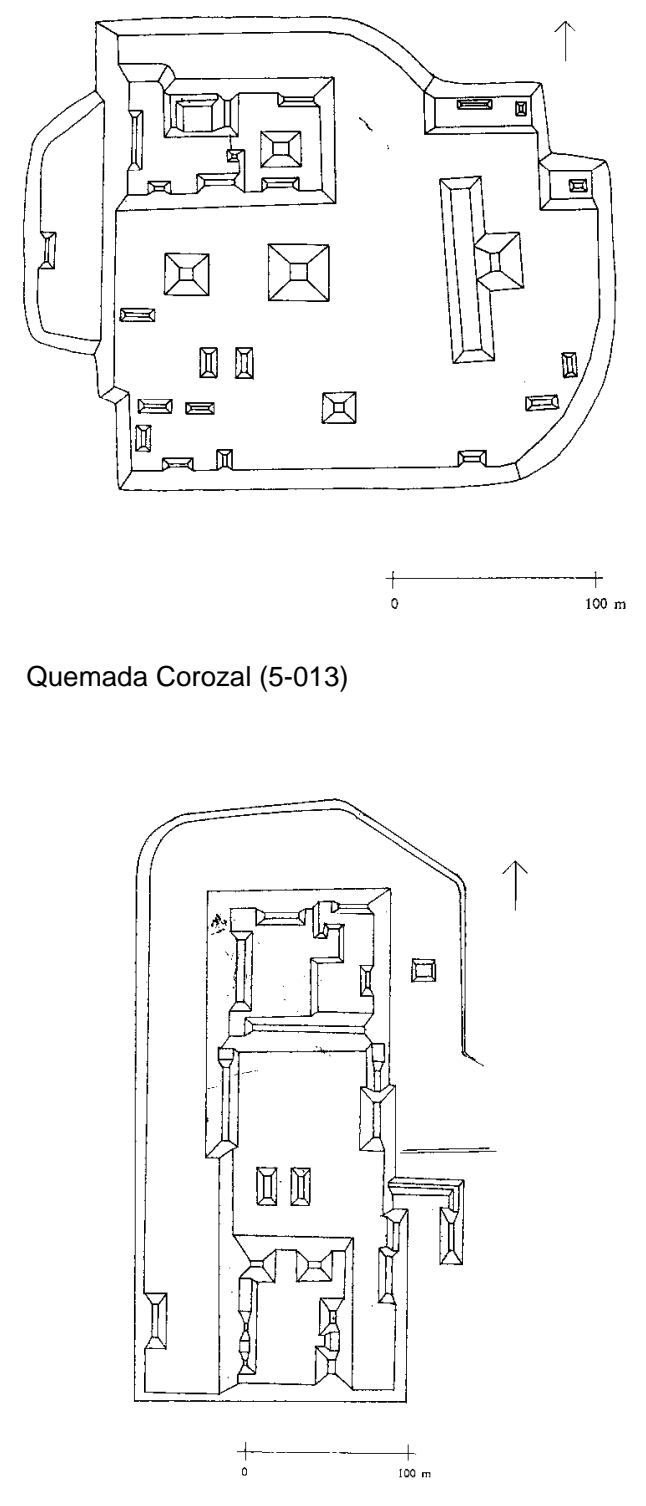

San Clemente (5-014) 


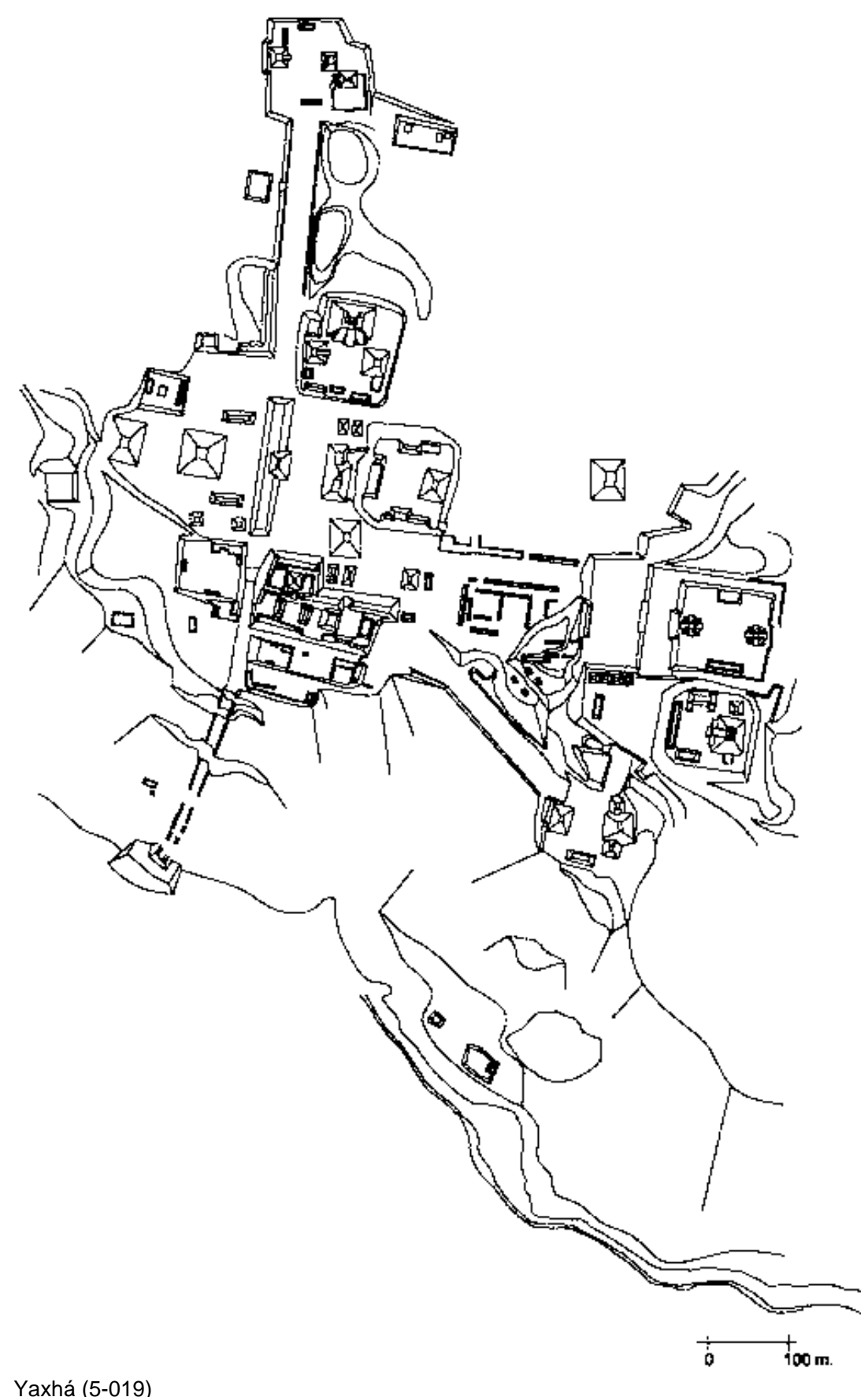

Yaxhá (5-019) 


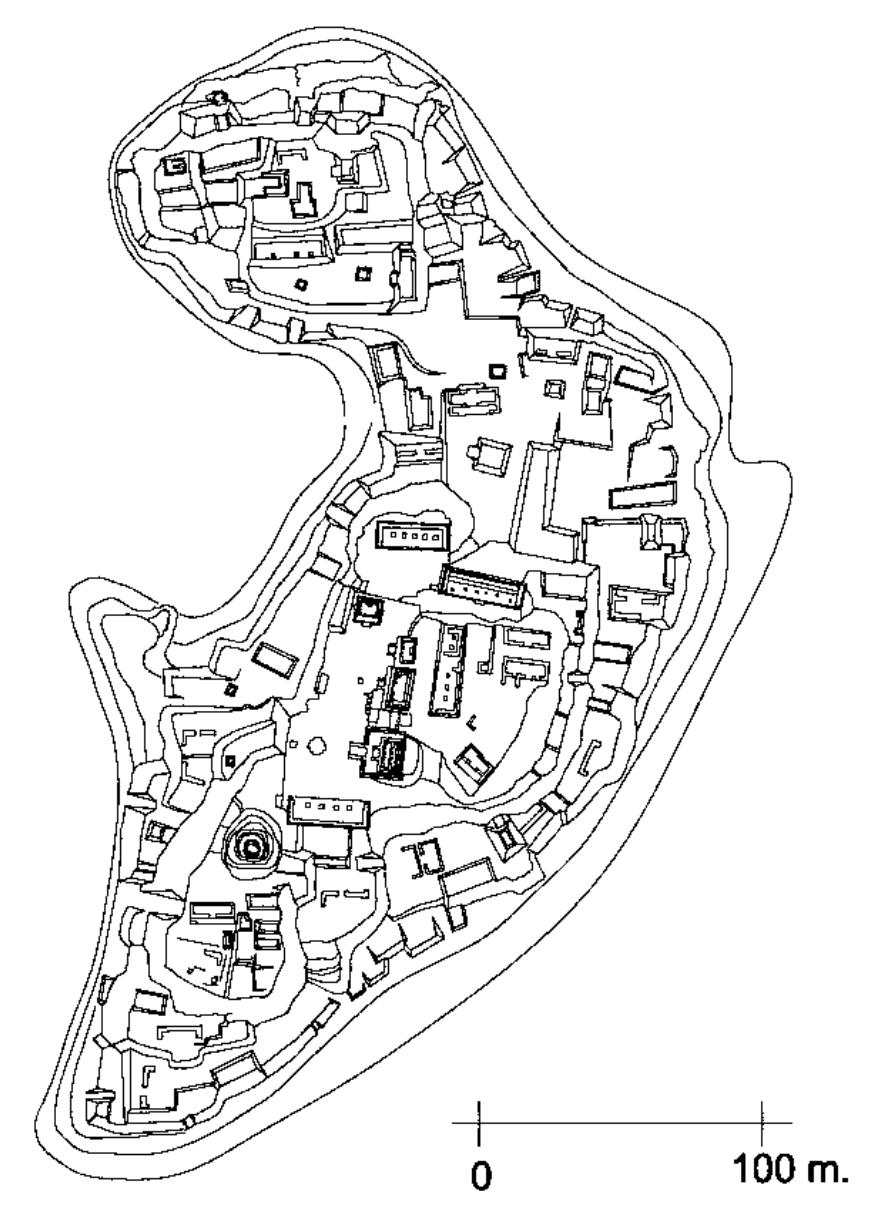

Topoxté (5-020) 


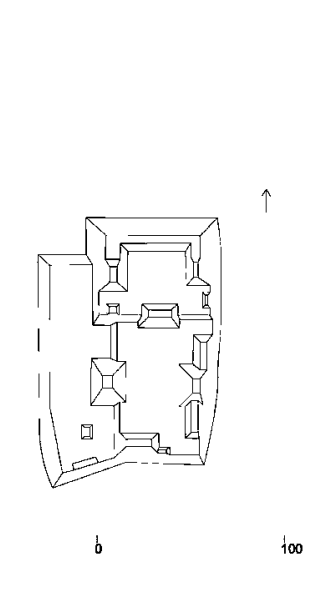

El Venado (5-023)

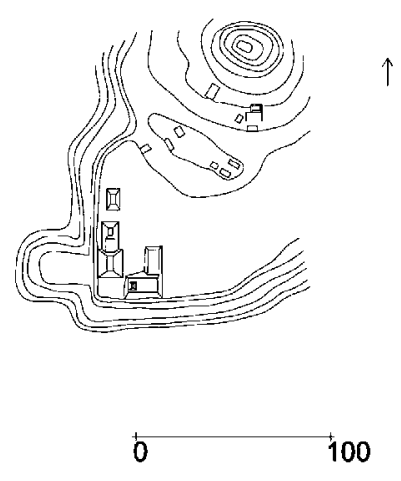

Canchén (5-030)

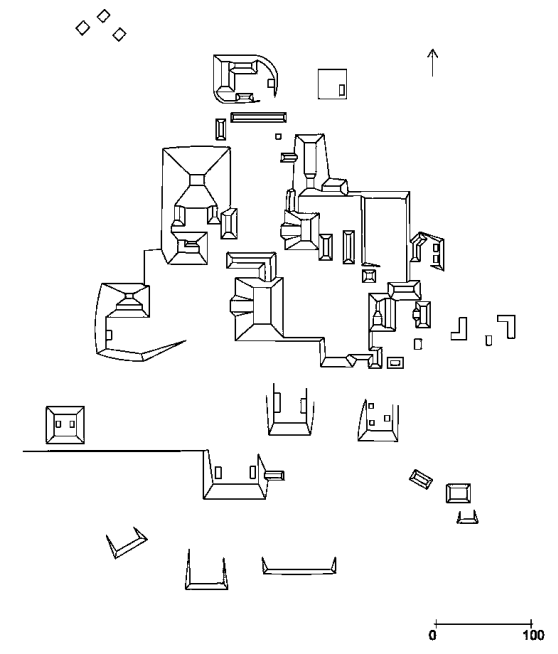

Trinidad (5-028)
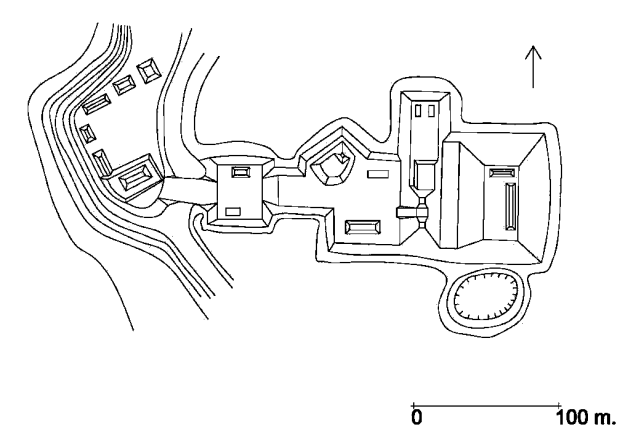

Juleque (5-031). 


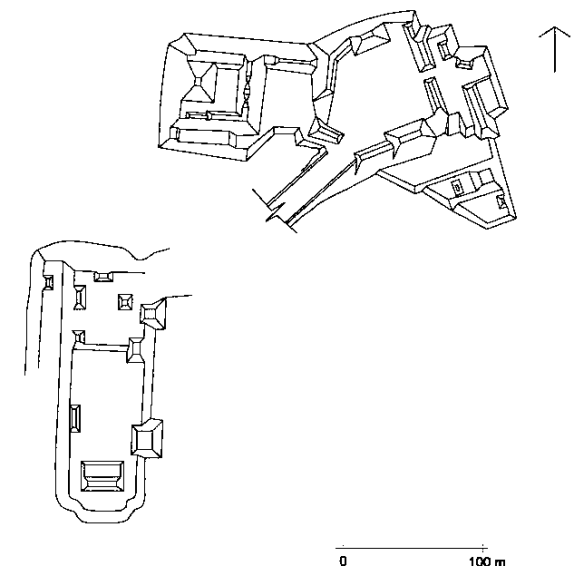

Tzikintzakán (6-001)

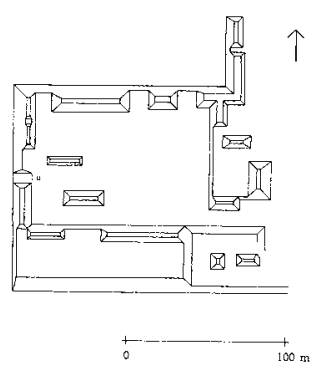

Aguacate (6-003)

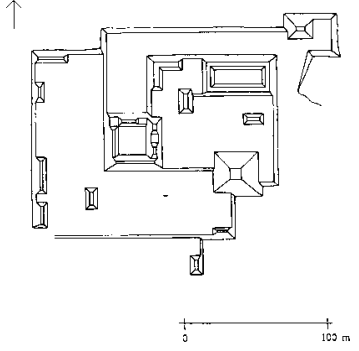

Chunhuitz (6-002)

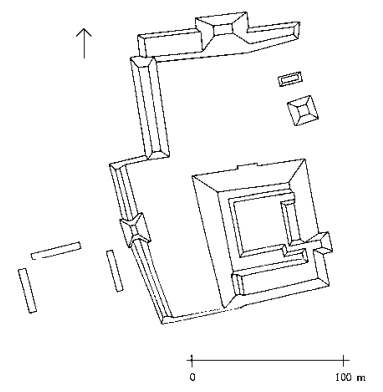

La Blanca (6-004)

(Área central) 


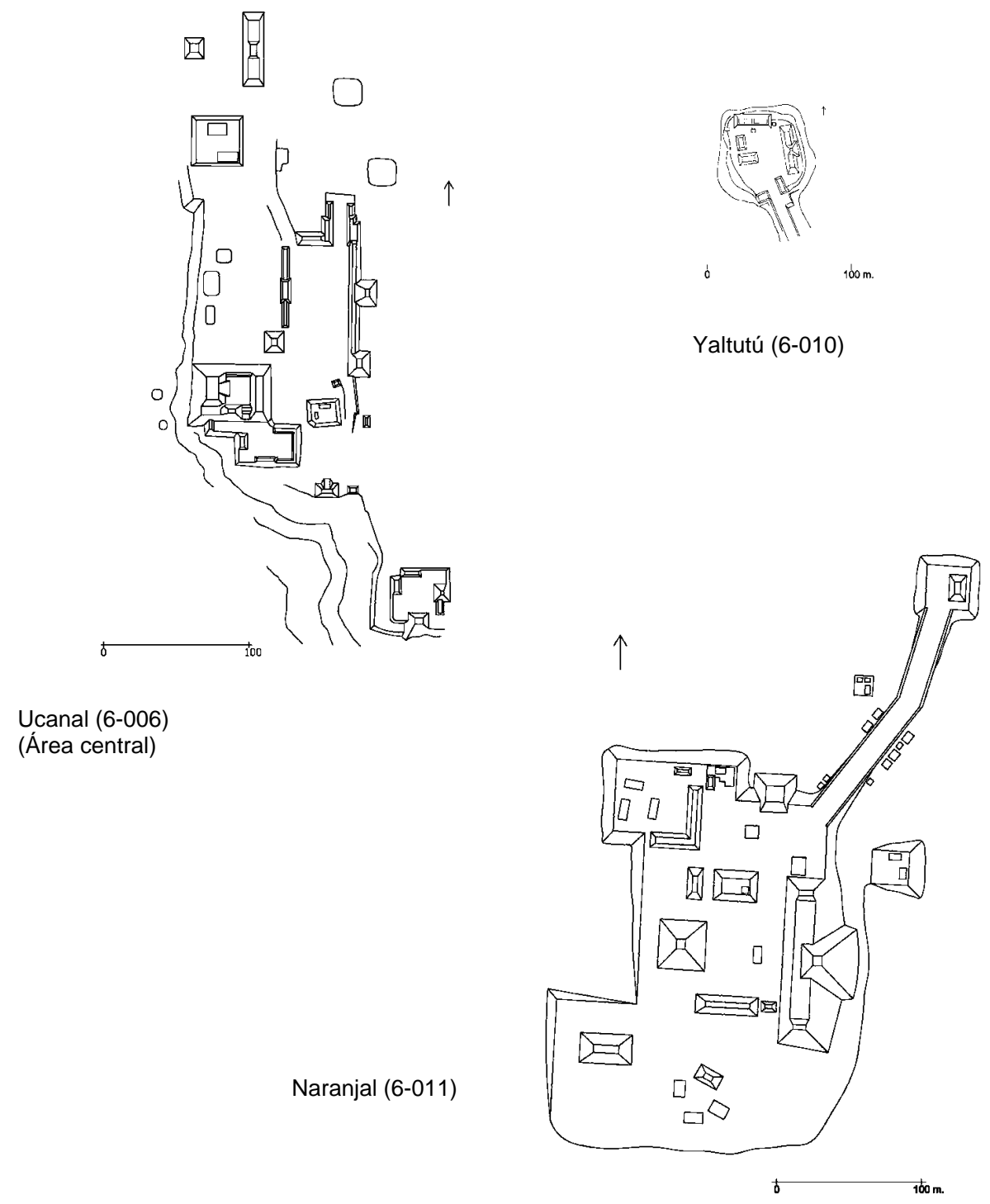




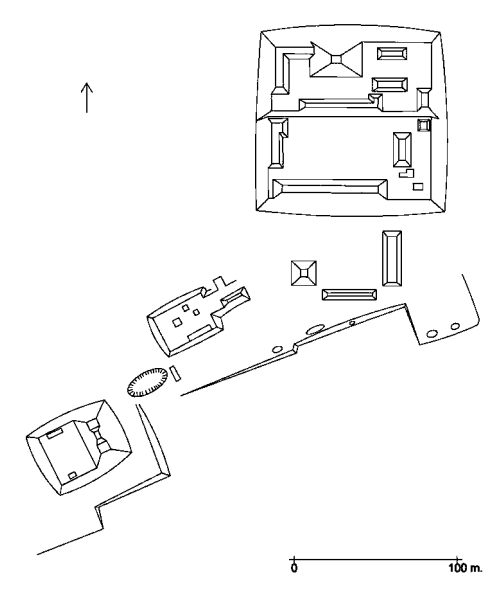

Yok' Ol Wits (6-012)

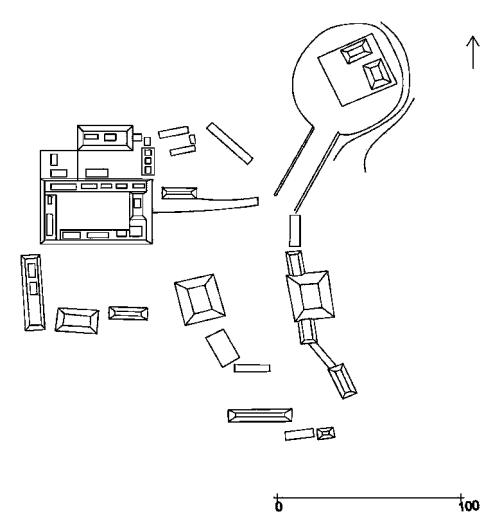

Dos Hermanas (6-016)

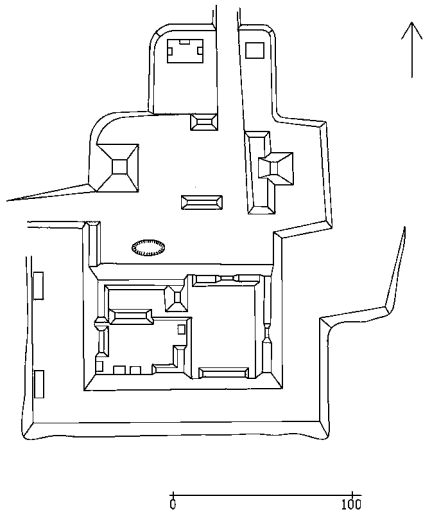

Calabazal (6-013)

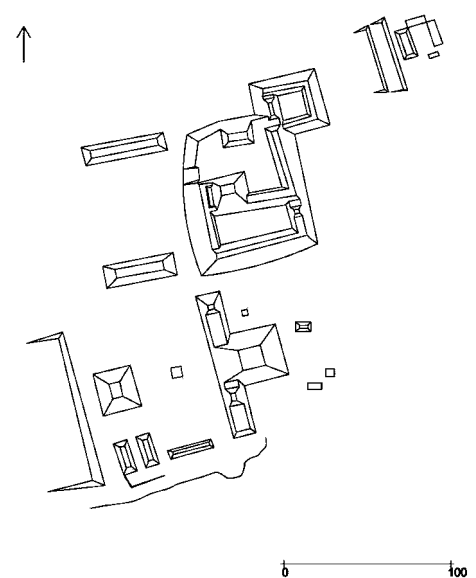

Camalote (6-017) 


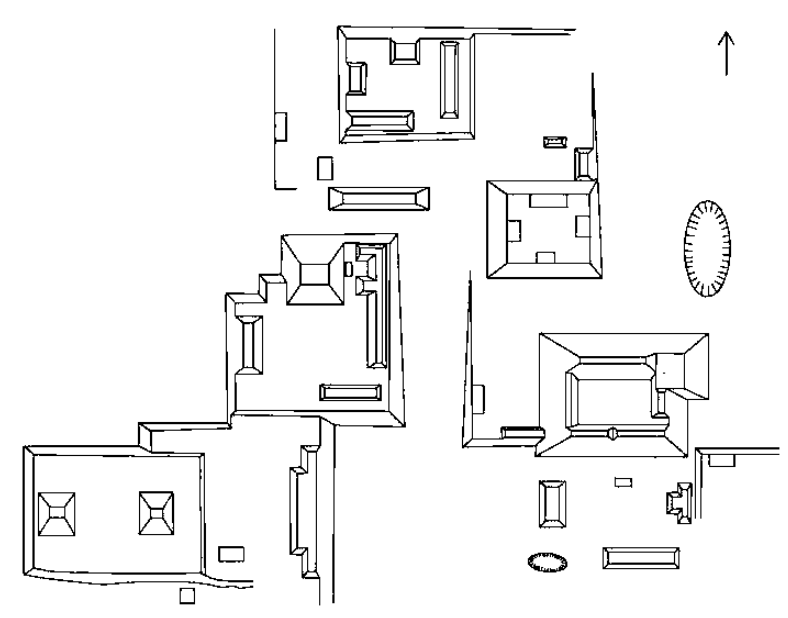

La Amapola (6-019)
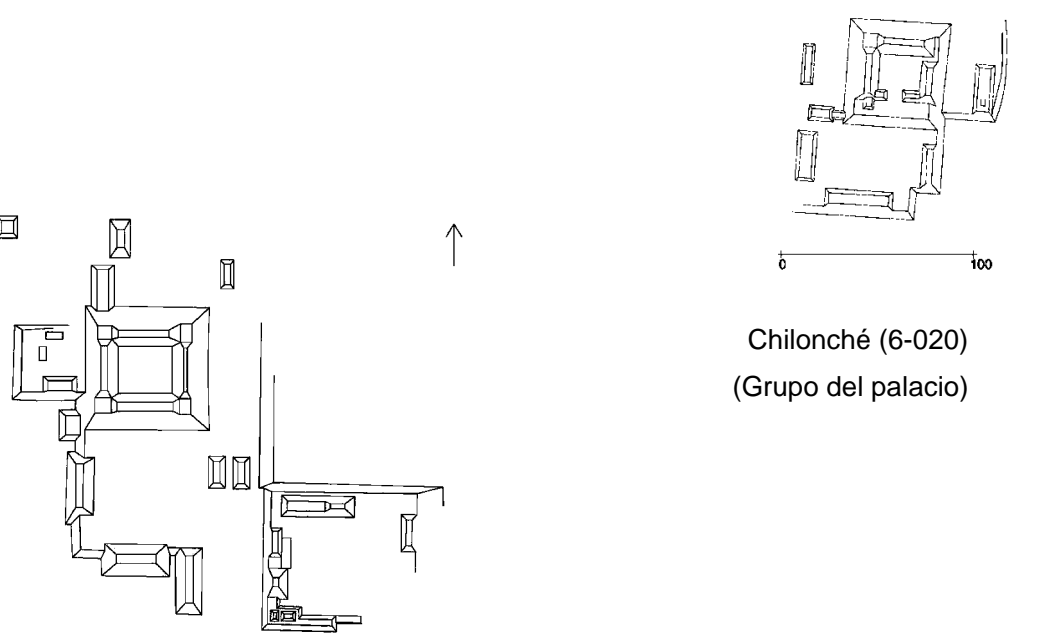

El Mango (6-021) 


\section{ÍNDICE DE ILUSTRACIONES}

Primera parte

Fig. 01. Mapa de la península de Yucatán

con ubicación del área de estudio

Fig. 02. Esquema de la estructura

orográfica en el noreste de Petén

Fig. 03. Cuadro cronológico del área en estudio

Fig. 04. La región maya, con las tres principales áreas

(norte, centro y sur) y algunos sitios arqueológicos

Fig. 05. Metodología, apartados y resultados

parciales y totales del esquema

Fig. 06. Apartado 3, Investigación. Estado de conservación del patrimonio edificado

Fig. 07. Apartado 4, espacio construido intervenido

Fig. 08. Esquema diseñado por Hohmann-Vogrin para mostrar las interrelaciones entre el ambiente construido, el ser humano y las intenciones que impulsaron al ambiente construido

Fig. 09. Apartado 3, Investigación.

Composición arquitectónica

Segunda parte

Fig. 10. Relaciones visuales

entre Tikal-Yaxhá

Fig. 11. Relación de elementos formales

en cinco niveles de análisis

Fig. 12. Elementos generadores

del espacio construido

Fig. 13. Grupos de patios

Fig. 14. Otros elementos 
Fig. 15. Grafito en pared del Edificio Y,

Acrópolis Central, Nakum

Fig. 16. Elementos de arquitectura identificados

Fig. 17. Sistema de cajuelas en las plataformas

escalonadas del Edificio 5D-33,I Clásico Tardío, Tikal

Fig. 18. Detalles de sistemas constructivos en muros

Fig. 19. Sistemas constructivos de techos

Fig. 20. Materiales de construcción,

Cantera y Calera de Nakum,

fotografía Noriega y Quintana

Tercera parte

Fig. 21. Daños en edificios por saqueo,

fotografía Noriega

Fig. 22. Tres estados de presentación

del patrimonio edificado, fotografías Noriega, Inguat

Fig. 23. Concepto, acciones y visiones de conservación

Fig. 24. Edificio N, Nakum,

fotografía de 1910 Tozzer y 2000 Noriega

Fig. 25. Edificio 216, Yaxhá, fotografía Noriega

Fig. 26. Edificio C, Topoxté, fotografía Noriega

325

Fig. 27. Área del palacio. San Clemente,

fotografía Noriega

Fig. 28. Infraestructura turística en Nakum,

cartel informativo del Edificio E, fotografía Noriega

Cuarta parte

Fig. 29. La región noreste y los conjuntos estratégicos 


\section{CREDITO DE ILUSTRACIONES}

-Las ilustraciones $01,02,03,04,05,06,07,09,10,11,12,13,14,16$, $17,18,19,23$ y 29 han sido elaboradas por el autor.

-La ilustración 08 esta basada en el esquema desarrollado por Annegrete Hohmann-Vogrin.

-Las ilustraciones, 20, 20, 21 y 22 fotografías de Oscar Quintana,

Raúl Noriega e Inguat

-llustración 24 foto Merwin en Tozzer 1913 y Raúl Noriega

-llustraciones 25, 26, 27 y 28 fotos Raúl Noriega

Cuadros estadísticos 1 al 10, Oscar Quintana y Michelle Salazar

Planos esquemáticos

1. Sitios arqueológicos que conforman la muestra

Oscar Quintana y Raúl Noriega

2. Planos esquemáticos CUENCA MIRADOR

El Mirador (1-001), Nakbé (1-002), Wakna (1-005), tomados de ciudades mayas del noreste del Petén, Guatemala. Un estudio urbanístico comparativo QUINTANA, Óscar y Wolfgang W. WURSTER 2001

La Florida (1-007), Xulnal (1-008), La Muerta (1-011), El Porvenir (1012), Oscar Quintana y Raúl Noriega, basados en datos de SUYUC et al 2005, HANSEN et al 2006 y MEJÍA et al 2007

3. Planos esquemáticos ÁREA TIKAL

El Zotz (2-001), El Diablo (2-002), Bejucal (2-003), Uaxactún (2-004), Ramonalito (2-005), La Pita (2-006), Corozal (2-009), tomados de ciudades mayas del noreste del Petén, Guatemala. Un estudio 
urbanístico comparativo QUINTANA, Óscar y Wolfgang W. WURSTER 2001

Jimbal (2-013), El Encanto (2-014), El Palmar (2-015).

Oscar Quintana y Raúl Noriega

4. Planos esquemáticos CUENCA IXCÁN

Manantial (3-001), Xultún (3-003), San Bartolo (3-004), Río Azul (3005), Kinal (3-006), Chochkitam (3-007), Xmakabatún (3-008), La Honradez (3-009), tomados de ciudades mayas del noreste del Petén, Guatemala. Un estudio urbanístico comparativo QUINTANA, Óscar y Wolfgang W. WURSTER 2001

El Susto (3-011), Ratón-Pucteal (3-013), Las Cubetitas (3-014), QUINTANA, Óscar 2004, La Línea (3-015). QUINTANA, Óscar y Raúl NORIEGA.

5. Planos esquemáticos CUENCA HOLMUL

Dos Aguadas (4-001), Holmul (4-002), Cival (4-004), Naranjito (4017), Poza Maya (4-020) tomados de ciudades mayas del noreste del Petén, Guatemala. Un estudio urbanístico comparativo, QUINTANA, Óscar y Wolfgang W. WURSTER 2001

Caracol (4-007), Pacayal (4-008), El Perú-Holmul (4-009), Witzná (4012), Kanajau (4-022), Ciudadela Naranjo (4-023), El Danto (4-024), Oscar Quintana y Raúl Noriega Naranjo (4-014), QUINTANA, Óscar y Wolfgang W. WURSTER 2004 Nakum (4-015), QUINTANA, Óscar y Wolfgang W. WURSTER 2002 El Pital (4-025). QUINTANA, Óscar 2007c

\section{Planos esquemáticos CUENCA DE LOS LAGOS}

Motul (5-001), Ixlú (5-006), Corozal Torre (5-011), Zapote Corozal (5012), Quemada Corozal (5-013), San Clemente (5-014), Yaxhá (5019), Topoxté (5-020), ), tomados de ciudades mayas del noreste del 
Petén, Guatemala. Un estudio urbanístico comparativo, QUINTANA, Óscar y Wolfgang W. WURSTER 2001

Acte (5-003), Paxcamán (5-007), El Venado (5-023), Trinidad (5-028),

Canchén (5-030), Juleque (5-031). Oscar Quintana y Raúl Noriega.

7. Planos esquemáticos CUENCA RíO MOPÁN

Tzikintzakán (6-001), Chunhuitz (6-002), Aguacate (6-003), La Blanca (6-004), tomados de ciudades mayas del noreste del Petén, Guatemala. Un estudio urbanístico comparativo, QUINTANA, Óscar y Wolfgang W. WURSTER 2001

Yaltutú (6-010), Naranjal (6-011), Yok' Ol Wits (6-012), Calabazal (6013), Dos Hermanas (6-016), Ucanal (6-006), Camalote (6-017), La Amapola (6-019), Chilonché (6-020), El Mango (6-021). Oscar Quintana y Raúl Noriega.

En la elaboración de los planos esquemas se contó con el apoyo de Telma Tobar, Breitner González y Raúl Noriega. 
ANEXO 2

CONCLUSIONES EN ALEMÁN 
Als Stipendiat der deutschen Regierung, im Rahmen eines Stipendiums des Deutschen Akademischen Austauschdiensts e. V. hatte ich die Möglichkeit einen Aufbaulehrgang für Denkmalpflege an der Technischen Universität München zu absolvieren. Dort lernte ich zwei Professoren kennen, die mich ermunterten, meine Kenntnisse in Denkmalpflege und der Maya-Kultur zu vertiefen. Einer von innen war Professor Michael Petzet, der mich unterstützte, damit ich als Freiwilliger im Bayerischen Landesamt für Denkmalpflege, in der Außenstelle Schloss Seehof, Bamberg, arbeiten konnte. Folglich konnte ich auch den Aufbaulehrgang für Denkmalpflege wiederholen, diesmal jedoch unter dem Gesichtspunkt der Kunstgeschichte in der Universität Bamberg unter Professor Achim Hubel.

An der Technischen Universität München, gab es seinerzeit keinen Professor, der mich im Bezug auf die Maya-Kultur beraten konnte. Daher empfahlen mir meine Professoren mich an einen ehemaligen Studenten der TU München um Rat zu wenden. So begab ich mich nach Bonn zur Kommission für Allgemeine und Vergleichende Archäologie des Deutschen Archäologischen Instituts und lernte Professor Wolfgang Wilhelm Wurster kennen, den Paten dieser Arbeit.

Ursprünglich war als Thema dieser Doktorarbeit die architektonische Komposition von Maya-Treppen angedacht. Jedoch überzeugte mich Professor Wurster, dass das Themengebiet meiner Arbeit erweitert werden sollte, um einen größeren Nutzen für Guatemala zu erzielen. Meine Forschung und die Verfassung der Doktorarbeit mussten sich jedoch zunächst dem Angebot für das guatemaltekische Kultur- und Sportministerium in Tikal zu arbeiten, unterordnen. 
Dass ich nunmehr diese Arbeit abschließen konnte, ist ein Verdienst von vielen Beteiligten, die mich über lange Jahre hin, sowohl in der Feldforschung, als auch bei der Erarbeitung der theoretischen Konzepte, unterstützt haben. Damit verwirklichte sich mein Wunschzutragen zur besseren Kenntnis und zum Schutz des monumentalen Erbes der Maya-Kultur beizutragen.

Die Studie beschäftigt sich mit einem begrenzten geographischen Gebiet von hundert mal hundert Kilometern im zentralen Maya-Tiefland des nordöstlichen Quadranten des Petén. In diesem Gebiet wurden verschiedenste Untersuchungen, Analysen, Synthesen und Interventionen unternommen. Die erste Aufgabe stellte sich darin, in mehreren Reisen das gesamte Studiengebiet zu erforschen, um Kenntnisse über den Zustand der architektonischen Zusammensetzung und den Grad der Konservierung der monumentalen Maya-Bauten, welche den spezifischen Fokus dieser Arbeit darstellen, zu erhalten

Die generelle Zielsetzung bestand darin, eine Feststellung der geistigen Prozesse und durchgeführten Arbeiten während der Feldarbeit im Petén zu erzielen. Das wissenschaftliche Ziel war auf zwei Aspekte ausgerichtet. Zum einen wurde angestrebt mittels einer wissenschaftlichen Methode die Grundlagen der Zusammensetzung des urbanen Raums und die architektonischen Formen der prähispanischen Monumentalarchitektur zu untersuchen. Zum anderen sollten Indikatoren und Verfahren zur Konservierung des architektonischen Erbes der Maya erstellt werden.

Das Hauptthema der Untersuchung bestand in der Umschreibung der monumentalen Steinbauten, welche im Zeitraum zwischen 500 vor Christus und 1697 AD errichtet wurden. Diese Zeitspanne umfasst 
somit die Epochen der späten Frühklassik, der Klassik und der PostKlassik der Maya-Kultur.

Nach 1697 wurden keine weiteren Maya-Städte errichtet, das Siedlungsgebiet praktisch aufgegeben und vom tropischen Urwald zurückerobert. Dadurch haben wir es mit dem Studienobjekt de facto mit einer „architektonischen Ruine“ zu tun, dessen wissenschaftliche Untersuchung eine spezielle Methode erforderlich macht. Selbiges gilt auch für die Entwicklung von Konservierungsvorschlägen für Gebäude und archäologische Stätten der Region.

Das Hauptcharakteristikum des ausgewählten Gebietes ist seine äußerst aktive, kulturelle, vorspanische Aktivität, welche bis dato nur marginal untersucht wurde. Obwohl die für diese Arbeit erhobene Stichprobe nicht die gesamte kulturelle Vielfalt des Gebietes darstellt, so enthält sie doch repräsentative Ergebnisse, von denen entsprechende Schlussfolgerungen, Vergleiche, Interventionen und weitere Untersuchungs- sowie Konservierungsvorschläge abgeleitet werden können.

Expeditionen zu Maya-Stätten fanden bereits seit Ende des 16. Jahrhunderts statt. Im spezifischen Studiengebiet allerdings, begann die Erforschung erst mit dem Besuch von Modesto Méndez in Tikal im Jahre 1848.

Ein Großteil des Studiengebietes hat weder aktuelle Siedlungen, noch befahrbare Straßen und Wege zu verzeichnen. Die Hauptaktivität der lokalen Bevölkerung bestand ursprünglich in der Sammlung von "Chicle" (Latex des Chicozapote-Baums). Ab den 1960ern kam die Ausbeutung der Tropenhölzer (vor allem Caoba und Zeder) hinzu. Seit 
1990 ist jedoch der Großteil des erforschten Gebietes Teil der "Reserva de la Biosfera Maya", eines Natur- und Kulturschutzgebietes.

Vor der Verfassung dieser Arbeit, waren weder systematischen Studien über die urbane Komposition und prähispanischen Architekturformen, noch über den aktuellen Stand der Konservierung des architektonischen Erbes verfügbar. Die erzielten Ergebnisse bestätigen nunmehr, dass das Gebiet für die wissenschaftliche Erforschung und korrektive Maßnahmen zur Rettung der prähispanischen Bauten sowie des Erbes der Maya-Kultur, von essentieller Bedeutung ist.

Die Arbeit gliedert sich in vier Abschnitte. Der erste Abschnitt legt den Referenzrahmen und die gewählte wissenschaftliche Methode fest (Kapitel 1 und 2). Im zweiten Teil werden die Ergebnisse der Forschung über die verbauten Räume präsentiert (Kapitel 3 bis 7). Durch die Kenntnis der architektonischen Zusammensetzung und der Bausysteme kann der aktuelle Grad der Erhaltung und Interventionen bestimmt werden (Kapitel 8 bis 11). Im letzten Abschnitt werden die wissenschaftlichen Forschungsergebnisse mit den Erkenntnissen der Feldstudien kombiniert um daraus ein Modell zur Konservierung der Baudenkmäler und somit zur Entwicklung der nordöstlichen Region des Petén (Kapitel 12). Abschließend werden anhand der Schlussfolgerungen mögliche Schritte zur weiterführenden Untersuchung der Region sowie die erforderlichen Interventionen aufgezeigt, welche für eine nachhaltige Rettung des baulichen Erbes notwendig sind.

Die im zweiten Kapitel aufgestellte Methode zieht sich als roter Faden durch diese Arbeit. Der Prozess basiert auf einem in sechs Abschnitte gegliederten Schema. Der erste Abschnitt umschreibt das ausgewählte Studiengebiet, gefolgt von der Beschreibung der in den 
Feldforschungen gesammelten Samples (zweiter Abschnitt). Im dritten Abschnitt (Untersuchungen) werden die zwei Hauptziele dieser Arbeit untersucht und die Ergebnisse präsentiert (zweiter und dritter Teil dieses Dokuments). Die folgenden Abschnitte (vier, fünf und sechs) erstellen die Strategie zur Rettung, Bewahrung und weiteren Verwendung der monumentalen Steinbauten der Maya. Der Prozess entwickelt sich ständig weiter und belebt sich dadurch selbst, um zu einem Planungsmodell für die Rettung der Bausubstanz und für die weitere Regionalentwicklung zu werden.

Die erste Schlussfolgerung dieser Studie bestätigt, dass das kulturelle Potenzial des nordöstlichen Quadranten des Peténs nicht nur ein gemeinsames Erbe ist, sondern eine einmalige und außergewöhnliche Region mit monumentalen Maya-Städten darstellt und dadurch einen Gesamtüberblick über die unterschiedlichen Phasen der Maya-Architektur ermöglicht. Dieses historische Erbe läuft Gefahr, für immer verloren zu sein, sofern nicht zeitgerecht Rettungsmaßnahmen ergriffen werden und dieses Gebiet somit zum größten guatemaltekischen Gebiet in der Kategorie des UNESCO Weltkulturerbes werden könnte.

Auch die restlichen Regionen des Petén besitzen viele monumentale Zeugnisse der Maya-Zivilisation, nicht jedoch in der Konzentration und Dimension wie es im nordöstlichen Quadranten des Petén der Fall ist. Weiters findet man in diesem Gebiet sichtbare Beispiele des Urbanismus und der Maya-Architektur aus den drei wichtigsten Kulturepochen der Maya (Frühklassik, Klassik und Spätklassik). Zusätzlich trägt der Umstand der weit verbreiteten tropischen Urwaldvegetation und die Tatsache, dass das Gebiet Teil des 
Naturschutzgebietes der „Biosfera Maya“ ist, zum außergewöhnlichen Charakter des Studiengebietes bei.

Die Ergebnisse der Forschungsarbeiten werden in drei Gruppen präsentiert. Die erste gibt Antwort auf die Frage was das kulturelle Erbe aus monumentalen Steinbauten der Maya alles umfasst. Hierzu wurde 128 Maya-Stätten stichprobenartig, die aktualisierte und vergleichbare Daten lieferte. Damit konnte bewiesen werden, dass die architektonische Zusammensetzung außergewöhnlich und der Grad der Erhaltung der Bauten äußerst bedrohlich ist.

Die Forschungsergebnisse im verbauten Raum zeigen die große Vielfalt an räumlichen Lösungen welche die Maya beim Bau ihrer Stätten entwickelten. Weiters wurde auch die räumliche Ausrichtung der Bauten sowie der Stätten an sich untersucht und herausgefunden, dass diese strategisch zur Kontrolle des Umlandes gewählt und in Sichtkontakt untereinander standen.

Ein strategisches Instrument bei der Verbauung des Raumes stellen Plattformen und Überbauungen dar. Diese und die freien, urbanen Räume wie Plätze, Höfe und Zeremonialstraßen stellen einen Aspekt des urbanen Charakters dar. Die zweite Komponente sind Gebäude, sowohl horizontale, als auch vertikale, die auf den verschiedenen Plattformen errichtet wurden um so ihre unterschiedliche Stellung im urbanen Raum darzustellen.

Die zweite Gruppe an Schlussfolgerungen behandelt die Frage in welchem Zustand sich die monumentalen Steinbauten der Maya 
befinden und welche Maßnahmen zur Erhaltung dieses reichen Bauerbes notwendig sind.

Die Forschungen über den aktuellen Erhaltungsgrad der Baudenkmäler zeigen deutlich den bedrohlichen Zustand vieler Bauten. Daher sind rasche Rettungsmaßnahmen erforderlich um den unwiderruflichen Verlust von sichtbarer Architektur zu verhindern. Besondere Gefahr geht von den illegalen Aktivitäten der Grabräuber aus, die in den letzten fünfzig Jahren beträchtliche Schäden angerichtet haben. So sind in den aktuellen Registern mehr als 5700 Diebstähle verzeichnet. Die größte illegale Aktivität gab es in der Cuenca Mirador (somit sind dringende Maßnahmen in den Stätten La Muralla, Naachtún und Tintal erforderlich), gefolgt von der Cuenca Ixcán, wo die Stabilität von monumentalen Strukturen massiv gefährdet ist (Río Azul, Kinal, Chochkitam, Xmakabatún, La Honradez und Xultún). Dritte Priorität haben die Cuencas von Holmul (Holmul und Witzná) und das Gebiet um Tikal (El Zotz und El Diablo).

Nach derzeitigem Stand (mit ungefähr 4000 registrierten Bauten) können drei Gruppen von notwendigen Konservierungsmaßnahmen identifiziert werden:

- Erstens die Gruppe der archäologischen Stätten ohne sichtbare gefährdete Architektur (Hügel, bedeckt mit Schutt, Humus und Vegetation: 62\% der identifizierten Gebäude). Durch relative neue Grabräuberaktivitäten wurden zwar einige Architekturelemente freigelegt, jedoch besteht kein Risiko des endgültigen Verlustes. 
- Die zweite Gruppe teilt mit der ersten den Umstand, dass die meisten Gebäude bedeckt sind, jedoch einige Bauten beziehungsweise Bauelemente wie Dächer oder Wände sichtbar oder strukturell gefährdet sind. Darüber hinaus haben die Raubgrabungen die Stabilität der sichtbaren Architektur (38\%) weiter gefährdet. Somit erfordern zirka 1500 Oberflächenelemente von Maya-Bauten Interventionen zu deren Rettung.

- Die dritte Gruppe ist Teil der zweiten, wobei die Bauten dieser Gruppe (11.3\% der gefährdeten, sichtbaren Architektur oder 168 Baudenkmäler) bereits in den Jahren 1959 bis 2007 Gegenstand von gesamtheitlichen oder teilweisen, guten oder schlechten, notwendigen oder überflüssigen Konservierungsmaßnahmen waren. Der Großteil davon entfällt auf das Gebiet Tikal-Uaxactún (96 Bauten) und das Triangulo Cultural Yaxhá-Nakum-Naranjo (58 Bauten).Des Weitern müssen zu dieser Gruppe noch einige für die lokale Architektur wichtige Gebäude hinzugezählt werden, bei denen kurz- und mittelfristig dringender Handlungsbedarf besteht (sehr dringend: 34 Gebäude, dringend: zwanzig Gebäude).

Daher besteht Bedarf an einer generellen Strategie, die festlegt, wo zuallererst die strukturelle Stabilität der Bauten wieder hergestellt werden muss, um einen irreversiblen Verlust der Bausubstanz zu verhindern. In weiterer Folge sollten andere Zweige der Wissenschaft einen Beitrag zum besseren Verständnis der Maya-Kultur leisten (z.B. im Zusammenhang mit der Frage, warum die blühenden Zentren plötzlich aufgegeben wurden, etc.) 
Die dritte Schlussfolgerungen beschäftigt sich mit der Frage nach weiteren Interventionen zur Rettung des gefährdeten Kulturerbes.

Dazu wird ein systematischer und regional angepasster Prozess zur Konservierung der gefährdeten Baudenkmäler im nordöstlichen Petén entworfen. Dieser basiert auf 19 Jahren Feldforschung sowie den wissenschaftlichen Forschungsergebnissen. Erforderlich sind ein interdisziplinäres Team und verschiedene Interventionsphasen um das monumentale Erbe zu erhalten. Die in dieser Arbeit vorgeschlagenen Maßnahmen wurden bereits erfolgreich in der Praxis erprobt und es gibt ausgebildetes Personal des Kultur- und Sportministeriums von Guatemala, mit welchem sich die Arbeit fortsetzen ließe.

Ein Grund für den aktuellen Grad der Erhaltung des prähispanischen Kulturerbes ist kultureller Vandalismus. Diese bewussten menschlichen Zerstörungen, zusammen mit dem Alter der Bauten, den klimatischen Gegebenheiten, der unkontrollierten tropischen Vegetation, der institutionellen Vernachlässigung und die Haltung der derzeitigen Bewohner (Siedlungen auf archäologischen Stätten, Straßen, die Maya-Stätten in zwei Teile trennen, oder landwirtschaftliche Nutzung des historischen Bodens) erklären den teils katastrophalen Erhaltungszustand der Bauten und Maya-Stätten. Daher ist es dringend notwendig ein Bewusstsein für die Rettung und Bewahrung des monumentalen, architektonischen Erbes der Maya im nordöstlichen Petén zu schaffen.

In den Sechzigerjahren des vergangenen Jahrhunderts kam zum ersten Mal die Idee auf, Fassaden von Maya-Bauten zu restaurieren 
um damit Besucher anzulocken. Generell gesprochen, besteht dieser Ansatz bis heute und ist in den Nachbarregionen Mexikos und Belizes üblich.

Historisch gesehen zielten die meisten der genehmigten,

archäologischen Projekte im Petén nicht auf Konservierungsmaßnahmen an den untersuchten Gebäuden ab. Nur vereinzelte und relativ neue Arbeiten beziehen Rettungs-Maßnahmen und Dokumentationsmaßnahmen sowie das Wiederauffüllen von Raubgrabungen mit ein.

Ein anderer Fall ist jedoch das Investitionsprojekt "Proyecto Nacional Tikal" (PRONAT) des guatemaltekischen Kultur- und Sportministeriums. Dieses kann auf eine lange Tradition an wissenschaftlichen Untersuchungen und Restaurationstätigkeiten zurückblicken. Seit 1980 wurden in diesem Rahmen mehr als siebzig Gebäude unter anderem in Tikal, Uaxactún, Topoxté, Yaxhá, Nakum, San Clemente, Naranjito, Poza Maya, Corozal Torre restauriert. Nunmehr stellen die geretteten Bauten und ihre erforschten MayaStädte ein greifbares Zeugnis der Vergangenheit dar und sind für Besucher gerüstet. Somit stellen diese zugänglich gemachten archäologischen Stätten nicht nur eine Einnahmequelle für den Tourismussektor dar, sondern tragen auch zur Entstehung einer lokalen Identität bei.

Im Projekt "Triangulo Cultural" wurden Arbeiten im großen Rahmen durchgeführt. Das Konzept der „Schule von Tikal“ konnte hier keine Anwendung finden, wodurch eine integrierte und and die lokalen Umstände sowie an die Urwaldlandschaft angepasste Lösung gefunden werden musste, welche auch eine Visualisierung des 
urbanen Raumes beinhaltete. Dieser Ansatz steht im Gegensatz zu dem in Tikal verwendeten „Überraschungseffekts“, bei welchem nur Teile der Fassaden restauriert werden um beim Besucher einen möglichst großen Eindruck zu hinterlassen. Im "Triangulo Cultural“ hingegen wird der verbaute Raum durch Landschaftsarchitektur und die Kontrolle der Vegetation auf den Bauten, Plätzen und Innenhöfen sichtbar gemacht, sodass der Besucher ein Gesamtensemble wahrnehmen kann. Die Gebäude, an welchen Interventionen erforderlich sind, werden nicht nur an ihrer Fassadenseite, sondern in ihrer Gesamtheit restauriert. Die Vernunft gebietet, die strukturelle Stabilität der Gebäude zu gewährleisten und nicht sich in deren Inneren auf Schatzsuche zu begeben, oder restaurierte Fassaden darzustellen, um politischen Wünschen zu entsprechen, die einen raschen Ausbau des Tourismus herbeisehnen.

Ein anderer Aspekt, und gleichzeitig eines der größten Verdienste, war der Aufbau eines Gebietes, heute bekannt als kulturelles Dreieck „Triangulo Cultural- Yaxhá-Nakum-Naranjo". Dieses Pilotprojekt konnte zusammenfassend eine Gruppe an Maya-Stätten in einen Nationalpark verwandeln (2003), der mittlerweile ein aktiver und fixer Bestandteil der wirtschaftlichen und kulturellen Entwicklung seiner Region ist.

In Bezug auf die Schaffung eines Bewusstseins für den kulturellen Wert des Erbes der Maya, besteht die Möglichkeit, die lokale Bevölkerung in der Ausführungsphase des Projektes aktiv miteinzubeziehen. Damit kann den Bewohner die Wichtigkeit der kulturellen Überreste, deren Schutz, behutsame Verwendung und auch deren Genuss näher gebracht und verdeutlicht werden. Beispiele wie jenes von San Clemente im Rahmen des „Triangulo Cultural“ hinterlassen bei den angrenzenden Gemeinden einen tiefen, 
positiven Eindruck und aktivieren das lokale Bewusstsein. Weitere Versuche, die lokalen Gemeinden miteinzubeziehen erfolgten ebenso in El Remate, Uaxactún und La Máquina.

Schon durch kleine Anstrengungen könnten strategisch ausgewählte Maya-Stätten für ein gesamtheitliches Konzept (Natur, lokales Handwerk, regionale Küche, Archäologie) vorbereitet werden. Somit würde einerseits die lokale Produktivität gesteigert, als auch eine Einnahmequelle durch den Tourismus erschlossen. Im Falle des „Triangulo Cultural“ ist ein positiver Effekt auf die umliegenden Gemeinden spürbar: Die lokale Bevölkerung begann ein Interesse für ihre Umgebung zu entwickeln und sah, dass durch eine angemessene Restauration und in weiterer Folge auch Präsentation der MayaStätten zusätzliche finanzielle Einnahmen erzielt werden können.

Auf keinen Fall dürfen wissenschaftlich unfundierte FantasieRestaurierungen zur Unterhaltung der Touristen unternommen werden. Der echte Wert der prähispanischen Kulturgüter besteht in seiner nachhaltigen Konservierung unter Beibehaltung seiner historischen Rolle und Funktion und nicht in gefälschten PseudoMaya Fassaden.

Es ist notwendig, einen strategischer Plan auszuarbeiten und umzusetzen. Dieser muss alle kurz-, mittel- und langfristigen Aspekte und Prioritäten mit weiteren Investitions- und Forschungsprojekten kombinieren um in weiterer Folge die wichtigsten Maya-Stätten zu restaurieren. Der geographische Fokus sollte dabei auf die 16 in dieser Arbeit identifizierten Investitionsprojekte gelegt werden.

Auf der Suche nach einem generellen Ansatz zur Konservierung des kulturellen Erbes der Region konnte bestätigt werden, dass die 
regelmäßige Kontrolle der Vegetation innerhalb der verbauten Gebiete eine wichtige präventive Maßnahme darstellt. Nachdem dies keine größeren Investitionen erfordert und periodisch mit geschultem Personal zu relativ geringen Kosten durchgeführt werden kann, entspricht dieser Ansatz den lokalen Möglichkeiten um kurz- und mittelfristig die Bausubstanz zu schützen.

Zu wissen, dass der Nordosten des Petén eine außergewöhnliche kulturelle Stellung besitzt, bringt nichts, sofern man dies nicht im Gewissen der Guatemalteken zu verankern vermag.

Der Umstand, dass die Region abgelegen und ohne nahe Siedlungen (zumindest im Zentrum und Norden des Quadranten) ist sowie dass den Maya-Stätten das Image von im endlosen Dschungel verborgenen Städten anhaftet, kann ein Element für deren Schutz sein, wobei die präventive Konservierung des Kulturerbes die wichtigste Entwicklungsachse für die gesamte Region darstellen sollte.

Daher muss der Charakter einer schwer zugänglichen Region erhalten bleiben, eine Wiederausbreitung des tropischen Urwaldes ermöglicht und das gesamte Gebiet zu einer „fragilen Zone“ erklärt werden, die, um ein Beispiel zu nennen, vom Massentourismus verschont bleiben muss. Stattdessen soll sich die Region darauf spezialisieren, individuelle und einzigartige Erlebnisse zu bieten, wobei die historischen Spuren der Maya in Symbiose mit der Unberührtheit des endlosen tropischen Urwaldes wahrgenommen werden können.

Der wirkliche, universelle Wert des monumentalen Erbes der Maya im Petén, Teil des UNESCO Weltkulturerbes, besteht darin seine Qualität 
und Authentizität zu bewahren. Die Herausforderung lautet somit, dieses Erbe adäquat und weise in das tägliche Leben miteinzubeziehen und somit für die Zukunft zu bewahren. 
ANEXO 3

RESUMEN

Resumen en español

Resumen en valenciano

Resumen en ingles

Resumen en alemán 


\title{
LA COMPOSICIÓN ARQUITECTONICA Y LA CONSERVACIÓN DE LAS EDIFICACIONES MONUMENTALES MAYAS DEL NORESTE DE PETÉN.
}

\author{
Doctorando: Óscar Antonio Quintana Samayoa \\ Director: Gaspar Muñoz Cosme \\ Departamento de Composición Arquitectónica
}

\begin{abstract}
La investigación se realizó en las tierras bajas mayas centrales (cuadrante noreste de Petén, Guatemala). El tema principal se refiere a las edificaciones monumentales de piedra erigidas entre los años 500 a.C. a 1697 d.C. Este espacio corresponde a las épocas del Preclásico Tardío, el Clásico y el Posclásico maya. La base del trabajo se fundamenta en varios sondeos en el campo que formaron una muestra actualizada y sistematizada de 128 sitios arqueológicos con aproximadamente 4000 edificaciones registradas.
\end{abstract}

El estudio presenta primero los antecedentes y la metodología. Luego los resultados de las investigaciones sobre la composición arquitectónica (capítulos 3 al 7) y el estado de conservación, (capítulos 8 al 11). Después las investigaciones y acciones realizadas se integran y combinan para formular una propuesta de actuación, conservación y desarrollo específico para el cuadrante noreste de Petén (Capítulo 12).

Anteriormente, en esta región, no se había realizado un estudio sistemático sobre la composición urbana y las formas de arquitectura de los edificios prehispánicos; tampoco se sabía sobre la condición y 
el estado actual de las edificaciones monumentales. Los resultados del estudio confirman que esta zona es prioritaria para la investigación de la composición arquitectónica y que es urgente la realización de acciones correctivas para rescatar el patrimonio edificado prehispánico y la herencia cultural maya.

Las conclusiones nos indican que se necesita inculcar un sentido de urgencia para abordar el rescate de este excepcional territorio. En la búsqueda de un procedimiento de conservación que pueda aplicarse a la generalidad del recurso cultural del área en estudio, se comprobó que una conservación preventiva podría dar una respuesta a la condición de emergencia en que se encuentra el patrimonio monumental edificado. 


\title{
LA COMPOSICIÓ ARQUITECTÒNICA I LA CONSERVACIÓ DE LES EDIFICACIONS MONUMENTALS MAIES DEL NORD-EST DE PETÉN.
}

\author{
Doctorand: Óscar Antonio Quintana Samayoa \\ Director: Gaspar Muñoz Cosme \\ Departament de Composició Arquitectònica
}

\begin{abstract}
La investigació es va realitzar a les terres baixes maies centrals (quadrant nord-est de Petén, Guatemala). El tema principal es refereix a les edificacions monumentals de pedra erigides entre els anys 500 a. C. a 1697 d. C. Aquest espai correspon a les èpoques del preclàssic tardà, el clàssic i el postclàssic maia. La base del treball es fonamenta en diversos sondejos al camp que van formar una mostra actualitzada i sistematitzada de 128 llocs arqueològics amb aproximadament 4000 edificacions registrades.
\end{abstract}

L'estudi presenta primer els antecedents i la metodologia. Després els resultats de les investigacions sobre la composició arquitectònica (capítols 3 al 7) i l'estat de conservació (capítols 8 a l'11). Després les investigacions $\mathrm{i}$ accions realitzades s'integren i es combinen per a formular una proposta d'actuació, conservació i desenvolupament específic per al quadrant nord-est de Petén (capítol 12).

Anteriorment a aquesta investigació no s'havia fet un estudi sistemàtic sobre la composició urbana i les formes d'arquitectura dels edificis prehispànics; tampoc es coneixia la condició i l'estat actual de les 
edificacions monumentals. Els resultats de l'estudi confirmen que aquesta zona és prioritària per a la investigació de la composició arquitectònica i que és urgent la realització d'accions correctives per a rescatar el patrimoni edificat prehispànic i l'herència cultural maia.

Les conclusions ens indiquen que es necessita inculcar un sentit d'urgència per a abordar el rescat d'aquest excepcional territori. En la recerca d'un procediment de conservació que puga aplicar-se a la generalitat del recurs cultural de l'àrea en estudi, es va comprovar que una conservació preventiva podria donar una resposta a la condició d'emergència en què es troba el patrimoni monumental edificat. 
EXECUTIVE SUMMARY DOCTORAL THESIS

\section{THE ARCHITECTURAL COMPOSITION AND THE CONSERVATION OF MONUMENTAL MAYA CONSTRUCTIONS IN THE NORTHEAST OF PETÉN}

Doctorate of: Óscar Antonio Quintana Samayoa

Thesis supervisor: Gaspar Muñoz Cosme

Department of Architectural Compositions

The investigation was undertaken in the central Maya lowlands (the northeastern quadrant of Petén, Guatemala). The main focus is placed on the monumental constructions made of stone, erected between $500 \mathrm{BC}$ and $1697 \mathrm{AD}$. This timeframe corresponds to the Late Preclassic, Classic and Post Classic Period of the Maya civilization. The foundations of this work can be found in various test drillings in the field which led to an actual and systematic sample of 128 sites with approximately 4000 registered constructions.

This study firstly describes the background and the method applied. Subsequently, the results of the investigation on the architectural composition (chapters 3 to 7 ) and the state of conservation (chapters 8 to 11) are presented. Then the results of the investigation and the already undertaken actions are combined to present suggestions for further actions, conservation and the specific development of the northeastern quadrant of Petén (chapter 12). 
The urban composition and architectural forms of prehispanic buildings of that region have never been subject to a systematic investigation. Nor did any knowledge of the conditions and actual state of conservation of these monumental buildings exist. In this context this study is breaking completely new ground. The results confirm that the zone of northeastern Petén has to be a priority for the investigation of architectural composition and that corrective actions have to be taken urgently to save the constructed prehispanic heritage and consequently the cultural legacy of the Maya culture.

The conclusions clearly show that it is absolutely necessary to instill a sense of urgency to come to rescue this exceptional territory. On the quest for how to proceed with the efforts of conservation - always bearing in mind the general applicability for the whole study region - it has been proved that preventive conservation could be an answer to save the constructed monumental heritage from the state of emergency in which it currently finds itself. 
DIE ARCHITEKTONISCHE KOMPOSITION UND DIE KONSERVIERUNG DER MONUMENTALEN MAYA BAUTEN IM NORDÖSTLICHEN PETÉN

Doktorand: Óscar Antonio Quintana Samayoa

\section{Doktorvater: Gaspar Muñoz Cosme}

Institut für Architektonische Zusammensetzung

Die Studie wurde im zentralen Maya Tiefland (im nordöstlichen Quadranten des Petén, Guatemala) durchgeführt. Der Fokus liegt dabei auf den monumentalen Bauten aus Stein, welche in der Zeit von 500 vor Christus und 1697 AD errichtet wurden. Dieser Zeitraum entspricht somit der späten vorklassischen, der klassischen und der spätklassischen Epoche der Maya Zivilisation. Die Grundlagen dieser Arbeit stellten verschiedene Probegrabungen im Feld dar, welche $z u$ einem aktuellen und systematischen Sample von 128 Maya Stätten mit insgesamt ungefähr 4000 registrierten Strukturen führten.

Diese Arbeit beschreibt zuerst den Hintergrund und die angewandte Methode. Der folgende Abschnitt erklärt die Erforschung der architektonischen Zusammensetzung (Kapitel 3 bis 7). Darauf folgen die Beschreibung der Feldarbeiten und der aktuelle Zustand der Strukturen (Kapitel 8 bis 11). Schließlich werden die wissenschaftlichen Forschungsergebnisse mit den erzielten Erkenntnissen der Feldforschung verknüpft und daraus Empfehlungen für weitere Interventionen, Konservierungsmaßnahmen und die 
spezifische Regionalentwicklung im nordöstlichen Quadranten des Petén abgeleitet (Kapitel 12).

Die urbane Zusammensetzung und architektonischen Formen der prähispanischen Bauten in dieser Region waren bislang noch nie Gegenstand systematischer, wissenschaftlicher Forschungen. Genauso wenig gab es Erkenntnisse über den aktuellen Zustand sowie Grad der Konservierung dieser Monumentalbauten. Somit stellt diese Arbeit einen neuen Ansatz in der Maya-Forschung dar. Die erzielten Ergebnisse bestätigen, dass die untersuchte Region für die Erforschung der architektonischen Zusammensetzung von essentieller Bedeutung ist und dass weitere korrigierende Maßnahmen dringend erforderlich sind, um das architektonische, prähispanische Erbe und somit das Vermächtnis der Maya-Hochkultur zu erhalten.

Die Schlussfolgerungen zeigen deutlich die Wichtigkeit und vor allem Dringlichkeit eine umfassende Rettung der Schätze dieses außergewöhnlichen Gebietes in Angriff zu nehmen. Auf der Suche nach einem allgemein gültigen und anwendbaren Verfahren zur Konservierung der kulturellen Denkmäler der untersuchten Region, wurde deutlich, dass präventive Schutzmassnahmen eine probate Antwort auf den gefährdeten Zustand der Bauten sein können, um den Erhalt des monumentalen, architektonischen Erbes zu garantieren. 